\title{
Atlas of modern dinoflagellate cyst distributions in the Black Sea Corridor: From Aegean to Aral Seas, including Marmara, Black, Azov and Caspian Seas
}

\author{
Mudie Peta J. ${ }^{1}$, Marret Fabienne ${ }^{2,{ }^{*}}$, Mertens Kenneth ${ }^{3}$, Shumilovskikh Lyudmila ${ }^{4}$, \\ Leroy Suzanne A.G. ${ }^{2,5}$
}

${ }^{1}$ Geological Survey of Canada, Box 1008, Dartmouth, NS B2Y 4A2, Canada

${ }^{2}$ School of Environmental Sciences, University of Liverpool, Liverpool, L69 7ZT, UK

${ }^{3}$ Research Unit Palaeontology, Ghent University, Krijgslaan 281 S8, 9000 Gent, Belgium

${ }^{4}$ Department of Palynology and Climate Dynamics, University of Göttingen, Untere Karspüle 2, 37073

Göttingen, Germany

${ }^{5}$ CEREGE, Technopôle de l'Arbois BP 80, 13545, Aix-en-Provence, cedex 4, France

* Corresponding author : Fabienne Marret, email address : f.marret@liverpool.ac.uk

\begin{abstract}
:
We present the first comprehensive taxonomic and environmental study of dinoflagellate cysts in 185 surface sediment samples from the Black Sea Corridor (BSC) which is a series of marine basins extending from the Aegean to the Aral Seas (including Marmara, Black, Azov and Caspian Seas). For decades, these low-salinity, semi-enclosed or endorheic basins have experienced large-scale changes because of intensive agriculture and industrialisation, with consequent eutrophication and increased algal blooms. The BSC atlas data provide a baseline for improved understanding of linkages between surface water conditions and dinoflagellate cyst (dinocyst) distribution, diversity and morphological variations. By cross-reference to dinocyst occurrences in sediment cores with radiocarbon ages covering the past c. 11,700 years, the history of recent biodiversity changes can be evaluated. The seabed cyst samples integrate seasonal and multi-year data which are not usually captured by plankton samples, and the cyst composition can point to presence of previously unrecorded motile dinoflagellate species in the BSC. Results show the presence of at least 71 dinocyst taxa of which $36 \%$ can be related to motile stages recorded in the plankton. Comparison with sediment core records shows that five new taxa appear to have entered or re-entered the region over the past century. Statistical analysis of the atlas data reveals the presence of four ecological assemblages which are primarily correlated with seasonal and annual surface water salinity and temperature; correlation with phosphate, nitrate and silicate nutrients, chlorophyll-a and bottom water oxygen is less clear but may be important for some taxa. Biodiversity indices reveal strong west - east biogeographical differences among the basins that reflect the different histories of Mediterranean versus Ponto-Caspian connections. The atlas data provide a standardised taxonomy and regional database for interpreting downcore cyst variations in terms of quantitative oceanographic changes. The atlas also provides a baseline for monitoring further changes in the BSC dinocysts that may accompany the accelerating development of the region.
\end{abstract}




\section{Highlights}

- Study of dinoflagellate cyst distribution in 185 surface sediment samples from the Black Sea Corridor 71 dinocyst taxa are described, illustrated, and related to motile stages and HABS. Spatial distribution of modern taxa is mapped and related to sediment-core time-series. Biogeography and relation of taxa to SST, SSS, nutrients and oxygen are discussed.

Keywords : Phytoplankton, harmful algae, biodiversity, paleoceanography, surface samples 


\section{Introduction}

Organic-walled dinoflagellate cysts (dinocysts) are generally abundant and well-preserved in the sediments of the Black Sea Corridor (hereafter abbreviated as BSC), which is the series of marine and lacustrine basins extending from the Marmara to the Aral Seas, including the Black, Azov and Caspian Seas (Figure 1). In the low-oxygen stratified waters of these brackish water basins, dinocysts are the main proxy for studying changes in sea-surface conditions and phytoplankton biodiversity (Mudie et al. 2002a; Marret et al. 2004; Sorrel et al., 2006; Bradley and Marret, 2013). The value of the dinocysts as environmental indicators in the BSC is because 1) calcareous phytoplankton (nannofossils) are frequently sparse, poorly preserved, and of low diversity because they are at their salinity limit and carbon dissolution is high (Giunta et al., 2007); 2) in the BSC, planktonic foraminifera occur only in the Marmara Sea (Mudie et al., 2002a); and 3) siliceous fossils (mostly diatoms) are subject to dissolution (Piskaln, 1991) and to loss of opal relative to calcium carbonate (Piskaln and Pike, 2001). Calcareous dinocysts are common in the Marmara and western Black Seas: their calcareous skeletons are not always preserved (Aksu et al., 2002) but they can be traced from their organic linings recovered in the palynological residues after acid treatment. Therefore, calcareous dinocysts are included in this atlas.

[Figure 1 goes here - Map of region with place names]

The composition of dinocyst assemblages in modern sediments is tightly linked to the biological, physical and chemical oceanographic conditions of the surface water $(0-20 \mathrm{~m})$ and the bottom depositional environment (e.g. Zonneveld et al., 2013 and references therein). Modern and fossil dinocysts can therefore provide an index of environmental change in the BSC 
(e.g. Mudie et al., 2004; Leroy et al., 2006; 2012; Sorrel et al., 2006; Giosan et al., 2012;

Mousing et al., 2013), and they record biodiversity shifts resulting from anthropogenic impacts (Bradley et al., 2012). Mapping of the cyst assemblages also provides information on possible dinoflagellate-induced harmful algal blooms and on invasion rates of harmful species, as shown for other areas (Anderson et al., 2012; Ribeiro et al., 2012).

Global atlases (Marret and Zonneveld, 2003; Zonneveld et al., 2013) provide few data for the low salinity marine to brackish waters of the BSC. This is an important omission because these are the world's largest semi-enclosed or land-locked seas and they are currently undergoing major anthropogenic changes, including rapid increases of salinity, eutrophication and harmful species invasions (Glantz and Zonn, 1996; Beşiktepe et al., 1997; Mee et al., 2005; Zavialov, 2005; Micklin, 2007; Boomer, 2012; Nasrollahzadeh et al., 2014). Outbreaks of harmful dinoflagellate algal blooms (including non-toxic red tides) in the Marmara and Black Seas (Koray, 1984; Velikova et al., 1999; Feyzioğlü and Öğ̈̈t, 2006; Yasakova, 2013; Balkis et al., 2011; Krakhmalny et al., 2012; Leroy et al., 2013a) point to the need for study of latent cyst reservoirs in the surface sediments (Aydin and Uzar, 2014; Balkis et al., 2016).

Detailed mapping of recent-present-day dinocyst assemblages is required to investigate and quantify the relationship between modern environmental conditions and the geographic distribution of the cysts. Paleoecological transfer functions then use these linkages to quantify past oceanographic changes (e.g. de Vernal et al., 2005; Zonneveld and Siccha, 2016). Although studies involving dinocysts and dinoflagellates from the Black and Caspian seas have proliferated over the past decade (e.g. Marret et al., 2004; Mudie et al., 2004; 2011; Atanassova, 2005, Kovaleva, 2008; Giosan et al., 2012; Shumilovskikh et al., 2013, 2014; Bradley and Marret, 2013), the wide diversity of unique BSC environments poses several challenges to researchers. Firstly, the geographic range of the marginal seas extends over 3,800 km, including 
11 Eastern European-Central Asian countries with limited access to international journals and publications in 11 languages and various alphabets. This circumstance has restricted exchange of taxonomic data and prevented adoption of standardised processing and counting methods (e.g. Mertens et al. 2009a, 2012a; Mudie et al., 2011; Marret and Garcés, 2013, Price et al., 2016). Secondly, as first noted by Wall et al. (1973), several BSC dinocyst taxa are endemic, and exhibit wide morphological variation within seasonally variable ecological niches often lacking long-term observational data. Thirdly, the most common BSC dinocysts are cosmopolitan, euryhaline species such as Lingulodinium machaerophorum, which can make precise environmental reconstruction difficult because of their wide salinity and temperature tolerances. Fourthly, previously there has been little information on the cysts of freshwater dinoflagellates in the vast deltas and limans (estuaries and adjacent coastal lagoons) of rivers flowing into the BSC seas (Figure 1), including the Danube and Volga rivers which are the largest in Europe. These dinocysts are markers of deltaic environments and are crucial for understanding of the early Holocene seawater flooding history of the Black Sea which is a highly controversial topic despite decades of research (e.g. Hiscott et al., 2007; Yanko-Hombach et al., 2013; Lister et al., 2015). Dinocysts also mark the wide water-level fluctuations of the Caspian Sea, such as the Khvalynian highstand (late glacial) and the Mangyshlak (first millennium of the Holocene) lowstands (Leroy et al., 2007; 2014).

Despite these challenges, dinocysts have played an important role in understanding changes in Holocene sea-surface salinities (SSS) of the Marmara and Black Seas (Mudie et al., 2004; Marret et al., 2004; Mertens et al., 2012b; Bradley et al., 2012) and evaluating the impacts of global temperature change on the Caspian Sea water-levels (Leroy et al., 2013b; Leroy et al., 2014). Statistical calibration of relative abundances of Spiniferites cruciformis morphotypes against $\delta^{18} \mathrm{O}$ isotope salinity estimates (Mudie et al., 2001), and process length measurements of $L$. 
machaerophorum (Mertens et al., 2012b) enabled the first quantified and detailed time-series of Holocene paleosalinity in the Marmara and Black Sea basins. The process length measurements of L. machaerophorum can provide more reliable and longer records than SSS estimates derived from sources more prone to degradation, including deuterium/hydrogen isotope ratios in fossil alkenones (van der Meer et al., 2008; Giosan et al., 2012) and fossil genetic signatures (paleomes) which reconstruct environments by pyrosequencing of sedimentary eukaryotic $18 \mathrm{~S}$ rRNA (Coolen et al., 2013). Changes in concentrations (cysts/g dry sediment or cysts/ml wet sediment) and increases in relative abundances of $L$. machaerophorum have also been used as a proxy for sea level oscillations in the endorheic Caspian and Aral lacustrine basins. Here interior basin drainage and evaporation regulates flooding and desiccation (Sorrel et al., 2006; Leroy et al., 2013b, 2014). In the Kara-Bogaz Gol, entrance-barrier construction has further regulated alternating drying and reflooding for salt/mineral extraction during the 20th century (Leroy et al., 2006).

In the most recent global atlas of dinocysts (Zonneveld et al., 2013), 71 species are mapped and related to surface water conditions of temperature, salinity, nitrate and phosphate, and to sedimentary conditions, such as the redox state of the bottom and sedimentary pore waters. Our primary objectives for a multi-regional-scale dataset of modern organic-walled dinocyst species in the BSC are similar to the aims of the 2013 global study: 1) to illustrate the known modern distributions of the BSC dinocyst taxa (Table 1) in 185 surface sediment samples (Figure 2); 2) to define and apply a framework of standardised taxonomy and methodology that will be available for future collaboration and data exchange throughout the culturally diverse region (Romania to Uzbekistan); 3) to describe the relationships between the distribution of individual dinocyst species (as relative abundances of total cyst populations) and the water quality conditions. We consider that these details are a necessary step towards refining paleo- 
reconstructions of past SST in the marginal epicontinental seas, using paleotransfer functions (e.g. Desmet, 2013) in place of either semi-quantitative interpretations of dinocyst relative abundance data (e.g. Marret et al., 2004, 2009; Leroy et al., 2013b) or dinoflagellate abundance inferred from relative amounts of $18 \mathrm{~S}$ DNA as \% of total reads (Giosan et al., 2012). The BSC atlas data provide a new basis for improving the accuracy and precision of cyst-based paleoceanography studies for sediment cores from the BSC using refined transfer function methods. In particular, our BSC database fills a need for more coastal locations and greater range of low salinity reference sites than is available in the Northern Hemisphere database of de Vernal et al. (2013).

[Figure 2 goes here: Bathymetry, distribution of sample sites (red dots) and simplified surface water circulation. Stars mark locations of reference cores listed in Appendix A.

A secondary objective of our atlas is to show how dinocyst data can contribute to the research on the Black Sea algal biodiversity that dates back to 1866 when 19 dinoflagellate taxa were reported by Perejaslawzewa (1886; see also historical review of Krakhmalny et al., 2012). Traditionally, the Black Sea was considered relatively poor in terms of phytoplankton species richness, but technology advances and taxonomic standardisation have led to a revision of this perception. New dinoflagellate check-lists report 456 species, 467 varieties and forms, including c. 200 new species (Gómez and Boicenco, 2004; Nesterova et al., 2009). We have re-evaluated these check lists based on updated taxonomic data, and we show that although not all motile taxa are associated with cysts, better understanding of BSC dinoflagellate biodiversity is gained using the standardized dinocyst taxonomy and increased knowledge of assemblage-ecological linkages. The surface cyst assemblages integrate the seasonal and multiyear plankton production of cyst- 
producing species. Combined with biomolecular studies, surveys of modern cysts can reveal the presence of dinoflagellates not sampled by intermittent plankton surveys (e.g. Mertens et al., 2015a; Balkis et al., 2016). Our integrated knowledge of recent and Holocene distributions of the BSC cysts in 40 well-dated sediment cores also provides new insight about invasions of nonindigenous species (NIS) and the migration of dinoflagellates between the Aegean and semienclosed or inland seas.

[Table 1 goes here]

\section{Regional Setting}

The Black Sea Corridor (BSC) as defined in this paper extends from Turkey in Eastern Europe to Kazhakstan and Uzbekistan in Central Asia. The BSC is a series of marine or former marine (now lacustrine) basins in the Ponto-Caspian region, located between latitudes $36^{\circ}$ and 48 ${ }^{\circ} \mathrm{N}$, and extending c. $3800 \mathrm{~km}$ from longitudes $25^{\circ}$ to $60^{\circ} \mathrm{E}$ (Figure 1). From west to east, the study region includes four main components: 1) the world's largest anoxic marine basin, the Black Sea, and its shallow northeastern extension, the Sea of Azov (= Azov Sea); 2) the Marmara Sea Gateway, a small tectonic trough with narrow straits and shallow sills that link the Black Sea to the Aegean Sea and Mediterranean region; 3) the world's largest inland lake, the Caspian Sea, at c. -27 m a.s.l; and 4) until 1960, the world's fourth largest intracontinental lake, the Aral Sea at c. +53 m a.s.l. (Aksu et al., 2000; Sorokin, 2002; Chepalyga, 2007; Marret et al., 2004; Breckle and Geldyeva, 2012). Present water depths (Figure 2) range from <10 m in Azov and Aral Seas to 2,210 $\mathrm{m}$ in the Black Sea. 
The geological origin of this chain of seas is not well known but the marine basins are probably remnants of the Mesozoic Tethyan Ocean and the Mio-Pliocene Paratethyan seaways which were periodically linked to the Mediterranean Sea (Zenkevitch, 1963; Steininger and Wessely, 2000; Sosson et al., 2010). The Caspian and Marmara-Black Sea basins were largely interlinked until at least the late Miocene (c. 5 Ma; Popov et al., 2006). After c. 2.6 Ma (Akchagylian period), the Caspian Sea became isolated from the western seas except during occasional megaflood events when super-sea highstands and floodways again reconnected the four sub-basins (Forte and Cowgill, 2013). The eastern BSC corridor Caspian and Aral Sea basins remained periodically connected during the Pliocene, Late Pleistocene and early Holocene (Boomer et al., 2000; Naderi Beni et al., 2013; Haghani et al., 2016). The Aral Sea formed around 130,000 yr BP when the Caspian Sea overflowed into the Karakum Basin, and these seas were intermittently connected until c. 5 ka BP (Breckle and Geldyeva, 2012; Sorrel et al., 2006). The pre-1960 Aral Sea formed in the early Holocene when the Amu Darya (= Amu River) flowed northwards and filled the formerly periodically hypersaline or dry basin. This long history of intermittent basin connections is strongly reflected in the endemism of the ostracod benthic fauna (Boomer, 2012). Although the Black Sea has been reconnected with the Mediterranean since the early Holocene, the modern Ponto-Caspian fauna is still largely different from the adjacent Mediterranean marine region, with the Black and Caspian Seas sharing many taxa. The fauna of the much younger (Pliocene) Aral Sea was probably re-populated by immigration of ostracods from the east after multiple dessication phases (Boomer, 2012).

The dimensions and hydrological characteristics of the present BSC waterbodies are summarised in Table 2. Although the two eastern seas have been isolated from the MarmaraBlack Sea basins for most of the Holocene, they have been reconnected by shipping canals in recent time. In 1701, a canal from the Don River to the Volga began to connect the Azov and 


\section{1}

Caspian Seas, and in 1952, the Volga-Don Canal enabled passage of large ships from the Mediterranean to Caspian Sea. After 1967, a canal also connected the Caspian Sea and AmuDarya flowing to the Aral Sea. From the late $18^{\text {th }}$ to early $19^{\text {th }}$ centuries, the Dnieper River was linked to the Baltic Sea by the Dnieper-Bug Canal system. This canal system was rebuilt after 1940, thereby reconnecting the Baltic and Black Seas (Olenin, 2002).

\subsection{Anthropogenic Impacts.}

The BSC includes the world's largest semi-enclosed or land-locked seas that are the focus of world-wide attention because of large-scale anthropogenic changes, including creeping deadzones, salinization, and harmful species invasions. Rapid and large-scale commercial development is currently the main driving force of environmental degradation in the region which is of high strategic importance for its adjacent countries and for 17 others that share its drainage basins covering an area as big as Europe (Yanko-Hombach and Yilmaz, 2007). Main commercial interests include 1) many Black Sea areas with huge potential methane resources in subsurface gas hydrates; 2) emplacement of underwater oil/gas pipelines and cables, despite vulnerability to tectonic rupture and other natural geohazards; 3 ) harvesting of vast amounts of economically important raw materials, including sapropelic mud and its minerals (e.g. Glantz and Zonn, 1996; Beşiktepe et al., 1997; Yanko-Hombach et al., 2011); 4) the Caspian Basin has one of the world's largest oil and gas fields; and 5) Kara-Bogaz Gol has exploitable amounts of mirabilite, epsomite and bischofite (Giralt et al., 2003). Other environmental pressures focus on separate basins as outlined below.

[Table 2 goes here] 
Black Sea. Because of rapid commercialisation, expanded agriculture, political conflicts, and accidental introduction of invasive species over the past 50 years, the Black Sea ecosystem underwent a catastrophic decline of key habitats, overfishing, and trophic ecosystem collapse from which it is only now recovering due to imposed regulations (Mee et al., 2005; Llope et al., 2011). Of major concern was the spread of seasonal anoxic (= zero oxygen) "dead" zones from a small area north of Danube Delta in 1973 to a maximum of $30,000 \mathrm{~km}^{2}$ between Crimea to Bulgaria by 1990 (Sorokin, 2002).

Marmara Sea. A large increase in nitrogen levels, sewage and industrial waste in recent times has triggered hamful algal blooms and mucilage outbreaks (Balkis et al., 2016; Taş et al., 2016).

Caspian Sea. Called Europe's first desert, this region undergoes climate-driven decadal-scale $\pm 3-5 \mathrm{~m}$ fluctuations in water level, which combined with overgrazing and water table lowering due to agriculture, has led to desertification and erosion in the northeast region adjoining the sea. Damming of rivers, booming oil and gas industries, industrial air and water pollution, overfishing, and in 1999, introduction of invasive species like the comb-jelly Mnemiopsis leydii have all contributed to high loss of biodiversity over the past century (Nasrollahzadeh et al., 2008;

Nasrollahzadeh et al., 2013). Consequences of these impacts are severe outbreaks of Cyanophyte algae (Cyanobacteria) in the Caspian Sea and increased dinoflagellate blooms (Nasrollahzadeh et al., 2013; Moradi, 2014). Anoxic dead zones, high levels of petroleum hydrocarbons, organochlorinated compounds and heavy metals in the bottom sediments occur in many areas (Mahmoudi et al., 2015).

Aral Sea. The relatively shallow Aral Sea has undergone the largest changes. Since 1960, the ecosystems have collapsed due to damming of rivers alternating with flooding because of breached dam walls, diversion of water for irrigation, and intense agricultural development leading to high sedimentation (Breckle and Geldyva, 2012). These factors and climate warming 
caused $85 \%$ shrinkage of the sea down to a few eutrophic waterbodies separated by saltflats. The salinity of the former fresh- to brackish-water lake (mostly 7-12 in 1901-1902) exceeded 18 around 1960, and all the indigenous fish species died in the southern Aral Sea.These fish were replaced by euryhaline introduced species but with further salinisation, also the imported bottom fish died (Ermakhanov et al., 2012). Introduction of plankton-eating fish, crustaceans and molluscs from 1933 to 1989 then caused the spread of trematode parasites and further shifts in zooplankton populations (Aladin et al., 2008). Pre-historical geological records (Sorrel et al., 2006) and archeological evidence (Krivonogov et al., 2014) show, however, that similar major shoreline regressions have also occurred in response to "natural" pre-Anthropogene climate changes.

\subsection{Geography and hydrology}

Overall, the BSC region is topographically diverse (Cordova et al., 2009), with the marginal and intracontinental seas being flanked by extensive lowland steppes to the North and East, and by high mountain ranges of the Alborz, Caucasus, Pontic and Carpathian Mountains to the southeast, south and nortwest. The climate varies sub-regionally from Mediterranean summerdry conditions in the southwest to mid-latitude temperate climates in the north; eastwards, arid subtropical to cool mid-continent desert climates dominate in the Caspian and Aral Sea basins. The foothills of the Alborz Mountains southwest of Caspian Sea have a humid subtropical climate (Molavi-Arabshabi et al., 2016).

Table 2 shows the BSC water areas, salient hydrological features, and salient water chemistry characteristics as compared to the corresponding features of the nearest fully marine water body, the Aegean Sea. Subregional differences are outlined below. 
Aral Sea. The water level of the easternmost endorheic sea depends on river inflow from the Kura, Amu and Syr rivers fed by snowmelt in remote mountains because regional precipitation (P) is low and evaporation (E) is high (Table 2). This is the shallowest sea: 16-60 m (pre-1960) which is well-mixed, with salinity ranging from about $0.1-15$, with maxima $>60-70$ Further details are given by Zavialov (2005). Aral Sea is covered by sea-ice in winter, from November to March (Kouraev et al., 2003).

Caspian Sea. This endorheic sea (inland lake) includes three basins varying in depth from 1,025 $\mathrm{m}$ in the Southern Caspian to 5-20 $\mathrm{m}$ in the Northern Caspian. The surface waters are mostly well-mixed, with salinity of c. $0.1-15$ and maximum values of 18 . Water below $400 \mathrm{~m}$ in the central and southern Caspian basins has a salinity of c. 12.5 and it is hypoxic (>0 to c. $4 \mathrm{ml} / \mathrm{L}$ DO), with a residence time of c. 15 years (Peeters et al., 2000). The Northern Caspian Sea is covered by sea-ice in winter, from November to March (Kouraev et al., 2003). Futher details are given by Zenkevitch (1963), Kostianoy and Kosarev (2005) and Gunduz and Özsoy (2014).

Black Sea. The basins of the Black Sea are deeper (maximum 2,200 m) than the eastern seas (Figure 2), and they receive a large inflow (>300 $\mathrm{km}^{3}$.a) of marine (salinity c. $32-34$ ) Mediterranean bottom water. This relatively warm, saline water mixes with and displaces the large volume of surface water that is diluted by freshwater inflow from the Danube, Dniester, Dnieper and Don Rivers draining much of the European continent. The result is a surface salinity of c. 16-18, a net annual surface outflow of c. $300 \mathrm{~km}^{3}$ of well-stratified water, and bottom water conditions below 100-200 m that are anoxic to hypoxic,(Figures 3-5D). Residence time of water below $500 \mathrm{~m}$ is $\sim 625$ years. Ice regularly forms along shorelines throughout the northern regions and sometimes occurs in Bosphorus Strait. Further details are given by Sorokin (2002) and Toderascu and Rusu (2013). 
Sea of Azov. The shallow Sea of Azov (average depth 7 m, maximum $14 \mathrm{~m}$ ) is separated from the Black Sea by a narrow 15 m-deep channel. This is the world's shallowest sea and the large volume of freshwater from the Don and Kuban rivers reduces the surface salinity to 10-14 in our study area beyond the Don Estuary (=Taganrog Bay) which has a lower salinity of 2-7. Most of the area is regularly ice-covered from December to March. Details are given by Kosarev et al. (2007).

Marmara Sea. The three basins of the Marmara Sea are also deep (1,000-1,340 m) and receive a large inflow of marine (32-38) Mediterranean bottom water through the western Dardanelles Strait (55-ca. 75 (90) m depth). Outflow of the low salinity Black Sea surface water through the shallow Bosphorus Strait (average depth $=65 \mathrm{~m}$ ) results in strong stratification, with a thin (c. $20 \mathrm{~m}$ ) surface water layer of salinity 20-31 from east to west in Marmara Sea.

Residence time of water below $500 \mathrm{~m}$ is $12-19 \mathrm{yr}$ from $10-450 \mathrm{~m}$ depth in Marmara Sea, with periodic mixing being driven by strong, cold northern winds that force downwelling (Lee et al., 2002). Details are given by Beşiktepe et al. (1994).

[Figure 3 goes here - annual average of SSS, SST]

The data in Table 2 and the maps of the annual average sea-surface salinity (SSS; Figure 3A) show how salinity generally diminishes from west to east in the study area, with concomitant reduction in $\mathrm{Na}$ and $\mathrm{Mg}$ as the dominant cations, and a tendency for $\mathrm{Ca}$ to increase in the inland basins. The maps show that salinity also decreases from south to north in the basins. Our dataset covers a wide range of sea-surface temperature (SST), from a winter low of $-0.2^{\circ} \mathrm{C}$ in the Sea of Azov to summer high of $29^{\circ} \mathrm{C}$ in the southern Caspian Sea (Figure 3B) while the SSS ranges from maxima in Marmara Sea (20-32) to minima (below 10) in the Sea of Azov and Anzali 
Lagoon, SW Caspian Sea. Graphs of SST versus SSS (Figure 3C) clearly show that different watermasses distinguish the BSC seas. The strong gradients and differences from the adjacent Mediterranean waters are also evident in our maps of seasonal SSS and SST (Figure 4) which reveal that there are relatively small seasonal shifts in salinity but there are more substantial variations in water temperature, particularly in the Caspian Sea. The SSS versus SST plots (Figures 4I-L) show that the differences in water-mass characteristics remain evident seasonally.

[Figure 4 goes here: seasonal averages of SSS and SST]

Our maps of annual surface concentrations of dissolved inorganic nutrients in the BSC (Figures $5 \mathrm{~A}-\mathrm{C})$ show that phosphate $[\mathrm{P}]$ levels are mostly slightly higher $(0.2-0.4 \mu \mathrm{mol} / \mathrm{l})$ than the eastern Mediterranean waters and silicate levels [Si] are higher in the Marmara and Black Seas $(10-40 \mu \mathrm{mol} / \mathrm{l})$. However, nitrate $[\mathrm{N}]$ levels (variably nitrate + nitrite or only nitrate) are generally the same $(0-2 \mu \mathrm{mol} / \mathrm{l})$ as in the Aegean and Eastern Mediterranean Seas except in the Danube River discharge plume area of NW Black Sea where values increase up to c. $6 \mu \mathrm{mol} / \mathrm{l}$. The N:P ratios $(13-16)$ of the western BSC waters are almost the same as in the eastern Atlantic (14-16) and they are lower than western Mediterranean values (The MerMex Group, 2011; de Fommervault et al., 2015). The Caspian Sea waters vary from mostly oligotrophic to mesotrophic or eutrophic in polluted coastal areas (Nasrollahzadeh et al., 2008). A very large increase in dissolved organic matter (DOM) and chlorophyll-a [chl.-a] concentrations (Figure 6) occurs between the Aegean and Black Seas, with peak values in Marmara Sea (The MerMex Group, 2011). Our map (Figure 5D) of the bottom oxygen concentration $\left[\mathrm{O}_{2}\right]$ shows that in large areas of the Marmara and Black Seas and parts of the Caspian Sea, the values are lower $(<3$ 
$\mathrm{ml} / \mathrm{l}$ ) than in the adjacent Mediterranean waters (c. 4-6 ml/l); however, in some areas of the northern and eastern Caspian Sea, the water is very well ventilated $(6-8 \mathrm{ml} / \mathrm{l})$.

[Figure 5 goes here: abiotic nutrients and bottom oxygen.]

It was not possible to compile a comparable map of long-term [chl.-a] values but we show here (Figure 6) a NASA Worldview compilation for summer 2015 (July 27). This image illustrates the regional variation of [chl.-a] within the BSC and it highlights the salinity differences from [chl.-a] values in the adjacent relatively oligotrophic waters of the Aegean and eastern Mediterranean Sea (Figure 6). Mee et al. (2005, their fig. 6) also show SeaWifs satellite data for Marmara to Azov Seas, summer and winter 1997-2003, and they highlight the occurrences of maximum values on the NW shelf and in Sea of Azov during summer, as well as a winter bloom along the Turkish and Georgian coasts. In summer, highest [chl.-a] MODIS values of $>20,000 \mathrm{mg} / \mathrm{m}^{3}$ are recorded in Marmara Sea, Sea of Azov, Danube and Volga Delta regions, with large areas of slightly lower values in many parts of the Caspian Sea. Smaller [chl.a] maxima in the Black Sea are also associated with Rim Current gyres that induce cross-shelf mixing along the western and narrow southern shelves (Figure 2). Deeper water areas and the Kara-Bogaz Gol tend to have lower [chl.-a] comparable to those in the northernmost Aegean but much higher than the oligotrophic conditions of the southern Aegean and eastern Mediterranean Sea waters with values of $<2 \mathrm{mg} / \mathrm{m}^{3}$.

[Figure 6 goes here: Map of chlorophyll-a concentration in $\mathrm{mg} / \mathrm{m}^{3}$ in the BSC on July 27 , 2015, as recorded by MODIS imagery from worldview.earthdata.nasa.gov. 
The entire BSC region is noted for the presence of a high number of Ponto-Caspian species (endemic to the Black and Caspian Seas, and neighbouring lagoons or small seas) as noted by Zenkevitch (1963), Sorokin (2002), Moncheva and Kamburska (2002). Table 3A lists some comparative data for species numbers in both the phytoplankton and zooplankton censuses of the semi-enclosed and inland seas prior to 2002 . These statistics are highly site-specific, and in the Aral Sea, they are subject to rapidly changing surface area and SSS conditions, but they provide a broad baseline for comparison with shifts in dinocyst diversity as recorded by our new literature search, surface sediment samples, and our research of Holocene-Recent sediment core records. The locations of the 40 reference cores are shown in Figure 2; details of the core locations, water depths and chronological control data are given in Appendix A.

[Table 3 goes here]

3. Materials and Methods

\subsection{Materials}

The atlas includes 185 datapoints (Figure 2) obtained mostly from formerly unpublished datasets but including 16 BSC locations previously summarized in Zonneveld et al. (2013). Data from SW Turkish bays (Izmir and Elaiat) are not included because they belong to the hypersaline, oligotrophic Mediterranean marine ecosystems, not the low salinity-brackish water Ponto-Caspian ecosystems. Locations, water depths and type of sediment sampler used to recover the surface layer (0-1 or 0-2 cm depth) are given in Table 4. Most of the atlas samples are from the Black Sea (60\%) and the Caspian Sea (28\%), and the small Marmara Sea is also 
relatively well represented (6.6\%). Far fewer samples (3.7\%) represent the large Azov Sea region where collection is limited by low accessibility and few surface sample data are available. The remotely-located, now largely desiccated Aral Sea is also undersampled (4 samples, $1.6 \%$ of total). It will also be noticed that environmental variables could not be mapped for the Aral Sea because there are insufficient oceanographic data available for this formerly vast sea that was studied in detail by Ostenfeld (1908). In recent years, NASA satellite data collection (150 km resolution) was prevented by the highly reduced water area and the heavy dust cover. As a result, limited oceanographic data for Aral Sea are available for use in the BSC atlas.

[Table 4 goes here]

In this study, the term "surface sample" denotes sediment of modern age (including present and recent past), meaning that it includes the sediment deposited at the time of collection between either 1969 (Black Sea) or 1994 (Caspian Sea) and 2014, with most samples being collected between 2002 and 2014. The surface samples (0-2 cm depth) also usually contain sediment deposited at the site shortly before the year of collection, including bioturbated older sediment. The total amount of time represented by each surface sample depends on the sedimentation rate, sampling method, and amount of bioturbation at the sample site. Estimated rates range between less than five years to a few decades for most sites (see also Mertens et al., 2012b for locations with century-scale rates for some deeper water sites). Presence of Ambrosia pollen grains (2- $20 \%$ total pollen) in most shelf samples from the Black Sea and Marmara Sea indicates an age much younger than 1914 (first introduction in the Ukraine; N. Gerasimenko personal communication 2015) and probably less than 1990 AD when annual ragweed Ambrosia artemisiifolia began to proliferate in Eastern Europe (Kiss and Béres, 2006). Ambrosia pollen is 
much more abundant than the grains of burdock Xanthium spinosum that have similar morphology. All dinocyst data are from original counts of authors listed in Table 4 but are mapped as relative abundances (calculated by dividing the number of counted specimens of an individual species by the total number of counted dinocysts in the sample). Most counts are between 200 and 300 cysts or more and samples containing less than 80 cysts were excluded from the atlas except where noted by an asterisk on some maps for samples from the high sedimentation Azov Sea, Volga Delta and some Danube Delta areas where extremely low numbers of cysts were recovered. The shallow water Azov Sea samples in particular contained very low amounts of fine grained organic matter, including pollen grains, although organic linings of large benthic foraminifera are very common, suggesting that the scarcity of dinocysts was not the result of oxidation.

Detailed information on sediment recovery and preparation methods of previously published data are given by Marret and Zonneveld (2003), Mudie et al. (2004, 2011), Marret et al. (2004), Sorrel et al. (2006), Desmet (2013), Shumilovskikh et al. (2013), and Leroy et al. (2013a). Cyst extraction methods were standardized to prevent use of strong oxidative agents (such as acetolysis). Most of our methods used unheated hydrochloric acid ( $\mathrm{HCl})$ and unheated hydrofluoric acid (HF) to remove carbonates and silicates respectively, and used washing on a 10 $\mu \mathrm{m}$ screen to remove clay and finest silt particles; however, samples studied by Mertens (Verleye et al., 2009) used only $10 \% \mathrm{HCl}$ and sieving with a $20 \mu \mathrm{m}$ mesh. The basic exotic spore method of Stockmarr (1971) was used to estimate "absolute" cyst abundances; however, samples from the Caspian Sea report number of cysts/ml wet sediment, not the more commonly recorded number of cysts/g dry sediment used for most of the samples.

\subsection{Taxonomy}


In addition to a motile stage, some dinoflagellates produce resting cysts, commonly called dinocysts, as part of their life cycle. These resting cysts contribute to their endurance under unfavorable environmental conditions. They are usually the only geologically preservable stage in the dinoflagellate life cycle. The existence of these two life cycle stages has resulted in the creation of two taxonomic systems: one used by biologists and based primarily on the morphology of living motile cells, and the other developed by paleontologists and based on the fossil resting cyst morphology. We use the cyst-defined name except when it is not available and then the name based on the motile stage is used. The $>71$ dinocyst taxa were distinguished mainly using taxonomic concepts primarily based on those documented in Rochon et al. (1999), Matsuoka and Fukuyo (2000), Marret and Zonneveld (2003), Marret et al. (2004), Mertens et al. (2012b), and in part, as applied by Zonneveld et al. (2013). The authors have tried to standardise the taxonomy of the taxa by comparing specimens at scientific workshops, by exchange of slides and raw sediment samples, and additional extensive research by KNM who is largely responsible for most of the taxonomic designations we have used and for the majority of the taxa illustrations. However, Achomosphaera sp., Brigantedinium spp., cyst of Peridinium cf. willei, Spiniferites sp. 1 cf. S. bulloideus, Spiniferites cruciformis and most members in the category "Very Restricted Modern Occurrences" are the responsability of PJM, and the cyst of G. catenatum is the responsability of FM. Some taxa for which there are different taxonomic concepts or uncertain identifications are grouped together for the BSC atlas, as explained in Section 4 for individual species, including Echinidinium spp. and Spiniferites spp. These taxa are notably prevalent in the Black Sea where very large amounts of fine particulate organic matter (amorphogen) and/or clay particles adhere to spiny cyst and make certain identification impossible. In contrast, samples from the oligotrophic waters with less amorphogen in the 
neighboring Aegean Sea, including Izmir Bay, contain comparable spiny cysts and far fewer of these are in the unidentifiable category. In addition, for the BSC cyst assemblages, we have defined three artificial categories: Round Brown Cysts, Spiny Brown Cysts and Unknown Hyaline Cysts to accommodate cysts commonly seen but not identifiable to generic or species level with certainty.

Several difficult taxonomic issues need special mention here because of variable treatments used in the past. Firstly, the distinction between cysts of Gymnodinium catenatum and those of Gymnodinium nolleri and Gymnodinium microreticulatum is based on size and morphology (Bolch et al., 1999; Ribeiro et al., 2012). In the Eastern Atlantic, three distinct morphotypes are recognised on the basis of cyst diameter and the number of rows in the cingulum (Ribeiro et al., 2012). By size alone, G. catenatum is $35.6-53.3 \mu \mathrm{m}, G$. nolleri is $23.1-36.4 \mu \mathrm{m}$, and $G$.

microreticulatum is $20.5-34.3 \mu \mathrm{m}$ in diameter. In our study, however, some samples contained large $(>37 \mu \mathrm{m})$, brown, microreticulate cysts with cingular bands consisting of four rows of oriented, primarily five or six sided vesicles which were also categorised as G. catenatum cysts (Marret et al., 2009), based on their large size. Similar microreticulate cysts with a diameter of less than $37 \mu \mathrm{m}$ and two or fewer rows of vesicles were combined into the " $G$. nolleri/microreticulatum" group, which also includes microreticulate cysts with cingular bands for which no size separation was made during the counting process.

Secondly, cysts of Polykrikos schwartzii and Polykrikos kofoidii were identified following the re-established cyst-theca relationships of Matsuoka et al. (2009). We have grouped these species for the BSC atlas, however, because of the large amount of apparent intergradation between the ornamentation that characterises both forms, which makes it difficult to distinguish between the taxa unambiguously. 
Thirdly, it is also important to note that not all authors quantitatively separated specimens of Operculodinium centrocarpum sensu Wall and Dale 1966 with "normal" processes from those with "reduced" processes. Therefore, the maps and graphs show the combined distributions of Operculodinium centrocarpum sensu Wall and Dale 1966 with "normal" (>7 $\mu \mathrm{m})$ and "reduced" $(<5-7 \mu \mathrm{m})$ processes. Cysts with abnormal or variable processes are separated, including Operculodinium centrocarpum form B of de Vernal et al. (1989) and Operculodinium centrocarpum forma 1 of Londeix et al. (2009). Quantitative variations in O. centrocarpum sensu Wall and Dale 1966 process lengths are described by Jansson et al. (2014) who conclude that regional differences are evident in the correlation between process length, salinity (SSS) and temperature (SST). Likewise, in this atlas, Lingulodinium machaerophorum process lengths were not quantitatively measured in most samples, therefore they are listed and mapped as having processes $>10 \mu \mathrm{m}$ "normal form", $<10 \mu \mathrm{m}$ ("short" form) or clavate form ("club-shaped"). Details of the variations in morphology and process length of this taxon are published elsewhere (Mertens et al., 2009a, 2012b).

Fourthly, it will be noted that an especially large amount of description is provided for Spiniferites cruciformis to show how this this taxon differs from other genera having a "winged" ornament, including Pterocysta cruciformis, Galeacysta etrusca, and Romanodinium areolatum. This detail is provided because the concept of a "cruciform" endocyst shape has not previously been defined formally (Mudie et al., in press 2016) and consequently the term has been applied increasingly broadly to include cysts with subcruciform, rhomboidal and irregularly pentagonal endocysts. Furthermore, it has been suggested by Popescu et al. (2009) that a continuum exists between the above-listed group of taxa commonly referred to as the "Galeacysta etrusca complex". In fact, the genera actually differ in the basic structure of the ectophragm, ranging 
from that of the proximate cysts of S. cruciformis to the cavate cysts of Thalassiphora balcanica and Romanodinium (Mudie et al., in press 2016).

Fifthly, we provide an additional category of Very Restricted Modern Cyst Occurrences which includes widespread Paratethyan and Mediterranean taxa that have long stratigraphic ranges in long cores and exposed sections of the BSC region and are sporadically present in Holocene sediment cores but are rare in the modern dinoflagellate cyst flora. It is presently uncertain if these cysts are now extinct (some occur in late Holocene sediments $<3,000$ yrs BP) or just very rare, and some have been overlooked because of errors in identification. These taxa include Polysphaeridium zoharyi, Spiniferites pachydermus and Tuberculodinium vancampoae. In that section we also mention a few species previously reported as being present (Gonyaulax apiculata and cyst of cf. Peridinium inconspicuum of Brenner) but with few occurrences to confirm identifications.

A description of the cyst morphology focused on the main distinguishing characteristics is given with each surface distribution map. Where applicable, the first observed Holocene occurrence of a species in radiocarbon-dated BSC sediment cores (Table 3) is given to provide baseline data regarding the timing of BSC species invasions and for evaluating cyst diversity changes in recent times. A key to identification of the BSC cyst species by light microscopy is given in Appendix B. Most taxa are also included in the global-scale determination key of Zonneveld and Pospelova (2015), but some characteristics of the BSC variants are not included therein. The comments about phytoplankton stages of cyst taxa and occurrence of the taxon as a Harmful Algal Bloom (HAB) species are in accord with the listing of Moestrup et al. (2009 and onwards). However, we have not attempted to provide a full list of synonyms for all the motile stage forms of the cyst taxa because the complexity of that task is beyond the scope of this cystbased atlas. Comparisons are given as a guideline to unusual features of the BSC dinocyst taxa 
from inland seas compared to the world oceans and to assist in distinguishing between morphologically similar taxa or unusually variable taxa, e.g. Spiniferites cruciformis. Notes on associated ranges of sea-surface temperature (SST), salinity (SSS), phosphorus $[\mathrm{P}]$, nitrate $[\mathrm{N}]$ and silicate $[\mathrm{Si}]$ nutrients, chlorophyll-a, and dissolved oxygen $\left[\mathrm{O}_{2}\right]$ concentrations recorded for the cyst taxa are given in the distribution summaries wherever available.

\subsection{Mapping Tools and Statistical Analysis}

Distribution maps were created using the free software Ocean Display Visual (www. odv.awi.de), based on the percentages of the total number of cysts for all species in the sample. Where the total cyst count is below 80 , species occurrences are indicated with an asterix. Annual and seasonal (Winter: January-February-March; Spring: April-May-June; Summer: July-AugustSeptember; Autumn: October-November-December) sea-surface temperature (SST) and salinity (SSS), annual surface concentrations of dissolved inorganic Phosphate [P], Nitrate [N], Silicate

[Si] and of chlorophyll a [chl.-a.], and dissolved bottom oxgen concentration $\left[\mathrm{O}_{2}\right]$ were extracted for most sites from the World Ocean Atlas 2013 (Boyer et al., 2013). However, no equivalent environmental data are available for the Aral Sea because this sea has undergone drastic changes in the last decades and satellite images are often obscured by dust clouds. Chlorophyll-a data were also not available for the Caspian Sea, and World Ocean Atlas observations are patchy and of low reliability for the other basins. Therefore, we have not mapped these discontinuous [chl.a] data but instead show a snapshot of NASA MODIS chlorophyll-a concentrations for July 2015 (see Figure 6, worldview.earthdata.nasa.gov). Statistical analyses were carried out on the 185 samples using the software PRIMER 7 (Clarke and Gorley, 2015) to help identify species distribution patterns in relation to environmental conditions. A principal component analysis 
(PCA) was performed on the abiotic parameters for 181 sites (not including the four Aral Sea sites). Then, for the assemblages, the first step was to remove the samples with fewer than 80 counted cysts, which yielded a total of 172 samples. The second step was to remove samples without abiotic parameters or with an incomplete abiotic dataset, which yielded a final total of 169 sites. Of the 58 taxa that have been observed in these surface sediments, we also excluded Lejeunecysta marieae and Lejeunecysta sp. which only appear in one or two samples and in proportions of $1 \%$ or less. Raw counts were first standardised, then square-root transformed to enable low occurring taxa to be weighted in the statistical analysis. A shade plot was created based on square-root transformed percentages enabling a graphical summary of species distribution (58 species); a non-metric multi-dimensional scaling (nMDS) analysis was carried out on the 169 assemblages and the 56 taxa. We also performed two additional statistical analyses (RELATE, based on the Spearman rank correlation, and BEST, using Spearman Rank Correlation and Euclidean distances) to better understand which of the abiotic parameters best explain the assemblage relationships. In addition, number of taxa, Margalef's species richness (d) index, and Pielou evenness index were calculated and mapped. Margalef's diversity richness index is a simple measure of species richness (Margalef, 1958) and is calculated as Margalef's index $=(\mathrm{S}-1) / \ln \mathrm{N}$ where $\mathrm{S}=$ total species; $\mathrm{N}=$ total individuals in sample; $\ln =$ natural logarithm. Pielou's evenness Index (e) was calculated as (Pielou, 1966). e = H / ln S where H = Shannon-Wiener diversity index and $\mathrm{S}=$ total number of species in the sample (Pielou, 1966).

\section{Taxa and Geographic Distributions}

For the description of cyst taxa, we have largely used the simplified term "tabulation" without the "para" prefix to denote the "reflected" tabulation of the motile stage thecal plates (the 
number and organisation) which may be observed in the corresponding cyst morphology. However, it should be remembered that the cyst "tabulation" is an interpretation and is rarely shown to correspond precisely or to be exactly equivalent to the functional and morphological features of the theca stage (see Fensome et al., 1993). For simplicity, we avoid the now arbitrary use of the prefix "para" to denote cyst tabulation features. Note also that we consistently use Plate and Fig./Figs. when referring to the illustrations in this atlas, and we use pl. and fig./figs. to refer to illustrations in all other publications. Maps and text figures are referred to as Figures.

\subsection{Achomosphaera sp. sensu Evitt 1963}

Distinguishing characters: Based on the generic description of Evitt (1963), cysts of the BSC Achomosphaera sp. are characterised by an ovoid to subspherical body with a colourless wall lacking visible traces of sutural ridges. The outer wall is extended into long processes like those of Spiniferites; an apical boss may be present or absent. Only gonal processes are present; these are hollow or solid and are distally trifurcate. The processes may be perforate at the base, and the bases are sometimes elongated in the direction of the plate boundaries and they can then appear very faintly outlined; reduced processes may also be present. The precingular dorsal archeopyle is gonyaulacoid, $3^{\prime \prime}$, with a free operculum. The absence of clearly defined sutures is the key criterion that distinguishes Achomosphaera from the genus Spiniferites. The BSC morphotypes of Achomosphaera sp. have no visible traces of a cingulum or sutural tabulation and they bear processes with relatively simple trifurcate process tips as in Dinocyst sp. 1 of Desmet (2013; her pl. 3, figs. A-B). They also lack the wide reticulate or perforate platforms of Spiniferites septentrionalis Harland 1977 (see Sect. 4.53) or Achomosphaera andalousiensis Jan du Chêne 1977 emend. Jan du Chêne and Londeix 1988. 
Dimensions: Body length c. 37-50 $\mu \mathrm{m}$; width ca 25-44 $\mu \mathrm{m}$; process length 14-6 $\mu \mathrm{m}$, Synonymy: Dinocyst sp. 1 of Desmet 2013

Biological affinity: Unknown.

Comparison: Achomosphaera sp. is distinguished from A. andalousiensis by not having regularly complex fenestrate process tips and relatively thin body wall with a psilate surface. Achomosphaera sp. is distinguished from Achomosphaera ramulifera (Deflandre 1937) Evitt 1963 by the absence of fusion of either cingular or polar processes and by having relatively short distal process branches. Achomosphaera sp. differs from Spiniferites septentrionalis Harland 1977 (see Sect 4.53) by the absence of sutural ridges and by having simpler process ends with short branches and without fenestrate platforms. Observations of KNM indicate that the BSC cysts of Achomosphaera sp. may fall within the range of variation found in S. septentrionalis which has a similar distribution in the Black Sea but is confined to shelf areas.

Distribution: Achomosphaera $\mathrm{sp}$. is relatively rare $(\leq 2.3 \%)$ in surface samples from the BSC and its distribution is largely confined to the NW Black Sea, with a maximum on the outer Ukrainian shelf. The cysts are well-preserved and do not appear to be reworked. The taxon also occurs in low numbers $(0.4-6 \%$ of total cysts $<10,000 / \mathrm{g})$ at two sites on the Turkish shelf north and south of Bosphorus Strait and at one site in the Sea of Azov (Figure 7). Most sites are in water depths above $166 \mathrm{~m}$, and a weak polynomial correlation with depth to $746 \mathrm{~m}$ suggests downslope transport on the steep Ukrainian continental slope. The new BSC occurrences of Achomosphaera sp. greatly extend the previously recorded salinity range of the Achomosphaera andalousiensis-S. septentrionalis complex of Harland (1977) from the marine waters of the British Isles to include stratified estuarine conditions with annual SSS ranging from 16.1-18.1 (winter maximum) and a total seasonal range from 8.19 (autumn) to 18.08 (winter). However, maximum amounts of $2-3 \%$ (for total cysts $>16,000 / \mathrm{g}$ ) occur within a seasonal range of $\mathrm{c}$. 
17-18, and the Azov Sea site has much lower values of 8.2-9 (autumn-winter). Annual SST is $14.3{ }^{\circ} \mathrm{C}$, ranging from $6.6{ }^{\circ} \mathrm{C}$ (winter, NW Black Sea) to $23.1{ }^{\circ} \mathrm{C}$ (summer, SW Black Sea), with one low occurrence in the Azov Sea where winter SST is near $0{ }^{\circ} \mathrm{C}$. Associated nutrient levels are relatively low: [P] 0.05-0.25, [N] 0-4.5, [Si] 1.8-6.5 (-15.6 Azov), and [chl.-a] values are $0.52-2.74$, with maximum cyst amounts having values of $<1.0$. The bottom water $\mathrm{O}_{2}$ range is wide: $0.3-6.5 \mathrm{ml} / 1$.

Verleye et al. (2009) reported rare occurrences of Achomosphaera spp. in mid-late Holocene sediments of core GeoB7625-2 in the southwestern Black Sea and Shumilovskikh et al. (2013) documented Achomosphaera cf. andalousiensis in Holocene of core M72/5-22-GC3 from SE Black Sea. The occurrence of Achomosphaera sp. in the surface sediments of the BSC extends the Mediterranean range of the genus from its last appearance during Termination 1A (c. 14 ka BP) in the Alboran Sea (Turon and Londeix 1988).

[Figure 7. Distribution map of Achomosphaera sp. goes here]

\subsection{Ataxiodinium choane Reid 1974}

Distinguishing characters: Based on Reid (1974), Rochon et al. (1999) and Head (2007), Ataxiodinium choane cysts are proximochorate with a spherical to egg shaped central body and a transparent, thin, faintly microgranulate inner wall which is surrounded by a distinctive outer layer that forms a deeply crenulate outer wall (= pericoel lobes). The crenulations form irregularly where the outer wall is connected to the inner wall by funnel-shaped depressions (Plate 1, Figs. 1-6). The archeopyle apparently corresponds to the third precingular (3") plate with well- developed angles but no other tabulation is clearly evident, although convolutions of 
the outer layer may weakly reflect the sulcus. The outer wall is usually smooth but can be faintly microgranulate.

Dimensions: The inner body is $28-40 \mu \mathrm{m}$ in length and $26-37 \mu \mathrm{m}$ in width; the total size including outer wall is $47-50 \mu \mathrm{m}$ in length and 47-58 $\mu \mathrm{m}$ in width (Reid 1974).

Synonymy: Planinosphaeridium membranaceum is a senior synonym for A. choane according to Dale (1976), but Wall et al. (1977) retained Ataxiodinium (as Planinosphaeridium) choane.

Biological affinity: A. choane appears to be a cyst of a Gonyaulax sp., probably in the Gonyaulax spinifera complex (Dale 1976, 1983; Head, 1996). G. spinifera is quite common in plankton samples from Black Sea (Gómez and Boicenco, 2004) and is reported for the Caspian Sea (Bagheri and Fallahi, 2014) and more rarely (August only) in Marmara Sea (Balkis et al., 2016).

Comparison: Cysts of $A$. choane from British coastal waters (Reid, 1974), the NW Atlantic Ocean (Rochon et al., 1999) and possibly the Mediterranean Sea (Zonneveld and Pospelova, unpublished) mostly have a larger body and wider, more elongate pericoel lobes than BSC specimens. In contrast, the BSC specimens appear to be at the low end of the global size range and the pericoel undulations are fewer and less well developed (>10 cysts measured). Some BSC cysts resemble Ataxodinium zevenboomii Head 1997 in having relatively densely-spaced low pericoel undulations, but they do not have the characteristic ellipsoid to oval body shape of $A$. zevenboomii, and many have pericoel undulations within the range of A. choane. Londeix et al. (2009) informally describe two other Ataxiodinium taxa in mid-Holocene sediments of Marmara Sea: Ataxiodium cf. choane Reid, 1974, with a low pericoel (their plate 1, fig. 1), and Ataxiodinium sp. A (their plate 1, fig. 3) which has only a faintly developed pericoel. Possibly the reduced pericoel development of BSC taxa is related to the lower salinity for this typically fully marine species and in this study, we group together $A$. choane and $A$. cf. choane. 


\section{1}

Distribution: In the BSC, Ataxiodinium choane, including Ataxiodinium cf. choane, are infrequently present in surface samples from Marmara Sea and from the western to southern Black Sea (Figure 8). The taxon appears to be most common (up to $3.6 \%$ ) in more saline water (c. 17.9), with lower amounts $(<0.6 \%)$ occurring where winter salinity is $31-32$, and with peak amounts in deeper water sites of the outer Ukrainian shelf and upper slope. A. choane has only two deep water occurrences where it is rare $(<1 \%)$. It is not found at mapped salinities below 16 , although one sample on the Danube delta-front experiences periodic SSS values of 6.9-14 in winter and spring (Yanko-Hombach, personal communication). Associated SST is about $15^{\circ} \mathrm{C}$ annually, ranging from c. 6.1 (winter) to 26 (summer). Nutrient levels tend to be low: [P]

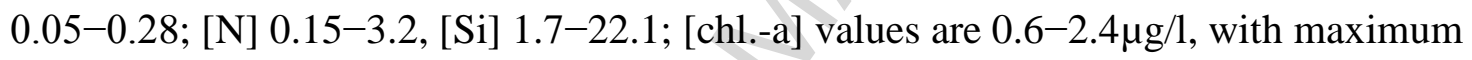
abundances at the lower end. The bottom $\mathrm{O}_{2}$ values range from $0.07-6.1 \mathrm{ml} / 1$, with no clear link to cyst \% abundance. In sediment cores, maximum abundance of A. choanum is in Marmara Sea, at the top of the M1 sapropel, c. 6,000 yr BP (e.g. Londeix et al., 2009). In the Black Sea SE basin core M72/5-22-GC3, it appears around 4,500 yr BP (Shumilovskikh et al., 2014). Globally, A. choane is also mostly found in low relative abundances (3\% or less) in coastal to open oceanic sediments from sub-polar to equatorial regions, with highest amounts in eutrophic environments (Marret and Zonneveld, 2003; Zonneveld et al., 2013). The Black Sea data extend the salinity range of the species well below the typical marine values with SSS $>23.6$ reported by Zonneveld et al. (2013).

[Figure 8. Distribution map of Ataxiodinium choane goes here.]

\subsection{Bitectatodinium tepikiense Wilson 1973}


Distinguishing characters: Based on Lewis et al. (2001), these proximate cysts are spherical to slightly oval in shape, with a thick, colourless wall and vermiculate surface lacking tabulation (Plate 2, Figs. 1-5). The cyst wall consists of a thin solid inner layer (pedium) and a vermiculate to deeply sinous outer layer (= luxuria) of closely-spaced lamellae with raised bases (Plate 2, Fig. 6). A small apical protuberance $(1-4 \mu \mathrm{m})$ may be present. The archeopyle is precingular, with well-defined angles and is very large (Plate 2, Fig. 1) because it is formed by the loss of the two almost equal-sized third and fourth precingular plates (Lewis et al., 2001). The opercular plates are usually fully detached, with a characteristic antapically-directed notch on the upper margin, marking the point of separation of the two precingular plates from the apical plate $3^{\prime}$ (Plate 2, Fig. 1), but in the Black Sea, a few specimens were found with one plate still attached (Plate 2, Fig. 2).

Dimensions: According to Rochon et al. (1999) and Lewis et al. (2001), the cyst body diameter is $38-56 \mu \mathrm{m}$; wall thickness: $2-4 \mu \mathrm{m}$ (61 cysts), apical boss c. $1-4 \mu \mathrm{m}$ (mean $=2.9$ for 12 cysts).

Synonymy: According to Harland (1977), Caledonidium vermiculatum Reid 1974 is a junior synonym of Bitectatodinium tepikiense Wilson 1973.

Biological Affinity: Lewis et al. (2001) suggest that Bitectatodinium tepikiense is the cyst produced by the motile dinoflagellate probably referable to Gonyaulax digitale (Pouchet 1883) Kofoid 1911 (= Protoperidinium digitale Pouchet 1883). G. digitale is reported for eight sites in the western Black Sea (Gómez and Boicenco, 2004) and for the SE Black Sea (Feyzioğlu and Seyhan, 2007), for two sites in the Caspian Sea (Bagheri and Fallahi, 2014) and in Marmara Sea, 
it is found in the Bosphorus area and the Gulf of Gemlik, Marmara Sea (Deniz and Taş, 2009; Balkis et al., 2016).

Comparison: B. tepikiense cysts from surface sediments of the BSC are similar to North Atlantic cysts described by Reid (1974) and Rochon et al. (1999). Bitectatodinium spongium (Zonneveld 1997) emend. Zonneveld and Jurkschat 1999 which is widely distributed in the Mediterranean Sea (Elshanawany et al., 2010) has a thicker wall and long flexible spines which extend beyond the lamellae; also, its archeopyle is formed by loss of $3^{\prime \prime}$ and the smaller 2 " plates, giving it a strongly asymmetrical appearance (Zonneveld and Jurkschat, 1999). This species has not yet been reported for the BSC. Unopened cysts of B. tepikiense may appear superficially similar to Tectatododinium pellitum (Plate 2, Figs. 8-10; also see Sect. 4.29), but this species is distinguished by thicker, spongy luxuria with interwoven fibrils.

Distribution: In the BSC surface sediments, B. tepikiense is largely restricted to Marmara Sea and the annually warmer southern sector of SE Black Sea where it occurs in low relative abundances $(<2 \%)$; there is only one other location in the northwestern Black Sea (Figure 9). The associated SST values in Marmara and southern Black Sea range from $6.7-23.8^{\circ} \mathrm{C}$ (winter-summer) which is about $1{ }^{\circ} \mathrm{C}$ warmer in winter than other areas of the western BSC. The associated SSS is 16.7-30.9 summer-winter), with low seasonal variation $(<2.5)$ and always about 5 higher than the average for the BSC. The single location on the NW shelf is relatively cooler by c. $2{ }^{\circ} \mathrm{C}$ and SSS is c. 4lower, but these salinity values are well within the reported global range of c. 9 to > 30 given by Zonneveld et al. (2013). Associated nutrient values tend to be low: [P] 0.06-0.14 $\mu \mathrm{mol} / \mathrm{l}$; [N] 0.1-3.1 $\mu \mathrm{mol} / \mathrm{l}$; [Si] 2.7-10.3 (20.1 at one site) $\mu \mathrm{mol} / \mathrm{l}$; chl.-a values are also low $(0.9-2.4 \mu \mathrm{g} / \mathrm{l})$. Bottom $\mathrm{O}_{2}$ is mostly less than 3.5 but is 5.5 at one site. In Black Sea cores, B. tepikiense is rare in mid-Holocene sediment of the SW Black Sea (c. 6 ka 
BP, Marret et al., 2009) and it is common in early-mid Holocene sediments of Marmara Sea cores (Mudie et al., 2002a; Londeix et al., 2009). B. tepikiense is widespread in the Mediterranean Sea (Zonneveld et al., 2013), and it is common in sub-recent sediments off the Po River Delta (Sangiorgi and Donders, 2004) although it is not reported for the Turkish Gulf of Izmir (Aydin et al., 2011). On a world-wide scale, B. tepikiense is normally associated with fully marine conditions, commonly in stratified waters with large seasonal changes in SST (Rochon et al., 1999). It is present in low salinity water but large numbers (>10\%) usually occur only where SST is $>16^{\circ} \mathrm{C}$ and SSS is $>30$ (Zonneveld et al., 2013); possibly, lower temperatures limit the northward spread of the taxon in the BSC. Zonneveld et al. (2013) report that the cysts are confined to well-ventilated bottom water; this requirement could explain the absence of the cysts in surface sediment of deepwater sites in Marmara Sea whereas it is present on the shelf.

[Figure 9. Distribution map of Bitectatodinium tepikiense goes here]

4.4 Brigantedinium cariacoense (Wall 1967) Lentin and Williams 1993

Distinguishing characteristics: Based primarily on Wall (1967), Harland (1983) and Rochon et al. (1999), these are relatively large $(>35 \mu \mathrm{m})$, dark brown spherical cysts with a thin, brownpigmented body wall (Plate 3, Figs. 1-4). The wall surface is typically smooth, non-tabulate and lacking ornament. The large dorsal archeopyle normally corresponds to loss of intercalary plate 2a and is a laterally elongated, symmetrically hexagonal, with a width about c. $2 \mathrm{x}$ greater than the height (Plate 3, Figs. 1, 3-4), and with a curved posterior margin. There may be folds or splits in the archeopyle area but no other indications of tabulation are present. Sometimes two 
intercalary plates are released (Plate 3, Fig. 3), giving the archeopyle a lunate shape (Sonneman and Hill, 1997). The operculum is usually free but can remain attached (Harland, 1983).

Dimensions: Body diameter is $36-63 \mu \mathrm{m}$; archeopyle width and height are $28 \times 16 \mu \mathrm{m}$, for specimens from the Cariaco Trench and Yucatan Basin (Wall, 1967; Wall and Dale, 1968).

Synonymy: Chytroeisphaeridia cariacoensis Wall 1967; cyst of Protoperidinium avellana (Meunier) Lebour 1974.

Biological Affinity: Cyst of Protoperidinium avellana (Meunier 1919) Balech 1974 as first shown by Wall and Dale (1968) and confirmed by Matsuoka (1984). Recently Liu et al. (2015) further confirmed the cyst-theca relationship and found the LSU rDNA sequence of this species to be closely related to sequences of Protoperidinium denticulatum (Gran and Braarud 1935) Balech 1974 and Protoperidinium abei (Paulsen 1931) Balech 1974. P. avellana theca and cysts are reported for the western Mediterranean (Montresor et al., 1998) but are not in BSC plankton records. However, Protoperidinium thorianum (Paulsen 1905) Balech 1973, P. abei (Paulsen 1931) Balech 1974 and Protoperidinium punctulatum (Paulsen 1907) Balech 1974 which produce similar cysts (Lewis et al., 1984; Liu et al., 2015) occur in the Black Sea (Gómez and Boicenco, 2004) but only P. punctulatum is recorded for Marmara Sea (Deniz and Taş, 2009). $P$. avellana is presumably one of many heterotrophic Protoperidinium species (Gómez, 2012) although the cyst-theca relationship this is not yet confirmed by laboratory studies.

Comparison: B. cariacoense is similar in colour and shape to the cyst of Protoperidinium thorianum which differs only in having a straight posterior margin and attached operculum (Lewis et al., 1984). It is also similar to Brigantedinium irregulare Matsuoka 1987 which differs in having an elongated archeopyle with sides of slightly uneven lengths, giving it an irregular shape; the operculum is also attached. An asymmetrical operculum is also found in the cyst of Protoperidinium punctulatum (Harland, 1983). When slightly oxidised, the cyst wall of $B$. 
cariacoense may be pale brown and in Mediterranean cysts, the contact with the third apical plate is often curved after excystment and the operculum remains laterally attached, as noted in a few specimens from the BSC and in illustrations of Wall and Dale (1968) and Harland (1983).

Distribution: In the BSC surface sediments, B. cariacoense is widespread in low relative abundances on the Black Sea shelves, with maxima (c. 5-7.5\%) on the outer Danube Shelf where periodic upwelling occurs and where there are maxima of $\mathrm{P}$ and $\mathrm{N}$ (Figure 3); it is rare in the deep water areas where productivity is lower (Sorokin, 2002) and is only found at one site in Marmara Sea (Figure 10). There is no clear association between \% abundance and either SST or SSS. Average annual SST is $11.7-16.4{ }^{\circ} \mathrm{C}$, with a seasonal range from $5.6{ }^{\circ} \mathrm{C}$ (winter) to $23.8{ }^{\circ} \mathrm{C}$ (summer); SSS values mostly range from c. 15.7-18.3 (spring-spring) but in the Marmara Sea and Bosphorus exit to the Black Sea, values are higher: 20.2-31.4 (summer-winter). Associated nutrient values are $[\mathrm{P}] 0.03-0.33 \mu \mathrm{mol} / 1$, with maximum $\%$ values at $0.24 \mu \mathrm{mol} / 1$; $[\mathrm{N}] 0-4$, with cyst $\%$ increasing upwards; [Si] is $2-14(20) \mu \mathrm{mol} / 1$. [chl.-a] values are $\sim 0.45-2.9 \mu \mathrm{g} / \mathrm{l}$, with maximum cyst $\%$ at the lower end around 0.75 . The bottom $\mathrm{O}_{2}$ values are $0-6.8$, with maximum cyst $\%$ around 5.8. Overall, these nutrient data do not support a strong link to high nutrient and [chl.-a] levels as expected for the cysts of a heterotrophic dinoflagellate. The history of $B$. cariacoense in the BSC is poorly known because it has usually been recorded as Brigantedinium spp. (see Sect. 4.6). However, B. cariacoense occurs in the sapropelic early Holocene sediments of Marmara Sea core MAR02-89P (<10.5 ka B) where TOC is $1.5 \%$ (Roberts, 2012). Brigantedinium spp. are reported as continuously present in the SW Black Sea after 9.1 ka BP (Marret et al., 2009). In SE Black Sea Holocene sediments, B. cariacoense is present after $7 \mathrm{ka}$ BP (Shumilovskikh et al., 2013). In the Mediterranean, B. cariacoense is found in Naples Bay, Adriatic Sea (Sangiorgi and Donders, 2004), and in the Alboran Sea (Turon and Londeix, 1988), as consistent with its motile stage distribution, but it is rare on the Nile Shelf (Kholeif and 
Mudie, 2009). Aydin et al. (2011) report small numbers of B. irregulare in Izmir Bay. On a world-wide scale, $B$. cariacoense is usually grouped with Brigantedinium spp. for mapping and core assemblage counts; consequently, little is known about the specific ecological affinity of $B$. cariacoense except that it appears most abundant in warm-temperate to tropical regions often associated with warm SST and high SSS; in the NE Atlantic, the cysts also occur in the cold water regions of the theca distribution (Dodge and Harland, 1991). The BSC surface sample data provide the first evidence for the widespread distribution of B. cariacoense in stratified, eutrophic waters with SSS ranging from c. 6 (spring flood) to 31, mainly between c. 16-18. In this region, the association with high nutrient and [chl.-a] values is not strong despite clustering of the occurrences in areas of eutrophication within the Sea of Azov and NW Black Sea.

[Figure 10. Distribution map of Brigantedinium cariacoense goes here]

4.5 Brigantedinium simplex (Wall, 1965) Lentin and Williams 1993

Distinguishing characteristics: Based on Wall and Dale (1968), Reid (1977) and Rochon et al. (1999), these are medium to dark brown cysts, normally round but sometimes slightly dorsoventrally compressed and ovoid in polar and lateral view (Plate 3, Figs. 5-9). The thin single- or double-layered brown-pigmented wall usually has a smooth surface in small specimens but larger forms may be rugulate or microgranular. The cysts are largely non-tabular but in suitable orientations, sulcal pore scars, polar projections and traces of a cingulum may be seen (Plate 3 , Fig. 9). The dorsal archeopyle corresponds to loss of intercalary 2a and is subtrapezoidal with four long and two very short sides, with a width about the same or slightly less than as the height (Plate 3, Fig. 7). The operculum remains attached or is free. 
Dimensions: Diameter of body is 29-54 $\mu \mathrm{m}$ according to Reid (1977) and Matsuoka (1987) for $>150$ specimens.

Synonymy: Chytroeisphaeridia simplicia Wall 1965; cyst of Protoperidinium conicoides (Wall 1967) Balech 1973.

Biological Affinity: Related to Protoperidinium conicoides (Paulsen 1905) Balech 1973 by Wall and Dale (1968) who studied the theca-enclosed cysts from the Woods Hole area of eastern USA. $P$. conicoides is presumed to be a heterotrophic species (Gómez, 2012; Balkis et al., 2016) although this is not yet confirmed by laboratory study. $P$. conicoides is reported for plankton samples from Black Sea (Gómez and Boicenco, 2004) and Marmara Sea (Balkis et al., 2016).

Comparison: McMinn et al. (2010) comment that the archeopyle in cysts of P. conicoides may include two intercalary plates but this has not been seen in specimens from the Black Sea. Many Black Sea specimens of $B$. simplex have a scabrate to microgranulate surface.

Distribution: In surface sediments of the BSC, B. simplex is widely distributed on the shelf to upper slope of the Black Sea and in all areas of Marmara Sea where it occurs in relative abundances of up to c. $8 \%$ (Figure 11). In the Black Sea, B. simplex tends to be more abundant in coastal areas and has a maximum abundance of c. $18 \%$ at one site in the SE, east of the Sakarya Peninsula where periodic upwelling occurs. Neither the cysts nor the motile stage have been reported for the endorheic Caspian and Aral Seas. Associated SST ranges seasonally from $5.5{ }^{\circ} \mathrm{C}$ (winter) to $24{ }^{\circ} \mathrm{C}$ (summer), with highest cyst $\%$ at annual average SST $=16{ }^{\circ} \mathrm{C}$; SSS has a seasonal range of 14.5 (spring) to 31.5 (winter), with most occurrences grouped between $\sim 14.5$ and 18.4. Associated nutrient values are [P] mostly $0.05-0.3$ (to 0.88$) \mu \mathrm{mol} / 1,[\mathrm{~N}] 0-5 \mu \mathrm{mol} / \mathrm{l}$; [Si] 2-15 (up to 26) $\mu \mathrm{mol} / \mathrm{l}$; [chl.-a] ranges from 0.0 to $3.2 \mu \mathrm{g} / \mathrm{l}$. The bottom $\mathrm{O}_{2}$ values range from $0-7 \mathrm{ml} / 1$, with the maximum cyst $\%$ being near 0 and $4 \mathrm{ml} / 1$. As noted for $B$. cariacoense 
(Sect. 4.5), the history of this taxon in the BSC is not well known because of grouping as Brigantedinium spp. In general, B. simplex is a cosmopolitan estuarine to inner neritic species, most commonly found in temperate waters, including the Alboran Sea where it comprises about $30 \%$ of the total Brigantedinium spp. throughout the Holocene. The species is present in Arctic waters (Mudie and Rochon, 2001) and in eutrophic fiords (Mudie et al., 2002b), but other geographical details are not available because B. simplex it is often grouped with other Brigantedinium spp. The BSC data provide the first record of for the widespread distribution of B. simplex in stratified, eutrophic waters with SSS ranging seasonally from c. 15 (spring) to 31 (summer) and clustered around 15-18, and show that in this region, the association with high nutrient and [chl.-a] values is not strong but distributions are clustered in areas of Rim Current gyres where there is periodic upwelling. It may also be important that the peak Mediterranean values of $B$. simplex are associated with the uniquely $\mathrm{NO}_{3}$-enriched temperate Alboran Sea where there is a shallow winter mixed layer depth and shallow nutracline (Pasqueron de Fommervault et al., 2015).

[Figure 11. Distribution map of Brigantedinium simplex goes here]

\subsection{Brigantedinium spp. Reid 1977}

Distinguishing characters: Brigantedinium spp. here refers to a group of round or ovoidal brown cysts with a smooth or finely granulate wall surface (Reid, 1977). Most of these cysts resemble $B$. cariacoense and B. simplex but cannot be identified to species level because a polygonal or subpolygonal intercalary archeopyle is obscured or can only partly be seen. These morphotypes are commonly grouped together as the category Brigantedinium spp. 
Dimensions: The cyst body diameter is $29-63 \mu \mathrm{m}$.

Comparison: Marret and Zonneveld (2003) consider that this group may include Brigantedinium cariacoense, Brigantedinium simplex and Dubridinium capitatum, but we do not entirely follow that format here because we separate identifiable specimens of Brigantedinium spp. and Dubridinium capitatum (Sect. 4.27). Also, we place other unidentifiable (often squashed or torn), non-reticulate, spherical-subspherical brown cysts without discernble archeopyles or sulcal features in the category "Round Brown Cysts" (see Sect. 4.40). It should also be noted that Brigantedinium majusculum Reid 1977 ex Lentin and Williams 1993 which is the cyst of Protoperidinium pentagonum (Gran 1902) Balech 1974 is probably also present in Black Sea where the motile stage is recorded for the Black Sea (Gómez and Boicenco, 2004; Taş and Okuş, 2006) and Marmara Sea (Balkis et al., 2016); this species appears to be overlooked because it differs from B. simplex only in its larger size $(73-92 \mu \mathrm{m})$ and thicker wall (Reid, 1977) and damaged cysts may not be recognizable.

Distribution: In the BSC surface sediments, Brigantedinium spp. are almost ubiquitous (Figure 12), often occurring in amounts of $>5 \%$ in all the seas except Azov Sea. They are also present in the freshwater Lake Sapanca (Leroy and Albay, 2010). In the Ponto-Caspian seas, associated seasonal SST ranges widely from $4.5^{\circ} \mathrm{C}$ (winter) to $29.5^{\circ} \mathrm{C}$ (summer), and SSS is from 12-31.5 (summer -winter), with clusters around 13 (Caspian sites) and 17 (Black Sea). Associated nutrients are relatively low, with $[\mathrm{P}]<0.35$ ) except for one site with $\sim 0.9 \mu \mathrm{mol} / \mathrm{l})$, [N] $<5$ with highest cyst $\%$ near $0,[\mathrm{Si}]$ mostly $3-15(-35 \mu \mathrm{mol} / 1)$, [chl.-a] mostly $<3.5(-6) \mu \mathrm{mol} / 1$. The bottom $\mathrm{O}_{2}$ values range widely from $0-7.5 \mathrm{ml} / 1$ without a clear relationship to cyst amounts. In general, Brigantedinium spp. are essentially cosmopolitan, being widespread in coastal to oceanic sediments of the North Atlantic, eastern North Pacific (e.g. Pospelova et al., 2008), and many other areas listed in Zonneveld et al. (2013). The cysts are often found in upwelling areas 
but have a broad range of SST, SSS and nutrient concentrations (Marret and Zonneveld, 2003). The presumably heterotrophic motile-stage species Protoperidinium avellana and $P$. conicoides are usually associated with eutrophic conditions but they can also be abundant in oligotrophic waters. All Brigantedinium cysts, however, are vulnerable to aerobic decay in oxygen-rich waters and aerated sediments. This factor may bias their apparent association with waters of enhanced biological production where high organic sediment deposition favours cyst preservation. However, the BSC data do not indicate a clear correlation between bottom $\mathrm{O}_{2}$ concentrations and $\%$ Brigantedium spp. in stratified waters of epicontinental seas.

[Figure 12. Distribution map of Brigantedinium spp.goes here].

\subsection{Caspidinium rugosum Marret in Marret et al. 2004}

Distinguishing characters: Based on Marret et al. (2004), the proximate cysts of Caspidinium rugosum are relatively large and are subspherical or slightly sub-cruciform, with a rounded apex without an apical horn or boss, and having a flat antapical area and rregularly rugose thick wall (Plate 4, Figs. 12-19). The cysts are slightly compressed dorsoventrally and are reniform in apical view (Plate 4, Fig. 16), with a dextral torsion. The epicyst is smaller than the hypocyst, making the cysts slightly pear-shaped in ventral view. The relatively thick $(1.5 \mu \mathrm{m})$ transparent wall with low sutural and solid broad to narrow ridges in some areas, and with distinctive coarsely rugulate to papillate intratabular ornamentation. The archeopyle corresponds to the third precingular plate (3") and is wide and arch-shaped (iso-camerate (Plate 4, Fig. 14), with a free operculum. Thickened sutural septa delimit an S-type gonyaulacacean tabulation (4', 6", 6c, ?6"', $\left.1 \mathrm{p}, 1^{\prime \prime \prime \prime}\right)$ but when specimens are broken these features cannot be seen. 
Dimensions: Body length is $45(52) 60 \mu \mathrm{m}$; body width is $45(52) 60 \mu \mathrm{m}$; average wall thickness is $1.5 \mu \mathrm{m}$ for 8 specimens (Marret et al. 2004).

Biological Affinity: Motile stage is presently unknown, but the number and arrangement of apical plates and the S-type tabulation point to a gonyaulacoidean affiliation (Marret et al., 2004).

Comparison: Caspidinium rugosum differs from species of Impagidinium and Corrudinium by its dextral torsion, solid septa, and its irregular, mostly incomplete tabulation. C. rugosum also differs from Cribroperidinium species by its S-type bulation. C. rugosum differs from the cyst of Gonyaulax apiculata in having an extra precingular plate (Evitt et al., 1985) and because the dextral torsion typically puts the $3 \mathrm{c} / 4 \mathrm{c}$ suture at the edge of the archeopyle margin, not the middle (Plate 4, Fig. 14); however, it should be noted that the tabulation (e.g. Plate 4, Figs. 1217) may correspond to Gonyaulax apiculata and is being studied further by KNM. However, the cyst of G. apiculata differs in having a prominent apical boss and a smooth to verrucate wall which is either atabular or has faintly-delineated cingular and other sutures marked by rows of verrucae or tubercles (Evitt et al., 1985). C. rugosum exhibits strong morphological variability in the thickness of the septa and height of the verrucae and intra-tabular ornamentation, with maximum thickening seen in specimens from the Volga Delta, in a modern cyst from the Ukrainian continental slope, and in a cyst from latest Pleistocene sediment of Atlantis II core 1474P in the Black Sea examined by P. Mudie. In the Caspian Sea, a strongly rugose morphotype (C. rugosum rugosum of Leroy et al., 2013b) has some intratabular areas almost covered by broad plate-like ornament (Plate 4, Fig. 18) but other specimens from the northern shelf have relatively smooth, papillate intratabular areas (Keith Richards, personal communication, 2015), as also seen in specimens from Aral Sea (Sorrel et al., 2006, pl. 3, fig.7). 
The C. rugosum cyst from Marmara Sea sediment in core MD01-2430 (Londeix et al., 2009, pl.e 3.4, fig. 15) also has a relatively smooth wall.

Distribution: In surface sediments, C. rugosum is largely restricted to the Caspian and Aral Seas, with the only other occurrence being one specimen at each of five scattered sites in the northern Black Sea (Figure 13). In the Caspian sea-surface sediments, it occurs in amounts up to c. $6 \%$ on the warmer southwestern shelf. Overall, it is associated with moderate temperatures (SST 4.5-28.8 ${ }^{\circ} \mathrm{C}$ winter-summer) and with annual SST average $13.6-20.0{ }^{\circ} \mathrm{C}$. There is a bimodal distribution of associated salinity, primarily clustered around the Caspian Sea reduced salinities with annual SSS average 12.4-12.9 (seasonally 12.1-13.5 winter-autumn), in wellventilated to hypoxic bottom water $\left(\mathrm{O}_{2} 2.5-7.4 \mathrm{ml} / \mathrm{l}\right)$. Rare occurrences of $C$. rugosum also occur in the low salinity (<2 psu) Volga and Danube and deltas (not included in statistics) where the rivers are frozen several months in winter. Associated nutrients are low: $[\mathrm{P}]$ is mostly $<0.15$ (0.07-0.24 $\mu \mathrm{mol} / 1),[\mathrm{N}]<1(0.01-0.39 \mu \mathrm{mol} / 1$, and [Si] mainly 0.2-3.9 (Caspian Sea) up to 6.1 $\mu \mathrm{mol} / \mathrm{l}$ in Black Sea. Few [chl.-a] data are available and these are also low $(0.45-0.97 \mu \mathrm{g} / 1)$. Zonneveld et al. (2013) report associated oligotrophic nutrient conditions for seven Caspian occurrences of $C$. rugosum although Nasrollahzadeh et al. (2013) indicate that there can be locally higher values in the southern Caspian Sea shelf (DIP $0.8 \mu \mathrm{mol} / 1$ and DIN $3.59 \mu \mathrm{mol} / 1$ at $20 \mathrm{~m}$ water depth in 2005). In Holocene sediment cores, small amounts of C. rugosum are occasionally present from c. 2000-300 yr BP in the North Aral Sea (Sorrel et al., 2006), and the cysts are common in the central Caspian Sea deep basin from c. 9 to $5.5 \mathrm{ka}$ BP but rare in the latest Holocene interval (Leroy et al., 2014). In the Black Sea, the species is rare in the early Holocene of the Black Sea basin core M72/5-25GC1 (Shumilovskikh et al., 2014) but it is not found in Holocene sediment cores of Marmara Sea after the Younger Dryas (Londeix et al., 2009; Roberts, 2012). 
[Figure 13. Distribution map of Caspidinium rugosum goes here]

4.8 Cyst of Alexandrium pseudogonyaulax (Biecheler 1952) Horiguchi ex Kita and Fukuyo 1992

Distinguishing characteristics: Based on Montresor et al. (1993) and Montresor (1995), the resting cysts of Alexandrium pseudogonyaulax are spherical with a transparent, smooth or microgranular wall (Plate 1, Figs. 7-12). The outer wall has characteristically faintly visible, relatively broad, low sutural crests of equal height that delimit the tabulation typical for the genus (Po, 4', 6", 6c, 5'"', 2'"'). Sutures are incomplete in the sulcal area and a small notch may reflect the ventral pore between $1^{\prime}$ and $4^{\prime}$; intraplate wall areas are smooth. The archeople is theropylic, small and notably variable in position. Montresor et al. (1993) report that it can form by loss of either the ventral 1c plate or the dorsal anterior 3" plate, or by opening of a Y- or Tshaped suture between plates $4 ", 4 \mathrm{c}$ and $5 \mathrm{c}$. The cyst of A. pseudogonyaulax is the only tabulate cyst in the genus Alexandrium and is unique in the variability of its archeopyle position and shape.

Dimensions: Montresor et al. (1993) give the endocyst diameter about 40-55 $\mu \mathrm{m}$; septa height c. $1 \mu \mathrm{m}$ for an unspecified number of cysts and Zmerli Triki et al. (2014) report a diameter of 40-72 $\mu \mathrm{m}$ for 30 cysts in Bizerte Lagoon, Tunisia; specimens we find in the BSC appear to be at the low end of the size range, as are the motile cells found in the Black Sea by Terenko (2005).

Synonymy: Motile stage has also been called Goniodoma pseudogoniaulax Biecheler 1952 and Triadinium pseudogonyaulax (Biecheler) J.D. Dodge 1981 (as "pseudogoniaulax"). 
Biological Affinity: The cyst-theca relation was established by Montresor et al. (1993) and Montresor (1995) through incubation of cysts from Lake Fusaro (coastal lagoon) on the Tyrrhenian coast (Mediterranean Sea), which was later confirmed by Bravo et al. (2006) for cysts isolated from recent sediments of the western Mediterranean coast (Alfacs Bay). The cyst is produced by the toxic armoured, bloom-forming, phototrophic and facultatively phagotrophic marine dinoflagellate Alexandrium pseudogonyaulax, some strains of which produce the phycotoxin goniodomin-A and have fungicidal properties (Faust and Gulledge, 2002). The species appears to have been introduced to Odessa Harbour, NW Black Sea, in 2002 (Terenko, 2005) but it was not widespread in 2004 (Gómez and Boicenco, 2004).

Comparison: Head (1996) remarks that the cysts of Alexandrium pseudogonyaulax superficially resemble the cyst-based genus Impagidinium in their low sutural crests and suppressed tabulation in the sulcal region. However, the ventral organization and hypocystal tabulation are different from Impagidinium, and the archeopyle in A. pseudogonyaulax cysts may include a cingular plate or plates as well as, or instead of, the third precingular plate which are features not seen in Impagidinium. Zmerli Trilki et al. (2014) find two types of $A$. pseudogonyaulax cysts in Tunisia: typical cysts with a tabulate wall and a morphotype with a smooth common wall. In the Black Sea, we do not recognise smooth-walled morphotypes and find mostly only the small cysts of A. pseudogonyaulax which are spherical (Plate 1, Figs. 7-10) and very pale in colour with a mucilaginous wall.

Distribution: In the BSC surface sediments, cysts of $A$. pseudogonyaulax are confined to the Black Sea where they are widespread and common (up to c. $21.5 \%$ ) in deeper water areas (214-2083 m) but are absent along the coastal and at most inner shelf sites (Figure 14). Average seasonal SST is $4.5-27.7^{\circ} \mathrm{C}$ (winter-summer), with average minimum and maximum of $6.8{ }^{\circ} \mathrm{C}$ 
and $24.0{ }^{\circ} \mathrm{C}$ respectively. Average SSS is 17.6 with less than 1 difference seasonally, and a total range from 16.3 (autumn) to 18.4 (spring). Terenko (2005) reports that A. pseudogonyaulax was first found in the phytoplankton during July, 2002, in the Odessa Bay where SST was $25.8^{\circ} \mathrm{C}$ and SSS was 14.5 , and she gives SST and SSS conditions of $25.0-26.6^{\circ} \mathrm{C}$ and $13.0-14.5$. These warmer and less saline values are consistent with the nearshore location in the vicinity of the Dnieper River estuary. Associated nutrients (Figure 5) are mostly low with $[\mathrm{P}]<0.25 \mu \mathrm{mol} / \mathrm{l}$; $[\mathrm{N}]$ $<2 \mu \mathrm{mol} / \mathrm{l}$; [Si] 1.8-14 $\mu \mathrm{mol} / \mathrm{l}$, with peak cyst $\%$ around $5.5 \mu \mathrm{mol} / \mathrm{l}$; [chl.-a] ranges from $\sim 0.4-2$ $\mu \mathrm{g} / \mathrm{l}$. The bottom $\mathrm{O}_{2}$ values range from $0-6.8 \mathrm{ml} / \mathrm{l}$, but maximum cyst $\%$ occurs in hypoxic conditions and decreases rapidly above $2 \mathrm{ml} / \mathrm{l}$. In the BSC, the cysts of $A$. pseudogonyaulax have not been found in sediment cores below the latest Holocene interval.

World-wide, the motile stage is found in coastal lagoons, neritic marine areas e.g. Norwegian Sea (Throndsen et al., 2007) and Bay of Fundy, Canada (Klein et al., 2010), and in brackish to marine water of western Europe,including Norwegian fiords (Balech, 1959) and the Mediterranean coast of France, Italy, Tunisia (Montresor et al., 1993; Zmerli Triki et al., 2014), Australia, Tasmania, New Zealand (McMinn et al., 2010), Japan (Kita and Fukuyo, 1988), west coast of Bering Sea (Orlova et al., 2002), and the Strait of Georgia, Botany Bay and Barkley Sound, British Columbia (Taylor and Haigh, 1993, 1996; Taylor and Harrison, 2002; Faust and Gulledge, 2002). A globally representative range of SST and SSS may be from $-15^{\circ}$ to $30{ }^{\circ} \mathrm{C}$ and 15-30 (in Oslofjord, Norway) to $11.5-29.5^{\circ} \mathrm{C}$ and $32.0-36.8$ (in Tunisia) where dissolved oxygen varies seasonally from $3.1 \mathrm{mg} 1 / 1$ in summer to $10 \mathrm{mg} 1 / 1$ in winter. Cysts of $A$. pseudogonyaulax are reported for sediment traps off Mauritania where they are most abundant in the upper well-ventilated water layer (Zonneveld et al., 2010). In contrast, our data show that the 
cysts are more abundant in the anoxic sediments of the central Black Sea, and in all BSC areas, the associated salinity is at the low end of previously reported ranges.

[Figure 14 Distribution map of cyst of Alexandrium pseudogonyaulax goes here].

\subsection{Cyst of Alexandrium spp.}

Distinguishing characters: Generally following Bravo et al. (2006), these transparent cysts are characterised by their spherical to elongate-cylindrical (ellipsoid) central body with rounded ends and thick walls that always have a distinctive hyaline (very reflective) appearance (Plate 5, Figs. 4-9). The outer wall of the central body is about $0.5 \mu \mathrm{m}$ thick, transparent, and more or less smooth. The body is sometimes covered by a thin mucilaginous membrane and may include reddish-brown pigment-containing plastids. The archeopyle is not commonly seen but is chasmic (a simple slit). No tabulation can be observed.

Dimensions: Size globally is $35-50 \mu \mathrm{m}$; in the BSC, $35 \mu \mathrm{m}$ is near the minimum size.

Biological affinity: These cysts are resting spores of Alexandrium spp., many of which cause red tide outbreaks and toxic algal blooms, making them targets of concern in coastal waters, including the coast of Bulgaria (Moncheva et al., 1995; Vershinin et al., 2006). BSC plankton surveys indicate the following occurrences: Alexandrium monilatum and Alexandrium minutum are widespread in the Black Sea but not found in Danube Delta or limans; Alexandrium cf. tamarense is reported for 2001-2006 in the NE Black Sea; Alexandrium pseudogonyaulax appeared in Odessa Bay in 2002, and there was a bloom of Alexandrium ostenfeldii in Sozopol Bay in 2005. Alexandrium minutum, Alexandrium affine and Alexandrium sp. are reported for 
Marmara Sea; Alexandrium catenella, Alexandrium minutum and Alexandrium tamarense are in the adjacent Aegean Sea.

Comparison: Overall, the cysts of Alexandrium species cannot be distinguished reliably based on morphological features (see Bravo et al., 2006, figs 2-18) and there is increasing reliance on detection of toxic species/strains by PCR or liquid chromatographic methods rather than microscope examination of plankton samples (Erdner et al., 2010; Burrell et al., 2013). However, Alexandrium cysts are distinguished from cysts of A. pseudogonyaulax by the absence of tabulation. The chain-forming Alexandrium species Alexandrium acatenella and Alexandrium catenella have not been reported in the BSC although they occur in the neighbouring Aegean Sea. Cysts of the red-tide algae Alexandrium monilatum and A. minutum are oval and about the same size as smaller cysts of $A$. tamarense; in lateral view, cysts of A. minutum are bean-shaped. Vershinin et al. (2006) comment that Bulgarian cysts first identified as those of A. tamarense showed a wide range of motile cell size, in morphology of the 6" plate, and in presence of toxins GTX2, GTX3 and GTX5. They concluded that A. minutum was also present in the population although the incubated cysts produced A. tamarense. A. minutum is also present in the Gulf of Gemlik, Marmara Sea, together with cysts of Alexandrium cf. affine and an unknown Alexandrium sp. (Balkis et al., 2016). The latter two taxa are spherical and relatively small $(<30$ $\mu \mathrm{m})$; similar cysts are common in surface sediments of the NW Black Sea shelf.

Distribution: In surface samples of the BSC, cysts of Alexandrium spp. are widely distributed in shelf and slope sites from Marmara to the Azov Sea (Figure 15). Relative abundances are relatively low $(<5 \%)$ in most samples from Marmara Sea and in shelf sediments of the Western Black Sea, with maxima of c. $8 \%$ in water of $<15$ off the Danube Delta where the spherical cysts of A. cf. affine are most common. Generally, there are fewer occurrences in the deep waters of the Black Sea basins, but peak abundances (up to 46\%) occur in deep slopes sites and other high 
values appear associated with the semi-permanent Sevastopol, Crimea and Kerch gyres of the Rim Current. There is also a large peak (41\%) in the polluted waters of Gelendzhik Bay.

Associated seasonal SST mostly ranges from 5.6-23.8 ${ }^{\circ} \mathrm{C}$ (winter-summer), without a clear link to cyst $\%$ values; the Azov site has a winter minimum of $0.66^{\circ} \mathrm{C}$. Associated SSS tends to be clustered between 15 and 18 at all seasons and is also not clearly correlated with cyst \% values; the overall range is 8.6-31.1 (autumn-winter). Associated nutrients are [P] 0.07-0.32, with maximum cyst amounts around $0.1 ;[\mathrm{N}]$ ranges from $0.15-4.8$ but with highest cyst $\%$ at $\mathrm{c}$. 0.4; [Si] ranges from 1.7-33.6, with peak cyst $\%$ around $5-6 \mu \mathrm{mol} / 1)$; [chl.-a] ranges from $0.69-3.3$, with peak cyst $\%$ being at values $<1$ ). The bottom $\mathrm{O}_{2}$ values are $0.15-6.9$, with no clear link to cyst $\%$ values. The first appearance of the cysts of Alexandrium spp. in Holocene Black Sea sediments is c. 900 yr BP on the SW Shelf (Marret et al., 2009). Streftaris et al. (2005) list $A$. tamarense as a non-indigenous species (NIS) recently introduced to the Black Sea. The cysts are not seen in palynological studies of most deepwater cores from the Black Sea but Coolen et al. (2013) report the presence of Alexandrium lusitanicum in a core from $970 \mathrm{~m}$ bsl (below sea level) as detected by pyrosequencing of sedimentary 18S rRNA genes.

On a world-wide scale, cf. cysts of Alexandrium tamarense (sometimes including Alexandrium catenella and Alexandrium acatenella) are found in temperate coastal sediments of the North Atlantic and North Pacific Oceans and in tropical-subtropical coastal sediment of the eastern Indian Ocean, in a wide range of SST and nutrients but more abundant in mesotrophiceutrophic water. Zonneveld et al. (2013) report restriction to well-ventilated bottom water in contrast to the values of BSC cysts of Alexandrium. The BSC SST values are generally higher than the world-wide average of $<5{ }^{\circ} \mathrm{C}$ that is associated with large peaks $(>80 \%)$ of cysts of Alexandrium tamarense in the NW Pacific (Zonneveld et al., 2013) and the SSS values are at the low end of the global range for A. tamarense. 
[Figure 15. Distribution map of cyst of Alexandrium spp.goes here].

4.10 Cyst of Barrufeta resplendens (Hulburt 1957) Gu, Luo and Mertens 2015

Description: Based on Gu et al. (2015a), the cyst of Barrufeta resplendens are brown and ovoid-shaped, with a relatively thick two-layered wall, the surface of which is microgranular and bears sturdy, straight, hollow processes terminating distally in platforms with irregular margins (Plate 6, Figs. 1-7). The process bases may be joined by low crests, particularly in the cingulum. The archeopyle is tremic, with a zigzag margin on the dorsal epicyst (Plate 6, Fig. 4).

Dimensions: Cysts are 38.7-40.9 $\mu \mathrm{m}$ long and 35.2-36.0 $\mu \mathrm{m}$ wide; process length 5.2-5.8 $\mu \mathrm{m}$.

Synonymy: None.

Biological Affinity: Incubation studies of Gu et al. (2015a) show that the cyst is produced by the gymnodinioid species Barrufeta resplendens (Hulburt 1957) Gu, Luo and Mertens 2015, formerly known as Gyrodinium resplendens Hulburt which is recorded for the BSC phytoplankton.

Comparison: Barrufeta cysts differ from cysts of Polykrikos kofoidii/schwartzii in having a lateral, not apical archeopyle, and in the shape of the processes. Barrufeta bravensis N. Sampedro and S. Fraga 2011 is a Mediterranean species which produces an oval, mucilagecovered, double-walled cyst in culture (Sampedro et al., 2011). Wall et al. (1973, pl. 1, fig. 25) illustrate a cyst with similar morphology from Sapelo and Albermarle Sounds in Georgia, USA.

Distribution: Cyst of B. resplendens is not mapped here because only two surface occurrences are reported, these being from the SE Black Sea continental slope cores 22-MUC-1 (-842 m) and 
25-MUC-2 (-418 m), east of the Sinop Peninsula, studied by Mousing et al. (2013) who did not report its presence in their $150 \mathrm{yr}$-long record. Associated salinity, nutrients and $\mathrm{O}_{2}$ values for these sites are similar to those shown in Table 4 for nearby sites 51-1 to 55-2MUC. A few cysts of Barrufeta resplendens are preserved downcore in carbonate and organic-rich late Holocene sediments of the SW Black Sea slope core GeoB7625-2, $347 \mathrm{~cm}$ (Plate 6, Figs. 5-7) although the cysts were not recovered in palynological preparations by Gu et al. (2015a). The time of its first appearance in the BSC is uncertain but it seems to coincide with the rise in Emiliania huxlei at the start of Greek shipping c. 3 ka BP (Marret et al., 2009). Outside of the BSC, Gu et al. (2015a) report that the cyst of B. resplendens occurs in the subtropical northern Gulf of Mexico off the Mississippi Delta (SSS 20-34) and temperate Chesapeake Bay, Sapelo and Altamaha Sounds, eastern USA, Maryland, with the motile stage also occurring in brackish water (SSS 11) of coastal Maryland, central eastern USA. As Gyrodinium resplendens, the motile stage has not been reported for the Black Sea and this is the first report for the occurrence of the cyst of Barrufeta resplendens in the BSC.

4.11 Cyst of cf. Biecheleria baltica (Kremp et al. 2005) Moestrup, Lindberg and Daugbjerg, 2009

Distinguishing characteristics: Based on the similarity to the cyst of Biecheleria baltica depicted by Kremp et al. (2005, as Woloszynsika halophila), the cyst of cf. Biecheleria baltica is characterised as being a small, transparent, spherical dinocyst with a relatively thick hyaline wall, the surface of which is uniformly and densely covered by short, straight or slightly conical hollow processes (Plate 7, Figs. 7-12) or by solid spines (Plate 7, Figs. 13-15). The archeopyle 
is not commonly seen, but in the NW Black Sea, a specimen was found with a tremic archeopyle forming a lunate slit about half the width of the cyst.

Dimensions: Cyst body diameter is $18.8(21.0) 26.9 \mu \mathrm{m}(\mathrm{n}=5)$; process length is $0.5(0.8) 2.1$ $\mu \mathrm{m}(\mathrm{n}=15)$.

Biological Affinity: Presently unknown but possibly a cyst of the woloszynskoid genus Biecheleria. Several Woloszynskia species are listed in the Black Sea phytoplankton of the Danube Delta coastal area by Török (2009), which could correspond to one of these species. Biecheleria baltica (= Wolozynskia halophila (Biecheler) Kremp et al. 2005 is a cold-water spring bloom-forming species (Kremp et al. 2005).

Comparison: The cyst of Biecheleria pseudopalustris (J. Schiller) Moestrup, Lindberg and Daugbjerg (= Gymnodinium pseudopalustre J. Schiller 1933, Gymnodinium palustre Schilling forma (Wołoszynska 1917), Gymnodinium excavatum Nygaard 1945; Woloszynskia pseudopalustris (J.Schiller) Kisselev 1954; Woloszynskia pseudopalustris (J. Schiller) Kisselev ex Elbrächter) as described by Moestrup et al. (2009) differs in being larger (body c. $30 \mu \mathrm{m}$ diameter) with irregular and branched hairlike processes. B. baltica has short processes which are denser and appear to be clustered within plate areas, giving their distribution a more irregular appearance than the BSC cysts of cf. Biecheleria baltica.

Distribution: In the BSC surface sediments, the cyst of cf. Biecheleria baltica is widespread in the shelf sediment of western Black Sea, with a few sites also in Marmara Sea but only one site in the eastern Black Sea (Figure 16). Largest amounts (13-23\%) occur within the Danube Delta discharge plume with an average annual SSS $\sim 16-18$, and maximum cyst $\%$ at the low end of this range; the seasonal range is $\sim 14.5-32.5$ (spring-winter). Associated SST ranges from -5.5-23.5, with most occurrences and maximum cyst amounts clustered around annual SST $14-15{ }^{\circ} \mathrm{C}$. Associated nutrients show a weak correlation with increasing $[\mathrm{P}]$ from $0.05-0.35$, 
and $[\mathrm{N}]$ from $0-5 \mu \mathrm{mol} / 1$ ); [Si] range is $\sim 4-23 \mu \mathrm{mol} / \mathrm{l}$ ), with maximum cyst $\%$ around 13 $\mu \mathrm{mol} / \mathrm{l})$; Chlorophyll-a values range from $0.5-3.2 \mu \mathrm{g} / \mathrm{l}$, with a largest amounts being $>2.8$. The bottom $\mathrm{O}_{2}$ range is $0-6.5 \mathrm{ml} / \mathrm{l}$, with the largest number of occurrences in well oxygenated water. On a world-wide basis, Biecheleria baltica $(=W$. halophila sensu Kremp et al. 2005) is listed as a marine species but Kremp et al. (2005) find that it grows at all salinities from 3-30; however, maximum growth rates were at salinities above 6.5 and the cells died when transferred to freshwater medium. The cyst of cf. Biecheleria baltica was not found in sediment cores, suggesting that it is a recent introduction to the Black Sea region. This increase may be because Wolozynskia halophila is becoming increasingly common in the Baltic Sea (Kremp et al., 2005) that is connected by canals to the Black Sea. Elsewhere, the motile stage of B. baltica is widespread in coastal areas of the NE Atlantic and it also occurs along the north shore of the Mediterranean Sea. This is the first report of the possible occurrence of Biecheleria baltica-type cysts in the Ponto-Caspian Seas where the distribution pattern suggests it could have entered from the Mediterranean and/or the Dniester-Bug canal system.

[Figure 16. Distribution map of cyst of Biecheleria goes here].

\subsection{Cyst of Cochlodinium polykrikoides sensu Li et al. 2015}

Distinguishing characteristics: Based on Li et al. (2015), these small, spherical cysts are light brown in colour and are covered by irregular polygons (Plate 8, Figs. 7-15). The angles of the polygons are ornamented by short, dark-brown, conical, solid spines. The short archeopyle is chasmic (Plate 8, Fig. 13). Although similar cysts of Warnowia cf. rosacea are destroyed after palynological treatment (Ellegaard et al., 2002a), we have found that the BSC cysts 
Cochlodinium polykrikoides sensu Li et al. 2015 survive our palynological treatments, possibly because of their occurrence in highly organic, often sub-oxic or anoxic sediment that provides good preservation of particulate organic matter.

Dimensions: Cyst diameter is $25.9-35.1 \mu \mathrm{m}$; spine length is $3 \mu \mathrm{m}$ ( $\mathrm{Li}$ et al. 2015).

Synonymy: Related to Cochlodinium polykrikoides by Li et al. (2015)Biological Affinity: The cyst was related to Cochlodinium polykrikoides by Li et al. (2015) and is possibly a cyst of Margalefidinium Gómez and Anderson 2017. C. polykrikoides can cause red tides and fish kills (Fukuyo et al., 2011) and it appears to be common in the BSC (Nesterova et al., 2009) although the relationship remains to be confirmed by biomolecular data. Terenko (2005) reports that cells and cysts of Cochlodinium polykrikoides Margaleff 1961were first found in Odessa Bay in 2001, being introduced either in ballast water or via water from Dardanelles Strait. In the same year, a monospecific bloom of $C$. polykrikoides occurred along on the coast of Bulgaria (Nesterova et al., 2009; Vershinin et al., 2005).

Comparison: Cysts of Warnowia cf. rosacea described by Ellegaard et al. (2002a) resemble the cyst of $C$. polykrikoides but do not show the occurrences of irregular polygons. As a whole, Cochlodinium polykrikoides is a complex of species with several ribotypes (e.g. Li et al., 2015). As such there have been several different cyst types associated with this species complex (see Kim et al., 2004; 2007; Tang and Gobler, 2012). The specimens from the Black Sea resemble the cysts from Li et al. (2015) and the polygonal ornament with spines distinguishes it from rounded C. polykrikos cysts of Kim et al. (2007) and Tang and Gobler (2012).

Distribution: In surface sediment of the BSC, cysts of C. polykrikoides ss Li et al. 2015 are almost confined to the Black Sea where they are widespread in low relative abundances, tending to be most abundant (c. 4-6\%, up to $8.75 \%$ ) on the outer shelf to upper slope of the northern shelf margins (Figure 17). There is one minor occurrence in the western Marmara Sea. 
Associated SST ranges from $\sim 5.5-24{ }^{\circ} \mathrm{C}$ (winter-summer), with annual average about $14.5{ }^{\circ} \mathrm{C}$; SSS ranges from 14 to 27.8 (summer-winter), with an annual average $\sim 17.5$ and maximum \% cysts around 18. Associated nutrients show higher cyst occurrences where $[\mathrm{P}]$ varies between 0.10 and $0.27 \mu \mathrm{mol} / 1,[\mathrm{~N}]$ ranges from 0 to $3 \mu \mathrm{mol} / 1$, [Si] from 1.8 to $10 \mu \mathrm{mol} / 1$, and [chl.-a] values vary from 0.5 to $2.7 \mu \mathrm{g} / \mathrm{l}$. The bottom $\mathrm{O}_{2}$ range is $0-7.5 \mathrm{ml} / \mathrm{l}$, with most occurrences in anoxic ( 0 oxygen $)$ and hypoxic $(<4 \mathrm{ml} / \mathrm{l})$ water. The cysts are very rare in sediment cores, being found only in sapropelic sediment at one site on the SW slope of the Black Sea (GeoB7625-2, $515 \mathrm{~cm}$ ), with a ${ }^{14} \mathrm{C}$ age of about $4 \mathrm{ka}$ BP. Blooms of Cochlodinium polykrikoides Margalef 1961 in the Black Sea are reported to occur in August, with SST 25-26.6, SSS 13-14.5 (Terenko, 2005).

Chain-forming colonies of Cochlodinium polykrikoides Margalef 1961 occur in coastal areas of the western Pacific from eastern Russia (rare) to the Philippines and Malayasia; in coastal inlets and bays water of the eastern Pacific from British Columbia to Baja California Sur, Manzanillo Bay in Mexico and off Guatemala; estuaries of the Southeast USA, the Mediterranean coasts of SE Spain, Sardinia, western Italy, SE Adriatic Sea, and near Goa in the Indian Ocean (Rosales-Loessener et al., 1996; Matsuoka et al., 2008). Where it is abundant as pellicle cysts (Pospelova and Kim, 2010), SST ranges from $12^{\circ}$ (winter) to $26^{\circ} \mathrm{C}$, SSS is $33-34$, and [chl.-a] averages c. $0.75 \mathrm{mg} / \mathrm{m}^{3}$. Field observations and culture experiments suggest that $C$. polykrikoides is generally well adapted to SST $>20{ }^{\circ} \mathrm{C}$ and to SSS of $30-33$, with the Mediterranean ribotype having a wide tolerance for SST and SSS variations, and with the eastern USA ribotype able to grow at lower temperature and salinity levels (Reñé al., 2013); Asian ribotypes appear to prefer high salinity, temperature and irradiance in summer (Kim et al., 2004). Growth rate and swim speed of $C$. polykrikoides may be inhibited by presence chain-forming diatoms and distribution of this dinoflagellate species may be inverse to the diatoms (Lim et al., 
2014). The occurrences in the Black Sea will extend the distribution of $C$. polykrikoides cysts into brackish water when confirmed by genetic studies.

[Figure 17. Distribution map of cyst of Cochlodinium polykrikoides ss Li et al., 2015 goes here.]

\subsection{Cyst of Cochlodinium sensu Fukuyo 1982}

Distinguishing characters: Based on Fukuyo (1982), these cysts are light to dark brown, ellipsoidal to sub-spherical in shape, and they have surface ornament comprising numerous short processes with rounded (lobate) or slightly denticulate blunt distal ends (Plate 6, Figs. 8-16). The cyst wall has two layers: a thin smooth endophragm and a periphragm which is typically raised into numerous short $(5-7 \mu \mathrm{m})$, irregular-shaped broad or narrow lobes. The lobes are apparently randomly distributed, and sometimes are reduced to large wart-like ornament (Plate 6, Figs. 13-14) or are wedge-shaped with blunt tips (Plate 6, Figs. 8-10). The surface is coarsely granular and the proximal bases of the processes may be joined laterally to form a partial reticulum. The chasmic archeopyle forms a large longitudinal fissure, typically about half the cyst diameter, but possibly larger in some Black Sea specimens (Plate 6, Figs. 12, 14-15).

Dimensions: Fukuyo (1982) does not give dimensions for his Cochlodinium sp. McMinn et al. (2010) give the size as 25-33 $\mu \mathrm{m}$ long and 38-40 $\mu \mathrm{m}$ wide. Black Sea specimens are mostly ellipsoidal and c. 35-40 $\mu \mathrm{m}$ wide with an archeopyle width of c. $20 \mu \mathrm{m}$.

Synonymy: Cysts of Cochlodinium polykrikoides sensu Matsuoka and Fukuyo (2000, their plate 1, fig. 2); Cochlodinium sp. 1 sensu Matsuoka and Fukuyo (2000, plate 5) 
Biological affinity: The cysts of Cochlodinium sp. sensu Fukuyo 1982 are produced by an unnamed short chain-forming species of the gyrodinoid dinoflagellate genus Cochlodinium Schütt 1896. According to McMinn et al. (2010), the cyst may be related to Cochlodinium geminatum (F.Schütt) F. Schütt in Engler and Prantl 1896 which is reported for the Black Sea by Gómez and Boicenco (2004).

Comparison: The apparent absence of cysts of Cochlodinium sp. in some cores from Marmara and the western Black Sea may be because of its superficial resemblance to smaller cysts of Polykrikos kofoidii which is similar in color and size.

Distribution: In our BSC surface samples, cysts of Cochlodinium sensu Fukuyo 1982 with wedge-shaped or lobate ornament are sporadically present in low numbers $(<2 \%)$ in Marmara, western and southern Black Sea, being most common on the outer Ukrainian Shelf (Figure 18). The highest \% abundance $(7.8 \%)$ is in eastern Marmara Sea, with lesser amounts in lower productivity deep water areas of western and eastern Black Sea. Associated SST generally ranges from $5.5^{\circ}$ (winter) to $24{ }^{\circ} \mathrm{C}$ (summer), with SSS values from 14.25 (autumn) to 31 (winter); however, a smaller SST range of $12.80-25.98{ }^{\circ} \mathrm{C}$ is found in Kerch Strait at the entrance to Azov Sea. Associated nutrients show cyst occurrences where [P] varies between 0.05 and $0.27 \mu \mathrm{mol} / 1$. [N] ranges from 0 to $3 \mu \mathrm{mol} / 1$ and [Si] from 2.7 to $20 \mu \mathrm{mol} / 1$, [chl.-a] ranges from 0.5 to $2.4 \mu \mathrm{g} / \mathrm{l}$. The bottom $\mathrm{O}_{2}$ range is $0-6.8 \mathrm{ml} / 1$. The cysts are also relatively common in two southern deep water cores as Cochlodinium spp., with the first occurrence at c. 4,600 yr BP in core GeoB 7630 (Verleye et al. 2009) and as cyst of Cochlodinium sp., it appears at c. 8 cal ka in Core M72/522GC3 (Shumilovskikh et al, 2013). These stratigraphic ranges show that the species is either native in the region or it was an early introduction from the Mediterranean Sea. The cysts are also common in core MAR02-88P from -257 m in northeastern Marmara Sea (PJM, unpublished), in sediments younger than at least $1065 \pm 15 \mathrm{yr}$ BP. The global distribution of this 
taxon is uncertain. The cyst of Cochlodinium sensu Fukuyo 1982 is sparsely distributed in coastal bays of Southern Japan, including the semi-landlocked Omura Bay, SW Japan with summer SST c. $20-29{ }^{\circ} \mathrm{C}$, SSS 32-33.5, and bottom dissolved oxygen (DO) 0-5 mg/l (Fukumoto and Kobayashi, 2005). Our BSC data show that the species may be found in waters of much lower salinity and with bottom $\left[\mathrm{O}_{2}\right]$ around $7 \mathrm{ml} / \mathrm{l}$.

[Figure 18. Distribution map of cyst of Cochlodinium sensu Fukuyo goes here.]

\subsection{Cyst of Diplopelta symmetrica Pavillard 1913}

Distinguishing characteristics: According to Dale et al. (1993), resting cysts of Diplopelta symmetrica are spherical with a moderately thick wall which is dark brown before excystment and lighter brown when empty (Plate 9, Figs. 10-18). The outer wall surface is partially covered by patches of densely-spaced, short $(1-4 \mu \mathrm{m})$ hair-like processes as seen under light microscopy. These processes appear more crystalline in SEM images but they are not calcareous. The archeopyle is theropylic, forming a zigzag split (Plate 9, Fig. 15) which probably represents the tabulation, following the boundaries of $1 \mathrm{a} / 2^{\prime \prime}, 1 \mathrm{a} / 2^{\prime}, 2 / 2 \mathrm{a}, 3^{\prime} / 2 \mathrm{a}$ and $3^{\prime} / 5^{\prime \prime}$. The polyplacoid operculum remains attached according to Dale et al. (1993), but our specimens show a detached operculum.

Dimensions: Cyst diameter is 37-50 $\mu \mathrm{m}$ according to Dale et al. (1993).

Synonymy: None; the synonym of D. symmetrica cited by WoRMS database, 2013, as Diplopsalopsis bomba (Stein ex Jorgensen) J. D. Dodge and S. Toriumi is incorrect. 
Biological Affinity: The theca-cyst relationship of the heterotrophic dinoflagellate Diplopelta symmetrica Pavillard 1913 was determined by incubation experiments of Dale et al. (1993). This species is not reported in Black Sea plankton records.

Comparison: The cysts of $D$. symmetrica differ greatly from cysts of Niea acanthocysta (= cyst of Diplopelta parva (Abé 1941) Matsuoka 1988 = Oblea acanthocysta (Abé 1941) Kawami et al. 2006; also see Mertens et al. 2015a). Cysts of Niea acanthocysta are smaller $(<45 \mu \mathrm{m})$ and are covered with many, longer $(6-8 \mu \mathrm{m})$, slightly curved, spiny processes with acicular tips and round bases (rarely rectangular). The late Holocene occurrence of a questionable Diplopelta symmetrica species 2 of Verleye et al. (2009) may be the same taxon as our cyst of $D$. symmetrica.

Distribution: In BSC surface sediments (Figure 19), cysts of D. symmetrica have widespread, sporadic occurrences in low amounts $(<3 \%)$ in the Black Sea, primarily on the northwest outer shelf and eastern upper continental slope areas; there is one occurrence in western Marmara Sea. Maximum \% values appear to be associated with the margins of the Sevastopol, Crimean and Kizilirmak quasi-stationary Rim Current gyres. Associated SST ranges seasonally from $5.7{ }^{\circ} \mathrm{C}$ (winter) to $24{ }^{\circ} \mathrm{C}$ (summer), with highest cyst $\%$ at annual average SST $=14-15{ }^{\circ} \mathrm{C}$; SSS has a seasonal range of 15.5 (spring) to 31 (winter), with most occurrences grouped between $\sim 16$ and 18. Associated nutrient values are [P] mostly $0.05-0.15,[\mathrm{~N}] 0-3.7$; [Si] 1.6-12.5 (up to 26); [chl.-a] ranges from 0.3 to 2.5 . The bottom $\mathrm{O}_{2}$ values range from $0-7$, with no particular relationship to cyst occurrences. In the Black Sea basin core M72-5-22GC3, the first occurrence of cyst of Diplopelta symmetrica is documented at $4.8 \mathrm{cal} \mathrm{ka} \mathrm{(Shumilovskikh} \mathrm{et} \mathrm{al.,} \mathrm{2013).} \mathrm{For}$ the SW Black Sea slope core GeoB7625-2, Verleye et al. (2009) report the occasional presence of Diplopelta symmetrica species 1 after c. $7.6 \mathrm{ka} \mathrm{BP}$. The holotype of the thecate stage of $D$. symmetrica is from Étang de Thau, a brackish French Mediterranean lagoon (Pavillard, 1913) 
and the cysts are present in a coastal lagoon near Naples, in the Gulf of Lion and the Ligurian Sea as well as inner Oslofjord, Norway (Dale et al., 1993) and the Baltic Sea (Nehring, 1994). Few other records are available, but the occurrences around Southern Ireland (Dale et al., 1993), South Australia (McMinn et al., 2010), and Korea (Kim et al., 2007) confirm it is a temperate region coastal species tolerant of a wide range of SSS (Dale et al., 1993). The BSC occurrences show that the cysts are not strictly confined to coastal areas where stratified, low-salinity waters prevail, and that contrary to questions about cyst preservation in sediments (Dale et al., 1993), the Black Sea records show that this species can occur in early Holocene sediments.

[Figure 19. Distribution map of cysts of Diplopelta symmetrica goes here].

\subsection{Cyst of Fragilidium sp. of Owen and Norris 1985}

Distinguishing characteristics: Following Owen and Norris (1985) these are large (c. $60 \mu \mathrm{m})$ cysts, with a spherical body often having a prominent red accumulations and with a hyaline wall covered by a thick layer of mucus, often with attached particles of detritus and irregular outline (Plate 5, Figs. 1-3). No reflected tabulation or excystment aperture is evident.

Dimensions: Cyst diameter (without mucus) is 39-41 $\mu \mathrm{m}$ according to von Stosch (1969), and 42 to $48 \mu \mathrm{m}$ without mucus to $60 \mu \mathrm{m}$ with the mucus layer according to Owen and Norris (1985).

Synonymy: None.

Biological Affinity: Owen and Norris (1985 p. 264) observed hypnocysts, from the Indian River lagoon, Florida, U.S.A., which they cultured and related to the sexual cycle of Fragilidium spp. Some Fragilidium species are mixotrophic (Jeong et al., 2010). 


\section{1}

Comparison: The large outer layer of mucus makes this species distinguishable from other dinoflagellate cyst species in surface sediments.

Distribution: In the BSC, cysts of Fragilidium have been observed at only two surface sample sites in the eastern Black Sea (MSM33 42-3MUC, Gelendzhik Ash 3) and at one northwestern site (SH5), therefore the taxon distribution is not mapped here. Average SST and SSS at the shallowest site (Ash 3) is $15.36{ }^{\circ} \mathrm{C}$ and 17.58 respectively, ranging from 8.34-23.26 SST and 17.53-17.71 SSS; nutrients are [P] .09, [N] 0.37, [Si] 6.1, [chl.-a] 0.51 and $\left[\mathrm{O}_{2}\right] 4.33$ at the shallowest site (Ash 3, $74 \mathrm{~m}$ ). The cysts also have not been observed in cores. It is not known if the cyst is a very recent introduction or does not survive sediment processing after burial. Very similar cysts have been reported for several other temperate region species of Fragilidium, including the North Sea (von Stosch, 1969; SST range $6-17^{\circ} \mathrm{C}, 34-35$ psu), Australian waters off Victoria (Sonneman and Hill, 1997; SST range $18-20{ }^{\circ} \mathrm{C}, 35-35.5 \mathrm{psu}$ ), Bahia de Chamela, Mexico, SST May 26-28, SSS 26-28 (Balech, 1987-1988), San Diego, California, SST average 24-24.5 ${ }^{\circ} \mathrm{C}$, SSS 33.2-33.6 (Balech, 1959), northern Sea of Japan, SST 0-20 ${ }^{\circ} \mathrm{C}$, SSS $31.5-35.5$ (Orlova and Morozova, 2009), and Sea of Okhotsk, SST range $-1-18{ }^{\circ} \mathrm{C}$, SSS c. $20-33$ (Selina and Orlova, 2009); Portugal to Mediterranean (Rodriguez et al., 2014). The large mucilagecovered cysts do not seem to be species specific. The BSC occurrences are the first record of the cyst of Fragilidium in brackish, strongly stratified waters.

\subsection{Cyst of Gymnodinium nolleri/microreticulatum}

Distinguishing characteristics: This category includes the cysts of the two species Gymnodinium nolleri Ellegaard and Moestrup 1999 and Gymnodinium microreticulatum Bolch and Hallegraeff 1999, both of which are spherical with a pale-brown to reddish-brown or purplish-brown body 
wall, the surface of which is covered by a network of low ridges (Plate 10, Figs. 4-9) forming small polygons $(0.3-1.9 \mu \mathrm{m})$ that correspond to the amphiesmal vesicles of the motile stage. The archeopyle is chasmic, usually forming along the sulcus from near the apex to the antapex; this area is marked by rows of smaller polygons (Plate 10, Figs. 7-8). The outline of the cingulum is also framed by two rows of polygonal, flattened or squarish paravesicles; in cysts of G. nolleri, there are 2-4 uneven rows of paravesicles $(0.45-2.3 \mu \mathrm{m})$ within the cingulum (Plate 10, Fig. 9). According to Ribeiro et al. (2012), in cysts of the small species $(<28 \mu \mathrm{m})$ of $G$. microreticulatum, there are more than four rows of cingular paravesicles.

Dimensions: Cyst body diameter is $28-38 \mu \mathrm{m}$ for G. nolleri (Ellegaard and Moestrup, 1999) and 17-28 $\mu \mathrm{m}$ for cysts of G. microreticulatum.

Biological Affinity: Cyst-theca relationships were established by Ellegaard and Moestrup (1999) and by Bolch et al. (1999) for G. nolleri and G. microreticulatum, respectively. These non-toxic taxa have not been recorded specifically for the BSC plankton. The trophic status of the taxon is not known, but G. catenatum and G. impudicum are mixotrophic (Jeong et al., 2010).

Comparison: According to Ribeiro et al. (2012), similar but larger, reticulate, round brown cysts of Gymnodinium catenatum Graham 1943 are 35.6-53.3 $\mu \mathrm{m}$ in diameter with more than four rows of oriented, primarily five- or six-sided paravesicles. However, Marret et al. (2009) report that large reticulate cysts in BSC Holocene sediments of Core MAR02-45 with two to four rows of oriented five- to six-sided paravesicles (Plate 10, Figs. 1-3) are more like $G$. catenatum cysts than G. nolleri or G. microreticulatum cysts. G. catenatum is an invasive HAB species in the Mediterranean and Hellenic Seas (Streftaris et al., 2005; Pancucci-Papadopoulou et al., 2005) but it is only present in late Holocene sediment at one site, so it is not included in the atlas map. 
Distribution: Small amounts of G. nolleri/microreticulatum cysts are very widely distributed in surface sediments of Marmara and Black Sea (Figure 20), occurring at most sites except in the Azov Sea. Relative abundances of cysts tend to increase from west to east where there are peaks of c. $12 \%$ at sites associated with the Crimean and Kizilirmak Rim Current gyres. Associated SST ranges seasonally from $5.5^{\circ} \mathrm{C}$ (winter) to $24{ }^{\circ} \mathrm{C}$ (summer), with peak cyst $\%$ at annual average SST $=15{ }^{\circ} \mathrm{C}$; SSS has a seasonal range of 14.6 (spring) to 31.4 (winter), with most occurrences grouped between $\sim 15$ and 18.25, although another cluster of lower percentages is found with SSS between 25.7 and 31.35. Associated nutrient values are [P] mostly $0.05-0.2$, [N] 0-2.5; [Si] 1.2-14.5 (up to 33.75); [chl.-a] ranges from 0.3-2.The bottom $\mathrm{O}_{2}$ values range from $0-7$, with the peak $\%$ amounts being near 0 and $1.5 \mathrm{ml} / 1$. In sediment cores, cysts combining characteristics of G. catenatum and G. nolleri (cysts of G. catenatum/nolleri) first appear around 4,800 cal BP in cores from the SW Black Sea shelf (Marret et al., 2009; Bradley et al., 2012) and form a peak around 2,000 yr BP. In deeper water cores, cysts of G.nolleri/microreticulatum are become relatively common by $8.3-7$ ka BP (Shumilovskikh et al., 2013). Cysts of $G$. nolleri/microreticulatum in Marmara Sea appear between c. 5.6 and 4.7 cal ka BP. Outside of the BSC, cysts of Gymnodinium cf. nolleri are common at some sites in Izmir Bay (Aydin et al., 2011) in the eastern Aegean Sea and on a world-wide scale, cysts of G. nolleri/microreticulatum are found in coastal sediments from temperate to sub-tropical regions where SST $>14.0^{\circ} \mathrm{C}$ in summer, and SSS is 26.8-38.8, and highest relative abundances are observed in oligotrophic/mesotrophic regions where bottom waters are moderately to well ventilated (Zonneveld et al., 2013). Our BSC data extend the distribution of these cysts into brackish, stratified waters with lower $[\mathrm{P}],[\mathrm{N}]$ and $[\mathrm{chl} .-\mathrm{a}]$ values than the global values and where peak \% $\mathrm{O}_{2}$ values are in anoxic bottom water. 
[Figure 20. Distribution map of cyst of Gymnodinium nolleri/microreticulatum goes here.]

4.17 Cyst of Kolkwitziella acuta (Apstein 1896) Elbrächter1993 emend. Mertens et al. 2015.

Distinguishing characteristics: Based on Mertens et al. (2015b), this brown cyst is reniform in polar view and is slightly compressed in both polar and dorsoventral directions; in ventral view, the cyst outline is bell-shaped, with convex sides (Plate 11, Figs. 8-16). A broad, rounded, ventrally-directed apical horn and two antapical horns are present, the latter being separated by slight excavation of the sulcal area; the hypocyst is shorter than the epicyst. The thin cyst wall wall $(0.5 \mu \mathrm{m})$ is reddish to chocolate-brown, with colourless lipid bodies in living cysts. The outer cyst wall is generally thin and undulating, having a wrinkled texture. Cingular lists are formed by thickening of the wall, and a small apical pore is present. The deeply excavated sulcus gives the cyst a reniform shape as seen in polar view; the sulcus tapers towards the apex and is broader towards the antapex, with two comma-shaped flagellar scars. The preformed archeopyle corresponds to loss of the anterior intercalary plate (2a) which is offset to the left from the dorsal midline and has rounded angles. The operculum remains attached along one of the theropylic archeopyle sutures.

Dimensions: Cysts $(\mathrm{n}=10)$ from southwestern Caspian Sea are larger $(\mathrm{L}=36.1-49.4$, mean $42.8 \mu \mathrm{m} ; \mathrm{W}=50.7-65.0$, mean $55.8 \mu \mathrm{m}$ ) than 4 cysts from Sällvik (Finland) with $\mathrm{L}=$ 32.6(35.1)36.6 $\mu \mathrm{m} ; \mathrm{W}=36.6(40.0) 45.6 \mu \mathrm{m}$ (Mertens et al., 2015b). Cysts in the Black Sea surface sediments are also larger than $35 \mu \mathrm{m}$.

Synonymy: Motile-stage name variously assigned to Diplopsalis acuta (Apstein) Entz, 1904; Peridinium latum Paulsen, 1908; Kolkwitziella salebrosa Lindemann, 1919; Entzia acuta 
(Apstein) Lebour, 1922; Kolkwitziella salebrosa var. gibbera Lindemann, 1924; Kolkwitziella gibbera (Lindemann) Lindemann, 1928; Apsteinia acuta (Apstein) Abe, 1981 [nom. nudum].

Biological Affinity: The cyst-theca relationship of the heterotrophic dinoflagellate $K$. acuta was re-established most recently by Mertens et al. (2015b). K. acuta is recorded for the Danube Delta (Török, 2009) and in the Black Sea (Gómez and Boicenco, 2004). Mertens et al. (2015b) report that ribosomal DNA sequences for $K$. acuta cysts indicate a close affinity with Protoperidinum excentricum in the Excentrica section of the genus Protoperidinium.

Comparison: In its polar and dorsoventral compression, the cyst of Kolkwitziella acuta is somewhere intermediate between the cyst-defined taxa Selenopemphix and Lejeunecysta, as emended by Head (1993) but differs in its wrinkled wall morphology, lack of spine-like processes and theropylic archeopyle with attached operculum. Some Black Sea morphotypes of K. acuta are more yellowish-brown and have a more uniformly-rounded reniform outline than the darker brown cysts from the Caspian Sea (Plate11, Figs. 8, 12-13).

Distribution: Cysts of Kolkwitziella acuta are common in low amounts (less than 4\%) on the Ukrainian and Danube Shelf areas of the Black Sea; they are occasionally present in the Azov Sea and are rare in southwestern Caspian Sea site CS, 25 m (Figure 21). The cysts of Kolkwitziella acuta also occur in Terkos and Büyücekmece lakes near Marmara Sea. The motile stage is recorded for plankton samples from Danube Delta but cysts were not seen in samples from the delta channels or Lake Razim. In the Black Sea, maximum \% values occur are in shallow, low salinity coastal water off the Danube Delta. Associated SST ranges seasonally from $5.5{ }^{\circ} \mathrm{C}$ (winter) to $24{ }^{\circ} \mathrm{C}$ (summer), with peak cyst $\%$ at annual average SST $=14.5{ }^{\circ} \mathrm{C}$ and with one occurrence in the Azov Sea with low SST (0.56 in winter); most occurrences are grouped for SSS between $\sim 14.6$ and 18.5. Associated nutrient values are [P] mostly $0.05-0.3,[\mathrm{~N}]$ 0-4.5; [Si] 2.5-17.3 (up to 33.7); [chl.-a] ranges from 0.05 to 3.25. The bottom $\mathrm{O}_{2}$ values range from $0-7$, 
with the peak cyst \% between 5.5 and $6 \mathrm{ml} / \mathrm{l}$. Cysts of Kolkwitziella acuta are common in the early Holocene sediments of the SW Black Sea core MAR02-45P, with the first occurrence around $8.38 \mathrm{ka} \mathrm{BP}$.On a global scale, associated annual SST ranges from sub-arctic $\left(5.2{ }^{\circ} \mathrm{C}\right.$, Bothian Bay, northern Baltic) to subtropical $\left(18.9^{\circ} \mathrm{C}\right.$, southwestern Caspian Sea); annual SSS ranges between 0 (lakes) and 22 (Kattegat). In general, $K$. acuta is widely distributed in Eurasia and there are two recorded occurrences in the U.S.A. near Lake Erie. The species is one of very few taxa recorded as living in both freshwater and low salinity marine environments. As a heterotrophic dinoflagellate, however, cyst abundance may also be related to prey availability.

[Figure 21. Distribution map of cyst of Kolkwitziella acuta goes here.]

\section{18 Cyst of Pentapharsodinium dalei Indelicato and Loeblich III 1986}

Distinguishing characteristics: Based on Dale (1977), Lewis (1991) and Rochon et al. (1999), these are small $(<45 \mu \mathrm{m})$, transparent proximochorate cysts with a spherical central body and a characteristically variable density of processes (Plate 12, Figs. 8-16). The endocyst wall is thin $(<0.5 \mu \mathrm{m})$ and has a smooth surface without indications of tabulation. The processes are solid, with distally expanded tips. Typically most processes are unbranched but usually a few branched processes occur on the same cyst. The position of the branching is irregular and the processes vary in width, with both slender and broader rods occurring on the same specimen (Plate 12, Fig. 11). The archeopyle is chasmic, being a simple split at an undetermined position.

Dimensions: Endocyst diameter is $19-36 \mu \mathrm{m}$; process length is 1-8 $\mu \mathrm{m}$ (Rochon et al. 1999). Most cysts in the BSC have longer processes but samples off the Danube Delta are dominated by cysts with shorter processes. 
Synonymy: None; however see notes below on cyst of Peridinium faeroense.

Biological Affinity: This cyst was originally assigned to Peridinium faeroense Paulsen 1905 by Dale (1977) and before 1994, this species was commonly referred to as either cyst of Peridinium faeroense Paulsen 1905 or as Peridinium faeroense sensu Dale 1977 (see Head, 1996). There are two records of $P$. dalei in the Black Sea phytoplankton (Vershinin and Velikova, 2008). Comparison: Cysts of Ensiculifera imariense, described by Kobayashi and Matsuoka (1995) from Japan are very similar in size and overall appearance to cysts of Pentapharsodinium dalei. Gu et al. (2013) show that the two genera are also genetically closely related. The differences between the species are presently unclear.

Distribution: In BSC surface sediments, $P$. dalei cysts are present throughout the region except the Sea of Azov north of Strait of Kerch (Figure 22). In the Marmara Sea and the shelf areas of Black Sea, relative abundances are mostly $<5 \%$, increasing to $10-23 \%$ in deeper water. In the Caspian and Aral Seas, up to $23 \%$ may be found in near-surface sediments of the deep basins, but lower \% avalues are found in southern shelf sites. Associated SST ranges seasonally from $5.5{ }^{\circ} \mathrm{C}$ (winter) to $29^{\circ} \mathrm{C}$ (summer), with peak cyst $\%$ at annual average SST $=14.5{ }^{\circ} \mathrm{C}$; SSS has a seasonal range of 11.8 (spring) to 31.5 (winter), with most occurrences grouped between $\sim 15$ and 18.5. Associated nutrient values are $[\mathrm{P}]$ mostly $0.05-0.2$. [N] 0-5; [Si] $\sim 1.5-15.5$ (up to 33.5); [chl.-a] ranges from 0.35 to 3.2. The bottom $\mathrm{O}_{2}$ values range from $0-7.8$, with the highest cyst $\%$ values being near 0 and $0.7 \mathrm{ml} / \mathrm{l}$. The cysts of Pentapharsdinium dalei are also commonly found in Holocene sediments cores throughout the study region (e.g. Londeix et al., 2009; Bradley et al., 2012; Leroy et al., 2013b, 2014; Sorrel et al., 2006). Coolen et al. (2013) also report the occurrences of biomolecular traces of Pentapharsodinium sp. and Pentapharsodinium tyrrhenicum in Holocene sediment of the Danube paleodelta. In contrast, there are only two 
published records of $P$. dalei for the BSC phytoplankton. These occurrences are only in the Black Sea where it was first reported in 2000 (Vershinin and Velikova, 2008).

In general, cysts of $P$. dalei are widely distributed in cold waters and are used as a paleoecological indicator of warming at high latitudes where the species presence is traced by microsatellite markers (Lundholm et al., 2014). Globally, the cysts are most abundant where surface water remains below $0{ }^{\circ} \mathrm{C}$ except in summer (Zonneveld et al., 2013). These authors also report that cysts of the Pentapharsodinium dalei-Ensiculifera imariense complex occur mainly where marine salinities are reduced year-round by meltwater or runoff (SSS: 11.3-39.3), in a wide range of trophic and bottom oxygen conditions but are more abundant where bottom oxygen is higher. The cysts can survive 9-12 months of sea-ice cover, which, combined with higher bottom oxygen levels, may explain their larger numbers in the Caspian and Aral Seas which have more winter ice and bottom $\left[\mathrm{O}_{2}\right]$ than the Black and Marmara Seas. There is no clear seasonal pattern to cyst production, but in the central Mediterranean Sea, cysts of the Pentapharsodinium dalei/Ensiculifera imariense complex are higher where phosphate levels are elevated (Zonneveld et al., 2012). In the BSC, there is no clear correlation with [P] up to the maximum observed value of $0.33 \mu \mathrm{mol} / 1$.

[Figure 22. Distribution map of cyst of Pentapharsodinium dalei goes here.]

\subsection{Cyst of Peridinium cf. willei Huitfeldt-Kaas 1900}

Distinguishing characteristics: Following McCarthy et al. (2011), these are transparent subspherical to ovoidal cysts which are cavate and proximate, with two closely appressed thin wall layers that are separated by $1-5 \mu \mathrm{m}$ in some areas (Plate 1, Figs. 13-15). The inner wall 
layer is transparent and smooth. The outer layer may have two small, shallow depressions in the sulcal region, appearing as two shoulder-like features in polar view. The outer wall may detach more widely during palynological processing (Plate 1, Fig. 13). The archeopyle is transapical, apparently involving opening of sutures along the apical, intercalary and 3" plates according to Norris and McAndrews (1970), with the multi-plate operculum remaining attached after excystment. The Black Sea cysts are often crumpled and possibly transported in discharge plumes from the largest rivers (Plate 1, Fig. 15).

Dimensions: McCarthy et al. (2011) give the outer cyst length in apical view as $47.1 \pm 7.0 \mu \mathrm{m}$ and the width, measured perpendicular to length, is $41.5 \pm 5.9 \mu \mathrm{m}$. Cysts in the varved sediments from Crawford Lake range from 48 to $58 \mu \mathrm{m}$ by 49 to $52 \pm 2 \mu \mathrm{m}$. Cysts up to $55 \mu \mathrm{m}$ diameter were found on inner Danube Shelf and in Kerch Strait.

Synonymy: May include Peridinium cysts of Type C and Type D of Norris and McAndrews 1970; according to McCarthy and Krueger (2013), these taxa are cysts of $P$. willei (Type C) and Peridinium volzii Lemmermann 1906 but the difference between these cyst taxa is not clearly established. P. willei and P. volzii were synonymised by Popopvský and Pfiester (1990) but not by Olrik (1992) for plankton in Danish Lakes where motile populations of the two taxa had different ecological preferences.

Biological Affinity: Cyst-theca relationship for P. willei is established by McCarthy et al. (2011). Török (2009) reports the common presence of both $P$. willei and $P$. volzii in the Danube Delta phytoplankton and it is listed for three Black Sea sites by Gómez and Boicenco (2004).

Comparison: According to McCarthy and Krueger (2013), cysts of Peridinium volzii are similar to $P$. willei cysts in being transparent, cavate and proximate subspherical cysts, but they are smaller $(\sim 38-45 \mu \mathrm{m}$ by $\sim 42-50 \mu \mathrm{m})$ than cysts of $P$. willei, and have less pronounced lobes and lack an apical flange (McCarthy and Krueger, 2013). 
Distribution: In the BSC surface sediments, these freshwater cysts occur in low numbers $(<5 \%)$ in Sfa Gheorghes river channel and in several sites of Razim Lake where salinities are <2; cysts of Peridinium cf. willei are also found at a few offshore sites on the Danube and Ukrainian Shelf and in the Azov Sea-Kerch Strait (Figure 23). Associated SST ranges seasonally from 5.5 ${ }^{\circ} \mathrm{C}$ (winter) to $23{ }^{\circ} \mathrm{C}$ (summer), with annual average SST $=13.8^{\circ} \mathrm{C}$; SSS has a seasonal range of 14.5 (summer) to 18 (winter). Associated nutrient values are $[\mathrm{P}]$ mostly $0.15-0.35,[\mathrm{~N}] 0-5$; [Si] 4-16.3; [chl.-a] ranges from 0 to 3.5. The bottom $\mathrm{O}_{2}$ values range from $4-6 \mathrm{ml} / \mathrm{l}$. There are few records of the cysts in BSC sediment cores but there are several specimens in the early Holocene lacustrine phase of Black Sea deepwater core 1474P. World-wide, the cyst of Peridinium willei and similar taxa are common in nutrient-rich lakes of North America (Carty, 2015), and the motile cells are present in the Baltic Sea. The Black Sea occurrences appear to be the first reports of the cysts for brackish water seas where they are associated with SST of $2.4^{\circ}$ (winter) to $24{ }^{\circ} \mathrm{C}$ (summer), and SSS (outside of the Danube Delta) ranging from 6.4 (spring) to 17.7 (winter).

[Figure 23. Distribution map of cyst of Peridinium cf. willei goes here.]

\subsection{Cyst of Polykrikos hartmannii Zimmermann 1930}

Distinguishing characteristics: Based on Matsuoka and Fukuyo (1986), these cysts are dark yellow brown before germination and very light brown after excystment because of the thin single-layered body wall (Plate 13, Figs. 1-3.). The smooth to micro-granulate wall is covered with many hollow, non-tabular, short spine-like processes with acuminate tips and a few striations on the rounded bases. The archeopyle is chasmic forming a simple slit about one-third 
to a half of the cysts diameter; however, the thin wall often results in folding of germinated cysts, obscuring the archeopyle.

Dimensions: Cyst diameter is $46-60 \mu \mathrm{m}$; process length is $8-12 \mu \mathrm{m}$ for 20 specimens (Matsuoka and Fukuyo, 1986).

Synonymy: Cyst of Pheopolykrikos hartmannii Matsuoka and Fukuyo 1986.

Biological Affinity: Cyst-motile stage relationship was first determined by Matsuoka and Fukuyo (1986) who emended the genus Pheopolykrikos Chatton 1933 and transferred Polykrikos hartmannii to Pheopolykrikos. Based on molecular analyses and ulrastructural features of the motile stage, Hoppenrath et al. (2009) returned Pheopolykrikos hartmannii to the genus Polykrikos. The motile stage of $P$. hartmannii has not yet been reported for the BSC. This species is reported to be mixotrophic, with Korean strains reported as feeding on Cochlodinium polykrikoides during red tide outbreaks (Lee et al., 2015).

Comparison: Cysts of P. hartmannii closely resemble Echinidinium granulatum which has quite similar processes but the latter cysts have fewer processes which are also longer (c. $10 \mu \mathrm{m})$.

Distribution: In the BSC surface sediments, small amounts of $P$. hartmannii cysts are widely distributed in Marmara and the Black Sea, with peak relative abundances of $8-10 \%$ in the western subregion and with smaller peaks of c. $4-6 \%$ associated with the Sevastopol, Crimean and Kizilirmak Rim Current gyres (Figures 2 and 24). Higher values tend to be found in deeper water, suggesting better preservation of these thin-walled cysts in hypoxic-anoxic conditions. Associated SST ranges seasonally from $5.5{ }^{\circ} \mathrm{C}$ (winter) to $24{ }^{\circ} \mathrm{C}$ (summer), with maximum cyst $\%$ at annual average $\mathrm{SST}=14.5^{\circ} \mathrm{C}$; SSS has a seasonal range of 14.5 (spring) to 27.7 (winter), with most occurrences grouped between $\sim 16.5$ and 18.4. Associated nutrient values are [P] mostly $0.01-0.32,[\mathrm{~N}] 0-5 ;$ [Si] $1.5-14.5$; [chl.-a] ranges from $0-4 \mathrm{ml} / \mathrm{l}$. The bottom $\mathrm{O}_{2}$ values range from $0-7$, with the peak cyst $\%$ being near 0 and $2 \mathrm{ml} / 1$. In cores, the cysts often have not 
been identified with certainty because they can be difficult to distinguish from other spiny round brown cysts, especially when damaged and/or obscured by clay and amorphous organic matter (AOM). In the Black Sea core GeoB 7625-2, however, new studies show that the cysts are occasionally present after the mid Holocene. World-wide there are also few data because the taxon is usually grouped with Echinidinium spp. for cyst distribution mapping. Radi et al. (2013) indicate that cysts of Polykrikos hartmannii are absent in high latitudes but are found in coastal areas of temperate to subtropical middle latitudes of the western and eastern Pacific Ocean.

[Figure 24. Distribution map of cyst of Polykrikos hartmannii goes here.]

4.21 Cyst of Polykrikos kofoidii/schwartzii sensu Matsuoka et al. 2009

Distinguishing characters: This is a group of large, brown reticulate cysts, mostly including cysts of Polykrikos kofoidii Chatton 1914 sensu Matsuoka et al. 2009 which are part of the Polykrikos schwartzii/kofoidii complex of Matsuoka and Fukuyo (2002). All these brown cysts (Plate 13, Figs. 4-15) are proximochorate with an ellipsoidal to ovate body that is slightly dorsoventrally compressed and relatively large (globally 50-125 $\mu \mathrm{m}$ total length). The archeopyle is polar (likely apical) of the tremic type, being roundly polygonal to circular with a slight zigzag margin (Plate 13, Figs. 7-12) and may have a small sulcal area just below the sulcal notch. The cyst wall is pale to dark brown and has three layers: a thick, smooth endophragm covered by a thin periphragm from which an exophragm of regular or irregular ornament arises, forming strongly fibrous muri (crests) and cylindrical funnel-shaped processes. Often the ornament is aligned in four to seven rows which are either irregular (Plate 13, Figs. 10-12) or sub-horizontal (Plate 13, Figs. 5-6). The bases of the crests are characteristically wrinkled and 
joined laterally. Most processes are hollow, with flaring, open ends. The fibrous process ends are usually recurved and either join to form a thin external epiphragm (exophragm) or remain separate. Most cysts from the BSC are less than $70 \mu \mathrm{m}$ long and are either reticulate or incompletely reticulate. Because it is often not possible to assign other BSC cysts to either $P$. kofoidii or P. schwartzii, we have grouped all these taxa together as Cyst of Polykrikos kofoidii/schwartzii sensu Matsuoka et al. 2009 for the atlas map (Figure 25).

Dimensions: Cyst body: 29-80 $\mu \mathrm{m}$ (width), 52-110 (length) $\mu \mathrm{m}$; length of processes: 6-18 $\mu \mathrm{m}$ overall but shorter $(6-11 \mu \mathrm{m})$ in cysts of $P$. kofoidii sensu Matsuoka et al. 2009 according to Marret and Zonneveld (2003), but sometimes less in Black Sea specimens.

Synonomy: May include cysts of Polykrikos kofoidii Chatton and/or Polykrikos schwartzii Bütschli.

Biological affinity: Matsuoka et al. (2009) showed the correct cyst-motile stage relationship for both Polykrikos species. Cysts of Polykrikos kofoidii/schwarztii are produced by large, naked, heterotrophic colonial dinoflagellates with two to eight nematocyst-bearing pseudo-cells (zooids) that can prey on chain-forming toxic dinoflagellates like Gymnodinium catenatum (Matsuyama et al., 1999). Black Sea plankton records for 2004 show Polykrikos kofoidii was present at only two of 144 plankton stations while $P$. schwartzii was found in nine samples (Nesterova et al., 2009). Terenko (2005) lists $P$. kofoidii as being one of the most frequent of the armoured [sic] dinoflagellates in Odessa Bay (Ukraine) but blooms are not reported elsewhere and the genus is not listed for the Northeastern Black Sea by Vershinin and Orlova (2008). Coolen et al. (2013) did not report presence of Polykrikos rDNA in Holocene sediment from the Danube continental slope. Balkis (2004) reported presence of cysts of $P$. schwartzii in Marmara Sea plankton samples and obtained cysts of $P$. kofoidii and $P$. schwartzii from surface sediment in Gemlik Gulf (Balkis et al., 2016); the ornament on these cysts suggest that both the large oval $P$. kofoidii 
cysts and the smaller rounded P. schwartzii cysts may be assigned to cyst of Polykrikos kofoidii/schwartzii sensu Matsuoka et al. 2009.

Comparison: Matsuoka et al. (2009) distinguish typical cysts of $P$. kofoidii and P. schwartzii by the larger cyst size and irregular, coarsely reticulate ornament in $P$. kofoidii compared to the smaller cysts of $P$. schwartzii which usually have even rows of shelf-like ornament. Most BSC specimens lack clearly separated processes that are elevated, are less than $70 \mu \mathrm{m}$ long and are reticulate with relatively low crests/muri and short processes. These features and the incomplete reticulation may reflect the lower salinity of the BSC surface water, as noted for other cyst genera by Wall et al. (1973) and Dale (1996). Large cysts of Polykrikos schwartzii sensu Matsuoka et al. (2009), with shelf-like ornament are found in sediment cores from the southern Black Sea, being shown as Dinoflagellate indeterminate sp. 1 of Wall et al. (1973) and as Polykrikos kofoidii by Verleye et al. (2009). Slightly smaller reticulate cysts of P. kofoidii from SW Shelf cores are illustrated by Marret et al. (2009) and Mudie et al. (2010). In Japan, Nagai et al. (2002) clearly distinguish cultured P. kofoidii cysts by their coarsely reticulate ornament and well-developed bifurcate, trifurcate and spinous processes in contrast to $P$. schwartzii cysts which are typically elongate-cylindrical, hatchet-shaped or spinous processes which form shelflike ornament. In the Black Sea, however, Verleye et al. (2009) and Desmet (2013) remark on the difficulty of distinguishing between the two species, and they group the taxa together as cysts of Polykrikos kofoidii/schwartzii.

Distribution: In the BSC, cysts of Polykrikos kofoidii/schwartzii are widely distributed in low relative abundances $(<7 \%)$ throughout the Western and Southern Black Sea and in Marmara Sea (Figure 25) and are also present in the Azov Sea, the slope south of Strait of Kerch, and on the Russian Shelf. Despite their frequent association with polluted coastal water, in the BSC there is a tendency for larger \% values to be present in deeper water areas away from the eutrophic shelf 
areas. In the samples studied by Mudie (Table 4), the cysts were not found in the low salinity limans and Danube delta-front, and generally, the morphotype with shelf-like ornament and high processes was much less common than the reticulated cysts with relatively low processes. Associated SST ranges seasonally from $5.5^{\circ} \mathrm{C}$ (winter) to $24^{\circ} \mathrm{C}$ (summer), with one occurrence in the Sea of Azov where low winter SST are found $\left(0.56^{\circ} \mathrm{C}\right)$ and with peak cyst $\%$ at annual average $\mathrm{SST}=15^{\circ} \mathrm{C}$; SSS has a seasonal range of 14.5 (spring) to 31.5 (winter), with highest occurrences found in $\mathrm{SSS}>20$. Associated nutrient values are $[\mathrm{P}]$ mostly $0.01-0.32,[\mathrm{~N}] 0-5$; [Si] 2-14.5 (up to 33.4); [chl.-a] ranges from 0.4 to 3.2. The bottom $\mathrm{O}_{2}$ values range from $0-7$.

The cysts of Polykrikos kofoidii/schwartzii have not been found in surface sediments or cores in the Caspian and Aral Seas. In cores from the Black Sea and Marmara Sea, cysts we now refer to as Polykrikos kofoidii/schwartzii sensu Matsuoka 2009 appear first around 4-5 ka BP (Mudie et al., 2002a; Marret et al., 2009). In the Mediterranean region, Aydin et al. (2011) report large numbers of cysts of $P$. kofoidii and rare cysts of $P$. schwartzii in surface sediments of the inner part of Izmir Bay off the Aegean Sea. The cyst of $P$. schwartzii occurs in anoxic sediment of the low salinity Etoliko lagoon (Koutsodendris et al., 2015) but is not listed for other lagoons in eastern Greece or Lesbos Island in the NE Aegean Sea (Ignatiades and Gotsis-Skretas, 2010). Zonneveld et al. (2009) found that low percentages $(<2 \%)$ of both Polykrikos cyst species were strongly associated with discharge of eutrophic Po River water in Italy.

On a global scale, cysts of Polykrikos kofoidii/schwartzii are often associated with highly polluted coastal waters and high levels of anthropogenic eutrophication. P. schwartzii (Bütschli 1873) sensu Matsuoka can also be most abundant (up to 77\%) in temperate or subtropical areas of upwelling. Zonneveld et al. (2013) find that cysts of P. schwartzii do not usually occur in anoxic bottom waters whereas cysts of $P$. kofoidii are found in a wide range of bottom oxygen levels. The common occurrence of Polykrikos cysts in the fully anoxic sediments of deepwater 
sites in the northern and southern Black Sea deep basin may reflect a difference in the environmental tolerance of the BSC taxon called cyst of Polykrikos kofoidii/schwartzii relative to P. schwartzii ss. Globally, cysts of both P. kofoidii and P. schwartzii species have a wide range of temperature and nutrient tolerance, but low $[\mathrm{P}]$ may limit growth; there is no evidence of a clear seasonal pattern in cyst production (Zonneveld et al., 2013).

[Figure 25. Distribution map of cyst of Polykrikos kofoidii/schwartzii goes here.]

\subsection{Cyst of Protoperidinium nudum (Meunier 1919) Balech 1974}

Distinguishing characteristics: Based on Wall and Dale (1968), these small spiny brown cysts are subspherical or oval, with weak polar compression and relatively long processes (Plate 14, Figs. 7-9). The body wall is smooth and has long, simple, intratabular processes with conical bases and pointed tips. Two parallel rows of processes delimit the cingular area. The subtriangular archeopyle corresponds to intercalary plate $2 \mathrm{a}$ and the operculum often remains attached so the archeopyle is not easily visible.

Dimensions: Cyst body is $22-25 \mu \mathrm{m}$ long, $25-37 \mu \mathrm{m}$ wide, with process length of $7-14 \mu \mathrm{m}$ for specimens from the Gulf of Naples (Montresor et al., 2010).

Synonymy: Cyst of Peridinium? nudum Meunier 1919.

Biological Affinity: Cyst-theca relationship was determined by Wall and Dale (1968) who obtained Peridinium? nudum from incubated cysts. Protoperidinium nudum (Meunier) Balech is reported in Black Sea plankton records and the Mediterranean, but is not present in plankton records for Marmara Sea. 
Comparison: The cysts of $P$. nudum are similar to the cysts of Protoperidinium conicum (= Selenopemphix quanta) but they are smaller and have relatively longer mostly intratabular processes. Harland (1983) considered that P. nudum? cysts belonged to the cyst-based genus Selenopemphix. In the low salinity BSC, it is possible that processes of $P$. nudum are reduced and it may not always be possible to distinguish this taxon from cysts of $P$. conicum. Most of the cysts of Shumilovskikh et al. (2013) reported as cyst of $P$. nudum have relatively short processes and for the map (Figure 26), we have grouped these short-process cysts of P. nudum with Selenopemphix quanta.

Distribution: In surface samples of the BSC, cysts of $P$. nudum sensu stricto are rare and are most common in the warmer, more saline surface water of Marmara Sea and southern Black Sea (Figure 26). Associated SST ranges seasonally from $8.4{ }^{\circ} \mathrm{C}$ (winter) to $24{ }^{\circ} \mathrm{C}$ (summer), and with maximum cyst $\%$ at annual average $\mathrm{SST}=14.2{ }^{\circ} \mathrm{C}$; SSS has a seasonal range of 16.6 (spring) to18.2 (winter), with highest occurrences found in SSS >18. Associated nutrient values are $[\mathrm{P}]$ mostly $0.01-0.25$, [N] 0-2; [Si] $\sim 3-14$; [chl.-a] ranges from 0.6 to 2.4. The bottom $\mathrm{O}_{2}$ values are $0-6$, with the highest occurrences in the lower range of bottom $\left[\mathrm{O}_{2}\right]$ : Small amounts $(<2 \%$ total cysts) are found in late Holocene sediments of the upper slope core MAR02-88P (northeastern Marmara Sea) and Verleye et al. (2009) record the cysts in one near-surface sample of the SW Black Sea slope core GeoB7625-2. In the SE Black Sea basin, there are rare occurrences in the late Holocene after c. 2 cal ka (Shumilovskikh et al., 2013).

For surface samples outside the BSC, Uzar et al (2010) and Aydin et al. (2014) report the cysts for Izmir Bay and they are present in the Tyrrhenian and Adriatic Seas and in the western Mediterranean (Montresor et al., 2010). The species is occasionally present around the British Isles and at one site in the Barents Sea (Harland,1983), in the western North Atlantic (Wall and Dale, 1968), along the east coast of India (Narale et al., 2013) and probably in the Persian Gulf. 
However, the worldwide cyst distribution is not fully known because this taxon is usually mapped together with S. quanta (e.g. Marret and Zonneveld, 2003) or with Multispinula quanta Bradford 1975 (see Bradford, 1975, his fig. 2, no. 7).

[Figure 26. Distribution map of cyst of Protoperidinium nudum goes here.]

\subsection{Cyst of Protoperidinium stellatum (Wall 1968) Balech 1994}

Distinguishing characteristics: Based on Rochon et al. (1999) and our observations, the cysts of $P$. stellatum are light-brown and they are characteristically pentagonal-shaped, with five typically long, largely solid horns (Plate 10, Figs. 10, 13) arranged at the angles of the cyst body which is dorsoventrally flattened (Plate 10, Figs. 10-17). Two small additional horns are often present on both sides of the sulcus (Plate 10, Fig.16), and another one may occur below the archeopyle. The epicyst is typically smaller than the hypocyst, with a cingulum evident in ventral view. The cyst wall is thin with a smooth to more rarely, scabrate surface. When present, the archeopyle is relatively large and intercalary, with the sutures along plates 1a and $2 \mathrm{a}$ and the operculum remaining attached after excystment. In the BSC, however, the archeopyle is rarely found open. Flagellar scars can be seen in SEM images and on LM images of well-preserved specimens. In most BSC specimens, the horns are long, of approximately equal length, with a hollow base tapering to a largely solid rod with a pointed tip; they appear flexible, often being strongly recurved (Plate 10, Figs. 12, 15), and occasionally the inward-curved, apparently solid antapical horns are not visibly separated (Plate10, Fig. 15). In poorly preserved cysts of $P$. stellatum, most of the horns can be broken (Plate 10, Fig. 16) and they end abruptly at the base of the solid horn section. However, in many other cysts from the NW Black Sea with short or no 
horns (Plate 10, Figs. 14, 17), the development of the spines appears to have been arrested and the cyst body is correspondingly larger, so that epicyst and hypocyst are of more equal size. In these morphotypes, the ends of the short horns are rounded or are blunt with internal thickening. These characteristics are more like those of Stelladinium reductum Bint 1988 which has a similar body shape (equal-sized epicyst and hypocyst). These variations may reflect reduced process development in the low salinity environment as found in many other dinocyst taxa (Wall et al., 1973; Dale, 1996).

Dimensions: In the BSC, cyst size (excluding horns) is about $30-50 \mu \mathrm{m}$ in body length and 23-47 $\mu \mathrm{m}$ in width, with the horn spines usually $8-21 \mu \mathrm{m}$ long. Globally, cyst dimensions are given as 35-103 $\mu \mathrm{m}$ (width) and 60-104 $\mu \mathrm{m}$ (length), including the horns (Marret and Zonneveld, 2003).

Synonyms: Cyst of Protoperidinium stellatum (Wall in Wall and Dale 1968) Head in Rochon et al., 1999; "Stelladinium stellatum" (Wall) Reid 1977.

Biological affinity: This cyst is produced by the heterotrophic species Protoperidinium stellatum first described as Peridinium stellatum Wall in Wall and Dale (1968; pl. 2, fig. 15) from plankton samples taken around Woods Hole, eastern USA. Protoperidinium stellatum is similar to Protoperidinium compressum (Abé 1927) Balech 1974 (see Rochon et al., 1999 for details of the complex taxonomic history). In the Black Sea, although the cysts of P. stellatum are common in the west and south, there are no plankton records of either $P$. stellatum or $P$. compressum. Balkis (2004) did not find motile cells in plankton tows from Marmara Sea but found the cysts in samples taken in 2010-2012 (Balkis et al., 2016). There is one report of $P$. compressum in the North Aegean Sea by Evagelopoulos and Nicolaidis (1996) who comment that the cysts of $P$. compressum (including P. stellatum Wall in Wall and Dale 1986) are more 
frequently recorded than the motile stage. Globally, the motile stage of $P$. stellatum is not common except off the NW coast of Africa (AlgaeDatabase map accessed Feb. 2014).

Comparison: In a study of the Persian Gulf (Bradford 1975), morphologically similar cysts of Peridinium stellatum were grouped with the cyst-based species Stelladinium reidii Bradford 1975. However, $S$. reidii differs from the cysts of $P$. stellatum in having horns that are hollow along most of their length. A few S. reidii cysts were seen in Black Sea surface samples but we have not included these in the database or mapped their sparse distribution because of lack of systematic recognition by all co-authors. Another similar species, Stelladinium robustum Zonneveld 1997 appears to differ from S. stellatum only in its larger size (mean $=108.5$ x 110 $\mu \mathrm{m})$ and in the absence of subsidiary horns, but its size range overlaps that of $P$. stellatum cysts which do not always have additional spines. None of the BSC morphotypes have seven sturdy spines in the cingular area as found in the Adriatic Sea (Zonneveld and Pospelova, 2015; fig. 6).

Distribution: In the BSC, cysts of $P$. stellatum are very common in Marmara Sea and are widespread in relatively low amounts $(<5 \%)$ in northern and southeastern Black Sea (Figure 27); there is only one report of a single cyst in a Caspian Sea surface sample (Desmet, 2013) and it is absent in the Azov and Aral Sea samples. Associated SST ranges seasonally from $5.5^{\circ} \mathrm{C}$ (winter) to $24.5{ }^{\circ} \mathrm{C}$ (summer), with highest cyst $\%$ at annual average $\mathrm{SST}=15{ }^{\circ} \mathrm{C}$; SSS has a seasonal range of 14.8 (spring) to 31 (winter), with maximal \% values found in SSS <18. Associated nutrient values are $[\mathrm{P}]$ mostly $0.01-0.30,[\mathrm{~N}] 0-5 ;$ [Si] 2-14.5 (up to 22.2); [chl.-a] ranges from 0.3 to 3 , with highest occurrences in the lowest range of [chl.-a]. The bottom $\mathrm{O}_{2}$ values range from $0-7$, with highest $\%$ in hypoxic waters (c. $2 \mathrm{ml} / \mathrm{l}$ ). In sediment cores, the cysts of $P$. stellatum s.l. (possibly including some P. reidii) are present in Marmara Sea by c. 6,000 yr BP (Londeix et al., 2009) and in the SE Black Sea by c. 4,800 yr BP. 
Cysts of P. stellatum are present in the innermost part of Izmir Bay, off the Aegean Sea (Aydin et al., 2011). Globally, cysts of Protoperidium stellatum appear to be restricted to coastal sites of temperate/sub-tropical to equatorial regions of both Pacific and Atlantic oceans and they are most abundant in the warmer regions. Maximum amounts (up to 26\%) are in upwelling areas off NW Africa and in fully marine sites which are seasonally mesotrophic to eutrophic (Zonneveld et al., 2013). However, occurrences in the coastal waters of the Danube Delta area of the Black Sea extend the distribution of this taxon into periodically lower salinity marine environments where there are also relatively high proportions of cysts with recurved or reduced processes. In Japan, cysts are produced in winter when temperatures are c. $10{ }^{\circ} \mathrm{C}$. The cysts are normally not reported from oxygen minimum zones or where bottom waters are anoxic (Zonneveld et al., 2013) and this may account for the low occurrence of excysted specimens seen in sediments of the BSC deep stratified basins with shallow oxygen minima.

[Figure 27. Distribution map of cyst of Protoperidinium stellatum goes here.]

4.24 Cyst of Scrippsiella trifida Lewis 1991 ex Head 1996 and cysts of Scrippsiella spp.

Distinguishing characters: Based on Head et al. (2006), these are ovoid-shaped cysts which have a slightly more pointed apex than antapex (Plate 5, Figs. 10-15). The cyst wall has an inner smooth organic layer and an outer undulating organic layer that reflects the shape of regularly positioned underlying calcareous processes which are not present in palynologically treated samples. In some places, the two organic walls are perforated. The zigzag-shaped chasmic archeopyle includes three apical plates and the 1a-3a intercalary plates. The archeopyle is very rarely seen in cysts from the BSC. 
Dimensions: Size ranges from 29-41 $\mu \mathrm{m}$ in length and 19-38 $\mu \mathrm{m}$ in width.

Biological Affinity: Cysts of Scrippsiella trifida are calcareous-walled resting spores of flagellate, organic-walled cells of S. trifida. The cyst-theca relationship is established and described by Lewis (1991) and Head et al. (2006); Head (1996) provides additional details. $S$. trifida is not reported for the plankton of either the BSC or the Mediterranean region east of the Ionian Sea, and is rare in the Atlantic. This apparent rarity may be because several Scrippsiella species can only be identified to species level when the cyst is known; without the cyst, the motile stage may be misidentified (e.g. Hoppenrath et al., 2009).

Comparison: Most of the cysts of Scrippsiella recorded in surface sediments of the BSC resemble those of $S$. trifida but do not show the typically pointed apex and they have a variable and/or weakly undulating outer layer. For mapping purposes in the BSC atlas, therefore, we show these atypical cysts as undifferentiated "cysts of Scrippsiella spp.". For the map, we also show the location of the cyst of Scrippsiella plana Luo, Mertens, Bagheri and Gu 2016, which is the first finding of this Scrippsiella in the BSC east of Black Sea (see Luo et al., 2016) and merits attention as an apparently new invasive species. It is important to note, however, that the small $(22.5-25 \mu \mathrm{m})$ spherical cyst of Scrippsiella plana differs from other Scrippsiella spp. in size and shape, and SEM images show either a smooth surface or finely fibrous outer layer.

Distribution: In BSC surface samples, cysts of S. trifida were identified with certainty only in samples studied by Verleye, Desmet and Mousing (Table 4), mostly from central Black Sea where the distribution is widespread, tending to increase in deeper water, with a large peak $(69 \%)$ in the SE Black Sea basin (Figure 28). In contrast, cysts of Scrippsiella spp. are much more widespread (Figure 29) but in lower relative abundances $(<10 \%)$ and including a large number of sites in the eastern Black Sea. Associated SST ranges seasonally from $5.5{ }^{\circ} \mathrm{C}$ (winter) to $23.3{ }^{\circ} \mathrm{C}$ (summer), with highest cyst $\%$ at annual average $\mathrm{SST}=14.5{ }^{\circ} \mathrm{C}$; $\mathrm{SSS}$ has a seasonal 
range of 16.6 (summer) to 18.3 (winter), with highest \% values found in SSS around 18 and above. Associated nutrient values are [P] mostly 0.04-0.20, [N] 0-3; [Si] 2-7.3 (up to 12.65); [chl.-a] ranges from 0.5 to 1.5 . The bottom $\mathrm{O}_{2}$ values range from $0-7$, with highest $\%$ in not well oxygenated waters. We include with Scrippsiella spp., the cyst of Scrippsiella plana recently found in a surface sediment sample from SW Caspian Sea shelf, $35 \mathrm{~m}$ water depth (Luo et al., 2016); this species is also present in the south China Sea. In sediment cores, the cyst of S. trifida is only reported as consistently present by Mousing et al. (2013) for SE Basin sediment younger than 150 yrs, implying that it is a recent invasive. However, Verleye et al. (2009) found the cyst in SW Black Sea, in Core GeoB7625-2, 596 cm, dated c. 6 ka BP and Londeix et al. (2009) report an occurrence at $6.4 \mathrm{ka}$ in Marmara Sea. Globally, Scrippsiella trifida is distributed in neritic and broadly temperate regions of the North Atlantic (Head et al., 2006), with the cysts most abundant in areas of reduced salinity (salinity $\pm 20 \mathrm{psu}$ ).

[Figure 28. Distribution map of cyst of Scrippsiella trifida goes here.]

[Figure 29. Distribution map of cyst of Scrippsiella spp. goes here.]

\subsection{Cyst of Scrippsiella trochoidea (Stein 1883) Loeblich III 1976}

Distinguishing characters: Based on Lewis (1991), these are small spherical to ovoid cysts (Plate 7, Figs. 1-6) with a thin outer wall bearing short $(<3 \mu \mathrm{m})$ calcareous processes, which are triangular in cross-section. The archeopyle is apical, about $25 \%$ of the cyst width, with the operculum remaining attached by one third of the cyst circumference. In well-preserved cysts, a reddish accumulation body might be present. (Plate 7, Figs. 3, 6). After acid treatment, only short 
vestiges of some processes remain on the outer wall, and there are also spherical morphotypes with almost smooth walls.

Dimensions: Size ranges from (18) $25-48 \mu \mathrm{m}$ in length $(\mathrm{n}=10), 25-44 \mu \mathrm{m}$ in width (Lewis, 1991; Attaran-Fariman and Bolch, 2012).

Biological affinity: The cyst-theca relationship for this species was established by e.g. Wall et al. (1970) and Lewis (1991); Head (1996) provides a detailed overview. The ITS rDNA suggests the presence of several cryptic species in S. trochoidea (e.g. Montresor et al. 2003; Soehner et al. 2012). Scrippsiella trochoidea is considered a non-toxic bloom-forming HAB species which is common in both the Black Sea and Marmara Sea (Velikova et al., 1999; Gómez and Boicenco, 2004; Nesterova et al., 2009; Balkis et al., 2016) and is widespread in the Caspian Sea (Gogorev, 2006), but it is not included as a marine HAB species in the IOC-UNESCO Taxonomic List of Harmful Algae (Moestrup et al., 2009). Frequent blooms of the motile stage and some cysts of $S$. trochoidea are recorded for the NW and Romanian Shelf, notably in spring and summer of 1980-1990 and continuing to 2005. S. trochoidea is a facultatively phagotrophic dinoflagellate that consumes bacteria, small diatoms and other small prey.

Comparison: More work is needed to distinguish the organic-walled cysts of Scrippsiella trochoidea remaining after acid treatment and spine removal. Balkis et al. (2016), using untreated sediment samples, has found cysts of Scrippsiella precaria in Marmara Sea in addition to $S$. trochoidea (up to $3200 / \mathrm{cm}^{3}$ ) and S. trifida (up to $2400 / \mathrm{cm}^{3}$ ). These cysts form a significant proportion of the total cyst population in surface sediments $(0-2 \mathrm{~cm})$ whereas samples treated with acid show amounts of organic linings <2\%). In addition, Aydin et al. (2011) reports two hyaline-walled cysts of Scrippsiella sp. in Izmir Gulf off the Aegean Sea, one of which may be Scrippsiella trochoidea. 
Distribution: In the Black Sea surface sediments, cysts of S. trochoidea are sporadically present in relatively low numbers in the Western Black and Marmara Sea (Figure 30). Cyst abundance appears to increase offshore towards the shelf edge beyond which numbers decline and the cysts do not occur in the deeper water where only S. trifida cysts are present. Associated SST ranges seasonally from $5.5^{\circ} \mathrm{C}$ (winter) to $23.5^{\circ} \mathrm{C}$ (summer), with highest cyst $\%$ at annual average $\mathrm{SST}=15{ }^{\circ} \mathrm{C}$; SSS has a seasonal range of 14 (summer) to 31 (winter), with highest $\%$ values found in SSS <18. Associated nutrient values are [P] mostly 0.04-0.26, [N] 0-3; [Si] 2-22.2; [chl.-a] ranges from 0.6 to 1.5 , with highest occurrences in the maximum range of [chl.-a]. The bottom $\mathrm{O}_{2}$ values range from $0-6 \mathrm{mg} / 1$. In cores from the Marmara Sea, cysts of Scrippsiella trochoidea appear first around 3.1 ka BP (PJM, unpublished; core MAR02-88P). In deep water off the Danube Delta, two strains of $S$. trochoidea are detected by rRNA fingerprinting of sediment from the earliest Holocene, and increasing with time from ca $8-5$ cal kyr and again after 1,000 cal. yr. BP (Coolen et al., 2013). Globally, the cysts of S. trochoidea are common and considered cosmopolitan by Attaran-Fariman and Bolch (2012), occurring in temperate to warm coastal waters with SST $10-30{ }^{\circ} \mathrm{C}$ and SSS is 5-39.1. Cysts retain viability down to $3^{\circ} \mathrm{C}$ but germination is light-regulated and relatively insensitive to temperature (Binder and Anderson, 1986; Nuzzo and Montresor, 1999).

[Figure 30. Distribution map of cyst of Scrippsiella trochoidea goes here.]

4.26 Cyst Type A of Verleye et al. 2009

Distinguishing characteristics: This cyst was first noted by Verleye et al. (2009, pl. 2, fig. 7) who called it Type A because at that time, it was not incubated to establish its dinoflagellate cyst 
identity. These cysts are spherical and light-brown to brown, with a two-layered wall, the outer wall appearing to be irregularly domed to slightly undulating in optical section when viewed by light microscopy (Plate 15, Figs. 8, 10, 14). The inner wall is brown and the closely attached outer wall is transparent and shows a distinct reticulation of even polygonal fields (Plate 15, Figs. 7-15). The large hexagonal archeopyle may have an attached or free operculum.

Dimensions: Cyst diameter (including outer wall): 35.2(38.3)42.6 $\mu \mathrm{m}(\mathrm{n}=6)$, width of outer wall is 2.7 (4.6) $7.7 \mu \mathrm{m}(\mathrm{n}=18)$.

Synonymy: Called Type A by Verleye et al. (2009).

Biological Affinity: Cyst of a presently unknown motile dinoflagellate.

Comparison: The cyst shows some superficial similarities to the microreticulate cysts of $G$. nolleri/microreticulatum, although Cyst type A of Verleye et al. 2009 is larger, the height of the reticulations is higher and more irregular, and the archeopyle is intercalary. The distinctive transparent outer wall of Cyst Type A which is usually irregularly domed (Plate 16, Fig. 8) is not found in cysts of $G$. nolleri/microreticulatum.

Distribution: Presently known only from the Black Sea where it is widely distributed in surface sediments, with highest \% values in shallower water of the SE basin; it is also found at two sites in western Marmara Sea (Figure 31). Associated SST ranges seasonally from $5.5{ }^{\circ} \mathrm{C}$ (winter) to $24{ }^{\circ} \mathrm{C}$ (summer), with maximum cyst $\%$ at annual average SST $=14.5{ }^{\circ} \mathrm{C}$; SSS has a seasonal range of 14.5 (spring) to 31.1 (winter), with highest occurrences found in SSS between 16 and 18.5. Associated nutrient values are [P] mostly 0.02-0.33, [N] 0.02-5; [Si] 2-14.5 (up to 22.1); [chl.-a] ranges from 0.3 to 3.3 , with highest $\%$ values in the lowest range of [chl.-a]. The bottom $\mathrm{O}_{2}$ values range from $0-7$, with highest $\%$ in not well oxygenated waters. Cyst Type A of Verleye et al. 2009 also occurs in Holocene sediments of core GeoB7625-2 from the SW slope of the Black Sea, with a first appearance at $464 \mathrm{~cm}$, which corresponds to about $3.5 \mathrm{ka} \mathrm{BP}$. 
[Figure 31. Distribution map of Cyst Type A of Verleye et al. goes here.]

\subsection{Dubridinium caperatum Reid 1977}

Distinguishing characteristics: Based on Reid (1977), Matsuoka (1987) and McMinn et al. (2010), these are dark- to light-brown, cavate cysts with a thick $(1-2 \mu \mathrm{m})$ inner wall and thinner, closely attached periphragm (Plate 3, Figs 10-15). The cyst shape is characteristically lenticular (round to sub-circular/oblate) being strongly polar compressed and is also weakly dorsoventrally compressed. The inner wall is yellow-brown and microgranulate (Reid, 1977) or smooth (Matsuoka, 1987); the periphragm shows weak tabulation as discontinuous cingular ridges and low sulcal traces on the hypocyst. The large gaping archeopyle is chasmic epicystal, remaining attached ventrally after opening almost completely around the circumference of the cyst (Plate 3, Fig. 15; see also Zonneveld and Pospelova, 2015, fig. 5).

Dimensions: Length 35-63 $\mu \mathrm{m}$; width 40-42 $\mu \mathrm{m}$ in 15 specimens (Reid, 1977; McMinn et al., 2010); mean diameter is $43.5 \mu \mathrm{m}$ in 19 specimens (Matsuoka, 1987).

Synonymy: Cyst of Diplopsalis lenticula forma minor Paulsen 1907, the junior synonym of which is Zygabikodinium lenticulatum (Paulsen) Loeblich and A.R. Loeblich 1970; cyst of Diplopeltopsis minor (Paulsen) Pavillard 1913 of Reid (1977), considered a taxonomic junior synonym of Preperidinium meunieri (see Head, 1996, p. 1211); cysts of Preperidinium meunieri (Pavillard) Elbrächter 1993.

Biological Affinity: Cyst of Preperidinium meunieri according to studies of Wall and Dale (1968) who incubated Diplopeltopsis minor, and as determined by the observations of Reid (1977) and Matsuoka (1987). This species is reported as present in the Black Sea (Gómez and 
Boicenco, 2004). The motile species Diplopsalis lenticulata in Marmara, Black and Caspian Sea phytoplankton records and a related species found in Aral Sea by Ostenfeld (1908) are different from the dinoflagellate that produces the cyst Dubridinium caperatum. A motile species of Diplopsalis is reported to cause red tides in the southern Black Sea (Fezioğlu and Öğlüt, 2006) but it is not listed as a HAB species by IOC-UNESCO (see Moestrup et al., 2009).

Comparison: D. caperatum differs from other species of the genus Dubridinium in having a thick microgranular inner wall and closely attached periphragm (Reid, 1977)

Distribution: In the BSC surface sediments, D. caperatum is widespread in low relative abundances $(<6 \%)$ mostly in shelf areas and is not present in the deep basins (Figure 32). The species is not reported for either the Caspian or Aral Seas. Associated SST ranges seasonally from $5.5^{\circ} \mathrm{C}$ (winter) to $24^{\circ} \mathrm{C}$ (summer), with maximum cyst $\%$ at annual average $\mathrm{SST}=15^{\circ} \mathrm{C}$; SSS has a seasonal range of 14 (summer) to 31.5 (winter), with highest percent values found in SSS between 16 and 18.3. Associated nutrient values are [P] mostly $0.05-0.33,[\mathrm{~N}] 0-5$; [Si] 2-34; [chl.-a] ranges from 0.4 to 3.3 , with highest \% values in the uppermost range of [chl.-a]. The bottom $\mathrm{O}_{2}$ values range from $0-7 \mathrm{ml} / \mathrm{l}$, with highest $\%$ values in well oxygenated waters.

Dubridinium caperatum may be under-represented because encysted specimens seen in polar view are often grouped with Brigantedinium spp. or "round brown" cysts. In deep basin sediment cores, the species is occasionally present in Holocene sediments (Verleye et al., 2009, core GeoB-7625, SW Black Sea; Shumilovskikh et al., 2013 core 22-GC3, SE Black Sea) and it occurs in late Holocene sediment in Marmara Sea shelf core MAR02-88P (P. Mudie, unpublished). In surface sediments outside of the BSC, D. caperatum is usually found in temperate climate marine settings with unstratified surface waters and where nutrients are seasonally enhanced by upwelling or heavy anthropogenic eutrophication (Zonneveld et al., 2013), but it can also be widespread in coastal and estuarine sites of Tasmania and S. Australia 
(McMinn et al., 2010). The new BSC occurrences extend the low end of this salinity range to at least 17, with rare occurrences in Lake Razim where summer salinity is 2.2.

[Figure 32. Distribution map of Dubridinium caperatum goes here.]

4.28 Echinidinium zonneveldiae Head 2003 and Echinidinium spp.

Distinguishing characteristics: Based on Head (2003), Echinidinium zonneveldiae is a characteristically light- to medium-brown spherical cyst with a very thin $(<0.3 \mu \mathrm{m})$, smooth to microgranulate wall, sometimes with scattered granules or spinules, and bearing paler brown, short, solid, non-tabular processes which taper to fine points (Plate 9, Figs. 1-9). Many of these thin-walled cysts are easily compressed in preservation (Plate 9, Figs. 7-8). The smooth spines are circular in along most of their length, but some processes on each cyst have irregularly rectangular bases. The width of the process shafts ranges from c. 1.3-3.0 $\mu \mathrm{m}$, with the wider processes also being expanded at the base. Most processes are about $6 \mu \mathrm{m}$ long, but there may also be a few slender processes as short as $2 \mu \mathrm{m}$ on a specimen, and sometimes up to three processes may form on the same base. The archeopyle is theropylic, forming a long straight split extending almost halfway around the cyst, probably corresponding to the cingulum.

Dimensions: Central body maximum diameter is 32.5 (42.5) $51.0 \mu \mathrm{m}$ and maximum process length is 5.0 (6.85) $10.0 \mu \mathrm{m}$, based on >31 specimens from Poland and Denmark (Head, 2003). Biological Affinity: Unknown.

Comparison: Head (2003) comments that E. zonneveldiae differs from other Echinidinium spp. except 'Echinidinium transparantum' by having solid, transparent or pale tapering processes that arise from irregularly rectangular process bases. The inner body wall is also sometimes 
granulate but this may be partly controlled by preservation. Echinidinium transparantum Zonneveld 1997 also has a few process bases on each specimen with angular (squarish, rectangular) outlines in cross section but E. transparantum is a smaller cyst with longer processes than E. zonneveldiae. In Marmara Sea, some morphotypes of E. zonneveldiae were seen with furcate processes or process tips (Plate 9, Fig. 9). In the BSC, however, specimens with processes as long as shown by Head (2003) for 'E. transparantum' (c. $1 / 4^{\text {th }}$ the cyst diameter) were not recognised. It is not totally clear for the BSC region if there are ' $E$. transparantum' morphotypes with reduced processes associated with the brackish water environment or if all the BSC morphotypes should be referred to E. zonneveldiae, thereby extending its recorded stratigraphic range from Eemian to present, so we map typical morphotypes and transitional or uncertain morphotypes separately (Figures 33, 34). In Marmara and Black Sea, there are also morphotypes with relatively short, rigid, hollow spiny processes which are distally closed and acuminate, and with sub-circular bases; these morphotypes resemble Echinidinium delicatum Zonneveld 1997 ex Head 2003 and are included with other Echinidinium specimens in which diagnostic features could not be seen clearly because of folding and/or obscuration by clay particles or organic matter. These uncertain Echinidinium morphotypes are grouped together here as Echinidinium spp. (Figure 33)

Distribution: In the BSC surface sediments, E. zonneveldiae occurs almost exclusively in shelf areas of Marmara and the Black Seas, (Figure 33) while the grouped Echinidinium spp. occur more frequently on the outer shelf-upper slope of the Black Sea and both shelf and basin areas of Marmara Sea (Figure 34). E. zonneveldiae is associated with seasonal SST ranges from $5.5^{\circ} \mathrm{C}$ (winter) to $23.5^{\circ} \mathrm{C}$ (summer), with maximum cyst $\%$ at annual average SST $=14.5{ }^{\circ} \mathrm{C}$; SSS has a seasonal range of 14.7 (spring) to 31.3 (winter), with highest \% values found in SSS between 14.7 and 18.5. Associated nutrient values are $[\mathrm{P}]$ mostly $0.06-0.28,[\mathrm{~N}] 0.02-5$; [Si] 
1-33.5; [chl.-a] ranges from 0.5 to 3 , with highest $\%$ cyst occurrences in the lowest range of [chl.-a]. The bottom $\mathrm{O}_{2}$ values range from $0-7$, with highest $\%$ in poorly oxygenated waters.

Echinidinium spp. have essentially the same association with oceanographic parameters but have highest occurrences in more saline waters (SSS 20-24) and where [P] values are higher: $0.03-0.33$.

In BSC sediment cores, E. zonneveldiae occurs in the late Holocene of core 22-GC3 from the SE Black Sea basin, where it is common after about 1.3 ka BP (Shumilovskikh et al., 2013). In the SW Black Sea, E. transparantum is present in low numbers after about $4 \mathrm{ka} \mathrm{BP.} \mathrm{Elsewhere} \mathrm{it}$ may be included in counts of Echinidinium spp. E. zonneveldiae is a species from coastal sediments of Eemian age in Denmark and Poland, and believed to be part of a low-salinity paleoenvironment as opposed to E. transparantum which appears to be most common in marine waters of Mediterranean to tropical regions. However, Marino et al. (2008) report a dominance of E. zonneveldiae in heterotrophic assemblages of early to mid Holocene sapropelic sediments of core SL21 in the southern Aegean Sea where SSS probably remained above 36 throughout the late Pleistocene-early Holocene despite significantly lighter ${ }^{18} \mathrm{O}$ values of planktonic foraminifers (Isler et al., 2016). Other Echinidinium species tend to be either coastal cysts with a widespread global distribution from sub-polar to tropical regions or are confined to warm water regions (see Zonneveld et al., 2013).

[Figure 33. Distribution map of Echinidinium zonneveldiae goes here.]

[Figure 34. Distribution map of Echinidinium spp. goes here.]

\subsection{Impagidinium caspienense Marret 2004}


Distinguishing characters: Based on Marret et al. (2004) and Mertens et al. (2017), these transparent proximate cysts are subspherical to ellipsoidal in shape (Plate 16, Figs. 1-12) and have a well-formed apical boss $2-4 \mu \mathrm{m}$ high which can make the body appear slightly pearshaped (Plate 16, Figs. 3, 7). The two-layered wall is thin $(1 \mu \mathrm{m})$ and appressed over most of the surface but it separates at sutural junctions to form irregular, low, undulating, cavate septa with a microgranular surface. The body wall also contains low intratabular linear relief, giving the cysts a wrinkled appearance. The ortho-camerate archeopyle is formed by loss of the third precingular $\left(3^{\prime \prime}\right)$ plate, and the operculum is free. In Caspian Sea specimens, there is a distinctive high septum on the antapical plate (Plate 16, Figs. 9, 12). In the Kerch Strait area of the Azov Sea, specimens are found with short, hollow trifurcate tips.

Dimensions: Body length: 35-50 $\mu \mathrm{m}$; width: $30-43 \mu \mathrm{m}$, with septa up to $5 \mu \mathrm{m}$ high (Marret et al. 2004).

Biological Affinity: Gonyaulax baltica Ellegaard et al. 2002, according to Mertens et al. (2017).

Comparison: I. caspienense differs from most other Impagidinium species by its cavate septa which are similar to those in Impagidinium aculeatum (Wall 1967) Lentin and Williams 1981 and Impagidinium variaseptum Marret and de Vernal 1997 but are much lower in I. caspienense (mostly $<2 \mu \mathrm{m}$ ) where they enclose wall areas with short intratabular ridges. I. caspienense also differs in having a high $(2-5 \mu \mathrm{m})$ septum between the postcingular plate $1^{\prime \prime \prime \prime}$ and the sulcus. Similar cysts are found in the Aral Sea but with lower septal cavations (Sorrel et al., 2006). Cysts from late Holocene sediment in Lake Sapanca near the southeastern Marmara Sea (Leroy and Albay, 2010; their figs 3-1, 3-5, 3-6) are more oval than the Caspian specimens, and they have relatively high septa and lack a well-developed apical boss. Rare cysts from Black Sea surface 
sediments have very low septa and are similar to cf. Spiniferites bentorii cysts with extremely reduced, essentially no processes but are distinguished by a more oval body. Kerch Strait specimens of I. caspienense are not clearly distinguishable from some cysts of Gonyaulax baltica illustrated by Ellegaard et al. (2002b). Gonyaulax baltica Ellegaard et al. 2002 produces a cyst with variable morphology that resembles small rounded to ovoid specimens of $I$. caspienense.

Distribution: Impagidinium caspienense is essentially endemic to the Caspian and Aral Seas where it occurs in abundances up to $100 \%$ of cyst assemblages, and is associated with oligotrophic conditions, low productivity, reduced salinities and well ventilated bottom waters (Figure 35). In this region, associated SST is mostly $4.6-29.5^{\circ} \mathrm{C}$ (winter-summer) but with a minimum winter value of $1.6^{\circ} \mathrm{C}$ in Volga Delta); SSS is $11.7-17.5$ (summer-winter) with highest occurences between 11.7 and 13.2. Associated nutrients are [P]: 0.04-0.25 $\mu \mathrm{mol} / \mathrm{l}$, [N]: $0.06-0.27 \mu \mathrm{mol} / 1$, [Si]: $1.2-5$ (up to 15.5 ), [chl.-a] $0.64 \mu \mathrm{g} / \mathrm{l}$, and bottom water $\mathrm{O}_{2}$ is $2-8.5 \mathrm{ml} / \mathrm{l}$. If the Lake Sapanca cysts are in place, this could also indicate tolerance of fresh water conditions, but the lake cysts are confined to a short interval and were possibly introduced there by historical canal building and/or transport by fishermen (Leroy and Albay, 2010). Rare cysts of cf. I. caspienense in surface samples from the Ukrainian continental slope (300-643 m) are not well preserved and may be reworked.In sediment cores, I. caspienense is common in Holocene to recent sediment of the Caspian Sea (Leroy et al., 2013a). It is present in late Holocene sediment (>1 ka BP) Aral Sea (Sorrel et al., 2006). Small amounts of I. caspienense are rare in the earliest Holocene sediments of core MAR02-89P from Marmara Sea shelf (Roberts, 2012) and the southwestern Black Sea core MAR 02-45P (Marret et al., 2009) but so far, this species has not been found in cores from deeper water.

[Figure 35. Distribution map of Impagidinium caspienense goes here.] 
4.30 Impagidinium inaequalis (Wall and Dale in Wall et al. 1973) Londeix in Londeix et al. 2010

Distinguishing characteristics: Based on Wall et al. (1973), these transparent, irregularshaped cysts have a distinctive flask-like (lageniform) shape, with a slender, elongate, subcylindrical epicyst and a broader, asymmetrical hypocyst of approximately equal length (Plate 4, Figs 1-11). The wall is thin, with a scabrate to microgranular surface. Gonyaulacoid tabulation is clearly marked by low sutures with or without small spine-like (sharp-pointed) processes. The mid-dorsal archeopyle corresponding to the third precingular plate ( $\left.3^{\prime \prime}\right)$ is large and iso-camerate, with a detached operculum. The epicyst is bell-shaped with an apical boss and tapered sides, but it expands unevenly towards the cingulum in the dorsal and ventral areas (Plate 4, Figs 1-6, 11), while in lateral view, the cyst is irregularly rectangular in shape. The cingulum is strongly descending and the hypocyst is broad, with a distinctive wide, flat, laterally expanded basal antapical plate. The sulcus is large and is unusual in contacting the fifth precingular plate $5^{\prime \prime}$ anteriorly and in its uneven subrectangular expansion on the hypocyst.

Dimensions: Body length $44-45 \mu \mathrm{m}$, width 33-43 um, with small septal spines less than 5 $\mu \mathrm{m}$ long.

Synonymy: Spiniferites inaequalis Wall and Dale in Wall et al., 1973.

Biological Affinity: Probably a cyst of a gonyaulacoid dinoflagellate (Wall et al., 1973). Londeix et al. (2009, corrected by Londeix et al., 2010) transferred the taxon to the genus Impagidinium Stover and Evitt 1978 based on the absence of processes.

Comparison: The unusual, bell-shaped dinocyst I. inaequalis is rarely found, even at the paratype locality which is the early Holocene sediment Unit 3 in the SE Black Sea basin core 
Atlantis II, 1474P; therefore, the range of cyst morphological variation is poorly known. Wellpreserved specimens occur in late Pleistocene-early Holocene sediment of Marmara Sea shelf core MAR98-09 (Mudie et al., 2002a; 2004) and these cysts display a wider epitract and shorter hypotract compared to the holotype (Plate 4, Figs. 8-11). This morphotype is similar to strongly lagenate cysts from the Volga Delta designated as I. caspienense by Richards et al. (2014, pl. 2, figs. n-p). Rare asymmetrical cysts in surface samples from the NW Black Sea slope appear similar to I. inaequalis but they are poorly preserved and probably reworked from late Pleistocene deposits. Elongate cysts without a distinctly expanded hypocyst are called Impagidinium sp. A by Londeix et al. (2009); these cysts are rare the postglacial interval of Marmara Sea cores MD01-2340 (Londeix et al., 2009) and MAR02-89P (Roberts, 2012) and in Unit 3 of SE Black Sea core 1474P. In dorso-lateral view these cysts appear to be slightly cruciform.

Distribution: In surface sediments of the BSC, well preserved I. inaequalis is present only in the northern Caspian Sea (Keith Richards, personal communication 2015) and it is not mapped here. In the Volga Delta, the salinity is $<5$ and the area is ice-covered from November to March. The species appears to be endemic to the BSC (Keith Richards, personal communication, May 2016), I. inaequalis is rare in the lacustrine Late Pleistocene-earliest Holocene sediment of Atlantis II, core 1474P in the Black Sea and occasional in cores from both the Marmara Sea shelf and central basin.

4.31 Lejeunecysta marieae (Harland in Harland et al. 1991) Lentin and Williams 1993

Distinguishing characteristics: Based on Head (1993), these dorso-ventrally compressed, light brown cysts have a conical epicyst which is longer than the hypocyst, has convex sides and a 
weakly developed apical horn (a slightly thickened boss $<1.5 \mu \mathrm{m}$ high). The hypocyst has a rounded trapezoidal outline in equatorial view, with two moderately to strongly divergent antapical horns of equal size, bearing solid acuminate tips (Plate 17, Figs. 1-3). The wall surface is faintly to moderately granulate under light microscopy; in SEM images, tiny granules/gemmae $(0.5 \mu \mathrm{m}$ or less wide) are seen and these are densely covered in microgranules $(<0.1 \mu \mathrm{m})$. There are also minute $(<1 \mu \mathrm{m})$ blunt spines along the transversely folded cingular margins and sometimes elsewhere. A shallow sulcus is present. The archeopyle corresponds to intercalary plate $2 \mathrm{a}$ and is iso-deltaform with short H3 and H5 sides; the operculum is free or attached to the adcingular margin.

Dimensions: Upper Pliocene specimens $(\mathrm{n}=22)$ have a body length of $27(36.8) 47 \mu \mathrm{m}$ and width of 27(33.4)38 $\mu \mathrm{m}$; the antapical horn tip length, from base to tip of the solid section, is 1.7(4.1)5.7 $\mu \mathrm{m}($ Head 1993). The BSC specimens have a near average body size and horn tip length.

Synonymy: Protoperidinium (Protoperidinium sect. Lejeunecysta) sp. B Harland 1992; the name Protoperidinium marieae was validly published in Harland in Harland et al. (1991), as $P$. mariea) because although Lejeunecysta as a section name was not validly published, the species was assigned to the valid generic name Protoperidinium (Fensome and Williams, 2004).

Biological Affinity: Presumably a cyst of a heterotrophic Protoperidium species previously thought to exist only as a late Pliocene taxon. The Black Sea occurrences extend the species range from Early Pleistocene to Recent.

Comparison: In the BSC, the L. marieae cysts appear to have a smoother wall than the Pliocene cysts, and cingular ornament is not seen by light microscopy. L.invisitatum Bradford 1975 differs from L. marieae in the shape of the epicyst which is much larger than the hypocyst, giving it a wide-topped mushroom-shape appearance in lateral view. L. marieae is smaller than 
Lejeunecysta diversiforma (Bradford 1977) Artzner and Döhrhöfer 1978 which also has a relatively wider cingular area with pronounced lists.

Distribution: In BSC surface samples, L. marieae is present in only one sample from the NW Black Sea (Sta. GC29, relative abundance of 0.33\%) and is not mapped. It is occasionally present in late Holocene sediments of the the deepwater Black Sea core GeoB 7625-2 (Verleye et al., 2009) and in late Holocene sediments of the Marmara Sea upper slope core MAR02-88P. These occurrences in sediments of the Marmara and Black Sea are the first evidence for tolerance of low surface water salinity (c. 16-22). At Sta. GC29, SSS varies around 17.50-18, and SST from $7{ }^{\circ} \mathrm{C}$ in winter to $22.1^{\circ} \mathrm{C}$ in summer. Associated $[\mathrm{P}]$ is in the medium range $(0.14)$ whereas $[\mathrm{N}]$ and [chl.-a] values are on the low side (0.48 and 0.52 respectively). Bottom oxygen concentration is relatively high $(4.35 \mathrm{ml} / 1)$. In the western European upper Pliocene-lowest Pleistocene locations (Head, 1993), the cysts are found associated with cool-temperate climate (with mild winters) and warm-temperate to subtropical/Mediterranean conditions in inner neritic, nutrient-rich waters.

\subsection{Lejeunecysta oliva (Reid 1977) Turon and Londeix 1988}

Distinguishing characteristics: Based on Reid (1977), Lejeunecysta oliva cysts are olive-brown, pentagonal in equatorial view, dorsoventrally compressed and diamond-shaped in lateral view, with a flattened apical horn and two pointed, solid-tipped antapical horns, separated by a deep to shallow antapical compression (Plate 17, Figs 4-5). The epicyst and hypocyst are of equal size; the epicyst has straight sides, sometimes with a cingular shoulder, while the hypocyst is concave. The wall is thin, with a smooth to microverrucate surface and with thickened ridges marking a narrow excavated cingulum. Two small posterior sulcal thickenings may be flagellar pore scars. 
Diverging wall thickenings may mark the margins of the wide deep sulcus in both the epitract and hypotract. The intercalary archeopyle is subrectangular, being elongated, with a length/breadth ratio of approximately $2: 1$ and detached operculum.

Dimensions: Reid (1977) gives the total length as 63-83 $\mu \mathrm{m}$ and breadth as $74-88 \mu \mathrm{m}$ for 15 specimens; thickness is $53 \mu \mathrm{m}$ for one specimen; cingulum width is 5-6 $\mu \mathrm{m}$ and the distance between antapical tips is $36-42 \mu \mathrm{m}$.

Synonymy: The taxonomic senior synonym given as Lejeunia (now Lejeunecysta) paratenella Benedek 1972 by Harland (1977) is incorrect according to Turon and Londeix (1988, p. 344) who retained Trinovantedinium (as Lejeunecysta) oliva. Confusingly, the specimen from Termination I in the Alboran Sea well SU 8107 identified as L. oliva by Turon and Londeix (1988, their pl. 5, fig. 7) differs in having a striated appearance and it may not be the same taxon.

Biological Affinity: According to Rochon et al. (1999, p. 46), L. oliva is probably a cyst of a Protoperidinium sp. indet.

Comparison: L. oliva cysts from late Pleistocene sediments in Marmara Sea core MAR02-89P $(225 \mathrm{~cm})$ and in Black Sea cores have microgranules along some sutural lines. In Holocene sediments from Marmara and the SW Black Sea, there may be rare specimens of Lejeunecysta sabrina (Reid 1977) Bujak 1984. Lejeunecysta oliva is distinguished from L. sabrina in having low thickened ridges on the cingular margins and two pairs of apically converging ridges on the epicyst" (Rochon et al. 1999, p. 46). This taxon is distinguished from the similar-shaped but dark brown protoperidinioid cysts of Quinquecuspis concreta by its thin, simple-layered wall and pale or yellow-brown colour. However, in poorly preserved (oxidised and/or torn) specimens, it is not always possible to distinguish the genera and Lejeunecysta species with certainty, and for this atlas, we have grouped these uncertain light brown Lejeunecysta-type taxa as Lejeunecysta spp. 
Distribution: In the BSC surface sediments, L. oliva is reported for only one site on the Turkish Shelf (Bradley et al., 2013) and is not mapped. At this site, SSS and SST values average 17.8 (from 17.8 to 17.9 ) and $15.2{ }^{\circ} \mathrm{C}$ (from 7.9 to $23.2{ }^{\circ} \mathrm{C}$ ) respectively, in general accord with reported global values but indicting tolerance of lower summer salinity. L. oliva is rare in some cores from the Black Sea and Marmara Sea where it appears in low numbers in Late Pleistoceneearliest Holocene sediments but is absent in the basin cores studied by Shumilovskikh et al. (2013). This species was described first for recent sediment along the south coast of the UK and in the Dee Estuary (Reid, 1977). In general, L. oliva is restricted to coastal areas of temperate to subtropical regions and is most abundant in areas of variable upwelling or river discharge and where bottom waters are poorly ventilated (Zonneveld et al., 2013). Associated SST is mainly 0$29.7^{\circ} \mathrm{C}$ (winter-summer) with summer SST $>8.2^{\circ} \mathrm{C}$ and SSS is $26.8-37.5$ (summer-winter). The BSC occurrences considerably lower this range of SSS values to at least 16.

\subsection{Lingulodinium machaerophorum (Deflandre and Cookson 1955)Wall 1967}

Distinguishing characteristics: Based on Deflandre and Cookson (1955), Wall (1967), Wall et al. (1973), Rochon et al. (1999), Marret et al. (2004), Mertens et al. (2009b), and our our own observations, these are pale, spherical to ovoid cysts with a finely but distinctly granulate wall surface, formed by interlinking fibrils of varying thickness, and with numerous nontabular processes of variable shape and length (Plate 18, Figs. 1-10). The cyst is usually transparent but is sometimes slightly brownish in anoxic conditions. The processes are hollow, arise from a circular base and taper distally. They are closed distally, usually pointed (acuminate or lingulate $=$ tongue-shaped; Plate 18, Figs. 1-2) and often have characteristic irregular, small spinules or granules around the unbranched tips, but this feature is very variable, as also shown by the large 
variety of processes observed in culture (Kokinos and Anderson, 1995). Process distribution also is often asymmetrical, with processes of notably different lengths on opposite sides. Processes shafts usually have a smooth surface, often with striations at the base and small spinules restricted to distal parts, particularly in specimens with longer processes. Within one population there may be two end-members: one with many, shorter processes and one with fewer, longer processes. Shorter processes may be conical or club-shaped. Sometimes processes can be nearly completely reduced or strongly folded onto the surface, which makes such "bald" cysts difficult to recognize (e.g. Nehring, 1994; Ellegaard, 2000). Rarely, processes of Caspian Sea shortspined cysts can be merged, forming broad flanges (Plate 18, Fig. 9). The characteristically complex archeopyle is formed by loss of one to five precingular plates: loss of multiple archeopyle plates often gives the cyst an ovoid or irregular body shape.

Dimensions: Specimens from the BSC show enormous variation in morphology: body diameter: 26.0 (47.6) $91 \mu \mathrm{m}(\mathrm{SD}=6.1 \mu \mathrm{m}, \mathrm{n}=2,370)$; process length: 0.5 (13.4) $29.6 \mu \mathrm{m}(\mathrm{SD}=5.5$ $\mu \mathrm{m}, \mathrm{n}=8,058$; Mertens et al., 2012b).

Synonymy: Cleistosphaeridium disjunctum according to Reid (1974); Cleistosphaeridium mikirii, according to Jain and Garg (1983); Hystrichosphaeridium ashdodense according to Wall (1967); Baltisphaeridium (subsequently Lingulodinium) funginum; Lingulodinium brevispinosum and Lingulodinium sadoense, all according to Kokinos and Anderson (1995); questionably Hystrichosphaeridium redonense according to Harland (1977) and Rochon et al. (1999). Stover and Evitt (1978) considered that Impletosphaeridium (as Lingulodinium) pycnospinosum may be a taxonomic junior synonym. Baltisphaeridium machaerophorum var. filiforme Rossignol 1964 was transferred to L. machaerophorum as Lingulodinium machaeophorum subsp. filiforme (Rossignol, 1964) Lentin and Williams 1973. 
Biological Affinity: A cyst of Gonyaulax (now Lingulodinium) polyedra Stein 1883, according to Wall and Dale $(1967 ; 1968)$. Since then, the cyst-theca relationship has been confirmed several times (Head, 1996; Lewis and Hallett, 1997). Single-cell polymerase chain reaction (PCR) data for L. machaerophorum with different process lengths from the Caspian Sea, Black Sea and California show that these are all the same species (Mertens et al., 2012b). Lingulodinium polyedra is also very widely reported in plankton samples for all BSC subregions, except the Aral Sea where there are few available modern data and it was absent in the survey of Ostenfeld (1908). This facultatively mixotrophic species (Jeorg et al., 2015) can reach harmful bloom proportions and it produces homoyessotoxin in mussels (Paz et al., 2008).

Comparison: Some Echinidinium granulatum cysts can look relatively similar but they have a brownish colour and a chasmic archeopyle. Some transparent, unpigmented copepod eggs can look similar to L. machaerophorum, but differ in size, have a smooth wall texture, longer spine length and shape (acute tips), and they open with a slit. Wall et al. (1973) comment that most specimens in their three Black Sea cores of Holocene sediment had simple 3" archeopyles; however, our widespread observations show that two or three archeopyle plates are usually missing in specimens from surface samples. Reduction of process length of this species within the BSC is associated with lowered salinities (Wall et al., 1973; Mertens et al. 2012b); Figueroa and Bravo (2005) have also shown that cysts of variable process length, including temporary sexual cysts without processes, are found in laboratory cultures and sometimes associated with variations in nutrient concentrations. Based on the shape of the processes, several morphotypes are recognised in the BSC. In Marmara Sea, these morphotypes include forms with long, relatively wide, straight processes with aculeate tips (Plate 18, Figs. 1-2), long processes with clavate tips (Pl. 18, Fig. 8), and forms with short process and club-shaped or blunt tips (Mudie et al., 2001, pl. 2). In the Caspian Sea area, in addition to the typical form with long processes, 
Leroy et al. (2006) recognise L. machaerophorum var. A in the hypersaline Kara-Bogaz Gol (KGB); this taxon has a spherical body (mean diameter $50 \mu \mathrm{m}$ ), strongly granulate wall surface, and numerous, relatively short $(9 \mu \mathrm{m}$ mean) processes with acuminate process tips and small striated conical bases (Leroy, 2010). Leroy et al. (2006) also describe L. machaerophorum var. B which occurs in both the KGB and the Caspian Sea; this taxon has a larger body (mean $60 \mu \mathrm{m})$, microgranulate wall surface and short (2-3 $\mu \mathrm{m}$ length), bulbous, microgranulate processes with large striated conical bases. Both the Caspian Sea forms have archeopyles formed by loss of three plates. In the Caspian Sea, Marret et al. (2004), recognise four morphotypes: $L$. machaerophorum var. A with thin, scabrate, longer than normal processes, without conical bases and with a scabrate body surface and processes (ssp. filiforme in Plate 18, Fig. 3); L.

machaerophorum var. B has most processes with bulbous tips and normal length (Plate 18, Figs. 4, 7, 9); L. machaerophorum var. C has shorter, acuminate, thin processes, c. $7 \mu \mathrm{m}$ long); and $L$. machaerophorum var. s.p. (short processes) has very short, bulbous or sometimes spine-like processes (Plate 18, Fig. 5).

Distribution: In surface samples of the BSC, L. machaerophorum is the most widespread and often the most abundant species (up to c. $84 \%$ of the assemblage) throughout the region (Figures $36-38)$. The species is almost ubiquitous, but it is absent in the low salinity ( $<3 \mathrm{psu})$ Danube and Volga Delta sediments and in coastal lagoons (limans) of the Ukraine, Romania and Bulgaria (PJM, unpublished; Marinova and Atanassova, 2006). Most populations contain a mixture of process lengths with long $(>10 \mu \mathrm{m})$ pointed-tip processes dominating in cooler (annual SST 11.7-16.3 ${ }^{\circ} \mathrm{C}$ ), more saline waters (annual SSS 16.4-18 psu), together with a smaller proportion (c. $10 \%$ ) of clavate forms (Figure 38). Short-process (length $<10 \mu \mathrm{m}$ ) morphotypes dominate in most areas of Caspian Sea and are associated with higher annual SST (17-20 $\mathrm{C})$ and lower SSS (12.4-13.2; Figure 37). Mertens et al. (2012b) show there is a significant correlation between 
process length and SSS, with shorter processes characterising areas of lower salinity down to SSS 11.9 in summer). Peak relative abundances of L. machaerophorum with normal long (>10 $\mu \mathrm{m})$ processes occur in the nutrient-rich waters of the Danube and Ukrainian shelves, with larger amounts of clavate cysts tending to occur in areas of periodically lower spring salinities (c. 5-10) off Danube Delta in the NW Black Sea where the average spring SSS range is 14.6-17.8 psu. Associated nutrient values (all morphotypes) are [P] 0.02-3.3, [N] 0-4.8, [Si] 1.5-37 $\mu \mathrm{mol} / \mathrm{l}$, [chl.-a] 0.5-2.9 $\mu \mathrm{g} / \mathrm{l}$, with no clear link with either cyst percentages or process length. The bottom $\mathrm{O}_{2}$ range is also wide $0.03-7.4 \mathrm{ml} / 1$ and is not clearly related to cyst amount or morphotype. Cysts with short processes dominate in the southern Caspian Sea, in amounts $>30-76 \%$; lesser amounts are common in lower numbers in the NW Black Sea and occur sporadically elsewhere in the western BSC. In sediment cores, L. machaerophorum becomes the co-dominant species with Operculodinium centrocarpum after c.10 ka BP in Marmara Sea and is dominant in Black Sea cores after c. 7.6 ka BP. In Caspian Sea cores, L. machaerophorum becomes abundant after c. 3,200 yr BP (Leroy et al., 2013b). In general, L. machaerophorum has a widespread distribution in coastal and shelf regions between the Arctic and Antarctic subtropical fronts (Zonneveld et al., 2013) where summer summer SST>10.1 ${ }^{\circ} \mathrm{C}$ and SSS is $8-$ 31.4 (summer-winter). Highest relative abundances are associated with upwelling cells, river discharge plumes, and the highly stratified waters of Marmara and the Black Seas. Seasonal cyst production may be related to relaxation of turbulence and development of stratified conditions after upwelling and nutrient enrichment. Laboratory cultures (Figueroa and Bravo, 2005) suggest that production of short-lived asexual ecdysal cysts may increase survival during turbulence or other unfavourable conditions and enable rapid seeding of the subsequently stratified waters but 2-4 months of dormancy are required before germination of the spiny resting cysts can occur. 
[Figure 36. Distribution map of Lingulodinium machaerophorum $>7 \mu \mathrm{m}$ goes here.]

[Figure 37. Distribution map of Lingulodinium machaerophorum $<7 \mu \mathrm{m}$ goes here.]

[Figure 38. Distribution map of Lingulodinium machaerophorum f. clavatum goes here.]

\subsection{Nematosphaeropsis labyrinthus (Ostenfeld 1903) Reid 1974}

Distinguishing characteristics: These chorate cysts are trabeculate and they have a transparent, ovoid central body, sometimes with a small apical node, and a thin, two-layered wall. The outer wall forms long, slender, terminally-branched gonal processes with their distal branches being linked by parallel pairs of ribbon-like trabeculae which form a characteristic loose network around the body (Plate 19, Figs. 8-16). The cysts seem delicate, often being folded or crumpled. The surface of the body and the processes appear smooth under light microscopy, but SEM images show that the body surface and trabeculae are either lightly scabrate or in Marmara Sea, they are microgranular (Plate 19, Figs. 14-17). The parallel trabeculae can make it difficult to see the low sutures and the archeopyle which corresponds to the third precingular plate $\left(3^{\prime \prime}\right)$ and has a free operculum.

Dimensions: Body length is $27-42 \mu \mathrm{m}$; process length is $11-23$; trabeculae are $1-1.5 \mu \mathrm{m}$ wide (Reid, 1974; Rochon et al., 1999).

Synonymy: Nematosphaeropsis balcombiana Deflandre and Cookson 1955 is a taxonomic junior synonym, according to Reid 1974 who recombined the fossil cyst Pterosperma labyrinthus Ostenfeld 1903 as Nematophaeropsis labyrinthea (incorrect orthography), although Wrenn (1988) disputed this change (see Rochon et al., 1999 for more details). 
Biological Affinity: Wall and Dale $(1967 ; 1968)$ carried out cyst-theca experiments which related N. labyrinthus to Gonyaulax spinifera (Claparède and Lachmann 1859) Diesing 1866. Cultures of G. spinifera produce cysts similar to N. labyrinthus at some salinities (Rochon et al., 2009) but trabeculation is not always complete in these cultured cysts which resemble partially trabeculate Spiniferites ramosus cysts; these cultures show that cyst development varies with salinity around 25-32. Continuing morphological and molecular studies may uncover distinct species within this G. spinifera complex (Rochon et al., 2009). G. spinifera is widespread in the Black Sea and is occasionally found in Marmara Sea (Gómez and Boicenco, 2004; Balkis et al., 2016). Although G. spinifera is a non-toxic red-tide species, the cyst form $N$. labyrinthus is usually found in very low numbers and has not been linked to bloom occurrences.

Comparison: Cysts of N. labyrinthus in Marmara Sea are very similar to those of the Oligocene-early Pleistocene species Nematosphaeropsis lemniscata Bujak 1984 but the latter differs in having both gonal and intergonal processes, so it appears to be more densely covered by long processes.

Distribution: In surface sediments, small amounts $(<2.5 \%)$ of $N$. labyrinthus are very rare in the BSC, being found only in a few samples from Marmara Sea (Figure 40). Associated SST ranges seasonally from $7.5{ }^{\circ} \mathrm{C}$ (winter) to $23^{\circ} \mathrm{C}$ (summer), with highest cyst $\%$ at annual average $\mathrm{SST}=15.5^{\circ} \mathrm{C}$; SSS has a seasonal range of 21 (summer) to 28.3 (winter). Associated nutrient values are $[\mathrm{P}]$ mostly $0.01-0.14,[\mathrm{~N}] 0-0.5 ;$ [Si] $\sim 0.5-10.5$; [chl.-a] $\sim 1$, with highest occurrences in the lowest range of [chl.-a]. The bottom $\mathrm{O}_{2}$ values range from 1.5-2.5. In Marmara Sea, it is occasionally present in Holocene sediments of shelf cores (Mudie et al., 2002a) and is more common in the deep basin core MD01-2430 (Londeix et al., 2009) where it appears first in the earliest Holocene. It is absent from Holocene sediments of the Black Sea (Shumilovskikh et al., 2013). N. labyrinthus is generally very common throughout the Mediterranean and Aegean Seas 
(see Zonneveld et al., 2013) but it is not reported for Izmir Bay. World-wide, N. labyrinthus occurs from arctic to tropical regions with SST of -2.1-29.8 ${ }^{\circ} \mathrm{C}$ (Zonneveld et al., 2013). It is abundant in both eutrophic and oligotrophic waters and occurs in both anoxic and oxic sediments but peak abundances are in well ventilated water. It is mostly restricted to fully marine environments and is absent from the low salinity Baltic and Caspian Seas as well as the hypersaline Red Sea and Gulf of Oman.

[Figure 39. Distribution map of Nematosphaeropsis labyrinthus goes here.]

\subsection{Operculodinium centrocarpum sensu Wall and Dale 1966}

Distinguishing characteristics: Based on Rochon et al. (1999); Mertens et al. (2011); PaezReyes and Head (2013), these transparent, chorate cysts are distinguished by a spherical body which is densely covered by radiating erect, slender, non-tabular, hollow processes, circular in cross-section with minutely expanded tips (Plate 20, Figs. 1-6, 8). Under transmitted light microscopy, the process tips appear capitate in lateral view and circular in polar view, but SEM images show they are dish-shaped with fringed margins and minute central perforations (Plate 20 , Figs. 6,8$)$. The wall of the central body is thin $(<1 \mu \mathrm{m})$, with a microfibrous surface bearing scattered granules and columellae, giving it a characteristic slightly rough appearance. The processes are simple, smooth, with slender shafts which are circular in cross-section and distally open. Typically, the processes are long (c. $1 / 4^{\text {th }}$ the body width). The processes broaden slightly at the bases which are polygonal and sometimes seen to be minutely striate. The archeopyle corresponds with the third precingular plate; it is large and pentagonal, but has rounded sides and may appear subtrapezoidal in light microscopy (Plate 20, Figs. 1, 5). The operculum is free. The 
processes may be variable in length or all are very reduced (Plate 20, Figs. 7-11); they are sometimes absent in the Baltic Sea according to Mertens et al. (2011). Overall, there are two end members: one with relatively few long processes and one with many short processes (or completely reduced). The short processes have furcate tips or truncated, round, open distal ends.

Dimensions: World-wide, the cyst body diameter is $33-48 \mu \mathrm{m}$ and the process length is typically $7-14 \mu \mathrm{m}$ but can be shorter. For the BSC surface samples, data published in Jansson et al. (2014) reports the presence of cysts with a smaller average body diameter for the Black Sea $(\mathrm{n}=72): 28.9(35.6) 47.2 \mu \mathrm{m}$, and for Marmara Sea $(\mathrm{n}=339): 27.8(35.8) 51.9 \mu \mathrm{m}$. Cysts with wider bodies are found in the Sea of Azov (n=6): 33.6(36.4)42.0 $\mu \mathrm{m}$ and in the Aral Sea $(n=50)$ : 35.2(42.4)61.6 $\mu \mathrm{m}(\mathrm{SD}=5.1, \mathrm{n}=50)$. In the BSC surface samples, average process lengths in cysts from the Black and Marmara Seas are at the low end of the global mean: 4.1(7.1)13.2 $\mu \mathrm{m}$ and 2.1(7.4)13.8 $\mu \mathrm{m}$, respectively. In the Sea of Azov and Aral Sea, processes are shorter: 3.6 (5.1) $7.5 \mu \mathrm{m}$ and $2.0(6.8) 10.9 \mu \mathrm{m}$ respectively.

Synonymy: Cyst of Protoceratium reticulatum (Claparède and Lachmann, 1859) Bütschli 1885; Head in Head and Wrenn (1992, p.24) considered this species to be the possible taxonomic senior synonym of Operculodinium wallii Matsuoka 1983.

Biological Affinity: O. centrocarpum sensu Wall and Dale 1966 was related to the motile stage Protoceratium reticulatum (Claparède and Lachmann, 1859) Bütschli 1885 by Wall and Dale (1966). In South Africa, it was related to the motile stage Gonyaulax grindleyi by Reinecke (1967). This motile stage is correlated with black tides, mussel and shellfish poisoning around South Africa (Grindley and Nel, 1968; 1970; Horstman 1981), and was linked to the production of yessotoxin-like substances. $P$. reticulatum has a widespread distribution in the Black Sea where it was first reported in 1935 (Bryanseva et al., 2016); it was also found in winter plankton samples from Dardanelles Strait, Marmara Sea (Turkoglu and Oner, 2010) but not in seasonal 
samples from eastern Marmara Sea (Balkis et al., 2016) and it is not recorded for the Caspian and Aral Seas.

Comparison: Matsuoka et al. (1997) considered the Miocene O. centrocarpum sensu stricto [Operculodinium centrocarpum (Deflandre and Cookson) Wall, 1967] as a different species, being significantly larger $(54-80 \mu \mathrm{m})$ with longer processes $(13-18 \mu \mathrm{m})$. In the BSC, the processes of cysts from both surface and late Pleistocene-Holocene sediments show great variability in length and process tips, including morphotypes described as Operculodinium centrocarpum form B by de Vernal et al. (1989), from the low salinity Bras d'Or Lake, Nova Scotia and the Pleistocene glacial Champlain Sea. This morphotype B is associated with low salinity semi-enclosed boreal or glacial-stage seas and the cysts are characterised by having fewer processes which are also of variable length, including some normal long, erect processes, shorter apparently weaker processes with bent distal ends, and scattered very short truncated processes. Londeix et al. (2009) illustrate several morphotypes from the late Quaternary of Marmara Sea that they described as "atypic forms", having processes low to very low, truncated, stout, etc. P. reticulatum cysts from the Baltic Sea (Mertens et al., 2011) with highly reduced processes have been incorrectly identified as Pyxidinopsis psilata by Dale (1996) and Brenner (2005), and these differ from Pyxidinopsis because of their microfibrous cyst wall.

Distribution: In surface samples of the BSC, O. centrocarpum sensu Wall and Dale 1966 is found at most sites in the Black Sea and is also common (up to 30\%) in Marmara Sea, in deeper water sites in the Black Sea and in Gelendzhik Bay (Figure 40). The atlas map for $O$. centrocarpum includes the morphotypes with reduced processes which are also widespread in lower amounts (c. 4\%). O. centrocarpum is found within a relatively narrow annual SST range of 13.4-16.2 ${ }^{\circ} \mathrm{C}$ (seasonally $5.6-23.4{ }^{\circ} \mathrm{C}$ (winter-summer), but it occupies a very wide annual SSS range of 14.4-29.5 (summer-winter). Associated nutrient values are [P] mostly 0.01-0.33, [N] 
0-5; [Si] 1.5-15.5 (up to 34); [chl.-a] ranges from 0.35 to 3.3, with highest \% cysts occurring in the lowest range of [chl.-a]. The bottom $\mathrm{O}_{2}$ values range from $0-7.5$, with highest $\%$ in poorly oxygenated waters. In Marmara Sea, the species, including many forms with variable process lengths, shows peak abundances in the early Holocene (Mudie et al., 2002a; Londeix et al., 2009). In the Black Sea, O. centrocarpum is very rare in the early Holocene but becomes common after c. 6-5 ka BP (Bradley et al., 2012; Verleye et al., 2009).

On a world-wide basis, Operculodinium centrocarpum sensu Wall 1966 and its short-process morphotypes (probably including intergrades with Operculodinium israelianum), is a cosmopolitan taxon commonly found in all environments from the polar to equatorial regions and from coastal to pelagic sites (Zonneveld et al., 2013). However, the taxon is most abundant in cool temperate regions of the North Atlantic Ocean where SST is $<0^{\circ} \mathrm{C}$ year-round; it also tends to be more common where salinity is reduced by glacial meltwater or river outflow and is associated with a wide range of SST and SSS, inorganic nutrients and $\mathrm{O}_{2}$. In the $\mathrm{BSC}$, all the nutrient values are all at the low end of the reported world-wide range, particularly $[\mathrm{P}]$ that must be $217 \mu \mathrm{mol} / \mathrm{l}$ or more for optimal growth (Gallardo Rodríguez et al., 2009). The absence of this globally very wide-ranging taxon in the Caspian Sea is notable and and is possibly related to the lower nutrient levels compared to the Black and Marmara Seas. Within the Baltic Sea-Skagerrak region, process length is strongly correlated with surface water density (SST and SSS) which in summer, can be represented by SST (Mertens et al., 2011). In the North Pacific, however, an inverse relationship is seen between process length and water density, indicating possible pseudo-cryptic speciation in this morphologically variable taxon (Mertens et al., 2012c). On a wider scale, statistical analysis shows that process length in cysts of P. reticulatum is a complex function of several variables, including nutrient levels (Jansson et al., 2014). The range of process lengths in cysts from the Marmara and Black Seas differs little from the world average, 
but shorter processes are found in six specimens from the Kerch Strait, which can be related to lower salinities in the Sea of Azov.

[Figure 40. Distribution map of cyst of Operculodinium centrocarpum sensu Wall and Dale goes here.]

\subsection{Operculodinium israelianum (Rossignol 1962) Wall 1967}

Distinguishing characteristics: Based on Rossignol (1962; 1964; Wall 1967; Head 1993), these transparent sub-spherical cysts are distinguished by a thin inner wall with a thick spongymicrofibrillar, pitted or granular outer layer and many non-tabular short, hollow, conical processes (Plate 12, Figs. 1-8). The process bases are striated and the distal ends are either pointed (acuminate) or they have minutely expanded tips. The archeopyle corresponds to the third precingular plate (Plate 12, Figs. 4-5).

Dimensions: Body diameter is $33-60 \mu \mathrm{m}$; process length is given as 6-10 $\mu \mathrm{m}$ by Rossignol 1964) but cysts from the Caribbean and Mediterranean Seas and the BSC can have very short processes one-tenth or less of the body diameter.

Synonymy: Hystrichosphaeridium israelianum Rossignol 1962; Batisphaeridium israelianum (Rossignol 1964) Downie and Sarjeant 1965; Operculodinium crassum Harland 1979 may be a senior synonym according to Harland in Head and Wrenn (1992).

Biological Affinity: Possibly a cyst of Protoceratium reticulatum (Claparède and Lachmann 1859) Bütschli 1885 according to interpretations of Wall and Dale (1968), but ongoing studies of Mertens and others suggest that this may not be correct. 
Comparison: $O$. israelianum is similar to cysts of $O$. centrocarpum sensu Wall and Dale 1966, but it is relatively larger with shorter processes which have broader bases that widen less abruptly. The process tips are also less expanded and can be acuminate. LM and SEM images show that $O$. israelianum possesses a spongy-fibrous outer wall layer (luxuria) which is not present in O. centrocarpum. BSC cysts of O. israelianum and those in Aegean Sea samples (Mudie et al., 2004) have shorter processes compared to some samples from Israel (Rossignol, 1964) and the Nile Delta area (Kholeif and Mudie, 2009) where the processes are about $1 / 4^{\text {th }}$ of the body width. Cysts in topotype samples from the Ashdod borehole in Israel appear to have more variable processes, ranging from short, with visibly capitate tips (Rossignol, 1963, pl. 1, fig. 9) to longer with mostly pointed tips (Rossignol, 1964, pl. 2, fig. 12). Cysts from surface sediments in the Gulf of Mexico (Limoges et al., 2013), however, look similar to those in the BSC. According to Head (1996), Neogene cyst populations of O. israelianum and the extinct, large $O$. centrocarpum s.s. show enough overlap in process length to allow grouping of these two species.

Distribution: O. israelianum is extremely rare in surface sediments of the BSC, being confined to NE Marmara Sea (Balkis et al., 2016), therefore it is not mapped here. It is also rare in Holocene sediments from Marmara Sea slope core MAR02-88P (P. Mudie, unpublished). In the Black Sea, it is reported for just one late Holocene sample of core GeoB7625-2 (Verleye et al., 2009) as well as in NE Black Sea Holocene core Ak-2575 (FM, pers. Comm.)

On a world-wide scale, $O$. israelianum is found mainly in fully marine waters and only in subtropical, tropical and equatorial regions where $\mathrm{SST}$ is $>14.3^{\circ} \mathrm{C}$ in winter and $24.2^{\circ} \mathrm{C}$ in summer (Zonneveld et al., 2013). Highest abundances (up to 20.3\%) are found in the Eastern Mediterranean, especially off the Nile Delta, northern Argentina/southern Brazil and nearshore areas of the central eastern Atlantic (Zonneveld et al., 2103). In the Gulf of Mexico, the species 
is most abundant off the Mississippi Delta (Limoges et al., 2014). Associated SST values are generally $1.8-29.8^{\circ} \mathrm{C}$ (winter-spring) with summer SST>10 ${ }^{\circ} \mathrm{C}$; SSS is generally $30.3-39.4$ (summer-autumn). The range of associated nutrients is slightly lower than that associated with O. centrocarpum but highest abundances are also found in well-ventilated bottom water. The associated SST values (annual average $14.9^{\circ} \mathrm{C}$, range $7.9-22.1^{\circ} \mathrm{C}$ winter-summer) at the single location in NE Marmara Sea are are well within the world range, but the SSS annual average of 22.1 is almost 10 lower.

4.37 Peridinium ponticum Wall and Dale in Wall et al. 1973

Distinguishing characteristics: Based on Wall et al. (1973) and our own observations, these brown protoperidinioid cysts are very variable in outline, being pentagonal to subspherical, with a moderately pointed to subrounded apex (Plate 21, Figs. 4-10) and broadly rounded antapex which is typically weakly indented between two lobes but can be almost straight-edged (Plate 21, Fig.7) or more rarely, it is rounded (Plate 21, Figs. 4-6). In polar view the cysts are weakly reniform; the ventral surface is flattened. The body wall is single-layered and thin, with the outer surface bearing numerous very short, delicate, curved or straight, transparent, organic-walled simple spines between which are scattered submicron-sized tubercules (micrograna; Plate 21, Fig. 10). The ornament is generally non-tabular but may be discontinuously aligned along the equator and antapex as indistinct peritabular lines. The large dorsal intercalary archeopyle is hexagonal, with a ratio of width: height ratio from ca $2: 1$ to $1.4: 1)$. The archeopyle is often offset towards the left, and the operculum is simple, usually remaining attached along the posterior margin or inside the cyst (Plate. 21, Figs. 6, 9). One or two short sutures may run from the 
anterior, sometimes V-shaped archeopyle sides towards the apex; these may be accessory archeopyle sutures which partly delimit a mid-dorsal apical plate-area, usually $3^{\prime}$ in Peridinium.

Dimensions: Wall and Dale (1973) give the body length as 43-59 $\mu \mathrm{m}$, width as $43-56 \mu \mathrm{m}$, and archeopyle as $15 \times 31$ to $25 \times 31 \mu \mathrm{m}$ in 50 specimens.

Biological Affinity: P. ponticum is probably the cyst of a Prototoperidinium species. An empty cyst from Oslofjord, Norway, was related to Protoperidinium cf. divergens by Dale (1983). P. divergens is reported for Marmara Sea (Balkis et al., 2016) but is not listed for the Black Sea.

Comparison: Wall et al. (1973) comment that some Black Sea specimens of P. ponticum were incorrectly reported as cysts of Peridinium cf. claudicans Paulsen; the latter have a pentagonal, not hexagonal 2a intercalary archeopyle. The Black Sea endemic thecate taxon Protoperidinium ponticum Vershinin and Morton 2006 is not related and differs in having a pentagonal 2a plate and in being strongly polar-compressed with wide cingular lists. In the BSC, the density and length of the hair-like processes in $P$. ponticum is very variable, in addition to the cyst outline variation. The shortest ornament was found in cysts from the SW Black Sea Holocene sediments and the longest was seen in dark-brown cysts from the NE Black Sea.

Distribution: In surface sediments of the BSC, Peridinium ponticum is widespread in both Marmara and the Black Seas but is much more abundant in parts of the western Black Sea where it can comprise up to $37.5 \%$ of dinocyst assemblages on the upper shelf slope (Figure 41) and up to $55 \%$ in SE Black Sea basin sediments younger than 2.7 ka BP (Shumilovskikh et al., 2013). In the BSC, $P$. ponticum is largely confined to a narrow range of annual SST $\left(13.4-16.2^{\circ} \mathrm{C}\right)$ and annual SSS (15.9-18.3) with a few outliers in salinities of 22-24. Associated nutrient values are $[\mathrm{P}]$ mostly $0.01-0.33,[\mathrm{~N}]$ 0.02-5; [Si] 1.5-14.5 (up to 22.1); [chl.-a] ranges from 0.3 to 3.3 , 
with highest $\%$ cyst values in the lowest range of [chl.-a]. The bottom $\mathrm{O}_{2}$ values range from $0-7$, with highest \% in poorly oxygenated waters.

Small amounts of Peridinium ponticum are present in Late Pleistocene to mid-Holocene sediments of Marmara and Black Sea shelf cores, becoming more abundant after c. 5.5 ka BP in Black Sea sediment cores, and less abundant in late Holocene sediments of Marmara Sea cores. It is not present in Eemian sediments (Shumilovskikh et al., 2013) and seems to be the best example of a recently evolved endemic BSC taxon, specifically being confined to the Marmara and Black Sea basins of the Ponto-Caspian Seas. Verleye et al. (2009) find a correlation between occurrence of $P$. ponticum, lowered salinity and increased plankton production.

P. ponticum is very rarely reported for areas outside of the BSC. Trace amounts are present in the early Holocene Sapropel 1 sediments of some Aegean Sea cores (Aksu et al., 1995) where it may have been transported in megaflood waters. The finding of $P$. ponticum in harbour sediments from Elaia, an ancient Greek settlement north of Izmir Bay, are attributed to shipping transport (Shumilovskikh et al., 2016). In surface sediments, it has also been found in low numbers in Oslofjord (Dale, 1983), the Baltic Sea, around Tunisia and the coast of Brittany (Mertens, this study), perhaps indicating recent spreading by ballast water from the Black Sea to the Baltic and via the Mediterranean to the North Atlantic Ocean. Zonneveld et al. (2013) give associated environmental parameters as SST 7.1-23.2 ${ }^{\circ} \mathrm{C}$ (winter-summer), SSS: 17.5-26.0 (summer-winter) which are much wider ranges than in the BSC where the highest \% values found. On a worldwide basis, $P$. ponticum is restricted to brackish or low salinity coastal environments with mesotrophic to eutrophic upper waters conditions.

[Figure 41. Distribution map of Peridinium ponticum goes here.] 
4.38 Pyxidinopsis psilata (Wall and Dale in Wall et al., 1973) Head 1994

Distinguishing characteristics: These cysts are transparent, with a thin, apparently singlelayered cyst wall lacking tabulation (Plate 22, Figs. 1-13). The cyst shape can be spherical, oval; rhombic, sub-cruciform or cruciform. Cruciform morphotypes are dorsoventrally compressed, and in equatorial view they have strongly concave sides between their typically rounded apical, lateral and antapical areas and they are prolate, being 1.7x longer than wide (Wall et al., 1973); sub-cruciform morphotypes (Plate 22, Figs. 10-12) tend to have relative straight or rounded hypocyst sides and are not so clearly compressed dorsoventrally. The surface of the body typically is very finely punctate and appears smooth to scabrate without tabulation (Plate 22, Figs. 1-3, 7, 8) but it can be verrucate or covered by irregular ridges, rods and granules (Plate 22, Fig. 14). Specimens from the Caspian Sea frequently have a corrugate or verrucate wall surface, sometimes with very strongly raised verrucae (Plate 22, Figs. 4-5, 9). The archeopyle corresponds to the third precingular plate $\left(3^{\prime \prime}\right)$ and is typically pentagonal with straight base and sides and with two short sloping apical sides (Plate 22, Figs. 1, 7, 12). The edges of the archeopyle also have a characteristically slightly jagged appearance. According to Wall et al. (1973), typically the operculum is attached (Plate 22, Fig. 7) or it is inside the body (Plate 22, Fig. 12), but in many specimens we have seen and in the holotype illustrations, the archeopyle appears be detached.

Dimensions: Topotype samples (as Tectatodinium psilatum) from Black Sea late Pleistocene sediment have spherical cysts $37-52 \mu \mathrm{m}$ in diameter, with archeopyle dimensions $15-22 \mu \mathrm{m} \mathrm{x}$ 19-31 $\mu \mathrm{m}$; cruciform cyst length is $46-65 \mu \mathrm{m}$, width is $37-50 \mu \mathrm{m}$, with archeopyle $15-22 \mu \mathrm{m}$ (Wall et al., 1973). 
Synonymy: Tectatodinium psilatum Wall and Dale in Wall et al. 1973; possibly also Pyxidinopsis? species A of Londeix in Londeix et al. 2009; not Pyxidinopsis psilata of either Dale (1988; 1996); or Brenner (2005, figs. 5-3, 4a, b) and cited in Brenner (2001a, b; 2005) and in Brenner and Meemken (2002); not Pyxidinopsis cf. psilata of Matthiessen and Brenner (1996).

Biological Affinity: Wall (in Head, 1994) suggests that $P$. psilata cysts are produced by Gonyaulax spinifera because of their typical angular pentagonal archeopyle shape. Specimens from the Baltic Sea referred to P. psilata by Dale, Brenner and Matthiessen (see synonymy) are considered to be reduced cysts of Protoceratium reticulatum, based on their fibrillar wall structure (Mertens et al., 2011). Head (1994) considers that some paratypes of P. psilata are the endocysts of Spiniferites cruciformis; unfortunately, efforts to culture these cysts have not yet succeeded in producing identifiable motile dinoflagellates.

Comparison: Head (1994) examined the range of morphological variation in P. psilata (as Tectatodinium psilatum) in a slide of Upper Quaternary sediments from the SW Black Sea holotype core-site (Wall et al., 1973). This slide also contained abundant cysts of Spiniferites cruciformis showing variable development of the processes (see also Sect. 4.44). He concluded that two paratypes of $T$. psilatum with verrucate rhombic or cruciform bodies may be detached endocysts of $S$. cruciformis. The same conclusion might be drawn for some specimens of $T$ psilata described by Wall et al. (1973) as showing traces of tabulation in the form of low sutural ridges. Londeix et al. (2009) only include in P. psilata cysts which are psilate, spherical to slightly cruciform and considered to be "close to the holotype"; they apply the name Pyxidinopsis? sp. A to cysts with a corrugate periphragm and cruciform shape. Londeix et al. (2009) considered their late Pleistocene taxon (last occurring during the Younger Dryas in Marmara Sea) to be a different species from Pyxidinopsis psilata sensu stricto. However, 
Pyxidinopsis? sp. A has an almost identical stratigraphic distribution to cysts of $P$. psilata in the same core, and its features fall within the range of morphology in Tectatodinium psilatum described by Wall et al. (1973). It is also possible that some Indeterminate Granular Cysts of Richards et al. (2014) from Volga Delta surface sediments are spherical morphotypes of $P$. psilata with an attached or included operculum.

In the BSC atlas, we have included in P. psilata all spherical, rhomboidal and cruciform morphotypes lacking tabulation, but we refer cruciform and rhomboidal specimens with tabulation delimited by low septa and or small spines to Spiniferites cruciformis Wall and Dale in Wall et al. (1973). This taxon is S. cruciformis form 5 of Mudie et al. (2001) and corresponds to the "unusual variety" of $T$. psilata illustrated by Wall et al. (1973, their pl. 3, fig. 6 ). $S$. cruciformis form 5 is distinguished from P. psilata by presence of low rounded sutures flanked by low septa, sometimes with small perforate or solid processes, in the cingular and apical areas. In surface sediments of the Black Sea, rare $P$. psilata cysts are psilate to finely punctate with a spherical to irregular, almost box-shaped outline. $P$. psilata specimens in surface sediments of the Caspian Sea are either cruciform to subcruciform, with a corrugate surface (Marret et al., 2004) or they are rounded and strongly rugose.

Distribution: In surface samples of the BSC, low relative amounts ( $<4 \%)$ of smooth-walled $P$. psilata cysts are occasionally present in the Black Sea and they are rare in the Marmara Sea; the verrucate morphotype is rare in the southern Caspian Sea (Figure 42). In these regions, the cysts are associated with an annual SST range of $14-17{ }^{\circ} \mathrm{C}$ and salinity of (12.9) $16.8-18$. P. psilata is also present in the Volga Delta of the northern Caspian Sea as part of the Indeterminate Granular Cyst assemblage of Richards et al. (2014; personal communication, Dec. 2015); here the salinity is $<1$ to $<3$ psu. Associated nutrient values are $[\mathrm{P}]$ mostly $0.05-0.17$, $[\mathrm{N}] 0.02-3$; [Si] $\sim 0.2-6.5$ 
(up to 22.1); [chl.-a] ranges from 0.5 to 2.6 , with highest $\%$ cyst occurrences in the lowest range of [chl.-a]. The bottom $\mathrm{O}_{2}$ values range from $0-5.6$, with highest $\%$ in poorly oxygenated waters.

In sediment cores, $P$. psilata morphotypes are common in late Pleistocene to early Holocene intervals of shelf and deep basin cores of the Marmara and Black Seas, as well as corresponding intervals of deep water cores of the Caspian Sea where they co-occur with brackish water species, e.g. S. cruciformis and I. caspienense. In the Caspian Sea, P. psilata remains abundant until 4.1 cal. ka in the middle basin (Leroy et al., 2014), and until 3.9 cal. ka in the south basin (Leroy et al., 2007, 2013b). The verrucate morphotype is mostly confined to the Caspian Sea. In the Black Sea, the relative abundance of $P$. psilata decreases from about $37 \%$ at $8.25 \mathrm{ka}$ BP to $<4 \%$ in the mid-late Holocene (Verleye et al., 2009).

On a world-wide scale, the distribution of $P$. psilata in surface samples shows a disjunct distribution centered on the temperate-subtropical regions between latitudes 40 and $20{ }^{\circ} \mathrm{N}$ in the Atlantic and eastern North Pacific Oceans; peak amounts (11.7\%) are reported for shallow tropical waters off western Florida. Associated global SST is $7.1-29^{\circ} \mathrm{C}$ (winter-summer) and SSS is $12.7-37.8$ (summer-winter); these values are significantly different from those found in the BSC, where it tends to be associated with higher levels of $[\mathrm{P}]$, lower $[\mathrm{N}]$ values and more variable $\left[\mathrm{O}_{2}\right]$ levels $(0-6 \mathrm{ml} / \mathrm{l})$ than the global range of nutrients and bottom water oxygen: [P] 0.1-0.8 $\mu \mathrm{mol} / 1,[\mathrm{~N}]$ 0.05-4.6 $\mu \mathrm{mol} / 1,\left[\mathrm{O}_{2}\right]$ 0.8-6.6 ml/1 (Zonneveld et al., 2013). P. psilata is usually found in coastal waters, including some outlying sites in the eastern North Sea. The reported global distribution values are notably inconsistent with the concept that this taxon is part of the Paratethyan brackish water assemblage; the Californian specimens include only smooth spherical morphotypes and they have not been found in cores from this region (Pospelova et al., 2008; 2015). 
[Figure 42. Distribution map of Pyxidinopsis psilata goes here.]

\subsection{Quinquecuspis concreta (Reid 1977) Harland 1977 and Quinquecuspis sp.}

Distinguishing characteristics: Based primarily on Reid (1977), with some notes from Rochon et al. (1999), these are large $(>60 \mu \mathrm{m})$, dark brown cysts which are pentagonal and bisymmetrical in equatorial view) and have a deep ventral sulcus flanked by broad lateral apophyses (= lateral expansions), with two widely spaced antapical horns separated by a shallow depression (Plate 17, Figs. 6-15). In polar view, the cyst is concavo-convex (Plate 17, Fig. 11). The cingulum is wide and excavated with slightly raised margins formed by ridge-like wall thickenings. The epicyst is usually slightly concave but can broaden above the cingulum; the hypocyst is always concave. The single-layered wall is irregularly thickened $(1-5 \mu \mathrm{m})$ with a microgranular surface, sometimes with scattered granules, and with a thickened apex; the antapical horns are rounded with variably thickened tips. The archeopyle formed by loss of plate $2 \mathrm{a}$ has a rounded subtriangular shape, and according to Rochon et al. (1999), it sometimes involves an adjacent apical plate. The operculum often seems to remain attached laterally (Plate 17, Figs. 13-15).

Dimensions: Reid (1977) gives the size for 16 specimens as length $60-80 \mu \mathrm{m}$, breadth $63-82$ $\mu \mathrm{m}$, thickness $49-61 \mu \mathrm{m}$, width of cingulum $7 \mu \mathrm{m}$, distance between antapical horn tips $25-28$ $\mu \mathrm{m}$, width of archeopyle $23-25 \mu \mathrm{m}$, and height of the archeopyle $23-28 \mu \mathrm{m}$.

Synonymy: Quinquecuspis concreta (Reid 1977) Harland 1977; Trinovantedinium concretum Reid 1977; Lejeunecysta concreta (Reid 1977) Matsuoka 1987; cyst of Peridinium leonis Pavillard; Protoperidinium (sect. Quinquecuspis) leonis in Harland 1983 [as a copy of Harland 1982]; cyst of Protoperidinium (Protoperidinium) leonis (Pavillard) Balech. 
Biological Affinity: Harland (1983) and Lewis et al. (1984) consider this species to represent the encysted stage of the heterotroph Protoperidinium leonis (Pavillard 1916) Balech1974, in part based on cyst germination from a Scottish loch. P. leonis is present in plankton samples from both the Black and Marmara Seas (Gómez and Boicenco, 2004; Balkis, 2004; 2016).

Comparison: Reid (1977) comments that Q. concreta differs from Lejeunecysta oliva in having large lateral apophyses, blunt antapical horns and microgranular surface, and it differs from L. sabrina in its darker, thicker wall, more pronounced girdle (=cingulum) and heavier horn thickenings. In the BSC, Q. concreta shows a wide range in morphology from typical forms with pronounced apophyses to a smaller more compact form with strongly reduced antapical horns and truncated posterior end (Plate 17, Figs. 13-15); the latter form resembles Lejeunia sp. A of Bradford (1977) from the Arabian Sea. A late Holocene specimen from the Alboran Sea (Turon and Londeix, 1988) appears similar to the typical forms in BSC surface sediments.

In polar view, it may be difficult to distinguish specimens of $Q$. concreta in Black Sea sediments from similar large brown cysts which are sub-ellipsoidal in polar view, have a wide subrectangular archeopyle and lack recognisable antapical horns. These cysts and similar specimens that are indeterminate because of folding or unsuitable orientation are referred to here as Quinquecuspis sp. and they are mapped separately for the BSC atlas to avoid possible overrepresentation of $Q$. concreta cysts.

Distribution: In the BSC surface sediments, Q. concreta (Figure 43) and Quinquecuspis sp. (Figure 44) are sporadically present in relatively small amounts $(<4 \%)$ in Marmara and the western Black Sea, with one occurrence in the Azov Sea. Maxima of Q. concreta occur off the Danube Delta and on the Ukrainian Shelf. Peridinium leonis is present in the phytoplankton of Marmara Sea (Balkis et al., 2016) but is not reported for the Black Sea. Quinquecuspis concreta has associated SST ranges seasonally from $0.5^{\circ} \mathrm{C}$ (winter) to $24^{\circ} \mathrm{C}$ (summer), with maximum 
cyst $\%$ at annual average $\mathrm{SST} \sim 15{ }^{\circ} \mathrm{C}$; SSS has a seasonal range of 10 (autumn) to 31.5 (winter), with highest occurrences found in SSS between 15.5 and 18.5. Nutrient values are $[\mathrm{P}]$ mostly 0.03-0.33, [N] 0.02-5; [Si] 2.5-22 (up to 34); [chl.-a] ranges from 0.5 to 3.3, with highest \% values in the upper range of [chl.-a]. The bottom $\mathrm{O}_{2}$ values range from $0-6$, with highest $\%$ in well oxygenated waters. These values are within the world-wide range reported by Zonneveld et al. (2013). Quinquecuspis sp. (Figure 44) has a similar distribution on the western shelves, with peak amounts occurring in Marmara on the SW Black Sea where the specimens are frequently poorly preserved. Associated oceanographic values are similar to Q. concreta but winter SST is higher $\left(5.5^{\circ} \mathrm{C}\right)$, SSS is higher with a seasonal range of 16 (spring) to 31.1 (winter), and nutrient values differ slightly: $[\mathrm{P}]$ is mostly $0.06-0.16,[\mathrm{~N}]$ 0-3; [Si] 3.3-26; [chl.-a] ranges from 0.5 to 2.6, with highest $\%$ cyst values around 1.5. Associated bottom $\mathrm{O}_{2}$ values also differ slightly, ranging from $0-7$, with highest $\%$ in poorly oxygenated waters.

Q. concreta and Quinquecuspis sp. are occasionally present in Holocene sediments of both basin and shelf cores. In the SE Black Sea basin core M72/5-22GC3, Q. concreta is continuously present in the Holocene, reaching maxima of $8-16 \%$ at $4-5 \mathrm{ka}$ BP in the Holocene (Shumilovskikh et al. 2013; pl. 1:6, fig. 5). Q. concreta is common in surface sediment of Izmir Bay (Aydin et al., 2011) and in the northern and western Mediterranean Sea, as well as the Arabian Sea and east coast of India (Narale et al., 2013). In general, Q. concreta is widespread in neritic waters from cool temperate to equatorial regions, mainly in coastal or upwelling regions (Zonneveld et al., 2013).

[Figure 43. Distribution map of Quinquecuspis concreta goes here.]

[Figure 44. Distribution map of Quinquecuspis sp. goes here.] 
4.40 Round Brown Cysts (sensu Matsuoka et al., 2006)

Distinguishing characteristics: This is an artificial category of round dinoflagellate cysts with brown walls and simple external morphology which were given the name Round Brown Cysts by Matsuoka et al. (2006) and generally include heterotrophic cysts of Protoperidinium and diplopsalid species such as Qia (Diplopsalis) lebourae Liu, Mertens and Gu 2015, Diplopsalopsis bomba (Stein, 1883) Dodge and Toriumi 1993 and Gotoius excentricus (Nie) Sournia 1984. In general, the Protoperidinium cysts are distinguished by an anterior intercalary saphopylic archeopyle consisting of one or two plates, while diplopsalids have theropylic archeopyles with various opening patterns described by Matsuoka (1988), Lewis (1991) and and Liu et al. (2015). In the BSC, diplopsalid cysts were observed to have wide, irregular theropylic archeopyles and outer wall texture varying from psilate to smooth (Plate 15, Figs. 1-6). Other taxa included in this category however, were folded and torn thin-walled brown, non-reticulate cysts without a discernable archeopyle.

Dimensions: Generally medium-sized cysts approximately $30-50 \mu \mathrm{m}$ in diameter; no systematic measurements are available for this diverse group of often poorly preserved brown cysts.

Synonymy: None.

Biological Affinity: Includes various peridinioid and diplopsaloid taxa of uncertain generic or specific nature.

Comparison: The Round Brown Cysts (commonly abbreviated as RBC) differ from Brigantedinium cysts in being thinner-walled and lacking any evidence of sulcal area or $2 \mathrm{a}$ 
intercalary archeopyle. Diplopsalid RBCs differ from Dubridinium caparatum in being thinwalled and not polar-compressed.

Distribution: In BSC surface sediments, RBCs are widespread in moderate amounts (5-20\%) on the shelves of the Black and Azov Seas, and they are present in Marmara Sea (Figure 45). Associated SST ranges seasonally from $5.5^{\circ} \mathrm{C}$ (winter) to $24^{\circ} \mathrm{C}$ (summer), with maximum cyst $\%$ at annual average $\mathrm{SST}=14.5-15^{\circ} \mathrm{C}$; $\mathrm{SSS}$ has a seasonal range of 14.2 (summer) to 31.1 (winter), with highest \% values found in SSS between 14.2 and 18.2. Associated nutrient values are $[\mathrm{P}]$ mostly $0.04-0.33,[\mathrm{~N}]$ 0.02-5; [Si] 2-22.2; [chl.-a] ranges from 0.4 to 3.3, with highest cyst $\%$ in the lowest range of [chl.-a]. The bottom $\mathrm{O}_{2}$ values range from $0-7$, with highest $\%$ in well oxygenated waters. RBCs are present in Holocene sediments of cores from the Marmara and Black Seas, particularly after c. 3,000 yr BP.

[Figure 45. Distribution map of Round Brown Cysts goes here.]

4.41 Selenopemphix nephroides Benedek 1972; emend. Bujak in Bujak et al. 1980; emend. Benedek and Sarjeant 1981

Distinguishing characteristics: Based on Head (1993), Rochon et al. (1999) and Marret and Zonneveld (2003), these are light brown cysts with strong polar compression and a circular to ovoidal or reniform outline in polar view (Plate 21, Figs. 11-13). The wall is two-layered, with a thin $(0.5 \mu \mathrm{m}$ thick $)$ brown smooth inner wall, and a thinner, colorless outer wall, appearing separated by up to $3 \mu \mathrm{m}$ on the ambitus. The outer wall surface is surface is smooth or microgranulate. In equatorial view, the epicyst has concave sides (Plate 21, Figs. 14-15). The conical hypocyst has a truncated posterior end with weakly developed or no antapical horns. The 
cingulum is narrow, deeply indented and bordered by slight thickening of the endophragm. The sulcus is indented, wide and short, with the flagellar pores often marked by two small depressions. The dorsal archeopyle is large and rounded, formed by loss of intercalary 2a plate and offset slightly left of the polar axis (Plate 21, Fig. 16).

Dimensions: Benedek (1972) and Bujak et al. (1980) give the range of body length from 28$60 \mu \mathrm{m}$ and width $36-75 \mu \mathrm{m}$, for 31 specimens.

Synonymy: Taxonomic junior synonyms are Selenopemphix alticincta (Bradford 1975) Matsuoka 1985 and Lejeunia (now Lejeunecysta) psilodora, according to Benedek and Sarjeant (1981), but Lentin and Williams (1985) and Head (1993) retained Lejeunia (as Lejeunecysta) psilodora.

Biological Affinity: Wall and Dale (1968) and Harland (1982) consider that S. nephroides is the cyst stage of Protoperidinium subinerme (Paulsen 1904) Loeblich III 1969. However, Head (1996) points out that there is disagreement about assigning cysts of $P$. subinerme to either Selenopemphix nephroides or S. alticincta (as Omanodinium alticincta Bradford 1975 from recent Persian Gulf sediment) or to neither of these cyst-defined taxa. Furthermore, Lewis et al. (1984) find that the modern cyst morphotype can differ from typical $P$. subinerme cysts in having a spherical shape that excludes it from Selenopemphix. Nonetheless, $P$. subinerme is reported as widespread in plankton records for the Black Sea (Gómez and Boicenco, 2004) and it is present in Marmara Sea (Balkis, 2004).

Comparison: S. nephroides differs from other similar Miocene-Recent species of Selenopemphix in lacking serrate, denticulate, spiniferous or undulating cingular margins (Matsuoka and Bujak, 1988; Verleye et al., 2011). The BSC cysts of S. nephroides also appear to have a lower apical protrusion and narrower cingular margins than in the Persian Gulf (Bradford 
and Wall, 1986, pl. 2, fig. 17). Some cysts from Marmara Sea Holocene sediments have an undulating inner cingular margin.

Distribution: In the BSC surface sediments, S. nephroides is occasionally present in low numbers in the Marmara and Black Seas, particularly in the outer Ukrainian Shelf area, but it is rare in the SE basin region (Figure 46). Associated SST ranges seasonally from $5.5^{\circ} \mathrm{C}$ (winter) to $24^{\circ} \mathrm{C}$ (summer), with maximum cyst $\%$ at annual average SST $=15.5^{\circ} \mathrm{C}$; SSS has a seasonal range of 15.2 (spring) to 31.1 (winter), with highest occurrences found in SSS above 24 . Associated nutrient values are $[\mathrm{P}]$ mostly $0.03-0.30,[\mathrm{~N}] 0-5 ;[\mathrm{Si}] \sim 1.5-27$; [chl.-a] ranges from 0.5 to 2.8 , with highest cyst $\%$ in the lowest range of [chl.-a]. Most of these values fall within the global range range reported by Zonneveld et al. (2013), but the BSC summer salinity values are slightly lower than the global range of SSS 17.5-24.0 (summer-winter). The bottom $\mathrm{O}_{2}$ values range from $0-6.5$, with highest $\%$ in well oxygenated waters. S. nephroides is occasionally present in cores from the Black and Marmara Seas, being rare or absent in the deep water cores but relatively common in upper slope and shelf cores, with first appearances at about 6,500 cal BP in Marmara Sea and around 4.2 ka BP in the SW Black Sea. In contrast, S. nephroides is common and continuously present for the past $30 \mathrm{ka}$ in a deepwater core from the Gulf of Cadiz at the entrance to the Mediterranean Sea (Peynaud et al., 2011). In addition, S. nephroides is widespread in recent sediments of the Mediterranean Sea, including Izmir Bay (Aydin et al, 2011), with peak occurrences (c. 7.5\%) in the NW Mediterranean Gulf of Lyons region (Zonneveld et al., 2013). In general, S. nephroides is mostly restricted to coastal areas of temperate to equatorial regions and has maximum abundances (up to 14\%) in areas of upwelling. Highest abundances are in seasonally variable mesotrophic to eutrophic upwelling areas which are oligotrophic at other times, and where bottom water is well ventilated. 
[Figure 46. Distribution map of Selenopemphix nephroides goes here.]

\subsection{Selenopemphix quanta (Bradford 1975) Matsuoka 1985}

Distinguishing characteristics: Based on Rochon et al. (1999) and Matsuoka (1985b), these are light to medium brown, polar compressed, spinous cysts which are sub-circular to slightly reniform in polar view (Plate 14, Figs. 1-7). The epicyst is convex with an apical horn bearing solid spines, and the hypocyst has two small antapical bosses; the cingulum is outlined by two rows of processes which are absent in the shallow sulcal area (Plate 14, Fig. 3). The wall surface is smooth, bearing six rows of solid processes which are slightly flexuous, with sharp or blunt tips and expanded bases. The archeopyle corresponds to intercalary plate $2 \mathrm{a}$ and is laterally offset, sub-hexagonal with rounded angles.

Dimensions: Rochon et al. (1999) give the body width as $40-83 \mu \mathrm{m}$, with process length of 10-6 $\mu \mathrm{m}$. In the BSC, cysts typically have processes shorter than $10 \mu \mathrm{m}$.

Synonymy: Multispinula quanta Bradford 1975; Protoperidinium conicum (Gran) Balech (Fukuyo, 1980); Protoperidinium (sect. Selenopemphix) conicum (Gran) Balech according to Harland (1982).

Biological Affinity: Kobayashi and Matsuoka (1984) incubated two morphotypes of S. quanta, both of which produced a thecate stage identified as Protoperidinium conicum, with form A possibly being a Pacific form in the sense of Abé (1981). Matsuoka (1985b) also considers that the resting spores of Protoperidinium conicum studied by Wall and Dale (1968) produced thecae of P. conicum. Kobayashi and Matsuoka (1984) show that laboratory-germinated thecate cells of two $P$. conicum cyst morphotypes can have slightly different plate distributions. Most recently, Gu et al. (2015b) studied the cyst-theca relationships and molecular phylogenetics of the two $P$. 
conicum morphotypes and confirm the thecate-stage morphological differences but show that morphotypes A and B have extremely similar partial LSU rDNA sequences. These authors consider that both cyst morphotypes fall within Bradford's (1975) description of Selenopemphix quanta from the Persian Gulf region. P.conicum is widespread in the Black and Marmara Seas (Boicenco and Gómez, 2004; Baytut et al., 2010; Balkis et al., 2016).

Comparison: Cysts of P. nudum are similar but they differ from S. quanta in having fewer, longer, more slender processes, with the cingulum marked by two parallel rows of processes. Head (1996) points out that Bradford (1975) defined the cyst species Selenopemphix quanta sufficiently broadly to accommodate cysts of P. nudum? sensu Wall and Dale (1968) and cysts of P. conicum, but the holotype of $S$. quanta is much closer to cysts of $P$. conicum. Harland (1983) also considered that P.?nudum is a separate species of the cyst genus Selenopemphix. Matsuoka (1985b) found that many specimens from waters around Japan are deformed and damaged so that the six rows of processes were rarely seen. In surface samples from the BSC, there is a wide range in variability of process length and width of the bases (see Plate 14, Figs. 2, 6, 7) and in shallow (<30 m), well-oxygenated water of Marmara and Black Sea, the cysts often appear oxidised and with heavily damaged processes.

Distribution: In the BSC surface sediments, Selenopemphix quanta is common in moderate amounts (c. 2-8\%) in Marmara Sea, and the western Black Sea (Figure 47). Maximum cyst \% occurs in the nearshore areas of the Danube Delta discharge plume where SSS is <10 in spring when there are large algal blooms, and beneath more saline water in deep slope areas of the southeastern Black Sea Basin (here algae blooms are commonly associated with upwelling). Associated SST ranges seasonally from $5.5^{\circ} \mathrm{C}$ (winter) to $24^{\circ} \mathrm{C}$ (summer), with peak cyst $\%$ at annual average $\mathrm{SST}=15^{\circ} \mathrm{C}$; SSS has a seasonal range of 14.5 (spring) to 31.1 (winter), with highest occurrences found in SSS between 16 and 18.5. Associated nutrient values are [P] mostly 
$0.01-0.33,[\mathrm{~N}] 0-5 ;$ [Si] $2-34$; [chl.-a] ranges from 0.2 to 3.3, with highest occurrences in the lowest range of [chl.-a]. The bottom $\mathrm{O}_{2}$ values range from $0-7$. These values fall within the global range (Zonneveld et al., 2013) except that the $\mathrm{N}$ values are lower than $15.6 \mu \mathrm{mol} / \mathrm{l}$, and although bottom water [O2] may be up to $8.0 \mathrm{ml} / \mathrm{l}$, our observations in the BSC suggest that cyst preservation is relatively poor in the shallowest well-oxygenated waters of the SE Marmara Sea shelf.

In sediment cores, the species is most common in the late Holocene interval $(<\mathrm{c} .4 \mathrm{ka} \mathrm{BP})$ but is also present in early Holocene and latest Pleistocene to early Holocene intervals of Marmara Sea cores. In contrast, S. nephroides is common and continuously present for the past $30 \mathrm{ka}$ in a deepwater core from the Gilf of Cadiz at the entrance to the Mediterranean Sea (Peynaud et al., 2011). S. quanta is rare in surface sediments of Izmir Bay (Aydin et al., 2011) but is widespread in the Mediterranean Sea, including Aegean Sea basins (Mudie et al., 2001), being especially common the Tyrrhenian Sea and Bay of Lyons (Zonneveld et al., 2013). Worldwide, S. quanta is very widely distributed, occurring in coastal sites and near frontal systems from polar to equatorial regions; the peak abundances (up to 44\%) are found in eutrophic regions.

[Figure 47. Distribution map of Selenopemphix quanta goes here.]

4.43 Spiny Brown Cysts, including Islandinium cf. minutum (Harland and Reid in Harland et al. 1980) Head et al., 2001

Distinguishing characteristics: This is another artificial category of relatively small $(<$ c. 50 $\mu \mathrm{m})$ brown dinoflagellate cysts which are characterised by a spherical central body bearing numerous non-tabular, relatively short, spinous processes that are more or less randomly 
distributed over the surface (see illustrations in Radi et al., 2013). A comparable group cyst from high northern latitudes was called "round brown spiny cysts" (RBSCs) by Radi et al. (2013); cyst - theca studies showed that those high latitude RBSCs included cysts produced by heterotrophic taxa Archaeperidinium species, Oblea acanthocysta and several different Protoperinium species. The BSC Spiny Brown Cysts differ from Radi et al.'s RBSC in that we have separated out recognisable cysts of Polykrikos hartmannii (see Sect 4.17) and Echinidinium species (see Sect. 4.28) and we can say that in the BSC, the Spiny Brown Cysts do not include the cyst of Oblea acanthocysta, Islandinium brevispinosum and Islandinium? cezare. However, our group includes a few cysts referred to Islandinium cf. minutum by Marret et al. (2009). This spiny round brown cyst taxon is distinguished by having a granulate surface with low verrucae or low coni, and it has short $(<1.5 \mu \mathrm{m})$ processes which are mostly solid to apiculocavate, circular, tapering distally and terminating in finely acuminate tips; the polygonal archeopyle is saphopylic and includes three plates in the apical area. It should also be noted that some cysts of $P$. hartmannii and possibly E. delicatum that are heavily covered by clay particles or amorphogen may be included in this category.

Dimensions: Relatively small to moderately large in size (c. $30-55 \mu \mathrm{m})$, including the processes which are less than $25 \%$ of the body width.

Synonymy: None

Biological Affinity: Includes cysts of various genera and species of uncertain taxonomic affinity

Comparison: Polykrikos hartmannii is distinguished from the Spiny Brown Cysts with a theropylic archeopyle by its hollow, relatively short and distally acuminate processes with a few striations near the base and a simple medially located theropylic archeopyle. Echinidinium species are distinguished from other RBSC by their relatively long, smooth spines which are 
circular along most of their length and are expanded at the base where some processes always have irregularly rectangular bases.

Distribution: In surface sediments of the BSC, Spiny Brown Cysts are widespread in low amounts (mostly $<3 \%)$ in the Black Sea and are present in the western Marmara Sea and northern Azov Sea (Figure 48). The polka-dot distribution of cysts probably reflects the artificial grouping of various taxa in this group, but it is notable that they are not reported for the Caspian or Aral Seas. Associated SST ranges seasonally from $0.5^{\circ} \mathrm{C}$ (winter) to $24^{\circ} \mathrm{C}$ (summer), with maximum cyst $\%$ at annual average $\mathrm{SST}=14.5^{\circ} \mathrm{C}$; $\mathrm{SSS}$ has a seasonal range of 8.5 (autumn) to 31.1 (winter), with highest \% values found in SSS above 25. Associated nutrient values are [P] mostly $0.03-0.26,[\mathrm{~N}] 0.02-3.2$; [Si] $1.5-34$; [chl.-a] ranges from 0.5 to 2 , with highest cyst $\%$ around 0.9 . The bottom $\mathrm{O}_{2}$ values range from $0-7.5$, with highest $\%$ in well oxygenated waters. Spiny Brown Cysts are occasionally present in the late Holocene of sediment cores from the Black Sea, but they were not systematically counted.

[Figure 48. Distribution map of Spiny Brown Cysts goes here.]

\subsection{Spiniferites belerius Reid 1974}

Distinguishing characteristics: Based on Reid (1974) and Rochon et al. (1999), these cysts are primarily distinguished from other transparent Spiniferites cysts by their small size and oval central body shape which sometimes has a small apical node and bears irregularly-shaped goal processes formed by sutural septa (Plate 23, Figs. 1-16). The body wall is usually smooth. Process tips may be distally trifurcate with recurred bifurcate tips or they are simple, branched, conical structures. Sutural crests are all relatively low but a characteristic complex trumpetshaped membranous processes usually forms between 1p and the antapical plate (Plate 23, Figs. 
7, 15-16). The ventral sulcus is also notably wide, expanding posteriorly, the antapical plate $1^{\prime \prime \prime \prime}$ is long and narrow, and the narrow cingulum is strongly displaced. The archeopyle is rarely seen but appears to be formed by loss of the pentagonal plate 3" (Plate 23, Figs. 15-16). Some Marmara Sea cysts have a scabrate to microgranular outer wall surface (Plate 23, Fig. 15).

Dimensions: Reid (1974) gives dimensions for 15 cysts from around the British Isles as body length 35-42 $\mu \mathrm{m}$; width 28-37 $\mu \mathrm{m}$; thickness 33-37 $\mu \mathrm{m}$. Maximum process length 7-10 $\mu \mathrm{m}$. Maximum posterior process length $10-15 \mu \mathrm{m}$.

Synonymy: Pterosperma ovum Gaarder 1954.

Biological Affinity: membranous cyst of Gonyaulax scrippsae Kofoid according to Wall and Dale (1968). G. scrippsae is recorded for plankton samples in the Black Sea (Boicenco and Gómez, 2004; Baytut et al., 2010).

Comparison: Reid (1974) comments that S. belerius is similar to Spiniferites elongatus Reid 1974 but it is smaller, oval not elongate, and it has different positions of the flaring posterior processes. S. belerius is also similar to Spiniferites membranaceus (Rossignol 1964) Sargeant 1970 which differs in being larger and in having longer processes and with higher, narrower, membranous sutural flanges in the antapical area compared to the wide low septum sometimes seen in S. belerius. In Black Sea early-mid Holocene sediments, the body shape of S. belerius can also appear sub-cruciform as in the Spiniferites cf. belerius morphotype of Marret et al. (2009) which has concave sides in the precingular area, but the cyst is not flattened dorsoventrally as in typical cruciform dinoflagellate cysts (see Mudie et al., accepted 2016). S. belerius can also resemble Spiniferites bentorii (Rossignol 1964) Wall and Dale 1970, but according to Reid (1974) and our observations for BSC specimens, S. belerius differs from Spiniferites bentorii (Rossignol 1964) Wall and Dale 1970 in being much smaller, less strongly pear-shaped with a smaller apical node and thinner wall with shorter, more delicate processes. 
Distribution: In the BSC surface sediments, S. belerius is common in low relative abundances $(<16 \%)$ throughout the Black Sea and is also found in coastal areas of the Caspian and the Aral Seas (Figure 49). There is a tendency for higher relative abundances $(9-13 \%)$ to occur in more saline slope sites, with a peak occurrence (16\%) in the periodically high salinity Kara-Bogaz Gol. Associated SST ranges seasonally from $5.5^{\circ} \mathrm{C}$ (winter) to $29.5^{\circ} \mathrm{C}$ (summer), with two peak cyst $\%$ occurring at annual average $\mathrm{SST}=14.5$ and $19.5^{\circ} \mathrm{C}$; SSS has a seasonal range of 12 (spring) to 31.1 (winter), with highest cyst \% found in SSS between 16 and 18.5. Associated nutrient values are $[\mathrm{P}]$ mostly $0.03-0.33,[\mathrm{~N}] 0-5$; [Si] $1.5-22.5$ (up to 33.7); [chl.-a] ranges from 0.3 to 3.3 , with maximum $\%$ values in the lowest range of [chl.-a]. The bottom $\mathrm{O}_{2}$ values range from $0-8.5$, with highest $\%$ in well oxygenated waters.

In the SW Black Sea core MAR02-45P, S. belerius appears with $S$. bentorii around 7.2 ka BP and has a peak occurrence and morphological diversity from ca 7-5 ka BP. Similarly, morphotypes of S. belerius have their maxima between 7.5 and 6 cal ka BP in core MAR05-13 (Bradley et al., 2012). In SE Black Sea core 22-GC3, S. belerius becomes dominant in the Holocene between 8 and 7 cal ka BP (Shumilovskikh et al., 2013). In the Caspian Sea, $S$. belerius has some sparse occurrences in the middle basin before the Mangyshlak lowstand (ca. 9-8 ka BP) and a more continuous record in the south basin (Leroy et al., 2013b, 2014). S. belerius was also found at one level of a core from Lake Urmia in a highstand, less saline, period of the last glacial (Djamali et al., 2008). The holotype of S. belerius is from the temperateclimate Severn Estuary (UK) which is a coastal area characterised by extreme variations in salinity during river flood events, high suspended sediment loads, and generally well-ventilated water. However, there are no available world-wide distribution data because the species is either not commonly present or has been grouped together with S. membranaceus. 
[Figure 49. Distribution map of Spiniferites belerius goes here.]

\subsection{Spiniferites bentorii (Rossignol 1964) Wall and Dale 1970}

Distinguishing characteristics: Based on Reid (1974) and Rochon et al. (1999), these spiniferate proximochorate cysts have a large ovoidal central body with a microgranular surface and a pronounced apical protuberance which can make the cyst appear pear-shaped (Plate 24, Figs. 1-13). The two-layered wall is $1-2 \mu \mathrm{m}$ thick and tabulation is marked by membranous fenestrate sutural septa or low granules. Very low sutural septa are found between gonal and occasional intergonal processes. When fully formed, the processes appear supported by solid, slender rods and are delicate with trifurcate or bifurcate tips and fenestrate bases. However, the processes may be conical in S. bentori subsp. truncata (Rossignol 1969) Lentin and Williams 1973 (Plate 24, Figs. 9, 11-13), or tapering, erect and recurved. In the BSC, they are often short and erect (Pl. 24, Figs. 8-13) and they may be reduced to crumpled knob-like structures as in $S$. bentorii var. nodosus of Bradford and Wall 1984. The dorsal precingular archeopyle in the holotype is hexagonal with rounded angles and usually with a detached operculum.

Dimensions: Body length 55-69 $\mu \mathrm{m}$, width 52-58 $\mu \mathrm{m}$; length of processes: 0-20 $\mu \mathrm{m}$ according to Reid (1974) for 15 specimens.

Synonymy: Hystrichosphaera bentori Rossignol 1964; Hystrichosphaera nodosa Wall 1967

Biological Affinity: Cyst of Gonyaulax digitale (Pouchet 1883) Kofoid 1911. G. digitale has a widespread occurrence in plankton samples throughout the Black Sea and is present in Marmara Sea but is rare in Caspian Sea and not reported for Aral Sea.

Comparison: The relatively large size and well-developed apical boss distinguish $S$. bentorii from other pear-shaped Spiniferites taxa. Reid (1974) comments that the similar taxon 
Spiniferites lazus Reid 1974 differs in being smaller with a more elongate, asymmetrical body (length $=44-58 \mu \mathrm{m})$ and bearing only well-developed processes $(12-15 \mu \mathrm{m})$, all with fenestrate bases. In the Black Sea surface sediments, specimens of $S$. bentorii display a wide range of morphological variation. S. bentorii ssp. truncata is rare but form "nodosa" and other morphotypes with short or weakly-developed processes are common. On the Ukrainian shelf of the Black Sea, morphotypes with normal or strongly reduced processes (Plate 24, Fig. 13) and enlarged or folded hypocystal area were also present. There are also morphotypes with a wide angular archeopyle, sometimes with an attached operculum.

Distribution: In surface sediments of Marmara and Black Seas, S. bentorii is the second-most common Spiniferites species (Figure 50) and it has peak abundances (22-35\%) in the northern Sea of Azov. However, it is not present in the Caspian Sea and it appears to be reworked in the Aral Sea (Sorrel et al., 2010). In sediment cores, S. bentorii is also commonly present (up to $\sim 10 \%$ relative abundance) in Holocene sediments of Marmara and Black Seas. Associated annual SST valuesfor $S$. bentorii are relatively low in the BSC: $11.7-16.3{ }^{\circ} \mathrm{C}$ (seasonally $5.7-23.9{ }^{\circ} \mathrm{C}$ winter-summer, except 0.6 in Azov winter) and the annual SSS range is 8.6(15.4)28.5, seasonally 9.0(14.6)30.6 winter-winter, mostly clustered between 14.6 and 18.4. Associated nutrient values are [P] 0.02-0.28, [N] 0.02-4.8 but mostly $<1.0$, [Si] 3.3-21.0 $\mu \mathrm{mol} / \mathrm{l}$, with maximum cyst $\%$ at values of $15.6-21 \mu \mathrm{mol} / 1$, and with [chl.-a] $0.4-3.3 \mu \mathrm{g} / \mathrm{l}$. The associated bottom $\mathrm{O}_{2}$ values are $0.07-6.5 \mathrm{ml} / 1$, with highest cyst $\%$ where $\left[\mathrm{O}_{2}\right]$ is $>5.8 \mathrm{ml} / \mathrm{l}$.

In general, Spiniferites bentorii is presently widespread in low amounts $(<5 \%)$ throughout the Mediterranean Sea (Zonneveld et al., 2013) and it also occurs in Izmir Bay (Aydin et al., 2011). The cysts are usually restricted to coastal sites between c. $60^{\circ} \mathrm{N}$ and $45^{\circ} \mathrm{S}$ and it is most abundant (up to 28\%) in mesotrophic to eutrophic water (Zonneveld et al., 2013) with a range of winter SST from $0.02-9.8^{\circ} \mathrm{C}$ ), but is not recorded where summer SST $<11.2^{\circ} \mathrm{C}$. Associated SSS is 
normally 27.5-40, and the species is not usually in brackish water (Marret and Zonneveld, 2003); Price and Pospelova (2011) also report a negative correlation between cysts abundances in Saanich Inlet and Fraser River discharge, SST, and solar insolation. The new BSC data, however, show that $S$. bentorii is found in salinities seasonally as low as $5.7-10$ off the Danube Delta and annually 8.2-9.2 in the outer Don River Estuary, as well as the entire western BSC area where mean annual SSS is 18.1.

[Figure 50. Distribution map of Spiniferites bentorii goes here.]

4.46 Spiniferites sp. 1 [cf. S. bulloideus (Deflandre and Cookson 1955) Sarjeant 1970 sensu stricto]

Distinguishing characteristics: This transparent spiniferate cyst resembles Spiniferites bulloideus Deflandre and Cookson (1955) Sarjeant 1970 sensu stricto, the diagnostic features of which are a small (c. $35 \mu \mathrm{m})$ spherical (bulloid) or subspherical cyst body bearing slender trifurcate gonal processes with widely separated distal branches and bifid tips, producing a circular outline (Plate 30, Figs. 7-9). The cyst wall is thin, with a smooth to scabrate surface and is easily folded. The processes are exclusively gonal, erect, and mostly about one third to one half of the body width, with slender simple shafts widening slightly at the base where a few may have combined bases with minute perforations visible only in SEM images. Tabulation appears to be gonyaulacoid and the $3^{\prime \prime}$ camerate archeopyle has a detached operculum.

Dimensions: Body diameter is $28(30) 33 \mu \mathrm{m}$ and the process length is $8-15 \mu \mathrm{m}(10$ specimens) which is slightly smaller than the dimensions of $S$. bulloideus as given by Deflandre and Cookson (1955). 
Synonymy: Hystrichosphaera bulloidea Deflandre and Cookson 1955; not synonymous with S. bulloideus sensu Wall 1965 which is has a different morphology from S. bulloideus sensu stricto and is not distinctly rounded.

Biological Affinity: Based on tabulation, probably a cyst of Gonyaulax.

Comparison: In polar view, the oval body of S. ramosus is also spheroidal and can appear similar to Spiniferites bulloideus sensu Deflandre and Cookson (1955) Sarjeant 1970 but $S$. ramosus has sturdier, shorter processes and is usually larger (see Sect. 4.52). Wall (1967) and Wall and Dale, (1968) describe a different morphotype of S. bulloideus as being characterised by a small ovoidal body with membranous sutural septa in the hypocystal area; Reid (1974) further decribes the presence of low sutural septa and sometimes, a strongly-developed complicated process forming a trumpet-shaped columnar process at the junction of hypocystal plates plates 4"' and 1"'". This morphotype is sometimes referred to as Spiniferites bulloideus sensu Wall 1965 or S. bulloideus sensu Wall and Dale 1968, but it is either a separate species from S. bulloideus (Deflandre and Cookson 1955) Sarjeant 1970 or a morphological variant of S. ramosus with two strong antapical processes and no intergonal processes or membranous developments. Ellegaard et al. (2002b) considered the ovoid cyst of Gonyaulax baltica Ellegaard, Lewis and Harding 2002 to be similar to S. bulloideus sensu Wall and Dale 1968 but G. baltica usually has shorter, wider processes. For the BSC atlas, only spherical cysts with relatively long, thin processes resembling those of the holotype are included in the category Spiniferites sp. $1 \mathrm{cf}$. S. bulloideus (Deflandre and Cookson 1955) Sarjeant 1970 sensu stricto.

Distribution: In surface sediments of the BSC, Spiniferites sp. 1 is less common than Spiniferites ramosus and occurs in lower amounts $(0.3-3.7 \%)$ which tend to decrease from west to east, with peak occurrences in Marmara Sea (Figure 51). In sediment cores, Spiniferites sp. 1 is sporadically present in Marmara Sea after c. 6 ka BP (Mudie et al., 2002a). Associated SST 
ranges seasonally from $5.5^{\circ} \mathrm{C}$ (winter) to $24^{\circ} \mathrm{C}$ (summer), with maximum cyst $\%$ at annual average $\mathrm{SST}=15^{\circ} \mathrm{C}$; SSS has a seasonal range of 14.5 (spring) to 31.1 (winter), with highest cyst \% found in SSS above 18 . Associated nutrient values are $[\mathrm{P}]$ mostly $0.03-0.33,[\mathrm{~N}] 0-5$; [Si] $\sim 0.5-14.5$ (up to 33.7); [chl.-a] ranges from 0.5 to 3.3, with highest cyst $\%$ in the lowest range of [chl.-a]. The bottom $\mathrm{O}_{2}$ values range from $0-7$, with highest $\%$ in poorly oxygenated waters. The world-wide distribution of the taxon is uncertain because of disagreement regarding the identity of the species which is often included in counts of either Spiniferites ramosus or Spiniferites bulloideus sensu Wall and Dale 1968.

[Figure 51. Distribution map of Spiniferites sp. 1 goes here.]

\subsection{Spiniferites cruciformis Wall and Dale in Wall et al. 1973}

Distinguishing characteristics: As determined by Wall et al. (1973), this is a transparent chorate cyst which is distinguished primarily by the shape of its central body which is cruciform (cross-shaped) in equatorial view (Plate 25, Figs. 1-10), moderately dorso-ventrally compressed, and bears processes connected by sutural septa of variable height and development. Typically, the septa are wide, perforated flanges (wing- or sheet-like structures) projecting out from the lateral equatorial area and apices (Plate 25, Figs. 1-6), but flange size can vary widely within a cyst population. The diagnostic cruciform shape is produced by noticeably concave precingular and postcingular lateral areas above and below the equatorial area (Plate 25, Figs. 2, 5), and like a crucifix, the cruciform endocysts are also characteristically strongly dorso-ventrally flattened. In equatorial view, the cyst body length: width ratio is $1.2: 1-1.55: 1$, and the apical, antapical and equatorial body areas are typically broadly rounded (except in the Caspian Sea). In polar view, the compressed body has an ovoid to subrectangular outline which lacks visible concave surfaces 
and it is almost circular near the apices (see images in Wall et al., 1973). In lateral profile, the body is subrectangular (width: depth ratio c. 1.4:1), tapering very gently from the equator towards rounded polar apices. The body wall is thin but is densely covered with scabrate and other irregularly corrugate surface ornament, displaying a beaded texture in SEM images (Plate 25, Figs. 14-15). The central body has reflected tabulation marked by sutural septa and processes.

Typically, the ornament development and extent of tabulation vary widely in large populations, ranging from cysts with only low sutural ridges $(<1 \mu \mathrm{m})$ to cysts with low to high septa. There are also conspicuous high membranous flanges which are entire or extensively irregularly perforate, sometimes with non-tabulate fenestrations. The distal margins of the septa may be deeply indented to form process-like structures that make the cysts appear "more spinose than membranous" (Wall et al., 1973; pl. 2, fig. 4; see also Mudie et al., accepted 2016). Process tips are often trifurcate with widely divergent branch tips of large processes running tangential to the body surface and linking adjacent processes. The ornament height within and between specimens varies from c. $55 \%$ of the body width to $<1 \mu \mathrm{m}$ high, typically being best-developed along the lateral equatorial cingular areas, in the lateral and intercalary posteroventral areas, and at both apices. When process and flange development is strong, the cyst outline is subcircular; however, many specimens are asymmetrical in equatorial view because the left posterolateral flange is much larger than the right flange. The camerate dorsal archeopyle corresponds to the third precingular plate and the operculum is detached. The reflected tabulation is well-expressed in dorsal and lateral cingular areas but is less clear seen ventrally. Lateral cingular areas $2 \mathrm{c}$ and 5c typically have strongly-developed sutural septa and flanges which are rectangular and either trumpet-shaped or they are closed distally to form box-like processes. 
Dimensions: Wall et al. (1973) measured >100 specimens from the late Pleistocene to early Holocene interval of Black Sea basin core Atlantis II, 1471P, and give dimensions as central body length $\mathrm{L}=46-65 \mu \mathrm{m}$, central body width $\mathrm{W}=34-56 \mu \mathrm{m}$; central body thickness (dorsal to ventral surface) $=28 \mu \mathrm{m}$; ornamentation extends up to $28 \mu \mathrm{m}$ beyond the body, giving a maximum total width of c. $84 \mu \mathrm{m}$. Mudie et al. (2001) obtained a similar central body size range of $L=45-63$ and $W=33-53$ for 65 cysts in Marmara Sea core MAR94-5, and found a maximum width of $73 \mu \mathrm{m}$ for $S$. cruciformis form 1 (cysts with spherical outline). Dimensions of 10 specimens from surface samples in the Black Sea fall within the same range, but some have relatively wider flanges, up to about $100 \%$ of the body width. Caspian cysts (Marret et al., 2004) have a larger range of body width, $48(58) 68 \mu \mathrm{m}$ and a smaller maximum flange width of $20 \mu \mathrm{m}$ (in morphotype A, for 25 cysts). Caspian morphotypes B and C also have larger endocysts: $\mathrm{L}=55(68) 78 \mu \mathrm{m} ; \mathrm{W}=48(53) 60 \mu \mathrm{m}(17$ cysts $)$ for type $\mathrm{B}$ and $\mathrm{L}=60(65) 70 \mu \mathrm{m} ; \mathrm{W}=48(52) 56 \mu \mathrm{m}$ for type C (20 cysts).

Biological Affinity: Probably gonyaulacoid lineage (Head, 1996) but cultures of living cysts have not yet produced viable motile cells, nor has the rDNA been determined so they cannot be traced with the biomolecular method used by Coolen et al. (2013).

Comparisons: The large range of variation in body shape, process length and surface ornament in S. cruciformis is often attributed to salinity variations, with the cruciform body shape and reduced processes/ornament associated with lower salinity (e.g. Wall et al., 1973; Dale, 1996). There have been several attempts to delimit morphotypes of S. cruciformis and relate them to SSS. Mudie et al. (2001) illustrate five forms of S. cruciformis for Marmara Sea late glacial sediments, based on process length and development: form 1 with well-developed flanges on epicyst and hypocyst giving a rounded outline; form 2 with well-developed flanges mostly on the hypocyst, giving an uneven outline; form 3 with long spines but low septa and 
weakly developed or no flanges; form 4 with relatively short processes (ca $30 \%$ or the less of body width); and form 5 with processes reduced to low ridges or very short processes (see Mudie et al., accepted 2016, fig. 2). Relative abundances of the forms were compared with SSS values derived from planktonic foraminiferal isotopes to show a weak negative correlation $\left(\mathrm{r}^{2}=0.4-\right.$ 0.6) with SSS in the estimated range 14-20 psu. Kouli et al. (2001) illustrate two morphotypes for late glacial sediment from freshwater Lake Kastoria (NW Greece): “e-type” with ellipsoidal body and relatively short processes (processes are similar to forms 3 and 4 above), and "c-type" cysts with a typical strongly cruciform body like those of forms 1 and 2 above. The cooccurrence of Kouli's two morphotypes and intergrades in a freshwater environment suggest that the variable process development is an inherent or a stress-induced characteristic, not a simple response to salinity change.

Marret et al. (2004) describe three morphotypes in Caspian Sea Holocene sediments based on development of flanges and cyst body shape. Morphotype A is cruciform with a conspicuous membranous flange (variably fenestrate) in ventral view, and sometimes with a large left postero-lateral flange; it largely corresponds to forms 1 and 2 of Mudie et al. (2001) but can differ in having a distinct apical boss. Morphotype B is mostly cruciform and relatively large, with stout processes lacking membranous flanges, and usually with rounded apices as in the holotype and the Black Sea forms of Mudie et al. (2001); however, some less cruciform Caspian specimens have a low apical boss or an elongated boss with a narrow ("pointed") tip (Plate 25, Figs. 12-13). Morphotype $\mathrm{C}$ also has a relatively large cyst body with a very prominent apical boss, less pronounced cruciform body shape, and processes which are usually straight without visible terminations or membranous flanges because the short processes are folded onto the endocyst (Plate 25, Figs. 9-11). In the Caspian Sea late-glacial-late Holocene basin core GS05, Morphotype A is most common (5-20\%), increasing to $40 \%$ during the interval from c. 8.4-4.4 
ka BP when Morphotype B also becomes more abundant (Leroy et al., 2013c); Morphotype C is present in lower amounts throughout. It is notable that the morphotypes of S. cruciformis with elongated apical bosses have not been seen in surface or Pleistocene-Holocene sediments of the Black and Aral Seas. Cysts reported as S. cruciformis from Late Pliocene (c. 4.20 Ma) freshwater sediment in the Ptolemais Basin of northern northern Greece (Kloosterboer-van Hoeve et al., 2001) have neither cruciform endocysts nor typical processes.

A superficial similarity exists between $S$. cruciformis and some morphotypes of the larger Miocene-Pleistocene species Galeacysta etrusca Corradini and Biffi 1988, as illustrated by Popescu et al. (2009) who group togethert several brackish water Paratethyan endemic taxa in their "Galeacysta etrusca complex". However, the holotype of G. etrusca clearly differs from $S$. cruciformis in being larger (70(85)100 $\mu \mathrm{m})$ and having an ellipsoid endocyst and a weakly tabular periphragm attached dorsolaterally and opening along the entire ventral region. Multiple other criteria distinguishing the two species are listed by Mudie et al. (accepted 2016). The cruciform species Pterocysta cruciformis Rochon in Rochon et al. (2002) differs from $S$. cruciformis and G. etrusca in being smaller (endocyst $\mathrm{LxW}=46 \mathrm{x} 41 \mu \mathrm{m}$ ), with a narrow, tabulate periphragm attached at the apices and covering only the central part of the ventral equatorial surface - the same area that is not covered by the hooded periphragm of G. etrusca.

Distribution: In surface sediments of the BSC, S. cruciformis is mostly very rare (absent or $<3 \%$ of the total cyst assemblage) in Marmara Sea and on the outer shelves or upper slopes of the Black Sea, with two occurrences in the southeastern basin; there is one anomalously high value (45.4\%) for one site on the outer Ukrainian Shelf (Figure 52). S. cruciformis is common and more abundant in the Caspian Sea (up to $75 \%$ in Anzali Lagoon), including Volga Delta (Richards et al., 2014) and it occurs in the Aral Sea (up to 20\%, Sorrel et al., 2006). It is also found in surface sediments of some freshwater lakes near Marmara Sea: Lake Sapanca (Leroy 
and Albay, 2010) and Lake Terkos (KNM, unpublished data). Spiniferites cruciformis is always abundant $(20->50 \%)$ in late Pleistocene-early Holocene sediments of basin and shelf cores of the Marmara and Black Seas and in deep basin cores from the Caspian Sea (e.g. Mudie et al., 2004; Marret et al., 2004; 2009; Leroy et al., 2007; 2013b; 2014). S. cruciformis is also common (10-20\%) in sediments of late-glacial-Holocene age at DSDP Site 380 in the SW Black Sea Basin (Ferguson et al., 2016). On the SW Black Sea shelf, S. cruciformis is common (c. 25\%) in MIS 3 to Holocene sediments of core MAR98-4 (Rochon et al., 2002).

In the BSC, the distribution of $S$. cruciformis has a relatively wide range of annual SST $\left(12-20.5^{\circ} \mathrm{C}\right)$, with peak relative abundances in the warmest areas, and it has a bimodal annual SSS distribution, with the main peak around 12.5 and a secondary peak around 17.7. Outside of the BSC, typical cruciform morphotypes of S. cruciformis are reported as rare $(<2 \%)$ in coastal areas of the eastern Mediterranean and Aegean Seas, occuring mostly in brackish water areas with high river discharge (Zonneveld et al., 2103). Overall, the total associated seasonal SST ranges from (1.6 Volga) $6.1-28.8^{\circ} \mathrm{C}$ (winter-summer) and seasonal SSS is (8.5) $12.1-18.3$ (31.4) summer-winter although three Mediterranean sites have SSS 37.7-39.0 (spring-autumn). Associated $[\mathrm{P}]$ and $[\mathrm{N}]$ values are relatively low and bottom water $\left[\mathrm{O}_{2}\right]$ is high: $6-8.5 \mathrm{ml} / \mathrm{l}$. Typical morphotypes of S. cruciformis also occur in late glacial freshwater sediments of Kastoria Lake, NW Greece (Kouli et al., 2001) in addition to the lakes near Marmara Sea. However, presently no evidence exists to support the suggestion (Kouli et al., 2010) that S. cruciformis is exclusively a freshwater species which was transported from mountain lakes to the BSC during cold climatic intervals.

[Figure 52. Distribution map of Spiniferites cruciformis goes here.] 


\subsection{Spiniferites delicatus Reid 1974}

Distinguishing characteristics: Based on Reid (1974) and Rochon et al. (1999), these transparent spiniferate cysts are characterised by a circular to ovoidal body with a small apical node or low boss and a microgranular to microreticulate wall (Plate 26, Figs. 1-11). The wall is thick, with membranous sutural flanges of various widths connecting the gonal processes which appear to be supported by thin skeletal rods (Plate 26, Figs. 4-5) but in SEM images, it can be seen that no rod structures are actually present (Plate 26, Figs. 10-11). The relatively broad processes are trifurcate with bifurcately branched tips which are a characteristic petaloid shape in plan view (Plate 26, Fig. 11). The archeopyle is formed by loss of precingular plate 3 " and may have a free or attached operculum.

Dimensions: Reid (1974) gives the body width x length as 40x35 to 60x54 $\mu \mathrm{m}$, maximum height of processes $29 \mu \mathrm{m}$, and cingulum width of 6-9 $\mu \mathrm{m}$ for 18 specimens. Black Sea cysts in surface samples may have much shorter processes (c. 5-15 $\mu \mathrm{m})$.

Synonymy: cf. Hystrichosphaera cf. tertiaria Morzadec-Kerfourn 1966.

Biological Affinity: Unknown but probably a Gonyaulax sp. according to Rochon et al. (1999).

Comparison: In surface sediments of the Black Sea, few specimens of S. delicatus have high membranes similar to like cysts found around the British Isles, in the Dee Estuary (Reid, 1974 or in the Celtic Sea (FM, unpublished), and most cysts have membranes that are missing, collapsed or crumpled, as described by G.L. Williams for some Atlantic morphotypes (cited in Reid, 1974). Rochon et al. (1999) and Verleye et al., (2009) group together S. delicatus with $S$. bulloideus and S. ramosus; we have separated the taxa based on presence of the membranous processes bearing petaloid process tips and occurrences of high crests in $S$. delicatus. $S$. delicatus 
has processes of similar shape as the Eemian species Spiniferites ristingensis Head 2007 but typically these are connected by higher sutural crests, and the body wall structure is characterized by a pedium with radial fibres and a thin granular tegillum so that the surface appears microgranular; in contrast, the tegillum of S. ristingensis forms densely distributed blisters up to $1.8 \mu \mathrm{m}$ wide. These distinctive "bubble-wrap"-like blisters, which are clearly visible in LM of S. ristingensis, are not seen in the BSC specimens of S. delicatus that also have a more reduced archeopyle than $S$. ristingensis. It is possible that the relatively low septa in the BSC specimens of $S$. delicatus is a response to low salinity compared to its occurrence in the Atlantic and Pacific Oceans; S. ristingensis is also associated with reduced salinities of c. 15-22 (Head, 2007).

Distribution: In the BSC surface sediments, S. delicatus is occasionally present in low amounts (maximum 5\%) in the shelf and upper slope areas of the Black Sea (Figure 53). It is also found in Holocene sediments of the NE Black Sea and in Marmara Sea where it is grouped with thermophilic marine taxa by Londeix et al. (2009). In the BSC, it is associated with with seasonal SST ranging from $5.5{ }^{\circ} \mathrm{C}$ (winter) to $24{ }^{\circ} \mathrm{C}$ (summer), with maximum cyst $\%$ at annual average $\mathrm{SST}=15^{\circ} \mathrm{C}$; SSS has a seasonal range of 14.5 (spring) to 27.7 (winter), with highest cyst \% found in SSS between 16 and 18.5. Associated nutrient values ( $\mu$ mol/l) are $[\mathrm{P}]$ mostly 0.02-0.33, [N] 0-5; [Si] 2-14.5; [chl.-a] ranges from 0.5 to 3.3, with maximum cyst $\%$ in the lowest range of [chl.-a]. The bottom $\mathrm{O}_{2}$ values range from $0-7 \mathrm{ml} / 1$, with highest $\%$ in well oxygenated waters as also reported by Zonneveld et al. (2013). In BSC cores, S. delicatus is occasionally present in the Marmara Sea from c. $10.8 \mathrm{ka}$ and it is reported as present in the SW Black Sea Holocene interval (Verleye et al., 2009) but is grouped with S. bulloideus and $S$. ramosus, so the distribution of this taxon is not known in detail. In general, the species is widespread along the Atlantic coasts from about $60{ }^{\circ} \mathrm{N}$ to $25^{\circ} \mathrm{S}$, in the N. Pacific from c. $30-25$ 
${ }^{\circ} \mathrm{N}$ in the eastern Indian Ocean (Zonneveld et al., 2013), being rare where summer SST is $<15^{\circ} \mathrm{C}$ but having a total temperature range: $-1.0-29{ }^{\circ} \mathrm{C}$ ). The $\mathrm{BSC}$ distribution extends the species occurrence into much lower salinity water than the reported global SSS range of 25.6-39.4 (Marret and Zonneveld, 2003).

[Figure 53. Distribution map of Spiniferites delicatus goes here.]

\subsection{Spiniferites hyperacanthus (Deflandre and Cookson 1955) Cookson and Eisenack 1974}

Distinguishing characteristics: Based on Deflandre \& Cookson (1955) and our own observations, these are transparent, spherical-subspherical spiniferate cysts with fine, sometimes indistinct sutures but with sturdy, erect gonal and intergonal processes clearly delimiting tabulation; sometimes there are two intergonal processes per suture. The process shafts are stiff, often slender, and are trifurcate with simple or bifurcate tips. The archeopyle is precingular 3" with a free operculum.

Dimensions: The Miocene type specimens from Balcombe Bay, SE Australia, have a body diameter 54-59 $\mu \mathrm{m}$, with process $13-20 \mu \mathrm{m}$, giving an overall diameter up to $97 \mu \mathrm{m}$. BSC specimens have a smaller body about $38-40 \mu \mathrm{m}$ and processes c. $10-18 \mu \mathrm{m}$ (10 specimens), which is close to the dimensions reported by Matsuoka (1985b) for specimens from surface samples in bays of western Japan.

Synonymy: Hystrichosphaera hyperacantha Deflandre and Cookson 1955.

Biological affinity: Unknown but probably a cyst of Gonyaulax based on the tabulation.

Comparison: Matsuoka (1985a, p. 35) considered that Hystrichosphaera furcata var. multiplicata Rossignol 1964 (as Spiniferites ramosus subsp. multiplicatus) is the same taxon as 
S. hyperacanthus, but $S$. ramosus subsp. multiplicatus differs in having only occasional intergonal processes and being more ovoidal than spherical. Spiniferites lenzii Below 1982 from the Albian (Lower Cretaceous) of Morocco is a similar morphotype but it differs in having higher septa than S. hyperacanthus. Tertiary specimens of $S$. lenzii may have perforations at the base of the processes. Specimens of S. hyperacanthus from the continental slope off Nova Scotia (Rochon et al. 1999, pl. 7, figs. 5-10) have only one intergonal per suture. Recently, Limoges et al. (accepted 2016) show that S. hyperacanthus is similar to Spiniferites hainanensis Sun and Song 1992 from Pleistocene dolomite on the tropical Hainan Island off SE China; this morphotype has also been seen in the BSC by KNM (Plate 27, Figs. 1-11). S. hainanensis differs from S. hyperacanthus in having an ellipsoidal body and solid processes that are connected at the base by low sutural ridges that are uniformly perforated at the process bases and have one or two small holes in the base of middle part of each process.

Distribution: For the BSC atlas, S. hyperacanthus and S. hainanensis are combined for mapping (Figure 54) and statistics, and they are discussed together with S. ramosus subsp. multiplicatus in Sect. 4.52.

[Figure 54. Distribution map of Spiniferites hyperacanthus, including cyst of S. hainanensis goes here.]

\subsection{Spiniferites membranaceus (Rossignol 1964) Sarjeant 1970}

Diagnostic characteristics: Based on Wall (1967) and Reid (1974), these transparent spiniferate proximochorate cysts have a circular to ovoidal body which is slightly elongate in equatorial view, with or without a small apical boss. The wall has two layers: a smooth 
endophragm and a scabrate to microgranulate periphragm, with characteristic membranous sutural septa of variable height which are raised where they fuse in gonal positions and include a diagnostic wide suturo-cavate process (flange) at the boundary between the $4^{\prime \prime \prime}$ and the $1^{\prime \prime \prime \prime}$ plates (Plate 28, Figs. 1-16). The exclusively gonal processes are trifurcate with bifurcate tips which may also appear as small spines on the antapical flange (Plate 28, Figs. 3, 7, 8). There may also be a small "crown" of membranous septa in the apical area (Plate 28, Figs. 2, 9) and the septa between weak membranous gonal processes may be finely perforate (Plate 28, Fig. 8). The archeopyle is precingular 3" usually with a free operculum. On specimens with elevated crests between all processes, intergonal processes can occur (Plate 28, Figs. 9-16).

Dimensions: For 16 specimens measured by Reid (1974) and measurements cited by Marret and Zonneveld (2003), the cyst body is 37-50 $\mu \mathrm{m}$ wide, $41-54 \mu \mathrm{m}$ long; the length of most processes is $12-17 \mu \mathrm{m}$, the antapical flange is $2-21$ (rarely 25) $\mu \mathrm{m}$ high, up to one-third the body diameter according to Wall (1967).

Synonymy: Hystrichosphaera furcata var. membranacea M. Rossignol 1964; Hystrichosphaera ramosus var. membranacea (M. Rossignol) Davey and Williams 1966; Hystrichosphaera membranacea (Rossignol 1964) Wall 1967.

Biological Affinity: Cyst of Gonyaulax spinifera (Claparède and Lachmann 1859) Diesing 1866, according to Dodge (1989) and cyst of G. spinifera complex according to Lewis et al. (1999), but later related to the cyst of Gonyaulax membranacea by Ellegaard (Ellegaard et al., 2003).

Comparison: S. membranaceus can superficially resemble S. mirabilis (Rossignol 1964) Sarjeant 1970 but differs in having weak, membranous gonal processes and having a distinctive “crown-like" antapical process-complex when seen in equatorial view. Lewis et al. (1999) found that cultured cysts may lack processes and virtually all reflected tabulation. These extremely 
reduced features were not recognised in BSC specimens of S. membranaceus; however, some cysts without processes and with weak tabulation were seen and recorded as Spiniferites spp. because of uncertainty as to species identity (see Sect. 4.53).

Distribution: In BSC surface sediments, S. membranaceus is widespread in Marmara and Black Seas but it is not recorded for the Caspian and Aral Seas (Figure 55). It has highest \% abundance in the deeper water areas of the Black Sea. Associated SST ranges seasonally from $0.5^{\circ} \mathrm{C}$ (winter) to $24^{\circ} \mathrm{C}$ (summer), with peak cyst $\%$ at annual average SST $=15.2{ }^{\circ} \mathrm{C}$; SSS has a seasonal range of 8 (autumn) to 31.1 (winter), with highest occurrences found in SSS between 16 and 18.5. Associated nutrient values are [P] mostly $0.03-0.28,[\mathrm{~N}] 0-3.5$; [Si] $1.5-33.5$; [chl.a] ranges from 0.4 to 2.4 , with highest occurrences in the lowest range of [chl.-a]. The bottom $\mathrm{O}_{2}$ values range from $0-7$, with highest $\%$ in poorly oxygenated waters. S. membranaceus is present in Holocene sediment cores for the Marmara and Black Seas. Elsewhere, S. membranaceus occurs in surface sediments of Izmir Bay (Aydin et al., 2011) and in general, S. membranaceus s.l. (including S. belerius) is widespread from cold-temperate to tropical regions, mainly in coastal areas but including some oceanic sites. It has maxiumum cysts \% values in temperate waters off China and is more common in subtropical-tropical areas (Zonneveld et al., 2013), being largely restricted to areas with summer $\mathrm{SST}>5.6^{\circ} \mathrm{C}$, frequently where there are seasonal reductions from river discharge. High relative abundances have been found in oligotrophic and mesotrophic environments and it is rare in eutrophic areas (Marret and Zonneveld, 2003).

[Figure 55. Distribution map of Spiniferites membranaceus goes here.]

\subsection{Spiniferites mirabilis (Rossignol 1964) Sarjeant 1970}


Distinguishing characteristics: Based on Reid (1974) and Rochon et al. (1999), S. mirabilis is a transparent proximochorate cyst with a broadly ovoidal to slightly elongate body which is circular in polar view and has a thin wall with a microgranular surface seen in SEM images (Plate 29, Fig. 10). The antapical area is characteristically marked by processes connected by a high sutural flange along the junction of plates 1 "'"' and $4{ }^{\prime \prime \prime} ;$ the associated large processes emerge from the flange at the junctions with $3^{\prime \prime \prime}$ and 5"' (Plate 29, Figs. 2, 5, 7-8). The numerous other processes are stout, rigid, hollow gonal and intergonal rods with distally furcate with bifurcate tips. Sutural septa are low or absent except in the antapical area, where the septa height is variable, from wide and elongate (Plate 29, Figs. 7-8) to short or rarely, it is essentially absent (Plate 29, Fig. 9). The precingular dorsal archeopyle (3") is pentagonal with rounded corners and a free operculum.

Dimensions: Reid (1974) gives the body width as 44-48 $\mu \mathrm{m}$, length 58-60 $\mu \mathrm{m}$, and process lengths as $15-21 \mu \mathrm{m}$ for 16 specimens.

Synonymy: Hystrichosphaera mirabilis M. Rossignol 1964.

Biological Affinity: Cyst of Gonyaulax spinifera (Claparède and Lachmann 1859) Diesing 1866.

Comparison: S. mirabilis appears similar to S. hyperacanthus which differs by not having the flanged antapical complex and in always having intergonal processes on all sutures. S. mirabilis also resembles morphotypes of $S$. membranaceus with strong processes, but it normally has a much wider antapical flange and more intergonal processes.

Distribution: In the BSC, S. mirabilis is widely distributed in low amounts (mostly less than $5 \%$ ) throughout the Marmara and Black Seas, with scattered peaks in warmer waters of Marmara Sea, Gelendzik Bay and the Ukrainian continental slope; it is rare in the low salinity Azov Sea where the antapical flange is strongly reduced and it appears to be absent from the Caspian and 
Aral Seas (Figure 56). Associated SST ranges seasonally from $5.5^{\circ} \mathrm{C}$ (winter) to $24^{\circ} \mathrm{C}$ (summer), with peak cyst $\%$ at annual average SST $=14.5{ }^{\circ} \mathrm{C}$; SSS has a seasonal range of 15 (spring) to 31.1 (winter), with highest cyst \% found in SSS above 21. Associated nutrient values are [P] mostly $0.01-0.28,[\mathrm{~N}]$ 0-3; [Si] 1-34, with highest \% values for [Si] below 10; [chl.-a] ranges from 0.3 to 2.5 , with maximum cyst $\%$ in the lowest range of [chl.-a]. The bottom $\mathrm{O}_{2}$ values range from $0-7$, with highest $\%$ in poorly oxygenated waters. $S$. mirabilis is commonly present in low numbers in Holocene sediments of shelf and basin cores from Marmara and the Black Sea. In Marmara Sea, it is continuously present after 10 ka BP (Roberts, 2012). In the SW Black Sea, S. mirabilis appears at about $7 \mathrm{cal} \mathrm{ka} \mathrm{BP,} \mathrm{becoming} \mathrm{continuously} \mathrm{present} \mathrm{after} \mathrm{c.} 5500 \mathrm{cal}$ BP.

On a worldwide-scale, $S$. mirabilis has been recorded from south of the Arctic Subpolar Front around $80^{\circ} \mathrm{N}$ to north of the Antarctic Subtropical Front at about $45^{\circ} \mathrm{S}$ (Zonneveld et al., 2013). Highest relative abundances occur in coastal samples and it is common (up to $20 \%$ ) in the western Mediterranean but less frequent in the eastern Mediterranean and Aegean Seas; it is rare in Izmir Bay (Aydin et al., 2011). This taxon has a global SST range of -0.8 and $29.8{ }^{\circ} \mathrm{C}$ (winterspring SST; no seasonal sea ice) but is generally not observed from sites with summer SST below $12{ }^{\circ} \mathrm{C}$ (Marret and Zonneveld, 2003). It occurs primarily in oligotrophic/mesotrophic fully marine environments but also sometimes where salinity is reduced by river discharge. In the North Atlantic, there is a significant negative relationship between phosphate/nitrate conditions and relative abundances of S. mirabilis (Devillers and de Vernal, 2000). Newly formed cysts have been found in sediment trap material from the Arabian Sea, deposited at the transition period between active upwelling to inter-monsoonal quieter surface water conditions (Zonneveld and Brummer, 2000). 
[Figure 56. Distribution map of Spiniferites mirabilis goes here.]

4.52 Spiniferites ramosus (Ehrenberg 1837) Mantell 1854; emend. Davey and Williams 1966

Distinguishing characteristics: Based on Davey and Williams (1966) and Marret and Zonneveld (2003), Spiniferites ramosus has transparent proximochorate cysts with an ovoidal to subspherical body as seen in lateral and equatorial views, and a thin wall having a smooth, reticulate or weakly granulate surface and bearing long, slender, tapering gonal processes which are much longer than the low sutural crests (Plate 19, Figs. 1-7). These gonal processes are either solid or have hollow bases tapering to distally closed tips. The gonal processes are typically trifurcate and the sutural processes are bifurcate; both commonly have small bifurcate tips which may be slightly recurved. The suture between the $1^{\prime}$ and 4 ' plate-areas is usually reduced and these apical plates may be fused; the precingular ventral plate 6 " is typically triangular. The archeopyle is formed by loss of precingular plate 3 " and the operculum is detached.

Dimensions: Cyst body: $\mathrm{L}=30-46 \mu \mathrm{m} ; \mathrm{W}=22-43 \mu \mathrm{m}$; process length $1.2-12 \mu \mathrm{m}$ (after Lewis et al., 1999; Rochon et al., 1999).

Synonymy: Hystrichosphaera ramosa (Ehrenberg1838) Deflandre 1937; Hystrichosphaera furcata (Ehrenberg) O. Wetzel emend Rossignol 1964. Hystrichosphaera bulloidea Wall and Dale 1970 is considered a junior synonym according to Harland (1977) and Reid (1974). This synonymy is not considered valid by Lentin and Williams (1981) but is accepted by Fensome and Williams (2004). Not synonymous with S. ramosus subsp. multiplicatus as proposed by Matsuoka (1985b). 
Biological Affinity: S. ramosus is a cyst of Gonyaulax spinifera (Claparède and Lachmann, 1859) Diesing, 1866, according to Wall and Dale (1970), Dodge (1989), Lewis et al. (1999) and confirmed by Ellegaard et al. (2003).

Comparison: In polar view, the body of S. ramosus is spherical and can appear similar to $S$. bulloideus (Deflandre and Cookson 1955) Sarjeant 1970 sensu Wall and Dale 1968. However, $S$. bulloideus sensu Wall and Dale 1968 is smaller (maximum length $\mathrm{x}$ width is $42 \mathrm{x} 38 \mu \mathrm{m}$ for 20 cysts), with more delicate, longer $(8-16 \mu \mathrm{m})$ processes and it has a characteristic broad, trumpetshaped hypocystal process at the junction of plates $4{ }^{\prime \prime \prime}$ and $1^{\prime \prime \prime \prime}$. The cyst-theca relationship of $S$. bulloideus sensu Wall and Dale 1968 is also different, being given as Gonyaulax scrippsae by Wall and Dale (1968) and by Ellegaard et al. (2003). In Black Sea surface samples, we have counted separately as Spiniferites sp. $1 \mathrm{cf}$. S. bulloideus spherical cysts with simpler and longer gonal processes. Other smaller, round spiniferate cysts with wide antapical processes and sometimes with widened delicate septa are counted as Spiniferites spp. because of uncertain identification.

Most BSC morphotypes are referable to the common Atlantic morphotype of S. ramosus var. ramosus of Davey and Williams (1966), based on the absence of intergonal processes. However, larger cysts with intergonals in the BSC and in surface sediments the Persian Gulf-Arabian Sea region (Bradford and Wall, 1984) may be S. ramosus var. multiplicatus (Rossignol 1964) Lentin and Williams 1973. This taxon, first described by Rossignol (1964) for Pleistocene- Recent samples from coastal Israel, is larger than var. ramosus and has 1-10 variously positioned bifurcate intergonal processes, including antapical intergonals up to $20 \mu \mathrm{m}$ long. The subspecies S. ramosus var.. multiplicatus (Rossignol 1964) Lentin and Williams 1973 closely resembles $S$. hyperacanthus (Deflandre and Cookson 1955) Cookson and Eisenack, 1974 but it does not have intergonal processes on all of the sutural ridges. Recently, Limoges et al. (accepted 2016) found 
that S. hyperacanthus is similar to the tropical species Spiniferites hainanensis Sun and Song 1992 which has also been seen in the BSC by KNM. S. hainanensis differs from $S$.

hyperacanthus in having an ellipsoidal body and solid processes that are connected at the base by low sutural ridges that are uniformly perforated at the distal ends (see Pl. 27, Figs. 6, 9-10) and have one or two small holes in the base of middle part of each process. For the BSC atlas, $S$. hainanensis is also grouped with S. ramosus ssp. multiplicatus and with S. hyperacanthus for mapping because until now, the difference among these taxa was not documented and with light microscopy, the morphological differences among these intergonal-bearing taxa are not always easily discerned.

Distribution: In surface sediments of the BSC, S. ramosus sensu lato (including both subspecies and including S. bulloideus in SW Black Sea samples studied by Verleye et al. (2009) is very widespread in low to moderate amounts $(<20 \%)$ throughout the Marmara, Black and Azov Seas, but it is not reported for the Caspian and Aral Seas (Figure 57). The distribution of $S$. hyperacanthus + S. hainanensis (Figure 56) is essentially the same but with fewer occurrences in Marmara Sea. Associated SST ranges seasonally from $5.5^{\circ} \mathrm{C}$ (winter) to $24^{\circ} \mathrm{C}$ (summer), with maximum cyst $\%$ at annual average $\mathrm{SST}=14.5^{\circ} \mathrm{C}$; $\mathrm{SSS}$ has a seasonal range of 14.5 (spring) to 31.1 (winter), with highest cyst \% found in SSS above17. Associated nutrient values are [P] mostly $0.02-0.33,[\mathrm{~N}] 0-5$; [Si] $1.5-33.5$; [chl.-a] ranges from 0.3 to 3.3 , with highest cyst $\%$ in the lowest range of [chl.-a]. The bottom $\mathrm{O}_{2}$ values range from $0-7$.

In sediment cores from Marmara Sea, S. ramosus s.1. is common (up to 35\%) in the Holocene, particularly after c. 2 ka BP (Mudie et al. 2002a; Londeix et al., 2009). In Black Sea sediments, S. ramosus is rare or absent before c. $7.6 \mathrm{ka} \mathrm{BP}$, with acmes either between about 7-6 ka BP (Verleye et al., 2009, who included S. delicatus Reid 1974) or after 5 ka BP (Bradley et al., 2013). S. ramosus is found in the Gulf of Izmir (Aydin et al., 2011) and is widespread in 
Mediterranean and Aegean Sea cores. World-wide, Zonneveld et al. (2013) report that $S$. ramosus is widespread in low amounts from sub-polar to equatorial regions of both hemispheres, with highest relative abundances associated with upwelling areas. Although it is observed in river plume areas, it is not more abundant in these regions. Associated environmental parameters are SST: (-2)0-29.8 ${ }^{\circ} \mathrm{C}$ (winter-spring) SSS: 17.5-39.4 (summer-autumn), [P]: 0.06-1.73 $\mu \mathrm{mol} / 1,[\mathrm{~N}]: 0.04-24.0 \mu \mathrm{mol} / 1$, chlorophyll-a: 0.06-20.9 ml/1, bottom water $\left[\mathrm{O}_{2}\right]$ : between 0.01$8.0 \mathrm{ml} / \mathrm{l}$. S. hainanensis is a Pleistocene species first described from arenaceous dolomite in the tropical Hainan Island, SE China, where it is associated with other cysts indicating a warm temperate neritic environment (Sun and Song, 1992).

[Figure 57. Distribution map of Spiniferites ramosus goes here.]

\subsection{Spiniferites septentrionalis Harland 1977}

Distinguishing characters: According to Harland (1977), these spiniferate cysts have an ovoid to subspherical body with a colourless wall and very faint sutural ridges, usually also with low septa around plate 3" (Plate 30, Figs. 1-6). An apical boss may be present or absent. Processes are long, slender and erect, exclusively gonal, mostly with complex trifurcate terminations but including some which may be simple. The shafts of more membranous processes are often somewhat perforate at the base (Plate 30, Figs. 5-6) and distally, the processes vary from being trifurcate with bifid tips to being trifurcate with perforate or fenestrate distal ends, this latter form is especially prominent on the cingular processes. Reduced processes may also be present. The archeopyle is gonyaulacoid, corresponds to plate $3 "$, with a free operculum. 
Dimensions: Cyst body length 33.75(40.52)47.50 $\mu \mathrm{m}$, width 27.50(31.04)37.50 $\mu \mathrm{m}$, wall thickness 1.0-2.0 $\mu \mathrm{m}$, process length 10.00(12.40)16.25 $\mu \mathrm{m}$ (Harland 1977).

Synonymy: Not Achomosphaera andalousiensis Jan du Chêne 1977. The fossil cyst species Achomosphaera andalousiensis Jan du Chêne in 1977 was emended by Jan du Chêne and Londeix (1988) who designated a lectotype and four topotypes because the holotype from Andalousia, Spain, was lost. Strauss and Lund (1992) transferred the species to Spiniferites as $S$. andalousiensis (Jan du Chêne 1977) Strauss in Strauss and Lund, 1992) but Head (1997) retained this species in Achomosphaera. Taxonomic junior synonyms are Spiniferites septentrionalis according to Harland (1983), and to Jan du Chêne and Londeix (1988); Spiniferites aquilonius of Strauss in Strauss and Lund (1992) is also a junior synonym. However, the synonymy of Achomosphaera andalousiensis and Spiniferites septentrionalis was questioned by Head and Wrenn (1992). Reid (1974) combines Achomosphaera ramulifera Deflandre 1937 with Spiniferites and he describes a species Spiniferites ramulifera (Deflandre) Reid 1974, with a rhomboidal to ellipsoidal body and gonal processes having complexly branched tips. Harland (1977) commented that Reid later incorrectly considered A. ramulifera (as S. ramulifera) to be the same taxon as $S$. septentrionalis but Londeix et al. (1999) determined A. ramulifera (as A. ramulifera subsp. ramosasimilis) to be the same as Achomosphaera ramosasimilis (Yun 1981) Londeix et al. 1999, which is a late Cretaceous species from western Germany.

Biological affinity: Harland (1977) considered that S. septentrionalis is a cyst of a Gonyaulax sp.but is otherwise unknown.

Comparison: A. andalousiensis is distinguished from S. septentrionalis primarily by its regular, complex fenestrate process tips. The perforate process bases are similar to S. lazus but the latter does not have fenestrate distal ends (Harland 1977, p. 103). Head (1997) distinguishes two subspecies of $A$. andalousiensis in the mid-Pliocene Coralline Crag microflora: $A$. 
andalousiensis ssp. andalousiensis with process platforms having seven or less large fenestrations, and A. andalousiensis ssp. suttonensis with c. 15 or more small fenestrations. Most of the BSC cysts have relatively few platform fenestrations, and several cysts have strongly perforate processes, with the wall surface being granulate to verrucate. Londeix et al. (2009) found both S. septentrionalis and Achomosphaera cf. andalousiensis in mid-late Holocene sediment of Marmara Sea and they separate S. septentrionalis from A. andalousiensis based on its presence of a non-rounded body shape, scabrate ornament, presence of faint trabeculae and fenestrate process tips. Verleye et al. (2009) found rare occurrences of Achomosphaera spp. in mid-late Holocene sediments of core GeoB7625-2 in the southern Black Sea, but they do not list or illustrate these taxa. It is possible that further study will show that the BSC cysts of these Achomosphaera spp. may fall within the range of variation in S. septentrionalis. Achomosphaera sp. sensu Evitt 1977 (Sect. 4.1) is separated in the BSC atlas based on absence of visible traces of tabulation and processes with only simple trifurcate process tips, without any wide reticulate or perforate platforms.

Distribution: S. septentrionalis is rare in surface samples from the BSC, and has a patchy distribution. It is found mainly in the NW Black Sea, with a maximum of $1.4 \%$ on the outer Ukrainian Shelf. The taxon also occurs in low numbers at a few sites on the Turkish Shelf, one in the Sea of Azov, and one in Marmara Sea (Figure 58). Associated SST ranges seasonally from $5.5{ }^{\circ} \mathrm{C}$ (winter) to $24^{\circ} \mathrm{C}$ (summer), with maximum cyst $\%$ at annual average SST $=14.5{ }^{\circ} \mathrm{C} ; \mathrm{SSS}$ has a seasonal range of 15.1 (spring) to 18.1 (winter), with highest cyst \% found in SSS above 17. Associated nutrient values are $[\mathrm{P}]$ mostly $0.07-0.27,[\mathrm{~N}] 0-4.5$; [Si] $32-14$; [chl.-a] ranges from 0.5 to 28 , with highest cyst $\%$ s in the lowest range of [chl.-a]. The bottom $\mathrm{O}_{2}$ values range from 0-5.5. S. septentrionalis is also rare to occasionally present in Holocene samples from Marmara Sea, south-western and southern Black Sea, with the first reported Holocene 
occurrence being about 8 ka BP in Core M72/5-22-GC3 as Achomosphaera cf. andalousiensis (Shumilovskikh et al., 2013).

Globally, there are few reports of cysts in the Achomosphaera andalousiensis-Spiniferites septentrionalis species complex for surface sediment samples, except at some coastal sites on the Irish Sea (Reid, 1974) where the salinity offshore is near normal marine (c. 33-35) and SST range is c. 8-18 (Marret and Scourse, 2002). The BSC occurrences of S. septentrionalis extend the previously recorded salinity range to include stratified estuarine conditions with salinity varying from 5.9 (winter, NW Black Sea) to 23 (fall and winter, Marmara Sea); an association with low nutrient levels is also indicated.

[Figure 58. Distribution map of Spiniferites septentrionalis goes here.]

4.54 Spiniferites spp. indet.

Distinguishing characteristics: This is an informal category which primarily includes transparent spiniferate cysts which were too poorly preserved (broken or crumpled) or too obscured by amorphogen for species identification. It also includes specimens with thin weak processes bi- or trifurcate processes and elongate spiniferate cysts with high septa resembling, but not the same as Spiniferites elongatus which is reported only for late Pleistocene-early Holocene sediments in cores from Marmara Sea (Londeix et al., 2009) and the southern Aegean Sea (Marino et al., 2008). The category may also include some cysts of cf. S. membranaceus lacking processes and with very weakly expressed tabulation.

Dimensions: Variable as indicated above.

Biological Affinity: Inderminate. 
Distribution: This taxon is present in relative abundances of up to $36 \%$ in most samples from the Black and Marmara Seas, with peaks in areas of high amorphogen on the central and outer shelves, and with lowest numbers in coarse-grained samples where little particulate organic matter is present. It is an artificial category both taxonomically and environmentally and is not mapped or included in statistical analyses.

\subsection{Tectatodinium pellitum Wall 1967 emend. Head 1994}

Distinguishing characteristics: Based on Wall (1967) and Head (1994), these transparent proximate cysts are sphaerical to slightly ovoid, with or without a small apical boss (c. $1-$ c. 1.5 $\mu \mathrm{m})$, and always with a thick, double-layered wall. The wall has a very thin $(0.1 \mu \mathrm{m})$ inner layer (pedium) and a thicker spongy outer layer (luxuria) comprising interwoven fibrils with open ends which give the surface a microgranular, granular or vesicular appearance under light microscopy (Plate 2, Figs. 7-12). The large precingular P3" archeopyle is trapezoidal and typically has an irregular margin and well-developed adcingular angles; the operculum is free (Plate 2, Fig. 7).

Dimensions: Cyst body diameter is $32-55 \mu \mathrm{m}$, with luxuria width of $1.8-7 \mu \mathrm{m}$ (measurements of Wall, 1997 and Head 1994); longer fibrils may extend beyond the luxuria by c. $2 \mu \mathrm{m}$.

Synonymy: According to Head (1994) and Head and Nøhr-Hansen (1999), junior synonyms are Tectatodinium grande Williams et al. 1993 and Tectatodinium rugulosum (Hansen 1977) McMinn 1988.

Biological affinity: May be a cyst of Gonyaulax spinifera (Claparède et Lachmann 1859) Diesing 1866 according to Wall and Dale (1968).

Comparison: Cysts in surface samples from the Black Sea are mostly thick-walled with fibrils extending beyond the surface of the luxuria (Plate 5, Fig. 10), similar to the specimen first described from the Ashdod borehole on the coast of Israel by Rossignol (1964, pl. 1, fig. 15) and 
incorrectly designated as Leiosphaeridia scrobiculata). However, Head (1994) comments for Black Sea cysts "the wall is somewhat thinner than usual and there are unusually numerous loose fibrils emanating from the surface"; similar specimens occur in sediment of Bølling/Allerød age from the western Mediterranean Alboran Sea (Turon and Londeix, 1988, pl. 4, figs. 1-3). T. pellitum may appear similar to specimens of Bitectatodinium spongiosum (Zonneveld) Zonneveld and Jurkschat 1998 when only one archeopyle plate is detached; however, $B$. spongiosum has a larger body $(48-63 \mu \mathrm{m})$ and thicker fibrous outer wall layer 5-11 $\mu \mathrm{m}$ wide.

Distribution: In surface samples of the BSC, T. pellitum is found in low relative abundances $(<5 \%)$ in Marmara Sea and many areas of the Black Sea, in a wide range of water depths, but tending to increase in deeper, more saline water (Figure 59). Associated SST ranges seasonally from $5.5{ }^{\circ} \mathrm{C}$ (winter) to $24{ }^{\circ} \mathrm{C}$ (summer), with maximum cyst $\%$ at annual average $\mathrm{SST}=15{ }^{\circ} \mathrm{C}$; SSS has a seasonal range of 15 (spring) to 31.1 (winter), with highest cyst \% found in SSS above 18. Associated nutrient values are $[\mathrm{P}]$ mostly 0.03-0.28, [N] 0-5; [Si] 1.5-15 (up to 34); [chl.a] ranges from 0.4 to 2.8 , with maximum cyst $\%$ in the lowest range of [chl.-a]. The bottom $\mathrm{O}_{2}$ values range from $0-7$, with highest $\%$ abundance in well oxygenated waters.

T. pellitum is sporadically present in low numbers in latest glacial Pleistocene and Holocene sediment cores of Marmara Sea and Black Sea cores south of the Bosphorus entrance (Londeix et al., 2009; Verleye et al. 2009; Bradley et al., 2012; Shumilovskikh et al., 2013); it is infrequently present in cores north of the Bosphorus (Marret et al, 2009). The BSC distributions of $T$. pellitum indicate that the taxon is not restricted to coastal areas of sub-tropical to equatorial regions, although its peak abundance (15\%) is along the east coast of the Gulf of Mexico (Zonneveld et al., 2013). Elshanawany et al. (2010) report that it is widely distributed in low numbers throughout the Mediterranean; however, it is rare in the Aegean Sea basins (Mudie et al., 2004) and is absent in Gulf of Izmir although it is common (up to c. 10\%) in Holocene 
sediment on the shelf core east of the Nile Delta (Morzdec-Kerfourn, 1988). Zonneveld et al. (2013) associate T. pellitum with summer SST $>14.4{ }^{\circ} \mathrm{C}$ and annual temperature range of 9.2-29.5 ${ }^{\circ} \mathrm{C}$, with SSS of 21.9-39.2; the species is most abundant in regions of high productivity, with a wide range of bottom water oxygen, including anoxic sediments.

[Figure 59. Distribution map of Tectatodinium pellitum goes here.]

4.56 Trinovantedinium applanatum (Bradford 1977) Bujak and Davies 1983

Distinguishing characteristics: Based on Bradford (1977) and Reid (1977), these transparent or yellowish cysts are pentagonal and dorsoventrally compressed, with a short thickening forming an apical boss and with two antapical horns of equal or unequal size (Plate 21, Figs. 1-3). The antapical horn tips are rounded or pointed and are separated by a shallow depression. The surface of the single-layered wall bears short sutural and intratabular spinous processes with pointed or minutely expanded tips which may appear capitate under light microscopy. The epicyst has straight or convex sides and is about the same length as the hypocyst which has straight or concave sides. The narrow excavated cingulum is bordered by rows of capitate processes; there are some smooth bare areas in the mid-ventral, sulcal and dorsal postcingular areas. The large dorsal intercalary (2a) archeopyle is hexagonal and sub-rectangular; the excystment aperture is rarely seen but the operculum appears to be free.

Dimensions: Reid (1977) gives the length of 15 specimens as 54-80 $\mu \mathrm{m}$, breadth 54-80 $\mu \mathrm{m}$, thickness $42 \mu \mathrm{m}$ (one specimen), maximum process height 5-7 $\mu \mathrm{m}$, cingulum width 4-6 $\mu \mathrm{m}$. Matsuoka $(1985,1987)$ indicates shorter processes of $3.2-5.2 \mu \mathrm{m}$ for 9 specimens of $T$. applanatum, including larger cysts up to $100.8 \mu \mathrm{m}$ long and $87.6 \mu \mathrm{m}$ wide. 
Synonymy: Trinovantedinium capitatum Bradford 1977 is a junior synonym for T. applanatum but this name is retained by Matsuoka $(1985 \mathrm{~b}, 1987)$ for cysts in surface sediment around Japan.

Biological Affinity: Gu et al. (2015b) suggest that T. applanatum is the cyst of Protoperidinium shanghaiense although Wall and Dale (1968) and Lewis et al. (1984) previously considered this species to be the resting cyst of Protoperidinium pentagonum (Gran 1902) Balech 1974. P. shanghaiense is not recorded for the BSC but $P$. pentagonum is present in several plankton records from Black Sea (Gómez and Boicenco, 2004; Taş and Okuş, 2006) and is rare in Marmara Sea records (Balkis, 2004). P. shanghaiense differs from P. pentagonum primarily in having no girdle displacement; possibly this feature has been overlooked in BSC plankton studies, as in the British studies.

Comparison: Bradley (1977) and Matsuoka (1985b) comment on a wide range of length: breadth ratio and the degree of development of the apical horns, which may be reduced to small wall thickenings. In the few specimens seen in the BSC, there is also a large range in morphology from smaller specimens with rounded epicyst sides and well-developed tapering horns to larger, straight-sided cysts with an almost straight antapical margin. Trinovantedinium pallidifulvum Matsuoka 1987 is a smaller, brown-coloured species (Mertens et al. 2017).

Distribution: In BSC surface sediments, T. applanatum is rare and is only present at a few sites in Marmara Sea and one site on the Turkish Shelf of the Black Sea, near Bosphorus Strait (Figure 60). Associated SST ranges seasonally from $5.5^{\circ} \mathrm{C}$ (winter) to $24{ }^{\circ} \mathrm{C}$ (summer), with maximum cyst $\%$ at annual average $\mathrm{SST}=15^{\circ} \mathrm{C}$; $\mathrm{SSS}$ has a seasonal range of 16.5 (spring) to 31.1 (winter), with highest cyst \% found in SSS between 16 and 18. Associated nutrient values are $[\mathrm{P}]$ mostly $0.07-0.25,[\mathrm{~N}] 0-2.1 ;[\mathrm{Si}] \sim 4.52-22.1$; [chl.-a] ranges from 0.6 to 1.6. The bottom $\mathrm{O}_{2}$ values range from 2.8-6. T. applanatum is rare in late Holocene sediment ( $\left.<3 \mathrm{ka} \mathrm{BP}\right)$ of Marmara Sea cores but has not been found in Black Sea cores. In contrast, it is continuously 
present in Late Pleistocene and Holocene sediments of the Alboran Sea (Turon and Londeix, 1988). In general, T. applanatum has a cosmopolitan distribution from the polar fronts to equatorial region, mainly in neritic areas but with maximum amounts in offshore equatorial regions, including the Amazon River plume where SSS is as low as 19.1 (Zonneveld et al., 2013). It is therefore surprising that this cyst is rare in Marmara and Black Sea, given that the presumed thecate stage $P$. pentagonum is present in these waters.

[Figure 60. Distribution map of Trinovantedinium applanatum goes here.]

\subsection{Votadinium calvum Reid 1977}

Distinguishing characteristics: Based on Reid (1977), Rochon et al. (1999) and Sarai et al. (2013), this large, dark to light brown cyst is dorsoventrally compressed and typically has a rounded heart-shaped (cordate) outline in equatorial view, with two approximately equal antapical lobate horns separated by a shallow depression and lacking thickened horn tips (Plate 31, Figs. 1-13). In lateral view, the cyst is trapezoidal, usually with a rounded apex, but Wall and Dale (1968) show that a round-tipped apical horn may be present. The single-layered cyst wall is thin $(1 \mu \mathrm{m})$ with a usually smooth surface but sometimes microgranulate, irregularly granulate or pitted; an inner hyaline layer may be visible after excystment. The intercalary archeopyle, formerly considered to correspond with plate $2 \mathrm{a}$, is now shown to be plate $1 \mathrm{a}$; it is hexagonal, of roughly equal length and height, with rounded sides; the operculum may remain attached to the apex as a flap or it becomes detached so that the apex is obliquely truncated. No other tabulation is evident.

Dimensions: Reid (1977) gives the size range as 54-72 x $74 \mu \mathrm{m}$ for 15 specimens. 
Biological Affinity: Wall and Dale (1968) determined this taxon as one of the cyst types of Peridinium oblongum (Aurivillius 1898) Paulsen 1907, and Reid (1977) considered it is the encysted stage of Protoperidinium oblongum. Rochon et al. (1999) comments that there is disagreement about the possibility that P. oblongum and Protoperidinium oceanicum Vanhöffen are separate species. In the Black Sea, $P$. oblongum and $P$. oceanicum are both present in plankton records, with the latter being more common, but they have not been reported for Marmara Sea plankton (Balkis et al., 2016). Recently, however, Sarai et al. (2013) show that three varieties within the $P$. oblongum complex in the Oceanica group should be recognised as independent species, and they consider that cordate cysts with an attached archeopyle described by Wall and Dale (1968) as P. oblongum are cysts of Protoperidinium latidorsale (Dangeard 1927) Balech 1974.

Comparison: In the BSC surface samples, V. calvum shows a wide range of wall surface characteristics in both Marmara and the Black Sea, from almost smooth to smoothly wrinkled or coarsely verrucate (Plate 30, Fig. 7). Morphotypes with a strongly developed apical horn were not observed.

Distribution: In the BSC surface sediments, V. calvum is occasionally present in the Marmara Sea and is widespread in low amounts (mostly 5\%) in the Black Sea where it is most abundant in the central parts of the basin (Figure 61), reaching maximum of 12\% at 2,174 m depth (MSM3366-15MUC). Associated SST ranges seasonally from $5.5{ }^{\circ} \mathrm{C}$ (winter) to $24{ }^{\circ} \mathrm{C}$ (summer), with peak cyst $\%$ at annual average $\mathrm{SST}=14.5^{\circ} \mathrm{C}$; SSS has a seasonal range of 14.5 (spring) to 31.1 (winter), with highest cyst \% found in SSS between 16 and 18.5. Associated nutrient values $(\mu \mathrm{mol} / \mathrm{l})$ are $[\mathrm{P}]$ mostly $0.05-0.33,[\mathrm{~N}] 0-5 ;[\mathrm{Si}] \sim 1.5-15$ (up to 22.1 ); [chl.-a] ranges from 0.3 to 3.3, with highest occurrences in the lowest range of [chl.-a]. The bottom $\mathrm{O}_{2}$ values range from $0-7$, with highest $\%$ in poorly oxygenated waters. Cysts and thecate cells of $V$. calvum are also 
reported for surface sediment samples from Marmara Sea and Gemlik Gulf (Balkis et al., 2016). The species is also occasionally present in mid-late Holocene sediment cores of Marmara and the SW Black Sea where it first appears after 7 ka BP in core GeoB 7625-2 (Verleye et al., 2009). In general, $V$. calvum is restricted to coastal sediments from sub-polar to equatorial regions and is found in both hypersaline and hyposaline environments. However, peak relative abundances are in eutrophic environments, including upwelling areas with high diatom and organic matter production, or anthropogenic eutrophication, particularly nitrate enrichment. In Marmara Sea, cyst production is highest in May and August (Balkis et al., 2016) but elsewhere it may be yearround or mainly in winter (Zonneveld et al., 2013).

[Figure 61. Distribution map of Votadinium calvum goes here.]

\subsection{Votadinium spinosum Reid 1977}

Distinguishing characteristics: Based on Wall and Dale (1968), Reid (1977) and our own observations, these cysts are very pale brown or almost transparent, strongly dorsoventrally compressed, and heart-shaped in equatorial view, with two uneven-sized antapical lobes separated by a shallow antapical depression (Plate 11, Figs. 1-7). The apex is rounded and the cyst is lunulate in polar view. The single-layered body wall is thin $(<1 \mu \mathrm{m})$ with a smooth surface mostly covered by irregularly distributed, short, solid, slightly curved, solid, spines; the deep antapical sulcal area is bare. The 2 a dorsal intercalary archeopyle is sub-rectangular or subpentagonal with rounded sides, and it truncates the apex obliquely. The operculum is usually free but may remain attached at the apex. 
Dimensions: Reid (1977) measured 15 specimens with a range in body size from 49x51 to 54x63 $\mu \mathrm{m}$, and spine length 3-7 $\mu \mathrm{m}$; however Wall and Dale (1968) indicate a larger size, up to 76x76 $\mu \mathrm{m}$ for the Bermuda area of the North Atlantic.

Biological Affinity: Wall and Dale (1968) germinated cysts of V. spinosum and obtained thecate cells of Protoperidinium claudicans (Paulsen, 1907) Balech, 1974 with a 2a archeopyle. New germination experiments (reviewed in Matsuoka and Head, 2013) were done using two morphotypes (straight vs. curved spines) of $V$. spinosum, resulting in thecate cells of different horn and archeopyle shape which cast doubt on the exact cyst-theca relationship. P. claudicans is commonly found in Black Sea plankton samples (Gómez and Boicenco, 2004) but is apparently rare in Marmara Sea records (Balkis, 2004).

Comparison: Cysts from BSC surface sediments appear to be at the lower end of the size range reported for this species. Reid (1977) noted that spines on specimens from the British Isles appear less pronounced than those from the Bermuda area. BSC morphotypes have spines mostly $<7 \mu \mathrm{m}$, sometimes with slightly expanded bases; there is also notable variation in the size and shape of the antapical horns, from strongly asymmetrical to almost symmetrical. Specimens from processed sediments also seem notably paler in colour than cysts in suspended sediment which are brown (Neslihan Balkis, personal communication 2013).

Distribution: In the BSC surface sediments, the delicate cysts of $V$. spinosum are rarely present in low numbers in Marmara and the Black Sea and are not mapped here. This Holocene species is not reported for the BSC cores except one specimen in SW Black Sea core GeoB76252, c. $3.6 \mathrm{ka} \mathrm{BP}$, and may be a recent Mediterranean re-invasive (or is possibly mistaken for poorly preserved cysts of T. applanatum or pale (oxidised) specimens of Peridinium ponticum). The species is rare in Izmir Bay (Aydin et al., 2011). In the Mediterranean Sea, Satta et al. (2010) found cysts of $P$. claudicans in highly polluted semi-enclosed bays of Spain and Sardinia 
and it occurs in the North Adriatic Sea (Sangiorgi and Donders, 2004). In general, V. spinosum is a coastal temperate to tropical species which is restricted to full-marine environments. Maximum relative abundances are associated with eutrophic (especially nitrate-enriched) or upwelling conditions with hypoxic to well ventilated bottom water. Larger amounts of cysts are also sometimes related to high diatom abundance (Zonneveld et al., 2013). World-wide, the associated SST is $0.7-29.4{ }^{\circ} \mathrm{C}$ (winter-summer) with summer SST $>9.0{ }^{\circ} \mathrm{C}$, and SSS: $25.5-37.7$ (spring-autumn); bottom water [O2]: 0.2-7.8 ml/1. The BSC occurrences extend the salinity range of $V$. spinosum to 19.9-20.2 (summer-winter).

\subsection{Xandarodinium xanthum Reid 1977}

Distinguishing characteristics: Based on Reid (1977) and Matsuoka et al. (1982), these pale brown or yellowish-brown, dorsoventrally compressed cysts are irregularly trapezoidal shape in equatorial view and bear penitabular processes of irregular shape and length (Plate 8, Figs. 1-6). The thin wall is smooth, with processes which are simple or that have circular or elongate bases with complex flanges and multifurcate spiny tips. The cysts have a concave, smooth midventral surface and a convex dorsal surface which is not ornamented in the archeopyle area. The wall extends out into processes which are aligned in the cingular area and which form a small process complex at the apex and on two low antapical bosses. The archeopyle is rounded hexagonal and probably corresponds to intercalary plate $2 \mathrm{a}$.

Dimensions: Reid (1977) gives a body size of 46x46 to 48x63 $\mu \mathrm{m}$ and process height, 5-19 $\mu \mathrm{m}$ for 15 specimens.

Biological Affinity: Matsuoka et al. (1982) and Lewis et al. (1984) report that Xandarodinium xanthum is the cyst-stage of Protoperidinium divaricatum (Meunier, 1919) Parke and Dodge 
1976. Head (1996) considered that the cysts of Matsuoka et al. (1982) may be a distinctive unnamed cyst species and mentioned that Harland (1983) tentatively correlated the cyst of $X$. xanthum with a Protoperidinium sp. indet.; however, it appears that the intergradation of morphotypes does not warrant separation of taxa. Recently, Gu et al. (2015b) incubated cysts of Protoperidinium divaricatum from the coast of China and found cysts with morphology within the range of Reid's description for $X$. xanthum. It is notable that $P$. divaricatum is not listed in the BSC plankton records or in the Mediterranean records of Gómez (2003) although it is listed for two sites in the Adriatic Sea by Guiry (2015).

Comparison: Matsuoka et al. (1982) remark that X. xanthum is similar to Selenopemphix (Multispinula) quanta but differs in having a pentagonal body shape and longer, sometimes furcate processes. Cysts from the BSC (Plate 3.45, Figs. 29, 30) can also be distinguished from $S$. quanta by presence of some broadly rectangular process bases, presence of long and short processes, some strongly furcate process tips, and the clustering of short spines on apical and antapical horns.

Distribution: In surface sediments of the BSC, X. xanthum is present in amounts up to c. $1 \%$ in Marmara Sea and lower amounts at a few locations in the western Black Sea (Figure 62). Associated SST ranges seasonally from $5.5^{\circ} \mathrm{C}$ (winter) to $24^{\circ} \mathrm{C}$ (summer), with maximum cyst $\%$ at annual average $\mathrm{SST}=14.5^{\circ} \mathrm{C}$; SSS has a seasonal range of 16.5 (spring) to 31.1 (winter), with highest cyst \% found in SSS above 24. Associated nutrient values are [P] mostly 0.05-0.22, [N] 0-2.5; [Si] 1.5-26.5; [chl.-a] ranges from 0.5 to 1.3, with maximum cyst $\%$ for [chlor.-a] $\sim 0.9$. The bottom $\mathrm{O}_{2}$ values range from 0-6. In Marmara Sea.It appears around 3,800 cal BP and becomes common after c. 300 cal BP. In the deep basin core Black Sea core M72/5-22GC3, $X$. xanthum is rarely present during the Holocene interval from 3.3-4.7 ka BP (Shumilovskikh et al., 2013). X. xanthum has a patchy distribution in the northern Mediterranean Sea, the Atlantic and 
northwestern Pacific Ocean (Zonneveld et al., 2013). In general, X. xanthum is mainly confined to coastal waters of temperate to tropical regions in the Northern Hemisphere, but also occurs at one site with $-1{ }^{\circ} \mathrm{C}$ (winter) and $-1.3{ }^{\circ} \mathrm{C}$ (spring). It is commonly associated with areas of brackish water (Baltic Sea) or high river discharge, but it is also widespread in full marine environments. It is found in both oligotrophic to eutrophic environments, including upwelling areas, where bottom waters are well ventilated. No clear seasonal cyst production is seen in the upwelling area west of Iberia (Ribeiro and Amorim, 2008).

[Figure 62. Distribution map of Xandarodinium xanthum goes here.]

\subsection{Unknown Hyaline cysts}

Distinguishing characteristics: This is an artificial category erected to accommodate the notably frequent occurrences in the NW Black Sea surface samples of medium-sized (c. $32 \mu \mathrm{m})$ spherical cysts with a thick refractive, colourless, hyaline wall and sometimes containing with red or yellowish accumulation bodies. Unknown hyaline cysts are smaller than those of Alexandium spp. and they lack mucilaginous outer wall coverings or any discernable tabulation, including excystment apertures. Some of the specimens may be temporary cysts or immature cysts of L. machaerophorum, O. centrocarpum sensu Wall and Dale 1966 or other dinoflagellate species, but no incubation experiments have been performed to validate their identity.

Dimensions: Diameter for 26 cysts, including wall thickness is $28(31.4) 40 \mu \mathrm{m}$; wall thickness $2(2.5) 4 \mu \mathrm{m}$.

Synonymy: None.

Biological Affinity: Unknown. 
Comparison: In addition to the notes given in Distinguishing characteristics above, these cysts are distinguishable from BSC Biecheleria spp. by their larger size and absence of surface ornament or processes. Rossignol (1963, pl. 1, figs. 1-9) illustrates similar hyaline cysts c. 30-50 $\mu \mathrm{m}$ wide, with wall thickness $1-6 \mu \mathrm{m}$, from surface sediments in the continental shelf off Israel and shows some of these formed inside hystrichosphaerid cysts, including Spiniferites bentorii and Operculodinium israelianum.

Distribution: In BSC surface sediments, theses unknown hyaline cysts are widely distributed in amounts up to $4 \%$ of total cyst assemblages in surface sediments of the Danube Shelf and are rare on the outer Ukrainian Shelf. They are not observed downcore, possibly reflecting their temporary nature. For the BSC atlas, these cysts are not mapped and they are not included in the database used for statistical analysis.

\subsection{Very Restricted Modern Cyst Occurrences}

This category includes various dinocysts that are are extremely rare and possibly reworked in the BSC surface sediment samples but have been reported as being occasionally present to common in the Holocene lacustrine facies of cores from Marmara and Black Sea or in Holocene sediments of the Ponto-Caspian basins. Three subcategories are recognised:

Group 1. Freshwater species, comprising the cyst of Gonyaulax apiculata (Pénard) Entz fil. 1891 sensu Evitt et al., 1985 and cf. Peridinium inconspicuum of Brenner.

Group 2. Thermophylic marine species currently living in surface sediments of the Mediterranean-Aegean Sea, including Polysphaeridium zoharyi (Rossignol 1962) Bujak et al. 1980, Spiniferites pachydermus (Rossignol 1964) Reid 1974 and Tuberculodinium vancampoae (Rossignol, 1962) Wall 1967. 
Group 3. Paratethyan and Ponto-Caspian relics, including Galeacysta etrusca Corradini and Biffi 1988, Romanodinium areolatum Balteş 1971, Thalassiphora balcanica Balteş 1971 and Pterocysta cruciformis Rochon et al. 2002.

\section{Group 1. Freshwater Cysts}

\subsubsection{Cyst of Gonyaulax apiculata (Pénard) Entz fil. 1891 sensu Evitt et al. 1985}

The cyst of Gonyaulax apiculata sensu Evitt et al. 1985 is one of a group of Gonyaulax cysts in recent sediments of Lake Zurich, Switzerland that were studied by Evitt et al. (1985) and morphologically related to Gonyaulax apiculata (Pénard) Entz fil. 1891; however, the motile stage was not recorded in annual plankton surveys. This morphologically variable cyst is superficially similar to Caspidinium rugosum, as explained in Sect. 4.7; however, the cyst of $G$. apiculata differs conspicuously in having a prominent apical boss and a smooth to verrucate wall that varies from being atabular to showing sutural traces marked by rows of verrucae or small tubercles (see Evitt et al., 1985, fig. 3, pl. I, II and III; Mudie et al., 2011, pl.1, fig. 15). In the BSC, the cyst of $G$. apiculata is rare in surface sediments of some coastal lakes and the species is reported for the phytoplankton of the Black Sea (Goméz and Boicenco, 2004), Romania (Caraus, 2012) and Spain (Alvárez Cobelas, 1984).The cysts occur in Holocene sediment of Lake Kastoria (Kouli et al., 2001, pl. 4, figs. 3-6) and in early Holocene sediments of the SE Black Sea core B7 of Mudie et al. (2001, 2002a).

\subsubsection{Cyst of cf. Peridinium inconspicuum sensu Brenner 2005.}


The cyst of cf. Peridinium inconspicuum sensu Brenner 2005 is the name given to a very small $(20-30 \mu \mathrm{m})$ transparent dinoflagellate first described by Wall et al. (1973, pl. 1, fig. 21) for the late Pleistocene-early Holocene intervals of Black Sea deep basin cores 1445P and 1474P. Wall et al. (1973) considered that these small specimens with well defined tabulation and small apical and antapical spinules were identical to the freshwater motile species Parvodinium inconspicuum (Lemmerman) Carty 2008 (formerly Peridinium inconspicuum Lemmermann 1899), and they thought that the taxon probably represented the cysts of this freshwater species that has been transported to the basin by freshwater inflow. However, they were not able to determine the nature of the archeopyle in order to validate their interpretation of this theca-like taxon. Brenner (2005, figs. 4a, b and 5a, b) illustrated a similar very small ( $<20 \mu \mathrm{m}$ width) taxon as the cyst of Peridinium sp. which co-occurs with G. apiculata in the freshwater Yoldia Sea Phase of the Baltic Gotland Basin (241 m deep) and he considered that this cyst was probably the same as the Wall et al's P. inconspicuum (Brenner, 2010, personal communication). The identity of this taxon remains enigmatic, but Tardio et al. (2009, figs. 2, 3) illustrate very similar small (c. $20 \mu \mathrm{m})$ specimens as the cyst of Peridinium umbonatum sensu lato prior to the shedding of the thecal plates, and they show that this unusual dinoflagellate with a hypothecal archeopyle is phylogenetically close to $P$. inconspicuum. In the BSC, the cyst of $P$. inconspicuum sensu Brenner 2005 occurs as single specimens within two surface samples from the Danube Shelf and it is common to occasionally present in early Holocene sediments of cores from Marmara, SW and SE Black Sea. Theca-like cysts from near-surface sediment in Lake Sapanca (Leroy and Albay, 2010, figs. 2.2-2.4) may also be the same taxon.

Group 2. Thermophylic Marine Species 


\subsubsection{Polysphaeridium zoharyi (Rossignol 1962) Bujak et al. 1980}

Based on Wall (1967), who provided the first valid description of Hemicystodinium zoharyi (Rossignol 1962) Wall 1967, P. zoharyi is a transparent, chorate cyst with a spherical to ovoidal central body, smooth to microreticulate or microgranulate wall surface bearing numerous, hollow processes of variable length (c. 6-15 $\mu \mathrm{m})$. The species is distinguished by its hemicystal archeopyle and processes that are open distally with mostly simple distal ends but include a few bifurcate tips. The process bases are weakly striated and can be fused. Under light microscopy, before excystment, $P$. zoharyii cysts are superficially similar to ungerminated specimens of Operculodinium centrocarpum. However, after opening, P. zoharyi differs in having a large hemispherical epicystal archeopyle (see images of Limoges et al., 2010, pl. 1, figs. 4-5 cf. fig. 6, and Wall, 1967); in polar view, the mid-ventral point of the open hypocyst is also characteristically marked by a small subrectangular projection. In the BSC surface samples, $P$. zoharyi has been recorded at only one location on the SW Black Sea shelf (Aydin et al., 2015) although its motile stage, determined by Wall and Dale (1969) as the HAB species Pyrodinium bahamense Plate 1906, is recorded for the Marmara Sea plankton (Balkis et al, 2016). The Pacific variety P. bahamense var. compressum Steidinger, Tester and FJR Taylor 1980 is a toxic HAB (Mertens et al., 2015d). P. zoharyi also sporadically occurs in low amounts $(<5 \%)$ in Holocene sediments of the Black Sea and Marmara Sea and it is common in surface sediments of the Aegean and Mediterranean, but does not occur in Izmir Bay. It is found in North Atlantic subtropical to warm temperate coastal regions between $30^{\circ} \mathrm{N}$ and $40^{\circ} \mathrm{S}$, with maximum occurrences (up to 40\%) in the Gulf of Mexico (Marret and Zonneveld, 2003) and off SW Mexico (Limoges et al., 2010). It is effectively confined to regions where winter SST is below 14.5 ${ }^{\circ} \mathrm{C}$, with maximum abundances where summer SST is c. $28{ }^{\circ} \mathrm{C}$, within a salinity range of 
16.2 and 36.6. It is widely associated with euryhaline tropical-subtropical coastal areas and shallow lagoons; it also occurs sporadically in oligotrophic open ocean sites of the Atlantic and South Pacific. The occurrence P. zoharyi appears anomalous as part of a Marmara Sea glacial stage "thermophilic assemblage" of Londeix et al. (2009).

\subsubsection{Spiniferites pachydermus (Rossignol 1964) Reid 1974}

Based on Reid (1974) and Mertens et al. (2015c), these transparent, circular to ovoidal proximochorate cyst have a low apical protuberance and a thick $(2 \mu \mathrm{m})$ wall with a radially striate inner layer covered by a thin periphragm that appears either coarsely reticulate and microgranulate or microreticulate/perforate (Mertens et al., 2015c, figs. 5 and 6). Processes are stout gonal trifurcate rods with bifid tips, joined by clear sutural septa, and the archeopyle is pentagonal with bevelled angles. Recent cyst-theca incubation and molecular studies of cysts from Izmir Bay show that the motile stage is a small species Gonyaulax ellegaardiae Mertens et al. 2015 which is most similar to Gonyaulax digitale (Pouchet) Kofoid sensu Lewis et al. 2001 and Gonyaulax membranacea (Rossignol) Ellegaard et al. 2003. In surface sediments of the BSC, a single microreticulate cyst of $S$. pachydermus is present in a few samples from the Ukrainian Shelf; a few specimens are also sporadically present in upper Holocene sediments of Marmara Sea core MAR02-88P. The Pleistocene holotype of Rossignol (1964) belongs to the same Eastern Mediterranean warm, hypersaline biogeographical province as the live specimens studied by Mertens et al. (2015c) from Izmir Bay, SW Turkey. World-wide, in surface sediments, low relative abundances (5\%) of S. pachydermus occur in coastal tropical and subtropical areas from $45^{\circ} \mathrm{S}$ to $30^{\circ} \mathrm{N}$, mostly restricted to warm temperature areas (SST 12.8 to 
$29.6{ }^{\circ} \mathrm{C}$, winter- summer) and high SSS ranges of 31.5 and 36.7, spring-summer (Marret and Zonneveld, 2003) but they can occur in a wider ranger of SST (Zonneveld et al., 2013).

\subsubsection{Tuberculodinium vancampoae (Rossignol 1962) Wall 1967}

Following Wall (1967, pl. 16, figs. 15, 16) and Matsuoka et al. (1998, figs. 4, 6), this is a large discoidal cyst $(62-113 \mu \mathrm{m}$ long) which has a subrectangular outline in lateral view and is subcircular in polar view, with the periphragm being supported by about 30-35 characteristic relatively short (c. $13 \mu \mathrm{m}$ ), hollow tubercules (barrel-shaped or sphaerical processes) with flaring distal ends merge with the outer wall. Wall (1967) describes the archeopyle as large and polyhedral; however, Matsuoka et al. (1998) consider that the archeopyle is a compound epicystal type although its outline cannot clearly be ascribed to apical or precingular plates arranged in longitudinal rows. T. vancampoae is the cyst of Pyrophacus steinii (Schiller) Wall and Dale 1971 and has been cultured to show that it grows in a range of salinity from 20-45 without significant change in morphology (Zonneveld and Susek, 2007) but tubercle length is strongly influenced by temperature above and below $27^{\circ} \mathrm{C}$ within the range from c. $16.5-34.8$. In the BSC, Pyrophacus steinii is part of the Black Sea plankton (Gómez and Boicenco, 2004) but the cysts have not been found in surface sediment although T. vancampoae occurs sporadically in late Pleistocene - earliest Holocene sediments of cores from Marmara Sea (Londeix et al., 2009; Roberts, 2012).

Group 3. Paratethyan Relic Species 
Pterocysta cruciformis is one of two essentially endemic Ponto-Caspian cysts with truly cruciform endocysts, as described and compared in Sect. 4.47. P. cruciformis is distinguished from Spiniferites cruciformis by its smaller size, absence of wide sutural septa and ventral tabulation on the endocysts and by the presence of a narrow, fenestrate periphragm attached to the ventral surface and covering the sulcal area (Rochon et al, 2002, pl. 1 and 2). A few relatively well-preserved specimens are present in surface and near-surface sediments of the outer Volga Delta (Richards et al., 2014; Richards et al., 2017). P. cruciformis is also sometimes present with S. cruciformis and $P$. psilata in Holocene sediments of cores from the central and southern basins of the Caspian Sea (SAGL, unpublished), and from the Aral Sea (Sorrel et al., 2006). P. cruciformis is the youngest of the cruciform taxa that appear to have evolved in the PontoCaspian basins of the Paratethyan Seas (see Mudie et al., 2016 accepted)

\subsubsection{Galeacysta etrusca Corradini and Biffi 1988}

As originally described by Corradini and Biffi (1988) from the Cava Serredi late Messinian section of Italy, this taxon has a relatively large, elliptical to subpolygonal endocyst with welldefined tabulation on the dorsal and lateral surfaces and with a distinctive claustrate periphragm attached dorsolaterally, forming a galeate structure that is open over the entire ventral sutural area (see Comparison sect. 4.47 and Mudie et al., 2016). Popescu et al. (2009) have informally broadened the criteria for this taxon to include a wide range of morphotypes with smaller endocysts and different, not clearly galeate ornament, based on the premise that there is a continuum of variation from camocavate forms with indiscernible tabulation to chorate cruciform taxa such as $S$. cruciformis. This complex taxon is considered to be a brackish water 
species that migrated from the Pontian-age Paratheyan seas into to Mediterranean during the Lago-Mare events. In the Black Sea, G. etrusca has one occurrence in a surface sediment sample from the upper Ukrainian continental slope but it is rare and possibly reworked in Holocene sediments of the western Black Sea (DSDP Site 380, Ferguson et al., 2016) and in the Caspian Sea (Leroy, personal observation, unpublished data).

\subsubsection{Romanodinium areolatum Balteş 1971}

The name Romanodinium areolatum is not fully valid because the holotype from the early Pliocene (Pontian stage) in the Pannonian Basin of Romania (Specimen L.C. 8992 - 60/118) was mistakenly related to an illustration of a Chytroeisphaeridia sp. by Balteş (1971, pl. 5, figs. 1-2). However, Balteş (1971 pl. 3, figs. 1-2) illustrates a large $(75-80 \mu \mathrm{m})$ camocavate cyst with a subsphaerical atabular endocyst and wide pylome-like apical aperture. The antapical area of the cyst is enveloped by a wide hyaline membrane described as being transparent and sometimes perforate. The LM illustrations of Balteş (1971) for $R$. areolatum show a very finely perforate periphragm lacking fenestration or tabulation except the archeopyle, and resembling the spongy fibrillar periphragm of the camocavate species Thalassiphora pelagica (Eisenack) Eisenack and Gocht 1960; emend. Benedek and Gocht 1981. These features are not present in the fenestrateclaustrate specimens from Holocene sediments of the Caspian and Aral Sea (Sorrel et al., 2006, fig. 8.1-8.5) which appear to be specimens of Thallasiphora balcanica Balteş 1971 (see Richards et al., 2014, pl. 3, g-h). R. areolatum has sporadic Holocene occurrences in the Caspian Sea. 
Balteş (1971) described the holotype of Thalassiphora balcanica from the same Lower Pliocene locality in Romania as Romanodinium areolatum (Specimen L.C. 6229 - 44/106). He distinguishes this very large $(120-130 \mu \mathrm{m})$ taxon as having an ellipsoid central body partly enfolded in a membranous periphragm in contact with the body only on one side (dorsal side? sic). The membrane is described as pterate and fibrous, quasi-reticulate and perforate, resembling a lamellate wing. The central body is described as having a vaguely outlined cingulum, and a trapezoidal paracingular archeopyle, but otherwise lacking tabulation. Stover and Evitt (1978, p. 194) considered that Thalassiphora pelagica was a senior synonym for this taxon. Sütö-Szentai (2002) transferred T. balcanica to Spiniferites, based on specimens from upper Pannonian deposits in Hungary, some of which have a fenestrate periphragm and attachments like those of Galeacysta etrusca (see Mudie et al., 2016 for details). The emended diagnosis of Spiniferites balcanicus (Balteş) Sütő-Szentai 2000 describes an ovoidal or spheroidal body with two membranes 'fixed both on the right and left side of the sulcus' and sometimes with two wing-like membranes that are 'differently perforated', one of them being arched in the apical area and being partially connected except in the ventral area. However, LM images (Sütö-Szentai 2000, pl. IX figs. 1-3) do not demonstrate these features clearly. Ongoing studies indicate that the range of variation illustrated by Sütö-Szentai is accommodated within the variability of Thalassiphora 'subreticulata' Fensome and Williams (2005) and the camocavate cyst species $T$. balcanica is incorrectly assigned to the chorate to proximochorate genus Spiniferites. Like Romanodinium areolatum (Sect. 4.61.8), Thalassiphora balcanica is reported as sporadically present in Holocene sediment of the Caspian Sea and in surface sediment of the Volga Delta (Richards et al., 2014 and personal communication, 2016). 


\section{Results and Discussion}

5.1. Taxonomic standardisation and morphological variation

\subsubsection{New reports for cyst taxa}

This atlas provides the first standardised taxonomy of the dinocysts occurring in modern sediments of the BSC, many of which have been used but not described or illustrated in previous biogeographical, biostratigraphic and paleoceanographic studies of Holocene sediment cores (e.g. Atanassova, 2005; Filipova-Marinova, 2006; Marinova and Atanassova, 2006; Mousing et al., 2013). The new atlas data show the presence of 71 dinoflagellate cyst taxa in the surface samples (Table 1, excluding uncertain modern species), compared to much smaller numbers (4-34 taxa) reported for several Holocene core sites in the western Black Sea (see reviews of Marret et al., 2009; Bradley et al., 2012). It is notable that this number of modern BSC taxa is as large as the total of 71 organic-walled taxa recorded for 2405 samples in the world's oceans (Zonneveld et al., 2013). Of the 71 BSC taxa, 18 are unquestionable new reports for the modern sediments: Cyst A of Verleye 2009, cyst of Alexandrium pseudogonyaulax, cyst of Barrufeta resplendens, cyst of Biechelieria baltica, cyst of Cochlodinium sensu Fukuyo, cyst of Cochlodinium polykrikoides sensu Li et al., cyst of Diplopelta symmetrica, cyst of Fragilidium, cyst of Kolkwitziella acuta (see Mertens et al., 2015b), cyst of Peridinium cf. willei, Echinidinium zonneveldiae, Lejeunecysta marieae, Spiniferites hainanensis, Spiniferites pachydermus, Spiniferites septentrionalis, Stelladinium reidii, and specifically for the Caspian Sea, the cyst of Scrippsiella plana (see Luo et al., 2016) and cyst of Protoperidinium stellatum. 
More work is needed to fully confirm that eight other rare/relict taxa (Table 1) are in place within the modern surface samples.

However, only five of these 18 new records (the cysts of A. pseudogonyaulax, Biechelieria, Fragilidium, Scrippsiella plana, and the species V. spinosum) appear to be recent invasives or to be invasives following a brief earlier mid-Holocene entry. This relatively low number of newly established dinocyst species is surprising given the large-scale anthropogenic changes that have accompanied the recent agricultural and industrial development, including accelerated shipping traffic and increased volume of ballast discharge (Öztürk, 2002; Sorokin, 2002). In contrast, Shiganova and Öztürk (2009) reported that 39 new Mediterranean motile dinoflagellate species arrived in the Black Sea between 1960 and 1993. Only two of these listed Mediterranean invasive species, A. pseudogonyaulax and Cochlodinium poykrikoides sensu Li et al., are known to produce cysts, and it is notable that the cyst of $C$. polykrikoides was found in sample of SW Black Sea core GeoB7625-2 dated c. 4,000 yr BP. Hence the apparently recent arrival of $C$. polykrikoides in Varna Bay in 2001 may be a re-invasion after an earlier failed establishment. Likewise, $V$. spinosum has one early occurrence around 3.6 ka BP core GeoB7625-2. All other 13 new Black Sea dinocyst occurrences appear to be associated with the Greco-Roman shipping trade beginning around 3,000 cal yr BP (Marret et al., 2009).

\subsubsection{Cyst preservation and recovery}

The updated taxonomy, detailed descriptions and illustrations of all BSC taxa now provide a consistent baseline for quantifying and correlating dinocyst records throughout the PontoCaspian region, and for comparing the range of morphological variation with populations from the global oceans. Preservation of organic-walled cysts and organic linings of calcareous cysts in 
both surface and Holocene sediments of the Marmara and Black Seas is generally excellent, as expected because of the widespread occurrence of reduced bottom oxygen levels (Fig. 5D). In addition, however, our standard laboratory processing methods for the BSC atlas surface samples do not use either hot chemical treatments, strong oxidants such as nitric acid and acetolysis mixture (acetic anhydride with sulphuric acid) or strong alkali treatments, such as potassium or sodium hydroxide (Mudie et al., 2011; Mertens et al., 2012b). This procedure is followed in order to minimise damage to thin-walled dinocyst taxa, particularly species that are susceptible to oxidation at the sediment-water interface and in the upper parts of Holocene sediment cores (see Zonneveld et al., 2013 and references therein for details). This laboratory procedure maximises recovery of oxidation-sensitive cysts but it has the disadvantage of not removing all fine-grained particulate organic matter (amorphogen) that is abundant in the modern sediments of the deeper waters of the eutrophic Marmara and Black Seas. Consequently, amorphogen and clay particles adhering to spinose cysts largely account for the categories Spiniferites spp., Echinidinium spp. and Spiny Brown Cysts which cannot be reasonably assigned to species. Other categories that presently cannot be speciated are the Unknown Hyaline Cysts, Round Brown Cysts and Quinquecuspis spp.

Despite these limitations, the surface samples and Holocene cores from the BSC, which includes the world's largest anoxic basin, show that our processing methods allow recovery of a wide spectrum of relatively thin-walled heterotrophic cysts, including many listed by Zonneveld et al. (2013) as surviving or prevailing only in low bottom oxygen environments: Ataxodinium choane, cysts of Alexandrium tamarense, cyst of Polykrikos kofoidii, Dubridinium caperatum, Lejeunecysta oliva, Peridinium ponticum, Pyxidinopsis psilata, Quinquecuspis concreta, Selenopemphix nephroides, Spiniferites delicatus, Spiniferites pachydermus, Tectatodinium pellitum, Votadinium calvum, and Xandarodinium xanthum. However, in the BSC, it is notable 
that the heterotrophic peridinioids, gymnodinioids and polykrikoids tend to have shorter Holocene ranges than most gonyaulacoid taxa. For example, 16 or fewer of the 26 heterotrophic taxa only appear by c. 4 ka BP (e.g. Marmara Sea cores MD02-2430, MAR97-02, MAR98-09, MAR02-88P; Black Sea cores Marmara Sea; Black Sea cores MAR02-45, MAR05-04G and 13P, GeoB7625-2, 22-GC3 25-GC1, B7), and they are sparse and of low diversity throughout cores GCAk 2571, GCAk-521, and Ash-8 from the NE Black Sea (Ivanova et al., 2012, 2014). An equally notable absence of heterotrophic taxa other than Brigantedinium sp. characterises the modern sediments of the Caspian and Aral Seas (see details in Sect. 5.2); this feature is also apparent in the low salinity "lacustrine" sediments of the early Holocene interval in Marmara and Black Sea cores. This absence may reflect a combination of higher bottom water oxygenation and lower availability of prey during intervals of isolation of the BSC from Mediterranean water inflow the strong vertical stratification breaks down as shown by lower organic carbon values $(<0.5 \%)$ and fewer geochemical tracers of anoxia (Mudie et al., 2002a; Slomp, 2013). An apparent link between the increase of oxidation-sensitive heterotrophs and eutrophication in late Holocene sediments of Marmara and Black Sea cores (Mudie et al., 2002a) needs more study in light of our new data on modern cyst distributions and bottom $\left[\mathrm{O}_{2}\right]$ conditions in the BSC.

\subsubsection{Morphological variation}

Several of our BSC atlas species descriptions and comparisons draw attention to an unusually large variation in cyst morphology that may be associated with the low salinity, stratified waters of the BSC region. The apparent link between cysts with distinctive cruciform endocysts and low salinity/brackish water was first noted by Wall and Dale (1973) and Wall et al. (1973) who documented a high degree of variability in endocyst shape for S. cruciformis and P. psilata (as 
Tectatodinium psilatum). Subsequently, Marret et al. (2004) and Leroy et al. (2006) reported further endocyst shape and surface ornament variations for $S$. cruciformis and $C$. rugosum cysts in the Caspian Sea. Many other Ponto-Caspian and Paratethyan taxa are characterised by either a sub-cruciform or sub-pentagonal endocyst shape and by highly variable development of septa and ectophragms (Popescu et al., 2009; Mudie et al., accepted 2016). The development of a distinctive cruciform endocyst shape and highly variable, often elaborate ornamentation (e.g. wide, perforate sutural septa; extreme variation in process length) are considered important features because they have been interpreted as reflecting morphological responses to salinity stress (Dale, 1996; Wall et al., 1973; Ellegaard 2000; Mudie et al., 2001). These taxa have been widely used as proxies for surface water salinity, sea level change, and marine-lacustrine linkages (e.g. Leroy et al., 2007; Londeix et al., 2007; Grothe et al., 2014), despite the previous lack of well-constrained data for their ecological distribution and salinity tolerance. Our distribution maps now provide precise ranges of SSS (Figure 63) and SST for these cruciform taxa and reveal that these "brackish water" indicators actually indicate a range of annual SSS from 5 to 20, with the seasonal range outside of freshwater lakes being SSS: (8.5)12.118.3(31.4) summer-winter for S. cruciformis.

[Figure 63. Salinity (A) and temperature (B) ranges for the 56 species and 169 sites retained for statistical analysis. Shaded areas show the minimum and maximum SSS values for each sea. * Azov Sea samples are in the Caspian Sea SSS range. Short vertical bars in Figure 63B mark the average annual SST values for the individual taxa.]

The endemic Ponto-Caspian species $P$. ponticum, I. inaequalis and C. rugosum also display a high degree of variation in cyst shape and/or wall surface relief although this is not clearly 
quantitatively correlated with SSS or other abiotic environmental parameters. Furthermore, in the $\mathrm{BSC}$, a high degree of variation in the process height and septa development has been observed in the cosmopolitan cyst taxa L. machaerophorum and O. centrocarpum sensu Wall and Dale 1966 (Wall et al., 1973; Mertens et al., 2012b; Jansson et al., 2014). Several other cosmopolitan species also show notably variable process lengths or morphologies in the BSC: A. choane, cyst of P. stellatum, S.belerius, S. bentorii, S. mirabilis and S. quanta.

The new atlas data provide the first records for the occurrence of 11 cosmopolitan, typically marine dinocyst taxa in low salinity, permanently stratified waters: cyst of G.nolleri/microreticulatum, Achomosphaera-Spiniferites septentrionalis complex, A.choane, B. cariacoense, B. simplex, cyst of Cochlodinium polykrikoides ss Li et al., D. caperatum, $S$. delicatus, S. bentorii, S. ramosus (possibly also S. hyperacanthus and S. hainanensis) and V. spinosum. However, this group of typically marine taxa does not display large morphological variations in shape or wall ornament in contrast to the Ponto-Caspian "brackish water" taxa. Of these widespread "marine" taxa now recorded for salinities much lower than global average of 35, four species belong to the euryhaline class erected by Londeix et al. (2007) for Messinian cyst assemblages in the central Mediterranean Sea: $S$. bentorii (in amounts $>2 \%$ of total cysts), $S$. membranaceus, S. mirabilis (amounts $>8 \%$ ) and S. ramosus.

5.2 Relationship between modern cyst distribution and oceanographic variables

The taxonomic standardisation provided by the BSC atlas surface sample data allows a refined linkage of the species assemblage composition with the oceanographic variables for 181 sites. Our data set covers the range of SST from $-0.2{ }^{\circ} \mathrm{C}$ (winter, Azov Sea) to $29^{\circ} \mathrm{C}$ (summer, southern Caspian Sea) and SSS values extending from 32 in the Marmara Sea to <10 in the Azov 
Sea and Anzali Lagoon, SW Caspian Sea (Figures 3 and 4). Exceptionally high values for the highly saline Kara-Bogaz Gol and post-1960s Aral Sea are not included because of their unstable nature and insufficient time-series data. The T-S diagrams (SST versus SSS) clearly show the different water masses distinguishing the seas (Figures 3C, 4I-L). In general, the 12 Marmara sites are distinguished by the highest SSS (20-32 winter maximum) and moderate relatively uniform SST values, with the widest range in summer $\left(\right.$ c. $\left.15-17^{\circ} \mathrm{C}\right)$, while the 51 Caspian Sea sites (excluding the Kara-Bogaz Gol, KBG) are distinguished by low SSS (5-13) with little seasonal variation and with high SST ranges: $0-13{ }^{\circ} \mathrm{C}$ winter and c. $22-30^{\circ} \mathrm{C}$ in summer. The KBG site is also distinguished by its low annual SST and high SSS. Three of the four Azov Sea sites cluster near the low salinity, cool end of the Caspian Sea values but the Kerch Strait site at the entrance of Black Sea water falls within the low salinity end of the Black Sea water mass. The 109 Black Sea sites (excluding Lake Razim south of Danube Delta) are all distinguished by intermediate SSS values (annual 15-18) with low variation (minimum 13, winter) and with annual SST values $\left(c .13-16^{\circ} \mathrm{C}\right.$ ) that largely overlap the lower end of the Caspian Sea water mass but are notably cooler in spring. Within the large set of Black Sea sites, some subregional variations are evident: most of the c. 50 NW Black Sea sites have cooler annual SST values of c. $13-15^{\circ} \mathrm{C}, \mathrm{SW}$ and NE sites are warmer $\left(\mathrm{c} .14-15.5^{\circ} \mathrm{C}\right)$ and have a smaller salinity range than the NW Black Sea; the four SE Black Sea sites are warmer (c. $15-16^{\circ} \mathrm{C}$ annually). The draftsman-plot data (Table 5) for the two-variable relationships between the 14 abiotic environmental variables indicate that a low correlation exists between annual SST and SSS values in contrast to relatively strong ties between seasonal values. Correlations among the physical SST and SSS parameters and the abiotic nutrients are also low. The relationships among the $\mathrm{P}, \mathrm{N}$ and $\mathrm{Si}$ nutrient concentrations, and $\left[\mathrm{O}_{2}\right]$ values are mostly very low $(0.07-0.44)$, with the highest value being 0.67 for $[\mathrm{P}]$ and $[\mathrm{N}]$. 
[Figure 64: Principal component (PCA) and non-metric multi-dimensional scaling analyses (nMDS) for abiotic and biotic data. A) PCA analysis results for the 181 sites based on 14 abiotic parameters (Table 4); B) nMDS plots based on Bray-Curtis similarities for the 169 assemblages with vector plots of abiotic parameters (Pearson correlation), and C) vector plots of species.]

The PCA results (Figure 64A) show that most of the variance of the 181 sites (excluding Aral Sea) is explained mainly by the first two axes, with the first axis (PC1) accounting for most of the variability (60.5\%), and PC2 for most of the remainder (22.5\%). SSSs are the main contributors to PC1, with coefficients varying between 0.356 for SSS-JAS and 0.460 for SSSJMF (Table 6). PC2 is explained by strong positive loadings of SSTs and a strong negative loading of [Si] (-0.695). The remaining abiotic parameters play little role in the distribution. This analysis clearly shows the influence of SST for the Caspian Sea samples, whereas SSS seems to have a greater control for sites in the Marmara and Black Seas. The RELATE (testing matched resemblance matrices) and BEST (Biota and Environment matching) analyses were also run to pinpoint which of the abiotic variables best explain the dinocyst assemblage distribution. A Rho of 0.62 was calculated between the two matrices, indicating a relatively strong similarity between the distribution of the biotic and abiotic variables. The BEST analysis shows that of the 14 abiotic variables, the strongest relationship (0.73) is explained by SSTY, SST-AMJ, SSTJAS, SSS-JAS, SST-OND and bottom oxygen concentration. The [Si] does not appear to have an influence on the pattern of dinocyst assemblages.

[Tables 5 and 6 go here] 
The shade plot of square-root transformed cyst relative abundances (Figure 65), including 58 taxa (Table 1) and 172 of the 185 sites, demonstrates the overall dominance of $L$. machaerophorum s.l. in the Marmara, Black and Azov Seas (counting for up to 27\% of the total assemblages) whereas L. machaerophorum with short processes and I. caspienense dominate assemblages in the Caspian Sea, respectively making up $14 \%$ and $10 \%$ of the total assemblages.

[Figure 65 goes here. Shade plot of square-root transformed cyst relative abundances, with 172 sites sorted according to their geographical sector. The 58 species are ranked according to their overall relative abundance.]

The nMDS analysis on the 169 assemblages and 56 species (Figure 64B) clearly shows grouping of samples in relation to specific abiotic environments, with the Caspian Sea assemblages having little in common with the rest of the BSC. Assemblages in the MarmaraBlack Sea basins form three clusters, with an opposition between smaller southwestern and northeastern clusters, and a large main group mostly comprising assemblages from the NW and the Marmara Sea. The W-E opposition is controlled mainly by the relative abundance of $L$. machaerophorum s.l. which is higher in the west whereas large occurrences of Alexandrium cysts, O. centrocarpum, S. ramosus, S. mirabilis and cyst of Scrippsiella spp. dominate assemblages in the eastern part of the basin. This west-east gradient is particularly interesting as it suggests that, although SSS is a major factor, SST also exerts a strong influence on the species distribution; indeed species which are usually occurring in salinity above 30 , seem to survive well in this low salinity (c. 18) environment where the annual SST is above $17.5^{\circ} \mathrm{C}$ and is above c. $24{ }^{\circ} \mathrm{C}$ in summer. 
The percentage distributions of the most dominant taxa amongst the 169 sites (Figure 66) clearly document the euryhaline character of L. machaerophorum s.1. whereas I. caspienense is strictly restricted to the Caspian Sea. Interestingly, forms of L. machaerophorum with short processes are highly abundant in the Caspian Sea, which confirms the influence of lower saline conditions on process length (Mertens et al., 2012b). The most significant accompanying species, in decreasing order of importance, are: O. centrocarpum, Brigantedinium spp., cyst of Scrippsiella spp., S. ramosus and cyst of Alexandrium sp. The bubble plots of these species show the strong dominance of I. caspienense in the eastern basins and the Azov Sea, and the confinement of most of the other dominants to the western basins. It is notable that Brigantedinium spp. is the only widely-occurring heterotrophic species in the Caspian area. It is also noteworthy that the "marine" species L. machaerophorum is present in amounts up to $25 \%$ in the brackish Caspian Sea (ca 50\% in the Kara-Bogaz Gol) and in the brackish to saline waters of the Aral Sea; this species is usually considered to be an indicator of marine connections in marginal seas (Filipova-Marinova. 2006; Popescu et al., 2009; Giosan et al., 2012; Suc et al., 2015). Our new observations show that it is essentially ubiquitous except in low salinity limans (coastal lagoons) of the NW Black Sea (Lister et al., 2015).

[Figure 66: Bubble-plots overlying the nMDS plot of the 169 assemblages in Fig. 65B and showing the geographical distributions and relative abundances of the most dominant species in the BSC.]

In contrast to the large-scale BSC study, PCA for 26 dinocyst taxa at 16 sites from the Aegean to SE Black Sea (Mudie et al., 2004) shows that an assemblage dominated by cysts of autotrophic gonyaulacoids distinguishes the Aegean Mediterranean water (SSS 31-38) but 
heterotrophic protoperidinioids characterise the low-salinity Marmara-Black Sea water (SSS 14-25), including cysts of $P$. stellatum, $S$. quanta, $P$. reticulata, $Q$. concreta, I. minutum, $P$. ponticum, P. schwartzii, Alexandrium cyst, S. bulloideus and S. cruciformis. The latter group could also be broadened to include the ubiquitous species Brigantedinium spp.

L.machaerophorum, S. bentorii and S. membranaceus. In the Gulf of Gemlik, Marmara Sea, a Canonical Redundancy Analyis (RDA) of 34 cyst taxa at five sites shows the dominance of average SSS followed by SST, then water depth and dissolved surface water oxygen; here a weak relation to [Si] and other nutrients (Balkis et al., 2016) was also found. In the Gulf of Gemlik, L. machaerophorum, O. centrocarpum and S. quanta, dominate the dinocyst assemblages but are not strongly influenced by the dominant variables. However, several taxa are strongly related to seasonality and water depth (from 50-100m): B. simplex, cyst of $P$. stellatum, cyst of S. trifida, cyst of S. trochoidea, P. minutum, Q. concreta, S. mirabilis, and T. pellitum; less commonly affected are several heterotrophic species: cyst of $P$. kofoidii, cyst of $P$. hartmannii, Brigantedinium spp., cyst of D. lenticula, T. applanatum and V. calvum.

The cyst concentrations in the BSC samples (Figure 68) are not simple to interpret because they are based on dry sediment weight (cysts/g) for the Marmara, Black and some Aral Sea samples, but are based on wet weight (cysts/ml) for Caspian Sea and two Aral Sea sites. Furthermore, concentration values were not determined for many deeper water Black Sea samples and all the Azov sites. In general, no large differences in cyst concentration are found among the BSC seas, with values of $10-20 \times 10^{3}$ cysts occurring at most sites. However, higher cyst concentrations of $40-60 \times 10^{3} / \mathrm{g}$ are common on the NW Black Sea Danube Shelf in the discharge plume of Danube River where there is also a major peak of $135.25 \times 10^{3}$ cysts $/ \mathrm{g}$. Intermediate values (c. $20-40 \times 10^{3}$ cysts/g) are common in deeper water areas the Black Sea; these amounts in part reflect the lower sedimentation rates measured at these sites (e.g. Mousing 
et al., 2013). In the Caspian Sea, the distribution of sites with higher cyst concentrations is more patchy (Figure 67B) and values are generally $<35 \times 10^{3} \mathrm{cyst} / \mathrm{ml}$. In the high sedimentation rate Aral Sea, cyst concentrations are mostly low (<1000 cyst/g or ml except at the northwestern site with a high value of c. $170.2 \times 10^{3}$ cyst $\left./ \mathrm{ml}\right)$.

[Figure 67: Map showing concentrations of total dinocysts in surface sediments of the BSC. A. Number/g dry weight; B. number/ml wet sediment.]

Comparison of cyst concentrations and bottom oxygen values (Figure 5D) is unfortunately limited in our data set because of missing values for many deep water sites. In the Black Sea, however, higher cyst concentrations tend to occur in deeper outer-slope sites, but peak abundances are found in the well-ventilated NW shelf sites. The ratio of photosynthetic (P) to heterotrophic $(\mathrm{H})$ cyst taxa $(\mathrm{P} / \mathrm{H}$, Figure 68$)$, where mixotrophs are grouped with the photosynthesing autotrophs) shows consistently high values $>0.6$ for the well-ventilated Caspian and Aral Sea sites, and perhaps points to lower preservation of thinner walled heterotrophic taxa such as cysts of Protoperidinium spp. (e.g Brigantedinium) and more oxidation-sensitive Spiniferites cysts in these inland seas. In the Marmara Sea, $\mathrm{P} / \mathrm{H}$ values are mostly low as expected for waters with high [chl.-a] values reflecting phytoplankon abundances that would favour production of predatory heterotrophs, and where low bottom $\left[\mathrm{O}_{2}\right]$ conditions favor preservation of their cysts. In contrast, however, consistently high $\mathrm{P} / \mathrm{H}$ ratios were found at five sites in the NE Gulf of Gemlik at all seasons when cysts were extracted by ultrasonification and sieving only (Balkis et al., 2016). Similarly Aydin et al. (2015) report autotrophic: heterotrophic ratios of $>0.7$ for four SW Black Sea shelf sites and 1.0 for two Dardanelles (a.k.a. Çanakkale) Strait sites. 
[Figure 68. Map showing distribution of ratios for cysts with motile taxa having autotrophic/photosynthetic $(\mathrm{P})$ versus heterotrophic $(\mathrm{H})$ modes of nutrition $(\mathrm{P} / \mathrm{H}$ ratio). Here the autotrophic photosynthetic taxa are grouped with mixotrophic motile taxa (Table 1) as the category P.]

In the Black Sea, most $\mathrm{P} / \mathrm{H}$ values are above 0.8 but two areas of low values occur. One area, as expected, is associated with deeper anoxic water in the central eastern region. The other area is in the relatively well-oxygenated water of the western shelves that are strongly influenced by Danube runoff and where intense cross-shelf mixing supports high $[\mathrm{P}],[\mathrm{N}]$ and $[\mathrm{Si}]$ levels (Figure 5). Here maxima of DOM and POM occur (Saliot et al., 2002) and very large spring diatom blooms are sustained by the high [Si] concentrations of the river water despite dam construction retaining larger amounts of sediment after c. 1972 (Grégoire et al. 1998; Lancelot et al., 2002; Mousing, 2013; Giosan et al., 2012).

\subsection{Biodiversity and plankton-cyst relationships}

\subsubsection{Sub-regional variations in diversity of modern cyst assemblages}

Traditionally, the flora and fauna of the Black Sea, the largest BSC basin, are considered to be distinguished by low species richness and diversity but relatively high productivity (Shiganova and Öztúrk, 2009). In part, the low taxonomic diversity has been attributed to the absence of deep water species in the anoxic zone below the pycnocline (125-200 m). However, recent investigations show the need to re-consider these perceptions for the Black Sea phytoplankton diversity, based on updated taxonomy and improved field and laboratory observations 
(Krakhmany et al., 2012). The results of the statistical analysis for 58 dinocyst taxa in 169 samples now reveal that the cyst diversity in the BSC surface sediments ranges widely from a monospecific assemblage (I. caspienense in the SW Caspian Sea, Elet site) to 33 taxa in the SE Black Sea (Figure 69). In general, there is no relationship between cyst abundance (per gram, or per $\mathrm{ml}$ ) and species diversity: $\mathrm{R}^{2}$ values are less than 0.01 for both sets of abundance estimates, but notable inter-basin differences occur in species diversity.

[Figure 69. Distribution of various measures of cyst biodiversity in the BSC: A) Species diversity (number of cyst taxa per site; B) species richness (Margalef d index) for 58 taxa at 169 sites; and C) Pielou's Index of evenness for the same data set.]

Excluding the Elet (a.k.a Alat) site on the SW coast of Caspian Sea, the lowest species diversity (9 taxa) and Margalef richness $(d<2)$ are found in the Caspian and Aral Seas, where the evenness ranges from 0.2 to 0.8 , led by variations in abundance for the two major taxa, $I$. caspienense and L. machaerophorum (including all its morphotypes). Two northern, low salinity sites in the NE Azov Sea near the Don River estuary show similar low richness and evenness values as the Caspian and Azov Seas. Two sites in the SW Black Sea north of Bosphorus Strait record the lowest evenness score of the dataset, and also have relatively low species richness (d <3) compared to other sites in the Black and Marmara Seas. The highest richness is found in the southeastern basin of the Black Sea, which may be explained by slightly higher SSTs compared to the western basin. When correlated with abiotic parameters (Table 5), the diversity indices show the strongest relationships with SST and SSS $\left(r^{2}>0.60\right)$ and low correlation with the other abiotic parameters. Sites from the northwestern BSC show a strong range in diversity and evenness that may be explained by the wide shelves and large rivers discharging into this basin, 
resulting in large nearshore-offshore gradients of seasonal SSS, nutrients and diatom blooms (Grégoire et al., 1998; Saliot et al., 2002; Yanko-Hombach et al., 2017). Lazăr et al. (2013) also note that runoff from the Danube and Dniester Rivers transports freshwater species onto the shelves where some of them can survive in the low salinity marine water, adding to species diversity.

In general, however, there appears to be surprisingly little diversity contribution from cysts of truly freshwater species in the BSC. Our dinocyst data do not support the idea of Dumont (1998) that in the Caspian Sea, Ponto-Caspian species of "marine" origin (as opposed to river origin) are adapted to not only marine salinities but also to low SSS down to 13 whereas true "marine" species cannot tolerate such low salinities and become relict species. The problem with Dumont's idea is his use of a salinity classification that is excessively broad in defining species of freshwater origin as tolerant of salinities up to 13 and species of marine origin as being tolerant of salinities as low as 13. In contrast, Mudie et al. (2011) have shown that in the BSC, a much narrower range of salinities should be assigned to the categories "freshwater" (0-2) and "brackish" water (ca. 2-11 or 12). Excessively wide use of the category "freshwater" has been a source of fundamental confusion in interpreting and understanding the history of the Black and Marmara Seas. For example, the broad use of "freshwater" for the lacustrine phase of the Black Sea (Wall et al., 1973) generated the hypothesis of early agriculture on exposed non-saline shelf areas of the Black Sea. The term "freshwater" is still mis-applied to some Ponto-Caspian fossil assemblages although we now have ample evidence for brackish water (ca. 2-11/13) during the entire lacustrine phase of the Black Sea (Mudie et al., 2001; Marret et al., 2009; YankoHombach et al., 2013). It would be retrogressive and add further confusion in paleoceanography to classify most BSC dinocysts as either of freshwater or of marine origin; possible exceptions are the cysts of Biecheleria, Peridinium cf. willei and cf. Peridinum inconspicuum of Brenner 
2005 which belong to taxa that are normally most abundant in freshwater lakes/delta ponds. Use of the excessively broad Venice system (ASLO, 1958), a "marine" classification for dinocyst species in synthetic paleoecological records to separate marine from lacustrine phases and to deduce sea-level transgression also tends to result in over-interpretation of minor dinocyst assemblage changes.

[Table 5 goes here - biodiversity abiotic parameter correlation]

Our BSC dinoflagellate cyst database is presently biased by patchy sampling of many nearshore inner shelf areas of the Marmara and Black Sea, by a restricted number of sites for the deep basins of the Black Sea, and by very limited data for the Azov, Aral and the northern Caspian Seas. In a few upper slope areas of the Black Sea, below $600 \mathrm{~m}$ water depth, the high percentage values of some of the typical "Caspi-brackish" species (e.g. S. cruciformis and $P$. psilata) raise questions about possible reworking of lacustrine-stage sediment at sites of submerged mud volcanoes or fresh-water venting in paleodeltas (see Shnyukov, 2013) and in shifting deltaic environments. However, benthic foraminifera from the same box-core samples are typical of the modern slope assemblages (Yanko-Hombach, personal communication May 2015), and our HERMES samples (H in Table 4) do not include any mud volcano sites.

Despite the sampling limitations, some regional comparisons may be warranted. Outside of the two deep SE basin samples with richness values of 6.2, the greatest dinocyst species diversity $(\mathrm{S}=15-32)$ is in the western Black Sea off the Danube Delta. There the shelf is wide and it is characterised by large inter-annual fluctuations of seasonal surface salinity and detrital organic matter; nutrient concentrations are also high because of decadal-scale spring floods that are retained on the shelf by quasi-persistent cyclonic gyres and periodic strong cross-shelf mixing 
(Grégoire et al., 1998; Saliot et al., 2002; Lazăr et al., 2013; Yanko-Hombach et al., 2017). In this area, the dinocyst species diversity decreases towards the coast where strong currents and mobile sandy sediments probably limit cyst deposition in addition to low salinities and periodic winter ice formation. On a smaller scale, a similar nearshore-offshore gradient occurs in the Marmara Sea where species diversity is the same (15-32) in our sample set; however, diversity is slightly higher $(\mathrm{S}=34)$ in highly polluted embayments such as the Gulf of Gemlik, NE Marmara Sea. This area is one of the most contaminated sectors of the BSC (Balkis et al., 2016) and is the hub of waste discharge from large international cargo liners that cannot transit the shallow Bosphorus Strait (Dobler, 2002). Species diversity appears to be lowest in the Aral Sea that has the most unstable environment and is also the most isolated basin with respect to potential import of taxa by shipping.

Unexpectedly, the atlas data show that despite the long history of intermittently connected basins, which is reflected by a high degree of endemism for the ostracod benthic fauna of the BSC (Boomer, 2012), the modern Ponto-Caspian dinocyst flora is not largely different from the adjacent Mediterranean marine region. Furthermore, the Black and Caspian Seas share many dinocyst taxa, and the young Aral Sea apparently does not have any strictly endemic taxa that produce resting cysts. Some important implications of these differences may be that 1) phytoplankton occupying the surface water layer of these inland seas tends to be less segregated than the more sedentary benthos and hence less prone to evolutionary divergence; 2) resting cyst formation in dinoflagellates is a critically important strategy for resistance to fluctuating adverse forces that promote evolutionary divergence in benthic meiofaunas.

\subsubsection{Dinoflagellate plankton-cyst linkages}


The BSC atlas database provides the first attempt at a synthesis of the dinoflagellate resting cyst and motile plankton records for the entire Ponto-Caspian region (Table 3B). Accurate linkage between benthic resting cysts and their motile phytoplankon stage in the surface water is essential to enable the living cysts in modern sediments to be used for prediction of the seasonal appearance of motile stages in the water column, for testing of deduced molecular phylogenetic relationships of fossil cysts, and calibration of molecular clocks in the geological record (Matsuoka and Head, 2013). Full understanding of cyst-motile stage linkages is also needed for accurate interpretation of paleocological and paleoproductivity records.

For the Black Sea, which is largest BSC sub-region, Krakhmalny et al. (2012) listed 456 motile dinoflagellate species for the phytoplankton (as 467 varieties and forms) but they did not provide species names that could be used to check the systematic assignments. In contrast, the earlier checklist of Gómez and Boicenco (2004) listed 267 species, including primarily freshwater taxa that are capable of surviving offshore. About one-third ( 89 species) of these 267 taxa were noted to be uncertain identifications, leaving only 178 confirmed taxa. Török (2009 and personal communication, 2015) further listed 70 motile dinoflagellate taxa for the Danube Delta, of which 31 taxa were reported by Gómez and Boicenco (2004), leaving a net addition of 39 taxa for a confirmed Black Sea total of 217. In addition, 16 other Mediterranean motile dinoflagellate species have been documented as arriving in the Black Sea between 1960 and 1993 (Shiganova and Öztürk, 2009), bringing the conservative total to 233 motile taxa (Table 3B). The Black Sea dinoflagellate records extend back to 1886 when 19 taxa were first recorded off Sevastopol on the Crimean Peninsula southeast of the Dnieper Estuary (Krakhmalny et al., 2012). From 1950-1969, a total of 177 species and intra-specific taxa were recorded, followed by an additional 48 taxa in the period of strong eutrophication from 1970 until late 1998 when dinoflagellate populations exceeded those of diatoms (Mee et al., 2005). After 1998, however, 
diatoms and/or other phytoplankton taxa again greatly exceeded dinoflagellate populations. Gómez and Boicenco (2004) considered that all but three of the 267 species recorded for the Black Sea up to 2003 are cosmopolitan taxa. In contrast, Shiganova and Öztürk (2009) reported that a total of 39 new Mediterranean motile dinoflagellate species arrived in the Black Sea between 1960 and 1993.

Most of the Black Sea dinoflagellate taxa are also present in the much smaller Marmara Sea where 45-85 taxa were reported for samples collected between 1998 and 2011 (Balkis, 2004; Balkis et al., 2016; Balci, 2013; Deniz and Taş, 2009). In contrast, from 1968 to 2003, only 44 motile dinoflagellate taxa were recorded for the Caspian Sea (Gogorev, 2015), although its area is almost as large as that of the Black Sea (Table 2). Bagheri and Fallahi (2014) reported fewer (23) taxa for 1996-2010, possibly indicating a recent decline in dinoflagellate taxa (21 spp.) following a large rise in Cyanophyta (Nasrollazadeh et al., 2008; 2011). Bukatov (in Leroy et al., 2006) reported only 12 dinoflagellate taxa for the plankton of the Kara-Bogaz Gol. In the Azov Sea, including the Don Estuary (Taganrog Bay), Zenkevitch (1963) reported the presence of 52 Peridineans (27.7\% of the phytoplankton) in comparison to $18.6 \%$ blue-green cyanophytes. Kosarev et al. (2007) noted that dinoflagellates (as pyrophytes) and blue-green algae comprise $95 \%$ of the phytoplankton. In contrast, Matishov et al. (2012) reported relatively low volumes of Azov Sea dinoflagellates, including blooms of Katodinium, Gymnodinium japonica var. throndseni Konovalova, Gymnodinium blax Harris (= Katodinium fungiforme (Anissimova) Fott, Glenodinium quadridens (Stein) Schill. (= Peridiniopsis quadridens (Stein) Bourrelly, Dinophysis acuminata Claparède and Lachmann, Diplopsalis lenticula Bergh., Scrippsiella trochoidea (Stein) Balech, and show relative amounts of c. 3-5\% in 2006 phytoplankton populations dominated by chlorophytes and diatoms. 
Comparable data on motile dinoflagellates in the Aral Sea are not available because of the scarcity of data and the volatile natural and anthropogenic changes that have occurred over the past century. Ostenfeld (1908) listed 10 taxa for historical records when the sea was at its greatest size. Orlova and Rusakova (1999) list eight taxa for northern Aral Sea in 2003, but Mirabdullayev et al. (2004) gave a range of 15 (1925) to 28 (1967-1974), decreasing to only three species by 2004 when the cyanophytes Oscillatoria woronichinii Anissimova (a cosmopolitan halophile), and Anabaena bergii Ostenfeld (now Chrysosporum bergii (Ostenfeld) E. Zapomelová, O. Skácelová, P. Pumann, R. Kopp and E. Janecek, (a brackish species) became dominant. This low number is the result of rapid dessication and salinity increase. Here we select the maximal numbers for comparison of motile stage and resting cyst populations in Aral Sea (Table 3A).

Most reports that compare dinoflagellate motile and resting cyst species diversity (e.g. Dale, 1976, 2009; Head, 1996; Leroy et al., 2006) indicate that only about $10-20 \%$ of marine dinoflagellates produce resting cysts, and about 84/350 (24\%) of motile freshwater dinoflagellates produce resting cysts (Mertens et al., 2012d). A larger proportion of cystproducing dinoflagellates are found in most of the low salinity BSC basins (Table 3B), particularly where the largest mixing of marine and fresh water occurs, as in Marmara Sea (estimated 39-50\% cysts), Azov Sea (36\%) and the Black Sea (30\%). A relatively lower proportion of cysts are found in the Caspian Sea (20\%) and using the maximum motile species diversity reported for Aral Sea, the proportion (10\%) is essentially the same as most of the world's oceans.

Most of the dinoflagellates in the BSC are cosmopolitan species that have entered from the Mediterranean Sea (Gómez and Boicenco, 2004). Comparison with the Mediterranean motile dinoflagellate flora indicates that biodiversity of free-living motile dinoflagellate species is 
higher in the more saline Mediterranean waters, with 673 species (Gómez, 2003), despite the much lower phytoplankton productivity of that region. However, because the Black Sea is ca 5.5 times smaller than the Mediterranean Sea, its motile dinoflagellate species diversity is remarkable. It is also notable that in the Mediterranean region, dinoflagellate species diversity generally diminishes from west to east - 498 taxa in the Ligurian Basin off Spain to 182 in the Aegean Sea — but in the Black Sea, the largest estimate (456) of Krakhmaly et al. (2015) is almost as high as the Ligurian Basin. The percentages of taxa represented by cysts in the surface sediments of the western basins of the BSC (30-59\%) are similar to or higher than values of $30-40 \%$ reported for other coastal sites (Dale, 2009).

In addition to the above comparisons based on published reports, Appendix $\mathrm{C}$ provides a new updated list of motile dinoflagellate species (mostly planktonic taxa but including some benthic taxa) as compiled from the available literature, using updated taxonomic treatments and current species names according to AlgaeBase (although excluding detailed synonymy and authorship of all synonyms). The updated taxonomic list of motile dinoflagellates in the BSC (Appendix C) suggests some previously unreported patterns in distribution. A total of 503 primary taxa (i.e. excluding the synonymous varieties) are reported here, of which about half ( $n=276)$ occur in the Black Sea. Only four motile taxa have been reported for all five of the seas and for Danube Delta. Six taxa occur in all subregions from Marmara to the Caspian Sea, and nine taxa are shared among the Black, Caspian and Aral Seas. Thirty taxa are shared by the Black Sea and the Danube Delta which has the largest proportion (39/70 taxa) of species apparently restricted to any of the six listed subregions. In contrast, the low salinity Azov Sea with 24 listed species shares only three taxa with the Danube Delta compared to $71 \%$ shared with the Black Sea. The Marmara, Caspian and Aral Seas have about 16-21\% of their species not shared with other subregions of the BSC although very few of these are endemic to the individual seas (Table 3B). 
5.4. Invasive Non-Indigenous species (NIS) and Harmful Algal Blooms (HABs)

Most previous studies of dinoflagellate cysts in the BSC have focussed on long-term changes in assemblage composition as a response to temperature, salinity and sea-level changes during the last glacial-interglacial cycle. The succession of cyst arrivals has largely been tied to changes in surface salinity related to shifts in hydrography (Leroy et al., 2014), global sea-level rise (Mertens et al., 2012b), Greco-Roman colonisation (Marret et al., 2009; Bradley et al., 2012), and increased eutrophication (Mudie et al., 2002a; Ivanova et al., 2014). Gómez and Boicenco (2004) further suggested that the paucity of endemic motile dinoflagellate taxa (Table 3B) can be explained by the fact that the quasi-enclosed Black Sea basin only came into contact with the world's oceans through the Bosphorus-Dardanelles Strait c. 12,000 yr BP. However, a low number of endemics is evident in the BSC plankton as a whole (Table 3A), with the notable exception of the Caspian Sea zooplankton (Table 3A).

Despite concern about the impact of invasives (= harmful non-native species) and the role of dinoflagellates in the recent eutrophication and trophic collapse of the Black Sea ecosystems (Sorokin, 2002; Mee et al., 2005; Llope et al., 2011), only one study (in the Marmara Sea) has investigated the linkages between cyst occurrences, motile dinoflagellate Non-Indigenous Species (NIS), and the potential occurrences of harmful algal blooms (Balkis et al., 2016). The new atlas data provide the opportunity to explore these topics on a broader scale, as applied to the whole BSC, not just the Marmara Gateway. In discussing harmful algal blooms, we include here certain non-toxic bloom-forming species in addition to the noxious species listed in Table 1. In Appendix C, the updated list of motile dinoflagellate species (mostly planktonics but including some benthic taxa) shows the HAB species reported by Gómez and Boicenco (2004). 
The International Oceanographic Commission (IOC) defines Harmful Algal Blooms (HABs) as "phytoplankton blooms, micro-algal blooms, toxic algae, red tides, or harmful algae that are naturally occurring phenomena which periodically form mass occurrences called blooms". The blooms of HABs, unlike normal population increases, are harmful because they cause benthic dead zones, water discoloration and a bad smell that is harmful to fishermen and tourist industries. A HAB species is considered harmful when their proliferation can cause massive fish kills, contaminate seafood with toxins, and alter ecosystems in ways that are considered destructive. The IOC classification of HABs distinguishes two groups of organisms: toxin producers that contaminate seafood or kill fish, and high-biomass producers that kill marine life when dense concentrations cause anoxia. About 29\% (87) of the total IOC-listed HABs are dinoflagellates, of which about one fourth (21 species/varieties) are also toxic.

A large general literature is available on recent biological invasions of alien, non-indigenous species (NIS) in the low salinity Black, Caspian, Azov and Aral Seas (e.g. Zaitzev and Mamaev, 1997; Sorokin, 2002; Grigorovitch et al., 2003; Dumont et al., 2004; Nasrollahzadeh et al., 2013, Beauchard et al., 2014; Micklin et al., 2014), as summarised earlier in Table 3A. Much less information is available for the Marmara Sea where detailed studies of the plankton only started after 1990 (Balkis et al., 2016; Taş et al., 2016). Of greatest concern has been the catastrophic, cascading trophic collapse of ecosystems in the Black Sea — the world's largest meromictic system and "natural laboratory" for study of marine ecosystem dynamics (Llope et al., 2011). Here, eutrophication and ecological instability, possibly triggered by overfishing, resulted in replacement of diatom-dominated phytoplankton populations in the pre-1960s by dinoflagellatedominated assemblages and more frequent dinoflagellate HABs, including five of the 18 cystproducing HAB species listed in Table 1: Alexandrium pseudogonyaulax, Alexandrium spp., Cochlodinium polykrikoides, Lingulodinium polyedra and Scrippsiella trochoidea. 
Mousing et al. (2013) investigated the last 150 year history (1850-2000 CE) of diatoms and dinoflagellate cyst production in short cores (25-MUC-2 and 22-MUC-1) from the SE Black Sea. They correlated post-1960 changes in abundance and assemblage composition of diatom and dinocyst populations with increased nutrient loads from the Danube River discharge which is transported southeastwards by the Rim Current (Figure 2). No NIS dinoflagellates were identified; however, two species of the heterotrophs Cochlodinium and Protoperidinium increased after 1960, and an unknown Spiniferites sp. appeared in large numbers after 1980. The deep water core shows increases in cysts of the HAB species L. polyedra and S. trochoidea after 1960. However, a deeper water core BC53 shows a different succession of species, with relatively low amounts of $L$. polyedra cysts only replacing the cysts of Scrippsiella spp. at the top of the core. In Gelendzhik Bay (NE Black Sea), Ivanova et al. (2014) looked at dinocyst population changes over the past 140 years in core Ash-8. They found a gradually increasing abundance of heterotrophic dinoflagellate species that suggests a nutrient increase starting in the 1920s. Potential HAB species Protoceratium reticulatum and Gymnodinium catenatum (here including G. nolleri, a non-HAB species) increased after c. 1930 and 1955, respectively. No identifiable NIS dinocysts occur at this site, but the Spiniferites sp. include a distinctive morphotype not found elsewhere in the BSC.

In the formerly oligotrophic southern Caspian Sea, the introduction of the predatory combjelly Mnemiopsis leidyii by 1999 was followed by massive outbreaks of algal blooms by 2002 in all areas with salinity >4 (Dumont et al., 2004); these blooms included the dinoflagellates Heterocapsa triqueta and Prorocentrum spp. (Ramezanpour et al., 2011; Baghieri et al., 2012). These dinoflagellates do not form degradation-resistant cysts; therefore, it is not possible to trace their history from sediment cores. In contrast, L. polyedrum contributed significantly to the 2009 bloom (Nasrollahzadeh et al., 2011, Leroy et al., 2013a). Of the 44 motile dinoflagellate taxa that 
have been listed for the entire Caspian Sea (Gogorev, 2006), including the Volga Delta and Kara-Bogaz Gol, seven species produce cysts in addition to Scrippsiella plana which appears to be the only NIS in the Caspian Sea. This NIS may have been introduced from either the NW Pacific or eastern USA according to the present information on its distribution (Luo et al., 2016). The seven other cyst-producing motile taxa are Gonyaulax digitale, Gonyaulax spinifera, Lingulodinium polyedra, Peridinium cinctum, Parvodinium umbonatum, Preperidinium meuneri and Scrippsiella trochoidea. It is notable that of this potential dinocyst-producing flora, only the cyst of L. polyedra (= Lingulodinium machaerophorum) is actually present in the 56 surface samples and cores from the Caspian and Aral Seas except for one sample from the Aral Sea that also includes the cyst of $G$. digitale (= Spiniferites bentorii). Furthermore, L. polyedra, a potentially toxic HAB species, does not always occur in the recent Caspian Sea algal blooms although cyst concentrations have increased greatly with rising SST and eutrophication (Leroy et al., 2013a). It is also notable for this inland sea that widespread and common occurrences of resting cysts for many taxa (e.g. Pentapharsodinium dalei, Gonyaulax scrippsae and Scrippsiella trochoidea) are not recorded in the phytoplankton censuses. This anomaly points to the need for more phytoplankton survey data and more precise identification for motile dinoflagellates and small spherical non-calcareous cysts like those of Scrippsiella plana where combined SEM and biomolecular studies were needed for determination of the cyst identity (Luo et al., 2016).

The magnitude of the $20^{\text {th }}$ century NIS trophic web impacts in the Black Sea triggered major international efforts to increase monitoring of phytoplankton biodiversity and changes in this western BSC "natural laboratory", with the aim of developing models for predicting the timing and locations of HAB outbreaks (Beauchard et al., 2014). Because the smaller Marmara and Azov Seas are the gateways for potential introduction of NIS and HABs, from 2007-2013, these adjoining regions of the Black Sea were also included in the monitoring program. The resulting 
new Black Sea biodiversity census potentially increases the 2002 total phytoplankton value (Table 3) from 350 to about 1,608 species, of which up to $40 \%$ (643) are dinoflagellates compared with the Table 3B estimate of 233-456 taxa. The new census includes 20 potentially toxic dinoflagellate species although few toxicity cases have been reported in the region, involving Alexandrium minutum, Prorocentrum lima, Prorocentrum minimum and Lingulodinium polyedra (Velikova et al., 1999; Koray, 2004; Vershinin and Yu, 2008; Nesterova et al., 2009 and Russian references therein; Turkoglu, 2013; Kalinova et al., 2015). Vershinin et al. (2006) reported occurrences of Alexandrium tamarense and Alexandrium minutum on the NE coast of the Black Sea during the years 2000 to 2004. Streftaris et al. (2005) list A. tamarense as a non-indigenous species recently introduced to the Black Sea.

The new large phytoplankton census number is attributed to 1) improved sampling strategy and frequency; 2) better research microscope quality; 3) fluctuating (decadal-scale) environmental changes in SSS and SST, plus longer-term trends in nutrient and bottom oxygen levels; and 4) the introduction of NIS. More than $68 \%$ of the NIS taxa in the Black Sea are listed as originating from the North Atlantic, 13\% from the Indo-Pacific and 8\% from the Western Pacific; the discharge of ship ballast waters is considered the primary factor. The European NIS database DAISIE lists the following alien Black Sea dinoflagellates: Alexandrium affine, Alexandrium minutum, Alexandrium pseudogonyaulax, Ceratium candelabrum, Cochlodinium polykrikoides, Gymnodinium catenatum, Noctiluca scintillans, and Prorocentrum minimum.

The Marmara Sea is characterized by high levels of industrial waste pollution and sewage effluents that are discharged into the relatively small sea where large and often prolonged phytoplankton blooms occur (Tüfekçí et al., 2010; Beauchard et al., 2014; Balkis et al., 2016). Toxic and harmful blooms became more widespread here and in the Black Sea during and after World War II (Nümann, 1955), increasing from only a few species of harmful dinoflagellates 
(Acara and Nalbantoglu, 1960) to 14-18 toxic/nuisance species in 2005 (Koray, 2004; Akton, 2005). Most of these HAB species (12/14) are dinoflagellates: Ceratium furca, Dinophysis acuminata, Dinophysis acuta, Dinophysis caudata, Dinophysis sacculus, Akashiwo sanguinea, Lingulodinium polyedra, Noctiluca scintillans, Phalacroma rotundatum, Prorocentrum lima, Prorocentrum micans, and Prorocentrum minimum. Of these taxa, only L. polyedra produces a degradation-resistant cyst. Balkis et al. (2016) reported the additional occurrence of Alexandrium minutum, Alexandrium sp. and Heterocapsa triqueta in Gemlik Bay, NE Marmara Sea. Starting in 2007, there have been major blooms of Noctiluca scintillans (Turgoklu, 2013) in the Marmara Sea and extensive areas of mucilage formation with associated widespread occurrences of Gonyaulax fragilis (Tüfekçí et al., 2010; Taş et al., 2016). In contrast to the Black Sea invasives, the NIS in the Marmara Sea are reported as comprising a higher proportion of West Pacific species (33\%), a relatively lower proportion of North Atlantic (34\%) and Indo-Pacific (11.4\%) species, plus $11.3 \%$ East Atlantic species, and one non-toxic HAB diatom Rhizosolenia calcaravis introduced from the Black Sea (Beauchard et al., 2014). For the Marmara Sea alone, no new records are available for the total number of phytoplankton species because the census total of 815 microalgae includes benthic taxa and it combines all data for the entire Turkish coastal area from Aegean to SE Black Seas. Cysts of non-toxic HAB dinoflagellates Alexandrium cf. affine, Alexandrium tamarense, Alexandrium spp., Cochlodinium sp., Gymnodinium catenatum/nolleri, Heterocapsa triqueta, and Scrippsiella trochoidea, and the potentially toxic Protoceratium reticulatum and Pyrodinium bahamense are reported from sediment surveys in Gemlik Gulf although these have not been identified in the plankton samples (Balkis et al., 2016). Most of these HABs are also reported by Aydin et al. (2015) for the Black Sea shelf near the Bosphorus entrance and/or the Dardanelles Strait entrance from the Aegean Sea. In these regions, however, cyst concentrations are low compared to the Aegean Izmir Bay and Homa Lagoon. 
Although the recent intensive plankton surveys point to a large increase in NIS within the western BSC since 2002, caution with this interpretation is needed; hence we have retained the more conservative numbers for the data in Table 3. Gómez (2008) stresses that the new NIS census numbers are overinflated for several important reasons: 1) a tendency for taxonomic splitting of species that have two or more synonyms, 2) incorrect listing of cosmopolitan species because they have "foreign" epithets although they may in fact be invasives in their type localities (e.g. Alexandrium tamarense and A. pseudogonyaulax); and 3) temporary geographicrange expansions of taxa at the margins of their survival during short-term climatic fluctuations in SST or SSS. For dinoflagellates, sometimes further confusion occurs in the listing of some species (e.g the predatory Noctiluca scintillans) with Protista and not Dinophyta/Pyrrophyta. The list of motile taxa in Appendix C attempts to remedy some of these problems, and it will be noted that the taxonomic refinement results in intermediate or lower total numbers of species compared to the values listed in Table 3.

In addition to these baseline problems, for the past decade, it has been determined that highresolution morphological studies of ultra-structures combined with biomolecular data are needed to enable accurate identification and motile-cyst stage linkages (Matsuoka and Head, 2013). For example, earlier studies of Quaternary cysts identified several morphologically distinct genera and species with plate configurations seemingly traceable to Gonyaulax spinifera (Table 1). However, subsequent excystment and culture studies (e.g. Ellegaard et al., 2003) have shown that two other species exist in the Gonyaulax spinifera-Spiniferites complex: Gonyaulax elongata $(\mathrm{cyst}=$ Spiniferites elongatus $)$ and Gonyaulax membranacea $(\mathrm{cyst}=$ Spiniferites membranaceus). Such detailed investigations have yet to be made for many BSC Spiniferites species, including the key species $S$. cruciformis that has either resisted germination in cultures or for which the emergent motile cells did not survive. The molecular characterization of single 
motile cells or resting cysts using the single-cell PCR (polymerase chain reaction) is becoming the standard method of investigation for extant dinoflagellates and allows determination of cryptic species and re-evaluation of assumed theca-cyst relationships. For example, Mertens et al. (2015c) cultured cysts of S. pachydermus from Izmir Bay which had the plate characteristics of Gonyaulax spinifera. SEM studies, however, showed small morphological differences in excysted motile cells and associated PCR data indicated a unique phylogenetic position that required the erection of a new species Gonyaulax ellegaardiae with affiliation to a yessotoxinproducing HAB dinoflagellate.

Molecular characterisation of dinoflagellates is also the basis of new cyst identification methods that use pyrosequencing of fossil $18 \mathrm{~S}$ rDNA or eukaryotic $18 \mathrm{~S}$ rRNA extracted from Late Pleistocene and Holocene Black Sea sediment core samples (Coolen et al., 2006). This method is constrained by the requirement that the dinoflagellate motile or resting cyst remains have been sufficiently sequenced for high-resolution matching and the data are entered in the internationally accessible GenBank database. At present, the paleome rRNA fingerprinting method (Coolen et al., 2013) fails to record many ecologically important dinocysts in Black Sea sediment cores, including cysts that produce HABs (Cochlodinium and Polykrikos) and the most abundant cyst species Lingulodinium machaerophorum in the same core samples (FilipovaMarinova et al., 2013). However, the method confirms the presence of Gymnodinium catenatum as well as G. microreticulatum and $G$. cf. nolleri that are difficult to distinguish only by morphology, and it traces a longer history for Scrippsiella trochoidea than is documented by the palynological record of organic cyst linings. Sterol geochemistry has also been used to identify dinoflagellate blooms in the Black Sea (Boon et al., 1979). However, no species identification is possible with this method and it is unclear that it is can be used for sediments other than sapropels. Likewise, a dinosterol record for core MD01-2430 from the deep central basin of 
Marmara Sea (Vidal et al., 2010) also terminates at the base of the sapropel in contrast to the longer palynological record (Londeix et al., 2009) from the same core.

The recent increase of biological invasions of dinoflagellate and diatoms to Europes's inland seas (Paavola et al., 2005) has raised the question "Are invasive species most successful in habitats of low native species richness across European brackish water seas?" This question is based on the hypothesis that NIS are most successful within a zone of minimum native species richness (= Artenminimum) in the Baltic, Black, Azov and Caspian Seas. This Artenminimum coincides with salinities of 5-8 that bridge the transition between the freshwater and marinederived saline waters of inland seas. The hypothesis assumes that salinity is the primary biological range-limiting factor and that native species richness is lowest at these intermediate salinities based on Remane's Richness Curve that delimits an envelope (a horohalinicum) for this zone. The horohalinicum is considered to be a physico-chemical barrier between freshwater and marine zooplankton populations in a brackish sea (Telesh et al., 2011) and it may provide unfavourable osmotic conditions for aquatic organisms because major ion-metabolism adjustments are required within this zone. Paavola et al.'s (2005) results suggest that most NIS taxa are well-adapted to the salinities in this zone and that total NIS richness in the brackish seas is maximal within the salinity range of the Artenminimum. Confirmation of a predictable pattern in the salinity range for NIS was considered an important tool for risk assessment of potential invasions in brackish seas — areas characterised by a combination of empty niches, suitable environmental conditions, and availability of transport vectors.

[Table 7 goes here: NIS dinoflagellate taxa in surface sediments] 
Paavola et al.'s (2005) results for dinoflagellates show only two NIS for the BSC:

Alexandrium monilatum and Gymnodinium uberrimum for the Black Sea and Sea of Azov (Table 7); no NIS is recorded for the Caspian Sea. In contrast, Moncheva and Kamburska (2002) list six additional Black Sea taxa of N. Atlantic, Australian or Pacific origins: Gymnodinium fuscum, Gymnodinium aureolum, Gyrodinium simplex, Spatulodinium pseudonoctiluca and Scaphodinium mirabile. Of these taxa, cysts are only known for Gymnodinium fuscum and Alexandrium monilatum (Walker and Steidinger, 1979); the latter is listed as a rare species in the BSC and some of these cysts may have been included in our grouped Alexandrium spp.

Temporary hyaline cysts are also produced by Gymnodinium uberrimum and spherical mucilagecovered cysts are produced by Gymnodinium aureolum, both of which are possibly included in our large Unknown Hyaline Cyst category (Table 1). Our atlas data for the Black Sea includeseven other cyst-producing NIS: Alexandrium pseudogonyaulax, Alexandrium spp., Barrufeta respendens, Biecheleria baltica, Cochlodinium polykrikoides sensu Li et al.2015, Cochlodinium sp. cf. Fukuyo, and Protoperidinium shanghaiense (cyst name Trinovantedinium applanatum). Although Paavola et al. (2005) concluded that as a whole, the NIS aquatic biodiversity of the European brackish seas maximal within the native species salinity minimum, the BSC dinoflagellate cyst data do not support this empty niche hypothesis. Table 7 shows that the nine listed NIS dinoflagellate taxa all occur in salinity ranges above the $5-8$ horohalinicum, and only the cyst of Alexandrium spp. and Protoperidinium shanghaiense occur in this range, where they are at the lowest end of their seasonal SSS values (see individual taxon descriptions in Sect. 4 for details). This apparent misfit with Remane's richness hypothesis may partly reflect the small number of our BSC samples that fall within the 5-8 SSS envelope, pointing to the need for many more samples in the low salinity coastal areas of the NW Black Sea and northern Azov and Caspian Seas. However, the misfit may also reflect widespread redistribution of cysts by 
bottom currents following their production during a seasonal window of temporarily lowered SSS not captured by the World Ocean Atlas database. Shiganova and Özturk (2002) also comment that in the Black Sea many invaders remain rare or are only sporadically abundant, suggesting a high degree of stability/resilience for the native ecosystems that have survived greater longer-term salinity fluctuations (lacustrine--marine re-connections) than other shallow seas.

In conclusion, our study reveals that contrary to the expected rise in dinoflagellate NIS in the BSC because of modern canalisation, aquaculture and increased shipping traffic, most of the cyst-forming species have been present for c. 3,000 years or more. Uncertainties remain about the identification of some possible modern alien species (e.g. Spiniferites and Cochlodinium) and regarding the long-term preservation of cysts produced by common invasive taxa e.g. cysts of Alexandrium, Biecheleria and Scrippsiella. Within these limits, however, we discern six new dinoflagellate resting cyst taxa in the surface sediments (Table 1), in addition to the new report of a Cochlodinium sp. and Polysphaeridium zoharyi for the Marmara Sea (Balkis et al., 2016) and Scrippsiella plana in the Caspian Sea (Luo et al., 2016). The frequency of occurrence and the abundances of four of these cysts - Alexandrium pseudogonyaulax, Alexandrium spp., Biecheleria cf. baltica and Cochlodinium polykrikoides — suggest that these NIS are being produced at least periodically by established motile dinoflagellate immigrant populations, rather than being dumped only once from ballast water. We also note that the distributions of the NIS cyst taxa (Figures 14-17) are concentrated along the three main shipping routes in the Black Sea, leading from the Marmara Sea entryway: (1) northwest to Odessa (with a branch to Crimea), (2) northeast to Novorössisk (with a branch to the Azov Sea), and (3) southeast to Batumi (Özturk, 2002). Presently, there is no clear evidence for invasion via the Danube, Dniester and Don shipping canals, and the transport vector for Scrippsiella plana into the southern Caspian Sea is 
not yet established (it may be linked to fish farming). In 2002, most of the shipping traffic in the Black Sea was from tropical waters (either SE China and/or southern USA Louisiana toTexas coasts) whereas shipping in the Gulf of Gemlik included vessels from a wider range of source areas, such as northern Europe and northeastern USA (Dobler, 2002). Our cyst data presently do not allow us to discern exact geographic origins for the dinocyst NIS, but a southern USA source of Fragilidium and a West Pacific source of C. polykrikoides is likely, while the distribution and amounts of cyst of Biecheleria cf. baltica suggest a northern or Danube River source. It is also notable that PCR analysis of modern L. machaerophorum cysts from the Caspian, Black and southern Californian seas show identical SSU, ITS and partial LSU rDNA biomolecular sequences (Mertens et al., 2012b), suggesting highly conservative genetic properties for this cosmopolitan species of widely variable process and archeopyle morphology.

The possible recent export of endemic BSC cysts to the world oceans also requires further investigation - particularly the apparently anomalous occurrences of the endemic species Peridinium ponticum and Pyxidinopsis psilata in surface sediments samples at locations far outside of the BSC. The best example of cyst export is $P$. ponticum that was recently found in surface sediment off Tunisia (KNM unpublished data). Core data further show that the transport of $P$. ponticum to the Aegean Sea started in early historical time as shown by regular occurrences of this dinocyst in the ancient Greek harbour of Elaia (north of Izmir Bay) between 2.3 and 1.6 ka BP which was an interval of active naval trading within the BSC. 


\section{Acknowledgements}

We are very grateful to Ali Aksu at Memorial University of Newfoundland (MUN) for providing over 50 surface samples and cores from Marmara and SW Black Sea, and to Helen Gillespie at the MUN CREAIT laboratory for palynological processing. We also sincerely thank Valentina Yanko-Hombach and Tatiana Kondaryuk of Odessa I.I. Mechnikov National University, Ukraine, for invaluable contribution of 74 samples from the Ukrainian (SH and HERMES samples) and Danube Shelves (MN samples). Gennady Matishov provided samples from the Sea of Azov. We also thank Helge W. Arz (Leibniz Institute for Baltic Sea Research Warnemünde) for providing of 25 surface samples from the deep basin of the Black Sea. Charlotte Desmet is acknowledged for her contributions to the dataset. Thomas Verleye is thanked for loan of slides to photograph specimens. Lee Bradley and Eric Mousing are thanked for sharing their published data. Speranta Popescu is thanked for sharing palynological residues from the Black Sea, and Neslihan Balkis at Istanbul University for valuable information on cysts cultured from Marmara Sea plankton and surface sediment samples. We are grateful to the multiple contributors of surface samples in the Caspian and Aral Seas, including H. Lahijani and his group at INIOAS, Peter Zavialov and his group at the Shirshov Institute of Oceanology (SIO), Irina Muschik via Adventurers and Scientists for Conservation, Francois Gasse and the INCO-Copernicus project, A. Kakroodi (University of Tehran), H. Nazrollahzadeh and his group at the Caspian Sea Ecology Research Center, and H. Nazari and his colleagues at the Geological Survey of Iran. Suzanne Yee at the Liverpool UniversitySchool of Environmental Sciences helped greatly with drafting of Fig. 1. Andre Rochon (ISMER) is thanked for his earlier SEM studies of Marmara Sea cysts. FMD would like to thank the Leverhume Trust (F/00025/AN) and the GNS-NZ for their hosting. PJM acknowledges NSERC funding support for Discovery Grant 
RGPIN55408) while at Memorial University 2008-2012. We all thank Vera Pospelova and

Francesca Sangiorgi for reviewing a previous version of the atlas.

\section{References}

Abé, T.H., 1981. Studies on the Family Peridinidae. An Unfinished Monograph of the Armored Dinoflagellata. Tokyo, Academia Scientific Book, 409 pp.

Acara, A., Nalbantoğlu, U., 1960. Preliminary report on the red-tide outbreak in the Gulf of Izmir, Rapp. p.-V. Reun. Comm. Int. Explor. Scient. Mer. Mèdit. 15(3), 33-38.

Aksu, A.E., Calon, T.J., Hiscott, R.N., 2000. Anatomy of the North Anatolian Fault Zone in the Marmara Sea, western Turkey: extensional basins above a continental transform. GSA Today 10(6), 3-7.

Aksu, A.E., Hiscott, R.N., Kaminski, M.A., Mudie, P.J., Gillespie, H., Abrajano, T.D. Yaşar, D., 2002. Last glacial Holocene paleoceanography of the Black Sea and Marmara Sea: stable isotopic, foraminiferal and coccolith evidence. Marine Geology 190, 119-149.

Aktan, Y., 2005. Toxic and harmful algal species in the Izmit Bay, Marmara Sea. UNESCO, Harmful Algal News 28, 6.

Aladin, N., Micklin, P., Plotnikov, I., 2008. Biodiversity of the Aral Sea and its importance to the possible ways of rehabilitating and conserving its remnant water bodies. In: Qi, J., Evered, K.T. (eds.), NATO Science for Peace and Security Series - C: Environmental Security. Environmental Problems of Central Asia and their Economic, Social and Security Impacts. Springer-Verlag: Berlin Heidelberg, pp. 73-98. 
Alvárez Cobelas, M. (1984). Catálogo de las algas continentales españolas. II. Craspedophyceae, Cryptophyceae, Chrysophyceae, Dinophyceae, Euglenophyceae, Haptophyceae, Phaeophyceae, Rhodophyceae, Xanthophyceae. Acta Bot. Malacitana 9, 27-40.

Anderson, D.M., Cembella, A.D., Hallegraeff, G.M., 2012. Progress in understanding Harmful Algal Blooms: paradigm shifts and new technologies for research, monitoring, and management. Ann. Rev. Mar. Sci. 4, 143-76.

ASLO, 1958. The Venice System for the classification of marine waters according to salinity. Limnology and Oceanography 3(3), 346-347.

Attaran-Fariman, G., Bolch, C.J.S., 2012. Morphology and phylogeny of Scrippsiella trochoidea (Dinophyceae) a potentially harmful bloom forming species isolated from the sediments of Iran's south coast. Iranian J. Fish. Sci. 11(2), 252-270.

Atanassova, J., 2005. Palaeoecological setting of the western Black Sea area during the last 15,000 years. The Holocene 15(4), 576-584.

Aydin, H., Uzar, S., 2014. Distribution and abundance of modern dinoflagellate cysts from Marmara, Aegean and Eastern Seas of Turkey. J. Environ. Biol. 35(2), 413-419.

Aydin, H., Matsuoka, K., Minareci, E., 2011. Distribution of dinoflagellate cysts in recent sediments from Izmir Bay (Aegean Sea, Eastern Mediterranean). Mar. Micropaleontol. 80(1-2), $44-52$.

Aydin, H., Yürür, E., Uzar, S., 2014. Dinoflagellate cyst assemblages in surface sediments from Homa Lagoon (Izmir Bay, eastern Aegean Sea, the Mediterranean. Fresenius Environ. Bull. 23(8), 1795-1801.

Aydin, H., Balcı, M., Uzar, S., Balkis, N., 2015. Dinoflagellate cyst assemblages in surface sediments of southwestern Black Sea and Çanakkale Strait (Dardanelles). Fresnius Environ. Bull. 24(12c), 4789-4798. 
Bagheri, S., Fallahi, M., 2014. Checklist of phytoplankton taxa in the Iranian waters of the Caspian Sea. Caspian J. Eviron. Sci. 12(1), 81-97.

Balc1, M., 2013. Temporal changes in phytoplankton species of the Gulf of Gemlik and ecological properties of the environment. PhD Dissertation, University of Istanbul, $240 \mathrm{pp}$.

Balech, E., 1959. Two new genera of dinoflagellates from California. Biol. Bull. 116(2), 195-203.

Balech, E., 1987-1988. Una espcie nueva del genero Fragilidium (Dinoflagellata) de la Bahia de Chamela, Jalisco, Mexico. Anales Inst. Biol., UNAM 58 (1987) Ser. Zool. (2), 479-486, 15VII-1988.

Balkis, N., 2004. List of phytoplankton of the Sea of Marmara. J. Black Sea/Medit. Environ. $10,123-141$.

Balkis, N., Atabay, H., Türetgen, I., Albayrak, S., Balkis, H., Tüfekçi, V., 2011. Role of single-celled organisms in mucilage formation on the shores of Büyükada Island (the Marmara Sea). J. Mar. Biol. Assoc. UK 91(4), 771-781.

Balkis, N., Balcı, M., Giannakourou, A., Venetsanopoulou, A., Mudie, P., 2016.

Dinoflagellate resting cysts in recent marine sediments from Gulf of Gemlik (Marmara Sea) and harmful algal blooms (HABs). Phycologia 55 (2), 187-209.

Balteş, N., 1971. Pliocene Dinoflagellata and Acritarcha in Romania. In: Farinacci, A. (ed.), 2nd Planktonic Conference, Rome, 1970, Proc. p.1-16. Edizioni Tecnoscienza, Rome, Italy.

Beauchard, O., Berg, T., Bizel, K.C., Bizel, N., Borja, A., and 26 others, 2014. Ecosystem overview of the European Regional Seas, Annex-3 D1.4. DEVOTES Project: http://www.devotes-project.eu/

Benedek, P.N., 1972. Phytoplanktonten aus dem Mittel- und Oberoligozän von Tönisberg (Niederrheingebiet). Palaeontographica, Abt. B 137, 1-71. 
Benedek, P.N., Sarjeant, W.A.S., 1981. Dinoflagellate cysts from the Middle and Upper Oligocene of Tönisberg (Niederrheingebiet): a morphological and taxonomic restudy. Nova Hedwigia 35, 313-356.

Beşiktepe, S.T., Sur, H.I, Öczoy, E., Latif, A., Oğuz, T., Ünlüata, Ü., 1994. The circulation and hydrography of the Marmara Sea. Progr. Oceanog. 34, 285-334.

Beşiktepe, S.T., Ünlüata, Ü., Bologa, A.S. (eds.), 1997. Environmental degradation of the Black Sea: challenges and remedies. NATO Science Series 2. Environ. Security 56, 393 pp.

Binder, B.J., Anderson, D. M., 1986. Physiological and environomental control of germination in Scrippsiella trochoidea (Dinophyceae) resting cysts. J. Phycol. 23, 99-107.

Bolch, C.J.S., Negri, A.P., Hallegraeff, G.M., 1999. Gymnodinium microreticulatum sp. nov. (Dinophyceae): a naked, microreticulate cyst-producing dinoflagellate, distinct from Gymnodinium catenatum and Gymnodinium nolleri. Phycologia 38(4), 301-313.

Boomer, I., 2012. Ostracoda as indicators of climatic and human-influenced changes in the Late Quaternary of the Ponto-Caspian Region (Aral, Caspian and Black Seas). In: Horne, D.J., Holmes, J.A., Rodreguez-Lazarro, J., Viehberg, F.A., (eds.), Ostracoda as proxies for Quaternary climate change, Devel. Quat. Sci. 17, 205-215.

Boomer, I., Aladin, N., Plotnikov, I., Whatley, R., 2000. The palaeolimnology of the Aral Sea: a review. Quat. Sci. Rev. 19, 1259-1278.

Boon, J.J., Rijpstra, W.I.C., de Lange, F., de Leeuw, J.W., 1979. Black Sea sterol — a molecular fossil for dinoflagellate blooms. Nature 277, 125-126.

Boyer, T.P., Antonov, J.I., Baranova, O.K., Coleman, C., Garcia, H.E., Grodsky, A., Johnson, D.R., Locarnini, R.A., Mishonov, A.V., O'Brien, T.D., Paver, C.R., Reagan, J.R., Seidov, D., Smolyar, I.V., Zweng, M.M., 2013. World Ocean Database 2013. Sydney Levitus, Ed.; Alexey Mishonov, Technical Ed.; NOAA Atlas NESDIS 72, 209 pp. 
Bradford, M.R., 1975. New dinoflagellate cyst genera from the recent sediments of the Persian Gulf. Can. J. Bot. 53, 3064-3074.

Bradford, M.R., 1977: New species attributable to the dinoflagellate cyst genus Lejeunia Gerlach, 1961 emend. Lentin and Williams 1975. Grana 16, 45-59.

Bradford, M.R., Wall, D.A., 1984. The distribution of Recent organic-walled dinoflagellate cysts in the Persian Gulf, Gulf of Oman, and northwestern Arabian Sea. Palaeontographica, Abt. B, 192, 16-84.

Bradley, L., Marret, F., 2013. Studying Holocene environmental change in the Marmara Sea, Black Sea and Caspian Sea using dinoflagellate cysts. In: Lewis, J. M., Marret, F., Bradley, L. (eds.), Biological and Geological Perspectives of Dinoflagellates. The Micropalaeontological Society, Spec. Publ., Geol. Soc., London, 127-131.

Bradley, L.R., Marret, F., Mudie, P.J., Aksu, A.E., Hiscott, R.N., 2012. Constraining Holocene sea-surface conditions in the south-western Black Sea using dinoflagellate cysts. J. Quat. Sci. 27, 835-843.

Bravo, I., Garcés, E., Diogéné, J., Fraga, S., Sampedro, N., Figueroa, R.I., 2006. Resting cysts of toxigenic dinoflagellate genus Alexandrium in recent sediments from the Western Mediterranean coast, including the first description of cysts of A. kutnerae and A. peruvianum. Euro. J. Phycol. 41(3), 293-302.

Breckle, S-W., Geldyeva, G.V., 2012. Dynamics of the Aral Sea in Geological and Historical Times. In: Breckle, S-W., Wucherer, W., Dimeyeva, L.A., Ogar, N.P. (eds.), Aralkum — a ManMade Desert: The Desiccated Floor of the Aral Sea (Central Asia); Springer-Verlag, Berlin and Heidelberg; Ecological Studies 218, 13-35.

Brenner, W.W., 2001a. Distribution of organic-walled microfossils within single laminae from Gotland Basin and their environmental evidence. Baltica 14, 34-39. 
Brenner, W.W., 2001b. Organic walled microfossils from the central Baltic Sea, indicators of environmental change and base for ecostratigraphic correlation. Baltica 14, 40-51.

Brenner, W.W., 2005. Holocene environmental history of the Gotland Basin (Baltic Sea) - A micropalaeontological model. Palaeogeog., Palaeoclimat., Palaeoecol. 220, 227-241.

Brenner, W.W., Meemken, H.-J., 2002. Öko- und chronostratigraphische Korrelierung der Zentralen Ostsee mit der Kieler Bucht anhand organischwandiger Mikrofossilien. Meyniana 54, $17-40$.

Bryantseva, Yu. V., Krakhmalny, A.F., Velikova, V.N., Sergeeva, A.V., 2016. Dinoflagellates in the Sevastopol Coastal Zone (Black Sea, Crimea). Int. J. Algae 18(1), 21-32.

Bujak, J.P., Downie, C., Eaton, G.L., Williams, G.L., 1980. Dinoflagellate cysts and acritarchs from the Eocene of southern England. Spec. Pap. Palaeontol. 24, 100 p.

Burrell, S., Gunnarsson, T., Gunnarsson, K., Clarke, D., Turner, A.D., 2013. First detection of paralytic shellfish poisoning (PSP) toxins in Icelandic mussels (Mytilus edulis): Links to causative phytoplankton species. Food Control 31, 295-301.

Caraus, I. (2012). Algae of Romania. A distributional checklist of actual algae. Version 2.3 third revision. Bacau: University of Bacau.

Carty, S., 2015. Freshwater Dinoflagellates of North America. Harrisburg, PA, Cornell Unversity Press, 240 pp.

Chepalyga, A. L., 2007. The late glacial great flood in the Ponto-Caspian basin. In: YankoHombach, V., Gilbert, A.S., Panin, N., Dolukhanov, P. (eds), The Black Sea Flood Question: Changes in Coastline, Climate and Human Settlement. Springer: Dordrecht, pp. 119-148.

Clarke, K.R., Gorley, R.N., 2015. PRIMER v7: User Manual/Tutorial. PRIMER-E, Plymouth, 296 pp. 
Coolen, M.J.L., Boere, A., Abbas, B., Baas, M., Wakeham, S.G., Sinninghe Damste, J.S., 2006. Ancient DNA derived from alkenone-biosynthesizing haptophytes and other algae in Holocene sediments from the Black Sea. Paleoceanography 21, PA1005, 1-17.

Coolen, M.J.L., Orsib, W.D., Balkema, C., Quince, C., Harris, K., Sylva, S.P., FilipovaMarinova, M., Giosan, L., 2013. Evolution of the plankton paleome in the Black Sea from the deglacial to Anthropocene. PNAS 110(21), 8609-8614.

Corradini, D., Biffi, U., 1988: Étude des dinokystes à la limite Messinien-Pliocène dans la coupe Cava Serredi, Toscane, Italie. Dinocyst study at the Messinian-Pliocene boundary in the Cava Serredi section, Tuscany, Italy. Bull. des Centres de Rech. Explor.-production ElfAquitaine 12(1), 221-236.

Cordova, C.E., Harrison, S.P., Mudie, P.J., Riehl, S., Leroy, S.A.G., Ortiz, N., 2009. Pollen, plant macrofossil and charcoal records for palaeovegetation reconstruction in the MediterraneanBlack Sea Corridor since the Last Glacial Maximum. Quat. Intern. 197, 12-26.

Dale, B., 1976. Cyst formation, sedimentation, and preservation: factors affecting dinoflagellate assemblages in Recent sediments from Trondheimsfjord, Norway. Rev. Palaeobot.Palynol. 22, 39-60.

Dale, B., 1977. New observations on Peridinium faeroense Paulsen (1905), and classification of small orthoperidinioid dinoflagellates. Brit. Phycol. Journ. 12 (3), 241-253.

Dale, B., 1983: Dinoflagellate resting cysts: "benthic plankton". In: Fryxell, G.A. (ed.), Survival Strategies of the Algae; Cambridge, UK, Cambridge University Press, pp. 69-136.

Dale, B., 1988. Low salinity dinoflagellate assemblages from Recent sediments of the Baltic region. $7^{\text {th }}$ International Palynological Congress, Brisbane, Abstracts, p. 33. 
Dale, B., 1996. Dinoflagellate cyst ecology: modelling and geological applications. In:

Jansonius, J.J., McGregor, D.L. (eds.), Palynology: Principles and Applications, Vol. 3, 1249-1275; AASP Foundation: College Station, Texas.

Dale, B., Montresor, M., Zingone, A., Zonneveld, K., 1993. The cyst-motile stage relationships of the dinoflagellates Diplopelta symmetrica and Diplopsalopsis latipeltata. European J. Phycol. 28(2), 129-137.

Davey, R.J., Williams, G.L., 1966. IV. The genera Hystrichosphaera and Achomosphaera. In:

Davey, R.J., Downie, C., Sarjeant, W.A.S., Williams, G.L. (eds.), Studies on Mesozoic and Cainozoic dinoflagellate cysts; Brit. Mus. (Nat. Hist.) Geol. Bull., Suppl. 3, 28-52.

Deflandre, G., Cookson, I.C., 1955. Fossil microplankton from Australian Late Mesozoic and Tertiary sediments. Austral. J. Mar.Freshwater Res. 6(2), 242-313.

Deniz, N., Taş, S., 2009. Seasonal variations in the phytoplankton community in the northeastern Sea of Marmara and a species list. J. Mar. Biol. Assoc. U. K. 89(2), 269-276.

Desmet, C., 2013. Recent distribution of dinoflagellate cysts in surface sediments of the Black Sea, the Caspian Sea and the Azov Sea, their ecological interpretation and application. MSc Dissertation, Ghent University, Faculty of Science, Dept. Geology, 137 pp.

de Vernal, A, Goyette C, Rodrigues, C., 1989. Contribution palynostratigraphique (dinokystes, pollen et spores) à la connaissance de la mer de Champlain: coupe de Saint-Cézaire, Quebec. Can. J. Earth Sci. 26, 2450-2464.

de Vernal, A., Eynaud, F., Henry, M., Hillaire-Marcel, C., Londeix, L., Mangin, S., Matthiessen, J., Marret, F., T. Radi, T., Rochon, A., Solignac, S., Turon, J.-L., 2005. Reconstruction of sea-surface conditions at middle to high latitudes of the Northern Hemisphere during the Last Glacial Maximum (LGM) based on dinoflagellate cyst assemblages. Quat. Sci. Rev. 24(7-9), 897-924. 
de Vernal, A., Hillaire-Marcel, C., Rochon, A., Fréchette, B., Henry, M., Solignac, S., Bonnet, S., 2013. Dinocyst-based reconstructions of sea ice cover concentration during the Holocene in the Arctic Ocean, the northern North Atlantic Ocean and its adjacent seas. Quat. Sci. Rev. 79, 111-121.

Devillers, R., de Vernal, A., 2000. Distribution of dinoflagellate cysts in surface sediments of the northern North Atlantic in relation to nutrient content and productivity in surface waters. Marine Geology 166, 103-124.

Djamali, M., de Beaulieu J.-L., Shah-Hosseini, M., Andrieu-Ponel, V., Ponel, P., Amini, A., Akhani, H., Leroy, S., Stevens, L., Lahijani, H., Brewer, S., 2008. A Late Pleistocene long pollen record from Lake Urmia, NW Iran. Quat. Res. 69, 413-420.

Dobler, J-P., 2002. Analysis of shipping patterns in the Mediterranean and Black seas. CIESM Workshop Monographs 20, 19-28.

Dodge, J. D., Harland, R., 1991. The distribution of planktonic dinoflagellates and their cysts in the eastern and northeastern Atlantic Ocean. New Phytol. 118, 593-603.

Dumont, H., 1998. The Caspian Lake: History, biota, structure, and function. Limnol. Oceanog. 43(1), 44-52.

Dumont, H., Shiganova, T.A., Niermann, U. (eds.), 2004. Aquatic Invasions in the Black, Caspian and Mediterranean Seas. NATO Science Series IV. Earth and Environ. Sci. 35. Dordrecht: Kluwer Academic Publishers.

Eker-Develi, E., Kideys, A.E., 2003. Distribution of phytoplankton in the southern Black Sea in summer 1996, spring and autumn 1998. J. Mar. Syst. 39, 203-211.

Ellegaard, M., 2000. Variations in dinoflagellate cyst morphology under conditions of changing salinity during the last 2000 years in the Limfjord, Denmark. Rev. Palaeobot. Palynol. 109(1), 65-81. 
Ellegaard, M., Moestrup, Ø., 1999. Fine structure of the flagellar apparatus and morphological details of Gymnodinium nolleri sp. nov. (Dinophyceae), an unarmored dinoflagellate producing a microreticulate cyst. Phycologia 38(4), 289-300.

Ellegaard, M., Dale, B., Amorim, A., 2002a. The acritarchous resting cyst of the thecate dinoflagellate Warnowia cf. rosea (Dinophyceae). Phycologia 40(6), 542-546.

Ellegaard, M., Lewis, J., Harding, I., 2002b. Cyst-theca relationship, life cycle, and effects of temperature and salinity on the cyst morphology of Gonyaulax baltica sp. nov. (Dinophyceae) from the Baltic Sea area. J. Phycol. 38(4), 775-789.

Ellegaard, M., Daugbjerg, N., Rochon, A., Lewis, J., Harding, I., 2003. Morphological and LSU rDNA sequence variation within the Gonyaulax spinifera-Spiniferites group (Dinophyceae) and proposal of G. elongata comb. nov. and G. membranacea comb. nov. Phycologia 42(2), $151-164$.

Elshanawany, R., Zonneveld, K., Ibrahim, M.I., Kholeif, S.E.A., 2010. Distribution patterns of recent organic-walled dinoflagellate cysts in relation to environmental parameters in the Mediterranean Sea. Palynology 34(2), 233-260.

Erdner, D.L., Percy, L., Keafer, B., Lewis, J., Anderson, D.M., 2010. A quantitative real-time PCR assay for the identification and enumeration of Alexandrium cysts in marine sediments. Deep Sea Res. Pt. 2, Top. Stud. Oceanogr. 57(3-4), 279-287.

Ermakhanov, Z.K., Plotnikov, I.S., Aladin, N.V., Micklin, P., 2012. Changes in the Aral Sea ichthyofauna and fishery during the period of ecological crisis. Lakes Reserv. Res. Manage. 17: 3-9.

Evagelopoulos, A., Nicolaidis, G., 1996. Morphology of Protoperidinium compressum (Peridiniales, Dinophyceae) in the North Aegean Sea, Greece. Nova Hedwigia 63(2-3), 301-307. 
Evitt, W.R., 1963. A discussion and proposals concerning fossil dinoflagellates, hystrichospheres, and acritarchs, I. Nat. Acad. Sci. Wash., Proc. 49, 158-164.

Evitt, W.R., Gocht, H., Netzel, H., 1985. Gonyaulax cysts from Lake Zurich sediments. Rev. Palaeobot. Palynol. 45(1-2), 35-46.

Faust, M.A., Gulledge, R.A., 2002. Identifying harmful marine dinoflagellate. Nat. Mus. Nat. Hist., Washington, DC, 144 pp.

Fensome, R.A., Williams, G.L., 2004. The Lentin and Williams Index of fossil dinoflagellates 2004 Edition. Am. Assoc.Stratig. Palynol. Contrib. Ser. 42, 909 pp.

Fensome, R.A., Williams, G.L., 2005. Scotian Margin PalyAtlas: version 1. Geological Survey of Canada Open File 677.

Ferguson, S., Warny, S., Escarguel, G., Mudie, P.J., 2016. MIS 5 to 1 dinoflagellate cyst analyses and morphometric evaluation of Galeacysta etrusca and Spiniferites cruciformis in southwestern Black Sea. Quat.Internat., available online.

Feyzioğlü, A.M., Öğüt, H., 2006. Red-tide observations along the eastern Black sea coast of Turkey. Turkish J. Botan., 30, 375-379.

Feyzioğlu, A. M., Seyhan, K., 2007. Phytoplankton composition of south east Black Sea coast. J. Black Sea/Mediterranean Environ. 13, 61-71.

Figueroa, R.I., Bravo, I., 2005. Sexual reproduction and two different encystment strategies of Lingulodinium polyedrum (Dinophyceae). J. Phycol. 41(2), 370-379.

Filipova-Marinova, M., 2006. Late Pleistocene/Holocene dinoflagellate cyst assemblages from the Southwestern Black Sea shelf. In: Ognjanova-Rumenova, N., Manoylov, K. (eds.), Advances in Phycological Studies, pp. 267-281. 
Filipova-Marinova, M., Pavlov, D., Coolen, M., Giosan, L., 2013, First high resolution marinopalynological stratigraphy of Late Quaternary sediments from the central part of the Bulgarian Black Sea area, Quat. Internat. 293, 170-183.

Flood, R.D., Hiscott, R.N., Aksu, A.E., 2009. Morphology and evolution of an anastomosed channel network where saline underflow enters the Black Sea. Sedimentology 65: 807-839.

Forte, A.M., Cowgill, E., 2013. Late Cenozoic base-level variations of the Caspian Sea: A review of its history and proposed driving mechanisms. Palaeogeog., Palaeoclim., Palaeoecol. $386,392-407$.

Fukumoto, T., Kobayashi, N., 2005. Bottom stratification and water exchange in enclosed bay with narrow entrance. J. Coastal Res. 21, 135-145.

Fukuyo, Y., 1982. Cysts of naked dinoflagellates. In: Okaichi, T. (ed.), Fundamental Studies of the Effects of the Marine Environment on the Outbreaks of Red Tides. Rep. Environ. Sci, B 148-R14-8, Monbusho, Tokyo, pp. 205-214.

Fukuyo, Y., Kodama, M., Omura, T., Furuya, K., Furio, E., Cayme, M., Lim, P.T., Dao, V.H., Kotaki, Y., Matsuoka, K., Iwataki, M., Ruijinard, S., Thaithaworn, L., 2011. Ecology and oceanography of harmful marine algae. In: Nishida, S., Fortes, M.D., Miyazaki, N., (eds.), Coastal Marine Science in Southeast Asia, Terrapub, Tokyo, pp. 23-48.

Gallardo Rodríguez, J. J., Cerón García, M.-C., García Camacho, F., Sánchez Mirón, A., Belarbi, E. H., Chisti, Y., Molina Grima, E., 2009. Macronutrients requirements of the dinoflagellate Protoceratium reticulatum. Harmful Algae 8, 239-246.

Giosan, L., Coolen, M.J.L., Kaplan, J.O., Constantinescu, S., Filip, F., Filipova-Marinova, M., Kettner, A.J., Thom, N., 2012. Early anthropogenic transformation of the Danube-Black Sea system. Sci. Rep. 2, 582; DOI:10.1038/srep00582. 
Giralt, S., Juliá, R., Leroy, S., Gasse, F., 2003. Cyclic water level oscillations of the KaraBogazGol-Caspian Sea system. EPSL 212, 225-239.

Giunta, S., Morigi, C., Negri, A., Guichard, F., Lericolais, G., 2007. Holocene biostratigraphy and paleoenvironmental changes in the Black Sea based on calcareous nannoplankton. Mar. Micropaleontol. 63(1-2), 91-110.

Glantz, M.H., Zonn, I.S., 1996. Scientific, Environmental, and Political Issues in the CircumCaspian Region. NATO ASI Ser. 2. Environ. 29, 312 pp.

Gómez, F., 2012. A quantitative review of the lifestyle, habitat and trophic diversity of dinoflagellates (Dinoflagellata, Alveolata). System. Biodivers. 10(3), 267-275.

Gómez, F., Boicenco, L., 2004. An annotated checklist of dinoflagellates in the Black Sea. Hydrobiologia 517, 43-59.

Gómez, F., Mindy L. Richlenb, M.L., Anderson, D.M., 2017. Molecular characterization and morphology of Cochlodinium strangulatum, the type species of Cochlodinium, and Margalefidinium gen. nov. for C. polykrikoides and allied species (Gymnodiniales, Dinophyceae) Harmful Algae 63, 32-44.

Gogorev, R. 2006. Check-list for Caspian Sea phytoplankton. In: Caspian Sea Biodiversity Project; http://www.zin.ru/projects/caspdiv/caspian_phytoplankton.html.

Grigorovitch, I.A., Therriault, T.W., MacIsaac, H.J., 2003. History of aquatic invertebrate invasions in the Caspian Sea. Biol. Invasions 5, 103-115.

Grindley, J.R., Nel, E.R., 1970. Red water and mussel poisoning at Elands Bay, December 1966. Fish. Bull. South Africa 6, 36-55.

Grégoire, M., Beckers, J.M., Nihoul, J.C.J., Stanev, E., 1998. Reconnaissance of the main Black Sea's ecohydrodynamics by means of a 3D interdisciplinary model. J. Mar. Systems 16, $85-105$. 
Grothe, A., Sangiorgi, F., Mulders, Y.R., Vasiliev, I., Reicheart, G-J., Brinkhuis, H., 2014. Black Sea desiccation during the Messinian Salinity Crisis: Fact or fiction? Geology 42, $563-566$.

Gu, H., Luo, Z., Zeng, N., Lan, B., Lan, D., 2013. First record of Pentapharsodinium (Peridiniales, Dinophyceae) in the China Sea, with description of Pentapharsodinium dalei var. aciculiferum. Phycol. Res. 61(4), 256-267.

Gu, H., Lu, Z., Merten, K.N., Price, A.M., Turner, R.E., 2015a. Cyst-motile stage relationship, morphology, ultrastructure and molecular phylogeny of the gymnodinioid dinoflagellate Barrufeta resplendens comb. nov., formerly known as Gyrodinium resplendens, isolated from the Gulf of Mexico. J. Phycol. 51(5), 990-999.

Gu, H., Liu, T., Mertens, K.N., 2015b. Cyst-theca relationship and phylogenetic positions of Protoperidinium (Peridiniales, Dinophyceae) species of the sections Conica and Tabulata, with description of Protoperidinium shanghaiense sp. nov. Phycologia 54(1), 49-66.

Guiry, Michael D., 2015. Protoperidinium divaricatum (Meunier) Balech. In: Guiry, M.D. and Guiry, G.M., 2015, AlgaeBase. World-wide electronic publication, National University of Ireland, Galway; http://www.algaebase.org.

Gunduz, M., Özsoy, E., 2014. Modelling seasonal circulation and thermohaline structure of the Caspian Sea. Ocean Sci., 10, 459-471.

Haghani, S., Leroy, S.A.G., Wesselingh, F.P., Rose, N.L., 2016. Rapid evolution of coastal lagoons in response to human interference under rapid sea level change: A south Caspian Sea case study. Quat. Intern. 408, 78-92.

Harland, R., 1977. Recent and Late Quaternary (Flandrian and Devensian) dinoflagellate cysts from marine continental shelf sediments around the British Isles. Paleontographica Abt. B 164, $87-126$. 
Harland, R., 1982. A review of Recent and Quaternary organic-walled dinoflagellate cysts of the genus Protoperidinium. Palaeontology 25 (2), 369-397.

Harland, R., 1983. Distribution maps of Recent dinoflagellate cysts in bottom sediments from the North Atlantic Ocean and adjacent seas. Palaeontology 26, 321-387.

Harland, R., Bonny, A.P., Hughes, M.J. and Morigi, A.N., 1991: The Lower Pleistocene stratigraphy of the Ormesby Borehole, Norfolk, England. Geol. Mag. 128(6), 647-660. Head, M.J., 1993. Dinoflagellate cysts, sporomorphs, and other palynomorphs from the marine uppermost Pliocene St. Erth Beds, Cornwall, southwestern England. Paleontol. Soc. Mem. 31, 162.

Head, M.J. (ed.), 1994. A forum on Neogene and Quaternary dinoflagellate cysts (The edited transcript of a round table discussion held at the Third Workshop on Neogene and Quaternary Dinoflagellates; with taxonomic appendix). Palynology 17, 201-239.

Head, M.J., 1996. Modern dinoflagellate cysts and their biological affinities. In: Jansonius, J.J., McGregor, D.C. (eds.), Palynology: principles and applications, v. 3, AASP Foundation: College Station, Texas; pp. 1197-1248.

Head, M.J., 1997. Thermophilic dinoflagellate assemblages from the mid Pliocene of eastern England. J. Paleontol.71(2), 165-193.

Head, M.J., 2003. Echinidinium zonneveldiae sp. nov., a dinoflagellate cyst from the Late Pleistocene of the Baltic Sea, northern Europe. J. Micropalaeontol. 21, 169-173.

Head, M.J., 2007. Last Interglacial (Eemian) hydrographic conditions in the southwestern Baltic Sea based on dinoflagellate cysts from Ristinge Klint, Denmark. Geol. Mag. 144: 9871013. 
Head, M.J., Nøhr-Hansen, H., 1999. The extant thermophilic dinoflagellate Tectatodinium pellitum (al. Tectatodinium rugulatum) from the Danian of Denmark. J. Paleontol. 73(4), $577-579$.

Head, M.J., Wrenn, J.H. (eds.), 1992. A forum on Neogene and Quaternary dinoflagellate cysts (The edited transcript of a round table discussion held at the Third Workshop on Neogene and Quaternary Dinoflagellates. In: Head, M.J., Wrenn, J.H. (eds.), Neogene and Quaternary Dinoflagellate Cysts and acritarchs, AASP Foundation: Dallas, Texas; pp. 1-31.

Head, M.J., Lewis, J., de Vernal, A., 2006. The cyst of the calcareous dinoflagellate Scrippsiella trifida: resolving the fossil record of its organic wall with that of Alexandrium tamarense. J. Paleont. 80(1), 1-18.

Hiscott, R.N., Aksu, A.E., Mudie, P.J., Kaminski, M.A., Abrajano, T., Yaşar, D., Rochon, A., 2007. The Marmara Sea Gateway since 16 Ka non-catastrophic causes of paleoceanographic events in the Black Sea at 8.4 and 7.15 ka. In: Yanko-Hombach, V., Gilbert, A.S., Panin, N., Dolukhanov, P. (eds.), The Black Sea Flood Question: Changes in Coastline, Climate and Human Settlement. Springer: Dordrecht; pp. 89-117.

Hoon, Y.H., Shin, H.H., 2012. Summary of the dinoflagellate cyst assemblages of modern sediments from Korean coastal waters and adjoining sea. Korean J. Environ. Biol. 31 (4), 243274.

Hoppenrath, M., Elbrachter, M., Drebes, G., 2009. Marine phytoplankton: Selected Microphytoplankton species from the North Sea around Helgoland and Sylt. Schweizer-bartsche Verlagsbuchhandlung: Kleine Senckenberg-Reihe 49, Stuttgart, Germany; 264 pp.

Horstman, D.A., 1981. Reported red tide outbreaks and their effect on fauna of the west and south coast of South Africa, 1959-1980. Fish. Bull. South Africa 15, 71-88. 
Ignatiades, L., Gotsis-Skretas, O., 2010. A Review on Toxic and Harmful Algae in Greek Coastal Waters (E. Mediterranean Sea). Toxins 2(5), 1019-1037.

IOC-UNESCO, accessed June 2015: http://iobis.org/mapper/?taxon=Diplopelta symmetrica .

Isler, E.B., Aksu, A.E., Hiscott, R.N., 2016. Late Quaternary paleoceanographic evolution of the Aegean Sea: planktonic foraminifera and stable isotopes. Turkish J. Earth Sci. 25, 19-45.

Ivanova, E.V., Murdmaa, I.O., Karpuk, M.S., Schornikov, E.I., Marret, F., Cronin, T.M., Buynevich, I.V., Platonova. E.A., 2012. Paleoenvironmental changes on the northeastern and southwestern Black Sea shelves during the Holocene. Quat. Intern. 261, 91-104.

Ivanova, E. I., Muurdma, I.O., Karpuk, M.S., Schornikov, E.I., Marret, F., Cronin, T.M., Buynevich, I.V., Platonova, E.A., 2014. Paleoenvironmental changes on the northeastern and southwestern Black Sea shelves during the Holocene. Quat. Intern. 261, 91-104.

Jain, K.P., Garg, R., 1983: Cleistosphaeridium mikiril Mehrotra, a junior synonym of Lingulodinium machaerophorum (Deflandre and Cookson) Wall, 1967. J. Palaeont. Soc. India $28,61-62$.

Jan du Chêne, R., Londeix, L., 1988. Données nouvelles sur Achomosphaera andalousiensis Jan du Chêne 1977, kyste de Dinoflagellé fossile. Bull. Centres Rech. Explor. Prod. ElfAquitaine 12(1), 237-250.

Jansson, I-M., Mertens, K.N., Head, M.J., 2014. Statistically assessing the correlation between salinity and morphology in cysts produced by the dinoflagellate Protoceratium reticulatum from surface sediments of the North Atlantic Ocean, Mediterranean-Marmara-Black Sea region, and Baltic-Kattegat-Skagerrak estuarine system. Palaeogeog., Palaeoclim., Palaeoecol. 399, 202-213. 
Jeong, H.J., Yoo, Y.D., Kim, J.S., Seong, K.A., Kang, N.S., Kim, T.H., 2010. Growth, feeding and ecological roles of the mixotrophic and heterotrophic dinoflagellates in marine planktonic food webs. Ocean Sci. J. 45(2), 65-91.

Kalinova, G., Mechkarova, P., Marinova, M., 2015. A study of paralytic toxins in cultured mussels from Bulgarian Black Sea. Trakia J. Sci. 13, Suppl. 2, 303-308.

Kholeif, S.E.A, Mudie, P.J., 2009. Palynological records of climate and oceanic conditions in the Late Pleistocene and Holocene of the Nile Cone, southestern Mediterranean, Egypt. Palynology 33, 1-24.

Kim, D-I., Matsuyama, Y., Nagasoe, S., Yamaguchi, M., Yoon, Y-H, Oshima, Y., Imada, N., Honjo, T., 2004. Effects of temperature, salinity and irradiance on the growth of the harmful red tide dinoflagellate Cochlodinium polykrikoides Margalef (Dinophyceae). J. Plankton Res. 26 (1), 61-66.

Kim, C-J., Kim, H-G., Kim, C-H., Hee-Mock Oh, H-M., 2007. Life cycle of the ichthyotoxic dinoflagellate Cochlodinium polykrikoides in Korean coastal waters. Harmful Algae 6, 104-111.

Klein, G., Martin, J.L., Kaczmarska, I., 2010. Biological synopsis of phytoplankton new to the Bay of Fundy, Can. Manuscr. Rep. Fish. Aquat. Sci. 2919, 28 pp.

Kiselev, I.A., 1950. Pantsirnye zhgutikonostsy Dinoflagellata morel ismesnykh vod SSSR (Armoured Flagellates of the Sea and Fresh Waters of the USSR). Moscow, Leningrad: Izd-vo AN SSSR [Acad. Sci. USSR, in Russian].

Kiss, L., Béres, I., 2006. Anthropogenic factors behind the recent population expansion of common ragweed (Ambrosia artemisiifolia L.) in Eastern Europe: is there a correlation with political transitions? J. Biogeog. 33, 2154-2157. 
Kita, T., Fukuyo, Y., 1988. Description of the gonyaulacoid dinoflagellate Alexandrium hiranoi sp. nov. inhabiting tidepools on Japanese Pacific coast. Bull. Plankton Soc. Japan 35, $1-7$.

Kloosterboer-van Hoeve, M.L., Steenbrink, J., Brinkhuis, H., 2001. A short-term cooling event, 4.205 million years ago, in the Ptolemais Basin, northern Greece. Palaeogeog., Palaeoclim., Palaeoecol. 173, 61-73.

Kobayashi, S., Matsuoka, K., 1984. Cyst and theca forms of Protoperidinium conicum (Gran) Balech (Dinophyceae). Japanese J. Phycol. 32, 251-256.

Kobayashi, S., Matsuoka, K., 1995. A new species of Ensiculifera, E. imariense (Dinophyceae), producing organic-walled cysts. J. Phycol. 31, 146-152.

Kokinos, J.P., Anderson, D.M., 1995: Morphological development of resting cysts in cultures of the marine dinoflagellate Lingulodinium polyedrum (= L. machaerophorum). Palynology 19, $143-166$.

Koray, T., 1984. The occurrence of red-tides and causative organisms in İzmir Bay. Ege U. Faculty Sci. Journ. Ser. B7, 75-83.

Koray, T., 2004. Potentially toxic and harmful phytoplankton species along the coast of the Turkish Seas. In: Steidinger, K.A., J.H. Landsberg, C.R. Tomas, and G.A. Vargo (Eds.). Harmful Algae 2002. Florida Fish and Wildlife Conservation Commission, Florida Inst. Oceanog., and Intergovernmental Oceanographic Commission of UNESCO, pp. 335-340.

Kosarev, A.N., Kostianoy, A.G., Tamara A., Shiganova, T.A., 2007. The Sea of Azov. In: A.G. Kostianoy, A.N. Kosarev, (Eds.), Hdb. Env. Chem. 5: Water Pollution, pp. 1-28. SpringerVerlag Berlin Heidelberg. 
Kostianoy, A.G., Kosarev, A.N., eds., 2005. The Caspian Sea Environment. Hdb Env Chem. 5P, Springer-Verlag Berlin Heidelberg. Hdb Env Chem. 5: Water Pollution, pp. 1-28. SpringerVerlag Berlin Heidelberg.

Kouli, K., Brinkhuis, H., Dale, B., 2001. Spiniferites cruciformis: A fresh water dinoflagellate cyst? Rev. Palaeobot. Palynol. 113(4), 273-286.

Kouraev, A.V., Papa, F., Mognard, N.M., Buharizin, P.I., Cazenave, A., Cretaux, J-F., Dozortseva, J., Remy, F., 2003. Sea ice cover in the Caspian and Aral Seas from historical and satellite data. J. Mar. Syst. 47, 89-100.

Koutsodendris, A., Brauer, A., Zacharias, I., Putyrskaya, V., Klemt, E., Sangiorgi, F., Pross, J., 2015. Ecosystem response to human- and climate-induced environmental stress on an anoxic coastal lagoon (Etoliko, Greece) since 1930 AD. J. Paleolimnol. 53, 255-270.

Kovaleva, G.V., 2008. Phytoplankton of the Sea of Azov and adjacent reservoirs. In: The Sea of Azov in the End of XX and Beginning of XXI Centuries: Geomorphology, Sedimentation, and Pelagic Communities, Karel. Nauchn. Tsentr, Ross. Akad. Nauk, Apatity, Vol. 10, 134-223 [In Russian].

Krakhmalny, A., Bryantseva, Y., Velikova, V., Sergeeva, O., Skuratova, K., Dereziuk, N., 2012. Black Sea Dinoflagellata (History of the Research and Current Biodiversity). Turk. J. Fish. Aquat. Sci. 12(5), 539-546.

Kremp, A., Elbrächter, M., Schweikert, M., Wolny, J.L., Gottschling, M., 2005. Woloszynskia halophila (Biecheler) comb. nov.: a bloom-forming cold-water dinoflagellate co-occuring with Scrippsiella hangoei (Dinophyceae) in the Baltic Sea. J. Phycol. 41, 629-642.

Krivonogov, S.K., Burr, G.S., Kuzmin, Y.V., Gusskov, S.A., Kurmanbaev, R.K., Kenshinbay, T.I., Voyakin, D.A., 2014. The fluctuating Aral Sea: A multidisciplinary-based history of the last two thousand years. Gondwana Res. 26, 284-300. 
Lamy, F, Arz, H.W., Bond, G.C., Bahr, A., Pätzold, J., 2006. Multicentennial-scale hydrological changes in the Black Sea and northern Red Sea during the Holocene and the Arctic/North Atlantic Oscillation. Paleoceanography 21(1), PA1008, doi:10.1029/2005PA001184.

Lancelot, C., J. Staneva, J., Van Eeckhout, D., J.-M. Beckers, J-M., E. Stanev, E., 2002. Modelling the Danube-influenced North-western Continental Shelf of the Black Sea. II: ecosystem response to changes in nutrient delivery by the Danube River after its damming in 1972. Estuar. Coast. Shelf Sci. 54, 473-499.

Lazăr, L., Boicenco, L., Coatu, V., Oros, A., Țigănuş, D., Mihailov, M-E., 2013. Nutrient levels and eutrophication of the Romanian Black Sea waters (2006-2011) — assessment related to the marine strategy framework disrective implementation. Cercetări Marine 43, 162-173.

Lee, B-S., Bullister, J.L., Murray, J.W., Sonnerup, R.E., 2002. Anthropogenic chlorofluorocarbons in the Black Sea and Sea of Marmara. Deep-Sea Res. I 49, 895-913.

Lee, M.J., Jeong, H.J., Lee, K.H., Jang, S.H., Kim, K.Y., 2015. Mixotrophy in the nematocyst-taeniocyst complex-bearing phototrophic dinoflagellate Polykrikos hartmannii. Harmful Algae 49, 124-134.

Lentin, J., Williams, G.L., 1981. Fossil dinoflagellates: index to genera and species, 1981 edition. Bedford Institute of Oceanography, Report Series, no.BI-R-81-12, 345 p.

Leroy, S.A.G., Albay, M. 2010. Palynomorphs of brackish and marine species in cores from the freshwater Lake Sapanca, NW Turkey. Rev.Palaeobot. Palynol. 160(3-4), 181-188.

Leroy, S.A.G., Marret, F., Giralt, S., Bulatov, S.A., 2006. Natural and anthropogenic rapid changes in the Kara-Bogaz Gol over the last two centuries reconstructed from palynological analyses and a comparison to instrumental records. Quat. Internat. 150(1), 52-70. 
Leroy, S.A.G., Marret, F., Gibert, E., Chalié, F., Reysse, J.-L., Arpe, K., 2007. River inflow and salinity changes in the Caspian Sea during the last 5500 years. Quat. Sci. Rev. 26, 33593383.

Leroy, S.A.G, Schwab, M.J., Costa, P.J.M., 2010. Seismic influence on the last 1500-year infill history of Lake Sapanca (North Anatolian Fault, NW Turkey). Tectonophysics 480(1-4), $15-27$.

Leroy, S.A.G., Lahijani, H.A.K., Reyss, J.-L., Chalié, F., Haghani, S., Shah-Hosseini, M., Shahkarami, S.A., Tudryn, A., Arpe, K., Habibi, P., Nasrollahzadeh, H.S., Makhlough, A., 2013a. A two-step expansion of the dinocyst Lingulodinium machaerophorum in the Caspian Sea: the role of changing environment. Quat. Sci. Rev. 77, 31-45.

Leroy, S.A.G., Tudryn, A., Chalié, F., López-Merino. L., Gasse, F., 2013b. From the Allerød to the mid-Holocene: palynological evidence from the south basin of the Caspian Sea. Quat. Sci. Rev. 78, 77-97.

Leroy, S.A.G., Kakroodi, A.A., Kroonenberg, S.B., Lahijani, H.A.K., Alimohammadian, H., Nigarov, A., 2013c. Holocene vegetation history and sea level changes in the SE corner of the Caspian Sea: relevance to SW Asia climate. Quat. Sci. Rev. 70, 28-47.

Leroy, S.A.G., López-Merino, L., Tudryn, A., Chalié, F., Gasse, F., 2014. Late Pleistocene and Holocene palaeoenvironments in and around the middle Caspian basin as reconstructed from a deep-sea core. Quat. Sci. Rev. 101, 91-110.

Lewis, J., 1991. Cyst-theca relationships in Scrippsiella (Dinophyceae) and related orthoperidinioid genera. Bot. Marina 34, 91-106.

Lewis, J., Hallett, R., 1997. Lingulodinium polyedrum (Gonyaulax polyedra) a blooming dinoflagellate. Oceanog. Mar. Biol. Ann. Rev. 35, 97-161. 
Lewis, J., Dodge, J.D., Tett, P., 1984. Cyst-theca relationships in some Protoperidinium species (Peridiniales) from Scottish sea lochs. J. Micropalaeontol. 3(2), 25-34.

Lewis, J., Rochon, A., Harding, I., 1999. Preliminary observations of cyst-theca relationships in Spiniferites ramosus and Spiniferites membranaceus (Dinophyceae). Grana 38, 113-124.

Lewis, J., Rochon, A., Ellegaard, M., Mudie, P., Harding, I., 2001. The cyst-theca relationship of Bitectatodinium tepikiense (Dinophyceae). Euro. J. Phycol. 36(2), 137-146.

Li, Z., Han, M-S, Matsuoka, K., Kim, S-Y., Shin, H.H., 2015. Identification of the resting cysts of Cochlodinium polykrikoides Margalef (Gymnodiniales, Dinophyceae) in Korean coastal sediments. J. Phycol. 51(1), 206-210.

Lim, A.S., Jeong, H.J., Jang, T.Y., Jang, S.H., Franks, P.J.S., 2014. Inhibition of growth rate and swimming speed of the harmful dinoflagellate Cochlodinium polykrikoides by diatoms: implications for red tide formation. Harmful Algae 37, 53-61.

Limoges, A., Kielt, J-F., Radi, T., Ruiz-Fernandez, A.C., de Vernal, A., 2010. Dinoflagellate cyst distribution in surface sediments along the south-western Mexican coast $\left(14.76^{\circ} \mathrm{N}\right.$ to 24.75N). Mar. Micropaleontol. 76, 104-123.

Limoges, A., Londeix, L., de Vernal, A., 2013. Organic-walled dinoflagellate cyst distribution in the Gulf of Mexico. Mar. Micropaleontol. 102, 51-68.

Limoges, A., de Verrnal, A., Van Nieuwenhove, N., 2014. Long-term hydrological changes in the northeastern Gulf of Mexico (ODP-625B) during the Holocene and late Pleistocene inferred from organic-walled dinoflagellate cysts. Palaeogeogr., Palaeoclimatol., Palaeoecol. 414, $178-191$.

Limoges, A., Londeix, L., Mertens, K.N., Rochon, A., Pospelova, V., de Vernal, A., del Carmen Cuéllar, T., 2016. Towards an identification key for Pliocene and Quaternary 
Spiniferites taxa bearing intergonal processes based on observations from estuarine and coastal environments. Palynology, accepted 2016.

Lister, C.J., Hiscott, R.N., Aksu, A.E., Mudie, P.J., 2015. Compositional trends through the Holocene mud succession of the southwestern Black Sea shelf: implications for sedimentary provenance and water-level history. Sed. Geol. 316, 13-25.

Liu, T., Mertens, K.N., Ribeiro, S., Ellegaard, M., Matsuoka, K., Gu, H., 2015. Cyst-theca relationships and phylogenetic positions of Peridiniales (Dinophyceae) with two anterior intercalary plates, with description of Archaeperidinium bailongense sp. nov. and Protoperidinium fuzhouense sp. nov. Phycol. Res. 63, 134-151.

Llope, M., Daskalov, G.M., Rouyer, T.A., Mihnevas, V., Chan, K-S., Grishin, A.N., Stenseth, N.C., 2011. Overfishing of top predators eroded the resilience of the Black Sea system regardless of the climate and anthropogenic conditions. Global Change Biol. 17, 1251-1265.

Londeix, L., Benzakour, M., Suc, J.-P., 2007. Messinian palaeoenvironments and hydrology in Sicily (Italy): The dinoflagellate cyst record. Geobios 40, 233-250.

Londeix, L., Benzakour, M., de Vernal, A., Turon, J.-L., Suc, J.-P., 1999: Late Neogene dinoflagellate cyst assemblages from the Strait of Sicily, central Mediterranean Sea: paleoecological and biostratigraphical implications. In: Wrenn, J.H., Suc, J.-P., Leroy, S.A.G. (eds), The Pliocene: Time of Change, p.65-91; AASP Foundation, Dallas, U.S.A.

Londeix, L., Herreyre, Y., Turon, J.-L., Fletcher, W., 2009. Last Glacial to Holocene hydrology of the Marmara Sea inferred from a dinoflagellate cyst record. Rev. Palaeobot. Palynol. 158, 52-71.

Londeix, L., Herreyre, Y., Turon, J.-L., Fletcher, W., 2010. Erratum to "Last glacial to Holocene hydrology of the Marmara Sea inferred from a dinoflagellate cyst record" [Review Palaeobotany and Palynology 158 (2009) 52-71]. Rev. Palaebot. Palynol. 159(3-4), 204. 
Lundholm, N., Nielsen, L.R., Ribeiro, S., Ellegaard, M., 2014. Microsatellite markers for the palaeo-temperature indicator Pentapharsodinium dalei (Dinophyceae). J. Appl. Phycol. 26, 417-420.

Luo, Z, Mertens, K.N., Bagheri, S., Aydin, Takano, Y., Matsuoka, K., McCarthy, M.G., Gu, H., 2016. Cyst-theca relationship and phylogenetic positions of Scrippsiella plana sp. nov. and $S$. spinifera (Peridiniales, Dinophyceae). European J. Phycology online, ISSN 0967-0262 (Print), 1469-4433 (Online).

Mahmoudi, N., Robeson II, M.S., Castro, H.F., Fortney, J.L., Techtmann, S.M., Joyner, D.C., Paradis, C.J., Pfiffner, S.M., Hazen, T.C., 2015. Microbial community composition and diversity in Caspian Sea sediments. FEMS Microb. Ecol. 91, 1-11.

Marinova, E., Atanassova, J., 2006. Anthropogenic impact on vegetation and environment during the Bronze Age in the area of Lake Durankulak, NE Bulgaria: pollen, microscopic charcoal, non-pollen palynomorphs and plant macrofossils. Rev. Palaeobot. Palynol. 141, 165178.

Marino, G., Sangiorgi, F., Brinkhuis, H., 2008. Reconstructing changes in marine productivity at the time of S1 deposition in the eastern Mediterranean; a marine palynological approach. Chapter 4 of PhD Dissertation of G. Marino, Inst. Environ. Biology, Utrecht University, pp.73-90.

Marret, F., Scourse, J., 2002. Control of modern dinoflagellate cyst distribution in the Irish and Celtic seas by seasonal stratification dynamics. Mar. Micropaleontol. 47, 101-116.

Marret, F., Zonneveld, K.A.F., 2003. Atlas of Organic-Walled Dinoflagellate Cyst Distribution. Rev. Palaeobot. Palynol. 125, 1-200.

Marret, F., Garcés, 2013. Future research foci for the ecology and palaeoecology of dinoflagellates and their cysts. In: Lewis, J., Marret, F., Bradley, L. R. (eds.), Biological and 
Geological Perspectives of Dinoflagellates. Micropalaeo. Soc., Spec. Publ. Geol. Soc., London, pp. $181-188$.

Marret, F., Leroy, S., Chalié, F., Gasse, F. 2004. New organic-walled dinoflagellate cysts from recent sediments of Central Asian seas. Rev. Palaeobot. Palynol. 129, 1-20.

Marret, F., Mudie, P., Aksu, A., Hiscott, R.N., 2009. A Holocene dinocyst record of a twostep transformation of the Neoeuxinian brackish water lake into the Black Sea. Quat. Internat. 197(1), 72-86.

Matishov, G.G., Stepan'yan, O.V., Kovaleva, G.V., Povashnyi, V.V., Kreneva, K.V., 2012. Specific structural features of the Sea of Azov pelagic community during the abnormally cold winter of 2005-2006. Southern Research Center Russian Acad. Sci. 8(4), 66-75. [In Russian].

Matsuoka, K., 1982. Dinoflagellate cysts in surface sediments of Omura Bay, West Kyushu, Japan. In Fundamental Studies of the Effects of Marine Environment of the Outbreak of Red Tides. Reports Environ. Sci., B. 148-R14-8. Monbusho: Tokyo, Japan, pp. 197-204.

Matsuoka, K., 1984. Cyst and theca of Protoperidinium avellana (Meunier) Balech, (Dinophyceae). Bulletin of the Faculty of Liberal Arts, Nagasaki University. Natural Science $25(1), 37-47$.

Matsuoka, K., 1985a. Archeopyle structure in modern Gymnodinialean dinoflagellate cysts. Rev. Palaeobot. Palynol. 44, 217-281.

Matsuoka, K., 1985b. Organic-walled dinoflagellate cysts from surface sediments of Nagasaki Bay and Senzaki Bay, west Japan. Faculty of Liberal Arts, Nagasaki University, Nat. Sci., Bull. $25(2), 21-115$.

Matsuoka, K., 1987: Organic-walled dinoflagellate cysts from surface sediments of Akkeshi Bay and Lake Saroma, north Japan. Faculty Liberal Arts, Nagasaki U., Nat. Sci., Bull. 28, $35-123$. 
Matsuoka, K., 1988. Cyst-theca relationship in the diplopsalid group (Peridiniales, Dinophyceae). Rev. Palaeobot. Palynol. 56: 95-122.

Matsuoka, K., Bujak, J.P., 1988. Cenozoic dinoflagellate cysts from the Navarin Basin, Norton Sound and St. George Basin, Bering Sea. Nagasaki U., Faculty-Liberal Arts, Nat. Sci., Bull. 29, 1-147.

Matsuoka, K., Fukuyo, Y., 1986. Cyst and motile morphology of a colonial dinoflagellate Pheopolykrikos hartmannii (Zimmermann) comb. nov. J. Plankton Res. 8(4), 811-818.

Matsuoka, K., Fukuyo, Y., 2000. Technical Guide for Modern Dinoflagellate Cyst Study. WESTPAC-HAB/WEATPAC/IOC, Japanese Society for the Promotion of Science, 29 pp. Matsuoka, K., Fukuyo, Y., 2003. Taxonomy of Cysts. In Hallegraeff, G.M., Anderson, D.M. and Cembella, A.D. (eds.), Manual on Harmful Marine Microalgae, pp. 563-592, Monographs on Oceanographic Methodology, UNESCO Publishing.

Matsuoka, K., Head, M.J., 2013. Clarifying cyst-motile stage relationships dinoflagellates. In: Lewis, J.M., Marret, F., Bradley, L. (eds.), Biological and geological perspectives of dinoflagellates, The Micropalaeo. Soc. Spec. Publ., Geol. Soc., London; pp. 325-50.

Matsuoka, K., Kobayashi, S., Iizuka, S., 1982. Cysts of Protoperidinium divaricatum (Meunier) Parke et Dodge 1976 in surface sediment of Omura Bay, West Japan. Rev. Paleobot. Palynol. 38, 109-118.

Matsuoka, K., McMinn, A., Wrenn, J.H., 1997. Restudy of the holotype of Operculodinium centrocarpum (Deflandre \& Cookson) Wall (Dinophyceae) from the Miocene of Australia, and the taxonomy of related species. Palynology 21, 19-33.

Matsuoka, K., Pholpunthin, P., Fukuyo, Y., 1998. Is the archeopyle of Tuberculodinium vancampoae (Rossignol) (Gonyaulacales, Dinophyceae) on the hypocyst? Paleontolog. Res. 2(3), 183-192. 
Matsuoka, K., Iwataki, M., Kawami, Fujii, R., H., Iwataki, M., 2006. Further examination of the cyst-theca relationship of Protoperidinium thulesense (Peridiniales, Dinophyceae) and the phylogenetic significance of round brown cysts. Phycologia 45 (6), 632-641.

Matsuoka, K., Iwataki, M., Kawami, H., 2008. Morphology and taxonomy of chain-forming species of the genus Cochlodinium (Dinophyceae). Harmful Algae 7(3), 261-270.

Matsuoka, K., Kawami, H., Nagai, S., Iwataki, M., Takayama, H., 2009. Reexamination of cyst-motile relationships of Polykrikos kofoidii Chatton and Polykrikos schwartzii Bütschli (Gymnodiniales, Dinophyceae). Rev. Palaeobot. Palynol. 154 (1-4), 79-90.

Matthiessen, J., Brenner, W.W., 1996. Dinoflagellate cyst ecostratigraphy of Pliocene/Pleistocene sediments from Yermak Plateau (Arctic Ocean, Hole 911A). In: Thiede, J., Myhre, A.M., Firth, J.V., Johnson, G.L., Ruddiman, W.F. (eds.), Proc. ODP, Sci. Results 151, Government Printing Office: College Station, Texas; pp. 243-253.

McCarthy, F.M.G., Krueger, A.M. 2013. Freshwater dinoflagellates in palaeolimnological studies: Peridinium cysts as proxies of cultural eutrophication in the SE Great Lakes region of Ontario, Canada. In: Lewis, J.M., Marret, F., Bradley, L. (eds.), Biological and Geological Perspectives of Dinoflagellates. The Micropalaeontological Society, Special Publications. Geological Society, London, pp. 133-139.

McCarthy, F.M.G., Mertens, K.N., Ellegaard, M., Sherman, K., Pospelova, V., Ribeiro, S., Blasco, S., Vercauteren, D., 2011. Resting cysts of freshwater dinoflagellates in southeastern Georgian Bay (Lake Huron) as proxies of cultural eutrophication. Rev. Palaeobot. Palynol. 166, 46-62,

McMinn, A, Bolch, C.J.S., De Salas, M.F., Hallegraeff, G.M., 2010. Recent dinoflagellate cysts. In: Hallegraeff,, G.M., Bolch, C.J.S., Hill, D.R.A., Jameson, I., LeRoi, J.M., McMinn, A., 
Murray, S.,de Salas, M.F., Saunders, K. (eds.), Algae of Australia: Phytoplankton of Temperate Coastal Waters, Australian Biological Resources Study/CSIRO Publishing, pp. 260-292.

Mee, L.D., Friedrich, J., Gomoiu, M.T., 2005. Restoring the Black Sea in times of uncertainty. Oceanography 18(2), 100-111.

Mertens, K.N., Verhoeven, K.; Verleye, T.J.; Louwye, S.; Amorim, A.; Ribeiro, S.; Deaf, A.S.; Harding, I.C.; De Schepper, S.; Kodrans-Nsiah and 26 others, 2009a. Determining the absolute abundance of dinoflagellate cysts in recent marine sediments: The Lycopodium markergrain method put to the test. Rev. Palaeobot. Palynol. 157(3-4), 238-252.

Mertens, K.N., Ribeiro, S., Bouimetarhan, I., Caner, H., Combourieu Nebout, N., Dale, B., de Vernal, A., Ellegaard, M., Filipova, M., Godhe, A., Grøsfjeld, K. and 18 others, 2009b. Process length variation in cysts of a dinoflagellate, Lingulodinium machaerophorum, in surface sediments: Investigating its potential as salinity proxy. Mar. Micropaleontol. 70(1-2), 54-69.

Mertens, K.N., Dale, B., Ellegaard, M., Jansson, I-M., Godhe, A., Kremp, A., Louwye, S., 2011. Process length variation in cysts of the dinoflagellate Protoceratium reticulatum, from surface sediments of the Baltic-Kattegat-Skagerrak estuarine system: a regional salinity proxy. Boreas 40(2), 242-255.

Mertens, K.N., Price, A.M., Pospelova, V., 2012a. Determining the absolute abundance of dinoflagellate cysts in recent marine sediments II: Further tests of the Lycopodium marker-grain method. Rev. Palaeobot. Palynol. 184, 74-81.

Mertens, K.N., Bradley, L.R., Mudie, P.J., Aksu, A.E., Hiscott. R.N. and 7 others, $2012 b$. Quantitative estimation of Holocene surface salinity variation in the Black Sea using dinoflagellate cyst process length. Quat. Sci. Rev. 39(16), 45-59.

Mertens, K.N., Bringué, M., Van Nieuwenhove, N., Takano, Y., Pospelova, V., and 9 others, 2012c. Process length variation of the cyst of the dinoflagellate Protoceratium reticulatum in the 
North Pacific and Baltic-Skagerrak region: calibration as an annual density proxy and first evidence of pseudo-cryptic speciation. J. Quat. Sci. 27(7), 734-744.

Mertens, K.N., Rengefors, K., Moestrup, Ø., Ellegaard, M., 2012d. A review of recent freshwater dinoflagellate cysts: taxonomy, phylogeny, ecology and palaeocology. Phycologia $51(6), 612-619$.

Mertens, K.N., Takano, Y., Gu, H., Yamaguchi, A., Poselova, V., Ellegaard, Matsuoka, K., 2015a. Cyst-theca relationship of a new dinoflagellate with a spiny round brown cyst, Protoperidinium lewisiae sp. nov., and its comparison to the cyst of Oblea acanthocysta. Phycol. Res. 63(2), 110-124.

Mertens, K.N., Takano, Y., Yamaguchi, A., Gu, H., Bogus, K., Kremp, A., Bagheri, S., Matishov, G., Matsuoka, K., 2015b. The molecular characterization of the enigmatic dinoflagellate Kolkwitziella acuta reveals an affinity to the Excentrica section of the genus Protoperidinium. Syst. Biodivers. 13(6), 509-524.

Mertens, K.N., Aydin, H., Uzar. S., Takano, Y., Yamaguchi, A., Matsuoka, K., 2015c. Relationship between the dinoflagellate cyst Spiniferites pachydermus and Gonyaulax ellegaardiae sp. nov. from Izmir Bay, Turkey, and molecular characterization. J. Phycol. 51(3), $560-573$.

Mertens, K.N., Wolny, J., Carbonell-Moore, C., Bogus K., Ellegaard, M., and six others, 2015d. Taxonomic re-examination of the toxic armored dinoflagellate Pyrodinium bahamense Plate 1906: Can morphology or LSU sequencing separate P. bahamense var. compressum from var. bahamense? Harmful Algae 41, 1-24.

Mertens, K.N., Gu, H., Takano, Y., Price, A.M., Pospelova, V., Bogus, K., Versteegh, G.J.M., Marret, F., Turner, R.E., Rabalais, N.N., Matsuoka, K., 2017. The cyst-theca relation of 
Trinovantedinium pallidifulvum, with erection of Protoperidinium lousianensis sp. nov. and their phylogenetic position within the Conica group. Palynology 41(2), 183-202.

Mertens, K.N., Takano, Y., Gu, H., Bagheri, S., Pospelova, V., Pieńkowski, A.J., Leroy, S., Matsuoka, K., in press. Cyst-theca relationship and phylogenetic position of Impagidinium caspienense incubated from Caspian Sea surface sediments: evidence for heterospory within gonyaulacoid dinoflagellates. Journal of Eukaryotic Microbiology, accepted April 2017.

Micklin, P., 2007. The Aral Sea disaster. Ann. Rev. Earth Planet. Sci. 35, 47-72.

Micklin, P., Aladin, N.V., Plotnikov, I. (eds.), 2014. The Aral Sea. The Devastation and Partial Rehabilitation of a Great Lake. Berlin, Heidelberg: Springer-Verlag.

Mirabdullayev, I.M., Joldasova, I.M., Mustafaeva, Z.A. 2004. Succession of the ecosystems of the Aral Sea during its transition from oligohaline to polyhaline water body, J. Mar. Syst., 47, $101-107$.

Moestrup, Ø., Lindberg, K., Daugbjerg, N. 2009. Studies on wolosynskoid dinoflagellates IV: The genus Biecheleria gen. nov. Phycol. Res. 57, 203-220.

Moestrup, Ø., Akselmann, R., Fraga, S., Hansen, G., Hoppenrath, M., Iwataki, M., Komárek, J., Larsen, J., Lundholm, N, Zingone, A. (eds.) (2009 onwards). IOC-UNESCO Taxonomic Reference List of Harmful Micro Algae. Accessed at http://www.marinespecies.org/hab in February 2016.

Molavi-Arabshahi, M., Arpe, K., Leroy, S.A.G., 2016. Precipitation and temperature of the Southwest Caspian Sea during the last 55 years, their trends and teleconnections with large-scale atmospheric phenomena. Internat. J. Climatol. 36, 2156-2172.

Moncheva, S. P., Kamburska, L.T., 2002. Plankton stowaways in the Black Sea — impacts on biodiversity and ecosystem health. CIESM Workshop Monographs 20, 47-51. 
Moncheva, S., Petrova-Karadjova, V., Palasov, A., 1995. Harmful algal blooms along the Bulgarian Black Sea Coast and possible patterns of fish and zoobenthic mortalities. In: Lassus, P., Arzul, G., Erard, P., Gentien, E., Marcaillou, C. (eds.), Harmful Marine Algal Blooms, Lavoisier Intercept Ltd.: Paris; pp. 193-198.

Montresor, M., 1995. The life history of Alexandrium pseudogonyaulax. Phycol. 34(6), 444-448.

Montresor, M., Zingone, A., Marino, D., 1993. The paratabulate resting cyst of Alexandrium pseudogonyaulax (Dinophyceae). In: Smayda, T.J., Shimizu, Y., (eds.), Toxic Phytoplankton Blooms in the Sea, Developments in Marine Biology 3, Elsevier Science Publications: Amsterdam; pp. 159-164.

Montresor, M., Zingone, A., Sarno, D., 1998. Dinoflagellate cyst production at a coastal Mediterranean site. J. Plankton Res. 20(12), 2291-2312.

Montresor, M., Sgrosso, S., Procaccini, G., Kooistra, W.H.C.F., 2003. Intraspecific diversity in Scrippsiella trochoidea (Dinophyceae): evidence for cryptic species. Phycologia 42, 56-70.

Montresor, M., Bastianini, M., Cucchiari, E., Giacobbe, M.G., Penna, A., Rubino, F., Satta, C.T., 2010. Stadi di resistenza del fitoplancton. In: Socal, G, Buttino, I., Cabrini, M., Mangoni, O., Penna, A. et al., (eds.). Metodologie di studio del plancton marino. Roma: ISPRA. pp. $258-273$.

Moradi, M., 2014. Comparison of the efficacy of MODIS and MERIS data for detecting cyanobacterial blooms in the southern Caspian Sea. Mar. Pollut. Bull. 87(1-2), 311-322.

Mousing, E.A., Andersen, T.J., Ellegaard, M., 2013. Changes in the abundance and species composition of phytoplankton in the last 150 Years in the Southern Black Sea. Estuar. Coasts 36(6), 1206-1218. 
Mudie, P.J., Rochon, A., 2001. Distribution of dinoflagellate cysts in the Canadian Arctic marine region. J. Quat. Sci. 16(7), 603-620.

Mudie, P.J., Aksu, A.E., Yaşar, D., 2001. Late Quaternary dinoflagellate cysts from the Black, Marmara and Aegean seas: variations in assemblages, morphology and paleosalinity. Mar. Micropaleontol. 43(1-2), 155-178.

Mudie, P.J., Rochon, A., Aksu, A.E., Gillespie, H., 2002a. Dinoflagellate cysts, freshwater algae and fungal spores as salinity indicators in Late Quaternary cores from Marmara and Black seas. Mar. Geol. 190, 203-231.

Mudie, P.J., Rochon, Levac, E., 2002b. Palynological records of red tide producing species in Canada: Past trends and implications for the future. Palaeogeog., Palaeoclimatol., Palaeoecol. $180(1-3), 159-186$.

Mudie, P.J., Rochon, A., Aksu, A.E., Gillespie, H., 2004. Late glacial, Halocene and modern dinoflagellate cyst assemblages in the Aegean-Marmara-Black Sea corridor: statistical analysis and re-interpretation of the early Holocene Noah's Flood hypothesis. Rev. Palaeobot. Palynol. $128,143-167$.

Mudie, P.J., Marret, F., Rochon, A., Aksu, A.E., 2010. Non-pollen palynomorphs in the Black Sea corridor. Veg. Hist. Archaeobot. 19, 531-544.

Mudie, P.J., Leroy, S.A.G., Marret, F., Gerasimenko, N., Kholeif, S.E.A., Sapelko, T., Filipova-Marinova, M., 2011. Nonpollen palynomorphs: Indicators of salinity and environmental change in the Caspian-Black Sea-Mediterranean corridor. Geol. Soc. Am., Spec. Paper 473, $1-27$.

Mudie, P., Rochon, A., Richards, K., Ferguson, S., Warny, S., 2016. Spiniferites cruciformis, Pterocysta cruciformis and Galeacysta etrusca: morphology and paleoecology. Palynology, accepted July 2016. 
Naderi Beni, A., Lahijani, H., Mousavi Harami, R., Arpe, K., Leroy, S.A.G., and 6 others, 2013. Caspian sea-level changes during the last millennium: historical and geological evidence from the south Caspian Sea. Clim. Past 9, 1645-1665.

Nagai, S., Matsuyama, Y., Takayama, H., Kotani, Y., 2002. Morphology of Polykrikos kofoidii and P. schwartzii (Dinophyceae, Polykrikaceae) cysts obtained in culture. Phycologia 41(4), 319-327.

Narale, D.D., Patil, J.S., Anil, A.C., 2013. Dinoflagellate cyst distribution in recent sediments along the south-east coast of India. Oceanologia 55 (4), 979-1003.

Nasrollahzadeh, H.S., Din, Z.B., Foong, S.Y., Maklough, A., 2008. Trophic status of the Iranian Caspian Sea based on water quality parameters and phytoplankton diversity. Cont. Shelf Res., 28, 1153-1165.

Nasrollahzadeh, H.S., Din, Z.B., Makhlough, A., 2013. The Water Chemistry and Phytoplankton Community of the Caspian Sea. LAP Publishing: Saarbrucken, Germany; 174 pp.

Nasrollahzadeh, H.S., Makhlough, A., Eslami F., Leroy, S.A.G., 2014. Features of the Phytoplankton Community in the Southern Caspian Sea, a decade after the invasion of Mnemiopsis leidyi. Iranian J. Fish. Sci. 13(1), 145-167.

Nehring, S., 1994. Spatial distribution of dinoflagellate resting cysts in Recent sediments of Kiel Bight, Germany (Baltic Sea). Ophelia 39(2), 137-158.

Nesterova, D., Moncheva, S., Mikaelyan, A., Vershinin, A., Akatov, V., Boicenco, L.Y., Aktan, Y., Sahin, F., Gvarishvili, T., 2009. State of Environment Report 2000 - 2006/7; Ch. 5, The State of Phytoplankton, pp. 135-158._http://www.blacksea-commission.org/_publSOE2009-CH5.asp.

Norris, G., McAndrews, J.H., 1970. Dinoflagellate cysts from post-glacial lake muds, Minnesota, U.S.A. Rev. Palaeobot. Palynol. 10, 131-156. 
Nümann W., 1955. Izmir Körfezi’nde “Balık kırılması”hadisesi. Hidrob. Mec., Ser. A, 3(2): 90-93. [In Turkish; cited by Beauchard et al., 2016].

Nuzzo, L., Montresor, M., 1999. Different excystment patters in two calcareous cystproducing species of the dinoflagellate genus Scrippsiella. J. Plankton Res. 21(10), 2009-2018.

Olenin, S., 2002. Black Sea-Baltic Sea invasion corridors. CIESM Workshop Monographs 20, 29-33.

Olrik, K., 1992. Ecology of Peridinium willei and P. volzii (Dinophyceae) in Danish lakes. Nord. J. Bot. 12, 557-568.

Orlova, M.I., Rusakova, O.M., 1999. Characteristics of coastal phytoplankton near Cape Tastubec (northern Aral Sea), September 1993. Internat. J. Salt Lake Res. 8: 7-18.

Orlova, T.Y., Morozova, T.V., 2009. Resting stages of microalgae in recent marine sediments of Peter the Great Bay, Sea of Japan. Russian J. Mar. Biol. 34(4), 313-322.

Orlova, T.Y, Konovalova, G.V., Stonik, I.V., Selina, M.S., Tatyana V. Morozova, T.V., Shevchenko, O.G., 2002. Harmful algal blooms on the eastern coast of Russia. In: F.J.R. "Max" Taylor and Vera L. Trainer, eds., Harmful algal blooms in the PICES region of the North Pacific. PICES Scientific Report 23: 47-57.

Ostenfeld, C.H., 1908. The phytoplankton of the Aral Sea and its affluents, with an enumeration of the Algae observed. St Petersburg, Russia. Wissenschaftliche Ergebnisse der Aralsee-Expedition. Lieferung 8, 123-225, pl. 5.

Özturk, B., 2002. The Ponto-Caspian region: predicting the identity of potential invaders. CIESM Workshop Monographs 20, 75-78.

Owen, K.C, Norris, D.R., 1985. Cysts and life cycle considerations of the thecate dinoflagellate Fragilidium. J. Coast. Res. 1(3), 263-266. 
Paez-Reyes, M., Head, M.J., 2013. The Cenozoic Gonyaulacacean dinoflagellate genera Operculodinium Wall, 1967 and Protoceratium Bergh, 1881 and their phylogenetic relationships. J. Paleontol. 87(5), 786-803.

Paavola, M., Olenin, S., Leppäkoski, E., 2005. Are invasive species most successful in habitats of low native species richness across European brackish water seas? Estuar. Coast. Shelf Sci. 64, 738-750.

Pancucci-Papadopoulou, M.A., Zenetos, A., Corsini-Foka, M., Politou, C-Y., 2005. Update of marine alien species in Hellenic waters. Med. Mar. Sci. 6 (2), 147-158.

Pasqueron de Fommervault, O., D’Ortenzio, F., Mangin, A., Serra, R., Migon, C., and eleven others, 2015. Seasonal variability of nutrient concentrations in the Mediterranean Sea: Contribution of Bio-Argo floats. J. Geophys. Res. Oceans 120, 8528-8550.

Paz, B., Daranas, A.H., Norte, M., Riobó, P., Franco, J.M., Fernández, J.J., 2008. Yessotoxins, a group of marine polyether toxins: an overview. Marine Drugs 6(2), 73-102. Peeters, F., Kipfer, R., Achermann, D., Hofer, M., Aeschbach-Hertig, W., Beyerle, U., Imboden, D.M., Rozanski, K., Fröhlich, K., 2000. Analysis of deep-water exchange in the Caspian Sea based on environmental tracers. Deep-Sea Res. I 47, 621-654.

Perejaslawzewa, S., 1886. Protozoa of the Black Sea. Schr. Naturforsch. Gesellsch. Odessa 10, $79-114$ (in Russian).

Piskaln, C.H., 1991. Biogenic aggregate sedimentation in the Black Sea Basin, In: Izdar, E., Murray, J.W. (eds.), Black Sea Oceanography, Kluwer Academic Publishers, The Netherlands., pp. $293-306$.

Piskaln, C.H., Pike, J. 2001. Formation of Holocene sedimentary laminae in the Black Sea and the role of the benthic flocculent layer. Paleoceanography 16, 1-19. 
Popescu, S-M., Dalesme, F., Jouannic, G., Escarguel, G., Head, M. J., Melinte-Dobrinescu, M. C., Süto-szentai, M., Bakrac, K., Clauzon, G., Suc, J-P., 2009. Galeacysta etrusca complex: dinoflagellate cyst marker of Paratethyan influxes to the Mediterranean Sea before and after the peak of the Messinian Salinity Crisis. Palynology 33 (2), 105-134.

Popov, S.V., Shcherba, I.G., Ilyina, L.B, Nevesskaya, L.A, Paramonova, N.P., Khondkarian, S.O., Magyar, I., 2006. Late Miocene to Pliocene palaeogeography of the Paratethys and its relation to the Mediterranean. Palaeogeog., Palaeoclimatol., Palaeoecol. 238, 91-106.

Pospelova, V., Kim, S.-J., 2010. Dinoflagellate cysts in recent estuarine sediments from aquaculture sites of southern South Korea. Mar. Micropaleontol. 76, 37-51.

Price, A.M., Pospelova, V., 2011. High-resolution sediment trap study of organic-walled dinoflagellate cyst production and biogenic silica flux in Saanich Inlet (BC, Canada). Mar. Micropaleontol. 80, 18-43.

Price, A.M., Gurdebeke, P.R., Mertens, K.N., Pospelova, V., 2016. Determining the absolute abundance of dinoflagellate cysts in recent marine sediments III: Identifying the source of Lycopodium loss during palynological processing and further testing of the Lycopodium markergrain method. Rev. Palaeobot. Palynol. 226, 78-90.

Radi, T., Bonnet, S., Cormier, M.A., de Vernal, A., Durantou, L., Faubert, E., Head, M.J., Henry, M., Pospelova, V., Rochon, A., Van Nieuwenhove, N., 2013. Operational taxonomy and (paleo)-autecology of round, brown, spiny dinoflagellate cysts from the Quaternary of high northern latitudes. Mar. Micropaleontol. 74(3-4), 59-74.

Ramezanpour, Z., Imanpour, J., Arshad, U., Mehdinezhad, K., 2011. Algal blooms in the Caspian Sea. Intergovern. Oceanogr. Commis. UNESCO. Harmful Algal News 44, 10-11.

Reid, P.C. 1974. Gonyaulacacean dinoflagellate cysts from the British Isles. Nova Hedwigia $25,579-637$. 
Reid, P.C., 1977. Peridiniacean and glenodiniacean dinoflagellate cysts from the British Isles. Nova Hedwigia 29, 429-463.

Reñé, A., de Salas, M., Camp, J., Balagué, V., Garcés, E., 2013. A new clade, based on partial LSU rDNA sequences, of unarmoured dinoflagellates. Protist. 164(5), 673-685.

Ribeiro, S., Amorim, A. 2008. Environmental drivers of temporal succession in recent dinoflagellate cyst assemblages from a coastal site in the North-East Atlantic (Lisbon Bay, Portugal). Mar. Micropaleontol. 68, 156-178.

Ribeiro, S., Amorim, A., Andersen, T.J., Abrantes, F., Ellegaard, M., 2012. Reconstructing the history of an invasion: the toxic phytoplankton species Gymnodinium catenatum in the Northeast Atlantic. Biol. Invasions 14 (5), 969-985.

Richards, K., Bolikhovskaya, N.S., Hoogendoorn, R.M., Kroonenberg, S.B., Leroy, S.A.G., Athersuch, J., 2014. Reconstructions of deltaic environments from Holocene palynological records in the Volga delta, northern Caspian Sea. The Holocene 24(10), 1226-1252.

Richards, K., Mudie, P., Rochon, A., Athersuch, J., Bolikhovskaya, N., Hoogendoorn, R., Verlinden, V., 2017. Late Pleistocene to Early Holocene vegetation, climate and depositional change in the Emba Delta, Kazakhstan, north-eastern Caspian Sea: evidence from sediments, ostracods, pollen and dinoflagellate cysts. Palaeogeog., Palaeoclim., Palaeoecol., online.

Roberts, K., 2012. Paleoenvironment of Marmara Sea: Palynology of Upper Pleistocene Holocene Sediments in Long Piston Cores. MSc Dissertation, Dept. Earth Sci., Memorial University of Newfoundland, $162 \mathrm{pp}$.

Rochon, A., de Vernal, A., Turon, J.L., Matthiessen, J., Head, M.J., 1999. Distribution of recent dinoflagellate cysts in surface sediments from the North Atlantic Ocean and adjacent seas in relation to sea-surface parameters. AASP Found. Contrib. Series 35, 1-152. 
Rochon, A, Mudie P.J., Aksu, A.E., Gillespie, H., 2002. Pterocysta gen. nov. dinoflagellate cyst from Pleistocene glacial-stage sediments of the Black and Marmara seas. Palynology, 26: $95-105$.

Rochon, A., Lewis, J., Ellegaard, M., Harding, I.C., 2009. The Gonyaulax spinifera (Dinophyceae) "complex": Perpetuating the paradox? Rev. Palaeobot. Palynol. 155, 52-60

Rodríguez, F., Riobó, P., Rial, P., Reguera, B., Franco, J.M., 2014. Feeding of Fragilidium cf. duplocampanaeforme and F. subglobosum on four Dinophysis species: prey specificity, local adaptation and fate of toxins. Aquatic Microbial Ecol. 72, 241-253.

Rosales-Loessener, F., Matsuoka, K., Fukuyo, Y., Sanchez, E.H., 1996. Cysts of harmful dinoflagellates found from Pacific coastal waters of Guatemala. In: Yasumoto, T., Oshima, Y., Fukuyo, Y. (eds.), Harmful and Toxic Algal Blooms. Intergovernmental Oceanographic Commission of UNESCO, Sendai, Japan; pp. 193-195.

Rossignol, M., 1962. Analyse pollinique de sédiments marins quaternaires en Israël II. Sédiments pleistocènes. Pollen et Spores 4, 121-148.

Rossignol, M., 1963. Aperçus sur le developpement des hystrichosphères. Bull., Mus. Nat. D’Hist. Ser. 2, 35(2), 207-212.

Rossignol, M., 1964. Hystrichosphères du Quaternaire en Méditerranée orientale, dans les sédiments Pléistocènes et les boues marines actuelles. Rev. de micropaléo.7(2), 83-99.

Saliot, A., Derieux, S., Sadouni, N., Bouloubassi, I., Fillaux, J., and 7 others, 2002. Winter and spring characterization of particulate and dissolved organic matter in the Danube-Black Sea Mixing Zone. Estuar. Coast. Shelf Sci. 54, 355-367.

Sampedro, N., Fraga, S., Penna, A., Casabianca, S., Zapata, M., Grünewald, C.F., Riobó, P., Camp, J., 2011. Barrufeta bravensis gen. nov. sp. (Dinophyceae): a new bloom-forming species from the northwestern Mediterranean Sea. J. Phycol. 47, 375-392. 
Sangiorgi, F., Donders, T.H., 2004. Reconstructing 150 years of eutrophication in the northwestern Adriatic Sea (Italy) using dinoflagellate cysts, pollen and spores. Estuar. Coast. Shelf Sci. 60, 69-79.

Sarai, C., Yamaguchi, A., Kawami, H., Matsuoka, K., 2013. Two new species formally attributed to Protoperidinium oblongum (Aurivillius) Park et Dodge (Peridiniales, Dinophyceae): Evidence from cyst incubation experiments. Rev. Palaeobot. Paynol.192, 103-118.

Satta, C.T., Anglès, S., Garcés, E., Lugliè, A., Padedda, B.M., Sechi, N., 2010. Dinoflagellate cysts in recent sediments from two semi-enclosed areas of the Western Mediterranean Sea subject to high human impact. Deep-Sea Res. II 57, 256-267.

Selina, M.S, Orlova, T.Y., 2009. Morphological peculiarities of Fragilidium mexicanum Balech 1988 (Dinophyta) from the far-eastern seas of Russia. Russian J. Mar. Biol. 35(2), 151-155.

Shiganova, T., Öztürk, B. Trend on increasing Mediterranean species arrival into the Black Sea. In: Briand, F. (ed.), CIESM, 2010. Climate forcing and its impacts on the Black Sea marine biota. $\mathrm{N}^{\circ} 39$ in CIESM Workshop Monographs, Monaco; 75-92.

Shnyukov, E.F., 2013. Mud volcanoes of the Black Sea as a prospecting indicator of methane gas hydrates. Lithology and Mineral Resources 48(2), 114-121.

Shumilovskikh, L.S., Marret, F., Fleitmann, D., Arz, H.W., Nowaczyk, N., Behling, H., 2013. Eemian and Holocene sea surface conditions in the southern Black Sea: organic-walled dinoflagellate cyst record from core 22-GC3. Mar. Micropaleontol. 101, 146-160.

Shumilovskikh, L.S., Fleitmann, D., N. R. Nowaczyk, N.R., Behling, H., Marret, F., Wegwerth, A., Arz, H.W., 2014. Orbital- and millennial-scale environmental changes between 64 and 20 ka BP recorded in Black Sea sediments. Clim. Past 10, 939-954. 
Shumilovskikh, L. S., Seeliger, M., Feuser, S., Novenko, E., Schlütz, F., Pint, A., Pirson, F., Brückner, H., 2016. The harbour of Elaia: A palynological archive for human/environmental interactions during the last 7500 years. Quat. Sci. Rev. 149, 167-187.

Soehner, S., Zinssmeister, C., Kirsch, M., Gottschling, M., 2012. Who am I — and if so, how many? Species diversity of calcareous dinophytes (Thoracosphaeraceae, Peridiniales) in the Mediterranean Sea. Org. Divers. Evol. 12, 339-348.

Sonneman, J.A., Hill, D.R.A., 1997. A taxonomic survey of cyst-producing dinoflagellates from recent sediments of Victorian coastal waters, Australia. Bot. Mar. 40, 149-177.

Sorokin, Y.I., 2002. The Black Sea - Ecology and Oceanography. Backhuys Publishers: Leiden, 875 pp.

Sorrel, P., Popescu, S.-M., Head, M.J., Suc, J.P., Klotz, S., H. Oberhänsli, H., 2006. Hydrographic development of the Aral Sea during the last 2000 years based on a quantitative analysis of dinoflagellate cysts. Palaeogeog., Palaeoclimat., Palaeoecol. 234, 304-327.

Sosson, M., Kaymaci, N., Stephenson, R., Bergerat, F., Starostenko, V., 2010. Sedimentary basin tectonics from the Black Sea and Caucasus to Arabian Platform: Introduction. In: Sosson, M., Kaymaci, N., Stephenson, R., Bergerat, F., Starostenko, V. (eds.), Sedimentary basin tectonics from the Black Sea and Caucasus to Arabian Platform. Geol. Soc. Lond. Spec. Publ. $340,1-10$.

Steininger, F.F., Wessely, G., 2000. From the Tethyan Ocean to the Paratethys Sea: Oligocene to Neogene Stratigraphy, Paleogeography and Paleobiogeography of the circum-Mediterranean region and the Oligocene to Neogene Basin evolution in Austria. Mitt. Öster. Geol. Ges. 92, 9516.

Stockmarr, J., 1971. Tablets with spores used in absolute pollen analysis. Pollen et Spores 13, $615-621$. 
Stover, L.E., Evitt, W.R., 1978. Analyses of pre-Pleistocene organic-walled dinoflagellates. Stanford U. Publ., Geol. Sci.15, 300 pp.

Strauss, C., Lund, J.J., 1992. A Middle Miocene dinoflagellate cyst microflora from Papendorf near Hamburg, Germany. Mitteil. Geolog.-Paläontolog. Inst. der Univ. Hamburg 73, 159-189.

Streftaris, N, Zenetos, A., Papathanassiou, E., 2005. Globalisation in marine systems: the story of non-indigenous marine species across European seas. Oceanog. Mar. Biol. Ann. Rev. 43, 419-453.

Sun, X., Song, Z., 1992. Quaternary dinoflagellates from arenaceous dolomite in Hainan Island. Acta Paleontolog. Sinica Mar. 9(1), 45-52.

Sütö-Szentai, M., 2000: Organic walled microplankton zonation of the Pannonian s.1. in the surroundings of Kaskantyú, Paks and Tengelic (Hungary). Ann. Rept. Geol. Inst. Hungary, 1994-1995, no. 2, 153-175.

Tang, Y.Z., Gobler, C.J., 2012. The toxic dinoflagellate Cochlodinium polykrikoides (Dinophyceae) produces resting cysts. Harmful Algae 20, 71-80.

Tardio, M., Ellegaard, M., Lundholm, N., Sangiorgi, S., Di Giuseppe, G., 2009. A hypocystal archeopyle in a freshwater dinoflagellate from the Peridinium umbonatum group (Dinophyceae) from Lake Nero di Cornisello, South Eastern Alps, Italy. Eur. J. Phycol. 44(2), 241-250.

Taş, S., Okuş, E., 2006. Investigation of qualitatively phytoplankton in the Turkish Coasts of the Black Sea and a species list. J. Black Sea/Mediterr. Environ. 12, 181-191.

Taş, S., Ergül, H.A., Balkis, N., 2016. Harmful algal blooms (HABs) and mucilage formations in the Sea of Marmara. In: Özoy, E., Çağatay, M.N., Balkis, Ne., Balkis, Nu., Özturk, B. (eds.), The Sea of Marmara Marine Biodiversity, Fisheries, Conservations and Governance. Publication No. 42, Istanbul, pp. 768-785. 
Telesh, I.V., Schubert, H., Skarlato, S.O., 2011. Revisiting Remane's concept: evidence for high plankton diversity and a protistan species maximum in the horohalinicum of the Baltic Sea. Mar. Ecol. Prog. Ser. 421, 1-11.

Terenko, L., 2005. New dinoflagellate (Dinoflagellata) species from the Odessa Bay of the Black Sea. Oceanol. Hydrobiol. Stud. 34 (Suppl. 3), 205-216 pp.

Terenko, L., Terenko, G., 2008. Dynamics of harmful algal blooms in the coastal Ukrainian Black Sea. Proc. 12th Intern. Conf. on Harmful Algae. - Hardbound, ISSHA and IOC of UNESCO: 291-295.

Throndsen, J., Hasle, G.R., Tangen, K., 2007. Phytoplankton of Norwegian coastal waters. Almater Forlag AS, Oslo. 343 p.

Toderascu, T., Rusu, E., 2013. Evaluation of the circulation patterns in the Black Sea using remotely sensed and in situ measurements. International J. Geosciences 2013(4), 1009-1017.

The MerMex Group: Durrieu de Madron, X, Guieu, C., Sempéré, R., Conan, P., Cossa, D., D’Ortenzio, F., Estournel, C., Gazeau, F., Rabouillem, C., Stemmann, L., and 84 others, 2011. Marine ecosystems' responses to climatic and anthropogenic forcings in the Mediterranean. Progress in Oceanog. 91, 97-166.

Török, L., 2009. The analysis of the information on algae and revised checklist from Danube Delta Biosphere Reserve. Sci. Annals Danube Delta Inst. (Tulcea, Romania) 15, 47-66.

Turon, J.-L., Londeix, L., 1988. Dinoflagellate assemblages in the western Mediterranean (Alboran Sea) evidence of the evolution of palaeoenvironments since the last glacial maximum. Bull. Centres Rech. Explor.-Prod.Elf-Aquitane 12, 313-344. [French, Engl.abstr.]. Tüfekçí, V., Balkis, N., Polat Beken, C., Edíger, D., Mantikçi, M., 2010. Phytoplankton composition and environmental conditions of a mucilage event in the Sea of Marmara. Turk. J. Biol. 34, 199-210. 
Turkoglu, M., 2013. Red tides of the dinoflagellate species Noctiluca scintillans associated with eutrophication in the Sea of Marmara (the Dardanelles, Turkey). Oceanologiia 55(3), 709-732.

Turkoglu, M., Oner, C., 2010. Short Time Variations of Winter Phytoplankton, Nutrient and Chlorophyll a of Kepez Harbor in the Dardanelles (Çanakkale Strait, Turkey). Turkish J. Fish. and Aquatic Sci. 10, 537-548.

Uzar, S., Aydin, H., Minareci, E., 2010. Dinoflagellate cyst assemblages in surface sediment from Izmir bay, Aegean Sea, East. Mediterr. Sci. Res. and Essays 5(3), 285-295.

van der Meer, M.T.J., Sangiorgi, F., Baas, M., Brinkhuis, H., Sinninghe Damsté, J.S., Schouten, S., 2008. Molecular isotopic and dinoflagellate evidence for Late Holocene freshening of the Black Sea. Earth Planet. Sci. Lett. 267, 426-434.

Velikova, V., Moncheva, S., Petrova, D., 1999. Plankton dynamics and red tide (1987-1997) in the Bulgarian Black Sea. Water Sci. Technol. 39(8), 27-36.

Verleye, T.J., Mertens, K.N., Louwye, S., Arz, H.W., 2009. Holocene salinity changes in the Southwestern Black Sea: a reconstruction based on dinoflagellate cysts. Palynology 33(1), $77-100$.

Verleye, T., Pospelova, V., Mertens, K.N., Louwye, S., 2011. The geographical distribution and (palaeo)ecology of Selenopemphix undulata sp. nov., a new late Quaternary dinoflagellate cyst from the Pacific Ocean. Mar. Micropaleontol. 78(3-4), 65-83.

Vershinin, A.O., Orlova, T. Yu., 2008.Toxic and Harmful Algae in the Coastal Waters of Russia. Oceanology 48(4), 524-537.

Vershinin A., Velikova V., 2008. New records and commonly misidentified dinoflagellates from the Black Sea. In: Sovremennie problemi Algologii: Materiali mejdunarodnoi nauchnoi konferencii VII Shkoli po morskoi biologii; Rostovna Donu, 448 pp. [in Russian, Engl abstr]. 
Vershinin, A.O., Moruchkov, A.A., Leighfield, T., Sukhanova, I., Morton, S., Pankov, S., Ramsdell, J., 2005. Potentially toxic algae in the composition of coastal phytoplankton of the northeast Black Sea in 2001-2002. Okeanologiya. 45(2), 240-248.

Vershinin, A.O., Morton, S., Leighfield, T., Pankov, S., Smith, L., Quilliam, M., Ramsdell, J., 2006. Alexandrium in the Black Sea - identity, ecology and PSP toxicity. African J. Mar. Sci. 28(2), 209-213.

Vidal, G., Ménot, G., Joly, C., Bruneton, H., Rostek, F., Çağatay, M.N., Major, C., Bard, E., 2010. Hydrology in the Sea of Marmara during the last $23 \mathrm{ka}$ : Implications for timing of Black Sea connections and sapropel deposition. Paleoceanography, PA1205, doi:10.1029/2009PA001735.

von Stosch, H.A., 1969. Dinoflagellaten aus der Nordsee II. Helgolandinium subglobosum gen. et spec.nov. Helgol. Wiss. Meeresunters 19, 569-577. [in German].

Walker, L.M., Steidinger, K.A., 1979. Sexual reproduction in the toxic dinoflagellate Gonyaulax monilata. J. Phycol. 15, 312-315.

Wall, D., 1967: Fossil microplankton in deep-sea cores from the Caribbean Sea. Palaeontology 10, 95-123.

Wall, D., Dale, B., 1966. "Living fossils" in western Atlantic plankton. Nature 211 (5053), $1025-1026$.

Wall, D., Dale, B., 1967. The resting cysts of modern marine dinoflagellates and their palaeontological significance. Rev. Palaeobot. Palynol. 2, 349-354.

Wall, D., Dale, B., 1968. Modern dinoflagellate cysts and evolution of the Peridiniales. Micropaleontology 14, 265-304.

Wall, D., Dale, B., 1969. The "hystrichosphaerid" resting spore of the dinoflagellate Pyrodinium bahamense, Plate, 1906. J. Phycology 5(2), 140-149. 
Wall, D., Dale, B., 1970. Living hystrichosphaerid dinoflagellate spores from Bermuda and Puerto Rico, Micropaleontology 16, 47-58.

Wall, D., Dale, B., 1973. Paleosalinity relationships of dinoflagellates in the late Quaternary of the Black Sea - a summary. Geosci. Man 7, 95-102.

Wall, D., Dale, B., Harada K., 1973. Descriptions of new fossil dinoflagellates from the late Quaternary of the Black Sea. Micropaleontology 19, 18-31.

Wall, D., Guillard, R.R.L., Dale, B., Swift, E., Watabe, N., 1970. Calcite resting cysts in Peridinium trochoideum (Stein) Lemmerman, an autotrophic marine dinoflagellate. Phycologia $9(2), 151-156$.

Wall, D., Dale, B., Lohmann, G.P., Smith, W.K., 1977: The environmental and climatic distribution of dinoflagellate cysts in modern marine sediments from regions in the North and South Atlantic Oceans and adjacent areas. Mar. Micropaleontol. 2, 121-200.

Wrenn, J.H., 1988. Differentiating species of the dinoflagellate cyst genus Nematosphaeropsis Deflandre \& Cookson 1955. Palynology12, 129-150.

Yanko-Hombach, V., Yilmaz, Y. 2007. IGCP 521: “'Black Sea-Mediterranean Corridor during the last $30 \mathrm{ka}$ : Sea level change and human adaptation', Istanbul, 2005. Quat. Intern. $167-168,1-3$.

Yanko-Hombach, V., Gilbert, A.S., Buyenevich, I.V., Martin, R.E., 2011. Preface. In: Buynevich, I.V., Yanko-Hombach, V., Gilbert, A.S., Martin, R.E. (eds.), Geology and Geoarchaeology of the Black Sea Region: Beyond the Flood Hypothesis. Geol. Soc. Am. Spec. Papers, 473, pp. v-vii.

Yanko-Hombach, V., Mudie, P.J., Kadurin, S., Larchenkov, E., 2013. Holocene marine transgression in the Black Sea: New evidence from the northwestern Black Sea shelf. Quat. Intern. 345, 100-118. 
Yanko-Hombach, V., Kondariuk, T., Motnenko, I., 2017. Benthic foraminifera indicate environmental stress from river discharge to marine ecosystems: example from the Black Sea. J. Foram Res., 47, 70-92.

Yasakova, O.N., 2013. The seasonal dynamics of potentially toxic and harmful phytoplankton species in Novorossiysk Bay (Black Sea). Russian J. Mar. Biol. 39(2), 107-115.

Zavialov, P., 2005. Physical Oceanography of the Dying Aral Sea. Springer-Praxis Books in Geophysical Science, Springer-Verlag, Berlin, Heidelberg, New York, 146 pp.

Zenkevich, L., 1963. Biology of the Seas of Russia. Interscience Publishers: New York; 955 pp.

Zmerli Triki, H., Daly-Yahia, O.K., Malouche, D., Komiha, Y., Deidun, A., Brahim, M., Laabir, M., 2014. Distribution of resting cysts of the potentially toxic dinoflagellate Alexandrium pseudogonyaulax in recently-deposited sediment within Bizerte Lagoon (Mediterranean coast, Tunisia). Mar. Pollut. Bull. 84, 172-181.

Zonneveld, K.A.F.; Brummer, G-J.A., 2000. (Palaeo-)ecological significance, transport and preservation of organic walled dinoflagellate cysts in the Somali Basin, NW Arabian Sea. Deep Sea Res. Pt. II: Topical Studies Oceanog. 47(9-11), 2229-2256.

Zonneveld, K.A.F., Jurkschat, T., 1999. Bitectatodinium spongium (Zonneveld, 1997) Zonneveld et Jurkschat, comb. nov. from modern sediments and sediment trap samples of the Arabian Sea (northwestern Indian Ocean): taxonomy and ecological affinity. Rev. Palaeobot. Palynol. 106, 153-169.

Zonneveld, K.A.F., Pospelova, V., 2015. A determination key for modern dinoflagellate cysts. Palynology 39 (3), 387-409. 
Zonneveld, K.A.F., Siccha, M., 2016. Dinoflagellate cyst based Modern analogue technique at test - a 300 year record from the Gulf of Taranto (Eastern Mediterranean). Palaeoclim., Palaeoecol., Palaeoceanog. 450, 17-37.

Zonneveld, K.A.F., Susek, E., 2007. Effects of temperature, light and salinity on cyst production and morphology of Tuberculodinium vancampoae (the resting cyst of Pyrophacus steinii). Rev. Palaeobot. Palynol. 145, 77-88.

Zonneveld, K.A.F., Chen, L., Möbius, J., Mamoud, M.S., 2009. Environmental significance of dinoflagellate cysts from the proximal part of the Po-river discharge plume (off southern Italy, Eastern Mediterranean). J. Sea Res. 62, 189-213.

Zonneveld, K.A.F., Versteegh. G.J.M., Kasten, S., Eglinton, T.I., Emeis, K-C., and 9 others, 2010. Selective preservation of organic matter in marine environments; processes and impact on the sedimentary record. Biogeosci. 7, 483-511.

Zonneveld, K.A.F., Chen, L., Elshanawany, R., Fischer, H.W., Hoins, M., Ibrahim, M.I., Pittauerova, D., Versteegh, G.J.M., 2012. The use of dinoflagellate cysts to seperate humaninduced from natural variability in the trophic state of the Po River discharge plume over the last two centuries. Mar. Pollut. Bull. 64(1), 114-132.

Zonneveld, K.A.F., Marret, F., Versteegh, G.J.M., Bogus, K., Bonnet, S., Bouimetarhan, I., Crouch, E., de Vernal A., Elshanawany, R., Edwards, L., and 33 others, 2013. Atlas of modern dinoflagellate cyst distribution based on 2405 data points. Rev. Palaeobot. Palynol. 191, 1-197. 


\section{Captions}

Appendix A. Table of cores with radiocarbon (C-14 age except where marked cal for calendar age) and radiometric ages used for stratigraphy. M1 = sapropel age; Y2 = tephra with wood age;

$\mathrm{OM}=$ organic matter; *correlation with core GeoB 7622-2 of Lamy et al., 2006.

Appendix B: Key to identification of most dinocyst taxa in BSCsurface sediments based on cyst wall pigmentation, texture, ornament and other distinctive morphological features. Identification should be confirmed further by cross-reference to the cyst descriptions, comparisons and Plate illustrations.

Appendix C: List of motile dinoflagellates reported for the BSC seas, where $\mathrm{M}=$ Marmara, D $=$ Danube Delta, $\mathrm{B}=$ Black Sea, $\mathrm{C}=$ Caspian, $\mathrm{A}=$ Aral, Azov $=$ Azov Sea. Partial synonymy and revised generic names are shown in parenthesis but authorship for the synonyms is given only in the data sources, as follows: Marmara Sea: Deniz and Taş, 2009; Balkis et al., 2016; Danube Delta: Tőrők, 2015; Black Sea: Gómez and Boicenco, 2004 + Terenko and Terenko, 2008 (for Odessa Bay) + Kiselev, 1950 (*); Azov Sea: Kiselev, 1950; Caspian Sea: Bulatov in Leroy et al., 2006; Gogorev, 2015 + Kiselev, 1950; Aral Sea: Orlova and Rusakova 1999 + Kiselev, 1950; Azov Sea $=$ Kiselev, 1950; Kovaleva, 2008. Names in bold type are listed as HAB species by Gómez and Boicenco, 2004. OB = Odessa Bay area of Black Sea only. SOA = Sea of Azov only. *Boxes with X show data recorded in 1950 but not subsequently.

Figure captions 
Figure 1. Regional setting and location map for the Black Sea Corridor (BSC), showing the five inland seas (blue shading) in the study region, the major rivers (names in italics), and 11 adjoining countries of eastern Europe and the Middle East (bold letters). Locations of Izmir Bay in Southwest Turkey and Kara-Bogaz Gol off Eastern Caspian Sea are also shown. Aral Sea is shown as its maximum size, not its current highly reduced size. Major rivers are shown in light blue. $R$ Lake Razim; $O B$ Odessa Bay.

Figure 2. Bathymetry of BSC seas, distribution of surface sample sites (red dots) and cores (black stars) mentioned in the text and listed in appendix A, and showing simplified surface water circulation. Black Sea circulation is adapted from Toderascu and Rusu (2013). Anticyclonic shelf eddies are indicated by thin solid lines, the geostrophic Main Rim Current with a thick solid line, and the inner quasi-permanent cyclonic circulation (thin line with arrows) and recurrent cyclonic eddies are shown as dashed lines.W.G: Western Gyre; E.G: Eastern Gyre; B: Bosphorus; Ba: Batumi; C: Caucasus; Cr: Crimea; K-a.: Kali-akra; Ki: Kizilirmak; Sa: Sakarya; Se: Sevastopol; Si: Sinop. A schematic surface circulation is also shown for the Caspian Sea, adapted from Gunduz and Özsoy (2014).

Figure 3. Maps of the Black Sea Corridor showing annual sea-surface salinity (A) and temperature (B) derived from WOA2013. Annual SSSs and SSTs at each site are plotted against each other as T-S diagrams (C), with symbols showing the geographical location of each site (see Table 4). No comparable data are available for the rapidly changing Aral Sea. AZS Azov Sea; BSSW,-SE, -NW, -NE Black Sea Southwest, Southeast, Northwest, Northeast, respectively; CASP Caspian Sea; KBG Kara-Bogaz Gol ; MAR Marmara Sea, 
Figure 4. Maps of the Black Sea Corridor showing seasonal averages for surface water temperature (SST) and salinity (SSS), with corresponding T-S plots using symbols based on the geographical location of each site (see Table 4). No comparable data are available for the rapidly changing Aral Sea. JFM = winter January to March; AMJ = spring April to June; JAS = summer July to September; OND = autumn October to December. AZS Azov Sea; BSSW, -SE, -NW, NE Black Sea Southwest, Southeast, Northwest, Northeast, respectively; CASP Caspian Sea; KBG Kar-Bogaz Gol Sea; MAR Marmara Sea.

Figure 5. Maps of the Black Sea Corridor showing annual phosphate, nitrate, silicate and bottom oxygen concentrations derived from WOA 2013. Table 5 shows the result of draftsman plots between abiotic parameters. No comparable data are available for the rapidly changing Aral Sea. Figure 6. Map of chlorophyll-a concentration in $\mathrm{mg} / \mathrm{m}^{3}$ in the BSC on July 27, 2015, as recorded by MODIS imagery for July 27, 2015 (NASA.gov source).

Figure 7. Distribution map of Achomosphaera sp. and percentages versus abiotic parameters plots: seasonal and annual SST and SSS, annual [P], [Si], [N], [chl.-a] and bottom $\left[\mathrm{O}_{2}\right]$.

Figure 8. Distribution map of Ataxiodinium choane and percentages versus abiotic parameters plots: seasonal and annual SST and SSS, annual [P], [Si], [N], [chl.-a] and bottom $\left[\mathrm{O}_{2}\right]$.

Figure 9. Distribution map of Bitectatodinium tepikiense and percentages versus abiotic parameter plots: seasonal and annual SST and SSS, annual [P], [Si], [N], [chl.-a], bottom $\left[\mathrm{O}_{2}\right]$.

Figure 10. Distribution map of Brigantedinium cariacoense and percentages versus abiotic parameter plots: seasonal and annual SST and SSS, annual [P], [Si], [N], [chl.-a], bottom $\left[\mathrm{O}_{2}\right]$. 
Figure 11. Distribution map of Brigantedinium simplex and percentages versus abiotic parameter plots: seasonal and annual SST and SSS, annual [P], [Si], [N], [chl.-a], bottom $\left[\mathrm{O}_{2}\right]$. Presence is indicated by a black asterix on the map.

Figure 12. Distribution map of Brigantedinium spp. and percentages versus abiotic parameter plots: seasonal and annual SST and SSS, annual [P], [Si], [N], [chl.-a] and bottom $\left[\mathrm{O}_{2}\right]$. Presence is indicated by a black asterix on the map.

Figure 13. Distribution map of Caspidinium rugosum and percentages versus abiotic parameter plots: seasonal and annual SST and SSS, and annual [P], [Si], [N], [chl.-a] and bottom $\left[\mathrm{O}_{2}\right]$. Presence is indicated by a black asterix on the map. Maximum value of $3.3 \%$ for [chl.-a] is because reliable satellite data are not available for higher cyst percentages in Caspian Sea.

Figure 14. Distribution map of cysts of Alexandrium pseudogonyaulax and percentages versus abiotic parameter plots: seasonal and annual SST and SSS, annual [P], [Si], [N], [chl.-a], bottom $\left[\mathrm{O}_{2}\right]$.

Figure 15. Distribution map of cysts of Alexandrium spp. and percentages versus abiotic parameter plots: seasonal and annual SST and SSS, annual [P], [Si], [N], [chl.-a], bottom $\left[\mathrm{O}_{2}\right]$. Presence is indicated by a black asterix on the map. 
Figure 16. Distribution map of cysts of Biecheleria baltica and percentages versus abiotic parameter plots: seasonal and annual SST and SSS, annual [P], [Si], [N], [chl.-a], bottom $\left[\mathrm{O}_{2}\right]$. Presence is indicated by a black asterix on the map.

Figure 17. Distribution map of cysts of Cochlodinium polykrikoides sensu Li et al. 2015 and percentages versus abiotic parameter plots: seasonal and annual SST and SSS, annual [P], [Si], $[\mathrm{N}]$, [chl.-a] and bottom $\left[\mathrm{O}_{2}\right]$.

Figure 18. Distribution of cysts of Cochlodinium sensu Fukuyo 1982 and percentages versus abiotic parameter plots: seasonal and annual SST and SSS, annual [P], [Si], [N], [chl.-a], bottom $\left[\mathrm{O}_{2}\right]$.

Figure 19. Distribution map of cysts of Diplopselta symmetrica and percentages versus abiotic parameter plots: seasonal and annual SST and SSS, annual [P], [Si], [N], [chl.-a], bottom $\left[\mathrm{O}_{2}\right]$.

Figure 20. Distribution map of cysts of Gymnodinium nolleri/microreticulatum and percentages versus abiotic parameter plots: seasonal and annual SST and SSS, annual [P], [Si], $[\mathrm{N}]$, [chl.-a] and bottom $\left[\mathrm{O}_{2}\right]$. Presence is indicated by a black asterix on the map.

Figure 21. Distribution map of cysts Kolkwitziella acuta and percentages versus abiotic parameter plots: seasonal and annual SST and SSS, annual [P], [Si], [N], [chl.-a] and bottom $\left[\mathrm{O}_{2}\right]$. Presence is indicated by a black asterix on the map. 
Figure 22. Distribution map of cysts of Pentapharsodinium dalei and percentages versus abiotic parameter plots: seasonal and annual SST and SSS, annual [P], [Si], [N], [chl.-a], bottom $\left[\mathrm{O}_{2}\right]$. Presence is indicated by a black asterix on the map.

Figure 23. Distribution map of cysts of Peridinium $c f$. willei and percentages versus abiotic parameter plots: seasonal and annual SST and SSS, annual [P], [Si], [N], [chl.-a] and bottom $\left[\mathrm{O}_{2}\right]$. Presence is indicated by a black asterix on the map.

Figure 24. Distribution map of cysts of Polykrikos hartmannii and percentages versus abiotic parameter plots: seasonal and annual SST and SSS, annual [P], [Si], [N], [chl.-a], bottom $\left[\mathrm{O}_{2}\right]$.

Figure 25. Distribution map of cysts of Polykrikos kofoidii/schwartzii and percentages versus abiotic parameter plots: seasonal and annual SST and SSS, annual [P], [Si], [N], [chl.-a], bottom $\left[\mathrm{O}_{2}\right]$. Presence is indicated by a black asterix on the map.

Figure 26. Distribution map of cysts of Protoperidinium nudum and percentages versus abiotic parameter plots: seasonal and annual SST and SSS, annual [P], [Si], [N], [chl.-a], bottom $\left[\mathrm{O}_{2}\right]$.

Figure 27. Distribution map of cysts of Protoperidinium stellatum and percentages versus abiotic parameter plots: seasonal and annual SST and SSS, annual [P], [Si], [N], [chl.-a], bottom $\left[\mathrm{O}_{2}\right]$

Figure 28. Distribution map of cysts of Scrippsiella trifida and percentages versus abiotic parameter plots: seasonal and annual SST and SSS, annual [P], [Si], [N], [chl.-a], bottom $\left[\mathrm{O}_{2}\right]$. 
Figure 29: Distribution map of cysts of Scrippsiella spp. and percentages versus abiotic parameter plots: seasonal and annual SST and SSS, annual [P], [Si], [N], [chl.-a], bottom $\left[\mathrm{O}_{2}\right]$.

Figure 30. Distribution map of cysts of Scrippsiella trochoidea and percentages versus abiotic parameter plots: seasonal and annual SST and SSS, annual [P], [Si], [N], [chl.-a], bottom $\left[\mathrm{O}_{2}\right]$.

Figure 31. Distribution of cysts of Type A of Verleye et al. 2009 and percentages versus abiotic parameter plots: seasonal and annual SST and SSS, annual [P], [Si], [N], [chl.-a], bottom $\left[\mathrm{O}_{2}\right]$.

Figure 32. Distribution map of Dubridinium caperatum and percentages versus abiotic parameter plots: seasonal and annual SST and SSS, annual [P], [Si], [N], [chl.-a], bottom $\left[\mathrm{O}_{2}\right]$. Presence is indicated by a black asterix on the map.

Figure 33. Distribution map of Echinidinium zonneveldiae and percentages versus abiotic parameter plots: seasonal and annual SST and SSS, annual [P], [Si], [N], [chl.-a], bottom $\left[\mathrm{O}_{2}\right]$. Presence is indicated by a black asterix on the map.

Figure 34. Distribution map of Echinidinium spp. and percentages versus abiotic parameter plots: seasonal and annual SST and SSS, annual [P], [Si], [N], [chl.-a] and bottom $\left[\mathrm{O}_{2}\right]$. Presence is indicated by a black asterix on the map. 
Figure 35. Distribution map of Impagidinium caspienense and percentages versus abiotic parameter plots: seasonal and annual SST and SSS, annual $[\mathrm{P}],[\mathrm{Si}],[\mathrm{N}]$, [chlor-a] and bottom $\left[\mathrm{O}_{2}\right]$. Presence is indicated by a black asterix on the map.

Figure 36. Distribution map of Lingulodinium machaerophorum and percentages versus abiotic parameter plots: seasonal and annual SST and SSS, annual [P], [Si], [N], [chl.-a] and bottom $\left[\mathrm{O}_{2}\right]$. Presence is indicated by a black asterix on the map.

Figure 37. Distribution map of Lingulodinium machaerophorum with short processes $(<10 \mu \mathrm{m})$ and percentages versus abiotic parameter plots: seasonal and annual SST, SSS, and annual $[\mathrm{P}],[\mathrm{Si}],[\mathrm{N}],[\mathrm{chl} .-\mathrm{a}]$ and bottom $\left[\mathrm{O}_{2}\right]$. Presence is indicated by a black asterix on the map.

Figure 38. Distribution map of Lingulodinium machaerophorum form clavatum and percentages versus abiotic parameter plots: seasonal and annual SST and SSS, annual [P], [Si], $[\mathrm{N}]$, [chl.-a] and bottom $\left[\mathrm{O}_{2}\right]$. Presence is indicated by a black asterix on the map.

Figure 39. Distribution map of Nematosphaeropsis labyrinthus and percentages versus abiotic parameter plots: seasonal and annual SST and SSS, annual [P], [Si], [N], [chl.-a], bottom [O $\left.\mathrm{O}_{2}\right]$.

Figure 40. Distribution map of Operculodinium centrocarpum sensu Wall and Dale 1966 and percentages versus abiotic parameter plots: seasonal and annual SST and SSS, annual [P], [Si], $[\mathrm{N}]$, [chl.-a] and bottom $\left[\mathrm{O}_{2}\right]$. 


\section{8}

Figure 41. Distribution map of Peridinium ponticum and percentages versus abiotic parameter plots: seasonal and annual SST and SSS, annual [P], [Si], [N], [chl.-a] and bottom $\left[\mathrm{O}_{2}\right]$. Presence is indicated by a black asterix on the map.

Figure 42. Distribution map of Pyxidinopsis psilata and percentages versus abiotic parameter plots: seasonal and annual SST and SSS, annual [P], [Si], [N], [chl.-a] and bottom $\left[\mathrm{O}_{2}\right]$.

Figure 43. Distribution map of Quinquecuspis concreta and percentages versus abiotic parameter plots: seasonal and annual SST and SSS, annual [P], [Si], [N], [chl.-a] and bottom $\left[\mathrm{O}_{2}\right]$.

Figure 44. Distribution map of Quinquecuspis sp. and percentages versus abiotic parameter plots: seasonal and annual SST and SSS, annual [P], [Si], [N], [chl.-a] and bottom [O $\left.\mathrm{O}_{2}\right]$.

Figure 45. Distribution map of Round Brown Cysts and percentages versus abiotic parameter plots: seasonal and annual SST and SSS, annual [P], [Si], [N], [chl.-a] and bottom $\left[\mathrm{O}_{2}\right]$. Presence is indicated by a black asterix on the map.

Figure 46. Distribution map of Selenopemphix nephroides and percentages versus abiotic parameter plots: seasonal and annual SST and SSS, annual [P], [Si], [N], [chl.-a], bottom $\left[\mathrm{O}_{2}\right]$.

Figure 47. Distribution map of Selenopemphix quanta and percentages versus abiotic parameter plots: seasonal and annual SST and SSS, annual [P], [Si], [N], [chl.-a] and bottom $\left[\mathrm{O}_{2}\right]$. 
Figure 48. Distribution map of Spiny Brown Cysts incertae and percentages versus abiotic parameter plots: seasonal and annual SST, SSS, annual [P], [Si], [N], [chl.-a] and bottom $\left[\mathrm{O}_{2}\right]$. Presence is indicated by a black asterix on the map.

Figure 49. Distribution map of Spiniferites belerius and percentages versus abiotic parameter plots: seasonal and annual SST and SSS, annual [P], [Si], [N], [chl.-a] and bottom $\left[\mathrm{O}_{2}\right]$. Presence is indicated by a black asterix on the map.

Figure 50. Distribution map of Spiniferites bentorii and percentages versus abiotic parameter plots: seasonal and annual SST and SSS, annual [P], [Si], [N], [chl.-a] and bottom $\left[\mathrm{O}_{2}\right]$. Presence is indicated by a black asterix on the map.

Figure 51. Distribution map of Spiniferites sp. $1 \mathrm{cf}$. S. bulloideus and percentages versus abiotic parameter plots: seasonal and annual SST and SSS, annual [P], [Si], [N], [chl.-a], bottom $\left[\mathrm{O}_{2}\right]$.

Figure 52. Distribution map of Spiniferites cruciformis and percentages versus abiotic parameter plots: seasonal and annual SST and SSS, and annual [P], [Si], [N], [chl.-a] and bottom $\left[\mathrm{O}_{2}\right]$. Presence is annotated with a black asterix on the map.

Figure 53. Distribution map of Spiniferites delicatus and percentages versus abiotic parameter plots: seasonal and annual SST and SSS, annual [P], [Si], [N], [chl.-a] and bottom $\left[\mathrm{O}_{2}\right]$. 
Figure 54. Distribution map of Spiniferites hyperacanthus/hainanensis and percentages versus abiotic parameter plots: seasonal and annual SST and SSS, annual [P], [Si], [N], [chl.-a], bottom $\left[\mathrm{O}_{2}\right]$.

Figure 55. Distribution map of Spiniferites membranaceus and percentages versus abiotic parameter plots: seasonal and annual SST and SSS, annual [P], [Si], [N], [chl.-a], bottom $\left[\mathrm{O}_{2}\right]$. Presence is indicated by a black asterix on the map.

Figure 56. Distribution map of Spiniferites mirabilis s. 1. and percentages versus abiotic parameter plots: seasonal and annual SST and SSS, annual [P], [Si], [N], [chl.-a], bottom [O $\left.\mathrm{O}_{2}\right]$.

Figure 57. Distribution map of Spiniferites ramosus and percentages versus abiotic parameter plots: seasonal and annual SST and SSS, and annual [P], [Si], [N], [chl.-a] and bottom $\left[\mathrm{O}_{2}\right]$.

Figure 58. Distribution map of Spiniferites septentrionalis and percentages versus abiotic parameter plots: seasonal and annual SST and SSS, annual [P], [Si], [N], [chlor-a], bottom [O $\left.\mathrm{O}_{2}\right]$.

Figure 59. Distribution map of Tectatodinium pellitum and percentages versus abiotic parameter plots: seasonal and annual SST and SSS, annual [P], [Si], [N], [chl-a] and bottom $\left[\mathrm{O}_{2}\right]$.

Figure 60. Distribution map of Trinovantedinium applanatum and percentages versus abiotic parameter plots: seasonal and annual SST and SSS, annual [P], [Si], [N], [chl.-a], bottom $\left[\mathrm{O}_{2}\right]$.

Figure 61. Distribution map of Votadinium calvum and percentages versus abiotic parameter plots: seasonal and annual SST and SSS, annual [P], [Si], [N], [chl.-a], and bottom $\left[\mathrm{O}_{2}\right]$. 
Figure 62. Distribution map of Xandarodinium xanthum and percentages versus abiotic parameter plots: seasonal and annual SST and SSS, annual [P], [Si], [N], [chl.-a], bottom $\left[\mathrm{O}_{2}\right]$.

Figure 63. Maximum-minimum ranges of salinity (A) and temperature (B) for the 56 species and 169 sites retained for statistical analysis. Shaded areas show the SSS range for each sea.* Azov Sea samples are in the Caspian Sea SSS range. Short vertical bars in Figure 63B mark average annual SST values for the individual taxa.

Figure 64: Principal component (PCA) and non-metric multi-dimensional scaling analyses (nMDS) for abiotic and biotic data. A) PCA analysis results for the 181 sites based on 13 abiotic parameters (Table 4); B) nMDS plots based on Bray-Curtis similarities for the 169 assemblages with vector plots of abiotic parameters (Pearson correlation), and C) vector plots of species.

Figure 65. Shade plot of square-root transformed cyst relative abundances, with 172 sites sorted according to their geographical sector. The 58 species are sorted according to their overall relative abundance.

Figure 66. Bubble-plots overlaying the nMDS plot of the 169 assemblages and showing the geographical distributions and relative abundances of the most dominant species in the BSC.

Figure 67. Map showing concentrations of total dinocysts in surface sediments of the BSC as estimated for number of cysts/g dry weight (A) and number of cysts/ml wet sediment (B). 
Figure 68. Map showing distribution of ratios for cysts from photosynthetic $(\mathrm{P})$ versus heterotrophic $(\mathrm{H})$ motile taxa $(\mathrm{P} / \mathrm{H}$ ratio) where autotrophs and mixotrophs are grouped with $\mathrm{P}$.

Figure 69. Distribution of various measures of cyst biodiversity in the BSC. (A) Species diversity (number of cyst taxa per site), (B) species richness (Margalef d index), and (C) Pielou's Index of evenness.

Table captions

Table 1. Dinocyst species included in the Black Sea Corridor Atlas, their corresponding Plate and map numbers, occurrence in Harmful Algal Blooms (HAB), and the trophic habit of corresponding motile stage $\mathrm{P}=$ photosynthetic (i.e. with pigments and either photo autotrophic, using light only, or auxotrophic, using organic nutrient supplements); $\mathrm{H}=$ heterotrophic (dependent on nutrients synthesised by other organisms); $\mathrm{M}=$ mixotrophic (using both photosynthesis and heterotrophy). $\mathrm{P}+$ and $\mathrm{H}+$ denote phototrophs and heterotrophs known to also be phagotrophic, as determined by Jeong et al. (2010); ? indicates uncertainty because of lack of laboratory data. $*=$ taxon is described but not mapped; red font $=$ apparent recent introductions. The Code column is for the statistical analyses.

Table 2. Water surface area and estimates of net potential evaporation (NPE) for Eurasian marginal and inland seas (from Hiscott et al., 2007 and Toroğlu, 2014), and average pre-2005 average surface salinity (SSS), Na, Mg and Ca concentrations (mg/l) of Black Sea Corridor seas (from Zenkevich, 1963; Sorokin, 2002; Zavialov, 2005; Kozarev et al., 2007). *excluding Don estuary and Sivash saltlakes. 
Table 3. Comparison of species numbers in phytoplankton and zooplankton of the BSC semienclosed and inland seas before 2002. A. Historical data for plankton records; B. Dinoflagellate records for motile and resting cyst stages and relative abundances of cyst taxa as a percentage of total motile taxa in each region.

Table 4. Locations, water depths, type of sampler used to recover the surface layer (0-1 or 0-2 cm depth) of sediments from samples in the BSC study region, and names of authors responsible for counts. $\mathrm{x}$ indicates samples not retained for statistical analysis due to incomplete or lack of abiotic parameters. * indicates samples not retained for statistical analysis due to cyst sum lower than 80 .

Table 5. Coefficient of correlations between the annual and seasonal surface water and abiotic parameters and the bottom oxygen levels calculated from the values at the seabed sample locations and diversity indices (number of species, richness and evenness). SSTY annual seasurface temperature; SSSY annual sea-surface salinity; JFM January, February, March; AMJ April, May, June; JAS July, August, September; OND October, November, December.

Table 6. PCA eigenvalues for the 14 abiotic parameters at 181 sites.

Table 7. NIS dinoflagellate taxa in surface sediments of the western BSC, showing associated regional and local surface water salinities, possible origin and general biogeography.

BSC Atlas Plate Captions 
Plate 1. Figs. 1-6: Ataxiodinium choane; Figs. 7-12 Cyst of Alexandrium pseudogonyaulax. 13-15: Cyst of Peridinium cf. willei. 1-6: A. choane light micrographs of single specimen from surface sediment from Marmara Sea (DM13), upper to lower focus, showing typical crenulations of outer wall. Archeopyle is situated on the upper left side. 7-9. Cyst of Alexandrium pseudogonyaulax: specimen from surface sediment from NW Black Sea (SH4). 10-12. Specimen from MSM33 42-3 MUC (slide 2), with torn apical area. 13-14. Cyst of Peridinium cf. willei: two different specimens from from SE Black Sea deep water core 1474P; 15. Specimen from Chilia Channel of Danube Delta, $0-2 \mathrm{~cm}$, slightly folded. All images by KNM except $13-15$ by PJM; all scale bars $=10 \mu \mathrm{m}$.

Plate 2. Figs. 1-6: Bitectatodinium tepikiense; Figs 7-12: Tectatodinium pellitum.

1. Bitectatodinium tepikiense: dorsal view of cyst from Marmara Sea core MAR02-88P, 160 $\mathrm{cm}$ showing archeopyle aperture formed by loss of two plates. 2. Specimen from Ukrainian continental slope, showing one archeopyle plate still attached (H35A). 3-5. Specimen from Black Sea core MAR02-45P $320 \mathrm{~cm}$ (slide 3). 3. Typical surface, partly showing archeopyle. 4. Typical cross section. 5. Zoom on upper surface. 6. SEM image from Marmara Sea (DM13), showing typical lamellar texture. 7. Tectatodinium pellitum specimen from Black Sea (SH5) showing archeopyle formed by loss of one precingular plate. 8-9. Specimen from Marmara Sea (DM13) showing upper focus and cross section. 10. Specimen from outer Danube Shelf (MN116-21); dorsal view, median focus showing very long fibrils occasionally found in cysts from BSC. 11. Wall surface in specimen from SE Black Sea (22-MUC-1) showing typical texture. 12. SEM of specimen from Marmara Sea (DM13) showing typical texture. Images by KNM except $1-2$ by PJM, all scale bars $=10 \mu \mathrm{m}$. 
Plate 3. Figs 1-4: Brigantedinium cariacoense; Figs. 5-9: Brigantedinium simplex; Figs. 1015: Dubridinium caperatum. 1-3. B. cariacoense: single specimen from Izmir Bay surface sediment (Sta. 8). 1. Typical archeopyle. 2. Cross section showing simple wall structure. 3. Specimen with two intercalary plates released. 4. Specimen from Marmara Sea core MAR0289P, $60 \mathrm{~cm}$, early Holocene, with pyrite inclusions and a lunate archeopyle shape. 5-6. B. simplex specimen from outer Danube Shelf (MN116-14), surface sediment, lateral view, from high focus ventral surface to low focus on archeopyle. 7-9. Light micrographs of single specimen from SE Black Sea (25-MUC-1, $1 \mathrm{~cm}$ ) showing archeopyle (dorsal view), and ventral flagellar scars. 10. D. caperatum specimen from Izmir Bay surface sediment (St. 8). 11-12. Specimen from SW Black Sea core GeoB7625-2 $1 \mathrm{~cm}$, ventro-lateral views. 13. Specimen from SW Black Sea core GeoB7625-2 $1 \mathrm{~cm}$, focus on sulcal area. 14-15. SEM Izmir Bay surface sediment (St. 29). All images by KNM, except images 4-6 by PJM, all scale bars $=10 \mu \mathrm{m}$.

Plate 4. Figs. 1-11: Impagidinium inaequalis, Figs. 12-19: Caspidinium rugosum. 1-4. A topotype of I. inaequalis of Wall et al. 1973. 5-7. Specimens of I. inaequalis from northern Caspian Sea (core IG34, $819 \mathrm{~cm}$ ). 8-11. SEM of I. inaequalis from SW Black Sea core MAR984, 130 cm. 12-17: various orientations of single specimen of Caspidinium rugosum from southern Caspian Sea surface sediment (CS45m) showing paratabulation. 14. View showing dextral torsion. 16. View showing renifom shape 18. Poorly preserved specimen from Aral Sea (AR17 0-2.5 cm). 19. SEM of specimen from US09 (Caspian Sea). Most images by KNM except 5-7 by SAGL and 8-11 by PJM, all scale bars $=10 \mu \mathrm{m}$.

Plate 5. Figs. 1-3: Fragilidinium sp.; Figs. 4-9: Cyst of Alexandrium spp.; Figs. 10-15: Cyst of Scrippsiella trifida. 1-2. Specimen of Fragilidinium sp. from MSM33 42-3 MUC (slide 2). 3. 
Specimen from Glendhrosk Ash 3 (slide 2). 4-6. Cyst of Alexandrium spp. from NW Black Sea surface sediment (GC27, 0-1 cm). 7-9. Specimen from NW Black Sea surface sediment (GC27 0-1 cm). 10-12. Cyst of Scrippsiella trifida from SW Black Sea core GeoB7625-2, $1 \mathrm{~cm} .13-15$. Specimen from SW Black Sea core GeoB7625-2, $112 \mathrm{~cm}$. Images by KNM, scale $=10 \mu \mathrm{m}$.

Plate 6. Figs. 1-7: Cyst of Barrufeta resplendens; Figs. 8-16: Cyst of Cochlodinium sensu Fukuyo. 1-4. Specimen of B. resplendens cyst from SE Black Sea, core 22, 0 cm. 5-7. Specimen of B. resplendens cyst from late Holocene sediment in SW Black Sea core GeoB7625-2, $347 \mathrm{~cm}$; black spots are pyrite crystals. 8-10. Specimen of Cochlodinium sensu Fukuyo cyst from SW Black Sea core GeoB7625-2, 464 cm. 11-16. Two specimens of Cochlodinium sensu Fukuyo 1982 cyst from SW Back Sea core GeoB7625-2, surface sediment, $1 \mathrm{~cm}$. Images by KNM, scale $=10 \mu \mathrm{m}$.

Plate 7. Figs. 1-6: Cyst of Scrippsiella trochoidea; Figs. 7-15: Cyst of cf. Biecheleria baltica. 1-3. Cyst of Scrippsiella trochoidea from NW Black Sea surface sediment (SH4). 4-6. Specimen from NW Black Sea surface sediment (SH4). 7-9. Cyst of cf. Biecheleria baltica from Marmara Sea surface sediment (B2KS33, 0-1 cm). 10-11. Specimen from Sea of Azov (SOA48). 12. Specimen from NW Black Sea surface sediment (SH5).

Plate 8. Figs. 1-6: Xandarodinium xanthum; Figs. 7-15: Cyst of Cochlodinium polykrikoides sensu Li et al. 2015. 1. Specimen of Xandarodinium xanthum, SW Black Sea core GeoB7625-2, $515 \mathrm{~cm}$. 2. Specimen from Izmir Bay surface sediment (Sta. 8). 3. Marmara Sea core MAR0288P, 100 cm. 4-5. Specimen from Izmir Bay surface sediment (Sta. 29) (slide 2). 6. Specimen from Izmir Bay surface sediment (Sta. 29). 7-12. Cyst of Cochlodinium polykrikoides from SW 
Black Sea core GeoB7625-2, $1 \mathrm{~cm}$. 13-15. Three different specimens with variable preservation from SW Black Sea, core GeoB7625-2, 515 cm. Images by KNM except 3 by PJM, scale = 10 $\mu \mathrm{m}$.

Plate 9. Figs. 1-9: Echinidinium zonneveldiae; Figs. 10-18: Cyst of Diplopelta symmetrica. 1-3. Echinidinium zonneveldiae specimen from SW Black Sea core GeoB7625-2, $515 \mathrm{~cm}$ (slide 2). 4-6. Specimen from NW Black Sea surface sediment (SH4). 7-8. Specimen from SW Black Sea core GeoB7625-2, $64 \mathrm{~cm}$ (slide 1). 9. Specimen from Marmara Sea core MAR02- 88P, 50 cm. 10-12. Cyst of Diplopelta symmetrica from NW Black Sea surface sediment (SH4). 13-15. Specimen from Izmir Bay surface sediment (Sta. 8). 16-18. Specimen from SW Black Sea core GeoB7625-2, $1 \mathrm{~cm}$. All images by KNM except 9 by PJM, all scale bars $=10 \mu \mathrm{m}$.

Plate 10. Figs. 1-3: Cyst of Gymnodinium catenatum (MAR02-45P, $110 \mathrm{~cm}$ ); Figs. 4-9: Cyst of Gymnodinium nolleri; Figs. 10-17: Cyst of Protoperidinium stellatum. 1-3. Cyst of Gymnodinium catenatum specimen from MAR02-45P, $110 \mathrm{~cm}$. 4-7. Cyst of Gymnodinium nolleri from Izmir Bay (Sta. 8). 8-9. SEM images of specimens from Izmir Bay (Sta. 29). 10. Cyst of Protoperidinium stellatum from SW Black Sea core GeoB7625-2, 515 cm. 11-12. Specimen from SW Black Sea core GeoB7625-2, 64 cm (slide 1). 13. Specimen from SW Black Sea core GeoB7625-2, $515 \mathrm{~cm}$ (slide 2). 14. Specimen from NW Black Sea surface sediment (SH4). 15. Specimen from Danube shelf (MN103-8) with strongly appressed antapical horns. 16. Specimen from Danube shelf (MN103-15) with truncated right lateral and antapical horns. 17. Specimen from Danube shelf (MN103-07) with all horns truncated. All images by KNM except 1-3 by FM, 15-17 by PJM, all scale bars $=10 \mu \mathrm{m}$. 
Plate 11. Figs. 1-7: Votadinium spinosum; Figs. 8-16: Cyst of Kolkwitziella acuta from southwestern Caspian Sea (CS 25 m). 1-4. Specimen of Votadinium spinosum from NW Black Sea (SH4). 5-7. Specimen from SW Black Sea core GeoB7625-2, $464 \mathrm{~cm}$ (slide 2). 8-10. Cyst of Kolkwitziella acuta with cell contents. 11-13. Another cyst after germination. 14-16. Cyst with cell contents. 8. Ventral view showing flagellar scar and narrowing of sulcus towards apex. 9. Apical view showing small apical pore (indicated by black arrow). 10. Apical view showing reniform shape and apical horn. 11. Ventral focus on right antapical horn, showing distinct wrinkly texture. 12. High focus on dorsal view. 13. Germinated cyst showing archeopyle and attached operculum. 14. Cyst showing typical bell-shape of cross-section. 15. Antapical view. 16. Cyst showing reniform cross-section. All images by KNM, all scale bars $=10 \mu \mathrm{m}$.

Plate 12. Figs. 1-7: Operculodinium israelianum; Figs. 8-16: Cyst of Pentapharsodinium dalei. 1-4. Specimen of Operculodinium israelianum: different focal views of Mediterranean specimen from Izmir Bay (Sta. 29). 4-5. Specimen from Marmara Sea core MAR02- 88P, 60 cm; lateral view, high and mid focus. 6-7. SEM image of specimen from Marmara Sea (DM13). 8-10. Cyst of Pentapharsodinium dalei from MSM33 42-3 MUC slide 2. 11. Specimen from NW Black Sea (SH4). 12-13. Specimen from SW Black Sea, core GeoB7625-2, 564 cm. 14-15. Specimen from SW Black Sea, core GeoB7625-2, 112 cm. 16. Specimen from SE Black Sea, 25MUC-1, $1 \mathrm{~cm}$. All images by KNM, except 4-5 by PJM, all scale bars $=10 \mu \mathrm{m}$.

Plate 13. Figs. 1-3: Cyst of Polykrikos hartmannii; Figs. 4-15: Cyst of Polykrikos kofoidii/schwartzii sensu Matsuoka et al., 2009. 1. Cyst of Polykrikos hartmannii from SW Black Sea core GeoB7625-2, 1 cm. 2. Specimen from Marmara Sea (DM5). 3. Specimen from midHolocene sediment, SW Black Sea core GeoB7625-2, $515 \mathrm{~cm} .4-6$. Cyst of Polykrikos 278 
kofoidii/schwartzii sensu Matsuoka et al. 2009 from SW Black Sea (GeoB7625-2, $1 \mathrm{~cm})$ : high to low focus. 7-8. Specimen from Izmir Bay surface sediment (slide 2). 9-10. Specimen from Izmir Bay surface sediment (Sta. 29). 11-12. Specimen from Izmir Bay surface sediment (Sta. 8). 1315. Specimen from SW Black Sea (SH5). All images by KNM, scale bars $=10 \mu \mathrm{m}$.

Plate 14. Figs. 1-7, 10-11: Selenopemphix quanta; Figs. 8-9: Cyst of Protoperidinium nudum 1-3. Selenopemphix quanta specimen from NW Black Sea (SH4), polar view. 4-6. Specimen from NW Black Sea (SH4), lateral view. 7. Specimen from Ukrainian Shelf surface sediment (H10 M). 8. Cyst of P. nudum with long processes from Marmara Sea core MAR02-88P-50. 9. Cyst of P. nudum from Marmara Sea core MAR02-88P, $200 \mathrm{~cm} .10-11$. SEMs of S. quanta from Izmir Bay surface sediment, Sta. 29 (10) and from Marmara Sea surface sediment, DM13 (11). Images by KNM, except 7-9 by PJM, all scale bars $=10 \mu \mathrm{m}$.

Plate 15. Figs. 1-6: Round brown cysts (RBC); Figs. 7-15: Type A of Verleye et al. 2009. 12. Cyst of Diplopsalid from SW Black Sea core GeoB7625-2, 1 cm. 3-4. Cyst of Diplopsalid from Izmir Bay surface sediment (St. 29) (slide 2). 5-6. Specimen (cyst of Diplopsalid) from SW Black Sea, core GeoB7625-2, $464 \mathrm{~cm}$ (slide 2). 7-8. Cysts with colored cell contents from NW Black Sea. 9-12. Germinated cyst from culture showing typical wall structure and composite archeopyle, from NW Black Sea. 13-14. Specimen from Marmara Sea surface sediment (B2KS33, 0-1 cm). 15. Specimen from Marmara Sea (DM5). Images by KNM, scale $=10 \mu \mathrm{m}$.

Plate 16. Figs. 1-12: Impagidinium caspienense. 1-3. Specimen from CS 25 m: apical view of epicyst showing opened operculum (3"); arrow indicates presence of pore on 4'. 2. Antapical view of hypocyst. 3. Dorsal view showing opened archeopyle. 4. Specimen from Caspian Sea 
(CS 25 m). 5. Specimen from CS 25 m. 6. Specimen from Caspian Sea (CS 25 m): longitudinal cross section. 7. Specimen from Caspian Sea (CS 25 m). 8. Specimen from Caspian Sea (CS 25 m). 9. Specimen with apical protrusion from middle Caspian Sea surface sediment (SH7). 10-12. SEM images of Impagidinium caspienense cysts isolated from station US09, a sample studied by Marret et al. (2004). 10. Finely granulate surface of the cysts and the precingular archeopyle. 11. Sulcal tabulation. 12. View of antapical plate. Images by KNM, except 9 by SL, scale $=10 \mu \mathrm{m}$.

Plate 17. Figs. 1-3: Lejeunecysta marieae; Figs 4-5: Lejeunecysta oliva; Figs. 6-15: Quinquecuspis concreta. 1-3. Specimen of Lejeunecysta marieae from SW Black Sea core GeoB7625-2 $302 \mathrm{~cm}$ (slide 2). 4-5: Specimen of Lejeunecysta oliva from SW Black Sea (MAR02-13P, $140 \mathrm{~cm}$ ), low to high focus, equatorial view. 6-7. Q. concreta specimen from Izmir Bay (Sta. 8). 8-10. Q. concreta specimen from Izmir Bay (Sta. 29, slide 2). 11-12. SEMs of Q. concreta specimen from Izmir (Sta. 29). 13-15. Q. concreta Specimen from Black Sea core MAR02-45P $320 \mathrm{~cm}$ (slide 3). All images by KNM, all scale bars $=10 \mu \mathrm{m}$.

Plate 18. Figs. 1-10: Lingulodinium machaerophorum. 1. Specimen bearing long processes from Marmara Sea surface sediment (DM5). 2. Specimen with lingulate processes, Marmara Sea core MAR 02-88P, $320 \mathrm{~cm}$. 3. Specimen corresponding to subsp. filiforme from SW Black Sea core GeoB7625-2, $1 \mathrm{~cm} .4$. Specimen with bulbous - clavate processes from NW Black Sea surface sediment, GC 29 0-1 cm. 5-6. Specimen from SW Black Sea core GeoB7625-2, $64 \mathrm{~cm}$. 6. Specimen with reduced processes from Caspian Sea surface sediment (CP04). 7. Specimen from Black Sea (BS2 Ghent). 8. Specimen from Marmara Sea (DM13). 9-10. Specimen from Caspian Sea surface sediment (US09). All images by KNM, except 2 by PJM, all scale bars $=10$ $\mu \mathrm{m}$. 
Plate 19. Figs. 1-7: Spiniferites ramosus; Figs. 8-16: Nematosphaeropsis labyrinthus. 1-4. LM images of Spiniferites ramosus specimen from NW Black Sea at mid-high focal levels (SH4). 5-6. Specimen from SW Black Sea core GeoB7625-2, $1 \mathrm{~cm}$. 7. SEM of cyst from Marmara Sea (DM13). 8-13. Specimen of Nematosphaeropsis labyrinthus from Marmara Sea surface sediment (DM13, 0-1 cm). 14-16. Specimen from Marmara Sea surface sediment (DM13, 0-1 cm). All images by KNM, all scale bars $=10 \mu \mathrm{m}$.

Plate 20. Figs. 1-11: Operculodinium centrocarpum sensu Wall and Dale 1966. 1-3. Specimen from SE Black Sea core 25-MUC-1, $1 \mathrm{~cm}$. 1. High focus showing precingular archeopyle. 2-3. High and median focus of same specimen. 4. Specimen with cell content from Danube Delta prodelta (MN103-19); optical section. 5. Specimen from Marmara Sea (DM13) showing precingular archeopyle. 6. Specimen from Marmara Sea (DM13) showing structure of process. 7. Specimen from Izmir Bay surface sediment (Sta. 8). 8. SEM of process bases on cysts Marmara Sea surface sediment (DM13). 9-11. Specimens with short processes. 9. Cyst from Marmara Sea DM13. 10. Specimen from Aral Sea (AR17 0-2.5). 11. Specimen from MAR0245P 440cm. All images by KNM, except 5 by PJM, all scale bars $=10 \mu \mathrm{m}$, except 6 scale bar $=1$ $\mu \mathrm{m}$.

Plate 21. Figs. 1-3: Trinovantedinium applanatum; Figs. 4-10: Peridinium ponticum. Figs. 11-16: Selenopemphix nephroides, all specimens from Danube shelf. 1-2. Specimen of Trinovantedinium applanatum from SW Black Sea surface sediment (MAR02-68). 3. Specimen from Marmara Sea surface sediment (DM13 0-1 cm). 4-5. Spherical specimen of Peridinium ponticum from SW Black Sea, core GeoB7625-2, $112 \mathrm{~cm}$. 6. Spherical specimen from SW Black 
Sea, core GeoB7625-2 515 cm. 7-8. Specimen from NW Black Sea (SH4). 9. Typical form on Ukrainian continental slope surface sediment (H-37a). 10. Specimen from NW Black Sea (SH5). 11-12. Selenopemphix nephroides specimen in apical view, surface focus on archeopyle (11) and optical section (12) (MN103-17). 13. Specimen from MN103-17A. 14-15. Equatorial view, high and mid focus of specimen from MN103-17. 16. Specimen from MN103-17. All images by KNM, except $1-2,6,11-16$ by PJM, all scale bars $=10 \mu \mathrm{m}$.

Plate 22. Figs.1-14: Pyxidinopsis psilata. 1-3. MAR02-45P $540 \mathrm{~cm}$. 4-6. Specimen from middle Caspian Sea surface sediment. 7-8. Specimen from Black Sea, core MAR02-45P $440 \mathrm{~cm}$. 9. Specimen with coarse ornamentation, southern Caspian Sea surface sediment. 10. Specimen from Black Sea, core MAR02-45P $380 \mathrm{~cm}$. 11. Specimen with apical horn from middle Caspian Sea surface sediment (SH7). 12. Specimen from middle Caspian Sea (GS18). 13. Specimen from SW Black Sea, core GeoB7625-2, $638 \mathrm{~cm}$. 14. Specimen from Caspian Sea surface sediment (US09). Images by KNM, except 4-6, 11 by SL, scale $=10 \mu \mathrm{m}$, except 13-14 = $1 \mu \mathrm{m}$.

Plate 23. Figs. 1-16: Spiniferites belerius. 1-8. Specimen from Black Sea, core Black Sea AK $257544-46 \mathrm{~cm}$; high to low focus showing variation in the membranous processes. 9-11. High to low focus of single specimen with intergonals from NW Black Sea (SH5). 12-14. Specimen from core MAR02-45P $320 \mathrm{~cm}$ (slide 3) with shorter processes; high to low focus. 15-16. SEM micrographs of two specimens from Marmara Sea (DM13). Images by KNM, scale $=10 \mu \mathrm{m}$.

Plate 24. Figs. 1-13: Spiniferites bentorii. 1-5. Single specimen from Black Sea (SH4), high focus on ventral side to low focus on dorsal side. 6-7. SEM image from Black Sea (SH5). 8-10. Form with reduced processes from NW Black Sea (SH2). 11-12. Form with very reduced 
processes from Sea of Azov. 13. Similar form with very reduced processes from outer Ukrainain Shelf (H-33a). All images by KNM, except 13 by PJM, all scale bars $=10 \mu \mathrm{m}$.

Plate 25. Figs. 1-15: Spiniferites cruciformis. 1-3. Specimen from core MAR02-45P $600 \mathrm{~cm}$, dorsal, mid and ventral views. 4-6. Specimen from Caspian Sea CS45m, high focus on dorsal side to low focus on ventral side. 7-8. S. cruciformis form 4 from surface sediment, Ukrainian continental slope (H-42a). 9-10. Specimen from Caspian Sea (CP04 0-2.5 cm III); 9. High focus on ventral surface; mid-focus. 11. Morphotype B of Marret et al. (2004) from southern Caspian Sea (CP14). 12-13. Morphotype C of Marret et al. (2004) from southern Caspian Sea (CP14). 14-15. Specimen from Marmara Sea (DM13), slightly obscured by fragments of other cysts. All images by KNM, except 7-8 by PJM, 11-13 by SL, all scale bars $=10 \mu \mathrm{m}$.

Plate 26. Figs. 1-11: Spiniferites delicatus. 1-6. Specimen from NW Black Sea (SH4), high focus, dorsal side to low focus, ventral side. 7-9. Specimen from NW Black Sea (SH1), High to low focus. 10-11. SEM images from NW Black Sea (SH5). Images by KNM, scale $=10 \mu \mathrm{m}$.

Plate 27. Figs. 1-11: Spiniferites hainanensis. 1-4. Specimen from NW Black Sea (SH4), high to mid focus showing details of processes and wall ornamentation. 5-7. Specimen from NW Black Sea (SH4). 8. Specimen from NW Black Sea (SH4). 9-11. Specimen from Marmara Sea surface sediment (DM13, 0-1 cm). All images by KNM, all scale bars $=10 \mu \mathrm{m}$.

Plate 28. Figs. 1-16: Spiniferites membranaceus. 1-4. Specimen from MSM33 42-3 (MUC slide 2). 5-7. Specimen from Izmir Bay Sta. 29 (slide 2). 8. Specimen from Marmara Sea (DM13). 9-12. Specimen from Black Sea AK 2575 44-46 cm L39-12, with elevated crests 
between all processes and accessory intergonal processes. 13-16. Specimen from Black Sea AK 2575 44-46 cm L39-12. All images by KNM, all scale bars $=10 \mu \mathrm{m}$.

Plate 29. Figs. 1-10: Spiniferites mirabilis. 1-3. LM from NW Black Sea (SH4). 4-6. Reduced specimen from Sea of Azov (SOA 48). 7-10. SEM of cysts from Holocene sediment, Marmara Sea (DM13). All images by KNM, all scale bars $=10 \mu \mathrm{m}$.

Plate 30. Figs. 1-6: Spiniferites septentrionalis; Figs. 7-9: Spiniferites sp. 1. 1-4. Single specimen of S. septentrionalis from surface sediment from Marmara Sea (DM5); high focus on ventral side and typical fenestrate process tips (1) to low focus on dorsal side (4), showing typical absence of sutural ridges in LM images. 5. SEM image of specimen from surface sediment, Marmara Sea (DM13). 6. SEM image of specimen from surface sediment, NW Black Sea (SH4); both SEM images show some parasutural ridges, a shagreenate surface, and fenestrate process bases. 7-8. Spiniferites sp. 1, LM images of single specimen from surface sediment from NW Black Sea (SH1). 9. SEM image from Marmara Sea core MAR98-12, midHolocene. All images by KNM except Figs. 10-12 of PJM, all scale bars = 10 microns.

Plate 31. Figs. 1-16: Votadinium calvum. 1-3. Specimen from MSM33 42-3 MUC (slide 2). 4-6. Specimen from MSM33 42-3 MUC (slide 2). 7. Specimen from Danube Shelf surface sediment (MN 116-05), ventral view. 8. Specimen from SE Black Sea, 22-MUC-1, 1 cm. 9. Specimen from Danube Shelf surface sediment (MN103-13) with rounded antapical horns. 1013. Specimen with cell contents from MSM33 42-3 MUC (slide 2). 14-15. Specimen with verrucae from Danube Shelf surface sediment (MN103-2). 16. Specimen with verrucae in lateral 
view from Danube shelf surface sediment (MN103-13). All images by KNM, except 7, 9, 14-16 by PJM, all scale bars $=10 \mu \mathrm{m}$. 


\begin{tabular}{|c|c|c|c|c|c|c|c|c|}
\hline o. & $\begin{array}{l}\text { Core } \\
\text { Number }\end{array}$ & $\begin{array}{l}\text { lati } \\
\text { tude }\end{array}$ & $\begin{array}{l}\text { long } \\
\text { itude }\end{array}$ & $\begin{array}{l}\text { wate } \\
\mathbf{r}\end{array}$ & Age & $\begin{array}{c}\text { No. C-14 ages, material } \\
\text { \& other }\end{array}$ & $\begin{array}{l}\text { Le } \\
\text { ngth }\end{array}$ & References \\
\hline & and Area & ${ }^{\circ} \mathbf{N}$ & ${ }^{\circ} \mathbf{E}$ & $\begin{array}{l}\text { dept } \\
\text { h (m) }\end{array}$ & $\begin{array}{l}\mathrm{ka} \mathrm{BP} / \mathrm{yr} \\
\mathrm{AD}\end{array}$ & age datums & )$^{(\mathbf{m}}$ & \\
\hline & $\begin{array}{l}\text { Marmara } \\
\text { Sea }\end{array}$ & & & & & & & \\
\hline 1 & MAR97-02 & $\begin{array}{r}40 . \\
86\end{array}$ & $\begin{array}{r}27.6 \\
06\end{array}$ & 1080 & $0-3.49$ & 3 , bivalves & $\begin{array}{r}2 . \\
20\end{array}$ & Aksu et al., 2002 \\
\hline 2 & MAR98-12 & $\begin{array}{r}40 . \\
842\end{array}$ & $\begin{array}{r}27.7 \\
95\end{array}$ & 549 & $0-10.66$ & 2 , molluscs & $\begin{array}{r}1 . \\
30\end{array}$ & Aksu et al., 2002 \\
\hline 3 & MD02-2430 & $\begin{array}{l}40 . \\
797\end{array}$ & $\begin{array}{r}27.7 \\
25\end{array}$ & 580 & $0-18.465$ & 4, molluscs, M1, Y2 & $\begin{array}{r}7 . \\
50\end{array}$ & Londeix et al., 2009 \\
\hline 4 & MAR97-11 & $\begin{array}{r}40 . \\
587\end{array}$ & $\begin{array}{r}28.3 \\
78\end{array}$ & 111 & $0-15.90$ & 3 , molluscs & $\begin{array}{r}2 . \\
35\end{array}$ & Aksu et al., 2002 \\
\hline 5 & MAR98-09 & $\begin{array}{r}40 . \\
923\end{array}$ & $\begin{array}{r}28.9 \\
47\end{array}$ & 64 & $0-10.22$ & 6 , molluscs & 1. & Aksu et al., 2002 \\
\hline 6 & MAR 02-89P & $\begin{array}{l}40 . \\
672\end{array}$ & $\begin{array}{r}28.8 \\
56\end{array}$ & 257 & $8-25.32$ & 8, mollusc; Y2 & $\begin{array}{r}8 . \\
13\end{array}$ & Roberts, 2012 \\
\hline 7 & $\begin{array}{l}\text { MAR02-88P } \\
\text { Black Sea: } \\
\text { SW }\end{array}$ & $\begin{array}{l}40 . \\
633\end{array}$ & $\begin{array}{r}28.8 \\
47\end{array}$ & 367 & $0-6.59 \mathrm{cal}$ & 2, Brissopsis; M1 & $\begin{array}{r}6 . \\
82\end{array}$ & Roberts, 2012 \\
\hline 8 & $\begin{array}{l}\text { SA03K7.1 } \\
(\mathrm{K} 7)\end{array}$ & $\begin{array}{r}40 . \\
717\end{array}$ & $\begin{array}{r}30.2 \\
6\end{array}$ & 31 & $\begin{array}{r}1950- \\
2009 \text { AD }\end{array}$ & Cs-137, Pb-201 & $\begin{array}{r}0 . \\
38\end{array}$ & $\begin{array}{l}\text { Leroy and Albay, } \\
2010\end{array}$ \\
\hline 9 & $\begin{array}{l}\text { SA03R6 } \\
\text { (R6) }\end{array}$ & $\begin{array}{r}40 . \\
717\end{array}$ & $\begin{array}{r}30.2 \\
6\end{array}$ & 31 & $\begin{array}{l}0.310- \\
2.656\end{array}$ & plant fragments & $\begin{array}{r}5 . \\
96\end{array}$ & Leroy et al., 2010 \\
\hline $\begin{array}{l}1 \\
0\end{array}$ & $\begin{array}{l}\text { MAR02- } \\
45 \mathrm{~T}+45 \mathrm{P}\end{array}$ & $\begin{array}{l}41 . \\
686\end{array}$ & $\begin{array}{r}28.3 \\
18\end{array}$ & 69 & $0-9.340$ & 14, molluscs & $\begin{array}{c}9 . \\
45\end{array}$ & Marret et al., 2009 \\
\hline 1 & & 41. & 31.1 & & & & 1. & \\
\hline 1 & MAR05-4G & 166 & 29 & 75 & $0-2.60 \mathrm{cal}$ & 2 , molluscs & 71 & Bradley et al., 2012 \\
\hline 1 & MAR05-13P & 41. & 31.1 & 75 & $1.38-$ & 6 , molluscs; 4 shell & 8. & Bradley et al., 2012 \\
\hline
\end{tabular}




\begin{tabular}{|c|c|c|c|c|c|c|c|c|}
\hline 2 & & 166 & 28 & & $11.00 \mathrm{cal}$ & fragments & 03 & \\
\hline 1 & MAR05- & 41. & 29.0 & & & 6 , molluscs, 2 shell & 7. & \\
\hline 3 & 50.51 & 484 & 74 & 91 & $0-10.270$ & fragments & 40 & Flood et al., 2009 \\
\hline 1 & & 41. & 31.0 & & & & 7. & \\
\hline \multirow[t]{2}{*}{4} & GeoB-7625-2 & 445 & 67 & 1242 & $0-8.910$ & 7, Mytilus shell*; calcite & 92 & Verleye et al., 2009 \\
\hline & $\begin{array}{l}\text { Black Sea: } \\
\text { SE }\end{array}$ & & & & & & & \\
\hline $\begin{array}{l}1 \\
5\end{array}$ & B-7 & $\begin{array}{r}42 . \\
50\end{array}$ & 37.0 & 2120 & $0-7.0$ & $\begin{array}{l}\text { varve counts, sapropel } \\
\text { base }\end{array}$ & $\begin{array}{r}1 . \\
20\end{array}$ & Mudie et al., 2002 \\
\hline 1 & Atlantis II & 42. & 37.6 & & & & 11 & \\
\hline 6 & 1474 & 38 & 1 & 2117 & $0-23.0$ & detrital OM, 3 shell ages & .00 & Wall et al., 1973 \\
\hline 1 & M72-3b: 25- & 42. & 37.6 & & $1850-$ & & 0. & \\
\hline 7 & MUC-2 & 353 & 24 & 418 & $2000 \mathrm{AD}$ & $\mathrm{Pb}-210, \mathrm{Ra}-226, \mathrm{Cs}-137$ & 10 & Mousing et al., 2013 \\
\hline 1 & M72-3b: 22- & 42. & 37.4 & & $1850-$ & & 0 . & \\
\hline 8 & MUC-1 & 225 & 92 & 842 & $2000 \mathrm{AD}$ & $\mathrm{Pb}-210, \mathrm{Ra}-226, \mathrm{Cs}-137$ & 10 & Mousing et al., 2013 \\
\hline $\begin{array}{l}1 \\
9\end{array}$ & $\begin{array}{l}\text { M72/5: 22- } \\
\text { GC3 }\end{array}$ & $\begin{array}{r}42 . \\
225\end{array}$ & $\begin{array}{r}36.4 \\
92\end{array}$ & 838 & $0-10.6 \mathrm{cal}$ & lithofacies and $\mathrm{Ca}-\mathrm{XRF}^{*}$ & $\begin{array}{r}8 . \\
39\end{array}$ & $\begin{array}{l}\text { Shumilovskikh et al., } \\
2013\end{array}$ \\
\hline & $\begin{array}{l}\text { Black Sea: } \\
\text { NE }\end{array}$ & & & & & & & \\
\hline $\begin{array}{l}2 \\
0\end{array}$ & $\begin{array}{l}\text { Ash-2009-8 } \\
\text { (Ash-8) }\end{array}$ & $\begin{array}{r}44 . \\
541\end{array}$ & $\begin{array}{r}38.0 \\
20\end{array}$ & 31 & $\begin{array}{l}1817- \\
2010 \mathrm{AD}\end{array}$ & $\mathrm{Pb}-210, \mathrm{Cs}-137$ & $\begin{array}{r}0 . \\
28\end{array}$ & Ivanova et al., 2014 \\
\hline 2 & & 44. & 38.6 & & & & 1. & \\
\hline 1 & GC Ak-2575 & 224 & 34 & 99 & $0-8.83$ & 11, molluscs & 86 & Ivanova et al., 2015 \\
\hline $\begin{array}{l}2 \\
2\end{array}$ & GC Ak-521 & $\begin{array}{r}44 . \\
257\end{array}$ & $\begin{array}{r}38.5 \\
38\end{array}$ & 101 & $0-10.45$ & $\begin{array}{l}\text { 4, Mytilus; } 5 \text { bivalve } \\
\text { shell }\end{array}$ & $\begin{array}{r}2 . \\
00\end{array}$ & Ivanova et al., 2012 \\
\hline & $\begin{array}{l}\text { Black Sea: } \\
\text { NW }\end{array}$ & & & & & & & \\
\hline $\begin{array}{l}2 \\
3\end{array}$ & Berezan B-2 & $\begin{array}{l}46 . \\
627\end{array}$ & $\begin{array}{r}31.4 \\
15\end{array}$ & 0 & $3.78-5.52$ & 2 Mytilus, Cardium & $\begin{array}{l}10 \\
.30\end{array}$ & $\begin{array}{l}\text { Yanko-Hombach et } \\
\text { al., } 2013\end{array}$ \\
\hline 2 & & 45. & 30.5 & & & & 3. & Yanko-Hombach et \\
\hline 4 & Odessa 342 & 719 & 74 & 31 & $4.46-8.99$ & 2, molluscs; 5 peat & 1 & al., 2013 \\
\hline $\begin{array}{l}2 \\
5\end{array}$ & Odessa 45B & $\begin{array}{l}44 . \\
671\end{array}$ & $\begin{array}{r}31,4 \\
15\end{array}$ & 107 & $0-8.17$ & 2 , molluscs & $\begin{array}{r}0 . \\
44\end{array}$ & $\begin{array}{l}\text { Yanko-Hombach et } \\
\text { al., } 2013\end{array}$ \\
\hline
\end{tabular}




\begin{tabular}{|c|c|c|c|c|c|c|c|c|}
\hline $\begin{array}{l}2 \\
6\end{array}$ & GGC18 & $\begin{array}{r}42 . \\
76\end{array}$ & $\begin{array}{r}28.6 \\
8\end{array}$ & 971 & $0-10.45$ & 18, detrital OM & $\begin{array}{r}2 . \\
05\end{array}$ & $\begin{array}{l}\text { Filipova-Marinova et } \\
\text { al., } 2013\end{array}$ \\
\hline $\begin{array}{l}2 \\
7\end{array}$ & Durankulak-3 & $\begin{array}{r}43 . \\
67\end{array}$ & $\begin{array}{r}28.5 \\
3\end{array}$ & 0 & $0-4.5 \mathrm{cal}$ & 5, wood fragments & $\begin{array}{r}2 . \\
4\end{array}$ & $\begin{array}{c}\text { Marinova \& } \\
\text { Atanassova, } 2006\end{array}$ \\
\hline & $\begin{array}{l}\text { Caspian Sea: } \\
\mathrm{N}\end{array}$ & & & & & & & \\
\hline $\begin{array}{l}2 \\
8\end{array}$ & $\begin{array}{l}\text { Volga Delta } \\
\text { D22, D24 }\end{array}$ & $\begin{array}{r}\text { c. } \\
45.6\end{array}$ & $\begin{array}{r}\text { c. } \\
47.9\end{array}$ & 0 & $0-5.2$ & 5, shells; 6 plants & $\begin{array}{r}8 . \\
95\end{array}$ & Richards et al, 2014a \\
\hline $\begin{array}{l}2 \\
9\end{array}$ & $\begin{array}{l}\text { Emba Delta } \\
\text { CDS cores }\end{array}$ & $\begin{array}{r}c . \\
46.22\end{array}$ & $\begin{aligned} & \text { c. } \\
& 52.41\end{aligned}$ & $2-4$ & $0-10.69$ & 1 bivalve; 1 ostracods & $\begin{array}{c}1 . \\
20\end{array}$ & Richards et al., 2017 \\
\hline $\begin{array}{l}3 \\
0\end{array}$ & $\begin{array}{l}\text { CDSE-12 } \\
\text { offshore }\end{array}$ & $\begin{array}{l}\mathrm{N} \\
\mathrm{A}\end{array}$ & NA & 3 & Holocene & 2, molluscs & 10 & $\begin{array}{l}\text { Richards et al., } \\
\text { 2014b; in prep. }\end{array}$ \\
\hline & $C^{\text {Caspian Sea: }}$ & & & & & & & \\
\hline $\begin{array}{l}3 \\
1\end{array}$ & CP21 & $\begin{array}{r}42 . \\
85\end{array}$ & $\begin{array}{r}49.8 \\
5\end{array}$ & 460 & $5.88-7.20$ & 2 , bulk carbonate & $\begin{array}{c}1 . \\
70\end{array}$ & Leroy et al., 2007 \\
\hline 3 & & 41. & 51.1 & & & & 1. & \\
\hline 2 & CP18 & 55 & 0 & 480 & $5.88-7.64$ & 2, bulk carbonate & 82 & Leroy et al., 2007 \\
\hline 3 & & 41. & 51.1 & & $3.55-$ & & 9. & \\
\hline 3 & GS18 & 548 & 01 & 479 & 12.26 & 6 , ostracods & 95 & Leroy et al. 2014 \\
\hline & S Caspian Sea: & & & & & & & \\
\hline $\begin{array}{l}3 \\
4\end{array}$ & CP14, US02 & $\begin{array}{r}39 . \\
267\end{array}$ & $\begin{array}{r}49.4 \\
67\end{array}$ & 330 & $0-6.74$ & $\begin{array}{l}3 \text {, bulk carbonate; } \mathrm{Pb}- \\
210\end{array}$ & $\begin{array}{r}1 . \\
4\end{array}$ & Leroy et al., 2007 \\
\hline $\begin{array}{l}3 \\
5\end{array}$ & US02 & $\begin{array}{r}39 . \\
267\end{array}$ & $\begin{array}{r}51.4 \\
67\end{array}$ & 315 & $\begin{array}{r}1709- \\
1994 \mathrm{AD}\end{array}$ & Pb-210, Cs-137 & 57 & Leroy et al. 2013a \\
\hline $\begin{array}{l}3 \\
6\end{array}$ & CS03 & $\begin{array}{r}37 . \\
591\end{array}$ & $\begin{array}{r}49.5 \\
71\end{array}$ & 250 & $\begin{array}{l}\text { c. } 1945- \\
2007 \mathrm{AD}\end{array}$ & Pb-210, Cs-137 & $\begin{array}{r}16 \\
6\end{array}$ & Leroy et al. 2013a \\
\hline $\begin{array}{l}3 \\
7\end{array}$ & GS05 & $\begin{array}{r}38 . \\
767\end{array}$ & $\begin{array}{r}51.5 \\
33\end{array}$ & 518 & $\begin{array}{l}5.40- \\
19.25\end{array}$ & $\begin{array}{l}6, \text { ostracods; } 8 \text { bulk } \\
\text { carbonate }\end{array}$ & $\begin{array}{r}9 . \\
57\end{array}$ & Leroy et al., 2013b \\
\hline $\begin{array}{l}3 \\
8\end{array}$ & drill-core TM & $\begin{array}{c}37 . \\
166\end{array}$ & $\begin{array}{r}54.0 \\
56\end{array}$ & $\begin{array}{r}2 \\
\text { a.s.l. }\end{array}$ & $\begin{array}{l}0-9.27 \\
17.36\end{array}$ & $\begin{array}{l}7 \text { mollusc shell; } 1 \\
\text { ostracod; } 1 \text { foram }\end{array}$ & $\begin{array}{r}26 \\
.5\end{array}$ & Leroy et al., 2013c \\
\hline
\end{tabular}


289

\begin{tabular}{|c|c|c|c|c|c|c|c|c|}
\hline $\begin{array}{l}3 \\
9\end{array}$ & 01 KGB99-08- & $\begin{array}{r}41 . \\
85\end{array}$ & $\begin{array}{r}53.0 \\
0\end{array}$ & 0.8 & $\begin{array}{r}1820- \\
1999 \text { AD }\end{array}$ & $\mathrm{Pb}-2010$ & $\begin{array}{r}0 . \\
98\end{array}$ & Leroy et al., 2006 \\
\hline & Aral Sea & & & & & & & \\
\hline $\begin{array}{l}4 \\
0\end{array}$ & $\mathrm{CH} 2 / 1$ & $\begin{array}{r}45 . \\
96\end{array}$ & $\begin{array}{r}59.2 \\
3\end{array}$ & 22 & $0-2.0 \mathrm{cal}$ & $\begin{array}{l}5, \text { green algae; } 2 \\
\text { carbonate }\end{array}$ & $\begin{array}{l}10 \\
.79\end{array}$ & Sorrel et al., 2006 \\
\hline & $40 \quad$ & & & & & & & \\
\hline
\end{tabular}


Appendix B

\begin{tabular}{|c|c|c|c|}
\hline & If & go to & Species Name \\
\hline & $\begin{array}{l}\text { CYSTS TRANSPARENT } \\
\text { CYSTS BROWN }\end{array}$ & 19 & \\
\hline & TRANSPARENT GROUP & & \\
\hline $\mathbf{1 a}$ & 1a Cysts without long spiniferate processes & 2 & \\
\hline $\mathbf{1 b}$ & 1b Cysts with spiniferate processes or cavate septa & 3 & \\
\hline $2 \mathrm{a}$ & Wall surface smooth or pitted with small warts & 4 & \\
\hline $2 \mathrm{~b}$ & Wall surface not smooth & 6 & \\
\hline $2 \mathrm{c}$ & Wall bearing very short spinose processes & 9 & \\
\hline $4 \mathrm{a}$ & Spherical or ovoidal, medium or small cysts & 5 & \\
\hline $4 \mathrm{~b}$ & Irregular shape & 7 & \\
\hline $5 \mathrm{a}$ & Atabular, with crenulate outer wall & & Ataxiodinium choane \\
\hline $5 b$ & Atabular, with spherical to cruciform body shape & & Pyxidinopsis psilata \\
\hline $5 \mathrm{c}$ & Tabulation marked by low septa & & Cyst of Alexandrium pseudogonyaulax \\
\hline $6 a$ & Finely vermiculate surface, compound archeopyle & & Bitectatodinium tepikiense \\
\hline $6 \mathrm{~b}$ & Tectate spongy surface, simple archeopyle & & Tectatodinium pellitum \\
\hline $6 \mathrm{c}$ & Rough, irregularly thickened wall surface & & Caspidinium rugosum \\
\hline $7 \mathrm{a}$ & Irregularly expanded hypocyst, not hyaline & & Impagidinium inaequalis \\
\hline $7 \mathrm{~b}$ & Irregular outline from mucilaginous layers, hyaline cysts & 8 & \\
\hline $8 \mathrm{a}$ & Large $(>50 \mu \mathrm{m})$, mucilage outline irregular & & Cyst of Fragilidium sp. \\
\hline $8 \mathrm{~b}$ & Smaller $(<50 \mu \mathrm{m})$, subspherical, no spines & & Cyst of Alexandrium spp. \\
\hline $8 \mathrm{c}$ & Undulating membranous outer layer, triangular spines & & Cyst of Scrippsiella trifida \\
\hline $9 \mathrm{a}$ & Spherical, processes hollow or with wide bases & 10 & \\
\hline $9 \mathrm{~b}$ & Spherical, thick hyaline wall, short rod-like processes $<3 \mu \mathrm{m}$ & & Cyst of cf. Biecheleria baltica \\
\hline $9 \mathrm{c}$ & Spherical or ovoidal, thin wall, short triangular processes & & Cyst of Scrippsiella trochoidea \\
\hline $10 \mathrm{a}$ & $\begin{array}{l}\text { Processes with widened bases and pointed tips that can be slightly } \\
\text { expanded }\end{array}$ & & Operculodinium israelianum \\
\hline $10 \mathrm{~b}$ & Microfibrous surface, hollow processes \& expanded tips & & $\begin{array}{l}\text { Operculodinium centrocarpum sensu } \\
\text { Wall and Dale } 1966\end{array}$ \\
\hline
\end{tabular}




\begin{tabular}{|c|c|c|c|}
\hline $\mathbf{3 a}$ & $\begin{array}{l}\text { Spiniferate with cruciform body shape, membranous } \\
\text { processes }\end{array}$ & & Spiniferites cruciformis \\
\hline $\mathbf{3 b}$ & Spiniferate with spherical, ovoid or pear-shaped body & 11 & \\
\hline $11 \mathrm{a}$ & Apical boss and usually with spiniferate process & 12 & \\
\hline $11 \mathrm{~b}$ & No apical boss, solid or membranous processes & 13 & \\
\hline $12 \mathrm{a}$ & Apical boss, processes reduced to undulating septa & & Impagidinium caspienense \\
\hline $12 \mathrm{~b}$ & Apical boss and clearly spiniferate process & 14 & \\
\hline 13a & $\begin{array}{l}\text { No apical boss, spherical to ovoidal body with exclusively } \\
\text { gonal pocesses }\end{array}$ & 15 & \\
\hline 13b & No apical boss, gonal and intergonal processes & 16 & \\
\hline $14 \mathrm{a}$ & Small, ovoidal, with trumpet-shaped ventral antapical process & & Spiniferites belerius \\
\hline $14 \mathrm{~b}$ & $\begin{array}{l}\text { Circular/ovoid, membranous exclusively gonal processes, broad } \\
\text { antapical flange }\end{array}$ & & Spiniferites membranaceus \\
\hline $14 \mathrm{c}$ & $\begin{array}{l}\text { Large, pear-shaped body, prominent apical boss, sometimes } \\
\text { intergonal }\end{array}$ & & Spiniferites bentorii \\
\hline $15 \mathrm{a}$ & Trifurcate process ends linked by trabeculae & & Nematosphaeropsis labyrinthus \\
\hline $15 \mathrm{~b}$ & Widely trifurcate free ends, non membranous, ovoid body & & Spiniferites ramosus \\
\hline $15 \mathrm{c}$ & Widely trifurcate free ends, spherical body & & Spiniferites sp. 1 \\
\hline $15 \mathrm{~d}$ & Membranous processes with petaloid process tips & & Spiniferites delicatus \\
\hline $15 \mathrm{e}$ & Membranous exclusively gonal processes, broad antapical flanges & & Spiniferites membranaceus \\
\hline $\mathbf{1 6 a}$ & $\begin{array}{l}\text { Cysts with gonal and intergonal processes, usually with } \\
\text { complete tabulation }\end{array}$ & 17 & \\
\hline $16 b$ & $\begin{array}{l}\text { Cysts with gonal and intergonal processes, incomplete } \\
\text { tabulation, complex process ends }\end{array}$ & 18 & \\
\hline $17 \mathrm{a}$ & $\begin{array}{l}\text { Solid gonal processes interconnected by low perforated sutural } \\
\text { ridges with small intergonal processes }\end{array}$ & & Spiniferites hyperacanthus \\
\hline $17 \mathrm{~b}$ & $\begin{array}{l}\text { Large cysts with stout rigid gonal and intergonal processes, wide, } \\
\text { complex antapical flange; sutures sometimes incompletely expressed }\end{array}$ & & Spiniferites mirabilis \\
\hline 18 & Incomplete paratabulation and complex process ends & & Spiniferites septentrionalis \\
\hline
\end{tabular}




\begin{tabular}{|c|c|c|c|}
\hline & BROWN GROUP & & \\
\hline $19 \mathbf{a}$ & $\begin{array}{l}\text { Brown round cysts with smooth or domed outer wall lacking } \\
\text { spinose processes }\end{array}$ & 20 & \\
\hline 19b & Brown cysts without round body shape & 24 & \\
\hline $20_{0}$ & Round cysts smooth or microoranulate wall & 21 & \\
\hline $20 \mathrm{ba}$ & Round cysts, undulating domed or reticulate wall & 22 & \\
\hline $20 c$ & Round cysts with spinose processes, chasmic archeopyle & 23 & \\
\hline $21 \mathrm{a}$ & Archeopyle large, wide intercalary, 1 or 2 plates & & Brigantedinium cariacoense \\
\hline $21 \mathrm{~b}$ & Archeopyle pentagonal, simple intercalary & & Brigantedinium simplex \\
\hline $21 \mathrm{c}$ & Archaeopyle not visible & & Round brown cysts (RBC) \\
\hline $21 d$ & Archeopyle large, chasmic; cyst polar compressed & & Dubridinium caperatum \\
\hline $22 \mathrm{a}$ & Domed, crenulated outer wall & & Cyst Type A of Verleye \\
\hline $22 b$ & Wall surface with finely reticulate surface & & $\begin{array}{r}\text { Cyst of Gymnodinium } \\
\text { nolleri/microreticulatum }\end{array}$ \\
\hline $23 \mathrm{a}$ & Spinose processes short, dense, equatorial arrangement & & Cyst of Diplopelta symmetrica \\
\hline $23 \mathrm{~b}$ & Spinose solid processes $>6 \mu \mathrm{m}$, rectangular base, pointed tip & & Echinidinium zonneveldiae \\
\hline $23 \mathrm{c}$ & Spinose processes hollow, with tapering tips & & Cyst of Polykrikos hartmannii \\
\hline $23 \mathrm{~d}$ & Spinose processes variable, not as above & & Spiny brown cysts \\
\hline $\mathbf{2 4 a}$ & Cyst shape irregular, bell-shaped or ovoidal & 25 & \\
\hline 24b & Cyst circular or pentagonal & 27 & \\
\hline $25 \mathrm{a}$ & Irregular shape, relatively few wide, forked processes & & Xandarodinium xanthum \\
\hline $25 b$ & Irregularly bell-shaped cysts, wall surface reticulate & & Cyst of Kolkwitziella acuta \\
\hline $25 \mathrm{c}$ & Ovoidal shape, many processes & 26 & \\
\hline $26 \mathrm{a}$ & With sturdy hollow rod-like processes, irregular tips & & Cyst of Barrufeta resplendens \\
\hline $26 b$ & With irregular lobate ornament & & Cyst of Cochlodinium ss Fukuyo \\
\hline $26 \mathrm{c}$ & With irregular thick solid spines connected by crests & & $\begin{array}{l}\text { Cyst of Cochlodinium polykrikoides ss } \\
\text { Li et al. } 2015\end{array}$ \\
\hline $26 \mathrm{~d}$ & With crested reticulum, often large & & $\begin{array}{l}\text { Cyst of Polykrikos kofoidii/schwartzii } \\
\text { ss Matsuoka et al. } 2009\end{array}$ \\
\hline
\end{tabular}




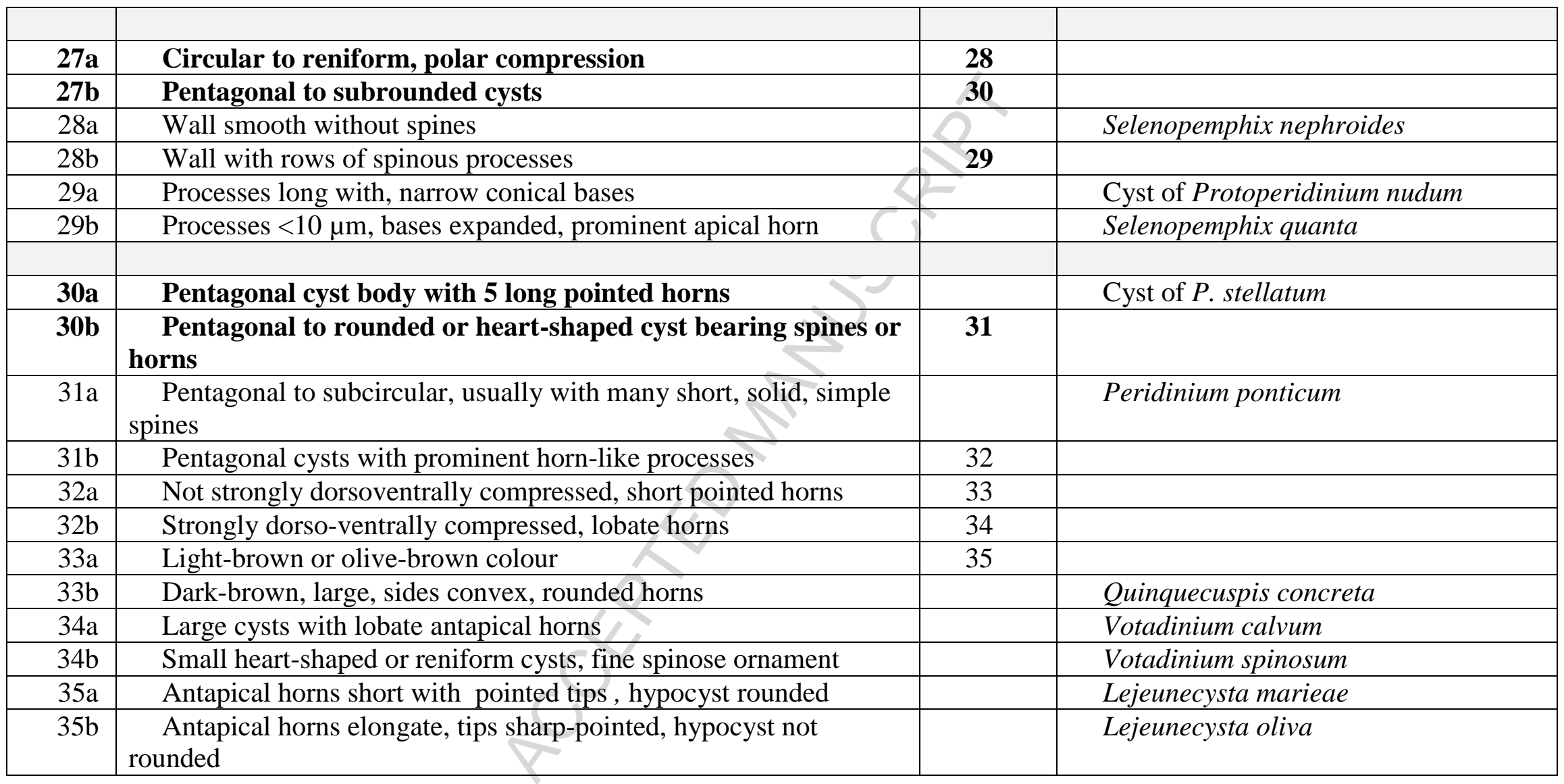


Appendix B . Provisional list of motile dinoflagellates in BSC seas: $\mathrm{M}=$ Marmara, $\mathrm{D}=$ Danube Delta, $\mathrm{B}=$ Black Sea, $\mathrm{C}=$ Caspian, $\mathrm{A}=$ Aral.

Akashiwo sanguinea(K.Hirasaka) G.Hansen \& Ø.Moestrup Akashiwo sanguinea(K.Hirasaka) G.Hansen \& Ø.Moestrup Akashiwo sanguinea(K.Hirasaka) G.Hansen \& Ø.Moestrup Akashiwo sanguinea(K.Hirasaka) G.Hansen \& Ø.Moestrup Akashiwo sanguinea(K.Hirasaka) G.Hansen \& Ø.Moestrup Akashiwo sanguinea(K.Hirasaka) G.Hansen \& Ø.Moestrup Akashiwo sanguinea(K.Hirasaka) G.Hansen \& Ø.Moestrup Akashiwo sanguinea(K.Hirasaka) G.Hansen \& Ø.Moestrup Akashiwo sanguinea(K.Hirasaka) G.Hansen \& Ø.Moestrup Akashiwo sanguinea(K.Hirasaka) G.Hansen \& Ø.Moestrup Akashiwo sanguinea(K.Hirasaka) G.Hansen \& Ø.Moestrup Akashiwo sanguinea(K.Hirasaka) G.Hansen \& Ø.Moestrup Akashiwo sanguinea(K.Hirasaka) G.Hansen \& Ø.Moestrup Akashiwo sanguinea(K.Hirasaka) G.Hansen \& Ø.Moestrup Akashiwo sanguinea(K.Hirasaka) G.Hansen \& Ø.Moestrup Akashiwo sanguinea(K.Hirasaka) G.Hansen \& Ø.Moestrup Akashiwo sanguinea(K.Hirasaka) G.Hansen \& Ø.Moestrup Akashiwo sanguinea(K.Hirasaka) G.Hansen \& Ø.Moestrup Akashiwo sanguinea(K.Hirasaka) G.Hansen \& Ø.Moestrup Akashiwo sanguinea(K.Hirasaka) G.Hansen \& Ø.Moestrup Akashiwo sanguinea(K.Hirasaka) G.Hansen \& Ø.Moestrup Akashiwo

sanguinea(K.Hirasaka) G.Hansen \& Ø.Moestrup Akashiwo sanguinea(K.Hirasaka) G.Hansen \& Ø.Moestrup

Alexandrium minutum Halim Alexandrium minutum Halim Alexandrium minutum Halim Alexandrium minutum Halim Alexandrium minutum Halim Alexandrium minutum Halim Alexandrium minutum Halim Alexandrium minutum Halim Alexandrium minutum Halim Alexandrium minutum Halim Alexandrium minutum Halim Alexandrium minutum Halim Alexandrium minutum Halim Alexandrium minutum Halim Alexandrium minutum Halim Alexandrium minutum Halim Alexandrium minutum Halim Alexandrium minutum Halim Alexandrium minutum Halim Alexandrium minutum Halim Alexandrium minutum Halim Alexandrium minutum Halim Alexandrium minutum Halim

Alexandrium monilatum(Howell) Balech Alexandrium monilatum(Howell) Balech Alexandrium monilatum(Howell) Balech Alexandrium monilatum(Howell) Balech

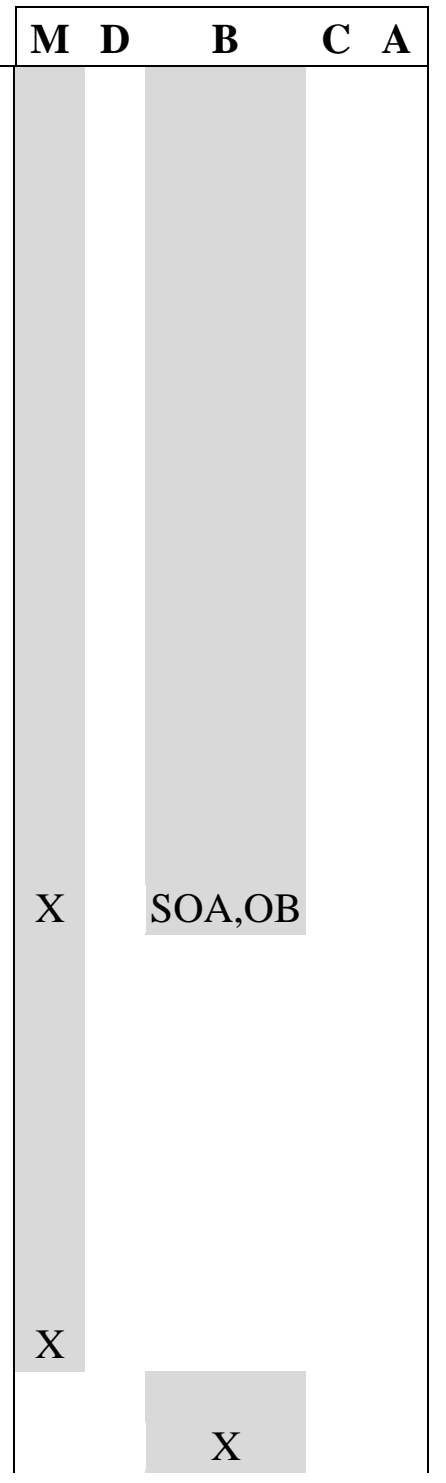


Alexandrium monilatum(Howell) Balech Alexandrium monilatum(Howell) Balech Alexandrium monilatum(Howell) Balech Alexandrium monilatum(Howell) Balech Alexandrium monilatum(Howell) Balech Alexandrium monilatum(Howell) Balech Alexandrium monilatum(Howell) Balech Alexandrium monilatum(Howell) Balech Alexandrium monilatum(Howell) Balech Alexandrium monilatum(Howell) Balech Alexandrium monilatum(Howell) Balech Alexandrium monilatum(Howell) Balech Alexandrium monilatum(Howell) Balech Alexandrium monilatum(Howell) Balech Alexandrium monilatum(Howell) Balech Alexandrium monilatum(Howell) Balech Alexandrium monilatum(Howell) Balech Alexandrium monilatum(Howell) Balech Alexandrium monilatum(Howell) Balech

Alexandrium ostenfeldii (Paulsen) Balech \& Tangen [Goniodoma

ostenfeldii]Alexandrium ostenfeldii (Paulsen) Balech \& Tangen [Goniodoma ostenfeldii]Alexandrium ostenfeldii (Paulsen) Balech \& Tangen [Goniodoma ostenfeldii]Alexandrium ostenfeldii (Paulsen) Balech \& Tangen [Goniodoma ostenfeldii]Alexandrium ostenfeldii (Paulsen) Balech \& Tangen [Goniodoma ostenfeldii]Alexandrium ostenfeldii (Paulsen) Balech \& Tangen [Goniodoma ostenfeldii]Alexandrium ostenfeldii (Paulsen) Balech \& Tangen [Goniodoma ostenfeldii]Alexandrium ostenfeldii (Paulsen) Balech \& Tangen [Goniodoma ostenfeldii]Alexandrium ostenfeldii (Paulsen) Balech \& Tangen [Goniodoma ostenfeldii]Alexandrium ostenfeldii (Paulsen) Balech \& Tangen [Goniodoma ostenfeldii]Alexandrium ostenfeldii (Paulsen) Balech \& Tangen [Goniodoma ostenfeldii]Alexandrium ostenfeldii (Paulsen) Balech \& Tangen [Goniodoma ostenfeldii]Alexandrium ostenfeldii (Paulsen) Balech \& Tangen [Goniodoma ostenfeldii]Alexandrium ostenfeldii (Paulsen) Balech \& Tangen [Goniodoma ostenfeldii]Alexandrium ostenfeldii (Paulsen) Balech \& Tangen [Goniodoma ostenfeldii]Alexandrium ostenfeldii (Paulsen) Balech \& Tangen [Goniodoma ostenfeldii]Alexandrium ostenfeldii (Paulsen) Balech \& Tangen [Goniodoma ostenfeldii]Alexandrium ostenfeldii (Paulsen) Balech \& Tangen [Goniodoma ostenfeldii]Alexandrium ostenfeldii (Paulsen) Balech \& Tangen [Goniodoma ostenfeldii]Alexandrium ostenfeldii (Paulsen) Balech \& Tangen [Goniodoma ostenfeldii]Alexandrium ostenfeldii (Paulsen) Balech \& Tangen [Goniodoma ostenfeldii]Alexandrium ostenfeldii (Paulsen) Balech \& Tangen [Goniodoma ostenfeldii]Alexandrium ostenfeldii (Paulsen) Balech \& Tangen [Goniodoma ostenfeldii]

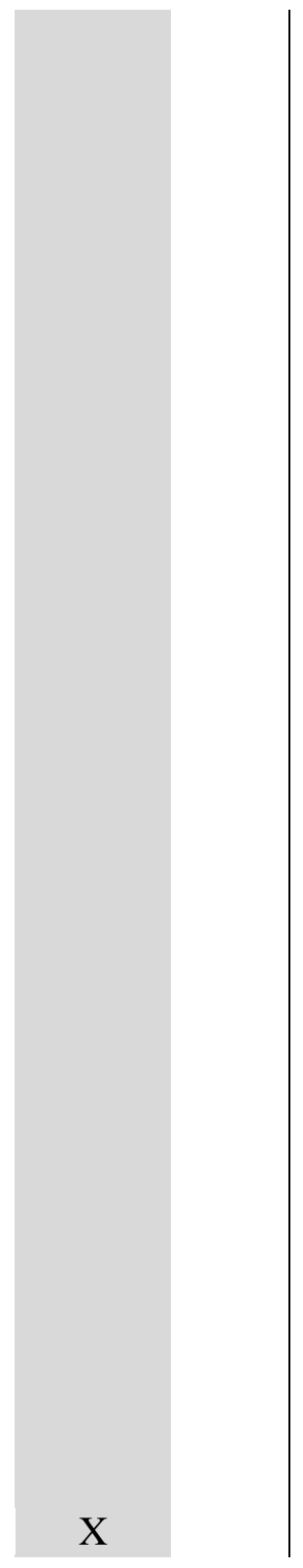


Alexandrium pseudogonyaulax (Biecheler) Horiguchi ex Yuki et Fukuyo, 1992 Alexandrium pseudogonyaulax (Biecheler) Horiguchi ex Yuki et Fukuyo, 1992 Alexandrium pseudogonyaulax (Biecheler) Horiguchi ex Yuki et Fukuyo, 1992 Alexandrium pseudogonyaulax (Biecheler) Horiguchi ex Yuki et Fukuyo, 1992 Alexandrium pseudogonyaulax (Biecheler) Horiguchi ex Yuki et Fukuyo, 1992 Alexandrium pseudogonyaulax (Biecheler) Horiguchi ex Yuki et Fukuyo, 1992 Alexandrium pseudogonyaulax (Biecheler) Horiguchi ex Yuki et Fukuyo, 1992 Alexandrium pseudogonyaulax (Biecheler) Horiguchi ex Yuki et Fukuyo, 1992 Alexandrium pseudogonyaulax (Biecheler) Horiguchi ex Yuki et Fukuyo, 1992 Alexandrium pseudogonyaulax (Biecheler) Horiguchi ex Yuki et Fukuyo, 1992 Alexandrium pseudogonyaulax (Biecheler) Horiguchi ex Yuki et Fukuyo, 1992 Alexandrium pseudogonyaulax (Biecheler) Horiguchi ex Yuki et Fukuyo, 1992 Alexandrium pseudogonyaulax (Biecheler) Horiguchi ex Yuki et Fukuyo, 1992 Alexandrium pseudogonyaulax (Biecheler) Horiguchi ex Yuki et Fukuyo, 1992 Alexandrium pseudogonyaulax (Biecheler) Horiguchi ex Yuki et Fukuyo, 1992 Alexandrium pseudogonyaulax (Biecheler) Horiguchi ex Yuki et Fukuyo, 1992 Alexandrium pseudogonyaulax (Biecheler) Horiguchi ex Yuki et Fukuyo, 1992 Alexandrium pseudogonyaulax (Biecheler) Horiguchi ex Yuki et Fukuyo, 1992 Alexandrium pseudogonyaulax (Biecheler) Horiguchi ex Yuki et Fukuyo, 1992 Alexandrium pseudogonyaulax (Biecheler) Horiguchi ex Yuki et Fukuyo, 1992 Alexandrium pseudogonyaulax (Biecheler) Horiguchi ex Yuki et Fukuyo, 1992 Alexandrium pseudogonyaulax (Biecheler) Horiguchi ex Yuki et Fukuyo, 1992 Alexandrium pseudogonyaulax (Biecheler) Horiguchi ex Yuki et Fukuyo, 1992

Alexandrium sp. Alexandrium sp. Alexandrium sp. Alexandrium sp. Alexandrium sp. Alexandrium sp. Alexandrium sp. Alexandrium sp. Alexandrium sp. Alexandrium sp. Alexandrium sp. Alexandrium sp. Alexandrium sp. Alexandrium sp. Alexandrium sp. Alexandrium sp. Alexandrium sp. Alexandrium sp. Alexandrium sp. Alexandrium sp. Alexandrium sp. Alexandrium sp. Alexandrium sp.

Alexandrium tamarense (Lebour) BalechAlexandrium tamarense (Lebour) BalechAlexandrium tamarense (Lebour) BalechAlexandrium tamarense (Lebour) BalechAlexandrium tamarense (Lebour) BalechAlexandrium tamarense (Lebour) BalechAlexandrium tamarense (Lebour) BalechAlexandrium tamarense (Lebour) BalechAlexandrium tamarense (Lebour) BalechAlexandrium tamarense (Lebour)

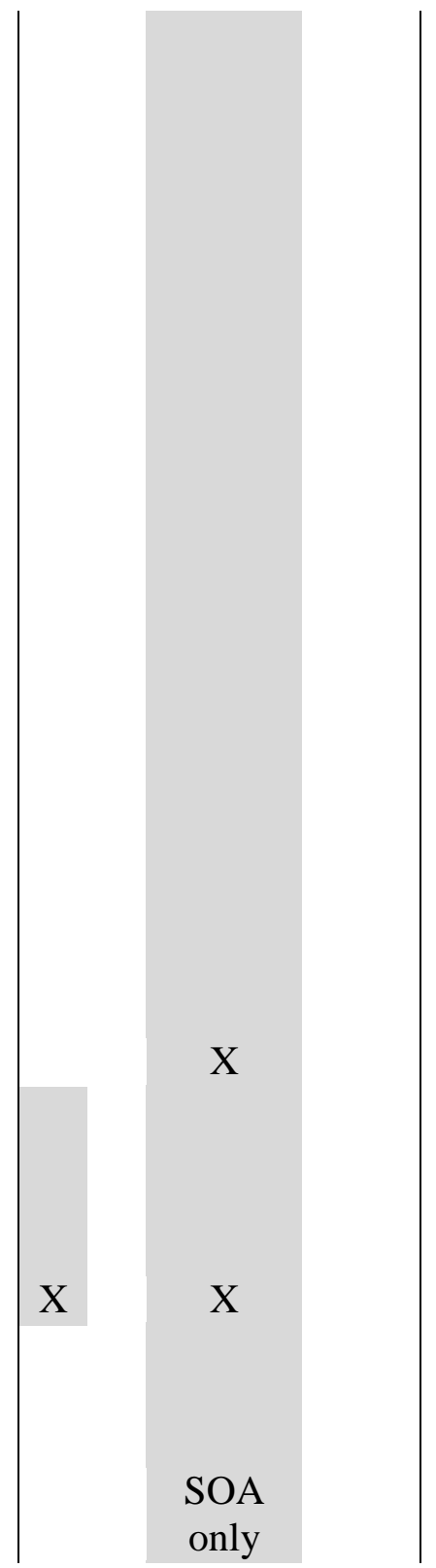


BalechAlexandrium tamarense (Lebour) BalechAlexandrium tamarense (Lebour) BalechAlexandrium tamarense (Lebour) BalechAlexandrium tamarense (Lebour) BalechAlexandrium tamarense (Lebour) BalechAlexandrium tamarense (Lebour) BalechAlexandrium tamarense (Lebour) BalechAlexandrium tamarense (Lebour) BalechAlexandrium tamarense (Lebour) BalechAlexandrium tamarense (Lebour) BalechAlexandrium tamarense (Lebour) BalechAlexandrium tamarense (Lebour) BalechAlexandrium tamarense (Lebour) Balech

Amphidinium acutissimum Schiller (Amphidinium acutum Schiller) Amphidinium acutissimum Schiller (Amphidinium acutum Schiller) Amphidinium acutissimum Schiller (Amphidinium acutum Schiller) Amphidinium acutissimum Schiller (Amphidinium acutum Schiller) Amphidinium acutissimum Schiller (Amphidinium acutum Schiller)

Amphidinium acutissimum Schiller (Amphidinium acutum Schiller) Amphidinium acutissimum Schiller (Amphidinium acutum Schiller) Amphidinium acutissimum Schiller (Amphidinium acutum Schiller) Amphidinium acutissimum Schiller (Amphidinium acutum Schiller) Amphidinium acutissimum Schiller (Amphidinium acutum Schiller) Amphidinium acutissimum Schiller (Amphidinium acutum Schiller) Amphidinium acutissimum Schiller (Amphidinium acutum Schiller) Amphidinium acutissimum Schiller (Amphidinium acutum Schiller) Amphidinium acutissimum Schiller (Amphidinium acutum Schiller) Amphidinium acutissimum Schiller (Amphidinium acutum Schiller) Amphidinium acutissimum Schiller (Amphidinium acutum Schiller) Amphidinium acutissimum Schiller (Amphidinium acutum Schiller) Amphidinium acutissimum Schiller (Amphidinium acutum Schiller) Amphidinium acutissimum Schiller (Amphidinium acutum Schiller) Amphidinium acutissimum Schiller (Amphidinium acutum Schiller)

Amphidinium acutissimum Schiller (Amphidinium acutum Schiller) Amphidinium acutissimum Schiller (Amphidinium acutum Schiller) Amphidinium acutissimum Schiller (Amphidinium acutum Schiller)

Amphidinium amphidinioides (Geitler) Schiller [Amphidinium geitleri; A. bourrellyi etc.]Amphidinium amphidinioides (Geitler) Schiller [Amphidinium geitleri; A. bourrellyi etc.]Amphidinium amphidinioides (Geitler) Schiller [Amphidinium geitleri; A. bourrellyi etc.]Amphidinium amphidinioides (Geitler) Schiller [Amphidinium geitleri; A. bourrellyi etc.]Amphidinium amphidinioides (Geitler) Schiller [Amphidinium geitleri; A. bourrellyi etc.]Amphidinium amphidinioides (Geitler) Schiller [Amphidinium geitleri; A. bourrellyi etc.]Amphidinium amphidinioides (Geitler) Schiller [Amphidinium geitleri; A. bourrellyi

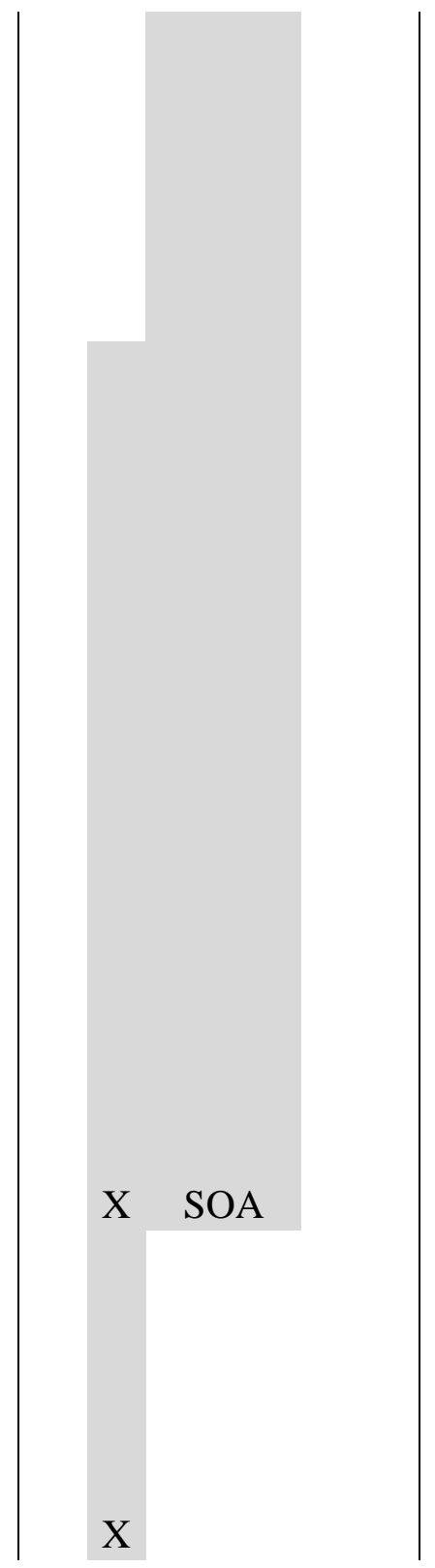


etc.]Amphidinium amphidinioides (Geitler) Schiller [Amphidinium geitleri; A. bourrellyi etc.]Amphidinium amphidinioides (Geitler) Schiller [Amphidinium geitleri; A. bourrellyi etc.]Amphidinium amphidinioides (Geitler) Schiller [Amphidinium geitleri; A. bourrellyi etc.]Amphidinium amphidinioides (Geitler) Schiller [Amphidinium geitleri; A. bourrellyi etc.]Amphidinium amphidinioides (Geitler) Schiller [Amphidinium geitleri; A. bourrellyi etc.]Amphidinium amphidinioides (Geitler) Schiller [Amphidinium geitleri; A. bourrellyi etc.]Amphidinium amphidinioides (Geitler) Schiller [Amphidinium geitleri; A. bourrellyi etc.]Amphidinium amphidinioides (Geitler) Schiller [Amphidinium geitleri; A. bourrellyi etc.]Amphidinium amphidinioides (Geitler) Schiller [Amphidinium geitleri; A. bourrellyi etc.]Amphidinium amphidinioides (Geitler) Schiller [Amphidinium geitleri; A. bourrellyi etc.]Amphidinium amphidinioides (Geitler) Schiller [Amphidinium geitleri; A. bourrellyi etc.]Amphidinium amphidinioides (Geitler) Schiller [Amphidinium geitleri; A. bourrellyi etc.]Amphidinium amphidinioides (Geitler) Schiller [Amphidinium geitleri; A. bourrellyi etc.]Amphidinium amphidinioides (Geitler) Schiller [Amphidinium geitleri; A. bourrellyi etc.]Amphidinium amphidinioides (Geitler) Schiller [Amphidinium geitleri; A. bourrellyi etc.]Amphidinium amphidinioides (Geitler) Schiller [Amphidinium geitleri; A. bourrellyi etc.]

Amphidinium conradii Schiller [ Gymnodinium glaucum]Amphidinium conradii Schiller [ Gymnodinium glaucum]Amphidinium conradii Schiller [ Gymnodinium

glaucum]Amphidinium conradii Schiller [ Gymnodinium glaucum]Amphidinium conradii Schiller [ Gymnodinium glaucum]Amphidinium conradii Schiller [ Gymnodinium glaucum]Amphidinium conradii Schiller [ Gymnodinium glaucum]Amphidinium conradii Schiller [ Gymnodinium glaucum]Amphidinium conradii Schiller [ Gymnodinium glaucum]Amphidinium conradii Schiller [ Gymnodinium glaucum]Amphidinium conradii Schiller [ Gymnodinium glaucum]Amphidinium conradii Schiller [ Gymnodinium glaucum]Amphidinium conradii Schiller [ Gymnodinium glaucum]Amphidinium conradii Schiller [ Gymnodinium glaucum]Amphidinium conradii Schiller [ Gymnodinium glaucum]Amphidinium conradii Schiller [ Gymnodinium glaucum]Amphidinium conradii Schiller [ Gymnodinium glaucum]Amphidinium conradii Schiller [ Gymnodinium glaucum]Amphidinium conradii Schiller [ Gymnodinium glaucum]Amphidinium conradii Schiller [ Gymnodinium glaucum]Amphidinium conradii Schiller [ Gymnodinium glaucum]Amphidinium conradii Schiller [ Gymnodinium glaucum]Amphidinium conradii Schiller [ Gymnodinium glaucum] 
Amphidinium crassum Lohmann [Amphidinium phaeocysticola ] Amphidinium crassum Lohmann [Amphidinium phaeocysticola] Amphidinium crassum Lohmann [Amphidinium phaeocysticola ] Amphidinium crassum Lohmann [Amphidinium phaeocysticola ] Amphidinium crassum Lohmann [Amphidinium phaeocysticola ] Amphidinium crassum Lohmann [Amphidinium phaeocysticola ] Amphidinium crassum Lohmann [Amphidinium phaeocysticola ] Amphidinium crassum Lohmann [Amphidinium phaeocysticola]

Amphidinium crassum Lohmann [Amphidinium phaeocysticola] Amphidinium crassum Lohmann [Amphidinium phaeocysticola] Amphidinium crassum Lohmann [Amphidinium phaeocysticola ] Amphidinium crassum Lohmann [Amphidinium phaeocysticola ] Amphidinium crassum Lohmann [Amphidinium phaeocysticola ] Amphidinium crassum Lohmann [Amphidinium phaeocysticola ] Amphidinium crassum Lohmann [Amphidinium phaeocysticola ] Amphidinium crassum Lohmann [Amphidinium phaeocysticola ] Amphidinium crassum Lohmann [Amphidinium phaeocysticola] Amphidinium crassum Lohmann [Amphidinium phaeocysticola] Amphidinium crassum Lohmann [Amphidinium phaeocysticola ] Amphidinium crassum Lohmann [Amphidinium phaeocysticola ] Amphidinium crassum Lohmann [Amphidinium phaeocysticola] Amphidinium crassum Lohmann [Amphidinium phaeocysticola] Amphidinium crassum Lohmann [Amphidinium phaeocysticola ]

Amphidinium cucurbita Kofoid \& Swezy Amphidinium cucurbita Kofoid \& Swezy Amphidinium cucurbita Kofoid \& Swezy Amphidinium cucurbita Kofoid \& Swezy Amphidinium cucurbita Kofoid \& Swezy Amphidinium cucurbita Kofoid \& Swezy Amphidinium cucurbita Kofoid \& Swezy Amphidinium cucurbita Kofoid \& Swezy Amphidinium cucurbita Kofoid \& Swezy Amphidinium cucurbita Kofoid \& Swezy Amphidinium cucurbita Kofoid \& Swezy Amphidinium cucurbita Kofoid \& Swezy Amphidinium cucurbita Kofoid \& Swezy Amphidinium cucurbita Kofoid \& Swezy Amphidinium cucurbita Kofoid \& Swezy Amphidinium cucurbita Kofoid \& Swezy Amphidinium cucurbita Kofoid \& Swezy Amphidinium cucurbita Kofoid \& Swezy Amphidinium cucurbita Kofoid \& Swezy Amphidinium cucurbita Kofoid \& Swezy Amphidinium cucurbita Kofoid \& Swezy Amphidinium cucurbita Kofoid \& Swezy Amphidinium cucurbita Kofoid \& Swezy

Amphidinium curvatum Schiller Amphidinium curvatum Schiller Amphidinium curvatum Schiller Amphidinium curvatum Schiller Amphidinium curvatum Schiller Amphidinium curvatum Schiller Amphidinium curvatum Schiller Amphidinium curvatum Schiller

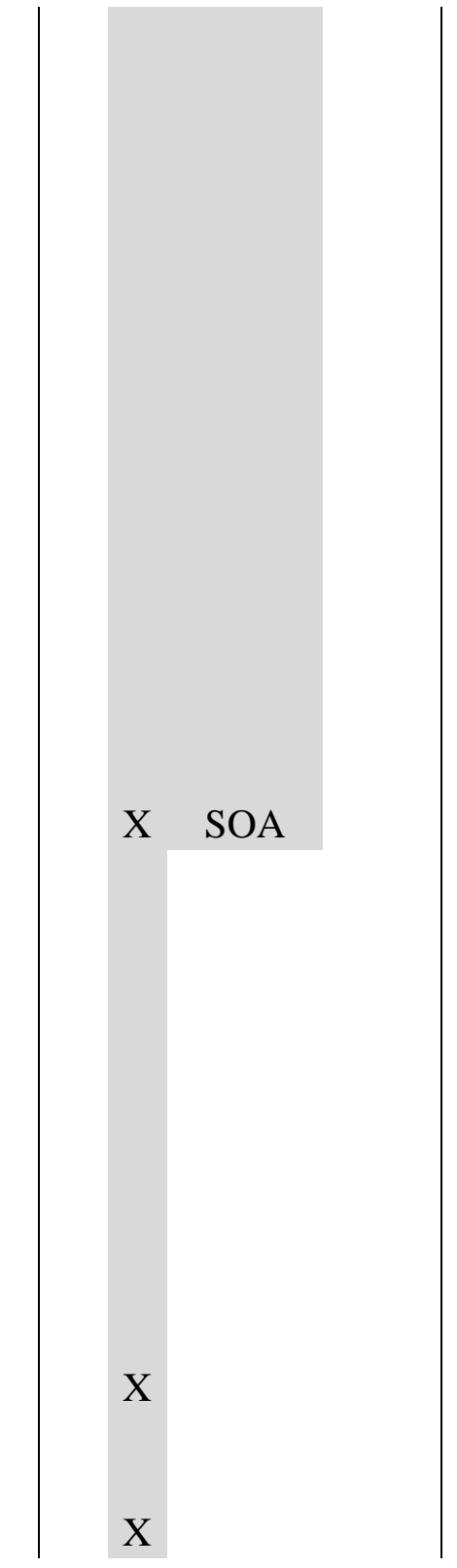


Amphidinium curvatum Schiller Amphidinium curvatum Schiller Amphidinium curvatum Schiller Amphidinium curvatum Schiller Amphidinium curvatum Schiller Amphidinium curvatum Schiller Amphidinium curvatum Schiller Amphidinium curvatum Schiller Amphidinium curvatum Schiller Amphidinium curvatum Schiller Amphidinium curvatum Schiller Amphidinium curvatum Schiller Amphidinium curvatum Schiller Amphidinium curvatum Schiller Amphidinium curvatum Schiller

Amphidinium elenkinii Skvortsov [Amphidinium larvale; Amphidinium hyalinum etc.] Amphidinium elenkinii Skvortsov [Amphidinium larvale; Amphidinium hyalinum etc.] Amphidinium elenkinii Skvortsov [Amphidinium larvale; Amphidinium hyalinum etc.] Amphidinium elenkinii Skvortsov [Amphidinium larvale; Amphidinium hyalinum etc.] Amphidinium elenkinii Skvortsov [Amphidinium larvale; Amphidinium hyalinum etc.] Amphidinium elenkinii Skvortsov [Amphidinium larvale; Amphidinium hyalinum etc.] Amphidinium elenkinii Skvortsov [Amphidinium larvale; Amphidinium hyalinum etc.] Amphidinium elenkinii Skvortsov [Amphidinium larvale; Amphidinium hyalinum etc.] Amphidinium elenkinii Skvortsov [Amphidinium larvale; Amphidinium hyalinum etc.] Amphidinium elenkinii Skvortsov [Amphidinium larvale; Amphidinium hyalinum etc.] Amphidinium elenkinii Skvortsov [Amphidinium larvale; Amphidinium hyalinum etc.] Amphidinium elenkinii Skvortsov [Amphidinium larvale; Amphidinium hyalinum etc.] Amphidinium elenkinii Skvortsov [Amphidinium larvale; Amphidinium hyalinum etc.] Amphidinium elenkinii Skvortsov [Amphidinium larvale; Amphidinium hyalinum etc.] Amphidinium elenkinii Skvortsov [Amphidinium larvale; Amphidinium hyalinum etc.] Amphidinium elenkinii Skvortsov [Amphidinium larvale; Amphidinium hyalinum etc.] Amphidinium elenkinii Skvortsov [Amphidinium larvale; Amphidinium hyalinum etc.] Amphidinium elenkinii Skvortsov [Amphidinium larvale; Amphidinium hyalinum etc.] Amphidinium elenkinii Skvortsov [Amphidinium larvale; Amphidinium hyalinum etc.] Amphidinium elenkinii Skvortsov [Amphidinium larvale; Amphidinium hyalinum etc.] Amphidinium elenkinii Skvortsov [Amphidinium larvale; Amphidinium hyalinum etc.] Amphidinium elenkinii Skvortsov [Amphidinium larvale; Amphidinium hyalinum etc.] Amphidinium elenkinii Skvortsov [Amphidinium larvale; Amphidinium hyalinum etc.] Amphidinium extensum Wulff Amphidinium extensum Wulff Amphidinium extensum Wulff Amphidinium extensum Wulff Amphidinium extensum Wulff Amphidinium extensum Wulff Amphidinium extensum Wulff Amphidinium extensum Wulff Amphidinium extensum Wulff Amphidinium extensum Wulff Amphidinium extensum Wulff Amphidinium extensum Wulff

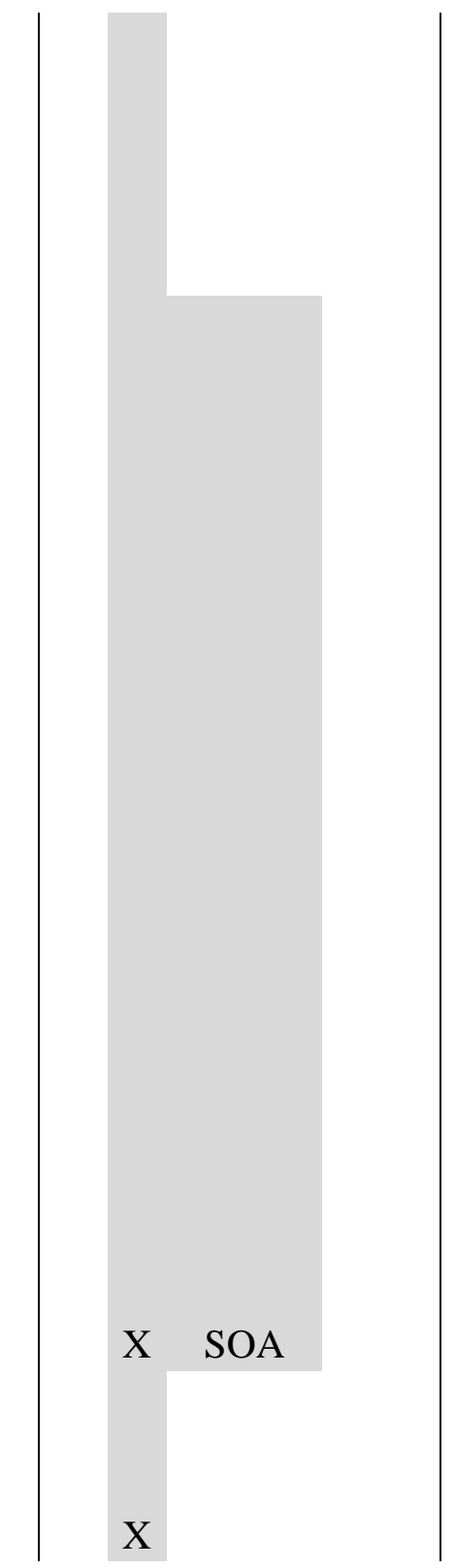


Amphidinium extensum Wulff Amphidinium extensum Wulff Amphidinium extensum Wulff Amphidinium extensum Wulff Amphidinium extensum Wulff Amphidinium extensum Wulff Amphidinium extensum Wulff Amphidinium extensum Wulff Amphidinium extensum Wulff Amphidinium extensum Wulff Amphidinium extensum Wulff

Amphidinium flagellans Schiller Amphidinium flagellans Schiller Amphidinium flagellans Schiller Amphidinium flagellans Schiller Amphidinium flagellans Schiller Amphidinium flagellans Schiller Amphidinium flagellans Schiller Amphidinium flagellans Schiller Amphidinium flagellans Schiller Amphidinium flagellans Schiller Amphidinium flagellans Schiller Amphidinium flagellans Schiller Amphidinium flagellans Schiller Amphidinium flagellans Schiller Amphidinium flagellans Schiller Amphidinium flagellans Schiller Amphidinium flagellans Schiller Amphidinium flagellans Schiller Amphidinium flagellans Schiller Amphidinium flagellans Schiller Amphidinium flagellans Schiller Amphidinium flagellans Schiller

Amphidinium fusiforme MartinAmphidinium fusiforme MartinAmphidinium fusiforme MartinAmphidinium fusiforme MartinAmphidinium fusiforme MartinAmphidinium fusiforme MartinAmphidinium fusiforme MartinAmphidinium fusiforme MartinAmphidinium fusiforme MartinAmphidinium fusiforme MartinAmphidinium fusiforme MartinAmphidinium fusiforme MartinAmphidinium fusiforme MartinAmphidinium fusiforme MartinAmphidinium fusiforme MartinAmphidinium fusiforme MartinAmphidinium fusiforme MartinAmphidinium fusiforme MartinAmphidinium fusiforme MartinAmphidinium fusiforme MartinAmphidinium fusiforme MartinAmphidinium fusiforme Martin

Amphidinium globosum Schröder Amphidinium globosum Schröder Amphidinium globosum Schröder Amphidinium globosum Schröder Amphidinium globosum Schröder Amphidinium globosum Schröder Amphidinium globosum Schröder Amphidinium globosum Schröder Amphidinium globosum Schröder Amphidinium globosum Schröder Amphidinium globosum Schröder Amphidinium globosum Schröder Amphidinium globosum Schröder Amphidinium globosum Schröder Amphidinium globosum Schröder Amphidinium globosum Schröder Amphidinium globosum Schröder Amphidinium globosum Schröder Amphidinium globosum Schröder Amphidinium globosum Schröder Amphidinium globosum Schröder Amphidinium globosum Schröder

Amphodinium inflatum KofoidiAmphodinium inflatum KofoidiAmphodinium inflatum KofoidiAmphodinium inflatum KofoidiAmphodinium inflatum KofoidiAmphodinium 
inflatum KofoidiAmphodinium inflatum KofoidiAmphodinium inflatum KofoidiAmphodinium inflatum KofoidiAmphodinium inflatum KofoidiAmphodinium inflatum KofoidiAmphodinium inflatum KofoidiAmphodinium inflatum KofoidiAmphodinium inflatum KofoidiAmphodinium inflatum KofoidiAmphodinium inflatum KofoidiAmphodinium inflatum KofoidiAmphodinium inflatum KofoidiAmphodinium inflatum KofoidiAmphodinium inflatum KofoidiAmphodinium inflatum KofoidiAmphodinium inflatum Kofoidi

Amphidinium lacustre Stein [Amphidinium lacustriforme, A. schroederi] Amphidinium lacustre Stein [Amphidinium lacustriforme, A. schroederi] Amphidinium lacustre Stein [Amphidinium lacustriforme, A. schroederi] Amphidinium lacustre Stein [Amphidinium lacustriforme, A. schroederi] Amphidinium lacustre Stein [Amphidinium lacustriforme, A. schroederi] Amphidinium lacustre Stein [Amphidinium lacustriforme, A. schroederi] Amphidinium lacustre Stein [Amphidinium lacustriforme, A. schroederi] Amphidinium lacustre Stein [Amphidinium lacustriforme, A. schroederi] Amphidinium lacustre Stein [Amphidinium lacustriforme, A. schroederi] Amphidinium lacustre Stein [Amphidinium lacustriforme, A. schroederi] Amphidinium lacustre Stein [Amphidinium lacustriforme, A. schroederi] Amphidinium lacustre Stein [Amphidinium lacustriforme, A. schroederi] Amphidinium lacustre Stein [Amphidinium lacustriforme, A. schroederi] Amphidinium lacustre Stein [Amphidinium lacustriforme, A. schroederi] Amphidinium lacustre Stein [Amphidinium lacustriforme, A. schroederi] Amphidinium lacustre Stein [Amphidinium lacustriforme, A. schroederi] Amphidinium lacustre Stein [Amphidinium lacustriforme, A. schroederi] Amphidinium lacustre Stein [Amphidinium lacustriforme, A. schroederi] Amphidinium lacustre Stein [Amphidinium lacustriforme, A. schroederi] Amphidinium lacustre Stein [Amphidinium lacustriforme, A. schroederi] Amphidinium lacustre Stein [Amphidinium lacustriforme, A. schroederi] Amphidinium lacustre Stein [Amphidinium lacustriforme, A. schroederi ]

Amphidinium lanceolatum Schröder Amphidinium lanceolatum Schröder Amphidinium lanceolatum Schröder Amphidinium lanceolatum Schröder Amphidinium lanceolatum Schröder Amphidinium lanceolatum Schröder Amphidinium lanceolatum Schröder Amphidinium lanceolatum Schröder Amphidinium lanceolatum Schröder Amphidinium lanceolatum Schröder Amphidinium lanceolatum Schröder Amphidinium lanceolatum Schröder Amphidinium lanceolatum Schröder Amphidinium lanceolatum Schröder Amphidinium lanceolatum Schröder Amphidinium lanceolatum Schröder Amphidinium

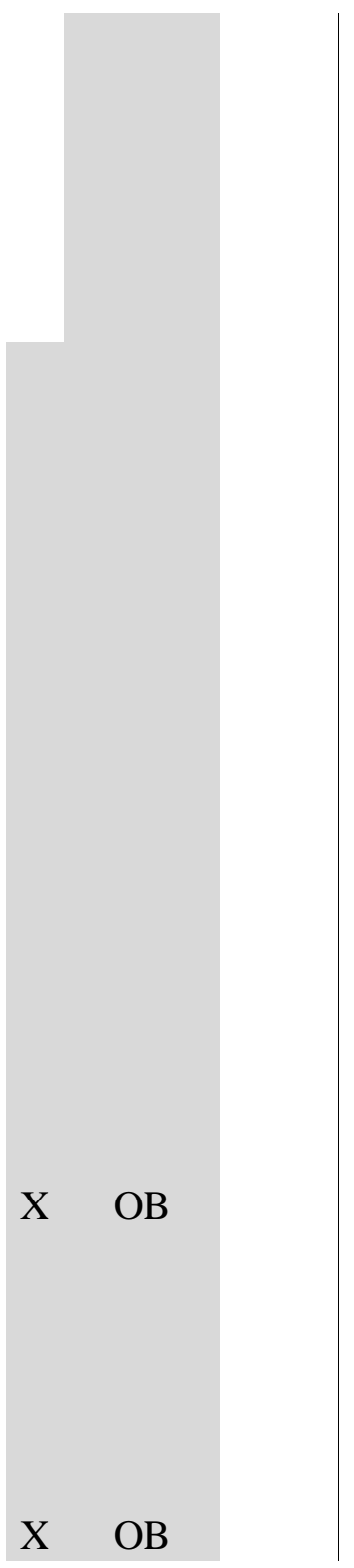


lanceolatum Schröder Amphidinium lanceolatum Schröder Amphidinium lanceolatum Schröder Amphidinium lanceolatum Schröder Amphidinium lanceolatum Schröder Amphidinium lanceolatum Schröder

Amphidinium longum Lohmann [Amphidinium acutum]Amphidinium longum Lohmann [Amphidinium acutum]Amphidinium longum Lohmann [Amphidinium acutum]Amphidinium longum Lohmann [Amphidinium acutum] Amphidinium longum Lohmann [Amphidinium acutum]Amphidinium longum Lohmann [Amphidinium acutum]Amphidinium longum Lohmann [Amphidinium acutum] Amphidinium longum Lohmann [Amphidinium acutum] Amphidinium longum Lohmann [Amphidinium acutum]Amphidinium longum Lohmann [Amphidinium acutum]Amphidinium longum Lohmann [Amphidinium acutum] Amphidinium longum Lohmann [Amphidinium acutum]Amphidinium longum Lohmann [Amphidinium acutum] Amphidinium longum Lohmann [Amphidinium acutum]Amphidinium longum Lohmann [Amphidinium acutum]Amphidinium longum Lohmann [Amphidinium acutum] Amphidinium longum Lohmann [Amphidinium acutum] Amphidinium longum Lohmann [Amphidinium acutum]Amphidinium longum Lohmann [Amphidinium acutum]Amphidinium longum Lohmann [Amphidinium acutum] Amphidinium longum Lohmann [Amphidinium acutum] Amphidinium longum Lohmann [Amphidinium acutum]

Amphidinium operculatum Claparède et Lachmann [Amphidinium klebsii] Amphidinium operculatum Claparède et Lachmann [Amphidinium klebsii] Amphidinium operculatum Claparède et Lachmann [Amphidinium klebsii] Amphidinium operculatum Claparède et Lachmann [Amphidinium klebsii] Amphidinium operculatum Claparède et Lachmann [Amphidinium klebsii] Amphidinium operculatum Claparède et Lachmann [Amphidinium klebsii] Amphidinium operculatum Claparède et Lachmann [Amphidinium klebsii] Amphidinium operculatum Claparède et Lachmann [Amphidinium klebsii] Amphidinium operculatum Claparède et Lachmann [Amphidinium klebsii] Amphidinium operculatum Claparède et Lachmann [Amphidinium klebsii] Amphidinium operculatum Claparède et Lachmann [Amphidinium klebsii] Amphidinium operculatum Claparède et Lachmann [Amphidinium klebsii] Amphidinium operculatum Claparède et Lachmann [Amphidinium klebsii] Amphidinium operculatum Claparède et Lachmann [Amphidinium klebsii] Amphidinium operculatum Claparède et Lachmann [Amphidinium klebsii] 
Amphidinium operculatum Claparède et Lachmann [Amphidinium klebsii] Amphidinium operculatum Claparède et Lachmann [Amphidinium klebsii] Amphidinium operculatum Claparède et Lachmann [Amphidinium klebsii] Amphidinium operculatum Claparède et Lachmann [Amphidinium klebsii] Amphidinium operculatum Claparède et Lachmann [Amphidinium klebsii] Amphidinium operculatum Claparède et Lachmann [Amphidinium klebsii] Amphidinium operculatum Claparède et Lachmann [Amphidinium klebsii] Amphidinium ovum Herdman Amphidinium ovum Herdman Amphidinium ovum Herdman Amphidinium ovum Herdman Amphidinium ovum Herdman Amphidinium ovum Herdman Amphidinium ovum Herdman Amphidinium ovum Herdman Amphidinium ovum Herdman Amphidinium ovum Herdman Amphidinium ovum Herdman Amphidinium ovum Herdman Amphidinium ovum Herdman Amphidinium ovum Herdman Amphidinium ovum Herdman Amphidinium ovum Herdman Amphidinium ovum Herdman Amphidinium ovum Herdman Amphidinium ovum Herdman Amphidinium ovum Herdman Amphidinium ovum Herdman Amphidinium ovum Herdman

Amphidinium vigrense Woloszynska Amphidinium vigrense Woloszynska Amphidinium vigrense Woloszynska Amphidinium vigrense Woloszynska Amphidinium vigrense Woloszynska Amphidinium vigrense Woloszynska Amphidinium vigrense Woloszynska Amphidinium vigrense Woloszynska Amphidinium vigrense Woloszynska Amphidinium vigrense Woloszynska Amphidinium vigrense Woloszynska Amphidinium vigrense Woloszynska Amphidinium vigrense Woloszynska Amphidinium vigrense Woloszynska Amphidinium vigrense Woloszynska Amphidinium vigrense Woloszynska Amphidinium vigrense Woloszynska Amphidinium vigrense Woloszynska Amphidinium vigrense Woloszynska Amphidinium vigrense Woloszynska Amphidinium vigrense Woloszynska Amphidinium vigrense Woloszynska Amphisolenia bidentata Schröder [non Amphisolenia bidentata] Amphisolenia bidentata Schröder [non Amphisolenia bidentata] Amphisolenia bidentata Schröder [non Amphisolenia bidentata] Amphisolenia bidentata Schröder [non Amphisolenia bidentata] Amphisolenia bidentata Schröder [non Amphisolenia bidentata] Amphisolenia bidentata Schröder [non Amphisolenia bidentata] Amphisolenia bidentata Schröder [non Amphisolenia bidentata] Amphisolenia bidentata Schröder 
[non Amphisolenia bidentata] Amphisolenia bidentata Schröder [non Amphisolenia bidentata] Amphisolenia bidentata Schröder [non Amphisolenia bidentata]

Amphisolenia bidentata Schröder [non Amphisolenia bidentata] Amphisolenia bidentata Schröder [non Amphisolenia bidentata] Amphisolenia bidentata Schröder [non Amphisolenia bidentata] Amphisolenia bidentata Schröder [non Amphisolenia bidentata] Amphisolenia bidentata Schröder [non Amphisolenia bidentata] Amphisolenia bidentata Schröder [non Amphisolenia bidentata] Amphisolenia bidentata Schröder [non Amphisolenia bidentata] Amphisolenia bidentata Schröder [non Amphisolenia bidentata] Amphisolenia bidentata Schröder [non Amphisolenia bidentata] Amphisolenia bidentata Schröder [non Amphisolenia bidentata] Amphisolenia bidentata Schröder [non Amphisolenia bidentata] Amphisolenia bidentata Schröder [non Amphisolenia bidentata]

Amylax triacantha (Jørgensen) Sournia [Gonyaulax triacantha, Amylax lata] Amylax triacantha (Jorgensen) Sournia [Gonyaulax triacantha, Amylax lata] Amylax triacantha (Jørgensen) Sournia [Gonyaulax triacantha, Amylax lata] Amylax triacantha (Jørgensen) Sournia [Gonyaulax triacantha, Amylax lata] Amylax triacantha (Jorgensen) Sournia [Gonyaulax triacantha, Amylax lata] Amylax triacantha (Jorgensen) Sournia [Gonyaulax triacantha, Amylax lata] Amylax triacantha (Jorgensen) Sournia [Gonyaulax triacantha, Amylax lata] Amylax triacantha (Jørgensen) Sournia [Gonyaulax triacantha, Amylax lata] Amylax triacantha (Jørgensen) Sournia [Gonyaulax triacantha, Amylax lata] Amylax triacantha (Jorgensen) Sournia [Gonyaulax triacantha, Amylax lata] Amylax triacantha (Jorgensen) Sournia [Gonyaulax triacantha, Amylax lata] Amylax triacantha (Jørgensen) Sournia [Gonyaulax triacantha, Amylax lata] Amylax triacantha (Jørgensen) Sournia [Gonyaulax triacantha, Amylax lata] Amylax triacantha (Jorgensen) Sournia [Gonyaulax triacantha, Amylax lata] Amylax triacantha (Jorgensen) Sournia [Gonyaulax triacantha, Amylax lata] Amylax triacantha (Jørgensen) Sournia [Gonyaulax triacantha, Amylax lata] Amylax triacantha (Jørgensen) Sournia [Gonyaulax triacantha, Amylax lata] Amylax triacantha (Jorgensen) Sournia [Gonyaulax triacantha, Amylax lata] Amylax triacantha (Jørgensen) Sournia [Gonyaulax triacantha, Amylax lata] Amylax triacantha (Jørgensen) Sournia [Gonyaulax triacantha, Amylax lata] Amylax triacantha (Jørgensen) Sournia [Gonyaulax triacantha, Amylax lata] Amylax triacantha (Jørgensen) Sournia [Gonyaulax triacantha, Amylax lata]

Bysmatrum subsalsum (Ostenfeld) M.A. Faust \& K.A. SteidingerBysmatrum subsalsum

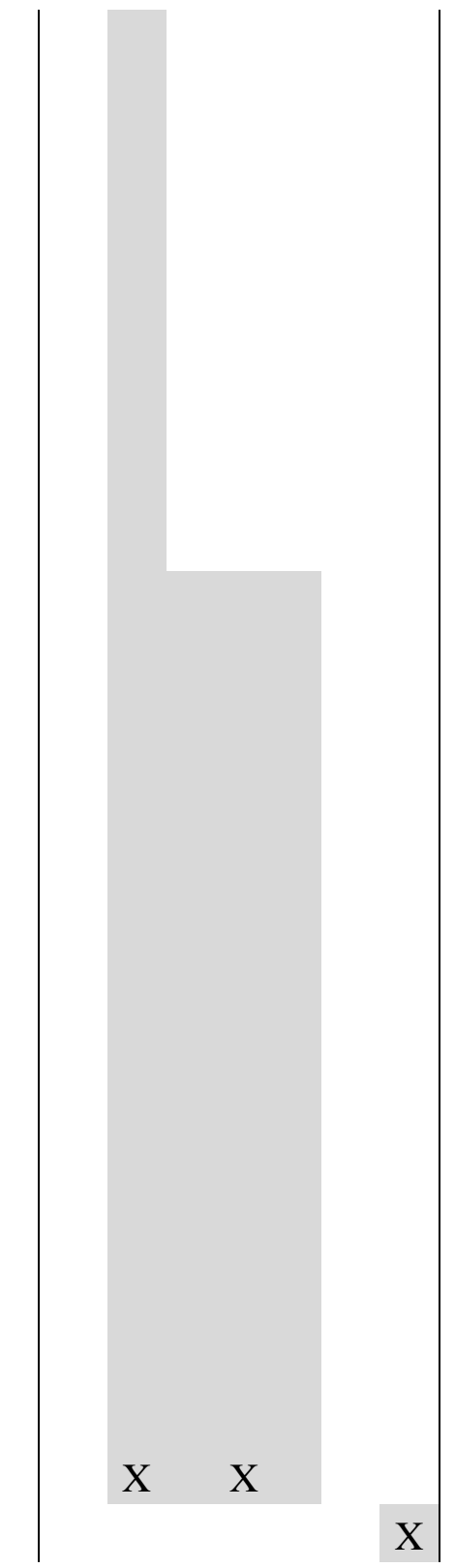


(Ostenfeld) M.A. Faust \& K.A. SteidingerBysmatrum subsalsum (Ostenfeld) M.A. Faust \& K.A. SteidingerBysmatrum subsalsum (Ostenfeld) M.A. Faust \& K.A.

SteidingerBysmatrum subsalsum (Ostenfeld) M.A. Faust \& K.A. SteidingerBysmatrum subsalsum (Ostenfeld) M.A. Faust \& K.A. SteidingerBysmatrum subsalsum (Ostenfeld) M.A. Faust \& K.A. SteidingerBysmatrum subsalsum (Ostenfeld) M.A. Faust \& K.A. SteidingerBysmatrum subsalsum (Ostenfeld) M.A. Faust \& K.A. SteidingerBysmatrum subsalsum (Ostenfeld) M.A. Faust \& K.A. SteidingerBysmatrum subsalsum (Ostenfeld) M.A. Faust \& K.A. SteidingerBysmatrum subsalsum (Ostenfeld) M.A. Faust \& K.A. SteidingerBysmatrum subsalsum (Ostenfeld) M.A. Faust \& K.A. SteidingerBysmatrum subsalsum (Ostenfeld) M.A. Faust \& K.A. SteidingerBysmatrum subsalsum (Ostenfeld) M.A. Faust \& K.A. SteidingerBysmatrum subsalsum (Ostenfeld) M.A. Faust \& K.A. SteidingerBysmatrum subsalsum (Ostenfeld) M.A. Faust \& K.A. SteidingerBysmatrum subsalsum (Ostenfeld) M.A. Faust \& K.A. SteidingerBysmatrum subsalsum (Ostenfeld) M.A. Faust \& K.A. SteidingerBysmatrum subsalsum (Ostenfeld) M.A. Faust \& K.A. SteidingerBysmatrum subsalsum (Ostenfeld) M.A. Faust \& K.A. SteidingerBysmatrum subsalsum (Ostenfeld) M.A. Faust \& K.A. Steidinger

Centrodinium intermedium Pavillard Centrodinium intermedium Pavillard Centrodinium intermedium Pavillard Centrodinium intermedium Pavillard Centrodinium intermedium Pavillard Centrodinium intermedium Pavillard Centrodinium intermedium Pavillard Centrodinium intermedium Pavillard Centrodinium intermedium Pavillard Centrodinium intermedium Pavillard Centrodinium intermedium Pavillard Centrodinium intermedium Pavillard Centrodinium intermedium Pavillard Centrodinium intermedium Pavillard Centrodinium intermedium Pavillard Centrodinium intermedium Pavillard Centrodinium intermedium Pavillard Centrodinium intermedium Pavillard Centrodinium intermedium Pavillard Centrodinium intermedium Pavillard Centrodinium intermedium Pavillard Centrodinium intermedium Pavillard Ceratium belone Cleve [C. pacificum, Tripos belone] Ceratium belone Cleve [C. pacificum, Tripos belone] Ceratium belone Cleve [C. pacificum, Tripos belone] Ceratium belone Cleve [C. pacificum, Tripos belone] Ceratium belone Cleve [C. pacificum, Tripos belone] Ceratium belone Cleve [C. pacificum, Tripos belone] Ceratium belone Cleve [C. pacificum, Tripos belone] Ceratium belone Cleve [C. pacificum, Tripos belone] Ceratium belone Cleve [C. pacificum, Tripos belone] Ceratium belone Cleve [C. pacificum, Tripos 
belone] Ceratium belone Cleve [C. pacificum, Tripos belone] Ceratium belone Cleve [C. pacificum, Tripos belone] Ceratium belone Cleve [C. pacificum, Tripos belone] Ceratium belone Cleve [C. pacificum, Tripos belone] Ceratium belone Cleve [C. pacificum, Tripos belone] Ceratium belone Cleve [C. pacificum, Tripos belone] Ceratium belone Cleve [C. pacificum, Tripos belone] Ceratium belone Cleve [C. pacificum, Tripos belone] Ceratium belone Cleve [C. pacificum, Tripos belone] Ceratium belone Cleve [C. pacificum, Tripos belone] Ceratium belone Cleve [C. pacificum, Tripos belone] Ceratium belone Cleve [C. pacificum, Tripos belone]

Ceratium buceros (Zacharias) Schiller [Tripos buceros]Ceratium buceros (Zacharias) Schiller [Tripos buceros]Ceratium buceros (Zacharias) Schiller [Tripos

buceros]Ceratium buceros (Zacharias) Schiller [Tripos buceros]Ceratium buceros (Zacharias) Schiller [Tripos buceros]Ceratium buceros (Zacharias) Schiller [Tripos buceros]Ceratium buceros (Zacharias) Schiller [Tripos buceros]Ceratium buceros (Zacharias) Schiller [Tripos buceros]Ceratium buceros (Zacharias) Schiller [Tripos buceros]Ceratium buceros (Zacharias) Schiller [Tripos buceros]Ceratium buceros (Zacharias) Schiller [Tripos buceros]Ceratium buceros (Zacharias) Schiller [Tripos buceros]Ceratium buceros (Zacharias) Schiller [Tripos buceros]Ceratium buceros (Zacharias) Schiller [Tripos buceros]Ceratium buceros (Zacharias) Schiller [Tripos buceros]Ceratium buceros (Zacharias) Schiller [Tripos buceros]Ceratium buceros (Zacharias) Schiller [Tripos buceros]Ceratium buceros (Zacharias) Schiller [Tripos buceros]Ceratium buceros (Zacharias) Schiller [Tripos buceros]Ceratium buceros (Zacharias) Schiller [Tripos buceros]Ceratium buceros (Zacharias) Schiller [Tripos buceros]Ceratium buceros (Zacharias) Schiller [Tripos buceros]

Ceratium candelabrum (Ehrenberg) Stein [Tripos candelabrus] Ceratium candelabrum (Ehrenberg) Stein [Tripos candelabrus] Ceratium candelabrum (Ehrenberg) Stein [Tripos candelabrus] Ceratium candelabrum (Ehrenberg) Stein [Tripos candelabrus] Ceratium candelabrum (Ehrenberg) Stein [Tripos candelabrus] Ceratium candelabrum (Ehrenberg) Stein [Tripos candelabrus] Ceratium candelabrum (Ehrenberg) Stein [Tripos candelabrus] Ceratium candelabrum (Ehrenberg) Stein [Tripos candelabrus] Ceratium candelabrum (Ehrenberg) Stein [Tripos candelabrus] Ceratium candelabrum (Ehrenberg) Stein [Tripos candelabrus] Ceratium candelabrum (Ehrenberg) Stein [Tripos candelabrus] Ceratium candelabrum (Ehrenberg) Stein [Tripos candelabrus] Ceratium candelabrum (Ehrenberg) Stein [Tripos candelabrus] Ceratium candelabrum

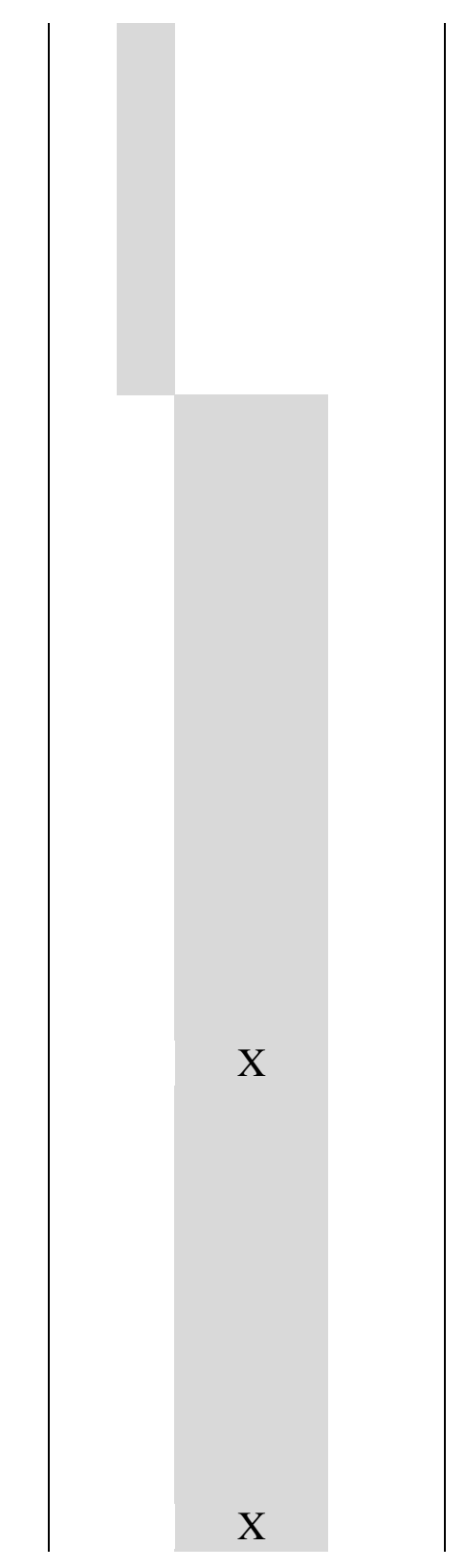


(Ehrenberg) Stein [Tripos candelabrus] Ceratium candelabrum (Ehrenberg) Stein [Tripos candelabrus] Ceratium candelabrum (Ehrenberg) Stein [Tripos candelabrus] Ceratium candelabrum (Ehrenberg) Stein [Tripos candelabrus] Ceratium candelabrum (Ehrenberg) Stein [Tripos candelabrus] Ceratium candelabrum (Ehrenberg) Stein [Tripos candelabrus] Ceratium candelabrum (Ehrenberg) Stein [Tripos candelabrus] Ceratium candelabrum (Ehrenberg) Stein [Tripos candelabrus]

Ceratium carriense Gourret [C. volans, C. massiliense, Tripos carriensis ] Ceratium carriense Gourret [C. volans, C. massiliense, Tripos carriensis ] Ceratium carriense Gourret [C. volans, $C$. massiliense, Tripos carriensis ] Ceratium carriense Gourret [C. volans, C. massiliense, Tripos carriensis ] Ceratium carriense Gourret [C. volans, $C$. massiliense, Tripos carriensis ] Ceratium carriense Gourret [C. volans, C. massiliense, Tripos carriensis ] Ceratium carriense Gourret [C. volans, C. massiliense, Tripos carriensis ] Ceratium carriense Gourret [C. volans, C. massiliense, Tripos carriensis ] Ceratium carriense Gourret [C. volans, C. massiliense, Tripos carriensis ] Ceratium carriense Gourret [C. volans, $C$. massiliense, Tripos carriensis ] Ceratium carriense Gourret [C. volans, $C$. massiliense, Tripos carriensis] Ceratium carriense Gourret [C. volans, C. massiliense, Tripos carriensis ] Ceratium carriense Gourret [C. volans, $C$. massiliense, Tripos carriensis ] Ceratium carriense Gourret [C. volans, C. massiliense, Tripos carriensis ] Ceratium carriense Gourret [C. volans, C. massiliense, Tripos carriensis ] Ceratium carriense Gourret [C. volans, C. massiliense, Tripos carriensis ] Ceratium carriense Gourret [C. volans, $C$. massiliense, Tripos carriensis ] Ceratium carriense Gourret [C. volans, C. massiliense, Tripos carriensis ] Ceratium carriense Gourret [C. volans, C. massiliense, Tripos carriensis ] Ceratium carriense Gourret [C. volans, $C$. massiliense, Tripos carriensis ] Ceratium carriense Gourret [C. volans, $C$. massiliense, Tripos carriensis ]

Ceratium compressum Gran [C. platycorne, see Balech (1988: 141), Tripos compressus] Ceratium compressum Gran [C. platycorne, see Balech (1988: 141), Tripos compressus] Ceratium compressum Gran [C. platycorne, see Balech (1988: 141), Tripos compressus] Ceratium compressum Gran [C. platycorne, see Balech (1988: 141), Tripos compressus] Ceratium compressum Gran [C. platycorne, see Balech (1988: 141), Tripos compressus] Ceratium compressum Gran [C. platycorne, see Balech (1988: 141), Tripos compressus] Ceratium compressum Gran [C. platycorne, see Balech (1988: 141), Tripos compressus] Ceratium compressum Gran

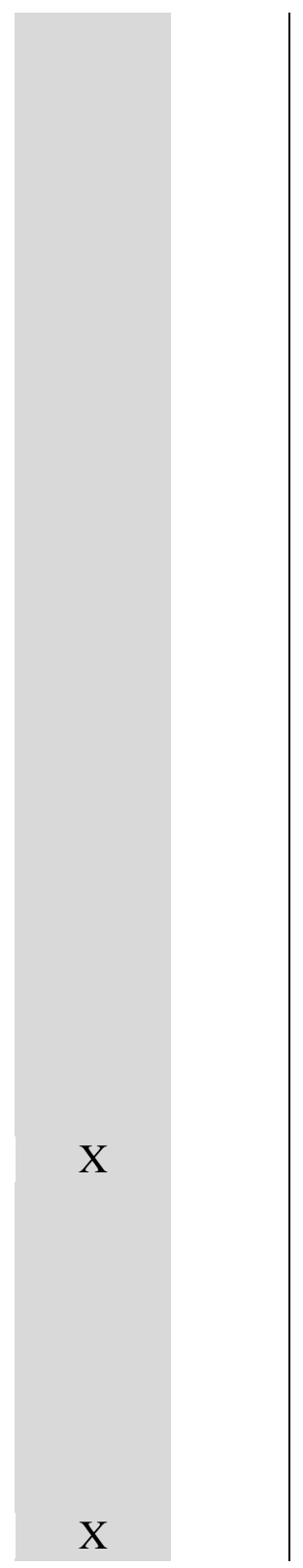


[C. platycorne, see Balech (1988: 141), Tripos compressus] Ceratium compressum Gran [C. platycorne, see Balech (1988: 141), Tripos compressus] Ceratium compressum Gran [C. platycorne, see Balech (1988: 141), Tripos compressus] Ceratium compressum Gran [C. platycorne, see Balech (1988: 141), Tripos compressus] Ceratium compressum Gran [C. platycorne, see Balech (1988: 141), Tripos compressus] Ceratium compressum Gran [C. platycorne, see Balech (1988: 141), Tripos compressus] Ceratium compressum Gran [C. platycorne, see Balech (1988: 141), Tripos compressus] Ceratium compressum Gran [C. platycorne, see Balech (1988: 141), Tripos compressus] Ceratium compressum Gran [C. platycorne, see Balech (1988: 141), Tripos compressus] Ceratium compressum Gran [C. platycorne, see Balech (1988: 141), Tripos compressus] Ceratium compressum Gran [C. platycorne, see Balech (1988: 141), Tripos compressus] Ceratium compressum Gran [C. platycorne, see Balech (1988: 141), Tripos compressus] Ceratium compressum Gran [C. platycorne, see Balech (1988: 141), Tripos compressus] Ceratium compressum Gran [C. platycorne, see Balech (1988: 141), Tripos compressus]

Ceratium declinatum (Karsten) Jørgensen [ C. tripos declinatum; Tripos declinatus] Ceratium declinatum (Karsten) Jørgensen [ C. tripos declinatum; Tripos declinatus] Ceratium declinatum (Karsten) Jørgensen [ C. tripos declinatum; Tripos declinatus] Ceratium declinatum (Karsten) Jørgensen [ C. tripos declinatum; Tripos declinatus] Ceratium declinatum (Karsten) Jørgensen [ C. tripos declinatum; Tripos declinatus] Ceratium declinatum (Karsten) Jørgensen [ C. tripos declinatum; Tripos declinatus] Ceratium declinatum (Karsten) Jørgensen [ C. tripos declinatum; Tripos declinatus] Ceratium declinatum (Karsten) Jørgensen [ C. tripos declinatum; Tripos declinatus] Ceratium declinatum (Karsten) Jørgensen [ C. tripos declinatum; Tripos declinatus] Ceratium declinatum (Karsten) Jørgensen [ C. tripos declinatum; Tripos declinatus] Ceratium declinatum (Karsten) Jørgensen [ C. tripos declinatum; Tripos declinatus] Ceratium declinatum (Karsten) Jørgensen [ C. tripos declinatum; Tripos declinatus] Ceratium declinatum (Karsten) Jørgensen [ C. tripos declinatum; Tripos declinatus] Ceratium declinatum (Karsten) Jørgensen [ C. tripos declinatum; Tripos declinatus] Ceratium declinatum (Karsten) Jørgensen [ C. tripos declinatum; Tripos declinatus] Ceratium declinatum (Karsten) Jørgensen [ C. tripos declinatum; Tripos declinatus] Ceratium declinatum (Karsten) Jørgensen [ C. tripos declinatum; Tripos declinatus] 
Ceratium declinatum (Karsten) Jørgensen [ C. tripos declinatum; Tripos declinatus] Ceratium declinatum (Karsten) Jørgensen [ C. tripos declinatum; Tripos declinatus] Ceratium declinatum (Karsten) Jørgensen [ C. tripos declinatum; Tripos declinatus] Ceratium declinatum (Karsten) Jørgensen [ C. tripos declinatum; Tripos declinatus] Ceratium extensum (Gourret) Cleve [C. strictum, C. biceps, Tripos biceps ] Ceratium extensum (Gourret) Cleve [C. strictum, C. biceps, Tripos biceps] Ceratium extensum (Gourret) Cleve [C. strictum, C. biceps, Tripos biceps ] Ceratium extensum (Gourret) Cleve [C. strictum, C. biceps, Tripos biceps] Ceratium extensum (Gourret) Cleve [C. strictum, C. biceps, Tripos biceps ] Ceratium extensum (Gourret) Cleve [C. strictum, $C$. biceps, Tripos biceps ] Ceratium extensum (Gourret) Cleve [C. strictum, C. biceps, Tripos biceps ] Ceratium extensum (Gourret) Cleve [C. strictum, C. biceps, Tripos biceps ] Ceratium extensum (Gourret) Cleve [C. strictum, C. biceps, Tripos biceps ] Ceratium extensum (Gourret) Cleve [C. strictum, C. biceps, Tripos biceps ] Ceratium extensum (Gourret) Cleve [C. strictum, C. biceps, Tripos biceps ] Ceratium extensum (Gourret) Cleve [C. strictum, C. biceps, Tripos biceps ] Ceratium extensum (Gourret) Cleve [C. strictum, C. biceps, Tripos biceps] Ceratium extensum (Gourret) Cleve [C. strictum, C. biceps, Tripos biceps ] Ceratium extensum (Gourret) Cleve [C. strictum, $C$. biceps, Tripos biceps ] Ceratium extensum (Gourret) Cleve [C. strictum, C. biceps, Tripos biceps ] Ceratium extensum (Gourret) Cleve [C. strictum, C. biceps, Tripos biceps ] Ceratium extensum (Gourret) Cleve [C. strictum, C. biceps, Tripos biceps ] Ceratium extensum (Gourret) Cleve [C. strictum, C. biceps, Tripos biceps ] Ceratium extensum (Gourret) Cleve [C. strictum, C. biceps, Tripos biceps ] Ceratium extensum (Gourret) Cleve [C. strictum, C. biceps, Tripos biceps ]

Ceratium falcatum (Kofoid) Jørgensen [C. pennatum $f$. falcate, Tripos

falcatus]Ceratium falcatum (Kofoid) Jørgensen [C. pennatum $f$. falcate, Tripos falcatus]Ceratium falcatum (Kofoid) Jørgensen [C. pennatum $f$. falcate, Tripos falcatus]Ceratium falcatum (Kofoid) Jørgensen [C. pennatum $f$. falcate, Tripos falcatus]Ceratium falcatum (Kofoid) Jørgensen [C. pennatum $f$. falcate, Tripos falcatus]Ceratium falcatum (Kofoid) Jørgensen [C. pennatum f. falcate, Tripos falcatus]Ceratium falcatum (Kofoid) Jørgensen [C. pennatum $f$. falcate, Tripos falcatus]Ceratium falcatum (Kofoid) Jørgensen [C. pennatum $f$. falcate, Tripos falcatus]Ceratium falcatum (Kofoid) Jørgensen [C. pennatum $f$. falcate, Tripos falcatus]Ceratium falcatum (Kofoid) Jørgensen [C. pennatum $f$. falcate, Tripos

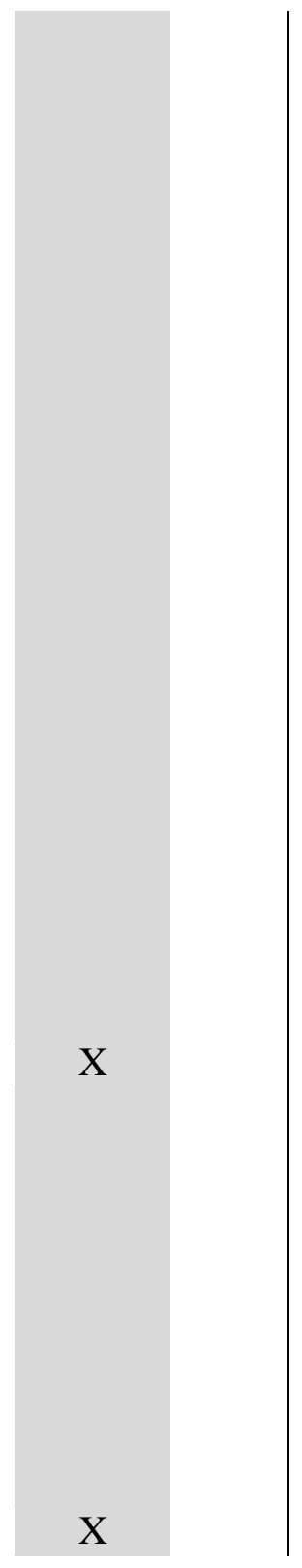


falcatus]Ceratium falcatum (Kofoid) Jørgensen [C. pennatum f. falcate, Tripos falcatus]Ceratium falcatum (Kofoid) Jørgensen [C. pennatum $f$. falcate, Tripos falcatus]Ceratium falcatum (Kofoid) Jørgensen [C. pennatum $f$. falcate, Tripos falcatus]Ceratium falcatum (Kofoid) Jørgensen [C. pennatum $f$. falcate, Tripos falcatus]Ceratium falcatum (Kofoid) Jørgensen [C. pennatum $f$. falcate, Tripos falcatus]Ceratium falcatum (Kofoid) Jørgensen [C. pennatum $f$. falcate, Tripos falcatus]Ceratium falcatum (Kofoid) Jørgensen [C. pennatum $f$. falcate, Tripos falcatus]Ceratium falcatum (Kofoid) Jørgensen [C. pennatum f. falcate, Tripos falcatus]Ceratium falcatum (Kofoid) Jørgensen [C. pennatum $f$. falcate, Tripos falcatus]Ceratium falcatum (Kofoid) Jørgensen [C. pennatum $f$. falcate, Tripos falcatus]Ceratium falcatum (Kofoid) Jørgensen [C. pennatum f. falcate, Tripos falcatus]

Ceratium furca (Ehrenberg) Claparède \& Lachmann [C. bipes, Tripos furca] Ceratium furca (Ehrenberg) Claparède \& Lachmann [C. bipes, Tripos furca] Ceratium furca (Ehrenberg) Claparède \& Lachmann [C. bipes, Tripos furca] Ceratium furca (Ehrenberg) Claparède \& Lachmann [C. bipes, Tripos furca] Ceratium furca (Ehrenberg) Claparède \& Lachmann [C. bipes, Tripos furca] Ceratium furca (Ehrenberg) Claparède \& Lachmann [C. bipes, Tripos furca] Ceratium furca (Ehrenberg) Claparède \& Lachmann [C. bipes, Tripos furca] Ceratium furca (Ehrenberg) Claparède \& Lachmann [C. bipes, Tripos furca] Ceratium furca (Ehrenberg) Claparède \& Lachmann [C. bipes, Tripos furca] Ceratium furca (Ehrenberg) Claparède \& Lachmann [C. bipes, Tripos furca] Ceratium furca (Ehrenberg) Claparède \& Lachmann [C. bipes, Tripos furca] Ceratium furca (Ehrenberg) Claparède \& Lachmann [C. bipes, Tripos furca] Ceratium furca (Ehrenberg) Claparède \& Lachmann [C. bipes, Tripos furca] Ceratium furca (Ehrenberg) Claparède \& Lachmann [C. bipes, Tripos furca] Ceratium furca (Ehrenberg) Claparède \& Lachmann [C. bipes, Tripos furca] Ceratium furca (Ehrenberg) Claparède \& Lachmann [C. bipes, Tripos furca] Ceratium furca (Ehrenberg) Claparède \& Lachmann [C. bipes, Tripos furca] Ceratium furca (Ehrenberg) Claparède \& Lachmann [C. bipes, Tripos furca] Ceratium furca (Ehrenberg) Claparède \& Lachmann [C. bipes, Tripos furca] Ceratium furca (Ehrenberg) Claparède \& Lachmann [C. bipes, Tripos furca] Ceratium furca (Ehrenberg) Claparède \& Lachmann [C. bipes, Tripos furca] 
Ceratium furcoides (Levander) Langhans Ceratium furcoides (Levander) Langhans Ceratium furcoides (Levander) Langhans Ceratium furcoides (Levander) Langhans Ceratium furcoides (Levander) Langhans Ceratium furcoides (Levander) Langhans Ceratium furcoides (Levander) Langhans Ceratium furcoides (Levander) Langhans Ceratium furcoides (Levander) Langhans Ceratium furcoides (Levander) Langhans Ceratium furcoides (Levander) Langhans Ceratium furcoides (Levander) Langhans Ceratium furcoides (Levander) Langhans Ceratium furcoides (Levander) Langhans Ceratium furcoides (Levander) Langhans Ceratium furcoides (Levander) Langhans Ceratium furcoides (Levander) Langhans Ceratium furcoides (Levander) Langhans Ceratium furcoides (Levander) Langhans Ceratium furcoides (Levander) Langhans Ceratium furcoides (Levander) Langhans

Ceratium fusus (Ehrenberg) Dujardin [var. fusus, var. seta, var. schuttii, Tripos fusus] Ceratium fusus (Ehrenberg) Dujardin [var. fusus, var. seta, var. schuttii, Tripos fusus] Ceratium fusus (Ehrenberg) Dujardin [var. fusus, var. seta, var. schuttii, Tripos fusus] Ceratium fusus (Ehrenberg) Dujardin [var. fusus, var. seta, var. schuttii, Tripos fusus] Ceratium fusus (Ehrenberg) Dujardin [var. fusus, var. seta, var. schuttii, Tripos fusus] Ceratium fusus (Ehrenberg) Dujardin [var. fusus, var. seta, var. schuttii, Tripos fusus] Ceratium fusus (Ehrenberg) Dujardin [var. fusus, var. seta, var. schuttii, Tripos fusus] Ceratium fusus (Ehrenberg) Dujardin [var. fusus, var. seta, var. schuttii, Tripos fusus] Ceratium fusus (Ehrenberg) Dujardin [var. fusus, var. seta, var. schuttii, Tripos fusus] Ceratium fusus (Ehrenberg) Dujardin [var. fusus, var. seta, var. schuttii, Tripos fusus] Ceratium fusus (Ehrenberg) Dujardin [var. fusus, var. seta, var. schuttii, Tripos fusus] Ceratium fusus (Ehrenberg) Dujardin [var. fusus, var. seta, var. schuttii, Tripos fusus] Ceratium fusus (Ehrenberg) Dujardin [var. fusus, var. seta, var. schuttii, Tripos fusus] Ceratium fusus (Ehrenberg) Dujardin [var. fusus, var. seta, var. schuttii, Tripos fusus] Ceratium fusus (Ehrenberg) Dujardin [var. fusus, var. seta, var. schuttii, Tripos fusus] Ceratium fusus (Ehrenberg) Dujardin [var. fusus, var. seta, var. schuttii, Tripos fusus] Ceratium fusus (Ehrenberg) Dujardin [var. fusus, var. seta, var. schuttii, Tripos fusus] Ceratium fusus (Ehrenberg) Dujardin [var. fusus, var. seta, var. schuttii, Tripos fusus] Ceratium fusus (Ehrenberg) Dujardin [var. fusus, var. seta, var. schuttii, Tripos fusus] Ceratium fusus (Ehrenberg) Dujardin [var. fusus, var. seta, var. schuttii, Tripos fusus] Ceratium fusus (Ehrenberg) Dujardin [var. fusus, var. seta, var. schuttii, Tripos fusus] Ceratium gibberum Gourret [Tripos gibberus] Ceratium gibberum Gourret [Tripos

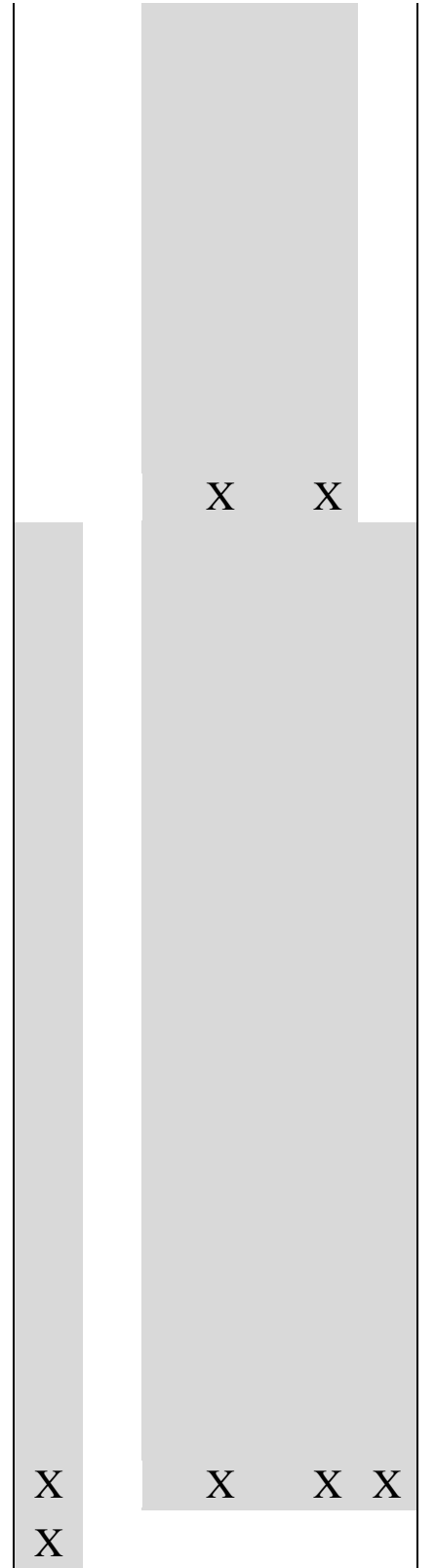


gibberus ] Ceratium gibberum Gourret [Tripos gibberus ] Ceratium gibberum Gourret [Tripos gibberus ] Ceratium gibberum Gourret [Tripos gibberus ] Ceratium gibberum Gourret [Tripos gibberus ] Ceratium gibberum Gourret [Tripos gibberus ] Ceratium gibberum Gourret [Tripos gibberus ] Ceratium gibberum Gourret [Tripos gibberus ] Ceratium gibberum Gourret [Tripos gibberus] Ceratium gibberum Gourret [Tripos

gibberus ] Ceratium gibberum Gourret [Tripos gibberus ] Ceratium gibberum Gourret [Tripos gibberus] Ceratium gibberum Gourret [Tripos gibberus ] Ceratium gibberum Gourret [Tripos gibberus] Ceratium gibberum Gourret [Tripos gibberus ] Ceratium gibberum Gourret [Tripos gibberus] Ceratium gibberum Gourret [Tripos gibberus ] Ceratium gibberum Gourret [Tripos gibberus ] Ceratium gibberum Gourret [Tripos gibberus ] Ceratium gibberum Gourret [Tripos gibberus ]

Ceratium hexacanthum Gourret [C. reticulatum, Tripos hexacanthus] Ceratium hexacanthum Gourret [C. reticulatum, Tripos hexacanthus] Ceratium hexacanthum Gourret [C. reticulatum, Tripos hexacanthus] Ceratium hexacanthum Gourret [C. reticulatum, Tripos hexacanthus] Ceratium hexacanthum Gourret [C. reticulatum, Tripos hexacanthus] Ceratium hexacanthum Gourret [C. reticulatum, Tripos hexacanthus] Ceratium hexacanthum Gourret [C. reticulatum, Tripos hexacanthus] Ceratium hexacanthum Gourret [C. reticulatum, Tripos hexacanthus] Ceratium hexacanthum Gourret [C. reticulatum, Tripos hexacanthus] Ceratium hexacanthum Gourret [C. reticulatum, Tripos hexacanthus] Ceratium hexacanthum Gourret [C. reticulatum, Tripos hexacanthus] Ceratium hexacanthum Gourret [C. reticulatum, Tripos hexacanthus] Ceratium hexacanthum Gourret [C. reticulatum, Tripos hexacanthus] Ceratium hexacanthum Gourret [C. reticulatum, Tripos hexacanthus] Ceratium hexacanthum Gourret [C. reticulatum, Tripos hexacanthus] Ceratium hexacanthum Gourret [C. reticulatum, Tripos hexacanthus] Ceratium hexacanthum Gourret [C. reticulatum, Tripos hexacanthus] Ceratium hexacanthum Gourret [C. reticulatum, Tripos hexacanthus] Ceratium hexacanthum Gourret [C. reticulatum, Tripos hexacanthus] Ceratium hexacanthum Gourret [C. reticulatum, Tripos hexacanthus] Ceratium hexacanthum Gourret [C. reticulatum, Tripos hexacanthus] Ceratium horridum (Cleve) Gran [C. tripos var. horridum, C. intermedium, Tripos horridus]Ceratium horridum (Cleve) Gran [C. tripos var. horridum, C. intermedium, Tripos horridus]Ceratium horridum (Cleve) Gran [C. tripos var. horridum, $C$. intermedium, Tripos horridus]Ceratium horridum (Cleve) Gran [C. tripos var.

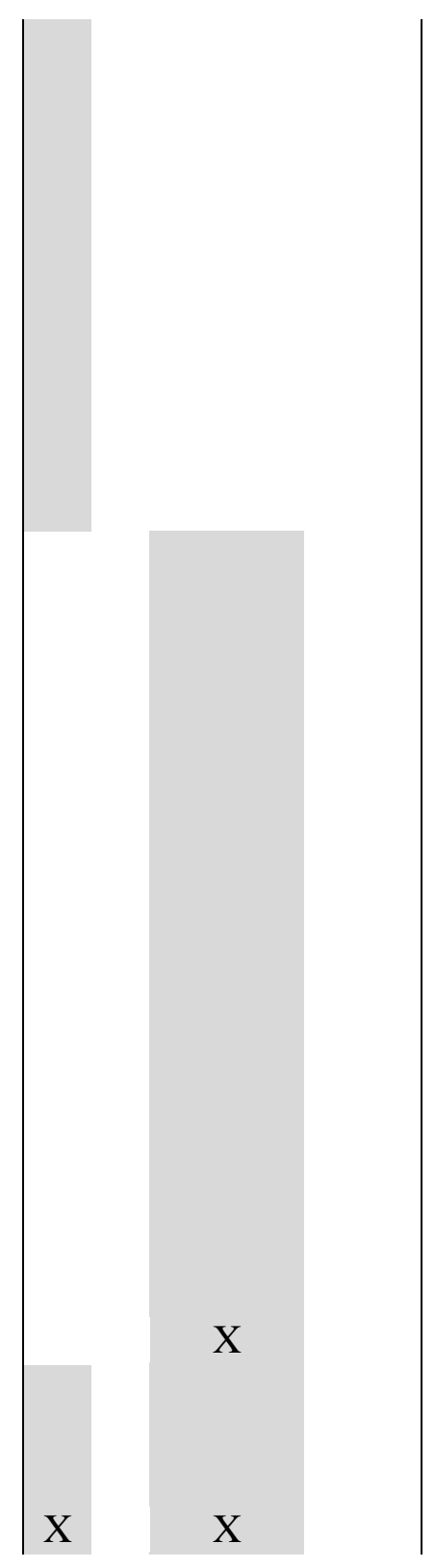


horridum, C. intermedium, Tripos horridus]Ceratium horridum (Cleve) Gran [C. tripos var. horridum, $C$. intermedium, Tripos horridus]Ceratium horridum (Cleve) Gran [C. tripos var. horridum, C. intermedium, Tripos horridus]Ceratium horridum (Cleve) Gran [C. tripos var. horridum, C. intermedium, Tripos horridus]Ceratium horridum (Cleve) Gran [C. tripos var. horridum, C. intermedium, Tripos horridus]Ceratium horridum (Cleve) Gran [C. tripos var. horridum, C. intermedium, Tripos horridus]Ceratium horridum (Cleve) Gran [C. tripos var. horridum, C. intermedium, Tripos horridus]Ceratium horridum (Cleve) Gran [C. tripos var. horridum, C. intermedium, Tripos horridus]Ceratium horridum (Cleve) Gran [C. tripos var. horridum, C. intermedium, Tripos horridus]Ceratium horridum (Cleve) Gran [C. tripos var. horridum, C. intermedium, Tripos horridus]Ceratium horridum (Cleve) Gran [C. tripos var. horridum, C. intermedium, Tripos horridus]Ceratium horridum (Cleve) Gran [C. tripos var. horridum, C. intermedium, Tripos horridus]Ceratium horridum (Cleve) Gran [C. tripos var. horridum, C. intermedium, Tripos horridus]Ceratium horridum (Cleve) Gran [C. tripos var. horridum, C. intermedium, Tripos horridus]Ceratium horridum (Cleve) Gran [C. tripos var. horridum, C. intermedium, Tripos horridus]Ceratium horridum (Cleve) Gran [C. tripos var. horridum, $C$. intermedium, Tripos horridus]Ceratium horridum (Cleve) Gran [C. tripos var. horridum, C. intermedium, Tripos horridus]Ceratium horridum (Cleve) Gran [C. tripos var. horridum, C. intermedium, Tripos horridus]

Ceratium incisum (Karsten) Jørgensen [Tripos incisus]Ceratium incisum (Karsten) Jørgensen [Tripos incisus]Ceratium incisum (Karsten) Jørgensen [Tripos incisus]Ceratium incisum (Karsten) Jørgensen [Tripos incisus]Ceratium incisum (Karsten) Jørgensen [Tripos incisus]Ceratium incisum (Karsten) Jørgensen [Tripos incisus]Ceratium incisum (Karsten) Jørgensen [Tripos incisus]Ceratium incisum (Karsten) Jørgensen [Tripos incisus]Ceratium incisum (Karsten) Jørgensen [Tripos incisus]Ceratium incisum (Karsten) Jørgensen [Tripos incisus]Ceratium incisum (Karsten) Jørgensen [Tripos incisus]Ceratium incisum (Karsten) Jørgensen [Tripos incisus]Ceratium incisum (Karsten) Jørgensen [Tripos incisus]Ceratium incisum (Karsten) Jørgensen [Tripos incisus]Ceratium incisum (Karsten) Jørgensen [Tripos incisus]Ceratium incisum (Karsten) Jørgensen [Tripos incisus]Ceratium incisum (Karsten) Jørgensen [Tripos incisus]Ceratium incisum (Karsten) Jørgensen [Tripos incisus]Ceratium incisum (Karsten) Jørgensen [Tripos incisus]Ceratium incisum

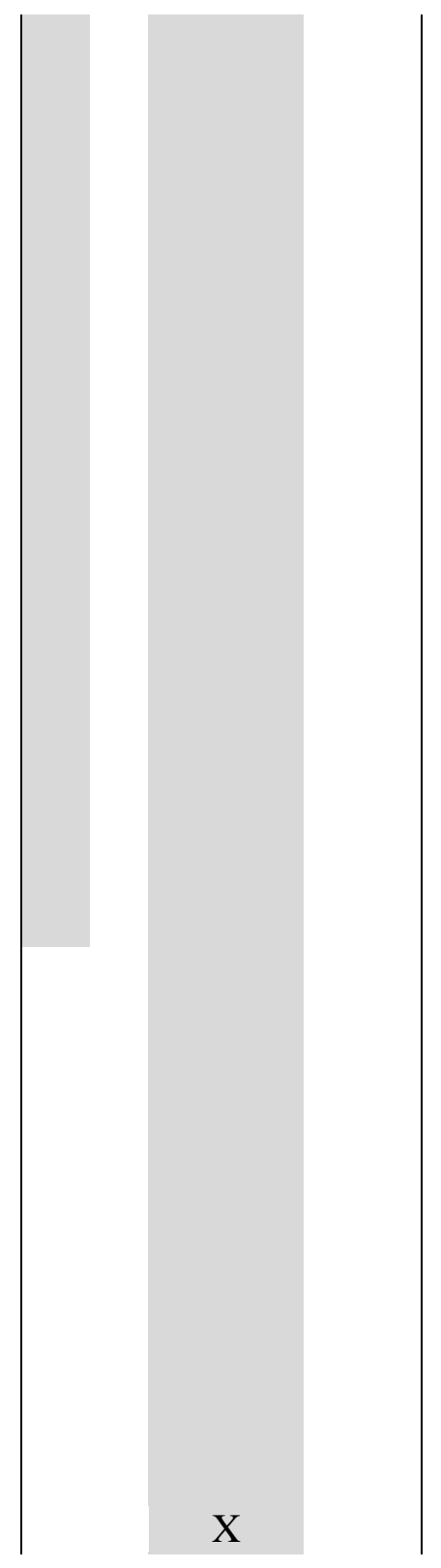


(Karsten) Jørgensen [Tripos incisus]Ceratium incisum (Karsten) Jørgensen [Tripos incisus]

Ceratium inflatum (Kofoid) Jørgensen [Tripos inflatus]Ceratium inflatum (Kofoid) Jørgensen [Tripos inflatus]Ceratium inflatum (Kofoid) Jørgensen [Tripos

inflatus]Ceratium inflatum (Kofoid) Jørgensen [Tripos inflatus]Ceratium inflatum (Kofoid) Jørgensen [Tripos inflatus]Ceratium inflatum (Kofoid) Jørgensen [Tripos inflatus]Ceratium inflatum (Kofoid) Jørgensen [Tripos inflatus]Ceratium inflatum (Kofoid) Jørgensen [Tripos inflatus]Ceratium inflatum (Kofoid) Jørgensen [Tripos inflatus]Ceratium inflatum (Kofoid) Jørgensen [Tripos inflatus]Ceratium inflatum (Kofoid) Jørgensen [Tripos inflatus]Ceratium inflatum (Kofoid) Jørgensen [Tripos inflatus]Ceratium inflatum (Kofoid) Jørgensen [Tripos inflatus]Ceratium inflatum (Kofoid) Jørgensen [Tripos inflatus]Ceratium inflatum (Kofoid) Jørgensen [Tripos inflatus]Ceratium inflatum (Kofoid) Jørgensen [Tripos inflatus]Ceratium inflatum (Kofoid) Jørgensen [Tripos inflatus]Ceratium inflatum (Kofoid) Jørgensen [Tripos inflatus]Ceratium inflatum (Kofoid) Jørgensen [Tripos inflatus]Ceratium inflatum (Kofoid) Jørgensen [Tripos inflatus]Ceratium inflatum (Kofoid) Jørgensen [Tripos inflatus]

Ceratium kofoidii Jørgensen [Tripos kofoidii] Ceratium kofoidii Jørgensen [Tripos kofoidii] Ceratium kofoidii Jørgensen [Tripos kofoidii] Ceratium kofoidii Jørgensen [Tripos kofoidii] Ceratium kofoidii Jørgensen [Tripos kofoidii] Ceratium kofoidii Jørgensen [Tripos kofoidii] Ceratium kofoidii Jørgensen [Tripos kofoidii] Ceratium kofoidii Jørgensen [Tripos kofoidii] Ceratium kofoidii Jørgensen [Tripos kofoidii] Ceratium kofoidii Jørgensen [Tripos kofoidii] Ceratium kofoidii Jørgensen [Tripos kofoidii] Ceratium kofoidii Jørgensen [Tripos kofoidii] Ceratium kofoidii Jørgensen [Tripos kofoidii] Ceratium kofoidii Jorgensen [Tripos kofoidii] Ceratium kofoidii Jørgensen [Tripos kofoidii] Ceratium kofoidii Jørgensen [Tripos kofoidii] Ceratium kofoidii Jørgensen [Tripos kofoidii] Ceratium kofoidii Jørgensen [Tripos kofoidii] Ceratium kofoidii Jørgensen [Tripos kofoidii] Ceratium kofoidii Jørgensen [Tripos kofoidii] Ceratium kofoidii Jørgensen [Tripos kofoidii]

Ceratium lineatum (Ehrenberg) Cleve [Tripos lineatus] Ceratium lineatum

(Ehrenberg) Cleve [Tripos lineatus] Ceratium lineatum (Ehrenberg) Cleve [Tripos lineatus] Ceratium lineatum (Ehrenberg) Cleve [Tripos lineatus] Ceratium lineatum (Ehrenberg) Cleve [Tripos lineatus] Ceratium lineatum (Ehrenberg) Cleve [Tripos

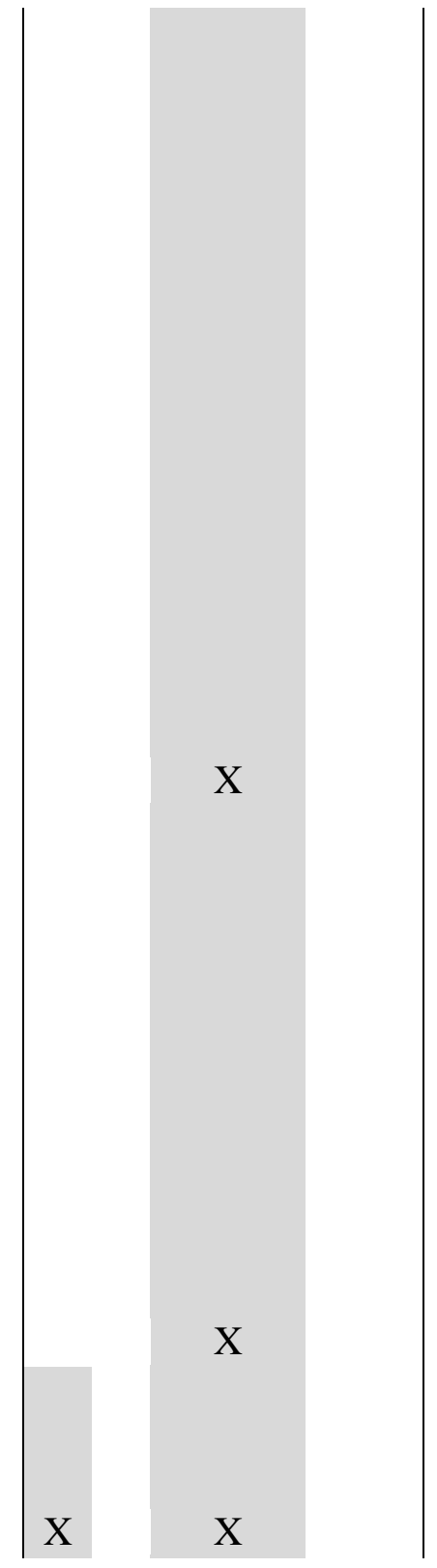


lineatus] Ceratium lineatum (Ehrenberg) Cleve [Tripos lineatus] Ceratium lineatum (Ehrenberg) Cleve [Tripos lineatus] Ceratium lineatum (Ehrenberg) Cleve [Tripos lineatus] Ceratium lineatum (Ehrenberg) Cleve [Tripos lineatus] Ceratium lineatum (Ehrenberg) Cleve [Tripos lineatus] Ceratium lineatum (Ehrenberg) Cleve [Tripos lineatus] Ceratium lineatum (Ehrenberg) Cleve [Tripos lineatus] Ceratium lineatum (Ehrenberg) Cleve [Tripos lineatus] Ceratium lineatum (Ehrenberg) Cleve [Tripos lineatus] Ceratium lineatum (Ehrenberg) Cleve [Tripos lineatus] Ceratium lineatum (Ehrenberg) Cleve [Tripos lineatus] Ceratium lineatum (Ehrenberg) Cleve [Tripos lineatus] Ceratium lineatum (Ehrenberg) Cleve [Tripos lineatus] Ceratium lineatum (Ehrenberg) Cleve [Tripos lineatus] Ceratium lineatum (Ehrenberg) Cleve [Tripos lineatus]

Ceratium longipes (Bailey) Gran [C. arcticum var. longipes, Tripos longipes]Ceratium longipes (Bailey) Gran [C. arcticum var. longipes, Tripos longipes]Ceratium longipes (Bailey) Gran [C. arcticum var. longipes, Tripos longipes]Ceratium longipes (Bailey) Gran [C. arcticum var. longipes, Tripos longipes]Ceratium longipes (Bailey) Gran [C. arcticum var. longipes, Tripos longipes]Ceratium longipes (Bailey) Gran [C. arcticum var. longipes, Tripos longipes]Ceratium longipes (Bailey) Gran [C. arcticum var.

longipes, Tripos longipes]Ceratium longipes (Bailey) Gran [C. arcticum var. longipes, Tripos longipes]Ceratium longipes (Bailey) Gran [C. arcticum var. longipes, Tripos longipes]Ceratium longipes (Bailey) Gran [C. arcticum var. longipes, Tripos longipes]Ceratium longipes (Bailey) Gran [C. arcticum var. longipes, Tripos longipes]Ceratium longipes (Bailey) Gran [C. arcticum var. longipes, Tripos longipes]Ceratium longipes (Bailey) Gran [C. arcticum var. longipes, Tripos longipes]Ceratium longipes (Bailey) Gran [C. arcticum var. longipes, Tripos longipes]Ceratium longipes (Bailey) Gran [C. arcticum var. longipes, Tripos longipes]Ceratium longipes (Bailey) Gran [C. arcticum var. longipes, Tripos longipes]Ceratium longipes (Bailey) Gran [C. arcticum var. longipes, Tripos longipes]Ceratium longipes (Bailey) Gran [C. arcticum var. longipes, Tripos longipes]Ceratium longipes (Bailey) Gran [C. arcticum var. longipes, Tripos longipes]Ceratium longipes (Bailey) Gran [C. arcticum var. longipes, Tripos longipes] Ceratium longirostrum Gourret [Tripos longirostrus]Ceratium longirostrum Gourret [Tripos longirostrus]Ceratium longirostrum Gourret [Tripos longirostrus]Ceratium longirostrum Gourret [Tripos longirostrus]Ceratium longirostrum Gourret [Tripos

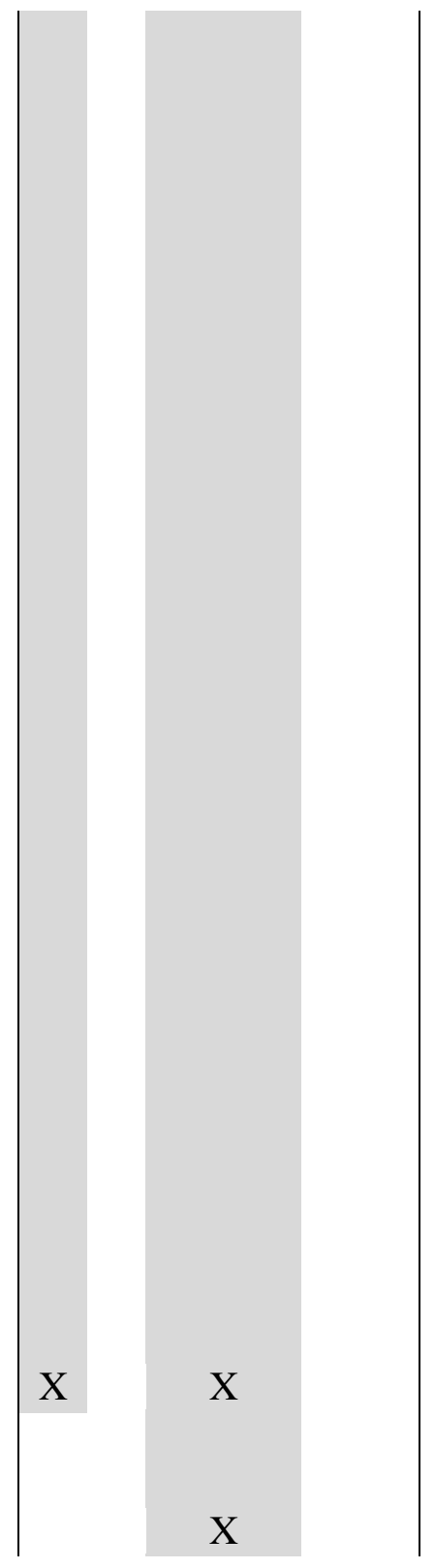


|longirostrus]Ceratium longirostrum Gourret [Tripos longirostrus]Ceratium longirostrum Gourret [Tripos longirostrus]Ceratium longirostrum Gourret [Tripos longirostrus]Ceratium longirostrum Gourret [Tripos longirostrus]Ceratium longirostrum Gourret [Tripos longirostrus]Ceratium longirostrum Gourret [Tripos longirostrus]Ceratium longirostrum Gourret [Tripos longirostrus]Ceratium longirostrum Gourret [Tripos longirostrus]Ceratium longirostrum Gourret [Tripos longirostrus]Ceratium longirostrum Gourret [Tripos longirostrus]Ceratium longirostrum Gourret [Tripos longirostrus]Ceratium longirostrum Gourret [Tripos longirostrus]Ceratium longirostrum Gourret [Tripos longirostrus]Ceratium longirostrum Gourret [Tripos longirostrus]Ceratium longirostrum Gourret [Tripos longirostrus]

Ceratium macroceros (Ehrenberg) Cleve [Tripos macroceros] Ceratium macroceros (Ehrenberg) Cleve [Tripos macroceros] Ceratium macroceros (Ehrenberg) Cleve [Tripos macroceros] Ceratium macroceros (Ehrenberg) Cleve [Tripos macroceros] Ceratium macroceros (Ehrenberg) Cleve [Tripos macroceros] Ceratium macroceros (Ehrenberg) Cleve [Tripos macroceros] Ceratium macroceros (Ehrenberg) Cleve [Tripos macroceros] Ceratium macroceros (Ehrenberg) Cleve [Tripos macroceros] Ceratium macroceros (Ehrenberg) Cleve [Tripos macroceros] Ceratium macroceros (Ehrenberg) Cleve [Tripos macroceros] Ceratium macroceros (Ehrenberg) Cleve [Tripos macroceros] Ceratium macroceros (Ehrenberg) Cleve [Tripos macroceros] Ceratium macroceros (Ehrenberg) Cleve [Tripos macroceros] Ceratium macroceros (Ehrenberg) Cleve [Tripos macroceros] Ceratium macroceros (Ehrenberg) Cleve [Tripos macroceros] Ceratium macroceros (Ehrenberg) Cleve [Tripos macroceros] Ceratium macroceros (Ehrenberg) Cleve [Tripos macroceros] Ceratium macroceros (Ehrenberg) Cleve [Tripos macroceros] Ceratium macroceros (Ehrenberg) Cleve [Tripos macroceros] Ceratium macroceros (Ehrenberg) Cleve [Tripos macroceros] Ceratium massiliense (Gourret) Karsten [also var. armatum, Tripos massiliense]Ceratium massiliense (Gourret) Karsten [also var. armatum, Tripos massiliense]Ceratium massiliense (Gourret) Karsten [also var. armatum, Tripos massiliense]Ceratium massiliense (Gourret) Karsten [also var. armatum, Tripos massiliense]Ceratium massiliense (Gourret) Karsten [also var. armatum, Tripos massiliense]Ceratium massiliense (Gourret) Karsten [also var. armatum, Tripos massiliense]Ceratium massiliense (Gourret) Karsten [also var. armatum, Tripos

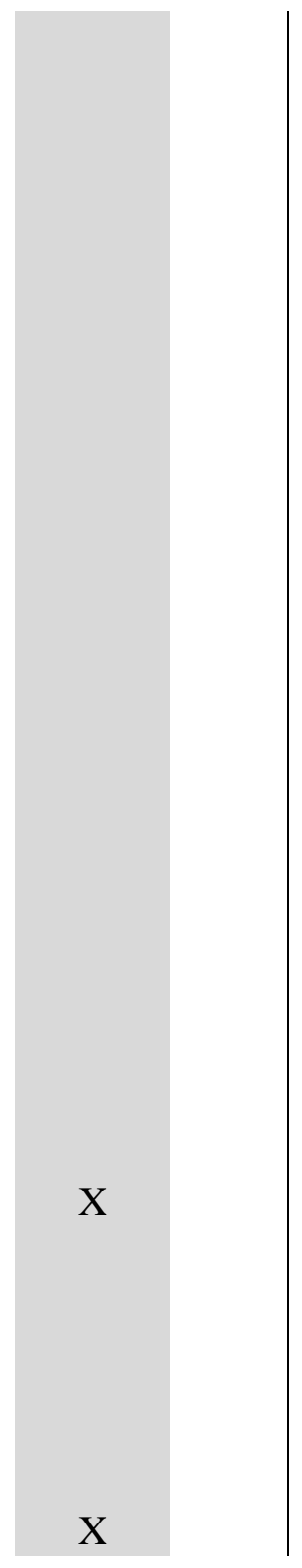


|massiliense]Ceratium massiliense (Gourret) Karsten [also var. armatum, Tripos massiliense]Ceratium massiliense (Gourret) Karsten [also var. armatum, Tripos massiliense]Ceratium massiliense (Gourret) Karsten [also var. armatum, Tripos massiliense]Ceratium massiliense (Gourret) Karsten [also var. armatum, Tripos massiliense]Ceratium massiliense (Gourret) Karsten [also var. armatum, Tripos massiliense]Ceratium massiliense (Gourret) Karsten [also var. armatum, Tripos massiliense]Ceratium massiliense (Gourret) Karsten [also var. armatum, Tripos massiliense]Ceratium massiliense (Gourret) Karsten [also var. armatum, Tripos massiliense]Ceratium massiliense (Gourret) Karsten [also var. armatum, Tripos massiliense]Ceratium massiliense (Gourret) Karsten [also var. armatum, Tripos massiliense]Ceratium massiliense (Gourret) Karsten [also var. armatum, Tripos massiliense]Ceratium massiliense (Gourret) Karsten [also var. armatum, Tripos massiliense]Ceratium massiliense (Gourret) Karsten [also var. armatum, Tripos massiliense]

Ceratium minutum Jørgensen [Tripos minutus] Ceratium minutum Jørgensen [Tripos minutus] Ceratium minutum Jørgensen [Tripos minutus] Ceratium minutum

Jørgensen [Tripos minutus] Ceratium minutum Jørgensen [Tripos minutus] Ceratium minutum Jørgensen [Tripos minutus] Ceratium minutum Jørgensen [Tripos minutus] Ceratium minutum Jørgensen [Tripos minutus] Ceratium minutum Jørgensen [Tripos minutus] Ceratium minutum Jørgensen [Tripos minutus] Ceratium minutum

Jørgensen [Tripos minutus] Ceratium minutum Jorgensen [Tripos minutus] Ceratium minutum Jørgensen [Tripos minutus] Ceratium minutum Jørgensen [Tripos minutus] Ceratium minutum Jørgensen [Tripos minutus] Ceratium minutum Jørgensen [Tripos minutus] Ceratium minutum Jørgensen [Tripos minutus] Ceratium minutum

Jørgensen [Tripos minutus] Ceratium minutum Jørgensen [Tripos minutus] Ceratium minutum Jørgensen [Tripos minutus]

Ceratium pentagonum Gourret [Tripos pentagonus]Ceratium pentagonum Gourret [Tripos pentagonus]Ceratium pentagonum Gourret [Tripos pentagonus]Ceratium pentagonum Gourret [Tripos pentagonus]Ceratium pentagonum Gourret [Tripos pentagonus]Ceratium pentagonum Gourret [Tripos pentagonus]Ceratium pentagonum Gourret [Tripos pentagonus]Ceratium pentagonum Gourret [Tripos

pentagonus]Ceratium pentagonum Gourret [Tripos pentagonus]Ceratium pentagonum Gourret [Tripos pentagonus]Ceratium pentagonum Gourret [Tripos

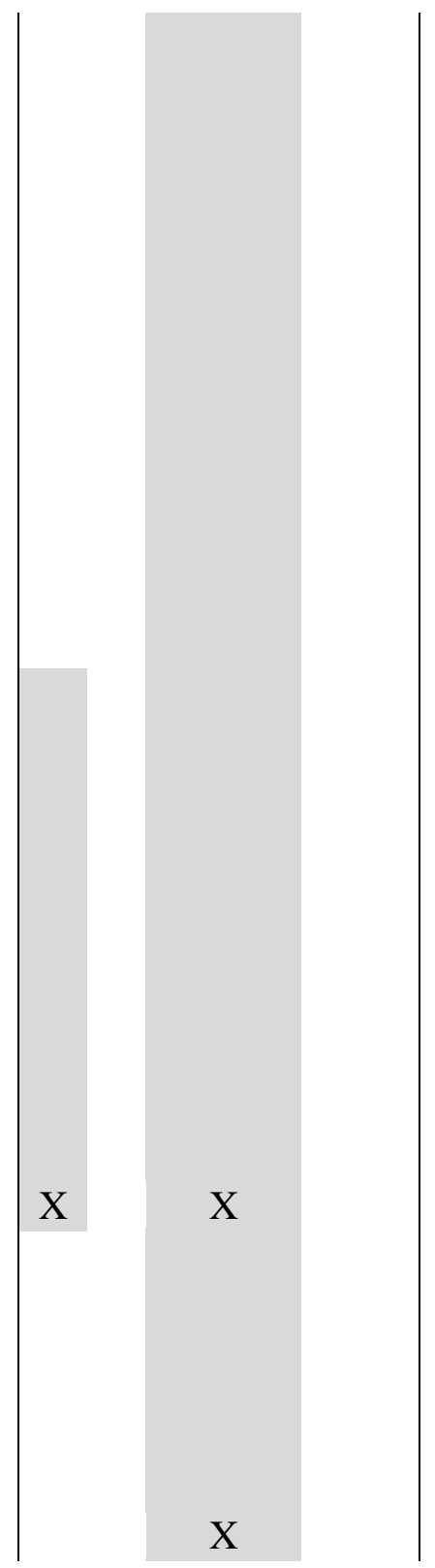


pentagonus]Ceratium pentagonum Gourret [Tripos pentagonus]Ceratium pentagonum Gourret [Tripos pentagonus]Ceratium pentagonum Gourret [Tripos

pentagonus]Ceratium pentagonum Gourret [Tripos pentagonus]Ceratium pentagonum Gourret [Tripos pentagonus]Ceratium pentagonum Gourret [Tripos pentagonus]Ceratium pentagonum Gourret [Tripos pentagonus]Ceratium pentagonum Gourret [Tripos pentagonus]Ceratium pentagonum Gourret [Tripos pentagonus]

Ceratium pulchellum Schröder [ C. tripos var. pulchellum, f. damaticum, Tripos pulchellus] Ceratium pulchellum Schröder [ C. tripos var. pulchellum, f. damaticum, Tripos pulchellus] Ceratium pulchellum Schröder [ C. tripos var. pulchellum, $f$. damaticum, Tripos pulchellus] Ceratium pulchellum Schröder [ C. tripos var. pulchellum, f. damaticum, Tripos pulchellus] Ceratium pulchellum Schröder [ C. tripos var. pulchellum, f. damaticum, Tripos pulchellus] Ceratium pulchellum Schröder [ C. tripos var. pulchellum, $f$. damaticum, Tripos pulchellus] Ceratium pulchellum Schröder [ C. tripos var. pulchellum, f. damaticum, Tripos pulchellus] Ceratium pulchellum Schröder [ C. tripos var. pulchellum, f. damaticum, Tripos pulchellus] Ceratium pulchellum Schröder [ C. tripos var. pulchellum, f. damaticum, Tripos pulchellus] Ceratium pulchellum Schröder [ C. tripos var. pulchellum, f. damaticum, Tripos pulchellus] Ceratium pulchellum Schröder [ C. tripos var. pulchellum, f. damaticum, Tripos pulchellus] Ceratium pulchellum Schröder [ C. tripos var. pulchellum, $f$. damaticum, Tripos pulchellus] Ceratium pulchellum Schröder [ C. tripos var. pulchellum, f. damaticum, Tripos pulchellus] Ceratium pulchellum Schröder [ C. tripos var. pulchellum, f. damaticum, Tripos pulchellus] Ceratium pulchellum Schröder [ $C$. tripos var. pulchellum, f. damaticum, Tripos pulchellus] Ceratium pulchellum Schröder [ C. tripos var. pulchellum, f. damaticum, Tripos pulchellus] Ceratium pulchellum Schröder [ C. tripos var. pulchellum, f. damaticum, Tripos pulchellus] Ceratium pulchellum Schröder [ C. tripos var. pulchellum, f. damaticum, Tripos pulchellus] Ceratium pulchellum Schröder [ C. tripos var. pulchellum, f. damaticum, Tripos pulchellus] Ceratium pulchellum Schröder [ C. tripos var. pulchellum, f. damaticum, Tripos pulchellus]

Ceratium teres Kofoid [Tripos teres] Ceratium teres Kofoid [Tripos teres] Ceratium teres Kofoid [Tripos teres] Ceratium teres Kofoid [Tripos teres] Ceratium teres Kofoid [Tripos teres] Ceratium teres Kofoid [Tripos teres] Ceratium teres Kofoid [Tripos teres] Ceratium teres Kofoid [Tripos teres] Ceratium teres Kofoid [Tripos teres] Ceratium

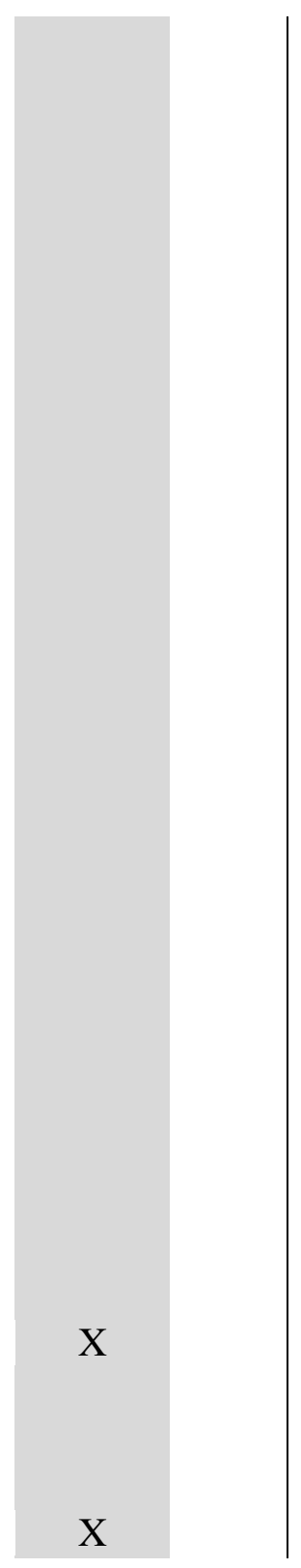


teres Kofoid [Tripos teres] Ceratium teres Kofoid [Tripos teres] Ceratium teres Kofoid [Tripos teres] Ceratium teres Kofoid [Tripos teres] Ceratium teres Kofoid [Tripos teres] Ceratium teres Kofoid [Tripos teres] Ceratium teres Kofoid [Tripos teres] Ceratium teres Kofoid [Tripos teres] Ceratium teres Kofoid [Tripos teres] Ceratium teres Kofoid [Tripos teres] Ceratium teres Kofoid [Tripos teres]

Ceratium trichoceros Ehrenberg [Tripos trichoceros]Ceratium trichoceros Ehrenberg [Tripos trichoceros]Ceratium trichoceros Ehrenberg [Tripos trichoceros]Ceratium trichoceros Ehrenberg [Tripos trichoceros]Ceratium trichoceros Ehrenberg [Tripos trichoceros]Ceratium trichoceros Ehrenberg [Tripos trichoceros]Ceratium trichoceros Ehrenberg [Tripos trichoceros] Ceratium trichoceros Ehrenberg [Tripos

trichoceros]Ceratium trichoceros Ehrenberg [Tripos trichoceros]Ceratium trichoceros Ehrenberg [Tripos trichoceros] Ceratium trichoceros Ehrenberg [Tripos

trichoceros]Ceratium trichoceros Ehrenberg [Tripos trichoceros]Ceratium trichoceros Ehrenberg [Tripos trichoceros] Ceratium trichoceros Ehrenberg [Tripos trichoceros]Ceratium trichoceros Ehrenberg [Tripos trichoceros]Ceratium trichoceros Ehrenberg [Tripos trichoceros] Ceratium trichoceros Ehrenberg [Tripos

trichoceros] Ceratium trichoceros Ehrenberg [Tripos trichoceros]Ceratium trichoceros Ehrenberg [Tripos trichoceros] Ceratium trichoceros Ehrenberg [Tripos trichoceros] Ceratium tripos (O.F. Müller) Nitzsch [ Ceratium schroederi etc., Tripos schroederi]Ceratium tripos (O.F. Müller) Nitzsch [ Ceratium schroederi etc., Tripos schroederi]Ceratium tripos (O.F. Müller) Nitzsch [ Ceratium schroederi etc., Tripos schroederi]Ceratium tripos (O.F. Müller) Nitzsch [ Ceratium schroederi etc., Tripos schroederi]Ceratium tripos (O.F. Müller) Nitzsch [ Ceratium schroederi etc., Tripos schroederi]Ceratium tripos (O.F. Müller) Nitzsch [ Ceratium schroederi etc., Tripos schroederi]Ceratium tripos (O.F. Müller) Nitzsch [ Ceratium schroederi etc., Tripos schroederi]Ceratium tripos (O.F. Müller) Nitzsch [ Ceratium schroederi etc., Tripos schroederi]Ceratium tripos (O.F. Müller) Nitzsch [ Ceratium schroederi etc., Tripos schroederi]Ceratium tripos (O.F. Müller) Nitzsch [ Ceratium schroederi etc., Tripos schroederi]Ceratium tripos (O.F. Müller) Nitzsch [ Ceratium schroederi etc., Tripos schroederi]Ceratium tripos (O.F. Müller) Nitzsch [ Ceratium schroederi etc., Tripos schroederi]Ceratium tripos (O.F. Müller) Nitzsch [ Ceratium schroederi etc., Tripos schroederi]Ceratium tripos (O.F. Müller) Nitzsch [ Ceratium schroederi etc., Tripos schroederi]Ceratium tripos (O.F. Müller) Nitzsch [ Ceratium schroederi etc., Tripos

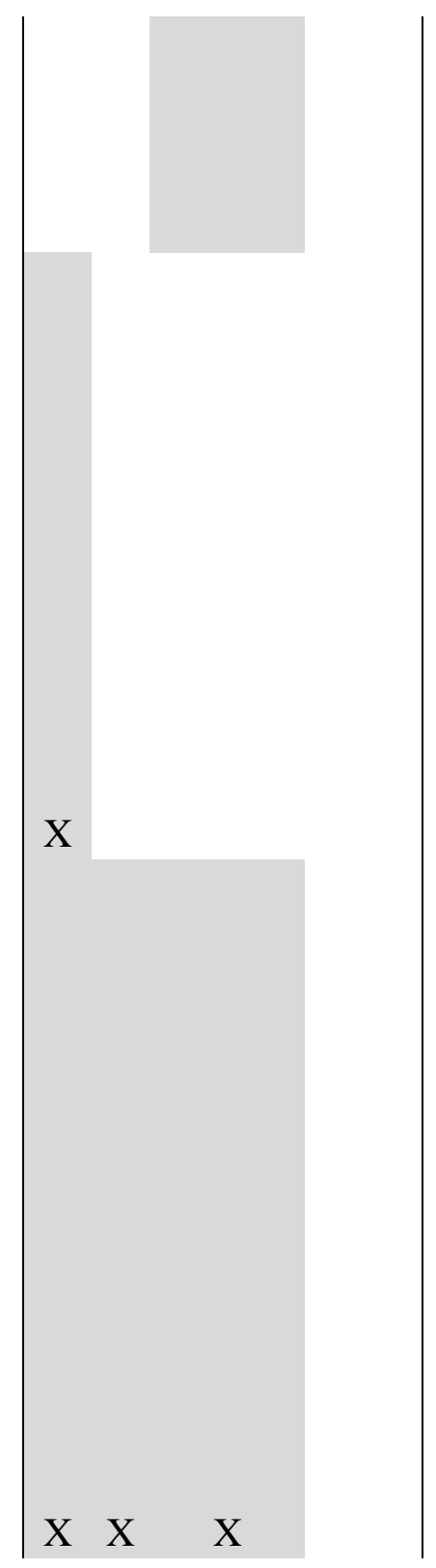


schroederi]Ceratium tripos (O.F. Müller) Nitzsch [ Ceratium schroederi etc., Tripos schroederi]Ceratium tripos (O.F. Müller) Nitzsch [ Ceratium schroederi etc., Tripos schroederi]Ceratium tripos (O.F. Müller) Nitzsch [ Ceratium schroederi etc., Tripos schroederi]Ceratium tripos (O.F. Müller) Nitzsch [ Ceratium schroederi etc., Tripos schroederi]Ceratium tripos (O.F. Müller) Nitzsch [ Ceratium schroederi etc., Tripos schroederi]

Ceratium volans Cleve [ C. carriense var. volans, Tripos volans] Ceratium volans Cleve [ C. carriense var. volans, Tripos volans] Ceratium volans Cleve [ C. carriense var. volans, Tripos volans] Ceratium volans Cleve [C. carriense var. volans, Tripos volans] Ceratium volans Cleve [ C. carriense var. volans, Tripos volans] Ceratium volans Cleve [ C. carriense var. volans, Tripos volans] Ceratium volans Cleve [ C. carriense var. volans, Tripos volans] Ceratium volans Cleve [ C. carriense var. volans, Tripos volans] Ceratium volans Cleve [ C. carriense var. volans, Tripos volans] Ceratium volans Cleve [ C. carriense var. volans, Tripos volans] Ceratium volans Cleve [ C. carriense var. volans, Tripos volans] Ceratium volans Cleve [C. carriense var. volans, Tripos volans] Ceratium volans Cleve [ C. carriense var. volans, Tripos volans] Ceratium volans Cleve [ C. carriense var. volans, Tripos volans] Ceratium volans Cleve [ C. carriense var. volans, Tripos volans] Ceratium volans Cleve [C. carriense var. volans, Tripos volans] Ceratium volans Cleve [ C. carriense var. volans, Tripos volans] Ceratium volans Cleve [ C. carriense var. volans, Tripos volans] Ceratium volans Cleve [ C. carriense var. volans, Tripos volans] Ceratium volans Cleve [C. carriense var. volans, Tripos volans] Ceratium carolinianum (Bailey) Jørgensen [Ceratium curvirostre Huitfeld-Kaas] Ceratium carolinianum (Bailey) Jorgensen [Ceratium curvirostre Huitfeld-Kaas] Ceratium carolinianum (Bailey) Jørgensen [Ceratium curvirostre Huitfeld-Kaas] Ceratium carolinianum (Bailey) Jørgensen [Ceratium curvirostre Huitfeld-Kaas] Ceratium carolinianum (Bailey) Jørgensen [Ceratium curvirostre Huitfeld-Kaas] Ceratium carolinianum (Bailey) J $\phi r g e n s e n$ [Ceratium curvirostre Huitfeld-Kaas] Ceratium carolinianum (Bailey) Jфrgensen [Ceratium curvirostre Huitfeld-Kaas] Ceratium carolinianum (Bailey) Jørgensen [Ceratium curvirostre Huitfeld-Kaas] Ceratium carolinianum (Bailey) Jørgensen [Ceratium curvirostre Huitfeld-Kaas] Ceratium carolinianum (Bailey) Jørgensen [Ceratium curvirostre Huitfeld-Kaas] Ceratium carolinianum (Bailey) Jørgensen [Ceratium curvirostre Huitfeld-Kaas] Ceratium carolinianum (Bailey) J $\phi r g e n s e n$ [Ceratium curvirostre Huitfeld-Kaas]

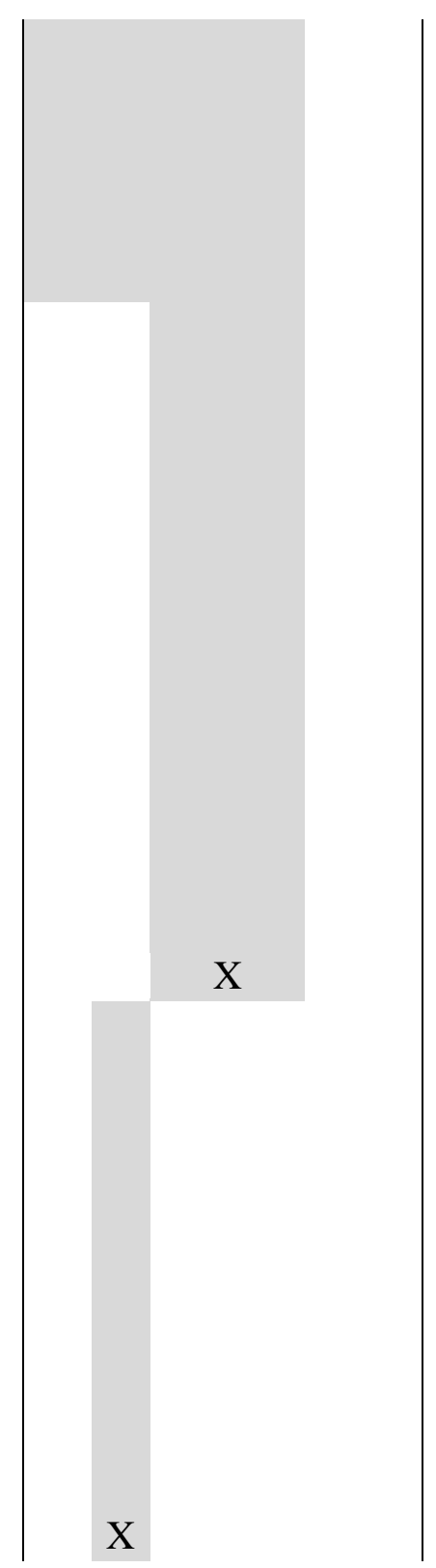


Ceratium carolinianum (Bailey) J $\phi r g e n s e n$ [Ceratium curvirostre Huitfeld-Kaas] Ceratium carolinianum (Bailey) Jørgensen [Ceratium curvirostre Huitfeld-Kaas] Ceratium carolinianum (Bailey) Jørgensen [Ceratium curvirostre Huitfeld-Kaas] Ceratium carolinianum (Bailey) Jørgensen [Ceratium curvirostre Huitfeld-Kaas] Ceratium carolinianum (Bailey) Jørgensen [Ceratium curvirostre Huitfeld-Kaas] Ceratium carolinianum (Bailey) Jorgensen [Ceratium curvirostre Huitfeld-Kaas] Ceratium carolinianum (Bailey) J $\phi$ rgensen [Ceratium curvirostre Huitfeld-Kaas] Ceratium carolinianum (Bailey) Jørgensen [Ceratium curvirostre Huitfeld-Kaas] Ceratium cornutum (Ehrenberg) Claparède et Lachmann Ceratium cornutum (Ehrenberg) Claparède et Lachmann Ceratium cornutum (Ehrenberg) Claparède et Lachmann Ceratium cornutum (Ehrenberg) Claparède et Lachmann Ceratium cornutum (Ehrenberg) Claparède et Lachmann Ceratium cornutum (Ehrenberg) Claparède et Lachmann Ceratium cornutum (Ehrenberg) Claparède et Lachmann Ceratium cornutum (Ehrenberg) Claparède et Lachmann Ceratium cornutum (Ehrenberg) Claparède et Lachmann Ceratium cornutum (Ehrenberg) Claparède et Lachmann Ceratium cornutum (Ehrenberg) Claparède et Lachmann Ceratium cornutum (Ehrenberg) Claparède et Lachmann Ceratium cornutum (Ehrenberg) Claparède et Lachmann Ceratium cornutum (Ehrenberg) Claparède et Lachmann Ceratium cornutum (Ehrenberg) Claparède et Lachmann Ceratium cornutum (Ehrenberg) Claparède et Lachmann Ceratium cornutum (Ehrenberg) Claparède et Lachmann Ceratium cornutum (Ehrenberg) Claparède et Lachmann Ceratium cornutum (Ehrenberg) Claparède et Lachmann Ceratium cornutum (Ehrenberg) Claparède et Lachmann

C. hirundinella (Müller) Bergh C. hirundinella (Müller) Bergh C. hirundinella (Müller) Bergh C. hirundinella (Müller) Bergh C. hirundinella (Müller) Bergh C. hirundinella (Müller) Bergh C. hirundinella (Müller) Bergh C. hirundinella (Müller) Bergh C. hirundinella (Müller) Bergh C. hirundinella (Müller) Bergh C. hirundinella (Müller) Bergh C. hirundinella (Müller) Bergh C. hirundinella (Müller) Bergh C. hirundinella (Müller) Bergh C. hirundinella (Müller) Bergh C. hirundinella (Müller) Bergh C. hirundinella (Müller) Bergh C. hirundinella (Müller) Bergh C. hirundinella (Müller) Bergh C. hirundinella (Müller) Bergh

Cochlodinium adriaticum Schiller [Gyrodinium adriaticum Schiller] Cochlodinium adriaticum Schiller [Gyrodinium adriaticum Schiller] Cochlodinium adriaticum Schiller [Gyrodinium adriaticum Schiller] Cochlodinium adriaticum Schiller [Gyrodinium 
adriaticum Schiller] Cochlodinium adriaticum Schiller [Gyrodinium adriaticum Schiller] Cochlodinium adriaticum Schiller [Gyrodinium adriaticum Schiller] Cochlodinium adriaticum Schiller [Gyrodinium adriaticum Schiller] Cochlodinium adriaticum Schiller [Gyrodinium adriaticum Schiller] Cochlodinium adriaticum Schiller [Gyrodinium adriaticum Schiller] Cochlodinium adriaticum Schiller [Gyrodinium adriaticum Schiller] Cochlodinium adriaticum Schiller [Gyrodinium adriaticum Schiller] Cochlodinium adriaticum Schiller [Gyrodinium adriaticum Schiller] Cochlodinium adriaticum Schiller [Gyrodinium adriaticum Schiller] Cochlodinium adriaticum Schiller [Gyrodinium adriaticum Schiller] Cochlodinium adriaticum Schiller [Gyrodinium adriaticum Schiller] Cochlodinium adriaticum Schiller [Gyrodinium adriaticum Schiller] Cochlodinium adriaticum Schiller [Gyrodinium adriaticum Schiller] Cochlodinium adriaticum Schiller [Gyrodinium adriaticum Schiller] Cochlodinium adriaticum Schiller [Gyrodinium adriaticum Schiller] Cochlodinium adriaticum Schiller [Gyrodinium adriaticum Schiller] Cochlodinium archimedes (Pouch.) LemmermannCochlodinium archimedes (Pouch.) LemmermannCochlodinium archimedes (Pouch.) LemmermannCochlodinium archimedes (Pouch.) LemmermannCochlodinium archimedes (Pouch.) LemmermannCochlodinium archimedes (Pouch.) LemmermannCochlodinium archimedes (Pouch.)

LemmermannCochlodinium archimedes (Pouch.) LemmermannCochlodinium archimedes (Pouch.) LemmermannCochlodinium archimedes (Pouch.) LemmermannCochlodinium archimedes (Pouch.) LemmermannCochlodinium archimedes (Pouch.) LemmermannCochlodinium archimedes (Pouch.) LemmermannCochlodinium archimedes (Pouch.) LemmermannCochlodinium archimedes (Pouch.) LemmermannCochlodinium archimedes (Pouch.) LemmermannCochlodinium archimedes (Pouch.)

LemmermannCochlodinium archimedes (Pouch.) LemmermannCochlodinium archimedes (Pouch.) LemmermannCochlodinium archimedes (Pouch.) Lemmermann

Cochlodinium brandtii Wulff Cochlodinium brandtii Wulff Cochlodinium brandtii Wulff Cochlodinium brandtii Wulff Cochlodinium brandtii Wulff Cochlodinium brandtii Wulff Cochlodinium brandtii Wulff Cochlodinium brandtii Wulff Cochlodinium brandtii Wulff Cochlodinium brandtii Wulff Cochlodinium brandtii Wulff Cochlodinium brandtii Wulff Cochlodinium brandtii Wulff Cochlodinium brandtii Wulff Cochlodinium brandtii Wulff Cochlodinium brandtii Wulff Cochlodinium brandtii Wulff Cochlodinium brandtii Wulff Cochlodinium brandtii Wulff

Cochlodinium citron Kofoid et Swezy Cochlodinium citron Kofoid et Swezy Cochlodinium

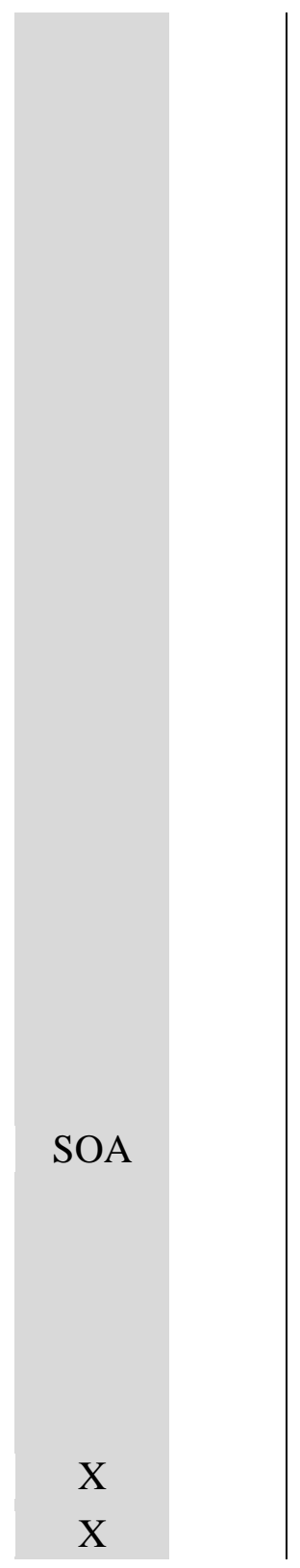


citron Kofoid et Swezy Cochlodinium citron Kofoid et Swezy Cochlodinium citron Kofoid et Swezy Cochlodinium citron Kofoid et Swezy Cochlodinium citron Kofoid et Swezy Cochlodinium citron Kofoid et Swezy Cochlodinium citron Kofoid et Swezy Cochlodinium citron Kofoid et Swezy Cochlodinium citron Kofoid et Swezy Cochlodinium citron Kofoid et Swezy Cochlodinium citron Kofoid et Swezy Cochlodinium citron Kofoid et Swezy

Cochlodinium citron Kofoid et Swezy Cochlodinium citron Kofoid et Swezy Cochlodinium citron Kofoid et Swezy Cochlodinium citron Kofoid et Swezy Cochlodinium citron Kofoid et Swezy

Cochlodinium geminatum (Schütt) Schütt [Gymnodinium geminatum] Cochlodinium geminatum (Schütt) Schütt [Gymnodinium geminatum] Cochlodinium geminatum (Schütt) Schütt [Gymnodinium geminatum] Cochlodinium geminatum (Schütt) Schütt [Gymnodinium geminatum] Cochlodinium geminatum (Schütt) Schütt [Gymnodinium geminatum] Cochlodinium geminatum (Schütt) Schütt [Gymnodinium geminatum] Cochlodinium geminatum (Schütt) Schütt [Gymnodinium geminatum] Cochlodinium geminatum (Schütt) Schütt [Gymnodinium geminatum] Cochlodinium geminatum (Schütt) Schütt [Gymnodinium geminatum] Cochlodinium geminatum (Schütt) Schütt [Gymnodinium geminatum] Cochlodinium geminatum (Schütt) Schütt [Gymnodinium geminatum] Cochlodinium geminatum (Schütt) Schütt [Gymnodinium geminatum] Cochlodinium geminatum (Schütt) Schütt [Gymnodinium geminatum] Cochlodinium geminatum (Schütt) Schütt [Gymnodinium geminatum] Cochlodinium geminatum (Schütt) Schütt [Gymnodinium geminatum] Cochlodinium geminatum (Schütt) Schütt [Gymnodinium geminatum] Cochlodinium geminatum (Schütt) Schütt [Gymnodinium geminatum] Cochlodinium geminatum (Schütt) Schütt [Gymnodinium geminatum] Cochlodinium geminatum (Schütt) Schütt [Gymnodinium geminatum]

Cochlodinium helicoides Lebour [C. helix Schütt pro parte]Cochlodinium helicoides Lebour [C. helix Schütt pro parte]Cochlodinium helicoides Lebour [C. helix Schütt pro parte]Cochlodinium helicoides Lebour [C. helix Schütt pro parte]Cochlodinium helicoides Lebour [C. helix Schütt pro parte]Cochlodinium helicoides Lebour [C. helix Schütt pro parte]Cochlodinium helicoides Lebour [C. helix Schütt pro parte]Cochlodinium helicoides Lebour [C. helix Schütt pro parte]Cochlodinium helicoides Lebour [C. helix Schütt pro parte]Cochlodinium helicoides Lebour [C. helix Schütt pro parte]Cochlodinium helicoides Lebour [C. helix Schütt pro parte]Cochlodinium helicoides Lebour [C. helix Schütt pro parte]Cochlodinium

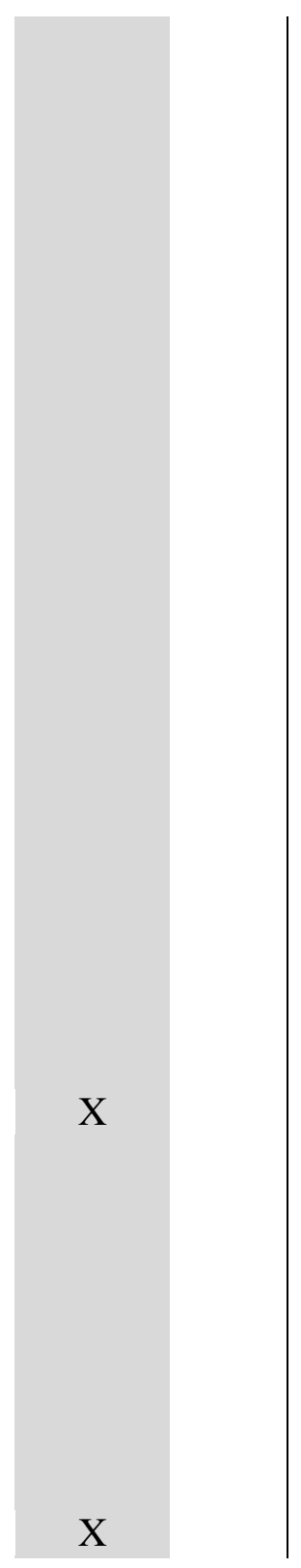


helicoides Lebour [C. helix Schütt pro parte]Cochlodinium helicoides Lebour [C. helix Schütt pro parte]Cochlodinium helicoides Lebour [C. helix Schütt pro parte]Cochlodinium helicoides Lebour [C. helix Schütt pro parte]Cochlodinium helicoides Lebour [C. helix Schütt pro parte]Cochlodinium helicoides Lebour [C. helix Schütt pro parte]Cochlodinium helicoides Lebour [C. helix Schütt pro parte]

Cochlodinium helix (Pouchet) Lemmermann

Cochlodinium lebourae Kofoid \& Swezy Cochlodinium lebourae Kofoid \& Swezy Cochlodinium lebourae Kofoid \& Swezy Cochlodinium lebourae Kofoid \& Swezy Cochlodinium lebourae Kofoid \& Swezy Cochlodinium lebourae Kofoid \& Swezy Cochlodinium lebourae Kofoid \& Swezy Cochlodinium lebourae Kofoid \& Swezy Cochlodinium lebourae Kofoid \& Swezy Cochlodinium lebourae Kofoid \& Swezy Cochlodinium lebourae Kofoid \& Swezy Cochlodinium lebourae Kofoid \& Swezy Cochlodinium lebourae Kofoid \& Swezy Cochlodinium lebourae Kofoid \& Swezy Cochlodinium lebourae Kofoid \& Swezy Cochlodinium lebourae Kofoid \& Swezy Cochlodinium lebourae Kofoid \& Swezy Cochlodinium lebourae Kofoid \& Swezy Cochlodinium lebourae Kofoid \& Swezy

Cochlodinium pirum (Schütt) Lemmermann [Gymnodinium pirum] Cochlodinium pirum (Schütt) Lemmermann [Gymnodinium pirum]Cochlodinium pirum (Schütt) Lemmermann [Gymnodinium pirum] Cochlodinium pirum (Schütt) Lemmermann [Gymnodinium pirum]Cochlodinium pirum (Schütt) Lemmermann [Gymnodinium pirum]Cochlodinium pirum (Schütt) Lemmermann [Gymnodinium pirum] Cochlodinium pirum (Schütt) Lemmermann [Gymnodinium pirum] Cochlodinium pirum (Schütt) Lemmermann [Gymnodinium pirum] Cochlodinium pirum (Schütt) Lemmermann [Gymnodinium pirum] Cochlodinium pirum (Schütt) Lemmermann [Gymnodinium pirum]Cochlodinium pirum (Schütt) Lemmermann [Gymnodinium pirum]Cochlodinium pirum (Schütt) Lemmermann [Gymnodinium pirum] Cochlodinium pirum (Schütt) Lemmermann [Gymnodinium pirum] Cochlodinium pirum (Schütt) Lemmermann [Gymnodinium pirum]Cochlodinium pirum (Schütt) Lemmermann [Gymnodinium pirum]Cochlodinium pirum (Schütt) Lemmermann [Gymnodinium pirum]Cochlodinium pirum (Schütt) Lemmermann [Gymnodinium pirum] Cochlodinium pirum (Schütt) Lemmermann [Gymnodinium pirum]Cochlodinium pirum (Schütt) Lemmermann [Gymnodinium pirum] Cochlodinium polykrikoides Margelef Cochlodinium polykrikoides Margelef Cochlodinium polykrikoides Margelef Cochlodinium polykrikoides Margelef

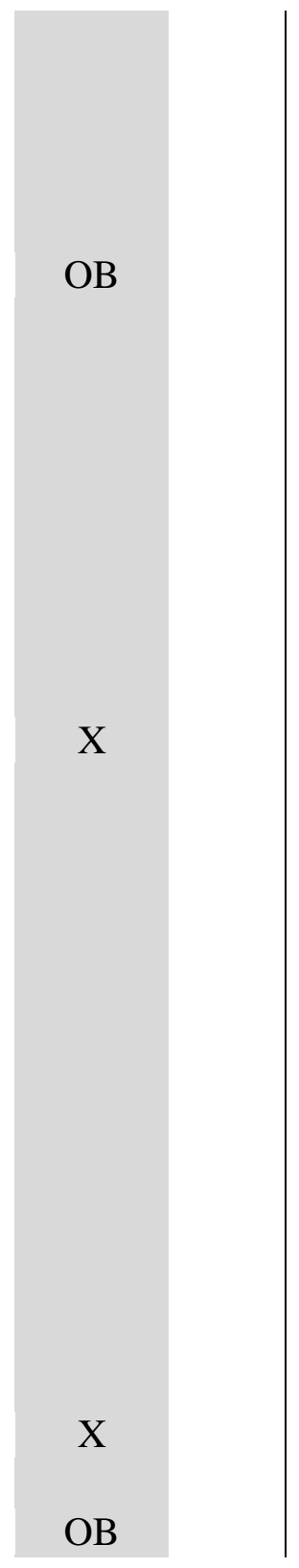


Cochlodinium polykrikoides Margelef Cochlodinium polykrikoides Margelef Cochlodinium polykrikoides Margelef Cochlodinium polykrikoides Margelef Cochlodinium polykrikoides Margelef Cochlodinium polykrikoides Margelef Cochlodinium polykrikoides Margelef Cochlodinium polykrikoides Margelef Cochlodinium polykrikoides Margelef Cochlodinium polykrikoides Margelef Cochlodinium polykrikoides Margelef Cochlodinium polykrikoides Margelef Cochlodinium polykrikoides Margelef Cochlodinium polykrikoides Margelef Cochlodinium polykrikoides Margelef

Corythodinium compressum (Kofoid) F.J.R. Taylor [Oxytoxum compressum] Corythodinium compressum (Kofoid) F.J.R. Taylor [Oxytoxum compressum] Corythodinium compressum (Kofoid) F.J.R. Taylor [Oxytoxum compressum] Corythodinium compressum (Kofoid) F.J.R. Taylor [Oxytoxum compressum] Corythodinium compressum (Kofoid) F.J.R. Taylor [Oxytoxum compressum] Corythodinium compressum (Kofoid) F.J.R. Taylor [Oxytoxum compressum] Corythodinium compressum (Kofoid) F.J.R. Taylor [Oxytoxum compressum] Corythodinium compressum (Kofoid) F.J.R. Taylor [Oxytoxum compressum] Corythodinium compressum (Kofoid) F.J.R. Taylor [Oxytoxum compressum] Corythodinium compressum (Kofoid) F.J.R. Taylor [Oxytoxum compressum] Corythodinium compressum (Kofoid) F.J.R. Taylor [Oxytoxum compressum] Corythodinium compressum (Kofoid) F.J.R. Taylor [Oxytoxum compressum] Corythodinium compressum (Kofoid) F.J.R. Taylor [Oxytoxum compressum] Corythodinium compressum (Kofoid) F.J.R. Taylor [Oxytoxum compressum] Corythodinium compressum (Kofoid) F.J.R. Taylor [Oxytoxum compressum] Corythodinium compressum (Kofoid) F.J.R. Taylor [Oxytoxum compressum] Corythodinium compressum (Kofoid) F.J.R. Taylor [Oxytoxum compressum] Corythodinium compressum (Kofoid) F.J.R. Taylor [Oxytoxum compressum] Corythodinium compressum (Kofoid) F.J.R. Taylor [Oxytoxum compressum] Corythodinium diploconus (Stein) F.J.R. Taylor [ Oxytoxum diploconus]Corythodinium diploconus (Stein) F.J.R. Taylor [ Oxytoxum diploconus]Corythodinium diploconus (Stein) F.J.R. Taylor [ Oxytoxum diploconus]Corythodinium diploconus (Stein) F.J.R. Taylor [ Oxytoxum diploconus]Corythodinium diploconus (Stein) F.J.R. Taylor [ Oxytoxum diploconus]Corythodinium diploconus (Stein) F.J.R. Taylor [ Oxytoxum 
diploconus]Corythodinium diploconus (Stein) F.J.R. Taylor [ Oxytoxum diploconus]Corythodinium diploconus (Stein) F.J.R. Taylor [ Oxytoxum diploconus]Corythodinium diploconus (Stein) F.J.R. Taylor [ Oxytoxum diploconus]Corythodinium diploconus (Stein) F.J.R. Taylor [ Oxytoxum diploconus]Corythodinium diploconus (Stein) F.J.R. Taylor [ Oxytoxum diploconus]Corythodinium diploconus (Stein) F.J.R. Taylor [ Oxytoxum diploconus]Corythodinium diploconus (Stein) F.J.R. Taylor [ Oxytoxum diploconus]Corythodinium diploconus (Stein) F.J.R. Taylor [ Oxytoxum diploconus]Corythodinium diploconus (Stein) F.J.R. Taylor [ Oxytoxum diploconus]Corythodinium diploconus (Stein) F.J.R. Taylor [ Oxytoxum diploconus]Corythodinium diploconus (Stein) F.J.R. Taylor [ Oxytoxum diploconus]Corythodinium diploconus (Stein) F.J.R. Taylor [ Oxytoxum diploconus]Corythodinium diploconus (Stein) F.J.R. Taylor [ Oxytoxum diploconus] Dinophysis acuminata Claparède et Lachmann [ D. ovum v. baltica, etc.]Dinophysis acuminata Claparède et Lachmann [ D. ovum v. baltica, etc.]Dinophysis acuminata Claparède et Lachmann [ D. ovum v. baltica, etc.]Dinophysis acuminata Claparède et Lachmann [ D. ovum v. baltica, etc.]Dinophysis acuminata Claparède et Lachmann [ D. ovum v. baltica, etc.]Dinophysis acuminata Claparède et Lachmann [ D. ovum v. baltica, etc.]Dinophysis acuminata Claparède et Lachmann [ D. ovum v. baltica, etc.]Dinophysis acuminata Claparède et Lachmann [ D. ovum v. baltica, etc.]Dinophysis acuminata Claparède et Lachmann [ D. ovum v. baltica, etc.]Dinophysis acuminata Claparède et Lachmann [ D. ovum v. baltica, etc.]Dinophysis acuminata Claparède et Lachmann [ D. ovum v. baltica, etc.]Dinophysis acuminata Claparède et Lachmann [ D. ovum v. baltica, etc.]Dinophysis acuminata Claparède et Lachmann [ D. ovum v. baltica, etc.]Dinophysis acuminata Claparède et Lachmann [ D. ovum v. baltica, etc.]Dinophysis acuminata Claparède et Lachmann [ D. ovum v. baltica, etc.]Dinophysis acuminata Claparède et Lachmann [ D. ovum v. baltica, etc.]Dinophysis acuminata Claparède et Lachmann [ D. ovum v. baltica, etc.]Dinophysis acuminata Claparède et Lachmann [ D. ovum v. baltica, etc.]Dinophysis acuminata Claparède et Lachmann [ D. ovum v. baltica, etc.]

Diplopsalis acuta (Apstein) Entz [Peridinium latum, Kolkwitziella acuta etc.] Diplopsalis acuta (Apstein) Entz [Peridinium latum, Kolkwitziella acuta etc.] Diplopsalis acuta

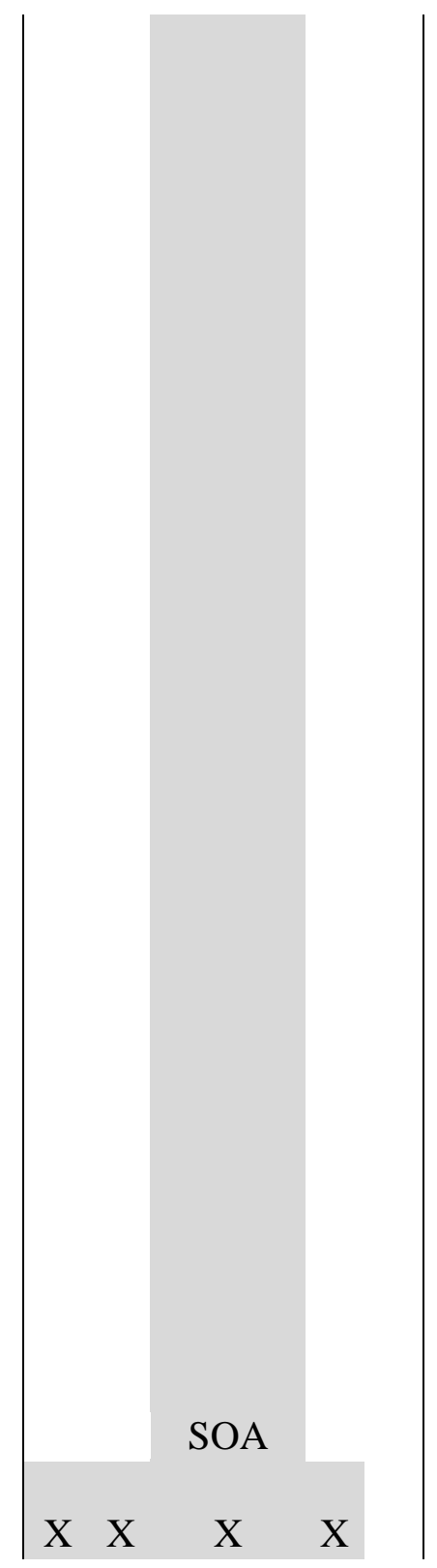


(Apstein) Entz [Peridinium latum, Kolkwitziella acuta etc.] Diplopsalis acuta (Apstein) Entz [Peridinium latum, Kolkwitziella acuta etc.] Diplopsalis acuta (Apstein) Entz [Peridinium latum, Kolkwitziella acuta etc.] Diplopsalis acuta (Apstein) Entz [Peridinium latum, Kolkwitziella acuta etc.] Diplopsalis acuta (Apstein) Entz [Peridinium latum, Kolkwitziella acuta etc.] Diplopsalis acuta (Apstein) Entz [Peridinium latum, Kolkwitziella acuta etc.] Diplopsalis acuta (Apstein) Entz [Peridinium latum, Kolkwitziella acuta etc.] Diplopsalis acuta (Apstein) Entz [Peridinium latum, Kolkwitziella acuta etc.] Diplopsalis acuta (Apstein) Entz [Peridinium latum, Kolkwitziella acuta etc.] Diplopsalis acuta (Apstein) Entz [Peridinium latum, Kolkwitziella acuta etc.] Diplopsalis acuta (Apstein) Entz. [Peridinium latum, Kolkwitziella acuta etc.] Diplopsalis acuta (Apstein) Entz [Peridinium latum, Kolkwitziella acuta etc.] Diplopsalis acuta (Apstein) Entz [Peridinium latum, Kolkwitziella acuta etc.] Diplopsalis acuta (Apstein) Entz [Peridinium latum, Kolkwitziella acuta etc.] Diplopsalis acuta (Apstein) Entz [Peridinium latum, Kolkwitziella acuta etc.] Diplopsalis acuta (Apstein) Entz [Peridinium latum, Kolkwitziella acuta etc.] Diplopsalis acuta (Apstein) Entz [Peridinium latum, Kolkwitziella acuta etc.]

Dinophysis acutoides Balech, non D. acutum Dinophysis acutoides Balech, non D. acutum Dinophysis acutoides Balech, non D. acutum Dinophysis acutoides Balech, non D. acutum Dinophysis acutoides Balech, non D. acutum Dinophysis acutoides Balech, non D. acutum Dinophysis acutoides Balech, non D. acutum Dinophysis acutoides Balech, non D. acutum Dinophysis acutoides Balech, non D. acutum Dinophysis acutoides Balech, non D. acutum Dinophysis acutoides Balech, non D. acutum Dinophysis acutoides Balech, non D. acutum Dinophysis acutoides Balech, non D. acutum Dinophysis acutoides Balech, non D. acutum Dinophysis acutoides Balech, non D. acutum Dinophysis acutoides Balech, non D. acutum Dinophysis acutoides Balech, non D. acutum Dinophysis acutoides Balech, non D. acutum Dinophysis acutoides Balech, non D. acutum

Dinophysis arctica Mereschkowsky [D. laevis, D. rotundata, D. granulata] Dinophysis arctica Mereschkowsky [D. laevis, D. rotundata, D. granulata] Dinophysis arctica Mereschkowsky [D. laevis, D. rotundata, D. granulata] Dinophysis arctica Mereschkowsky [D. laevis, D. rotundata, D. granulata] Dinophysis arctica Mereschkowsky [D. laevis, D. rotundata, D. granulata] Dinophysis arctica

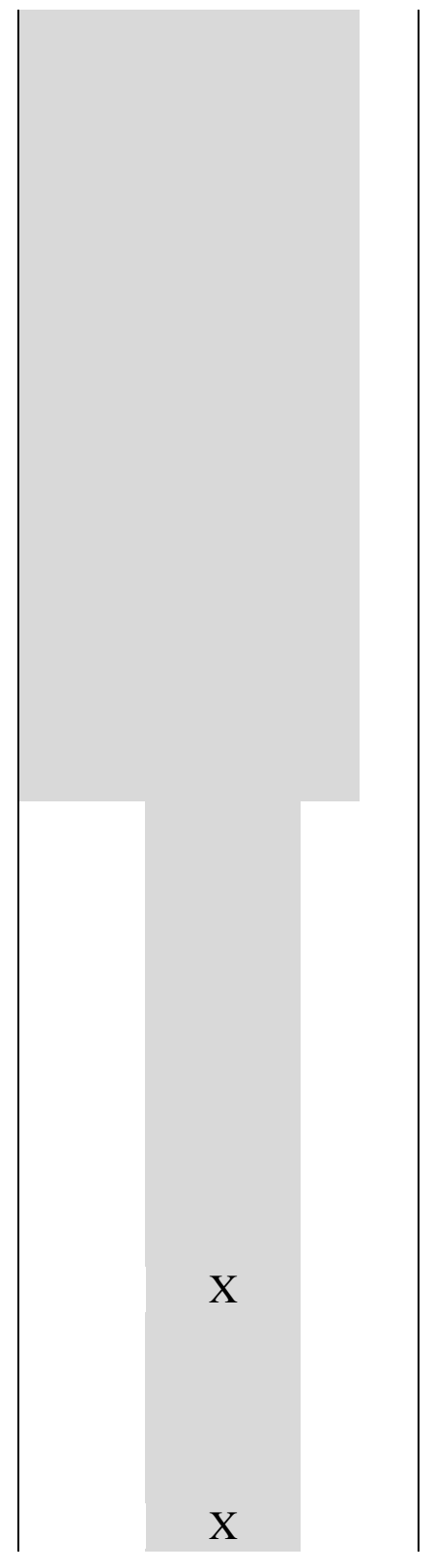


Mereschkowsky [D. laevis, D. rotundata, D. granulata] Dinophysis arctica Mereschkowsky [D. laevis, D. rotundata, D. granulata] Dinophysis arctica Mereschkowsky [D. laevis, D. rotundata, D. granulata] Dinophysis arctica Mereschkowsky [D. laevis, D. rotundata, D. granulata] Dinophysis arctica Mereschkowsky [D. laevis, D. rotundata, D. granulata] Dinophysis arctica Mereschkowsky [D. laevis, D. rotundata, D. granulata] Dinophysis arctica Mereschkowsky [D. laevis, D. rotundata, D. granulata] Dinophysis arctica Mereschkowsky [D. laevis, D. rotundata, D. granulata] Dinophysis arctica Mereschkowsky [D. laevis, D. rotundata, D. granulata] Dinophysis arctica Mereschkowsky [D. laevis, D. rotundata, D. granulata] Dinophysis arctica Mereschkowsky [D. laevis, D. rotundata, D. granulata] Dinophysis arctica Mereschkowsky [D. laevis, D. rotundata, D. granulata] Dinophysis arctica Mereschkowsky [D. laevis, D. rotundata, D. granulata] Dinophysis arctica Mereschkowsky [D. laevis, D. rotundata, D. granulata]

Dinophysis caudata Saville-Kent [D. homunculus, D. diegens, D. dentate ]Dinophysis caudata Saville-Kent [D. homunculus, D. diegens, D. dentate ]Dinophysis caudata Saville-Kent [D. homunculus, D. diegens, D. dentate ]Dinophysis caudata Saville-Kent [D. homunculus, D. diegens, D. dentate]Dinophysis caudata Saville-Kent [D.

homunculus, D. diegens, D. dentate ]Dinophysis caudata Saville-Kent [D. homunculus, D. diegens, D. dentate ]Dinophysis caudata Saville-Kent [D. homunculus, D. diegens, D. dentate ]Dinophysis caudata Saville-Kent [D. homunculus, D. diegens, D. dentate JDinophysis caudata Saville-Kent [D. homunculus, D. diegens, D. dentate ]Dinophysis caudata Saville-Kent [D. homunculus, D. diegens, D. dentate ]Dinophysis caudata Saville-Kent [D. homunculus, D. diegens, D. dentate ]Dinophysis caudata Saville-Kent [D. homunculus, D. diegens, D. dentate ]Dinophysis caudata Saville-Kent [D. homunculus, D. diegens, D. dentate ]Dinophysis caudata Saville-Kent [D. homunculus, $D$. diegens, D. dentate ]Dinophysis caudata Saville-Kent [D. homunculus, D. diegens, D. dentate ]Dinophysis caudata Saville-Kent [D. homunculus, D. diegens, D. dentate JDinophysis caudata Saville-Kent [D. homunculus, D. diegens, D. dentate ]Dinophysis caudata Saville-Kent [D. homunculus, D. diegens, D. dentate ]Dinophysis caudata Saville-Kent [D. homunculus, D. diegens, D. dentate ]

Dinophysis fortii Pavillard [D. laevis, D. lapidistrigiliformi, D. intermedia] Dinophysis fortii Pavillard [D. laevis, D. lapidistrigiliformi, D. intermedia] Dinophysis fortii

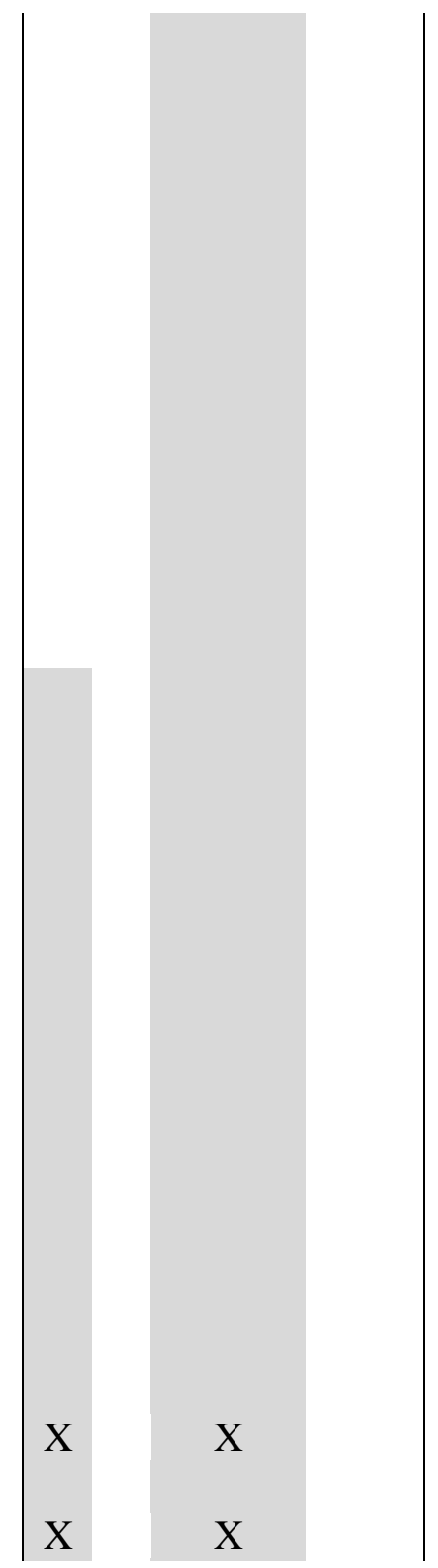


Pavillard [D. laevis, D. lapidistrigiliformi, D. intermedia] Dinophysis fortii Pavillard [D. laevis, D. lapidistrigiliformi, D. intermedia] Dinophysis fortii Pavillard [D. laevis, D. lapidistrigiliformi, D. intermedia] Dinophysis fortii Pavillard [D. laevis, D. lapidistrigiliformi, D. intermedia] Dinophysis fortii Pavillard [D. laevis, D. lapidistrigiliformi, D. intermedia] Dinophysis fortii Pavillard [D. laevis, D. lapidistrigiliformi, D. intermedia] Dinophysis fortii Pavillard [D. laevis, D. lapidistrigiliformi, D. intermedia] Dinophysis fortii Pavillard [D. laevis, D. lapidistrigiliformi, D. intermedia] Dinophysis fortii Pavillard [D. laevis, D. lapidistrigiliformi, D. intermedia] Dinophysis fortii Pavillard [D. laevis, D. lapidistrigiliformi, D. intermedia] Dinophysis fortii Pavillard [D. laevis, D. lapidistrigiliformi, D. intermedia] Dinophysis fortii Pavillard [D. laevis, D. lapidistrigiliformi, D. intermedia] Dinophysis fortii Pavillard [D. laevis, D. lapidistrigiliformi, D. intermedia] Dinophysis fortii Pavillard [D. laevis, D. lapidistrigiliformi, D. intermedia] Dinophysis fortii Pavillard [D. laevis, D. lapidistrigiliformi, D. intermedia] Dinophysis fortii Pavillard [D. laevis, D. lapidistrigiliformi, D. intermedia] Dinophysis fortii Pavillard [D. laevis, D. lapidistrigiliformi, D. intermedia]

Dinophysis hastata Stein [no Phalacroma hastatum Pav., non Ph. hastatum Hensen] Dinophysis hastata Stein [no Phalacroma hastatum Pav., non Ph. hastatum Hensen] Dinophysis hastata Stein [no Phalacroma hastatum Pav., non Ph. hastatum Hensen] Dinophysis hastata Stein [no Phalacroma hastatum Pav., non Ph. hastatum Hensen] Dinophysis hastata Stein [no Phalacroma hastatum Pav., non Ph. hastatum Hensen] Dinophysis hastata Stein [no Phalacroma hastatum Pav., non Ph. hastatum Hensen] Dinophysis hastata Stein [no Phalacroma hastatum Pav., non Ph. hastatum Hensen] Dinophysis hastata Stein [no Phalacroma hastatum Pav., non Ph. hastatum Hensen] Dinophysis hastata Stein [no Phalacroma hastatum Pav., non Ph. hastatum Hensen] Dinophysis hastata Stein [no Phalacroma hastatum Pav., non Ph. hastatum Hensen] Dinophysis hastata Stein [no Phalacroma hastatum Pav., non Ph. hastatum Hensen] Dinophysis hastata Stein [no Phalacroma hastatum Pav., non Ph. hastatum Hensen] Dinophysis hastata Stein [no Phalacroma hastatum Pav., non Ph. hastatum Hensen] Dinophysis hastata Stein [no Phalacroma hastatum Pav., non Ph. hastatum Hensen] Dinophysis hastata Stein [no Phalacroma hastatum Pav., non Ph. hastatum Hensen] Dinophysis hastata Stein [no Phalacroma hastatum Pav., non Ph. hastatum Hensen]

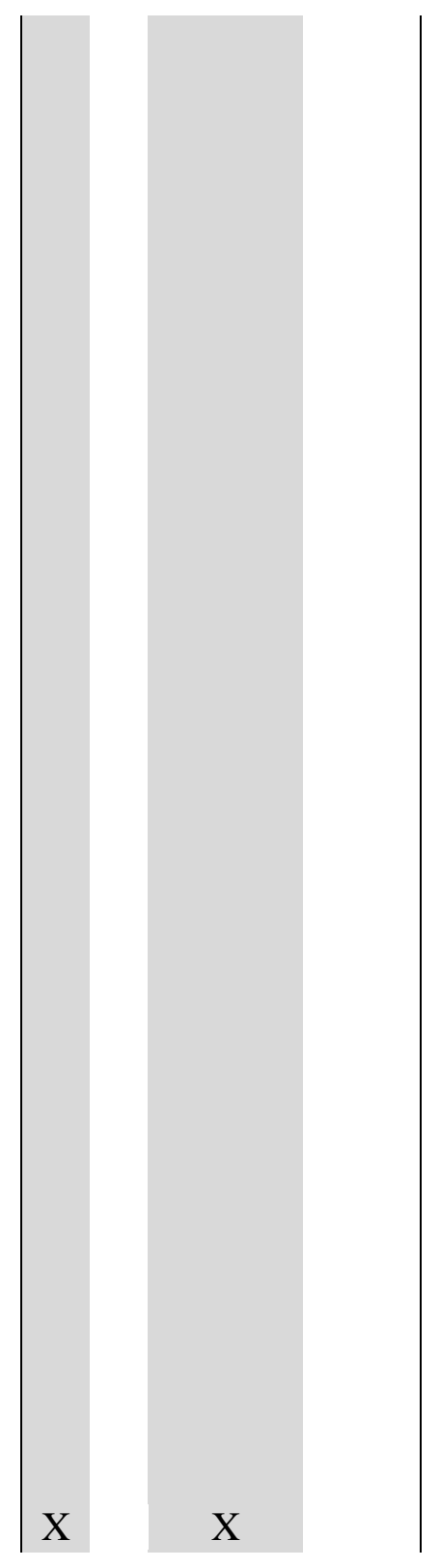


Dinophysis hastata Stein [no Phalacroma hastatum Pav., non Ph. hastatum Hensen] Dinophysis hastata Stein [no Phalacroma hastatum Pav., non Ph. hastatum Hensen] Dinophysis meunieri Schiller [D. cuneiformis, non D. cuneiformis Mangin] Dinophysis meunieri Schiller [D. cuneiformis, non D. cuneiformis Mangin] Dinophysis meunieri Schiller [D. cuneiformis, non D. cuneiformis Mangin] Dinophysis meunieri Schiller [D. cuneiformis, non D. cuneiformis Mangin] Dinophysis meunieri Schiller [D. cuneiformis, non D. cuneiformis Mangin] Dinophysis meunieri Schiller [D. cuneiformis, non D.

cuneiformis Mangin] Dinophysis meunieri Schiller [D. cuneiformis, non D. cuneiformis Mangin] Dinophysis meunieri Schiller [D. cuneiformis, non D. cuneiformis Mangin]

Dinophysis meunieri Schiller [D. cuneiformis, non D. cuneiformis Mangin] Dinophysis meunieri Schiller [D. cuneiformis, non D. cuneiformis Mangin] Dinophysis meunieri Schiller [D. cuneiformis, non D. cuneiformis Mangin] Dinophysis meunieri Schiller [D. cuneiformis, non D. cuneiformis Mangin] Dinophysis meunieri Schiller [D. cuneiformis, non D. cuneiformis Mangin] Dinophysis meunieri Schiller [D. cuneiformis, non D. cuneiformis Mangin] Dinophysis meunieri Schiller [D. cuneiformis, non D. cuneiformis Mangin] Dinophysis meunieri Schiller [D. cuneiformis, non D. cuneiformis Mangin]

Dinophysis meunieri Schiller [D. cuneiformis, non D. cuneiformis Mangin] Dinophysis meunieri Schiller [D. cuneiformis, non D. cuneiformis Mangin]

Dinophysis minuta (Cleve) Balech [Phalacroma minutum] Dinophysis minuta (Cleve) Balech [Phalacroma minutum] Dinophysis minuta (Cleve) Balech [Phalacroma minutum] Dinophysis minuta (Cleve) Balech [Phalacroma minutum] Dinophysis minuta (Cleve) Balech [Phalacroma minutum] Dinophysis minuta (Cleve) Balech [Phalacroma minutum] Dinophysis minuta (Cleve) Balech [Phalacroma minutum] Dinophysis minuta (Cleve) Balech [Phalacroma minutum] Dinophysis minuta (Cleve) Balech [Phalacroma minutum] Dinophysis minuta (Cleve) Balech [Phalacroma minutum] Dinophysis minuta (Cleve) Balech [Phalacroma minutum] Dinophysis minuta (Cleve) Balech [Phalacroma minutum] Dinophysis minuta (Cleve) Balech [Phalacroma minutum] Dinophysis minuta (Cleve) Balech [Phalacroma minutum] Dinophysis minuta (Cleve) Balech [Phalacroma minutum] Dinophysis minuta (Cleve) Balech [Phalacroma minutum] Dinophysis minuta (Cleve) Balech [Phalacroma minutum] Dinophysis minuta (Cleve) Balech [Phalacroma minutum]

Dinophysis norvegica Claparède \& Lachmann [ D. debilior] Dinophysis norvegica

Claparède \& Lachmann [ D. debilior] Dinophysis norvegica Claparède \& Lachmann [

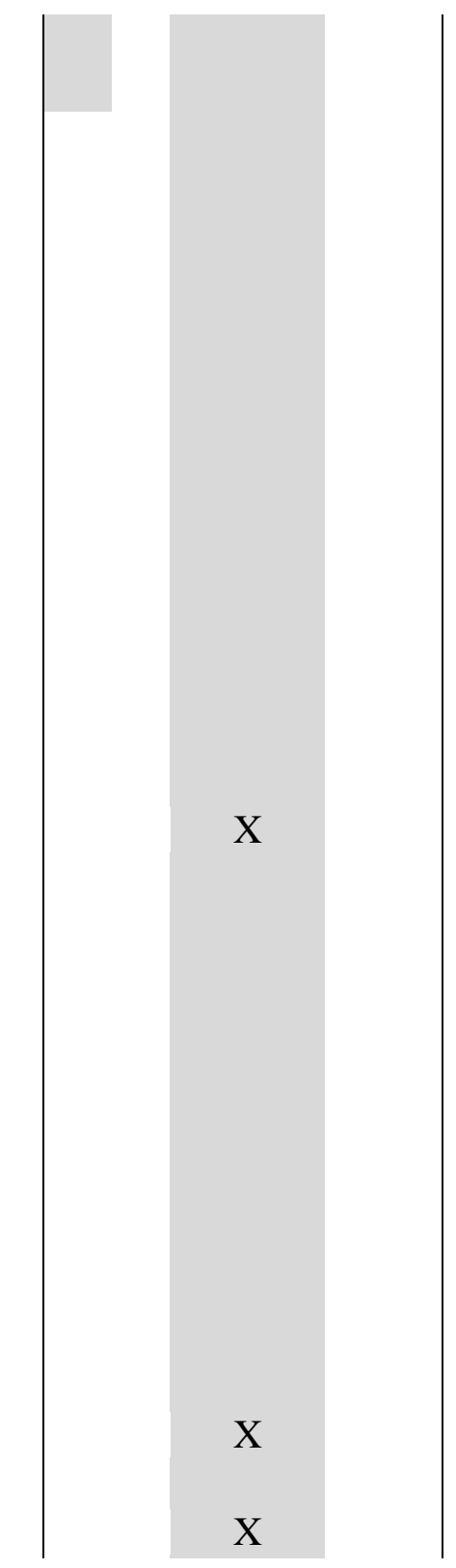


D. debilior] Dinophysis norvegica Claparède \& Lachmann [ D. debilior] Dinophysis norvegica Claparède \& Lachmann [ D. debilior] Dinophysis norvegica Claparède \& Lachmann [ D. debilior] Dinophysis norvegica Claparède \& Lachmann [ D. debilior] Dinophysis norvegica Claparède \& Lachmann [ D. debilior] Dinophysis norvegica Claparède \& Lachmann [ D. debilior] Dinophysis norvegica Claparède \& Lachmann [ D. debilior] Dinophysis norvegica Claparède \& Lachmann [ D. debilior] Dinophysis norvegica Claparède \& Lachmann [ D. debilior] Dinophysis norvegica Claparède \& Lachmann [ D. debilior] Dinophysis norvegica Claparède \& Lachmann [ D. debilior] Dinophysis norvegica Claparède \& Lachmann [ D. debilior] Dinophysis norvegica Claparède \& Lachmann [ D. debilior] Dinophysis norvegica Claparède \& Lachmann [ D. debilior] Dinophysis norvegica Claparède \& Lachmann [ D. debilior]

Dinophysis oviformis (possible small cell of D. rotundata)Dinophysis oviformis (possible small cell of D. rotundata)Dinophysis oviformis (possible small cell of D. rotundata )Dinophysis oviformis (possible small cell of D. rotundata)Dinophysis oviformis (possible small cell of D. rotundata)Dinophysis oviformis (possible small cell of D. rotundata)Dinophysis oviformis (possible small cell of D. rotundata)Dinophysis oviformis (possible small cell of D. rotundata)Dinophysis oviformis (possible small cell of D. rotundata)Dinophysis oviformis (possible small cell of D. rotundata)Dinophysis oviformis (possible small cell of D. rotundata)Dinophysis oviformis (possible small cell of D. rotundata)Dinophysis oviformis (possible small cell of D. rotundata)Dinophysis oviformis (possible small cell of D. rotundata)Dinophysis oviformis (possible small cell of D. rotundata)Dinophysis oviformis (possible small cell of D. rotundata)Dinophysis oviformis (possible small cell of D. rotundata)Dinophysis oviformis (possible small cell of D. rotundata)

Dinophysis ovum Schütt [ D. brevisulcus pro parte, non Phalacroma ovum Schütt] Dinophysis ovum Schütt [ D. brevisulcus pro parte, non Phalacroma ovum Schütt] Dinophysis ovum Schütt [ D. brevisulcus pro parte, non Phalacroma ovum Schütt] Dinophysis ovum Schütt [ D. brevisulcus pro parte, non Phalacroma ovum Schütt] Dinophysis ovum Schütt [ D. brevisulcus pro parte, non Phalacroma ovum Schütt] Dinophysis ovum Schütt [ D. brevisulcus pro parte, non Phalacroma ovum Schütt] Dinophysis ovum Schütt [ D. brevisulcus pro parte, non Phalacroma ovum Schütt] Dinophysis ovum Schütt [ D. brevisulcus pro parte, non Phalacroma ovum Schütt] Dinophysis ovum Schütt [ D. brevisulcus pro parte, non Phalacroma ovum Schütt]

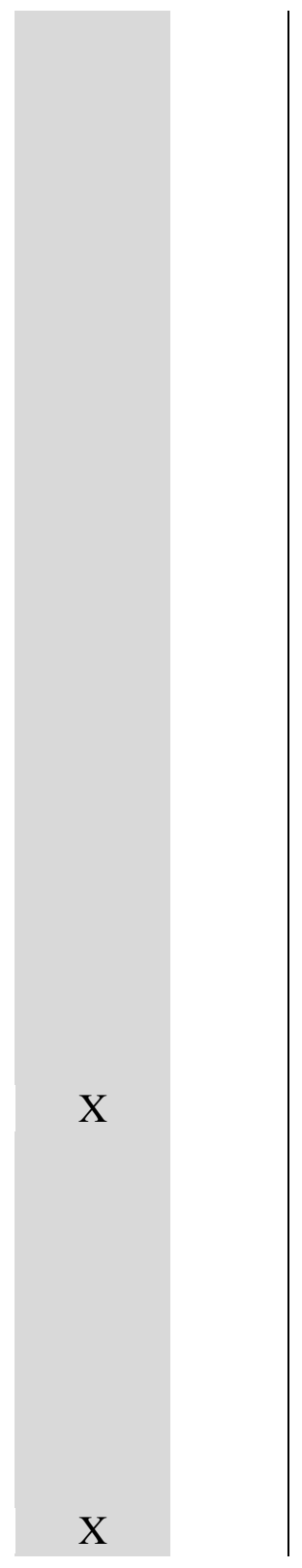


Dinophysis ovum Schütt [ D. brevisulcus pro parte, non Phalacroma ovum Schütt] Dinophysis ovum Schütt [ D. brevisulcus pro parte, non Phalacroma ovum Schütt] Dinophysis ovum Schütt [ D. brevisulcus pro parte, non Phalacroma ovum Schütt] Dinophysis ovum Schütt [ D. brevisulcus pro parte, non Phalacroma ovum Schütt] Dinophysis ovum Schütt [ D. brevisulcus pro parte, non Phalacroma ovum Schütt] Dinophysis ovum Schütt [ D. brevisulcus pro parte, non Phalacroma ovum Schütt] Dinophysis ovum Schütt [ D. brevisulcus pro parte, non Phalacroma ovum Schütt] Dinophysis ovum Schütt [ D. brevisulcus pro parte, non Phalacroma ovum Schütt] Dinophysis ovum Schütt [ D. brevisulcus pro parte, non Phalacroma ovum Schütt] Dinophysis parva Schiller [ D. infundibula] Dinophysis parva Schiller [D. infundibula] Dinophysis parva Schiller [ D. infundibula] Dinophysis parva Schiller [ D. infundibula] Dinophysis parva Schiller [ D. infundibula] Dinophysis parva Schiller [ D. infundibula] Dinophysis parva Schiller [D. infundibula] Dinophysis parva Schiller [D. infundibula] Dinophysis parva Schiller [ D. infundibula] Dinophysis parva Schiller [D. infundibula] Dinophysis parva Schiller [ D. infundibula] Dinophysis parva Schiller [ D. infundibula] Dinophysis parva Schiller [ D. infundibula] Dinophysis parva Schiller [ D. infundibula] Dinophysis parva Schiller [ D. infundibula] Dinophysis parva Schiller [ D. infundibula] Dinophysis parva Schiller [ D. infundibula] Dinophysis parva Schiller [ D. infundibula] Dinophysis punctata Jørgensen [non D. punctata Balech] Dinophysis punctata Jørgensen [non D. punctata Balech] Dinophysis punctata Jørgensen [non D. punctata Balech] Dinophysis punctata Jørgensen [non D. punctata Balech] Dinophysis punctata Jørgensen [non D. punctata Balech] Dinophysis punctata Jørgensen [non D. punctata Balech] Dinophysis punctata Jørgensen [non D. punctata Balech] Dinophysis punctata Jørgensen [non D. punctata Balech] Dinophysis punctata Jørgensen [non D. punctata Balech] Dinophysis punctata Jørgensen [non D. punctata Balech] Dinophysis punctata Jørgensen [non D. punctata Balech] Dinophysis punctata Jørgensen [non D. punctata Balech] Dinophysis punctata Jørgensen [non D. punctata Balech] Dinophysis punctata Jørgensen [non D. punctata Balech] Dinophysis punctata Jørgensen [non D. punctata Balech] Dinophysis punctata Jørgensen [non D. punctata Balech] Dinophysis punctata Jørgensen [non D. punctata Balech] Dinophysis punctata Jørgensen [non D. punctata Balech]

Dinophysis sacculus Stein [ D. acuminata f. reniformi, D. reniformis, D. pavillardii]Dinophysis sacculus Stein [ D. acuminata f. reniformi, D. reniformis, $D$.

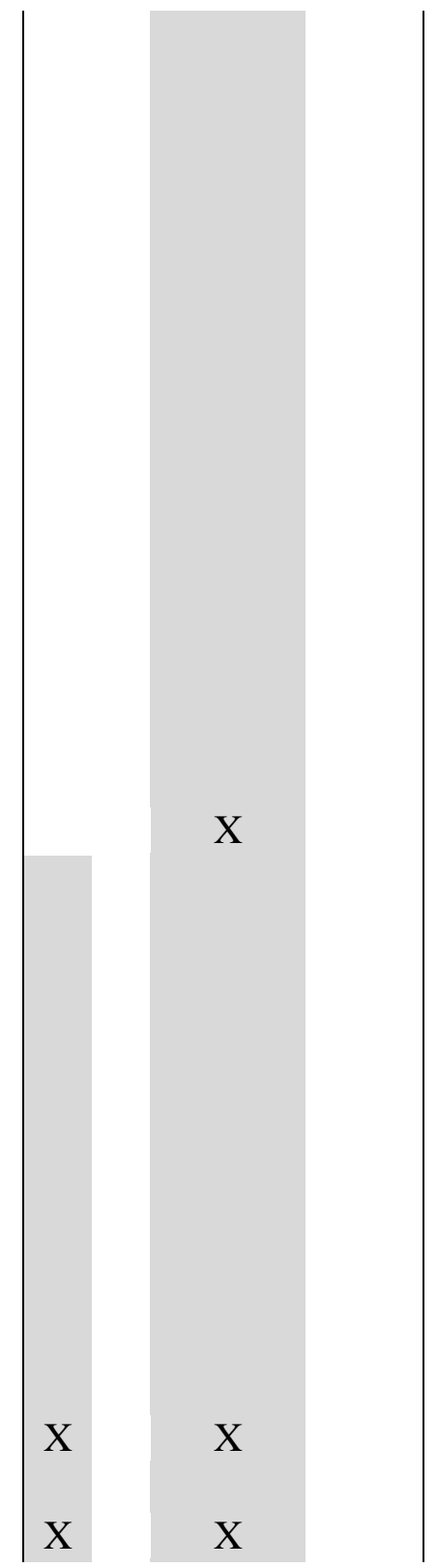


pavillardii]Dinophysis sacculus Stein [ D. acuminata f. reniformi, D. reniformis, D. pavillardii]Dinophysis sacculus Stein [ D. acuminata f. reniformi, D. reniformis, $D$. pavillardii]Dinophysis sacculus Stein [ D. acuminata f. reniformi, D. reniformis, $D$. pavillardii]Dinophysis sacculus Stein [D. acuminata f. reniformi, D. reniformis, D. pavillardii]Dinophysis sacculus Stein [D. acuminata f. reniformi, D. reniformis, $D$. pavillardii]Dinophysis sacculus Stein [D. acuminata f. reniformi, D. reniformis, $D$. pavillardii]Dinophysis sacculus Stein [ D. acuminata f. reniformi, D. reniformis, $D$. pavillardii]Dinophysis sacculus Stein [ D. acuminata f. reniformi, D. reniformis, $D$. pavillardii]Dinophysis sacculus Stein [ D. acuminata f. reniformi, D. reniformis, $D$. pavillardii]Dinophysis sacculus Stein [ D. acuminata f. reniformi, D. reniformis, $D$. pavillardii]Dinophysis sacculus Stein [ D. acuminata f. reniformi, D. reniformis, D. pavillardii]Dinophysis sacculus Stein [ D. acuminata f. reniformi, D. reniformis, $D$. pavillardii]Dinophysis sacculus Stein [D. acuminata f. reniformi, D. reniformis, $D$. pavillardii]Dinophysis sacculus Stein [ D. acuminata f. reniformi, D. reniformis, $D$. pavillardii]Dinophysis sacculus Stein [D. acuminata f. reniformi, D. reniformis, $D$. pavillardii]Dinophysis sacculus Stein [D. acuminata f. reniformi, D. reniformis, $D$. pavillardii]

Dinophysis ventrecta Schiller [ Dinophysis phaseolus]Dinophysis ventrecta Schiller [ Dinophysis phaseolus]Dinophysis ventrecta Schiller [ Dinophysis phaseolus]Dinophysis ventrecta Schiller [ Dinophysis phaseolus]Dinophysis ventrecta Schiller [ Dinophysis phaseolus]Dinophysis ventrecta Schiller [ Dinophysis phaseolus]Dinophysis ventrecta Schiller [ Dinophysis phaseolus]Dinophysis ventrecta Schiller [ Dinophysis phaseolus]Dinophysis ventrecta Schiller [ Dinophysis phaseolus]Dinophysis ventrecta Schiller [ Dinophysis phaseolus]Dinophysis ventrecta Schiller [ Dinophysis

phaseolus]Dinophysis ventrecta Schiller [ Dinophysis phaseolus]Dinophysis ventrecta Schiller [ Dinophysis phaseolus]Dinophysis ventrecta Schiller [ Dinophysis phaseolus]Dinophysis ventrecta Schiller [ Dinophysis phaseolus]Dinophysis ventrecta Schiller [ Dinophysis phaseolus]Dinophysis ventrecta Schiller [ Dinophysis phaseolus]Dinophysis ventrecta Schiller [ Dinophysis phaseolus]

Dinophysis schilleri Sournia [Phalacroma sphaeroideum] Dinophysis schilleri Sournia [Phalacroma sphaeroideum] Dinophysis schilleri Sournia [Phalacroma sphaeroideum] Dinophysis schilleri Sournia [Phalacroma sphaeroideum] Dinophysis schilleri Sournia [Phalacroma sphaeroideum] Dinophysis schilleri Sournia [Phalacroma sphaeroideum]




Dinophysis schilleri Sournia [Phalacroma sphaeroideum] Dinophysis schilleri Sournia [Phalacroma sphaeroideum] Dinophysis schilleri Sournia [Phalacroma sphaeroideum] Dinophysis schilleri Sournia [Phalacroma sphaeroideum] Dinophysis schilleri Sournia [Phalacroma sphaeroideum] Dinophysis schilleri Sournia [Phalacroma sphaeroideum] Dinophysis schilleri Sournia [Phalacroma sphaeroideum] Dinophysis schilleri Sournia [Phalacroma sphaeroideum] Dinophysis schilleri Sournia [Phalacroma sphaeroideum] Dinophysis schilleri Sournia [Phalacroma sphaeroideum] Dinophysis schilleri Sournia [Phalacroma sphaeroideum] Dinophysis schilleri Sournia [Phalacroma sphaeroideum] Dinophysis schuettii [D. uracantha, non D. uracantha Stein] Dinophysis schuettii [D. uracantha, non D. uracantha Stein] Dinophysis schuettii [D. uracantha, non D. uracantha Stein] Dinophysis schuettii [D. uracantha, non D. uracantha Stein] Dinophysis schuettii [D. uracantha, non D. uracantha Stein] Dinophysis schuettii [D. uracantha, non D. uracantha Stein] Dinophysis schuettii [D. uracantha, non D. uracantha Stein] Dinophysis schuettii [D. uracantha, non D. uracantha Stein] Dinophysis schuettii [D. uracantha, non D. uracantha Stein] Dinophysis schuettii [D. uracantha, non D. uracantha Stein] Dinophysis schuettii [D. uracantha, non D. uracantha Stein] Dinophysis schuettii [D. uracantha, non D. uracantha Stein] Dinophysis schuettii [D. uracantha, non D. uracantha Stein] Dinophysis schuettii [D. uracantha, non D. uracantha Stein] Dinophysis schuettii [D. uracantha, non D. uracantha Stein] Dinophysis schuettii [D. uracantha, non D. uracantha Stein] Dinophysis schuettii [D. uracantha, non D. uracantha Stein] Dinophysis schuettii [D. uracantha, non D. uracantha Stein] Dinophysis similis Kofoid \& Skogsberg [D. sphaerica, D. simple non Böhm, D. tai]Dinophysis similis Kofoid \& Skogsberg [D. sphaerica, D. simple non Böhm, D. tai]Dinophysis similis Kofoid \& Skogsberg [D. sphaerica, D. simple non Böhm, D. tai]Dinophysis similis Kofoid \& Skogsberg [D. sphaerica, D. simple non Böhm, D. tai]Dinophysis similis Kofoid \& Skogsberg [D. sphaerica, D. simple non Böhm, D. tai]Dinophysis similis Kofoid \& Skogsberg [D. sphaerica, D. simple non Böhm, D. tai]Dinophysis similis Kofoid \& Skogsberg [D. sphaerica, D. simple non Böhm, D. tai]Dinophysis similis Kofoid \& Skogsberg [D. sphaerica, D. simple non Böhm, D. tai]Dinophysis similis Kofoid \& Skogsberg [D. sphaerica, D. simple non Böhm, D. tai]Dinophysis similis Kofoid \& Skogsberg [D. sphaerica, D. simple non Böhm, D. tai]Dinophysis similis Kofoid \& Skogsberg [D. sphaerica, D. simple non Böhm, D. tai]Dinophysis similis Kofoid \& Skogsberg [D. sphaerica, D. simple non Böhm, D.

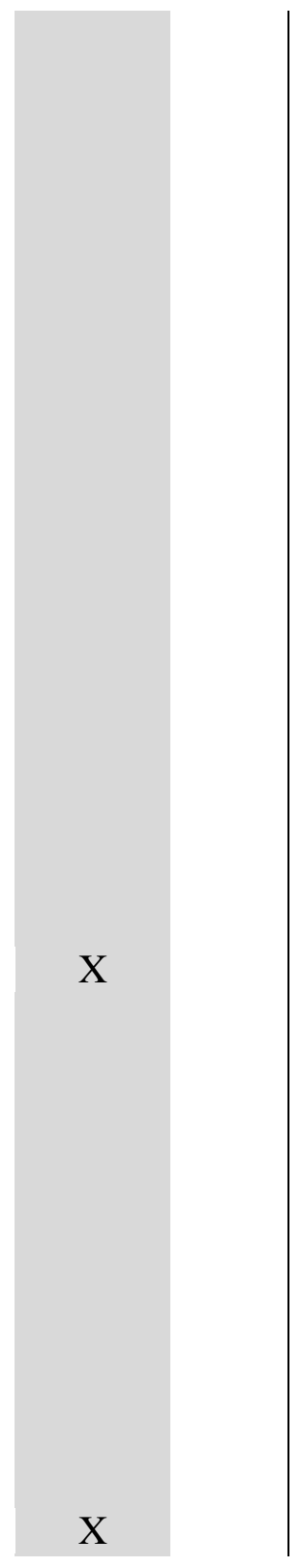


tai]Dinophysis similis Kofoid \& Skogsberg [D. sphaerica, D. simple non Böhm, D. tai]Dinophysis similis Kofoid \& Skogsberg [D. sphaerica, D. simple non Böhm, D. tai]Dinophysis similis Kofoid \& Skogsberg [D. sphaerica, D. simple non Böhm, D. tai]Dinophysis similis Kofoid \& Skogsberg [D. sphaerica, D. simple non Böhm, D. tai]Dinophysis similis Kofoid \& Skogsberg [D. sphaerica, D. simple non Böhm, D. tai]Dinophysis similis Kofoid \& Skogsberg [D. sphaerica, D. simple non Böhm, D. tai] Dinophysis sphaerica Stein [D. vanhoffenii] Dinophysis sphaerica Stein [D. vanhoffenii] Dinophysis sphaerica Stein [D. vanhoffenii] Dinophysis sphaerica Stein [D. vanhoffenii] Dinophysis sphaerica Stein [D. vanhoffenii] Dinophysis sphaerica Stein [D. vanhoffenii] Dinophysis sphaerica Stein [D. vanhoffenii] Dinophysis sphaerica Stein [D. vanhoffenii] Dinophysis sphaerica Stein [D. vanhoffenii] Dinophysis sphaerica Stein [D. vanhoffenii] Dinophysis sphaerica Stein [D. vanhoffenii] Dinophysis sphaerica Stein [D. vanhoffenii] Dinophysis sphaerica Stein [D. vanhoffenii] Dinophysis sphaerica Stein [D. vanhoffenii] Dinophysis sphaerica Stein [D. vanhoffenii] Dinophysis sphaerica Stein [D. vanhoffenii] Dinophysis sphaerica Stein [D. vanhoffenii] Dinophysis sphaerica Stein [D. vanhoffenii] Dinophysis tripos Gourret [ D. caudata var. tripos] Dinophysis tripos Gourret [ D. caudata var. tripos] Dinophysis tripos Gourret [ D. caudata var. tripos] Dinophysis tripos Gourret [ D. caudata var. tripos] Dinophysis tripos Gourret [ D. caudata var. tripos] Dinophysis tripos Gourret [ D. caudata var. tripos] Dinophysis tripos Gourret [ D. caudata var. tripos] Dinophysis tripos Gourret [D. caudata var. tripos] Dinophysis tripos Gourret [ D. caudata var. tripos] Dinophysis tripos Gourret [ D. caudata var. tripos] Dinophysis tripos Gourret [ D. caudata var. tripos] Dinophysis tripos Gourret [ D. caudata var. tripos] Dinophysis tripos Gourret [ D. caudata var. tripos] Dinophysis tripos Gourret [ D. caudata var. tripos] Dinophysis tripos Gourret [ D. caudata var. tripos] Dinophysis tripos Gourret [ D. caudata var. tripos] Dinophysis tripos Gourret [ D. caudata var. tripos] Dinophysis tripos Gourret [ D. caudata var. tripos] Diplopelta bomba Stein ex Jørgensen [Diplopsalis lenticula etc.] Diplopelta bomba Stein ex Jørgensen [Diplopsalis lenticula etc.] Diplopelta bomba Stein ex Jørgensen [Diplopsalis lenticula etc.] Diplopelta bomba Stein ex Jørgensen [Diplopsalis lenticula etc.] Diplopelta bomba Stein ex Jørgensen [Diplopsalis lenticula etc.] Diplopelta bomba Stein ex Jørgensen [Diplopsalis lenticula etc.] Diplopelta bomba Stein ex Jørgensen [Diplopsalis lenticula etc.] Diplopelta bomba Stein ex Jørgensen [Diplopsalis lenticula

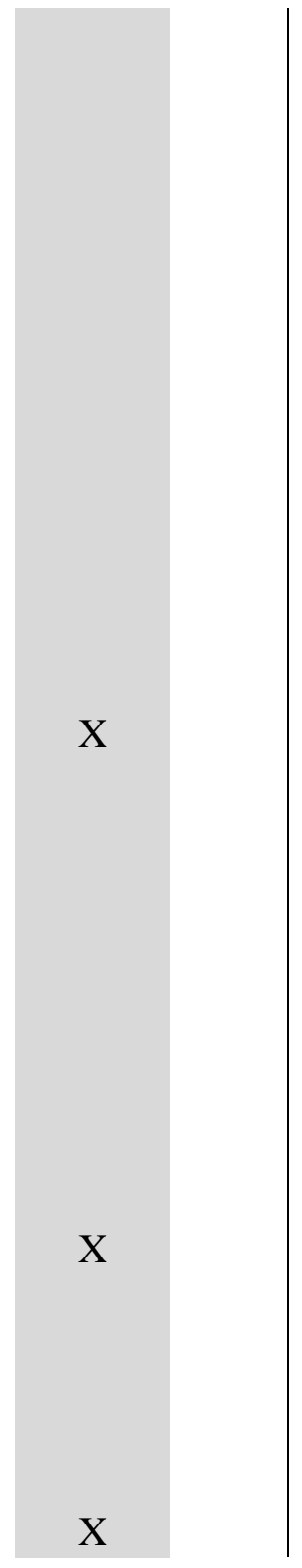


|etc.] Diplopelta bomba Stein ex Jørgensen [Diplopsalis lenticula etc.] Diplopelta bomba Stein ex Jørgensen [Diplopsalis lenticula etc.] Diplopelta bomba Stein ex Jørgensen [Diplopsalis lenticula etc.] Diplopelta bomba Stein ex Jørgensen [Diplopsalis lenticula etc.] Diplopelta bomba Stein ex Jørgensen [Diplopsalis lenticula etc.] Diplopelta bomba Stein ex Jørgensen [Diplopsalis lenticula etc.] Diplopelta bomba Stein ex Jørgensen [Diplopsalis lenticula etc.] Diplopelta bomba Stein ex Jørgensen [Diplopsalis lenticula etc.] Diplopelta bomba Stein ex Jørgensen [Diplopsalis lenticula etc.] Diplopelta bomba Stein ex Jørgensen [Diplopsalis lenticula etc.]

Diplopsalis acuta (Apstein) Entz [Peridinium latum]Diplopsalis acuta (Apstein) Entz

[Peridinium latum]Diplopsalis acuta (Apstein) Entz /Peridinium latum/Diplopsalis acuta (Apstein) Entz [Peridinium latum/Diplopsalis acuta (Apstein) Entz /Peridinium latum/Diplopsalis acuta (Apstein) Entz /Peridinium latum/Diplopsalis acuta (Apstein) Entz /Peridinium latum/Diplopsalis acuta (Apstein) Entz /Peridinium latum/Diplopsalis acuta (Apstein) Entz /Peridinium latum/Diplopsalis acuta (Apstein) Entz /Peridinium latum/Diplopsalis acuta (Apstein) Entz /Peridinium latum/Diplopsalis acuta (Apstein) Entz /Peridinium latum/Diplopsalis acuta (Apstein) Entz /Peridinium latum/Diplopsalis acuta (Apstein) Entz [Peridinium latum/Diplopsalis acuta (Apstein) Entz /Peridinium latum/Diplopsalis acuta (Apstein) Entz /Peridinium latum/Diplopsalis acuta (Apstein) Entz [Peridinium latum]

Diplopsalis caspica Ostenfeld 1901Diplopsalis caspica Ostenfeld 1901Diplopsalis caspica Ostenfeld 1901Diplopsalis caspica Ostenfeld 1901Diplopsalis caspica Ostenfeld 1901Diplopsalis caspica Ostenfeld 1901Diplopsalis caspica Ostenfeld 1901Diplopsalis caspica Ostenfeld 1901Diplopsalis caspica Ostenfeld 1901Diplopsalis caspica Ostenfeld 1901Diplopsalis caspica Ostenfeld 1901Diplopsalis caspica Ostenfeld 1901Diplopsalis caspica Ostenfeld 1901Diplopsalis caspica Ostenfeld 1901Diplopsalis caspica Ostenfeld 1901Diplopsalis caspica Ostenfeld 1901Diplopsalis caspica Ostenfeld 1901

Diplopsalis lenticula Bergh [Glenodinium lenticula,Dissodium lenticulum Diplopsalis lenticula Bergh [Glenodinium lenticula,Dissodium lenticulum Diplopsalis lenticula Bergh [Glenodinium lenticula,Dissodium lenticulum Diplopsalis lenticula Bergh [Glenodinium lenticula,Dissodium lenticulum Diplopsalis lenticula Bergh [Glenodinium lenticula,Dissodium lenticulum Diplopsalis lenticula Bergh [Glenodinium lenticula,Dissodium lenticulum Diplopsalis lenticula Bergh [Glenodinium lenticula,Dissodium lenticulum Diplopsalis lenticula Bergh

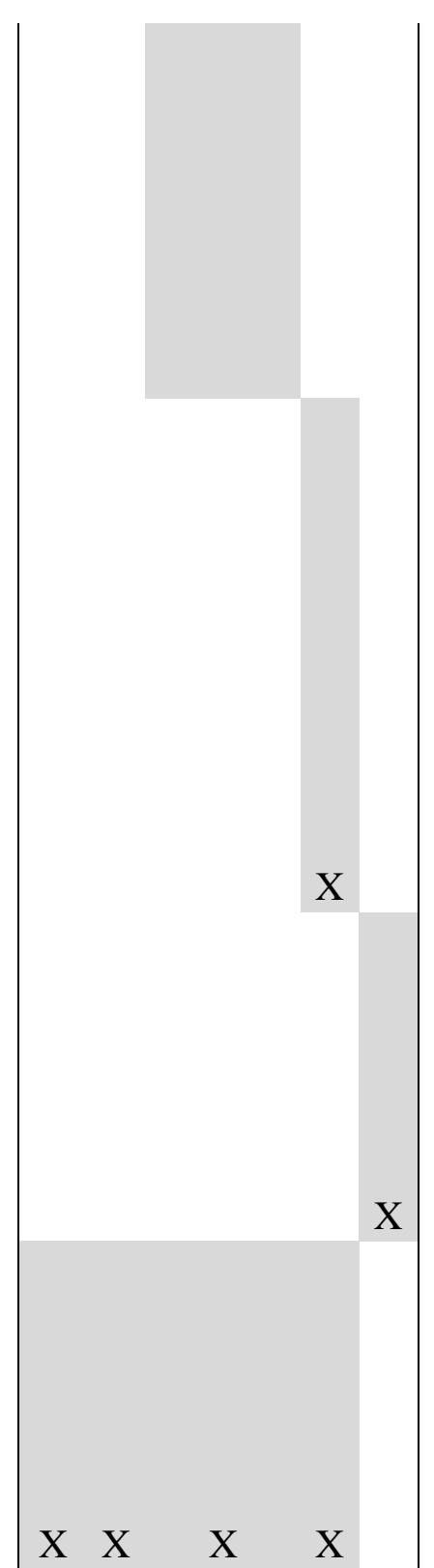


[Glenodinium lenticula,Dissodium lenticulum Diplopsalis lenticula Bergh [Glenodinium lenticula,Dissodium lenticulum Diplopsalis lenticula Bergh [Glenodinium lenticula,Dissodium lenticulum Diplopsalis lenticula Bergh [Glenodinium lenticula,Dissodium lenticulum Diplopsalis lenticula Bergh [Glenodinium lenticula,Dissodium lenticulum Diplopsalis lenticula Bergh [Glenodinium lenticula,Dissodium lenticulum Diplopsalis lenticula Bergh [Glenodinium lenticula,Dissodium lenticulum Diplopsalis lenticula Bergh [Glenodinium lenticula,Dissodium lenticulum Diplopsalis lenticula Bergh [Glenodinium lenticula,Dissodium lenticulum Diplopsalis lenticula Bergh [Glenodinium lenticula,Dissodium lenticulum

Diplopsalopsis orbicularis (Paulsen) Meunier [Peridinium orbiculare] Diplopsalopsis orbicularis (Paulsen) Meunier [Peridinium orbiculare] Diplopsalopsis orbicularis (Paulsen) Meunier [Peridinium orbiculare] Diplopsalopsis orbicularis (Paulsen) Meunier [Peridinium orbiculare] Diplopsalopsis orbicularis (Paulsen) Meunier [Peridinium orbiculare] Diplopsalopsis orbicularis (Paulsen) Meunier [Peridinium orbiculare] Diplopsalopsis orbicularis (Paulsen) Meunier [Peridinium orbiculare] Diplopsalopsis orbicularis (Paulsen) Meunier [Peridinium orbiculare] Diplopsalopsis orbicularis (Paulsen) Meunier [Peridinium orbiculare] Diplopsalopsis orbicularis (Paulsen) Meunier [Peridinium orbiculare] Diplopsalopsis orbicularis (Paulsen) Meunier [Peridinium orbiculare] Diplopsalopsis orbicularis (Paulsen) Meunier [Peridinium orbiculare] Diplopsalopsis orbicularis (Paulsen) Meunier [Peridinium orbiculare] Diplopsalopsis orbicularis (Paulsen) Meunier [Peridinium orbiculare] Diplopsalopsis orbicularis (Paulsen) Meunier [Peridinium orbiculare] Diplopsalopsis orbicularis (Paulsen) Meunier [Peridinium orbiculare] Diplopsalopsis orbicularis (Paulsen) Meunier [Peridinium orbiculare]

Glenodinium behningii (Lindemann) Kisselew [Diplopsalis behningii]Glenodinium behningii (Lindemann) Kisselew [Diplopsalis behningii]Glenodinium behningii (Lindemann) Kisselew [Diplopsalis behningii]Glenodinium behningii (Lindemann) Kisselew [Diplopsalis behningii]Glenodinium behningii (Lindemann) Kisselew [Diplopsalis behningii]Glenodinium behningii (Lindemann) Kisselew [Diplopsalis behningii]Glenodinium behningii (Lindemann) Kisselew [Diplopsalis behningii]Glenodinium behningii (Lindemann) Kisselew [Diplopsalis behningii]Glenodinium behningii (Lindemann) Kisselew [Diplopsalis

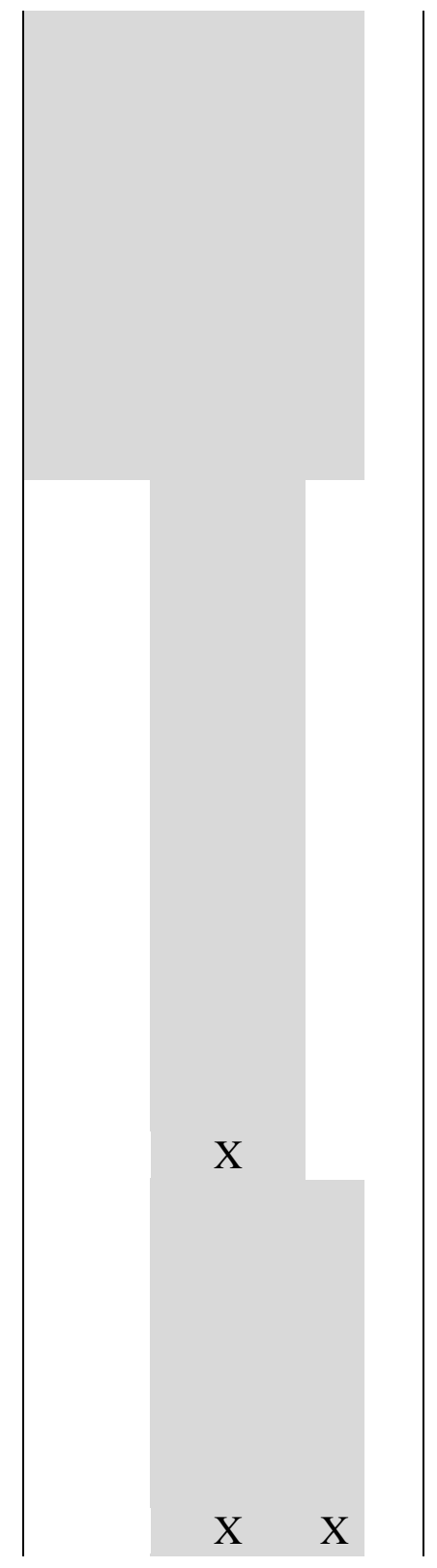


behningii]Glenodinium behningii (Lindemann) Kisselew [Diplopsalis behningii]Glenodinium behningii (Lindemann) Kisselew [Diplopsalis behningii]Glenodinium behningii (Lindemann) Kisselew [Diplopsalis behningii]Glenodinium behningii (Lindemann) Kisselew [Diplopsalis behningii]Glenodinium behningii (Lindemann) Kisselew [Diplopsalis behningii]Glenodinium behningii (Lindemann) Kisselew [Diplopsalis behningii]Glenodinium behningii (Lindemann) Kisselew [Diplopsalis behningii]Glenodinium behningii (Lindemann) Kisselew [Diplopsalis behningii]

Glenodinium caspicum (Ostenfeld) Schiller Glenodinium caspicum (Ostenfeld) Schiller Glenodinium caspicum (Ostenfeld) Schiller Glenodinium caspicum (Ostenfeld) Schiller Glenodinium caspicum (Ostenfeld) Schiller Glenodinium caspicum (Ostenfeld) Schiller Glenodinium caspicum (Ostenfeld) Schiller Glenodinium caspicum (Ostenfeld) Schiller Glenodinium caspicum (Ostenfeld) Schiller Glenodinium caspicum (Ostenfeld) Schiller Glenodinium caspicum (Ostenfeld) Schiller Glenodinium caspicum (Ostenfeld) Schiller Glenodinium caspicum (Ostenfeld) Schiller Glenodinium caspicum (Ostenfeld) Schiller Glenodinium caspicum (Ostenfeld) Schiller Glenodinium caspicum (Ostenfeld) Schiller Glenodinium caspicum (Ostenfeld) Schiller

Glenodinium danicum PaulsenGlenodinium danicum PaulsenGlenodinium danicum PaulsenGlenodinium danicum PaulsenGlenodinium danicum PaulsenGlenodinium danicum PaulsenGlenodinium danicum PaulsenGlenodinium danicum

PaulsenGlenodinium danicum PaulsenGlenodinium danicum PaulsenGlenodinium danicum PaulsenGlenodinium danicum PaulsenGlenodinium danicum

PaulsenGlenodinium danicum PaulsenGlenodinium danicum PaulsenGlenodinium danicum PaulsenGlenodinium danicum Paulsen

Glenodinium inflatum Meunier Glenodinium inflatum Meunier Glenodinium inflatum Meunier Glenodinium inflatum Meunier Glenodinium inflatum Meunier Glenodinium inflatum Meunier Glenodinium inflatum Meunier Glenodinium inflatum Meunier Glenodinium inflatum Meunier Glenodinium inflatum Meunier Glenodinium inflatum Meunier Glenodinium inflatum Meunier Glenodinium inflatum Meunier Glenodinium inflatum Meunier Glenodinium inflatum Meunier Glenodinium inflatum Meunier Glenodinium inflatum Meunier

Glenodinium lenticula Pouchet Glenodinium lenticula Pouchet Glenodinium lenticula Pouchet Glenodinium lenticula Pouchet Glenodinium lenticula Pouchet Glenodinium

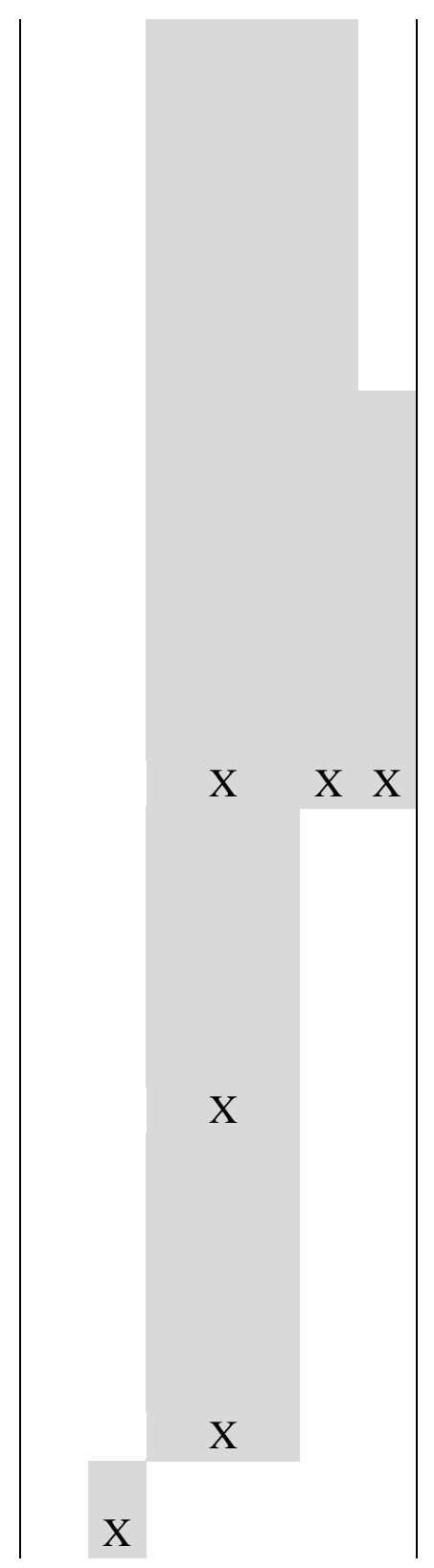


lenticula Pouchet Glenodinium lenticula Pouchet Glenodinium lenticula Pouchet Glenodinium lenticula Pouchet Glenodinium lenticula Pouchet Glenodinium lenticula Pouchet Glenodinium lenticula Pouchet Glenodinium lenticula Pouchet Glenodinium lenticula Pouchet Glenodinium lenticula Pouchet Glenodinium lenticula Pouchet Glenodinium lenticula Pouchet

Glenodinium lenticula (Berg) Shillerf. lenticula Glenodinium lenticula (Berg) Shillerf. lenticula Glenodinium lenticula (Berg) Shiller f. lenticula Glenodinium lenticula (Berg) Shiller f. lenticula Glenodinium lenticula (Berg) Shiller f. lenticula Glenodinium lenticula (Berg) Shiller f. lenticula Glenodinium lenticula (Berg) Shiller f. lenticula Glenodinium lenticula (Berg) Shillerf. lenticula Glenodinium lenticula (Berg) Shillerf. lenticula Glenodinium lenticula (Berg) Shillerf. lenticula Glenodinium lenticula (Berg) Shillerf. lenticula Glenodinium lenticula (Berg) Shillerf. lenticula Glenodinium lenticula (Berg) Shiller f. lenticula Glenodinium lenticula (Berg) Shiller f. lenticula Glenodinium lenticula (Berg) Shiller f. lenticula Glenodinium lenticula (Berg) Shiller f. lenticula Glenodinium lenticula (Berg) Shillerf. lenticula Glenodinium lenticulata (Mangin) Schiller v.asymmetrica Glenodinium lenticulata (Mangin) Schiller v.asymmetrica Glenodinium lenticulata (Mangin) Schiller v.asymmetrica Glenodinium lenticulata (Mangin) Schiller v.asymmetrica Glenodinium lenticulata (Mangin) Schiller v.asymmetrica Glenodinium lenticulata (Mangin) Schiller v.asymmetrica Glenodinium lenticulata (Mangin) Schiller v.asymmetrica Glenodinium lenticulata (Mangin) Schiller v.asymmetrica Glenodinium lenticulata (Mangin) Schiller v.asymmetrica Glenodinium lenticulata (Mangin) Schiller v.asymmetrica Glenodinium lenticulata (Mangin) Schiller v.asymmetrica Glenodinium lenticulata (Mangin) Schiller v.asymmetrica Glenodinium lenticulata (Mangin) Schiller v.asymmetrica Glenodinium lenticulata (Mangin) Schiller v.asymmetrica Glenodinium lenticulata (Mangin) Schiller v.asymmetrica Glenodinium lenticulata (Mangin) Schiller v.asymmetrica Glenodinium lenticulata (Mangin) Schiller v.asymmetrica

Glenodinium obliquum Pouchet Glenodinium obliquum Pouchet Glenodinium obliquum Pouchet Glenodinium obliquum Pouchet Glenodinium obliquum Pouchet Glenodinium obliquum Pouchet Glenodinium obliquum Pouchet Glenodinium obliquum Pouchet Glenodinium obliquum Pouchet Glenodinium obliquum Pouchet Glenodinium obliquum Pouchet Glenodinium obliquum Pouchet Glenodinium obliquum Pouchet Glenodinium obliquum Pouchet Glenodinium obliquum Pouchet Glenodinium obliquum Pouchet 
Glenodinium obliquum Pouchet

Glenodinium paululum Lindemann Glenodinium paululum Lindemann Glenodinium paululum Lindemann Glenodinium paululum Lindemann Glenodinium paululum Lindemann Glenodinium paululum Lindemann Glenodinium paululum Lindemann Glenodinium paululum Lindemann Glenodinium paululum Lindemann Glenodinium paululum Lindemann Glenodinium paululum Lindemann Glenodinium paululum Lindemann Glenodinium paululum Lindemann Glenodinium paululum Lindemann Glenodinium paululum Lindemann Glenodinium paululum Lindemann Glenodinium paululum Lindemann

Glenodinium pilula (Ostenfeld) Schiller Glenodinium pilula (Ostenfeld) Schiller Glenodinium pilula (Ostenfeld) Schiller Glenodinium pilula (Ostenfeld) Schiller Glenodinium pilula (Ostenfeld) Schiller Glenodinium pilula (Ostenfeld) Schiller Glenodinium pilula (Ostenfeld) Schiller Glenodinium pilula (Ostenfeld) Schiller Glenodinium pilula (Ostenfeld) Schiller Glenodinium pilula (Ostenfeld) Schiller Glenodinium pilula (Ostenfeld) Schiller Glenodinium pilula (Ostenfeld) Schiller Glenodinium pilula (Ostenfeld) Schiller Glenodinium pilula (Ostenfeld) Schiller Glenodinium pilula (Ostenfeld) Schiller Glenodinium pilula (Ostenfeld) Schiller Glenodinium pilula (Ostenfeld) Schiller

Glenodinium parvii f. major Lindeman Glenodinium parvii f. major Lindeman Glenodinium parvii f. major Lindeman Glenodinium parvii f. major Lindeman Glenodinium parviif. major Lindeman Glenodinium parvii f. major Lindeman Glenodinium parvii f. major Lindeman Glenodinium parvii f. major Lindeman Glenodinium parvii f. major Lindeman Glenodinium parvii f. major Lindeman Glenodinium parvii f. major Lindeman Glenodinium parvii f. major Lindeman Glenodinium parvii f. major Lindeman Glenodinium parvii f. major Lindeman Glenodinium parvii f. major Lindeman Glenodinium parvii f. major Lindeman Glenodinium parvii f. major Lindeman

Glenodinium penardii Lemmermann Glenodinium penardii Lemmermann Glenodinium penardii Lemmermann Glenodinium penardii Lemmermann Glenodinium penardii Lemmermann Glenodinium penardii Lemmermann Glenodinium penardii Lemmermann Glenodinium penardii Lemmermann Glenodinium penardii Lemmermann Glenodinium penardii Lemmermann Glenodinium penardii Lemmermann Glenodinium penardii Lemmermann Glenodinium penardii Lemmermann Glenodinium penardii Lemmermann

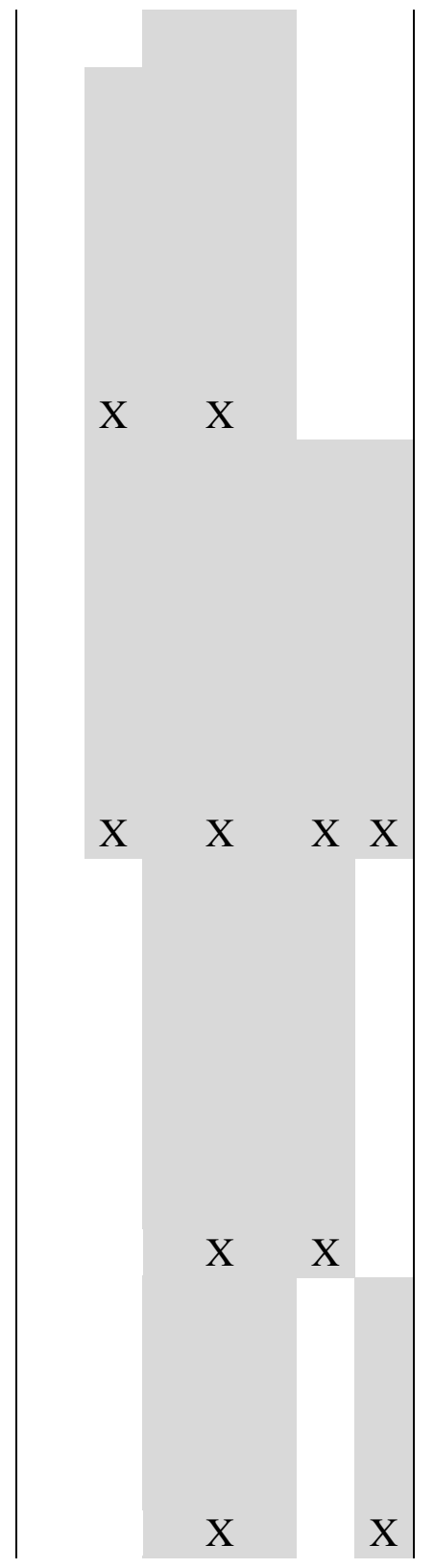


Glenodinium penardii Lemmermann Glenodinium penardii Lemmermann Glenodinium penardii Lemmermann

Glenodinium pulvisculus (Ehrenberg) Stein [Peridinium pulvisculus] Glenodinium pulvisculus (Ehrenberg) Stein [Peridinium pulvisculus] Glenodinium pulvisculus (Ehrenberg) Stein [Peridinium pulvisculus] Glenodinium pulvisculus (Ehrenberg) Stein [Peridinium pulvisculus] Glenodinium pulvisculus (Ehrenberg) Stein [Peridinium pulvisculus] Glenodinium pulvisculus (Ehrenberg) Stein [Peridinium pulvisculus] Glenodinium pulvisculus (Ehrenberg) Stein [Peridinium pulvisculus] Glenodinium pulvisculus (Ehrenberg) Stein [Peridinium pulvisculus] Glenodinium pulvisculus (Ehrenberg) Stein [Peridinium pulvisculus] Glenodinium pulvisculus (Ehrenberg) Stein [Peridinium pulvisculus] Glenodinium pulvisculus (Ehrenberg) Stein [Peridinium pulvisculus] Glenodinium pulvisculus (Ehrenberg) Stein [Peridinium pulvisculus] Glenodinium pulvisculus (Ehrenberg) Stein [Peridinium pulvisculus] Glenodinium pulvisculus (Ehrenberg) Stein [Peridinium pulvisculus] Glenodinium pulvisculus (Ehrenberg) Stein [Peridinium pulvisculus] Glenodinium pulvisculus (Ehrenberg) Stein [Peridinium pulvisculus]

Glenodiniopsis steini (Lemmermann) Woloszynska [Glenodinium steini]Glenodiniopsis steini (Lemmermann) Woloszynska [Glenodinium steini]Glenodiniopsis steini (Lemmermann) Woloszynska [Glenodinium steini]Glenodiniopsis steini (Lemmermann) Woloszynska [Glenodinium steini]Glenodiniopsis steini (Lemmermann) Woloszynska [Glenodinium steini]Glenodiniopsis steini (Lemmermann) Woloszynska [Glenodinium steini]Glenodiniopsis steini (Lemmermann) Woloszynska [Glenodinium steini]Glenodiniopsis steini (Lemmermann) Woloszynska [Glenodinium steini]Glenodiniopsis steini (Lemmermann) Woloszynska [Glenodinium steini]Glenodiniopsis steini (Lemmermann) Woloszynska [Glenodinium steini]Glenodiniopsis steini (Lemmermann) Woloszynska [Glenodinium steini]Glenodiniopsis steini (Lemmermann) Woloszynska [Glenodinium steini]Glenodiniopsis steini (Lemmermann) Woloszynska [Glenodinium steini]Glenodiniopsis steini (Lemmermann) Woloszynska [Glenodinium steini]Glenodiniopsis steini (Lemmermann) Woloszynska [Glenodinium steini]Glenodiniopsis steini (Lemmermann) Woloszynska [Glenodinium steini]

Goniodoma acuminatum (Ehrenberg) Stein [Peridinium acuminatum Ehrenberg] Goniodoma acuminatum (Ehrenberg) Stein [Peridinium acuminatum Ehrenberg]

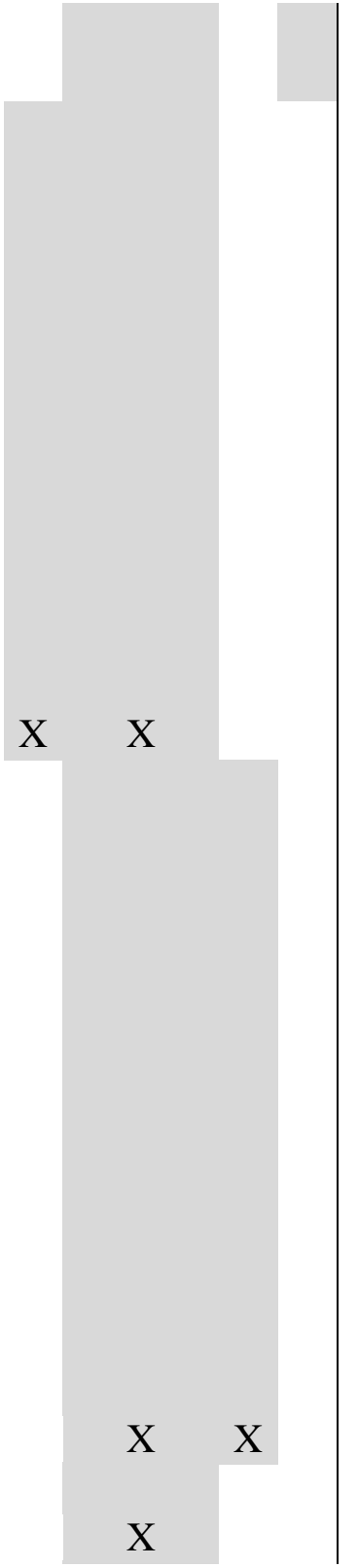


Goniodoma acuminatum (Ehrenberg) Stein [Peridinium acuminatum Ehrenberg] Goniodoma acuminatum (Ehrenberg) Stein [Peridinium acuminatum Ehrenberg] Goniodoma acuminatum (Ehrenberg) Stein [Peridinium acuminatum Ehrenberg] Goniodoma acuminatum (Ehrenberg) Stein [Peridinium acuminatum Ehrenberg] Goniodoma acuminatum (Ehrenberg) Stein [Peridinium acuminatum Ehrenberg] Goniodoma acuminatum (Ehrenberg) Stein [Peridinium acuminatum Ehrenberg] Goniodoma acuminatum (Ehrenberg) Stein [Peridinium acuminatum Ehrenberg] Goniodoma acuminatum (Ehrenberg) Stein [Peridinium acuminatum Ehrenberg] Goniodoma acuminatum (Ehrenberg) Stein [Peridinium acuminatum Ehrenberg] Goniodoma acuminatum (Ehrenberg) Stein [Peridinium acuminatum Ehrenberg] Goniodoma acuminatum (Ehrenberg) Stein [Peridinium acuminatum Ehrenberg] Goniodoma acuminatum (Ehrenberg) Stein [Peridinium acuminatum Ehrenberg] Goniodoma acuminatum (Ehrenberg) Stein [Peridinium acuminatum Ehrenberg] Goniodoma acuminatum (Ehrenberg) Stein [Peridinium acuminatum Ehrenberg] Goniodoma polyedricum(Pouchet)Jørgensen [Peridinium polyedricum,Triadinium polyedricum]Goniodoma polyedricum(Pouchet)Jørgensen [Peridinium polyedricum,Triadinium polyedricum]Goniodoma polyedricum(Pouchet)Jørgensen [Peridinium polyedricum,Triadinium polyedricum]Goniodoma polyedricum(Pouchet)Jørgensen [Peridinium polyedricum,Triadinium polyedricum]Goniodoma polyedricum(Pouchet)Jorgensen [Peridinium polyedricum,Triadinium polyedricum]Goniodoma polyedricum(Pouchet)Jørgensen [Peridinium polyedricum,Triadinium polyedricum]Goniodoma polyedricum(Pouchet)Jørgensen [Peridinium polyedricum,Triadinium polyedricum]Goniodoma polyedricum(Pouchet)Jørgensen [Peridinium polyedricum,Triadinium polyedricum]Goniodoma polyedricum(Pouchet)Jørgensen [Peridinium polyedricum,Triadinium polyedricum]Goniodoma polyedricum(Pouchet)Jørgensen [Peridinium polyedricum,Triadinium polyedricum]Goniodoma polyedricum(Pouchet)Jørgensen [Peridinium polyedricum,Triadinium polyedricum]Goniodoma polyedricum(Pouchet)Jørgensen [Peridinium polyedricum,Triadinium polyedricum]Goniodoma polyedricum(Pouchet)Jørgensen [Peridinium polyedricum,Triadinium polyedricum]Goniodoma polyedricum(Pouchet)Jørgensen [Peridinium polyedricum,Triadinium polyedricum]Goniodoma polyedricum(Pouchet)Jørgensen

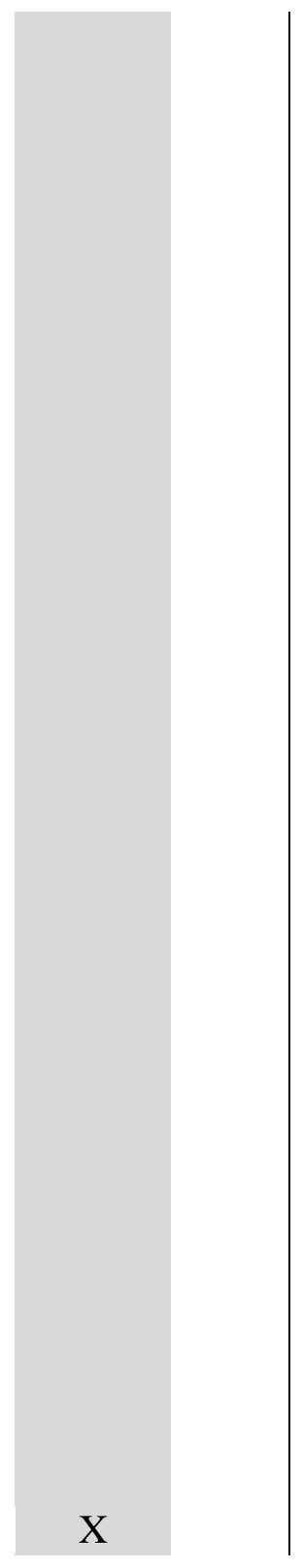


[Peridinium polyedricum,Triadinium polyedricum]Goniodoma polyedricum(Pouchet)Jørgensen [Peridinium polyedricum,Triadinium polyedricum] Goniodoma striatum Mang. Goniodoma striatum Mang. Goniodoma striatum Mang. Goniodoma striatum Mang. Goniodoma striatum Mang. Goniodoma striatum Mang. Goniodoma striatum Mang. Goniodoma striatum Mang. Goniodoma striatum Mang. Goniodoma striatum Mang. Goniodoma striatum Mang. Goniodoma striatum Mang. Goniodoma striatum Mang. Goniodoma striatum Mang. Goniodoma striatum Mang. Goniodoma striatum Mang.

Gonyaulax africana Schiller Gonyaulax africana Schiller Gonyaulax africana Schiller Gonyaulax africana Schiller Gonyaulax africana Schiller Gonyaulax africana Schiller Gonyaulax africana Schiller Gonyaulax africana Schiller Gonyaulax africana Schiller Gonyaulax africana Schiller Gonyaulax africana Schiller Gonyaulax africana Schiller Gonyaulax africana Schiller Gonyaulax africana Schiller Gonyaulax africana Schiller Gonyaulax africana Schiller

Gonyaulax apiculata (Pénard) Entz [ G. apiculata v.clevei etc.]Gonyaulax apiculata (Pénard) Entz [ G. apiculata v.clevei etc.]Gonyaulax apiculata (Pénard) Entz [ G. apiculata v.clevei etc.]Gonyaulax apiculata (Pénard) Entz [ G. apiculata v.clevei etc.]Gonyaulax apiculata (Pénard) Entz [ G. apiculata v.clevei etc.]Gonyaulax apiculata (Pénard) Entz [ G. apiculata v.clevei etc.] Gonyaulax apiculata (Pénard) Entz [ G. apiculata v.clevei etc.]Gonyaulax apiculata (Pénard) Entz [ G. apiculata v.clevei etc.]Gonyaulax apiculata (Pénard) Entz [ G. apiculata v.clevei etc.]Gonyaulax apiculata (Pénard) Entz [ G. apiculata v.clevei etc.]Gonyaulax apiculata (Pénard) Entz [ G. apiculata v.clevei etc.]Gonyaulax apiculata (Pénard) Entz [ G. apiculata v.clevei etc.]Gonyaulax apiculata (Pénard) Entz [ G. apiculata v.clevei etc.]Gonyaulax apiculata (Pénard) Entz [ G. apiculata v.clevei etc.]Gonyaulax apiculata (Pénard) Entz [ G. apiculata v.clevei etc.]Gonyaulax apiculata (Pénard) Entz [ G. apiculata v.clevei etc.]

Gonyaulax birostris Stein [Gonyaulax glyptorhynchus, G. highleyi]Gonyaulax birostris Stein [Gonyaulax glyptorhynchus, G. highleyi]Gonyaulax birostris Stein [Gonyaulax glyptorhynchus, G. highleyi]Gonyaulax birostris Stein [Gonyaulax glyptorhynchus, $G$. highleyi]Gonyaulax birostris Stein [Gonyaulax glyptorhynchus, G. highleyi]Gonyaulax birostris Stein [Gonyaulax glyptorhynchus, G. highleyi]Gonyaulax birostris Stein [Gonyaulax glyptorhynchus, G. highleyi]Gonyaulax birostris Stein [Gonyaulax glyptorhynchus, G. highleyi]Gonyaulax birostris Stein [Gonyaulax glyptorhynchus, G.

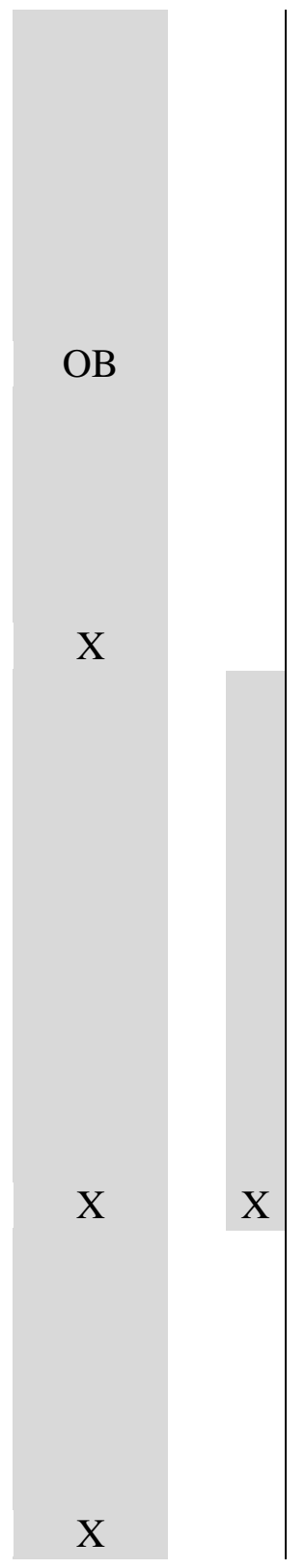


|highleyi]Gonyaulax birostris Stein [Gonyaulax glyptorhynchus, G. highleyi]Gonyaulax birostris Stein [Gonyaulax glyptorhynchus, G. highleyi]Gonyaulax birostris Stein [Gonyaulax glyptorhynchus, G. highleyi]Gonyaulax birostris Stein [Gonyaulax glyptorhynchus, G. highleyi]Gonyaulax birostris Stein [Gonyaulax glyptorhynchus, $G$. highleyi]Gonyaulax birostris Stein [Gonyaulax glyptorhynchus, G. highleyi]Gonyaulax birostris Stein [Gonyaulax glyptorhynchus, G. highleyi]

Gonyaulax cochlea Meunier [ G. polygramma Meunier] Gonyaulax cochlea Meunier [ G. polygramma Meunier] Gonyaulax cochlea Meunier [ G. polygramma Meunier] Gonyaulax cochlea Meunier [ G. polygramma Meunier] Gonyaulax cochlea Meunier [ G. polygramma Meunier] Gonyaulax cochlea Meunier [ G. polygramma Meunier] Gonyaulax cochlea Meunier [ G. polygramma Meunier] Gonyaulax cochlea Meunier [ G. polygramma Meunier] Gonyaulax cochlea Meunier [ G. polygramma Meunier] Gonyaulax cochlea Meunier [ G. polygramma Meunier] Gonyaulax cochlea Meunier [ G. polygramma Meunier] Gonyaulax cochlea Meunier [ G. polygramma Meunier] Gonyaulax cochlea Meunier [ G. polygramma Meunier] Gonyaulax cochlea Meunier [ G. polygramma Meunier] Gonyaulax cochlea Meunier [G. polygramma Meunier] Gonyaulax cochlea Meunier [ G. polygramma Meunier]

Gonyaulax diegensis Kofoid [ G. spinifera sensu Schütt]Gonyaulax diegensis Kofoid [ G. spinifera sensu Schütt]Gonyaulax diegensis Kofoid [ G. spinifera sensu Schütt]Gonyaulax diegensis Kofoid [ G. spinifera sensu Schütt]Gonyaulax diegensis Kofoid [ G. spinifera sensu Schütt]Gonyaulax diegensis Kofoid [ G. spinifera sensu Schütt]Gonyaulax diegensis Kofoid [ G. spinifera sensu Schütt]Gonyaulax diegensis Kofoid [ G. spinifera sensu Schütt]Gonyaulax diegensis Kofoid [ G. spinifera sensu Schütt]Gonyaulax diegensis Kofoid [ G. spinifera sensu Schütt]Gonyaulax diegensis Kofoid [ G. spinifera sensu Schüitt]Gonyaulax diegensis Kofoid [ G. spinifera sensu Schütt]Gonyaulax diegensis Kofoid [ G. spinifera sensu Schütt]Gonyaulax diegensis Kofoid [ G. spinifera sensu Schütt]Gonyaulax diegensis Kofoid [ G. spinifera sensu Schütt]Gonyaulax diegensis Kofoid [ G. spinifera sensu Schütt]

Gonyaulax digitale (Pouchet) Kofoid [G. spinifera Stein, Protoperidinium digitale] Gonyaulax digitale (Pouchet) Kofoid [G. spinifera Stein, Protoperidinium digitale] Gonyaulax digitale (Pouchet) Kofoid [G. spinifera Stein, Protoperidinium digitale] Gonyaulax digitale (Pouchet) Kofoid [G. spinifera Stein, Protoperidinium digitale] Gonyaulax digitale (Pouchet) Kofoid [G. spinifera Stein, Protoperidinium digitale]

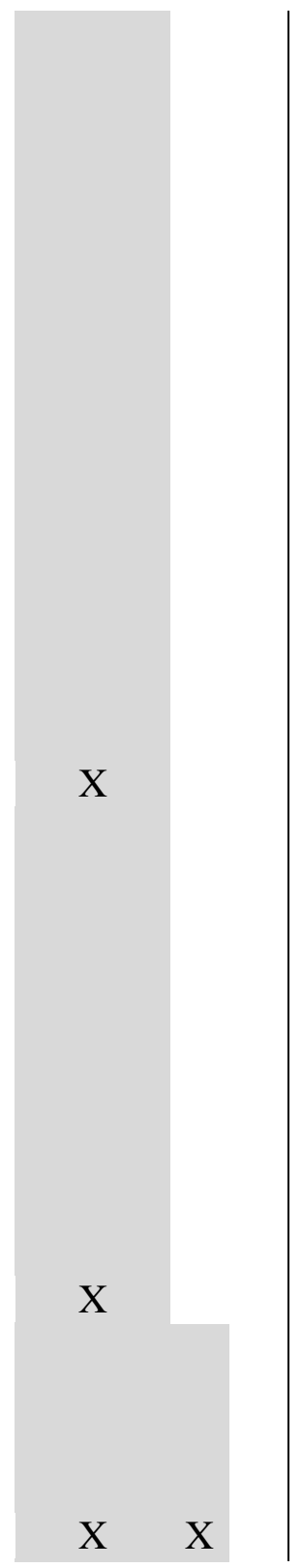


Gonyaulax digitale (Pouchet) Kofoid [G. spinifera Stein, Protoperidinium digitale] Gonyaulax digitale (Pouchet) Kofoid [G. spinifera Stein, Protoperidinium digitale] Gonyaulax digitale (Pouchet) Kofoid [G. spinifera Stein, Protoperidinium digitale] Gonyaulax digitale (Pouchet) Kofoid [G. spinifera Stein, Protoperidinium digitale] Gonyaulax digitale (Pouchet) Kofoid [G. spinifera Stein, Protoperidinium digitale] Gonyaulax digitale (Pouchet) Kofoid [G. spinifera Stein, Protoperidinium digitale] Gonyaulax digitale (Pouchet) Kofoid [G. spinifera Stein, Protoperidinium digitale] Gonyaulax digitale (Pouchet) Kofoid [G. spinifera Stein, Protoperidinium digitale] Gonyaulax digitale (Pouchet) Kofoid [G. spinifera Stein, Protoperidinium digitale] Gonyaulax digitale (Pouchet) Kofoid [G. spinifera Stein, Protoperidinium digitale] Gonyaulax digitale (Pouchet) Kofoid [G. spinifera Stein, Protoperidinium digitale] Gonyaulax elegans Rampi Gonyaulax elegans Rampi Gonyaulax elegans Rampi Gonyaulax elegans Rampi Gonyaulax elegans Rampi Gonyaulax elegans Rampi Gonyaulax elegans Rampi Gonyaulax elegans Rampi Gonyaulax elegans Rampi Gonyaulax elegans Rampi Gonyaulax elegans Rampi Gonyaulax elegans Rampi Gonyaulax elegans Rampi Gonyaulax elegans Rampi Gonyaulax elegans Rampi Gonyaulax elegans Rampi

Gonyaulax fragilis (Schütt) Kofoid [Steiniella fragilis Schütt] Gonyaulax fragilis (Schütt) Kofoid [Steiniella fragilis Schütt] Gonyaulax fragilis (Schütt) Kofoid [Steiniella fragilis Schütt] Gonyaulax fragilis (Schütt) Kofoid [Steiniella fragilis Schütt] Gonyaulax fragilis (Schütt) Kofoid [Steiniella fragilis Schütt] Gonyaulax fragilis (Schütt) Kofoid [Steiniella fragilis Schütt] Gonyaulax fragilis (Schütt) Kofoid [Steiniella fragilis Schütt] Gonyaulax fragilis (Schütt) Kofoid [Steiniella fragilis Schütt] Gonyaulax fragilis (Schütt) Kofoid [Steiniella fragilis Schütt] Gonyaulax fragilis (Schütt) Kofoid [Steiniella fragilis Schütt] Gonyaulax fragilis (Schütt) Kofoid [Steiniella fragilis Schütt] Gonyaulax fragilis (Schütt) Kofoid [Steiniella fragilis Schütt] Gonyaulax fragilis (Schütt) Kofoid [Steiniella fragilis Schütt] Gonyaulax fragilis (Schütt) Kofoid [Steiniella fragilis Schütt] Gonyaulax fragilis (Schütt) Kofoid [Steiniella fragilis Schütt] Gonyaulax fragilis (Schütt) Kofoid [Steiniella fragilis Schütt]

Gonyaulax gracilis Schiller Gonyaulax gracilis Schiller Gonyaulax gracilis Schiller Gonyaulax gracilis Schiller Gonyaulax gracilis Schiller Gonyaulax gracilis Schiller Gonyaulax gracilis Schiller Gonyaulax gracilis Schiller Gonyaulax gracilis Schiller Gonyaulax gracilis Schiller Gonyaulax gracilis Schiller Gonyaulax gracilis Schiller

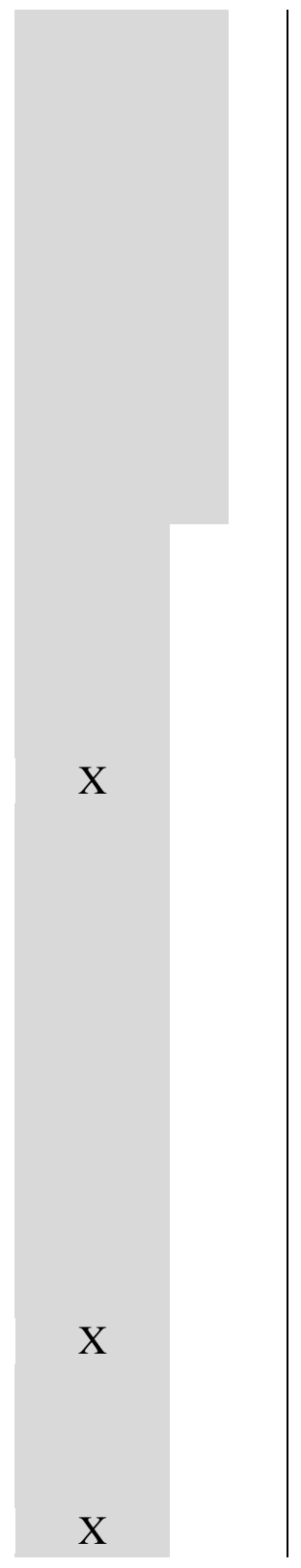


Gonyaulax gracilis Schiller Gonyaulax gracilis Schiller Gonyaulax gracilis Schiller Gonyaulax gracilis Schiller

Gonyaulax minuta Kofoid \& Michener [G. minima Matzenauer]Gonyaulax minuta Kofoid \& Michener [G. minima Matzenauer]Gonyaulax minuta Kofoid \& Michener [G. minima Matzenauer]Gonyaulax minuta Kofoid \& Michener [G. minima

Matzenauer]Gonyaulax minuta Kofoid \& Michener [G. minima Matzenauer]Gonyaulax minuta Kofoid \& Michener [G. minima Matzenauer]Gonyaulax minuta Kofoid \& Michener [G. minima Matzenauer]Gonyaulax minuta Kofoid \& Michener [G. minima Matzenauer]Gonyaulax minuta Kofoid \& Michener [G. minima Matzenauer]Gonyaulax minuta Kofoid \& Michener [G. minima Matzenauer]Gonyaulax minuta Kofoid \& Michener [G. minima Matzenauer]Gonyaulax minuta Kofoid \& Michener [G. minima Matzenauer]Gonyaulax minuta Kofoid \& Michener [G. minima Matzenauer]Gonyaulax minuta Kofoid \& Michener [G. minima Matzenauer]Gonyaulax minuta Kofoid \& Michener [G. minima Matzenauer]Gonyaulax minuta Kofoid \& Michener [G. minima Matzenauer]

Gonyaulax monacantha Pavillard Gonyaulax monacantha Pavillard Gonyaulax monacantha Pavillard Gonyaulax monacantha Pavillard Gonyaulax monacantha Pavillard Gonyaulax monacantha Pavillard Gonyaulax monacantha Pavillard Gonyaulax monacantha Pavillard Gonyaulax monacantha Pavillard Gonyaulax monacantha Pavillard Gonyaulax monacantha Pavillard Gonyaulax monacantha Pavillard Gonyaulax monacantha Pavillard Gonyaulax monacantha Pavillard Gonyaulax monacantha Pavillard Gonyaulax monacantha Pavillard

Gonyaulax monospina Rampi Gonyaulax monospina Rampi Gonyaulax monospina Rampi Gonyaulax monospina Rampi Gonyaulax monospina Rampi Gonyaulax monospina Rampi Gonyaulax monospina Rampi Gonyaulax monospina Rampi Gonyaulax monospina Rampi Gonyaulax monospina Rampi Gonyaulax monospina Rampi Gonyaulax monospina Rampi Gonyaulax monospina Rampi Gonyaulax monospina Rampi Gonyaulax monospina Rampi

Gonyaulax orientalis Lindemann [ Goniodoma orientale etc.]Gonyaulax orientalis Lindemann [ Goniodoma orientale etc.] Gonyaulax orientalis Lindemann [ Goniodoma orientale etc.] Gonyaulax orientalis Lindemann [ Goniodoma orientale etc.] Gonyaulax orientalis Lindemann [ Goniodoma orientale etc.] Gonyaulax orientalis Lindemann [ Goniodoma orientale etc.] Gonyaulax orientalis Lindemann [ Goniodoma orientale

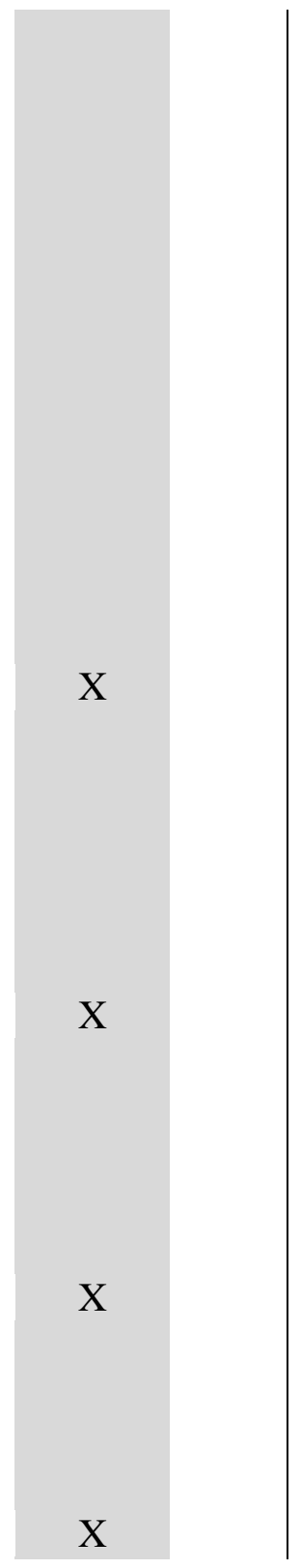


etc.]Gonyaulax orientalis Lindemann [ Goniodoma orientale etc.] Gonyaulax orientalis Lindemann [ Goniodoma orientale etc.] Gonyaulax orientalis Lindemann [ Goniodoma orientale etc.] Gonyaulax orientalis Lindemann [ Goniodoma orientale etc.] Gonyaulax orientalis Lindemann [ Goniodoma orientale etc.] Gonyaulax orientalis Lindemann [ Goniodoma orientale etc.] Gonyaulax orientalis Lindemann [ Goniodoma orientale etc.] Gonyaulax orientalis Lindemann [ Goniodoma orientale etc.]

Gonyaulax polygramma Stein [G. schuettii Lemmermann] Gonyaulax polygramma Stein [G. schuettii Lemmermann] Gonyaulax polygramma Stein [G. schuettii Lemmermann] Gonyaulax polygramma Stein [G. schuettii Lemmermann] Gonyaulax polygramma Stein [G. schuettii Lemmermann] Gonyaulax polygramma Stein [G. schuettii Lemmermann] Gonyaulax polygramma Stein [G. schuettii Lemmermann] Gonyaulax polygramma Stein [G. schuettii Lemmermann] Gonyaulax polygramma Stein [G. schuettii Lemmermann] Gonyaulax polygramma Stein [G. schuettii Lemmermann] Gonyaulax polygramma Stein [G. schuettii Lemmermann] Gonyaulax polygramma Stein [G. schuettii Lemmermann] Gonyaulax polygramma Stein [G. schuettii Lemmermann] Gonyaulax polygramma Stein [G. schuettii Lemmermann] Gonyaulax polygramma Stein [G. schuettii Lemmermann]

Gonyaulax scrippsae Kofoid Gonyaulax scrippsae Kofoid Gonyaulax scrippsae Kofoid Gonyaulax scrippsae Kofoid Gonyaulax scrippsae Kofoid Gonyaulax scrippsae Kofoid Gonyaulax scrippsae Kofoid Gonyaulax scrippsae Kofoid Gonyaulax scrippsae Kofoid Gonyaulax scrippsae Kofoid Gonyaulax scrippsae Kofoid Gonyaulax scrippsae Kofoid Gonyaulax scrippsae Kofoid Gonyaulax scrippsae Kofoid Gonyaulax scrippsae Kofoid Gonyaulax spinifera (Claparède \& Lachmann) Diesing [G. levanderi] Gonyaulax spinifera (Claparède \& Lachmann) Diesing [G. levanderi] Gonyaulax spinifera (Claparède \& Lachmann) Diesing [G. levanderi] Gonyaulax spinifera (Claparède \& Lachmann) Diesing [G. levanderi] Gonyaulax spinifera (Claparède \& Lachmann) Diesing [G. levanderi] Gonyaulax spinifera (Claparède \& Lachmann) Diesing [G. levanderi] Gonyaulax spinifera (Claparède \& Lachmann) Diesing [G. levanderi] Gonyaulax spinifera (Claparède \& Lachmann) Diesing [G. levanderi] Gonyaulax spinifera (Claparède \& Lachmann) Diesing [G. levanderi] Gonyaulax spinifera (Claparède \& Lachmann) Diesing [G. levanderi] Gonyaulax spinifera (Claparède \& Lachmann) Diesing [G. levanderi] Gonyaulax spinifera (Claparède \& Lachmann) Diesing [G. levanderi] Gonyaulax spinifera (Claparède \& Lachmann) Diesing [G.

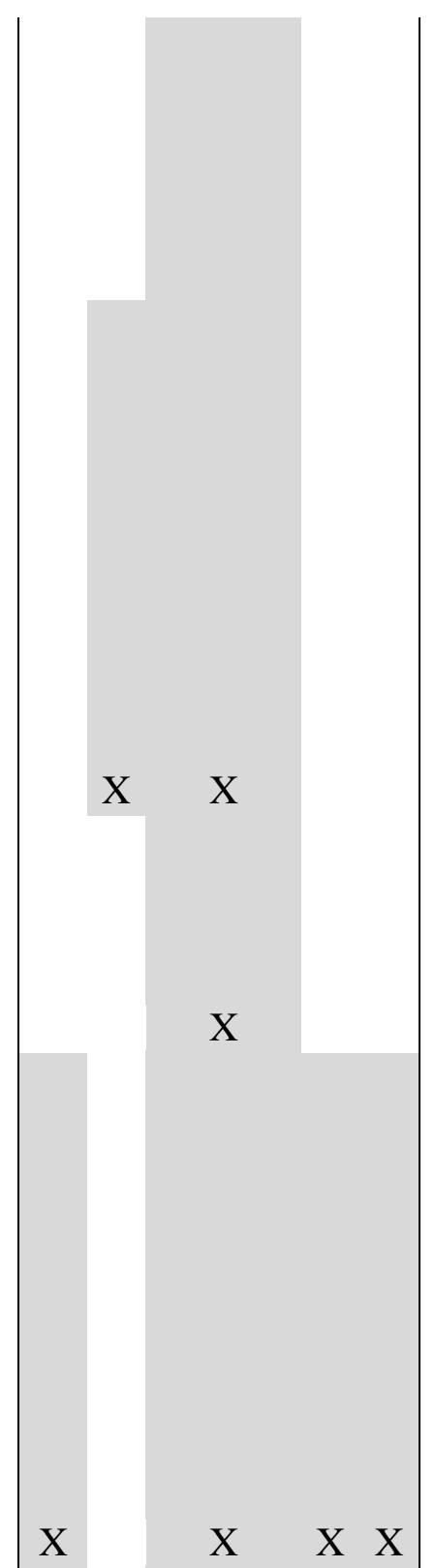


levanderi] Gonyaulax spinifera (Claparède \& Lachmann) Diesing [G. levanderi] Gonyaulax spinifera (Claparède \& Lachmann) Diesing [G. levanderi]

Gonyaulax verior Sournia [G. diacantha, G. longispina, Amylax diacantha] Gonyaulax verior Sournia [G. diacantha, G. longispina, Amylax diacantha] Gonyaulax verior Sournia [G. diacantha, G. longispina, Amylax diacantha] Gonyaulax verior Sournia [G. diacantha, G. longispina, Amylax diacantha] Gonyaulax verior Sournia [G. diacantha, G. longispina, Amylax diacantha] Gonyaulax verior Sournia [G. diacantha, G. longispina, Amylax diacantha] Gonyaulax verior Sournia [G. diacantha, G. longispina, Amylax diacantha] Gonyaulax verior Sournia [G. diacantha, G. longispina, Amylax diacantha] Gonyaulax verior Sournia [G. diacantha, G. longispina, Amylax diacantha] Gonyaulax verior Sournia [G. diacantha, G. longispina, Amylax diacantha] Gonyaulax verior Sournia [G. diacantha, G. longispina, Amylax diacantha] Gonyaulax verior Sournia [G. diacantha, G. longispina, Amylax diacantha] Gonyaulax verior Sournia [G. diacantha, G. longispina, Amylax diacantha] Gonyaulax verior Sournia [G. diacantha, G. longispina, Amylax diacantha] Gonyaulax verior Sournia [G. diacantha, G. longispina, Amylax diacantha]

Gonyostomum semen (Ehrenberg) Diesing [Monas semen, Raphidomonas semen]Gonyostomum semen (Ehrenberg) Diesing [Monas semen, Raphidomonas semen]Gonyostomum semen (Ehrenberg) Diesing [Monas semen, Raphidomonas semen]Gonyostomum semen (Ehrenberg) Diesing [Monas semen, Raphidomonas semen]Gonyostomum semen (Ehrenberg) Diesing [Monas semen, Raphidomonas semen]Gonyostomum semen (Ehrenberg) Diesing [Monas semen, Raphidomonas semen]Gonyostomum semen (Ehrenberg) Diesing [Monas semen, Raphidomonas semen]Gonyostomum semen (Ehrenberg) Diesing [Monas semen, Raphidomonas semen]Gonyostomum semen (Ehrenberg) Diesing [Monas semen, Raphidomonas semen]Gonyostomum semen (Ehrenberg) Diesing [Monas semen, Raphidomonas semen]Gonyostomum semen (Ehrenberg) Diesing [Monas semen, Raphidomonas semen]Gonyostomum semen (Ehrenberg) Diesing [Monas semen, Raphidomonas semen]Gonyostomum semen (Ehrenberg) Diesing [Monas semen, Raphidomonas semen]Gonyostomum semen (Ehrenberg) Diesing [Monas semen, Raphidomonas semen]Gonyostomum semen (Ehrenberg) Diesing [Monas semen, Raphidomonas semen]

Gymnodinium agile Kofoid et Swezy [non G. agile sensu Herdmann] Gymnodinium agile Kofoid et Swezy [non G. agile sensu Herdmann] Gymnodinium agile Kofoid et

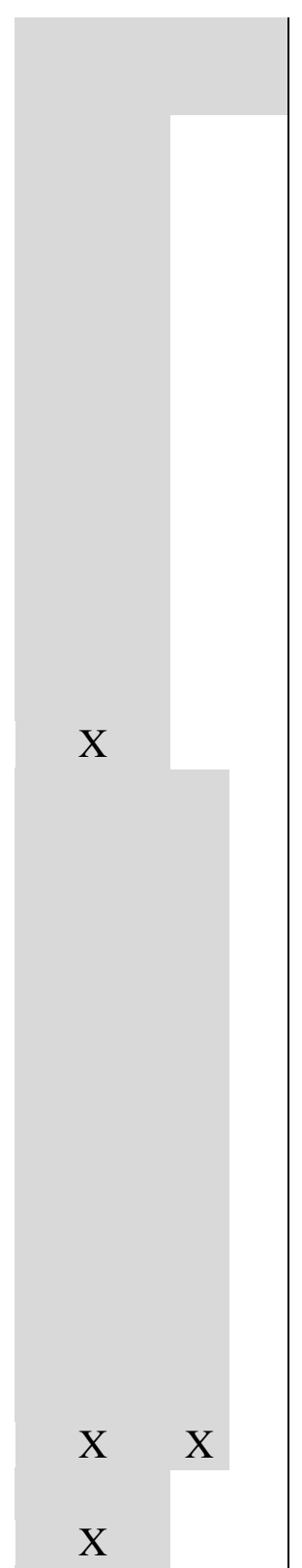


Swezy [non G. agile sensu Herdmann] Gymnodinium agile Kofoid et Swezy [non G. agile sensu Herdmann] Gymnodinium agile Kofoid et Swezy [non G. agile sensu Herdmann] Gymnodinium agile Kofoid et Swezy [non G. agile sensu Herdmann] Gymnodinium agile Kofoid et Swezy [non G. agile sensu Herdmann] Gymnodinium agile Kofoid et Swezy [non G. agile sensu Herdmann] Gymnodinium agile Kofoid et Swezy [non G. agile sensu Herdmann] Gymnodinium agile Kofoid et Swezy [non G. agile sensu Herdmann] Gymnodinium agile Kofoid et Swezy [non G. agile sensu Herdmann] Gymnodinium agile Kofoid et Swezy [non G. agile sensu Herdmann] Gymnodinium agile Kofoid et Swezy [non G. agile sensu Herdmann] Gymnodinium agile Kofoid et Swezy [non G. agile sensu Herdmann] Gymnodinium agile Kofoid et Swezy [non G. agile sensu Herdmann]

Gymnodinium agiliforme Schiller Gymnodinium agiliforme Schiller Gymnodinium agiliforme Schiller Gymnodinium agiliforme Schiller Gymnodinium agiliforme Schiller Gymnodinium agiliforme Schiller Gymnodinium agiliforme Schiller Gymnodinium agiliforme Schiller Gymnodinium agiliforme Schiller Gymnodinium agiliforme Schiller Gymnodinium agiliforme Schiller Gymnodinium agiliforme Schiller Gymnodinium agiliforme Schiller Gymnodinium agiliforme Schiller Gymnodinium agiliforme Schiller Gymnodinium aeruginosum Stein [G. acidotum, G. viride, G. campaniforme]

Gymnodinium aeruginosum Stein [G. acidotum, G. viride, G. campaniforme] Gymnodinium aeruginosum Stein [G. acidotum, G. viride, G. campaniforme] Gymnodinium aeruginosum Stein [G. acidotum, G. viride, G. campaniforme] Gymnodinium aeruginosum Stein [G. acidotum, G. viride, G. campaniforme] Gymnodinium aeruginosum Stein [G. acidotum, G. viride, G. campaniforme] Gymnodinium aeruginosum Stein [G. acidotum, G. viride, G. campaniforme] Gymnodinium aeruginosum Stein [G. acidotum, G. viride, G. campaniforme] Gymnodinium aeruginosum Stein [G. acidotum, G. viride, G. campaniforme] Gymnodinium aeruginosum Stein [G. acidotum, G. viride, G. campaniforme] Gymnodinium aeruginosum Stein [G. acidotum, G. viride, G. campaniforme] Gymnodinium aeruginosum Stein [G. acidotum, G. viride, G. campaniforme] Gymnodinium aeruginosum Stein [G. acidotum, G. viride, G. campaniforme] Gymnodinium aeruginosum Stein [G. acidotum, G. viride, G. campaniforme] Gymnodinium aeruginosum Stein [G. acidotum, G. viride, G. campaniforme]

Gymnodinium arcuatum KofoidGymnodinium arcuatum KofoidGymnodinium arcuatum

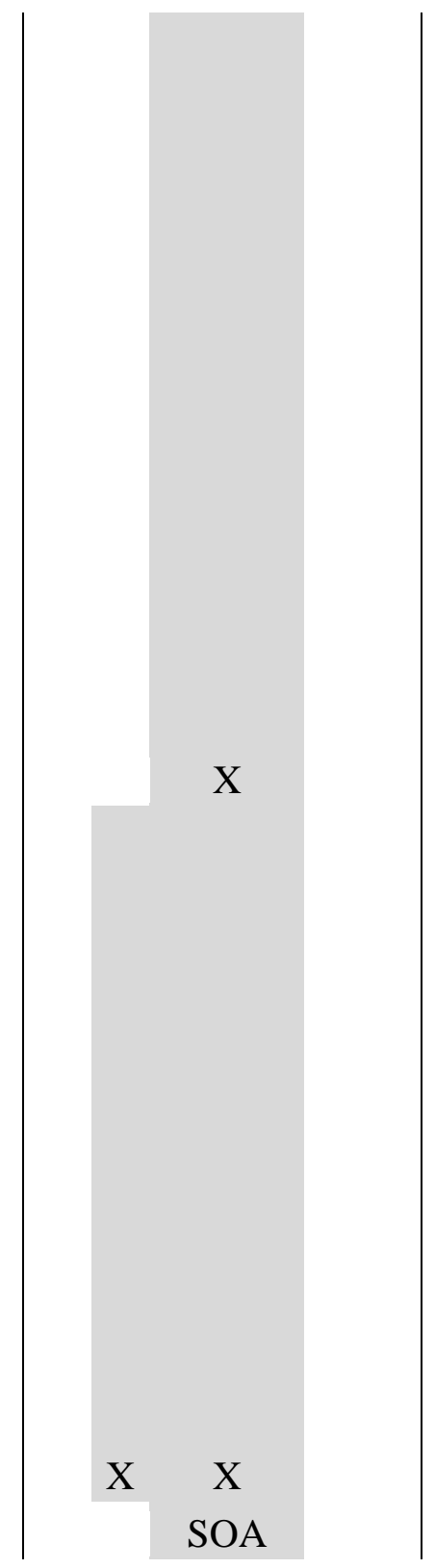


KofoidGymnodinium arcuatum KofoidGymnodinium arcuatum KofoidGymnodinium arcuatum KofoidGymnodinium arcuatum KofoidGymnodinium arcuatum

KofoidGymnodinium arcuatum KofoidGymnodinium arcuatum KofoidGymnodinium arcuatum KofoidGymnodinium arcuatum KofoidGymnodinium arcuatum KofoidGymnodinium arcuatum KofoidGymnodinium arcuatum Kofoid Gymnodinium auratum Kofoid et Swezy Gymnodinium auratum Kofoid et Swezy Gymnodinium auratum Kofoid et Swezy Gymnodinium auratum Kofoid et Swezy Gymnodinium auratum Kofoid et Swezy Gymnodinium auratum Kofoid et Swezy Gymnodinium auratum Kofoid et Swezy Gymnodinium auratum Kofoid et Swezy Gymnodinium auratum Kofoid et Swezy Gymnodinium auratum Kofoid et Swezy Gymnodinium auratum Kofoid et Swezy Gymnodinium auratum Kofoid et Swezy Gymnodinium auratum Kofoid et Swezy Gymnodinium auratum Kofoid et Swezy Gymnodinium auratum Kofoid et Swezy

Gymnodinium aureolum (Hulburt) Hansen [Gyrodinium aureolum] Gymnodinium aureolum (Hulburt) Hansen [Gyrodinium aureolum] Gymnodinium aureolum (Hulburt) Hansen [Gyrodinium aureolum] Gymnodinium aureolum (Hulburt) Hansen [Gyrodinium aureolum] Gymnodinium aureolum (Hulburt) Hansen [Gyrodinium aureolum] Gymnodinium aureolum (Hulburt) Hansen [Gyrodinium aureolum] Gymnodinium aureolum (Hulburt) Hansen [Gyrodinium aureolum] Gymnodinium aureolum (Hulburt) Hansen [Gyrodinium aureolum]Gymnodinium aureolum (Hulburt) Hansen [Gyrodinium aureolum] Gymnodinium aureolum (Hulburt) Hansen [Gyrodinium aureolum] Gymnodinium aureolum (Hulburt) Hansen [Gyrodinium aureolum]Gymnodinium aureolum (Hulburt) Hansen [Gyrodinium aureolum] Gymnodinium aureolum (Hulburt) Hansen [Gyrodinium aureolum] Gymnodinium aureolum (Hulburt) Hansen [Gyrodinium aureolum] Gymnodinium aureolum (Hulburt) Hansen [Gyrodinium aureolum] Gymnodinium biconicum Schiller Gymnodinium biconicum Schiller Gymnodinium biconicum Schiller Gymnodinium biconicum Schiller Gymnodinium biconicum Schiller Gymnodinium biconicum Schiller Gymnodinium biconicum Schiller Gymnodinium biconicum Schiller Gymnodinium biconicum Schiller Gymnodinium biconicum Schiller Gymnodinium biconicum Schiller Gymnodinium biconicum Schiller Gymnodinium biconicum Schiller Gymnodinium biconicum Schiller Gymnodinium biconicum Schiller




Gymnodinium conicum Kofoid et Swezy [G. viridis Lebour] Gymnodinium conicum Kofoid et Swezy [G. viridis Lebour] Gymnodinium conicum Kofoid et Swezy [G. viridis Lebour] Gymnodinium conicum Kofoid et Swezy [G. viridis Lebour] Gymnodinium conicum Kofoid et Swezy [G. viridis Lebour] Gymnodinium conicum Kofoid et Swezy [G. viridis Lebour] Gymnodinium conicum Kofoid et Swezy [G. viridis Lebour] Gymnodinium conicum Kofoid et Swezy [G. viridis Lebour] Gymnodinium conicum Kofoid et Swezy [G. viridis Lebour] Gymnodinium conicum Kofoid et Swezy [G. viridis Lebour] Gymnodinium conicum Kofoid et Swezy [G. viridis Lebour] Gymnodinium conicum Kofoid et Swezy [G. viridis Lebour] Gymnodinium conicum Kofoid et Swezy [G. viridis Lebour] Gymnodinium conicum Kofoid et Swezy [G. viridis Lebour] Gymnodinium conicum Kofoid et Swezy [G. viridis Lebour]

Gymnodinium excavatum van MeelGymnodinium excavatum van MeelGymnodinium excavatum van MeelGymnodinium excavatum van MeelGymnodinium excavatum van MeelGymnodinium excavatum van MeelGymnodinium excavatum van MeelGymnodinium excavatum van MeelGymnodinium excavatum van MeelGymnodinium excavatum van MeelGymnodinium excavatum van MeelGymnodinium excavatum van MeelGymnodinium excavatum van MeelGymnodinium excavatum van MeelGymnodinium excavatum van Meel

Gymnodinium euritopum SkujaGymnodinium euritopum SkujaGymnodinium euritopum SkujaGymnodinium euritopum SkujaGymnodinium euritopum SkujaGymnodinium euritopum SkujaGymnodinium euritopum SkujaGymnodinium euritopum

SkujaGymnodinium euritopum SkujaGymnodinium euritopum SkujaGymnodinium euritopum SkujaGymnodinium euritopum SkujaGymnodinium euritopum SkujaGymnodinium euritopum Skuja

Gymnodinium flavum Kofoid et Swezy [non Gyrodinium flavum Kofoid] Gymnodinium flavum Kofoid et Swezy [non Gyrodinium flavum Kofoid] Gymnodinium flavum Kofoid et Swezy [non Gyrodinium flavum Kofoid] Gymnodinium flavum Kofoid et Swezy [non Gyrodinium flavum Kofoid] Gymnodinium flavum Kofoid et Swezy [non Gyrodinium flavum Kofoid] Gymnodinium flavum Kofoid et Swezy [non Gyrodinium flavum Kofoid] Gymnodinium flavum Kofoid et Swezy [non Gyrodinium flavum Kofoid] Gymnodinium flavum Kofoid et Swezy [non Gyrodinium flavum Kofoid] Gymnodinium flavum Kofoid et Swezy [non Gyrodinium flavum Kofoid] Gymnodinium flavum Kofoid et Swezy [non Gyrodinium flavum Kofoid] Gymnodinium flavum Kofoid et Swezy [non Gyrodinium

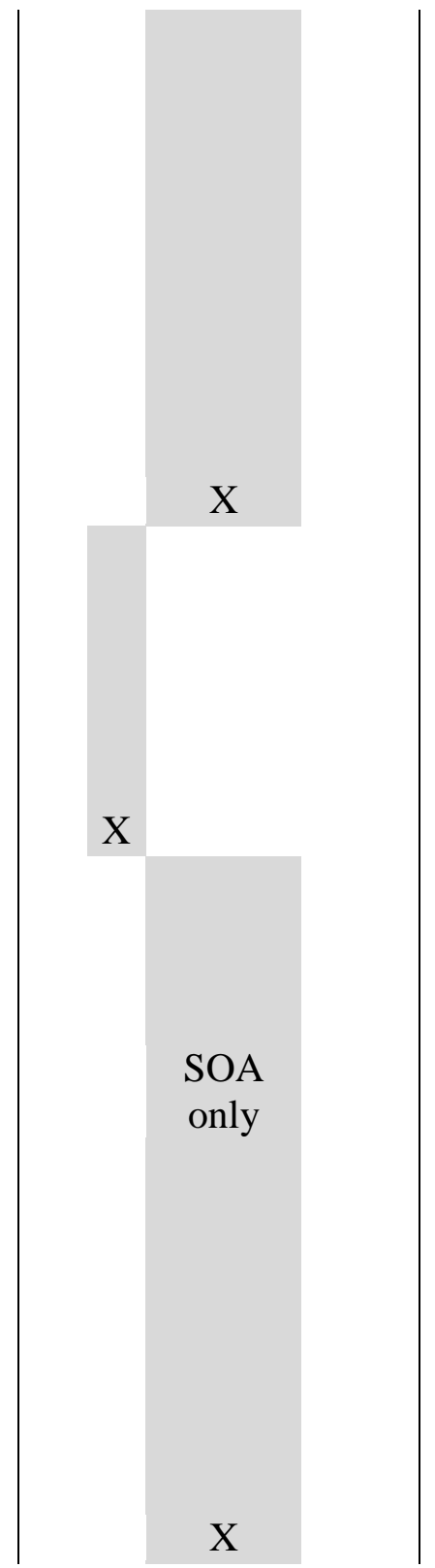


|flavum Kofoid] Gymnodinium flavum Kofoid et Swezy [non Gyrodinium flavum Kofoid] Gymnodinium flavum Kofoid et Swezy [non Gyrodinium flavum Kofoid] Gymnodinium flavum Kofoid et Swezy [non Gyrodinium flavum Kofoid]

Gymnodinium fuscum (Ehrenberg) Stein [G. caudatum,Cystodinium gessneri JGymnodinium fuscum (Ehrenberg) Stein [G. caudatum, Cystodinium gessneri JGymnodinium fuscum (Ehrenberg) Stein [G. caudatum,Cystodinium gessneri JGymnodinium fuscum (Ehrenberg) Stein [G. caudatum, Cystodinium gessneri JGymnodinium fuscum (Ehrenberg) Stein [G. caudatum, Cystodinium gessneri JGymnodinium fuscum (Ehrenberg) Stein [G. caudatum, Cystodinium gessneri JGymnodinium fuscum (Ehrenberg) Stein [G. caudatum, Cystodinium gessneri JGymnodinium fuscum (Ehrenberg) Stein [G. caudatum, Cystodinium gessneri JGymnodinium fuscum (Ehrenberg) Stein [G. caudatum,Cystodinium gessneri JGymnodinium fuscum (Ehrenberg) Stein [G. caudatum, Cystodinium gessneri JGymnodinium fuscum (Ehrenberg) Stein [G. caudatum, Cystodinium gessneri JGymnodinium fuscum (Ehrenberg) Stein [G. caudatum, Cystodinium gessneri JGymnodinium fuscum (Ehrenberg) Stein [G. caudatum,Cystodinium gessneri JGymnodinium fuscum (Ehrenberg) Stein [G. caudatum, Cystodinium gessneri] Gymnodinium fusiforme Kofoid \& SwezyGymnodinium fusiforme Kofoid \&

SwezyGymnodinium fusiforme Kofoid \& SwezyGymnodinium fusiforme Kofoid \& SwezyGymnodinium fusiforme Kofoid \& SwezyGymnodinium fusiforme Kofoid \& SwezyGymnodinium fusiforme Kofoid \& Swezy Gymnodinium fusiforme Kofoid \& SwezyGymnodinium fusiforme Kofoid \& SwezyGymnodinium fusiforme Kofoid \& Swezy Gymnodinium fusiforme Kofoid \& Swezy Gymnodinium fusiforme Kofoid \& Swezy Gymnodinium fusiforme Kofoid \& Swezy Gymnodinium fusiforme Kofoid \& Swezy Gymnodinium fusus Schütt Gymnodinium fusus Schütt Gymnodinium fusus Schütt Gymnodinium fusus Schütt Gymnodinium fusus Schütt Gymnodinium fusus Schütt Gymnodinium fusus Schütt Gymnodinium fusus Schütt Gymnodinium fusus Schütt Gymnodinium fusus Schütt Gymnodinium fusus Schütt Gymnodinium fusus Schütt Gymnodinium fusus Schütt Gymnodinium fusus Schütt

Gymnodinium helveticum Penard [Glenodinium apiculatum, Gyrodinium helveticum] Gymnodinium helveticum Penard [Glenodinium apiculatum, Gyrodinium helveticum] Gymnodinium helveticum Penard [Glenodinium apiculatum, Gyrodinium helveticum] Gymnodinium helveticum Penard [Glenodinium apiculatum, Gyrodinium helveticum]

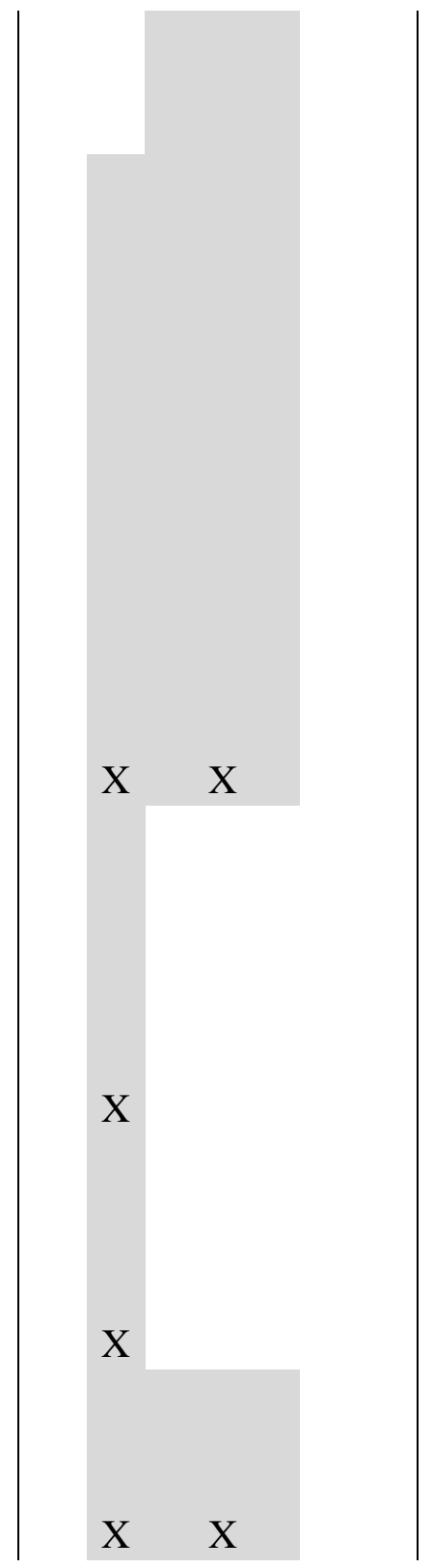


Gymnodinium helveticum Penard [Glenodinium apiculatum,Gyrodinium helveticum] Gymnodinium helveticum Penard [Glenodinium apiculatum, Gyrodinium helveticum] Gymnodinium helveticum Penard [Glenodinium apiculatum, Gyrodinium helveticum] Gymnodinium helveticum Penard [Glenodinium apiculatum, Gyrodinium helveticum] Gymnodinium helveticum Penard [Glenodinium apiculatum, Gyrodinium helveticum] Gymnodinium helveticum Penard [Glenodinium apiculatum, Gyrodinium helveticum] Gymnodinium helveticum Penard [Glenodinium apiculatum, Gyrodinium helveticum] Gymnodinium helveticum Penard [Glenodinium apiculatum, Gyrodinium helveticum] Gymnodinium helveticum Penard [Glenodinium apiculatum, Gyrodinium helveticum] Gymnodinium helveticum Penard [Glenodinium apiculatum, Gyrodinium helveticum] Gymnodinium gracile Bergh [G. spirale var. nobilis etc.] Gymnodinium gracile Bergh [G. spirale var. nobilis etc.] Gymnodinium gracile Bergh [G. spirale var. nobilis etc.]Gymnodinium gracile Bergh [G. spirale var. nobilis etc.] Gymnodinium gracile Bergh [G. spirale var. nobilis etc.] Gymnodinium gracile Bergh [G. spirale var. nobilis etc.]Gymnodinium gracile Bergh [G. spirale var. nobilis etc.] Gymnodinium gracile Bergh [G. spirale var. nobilis etc.] Gymnodinium gracile Bergh [G. spirale var. nobilis etc.]Gymnodinium gracile Bergh [G. spirale var. nobilis etc.] Gymnodinium gracile Bergh [G. spirale var. nobilis etc.] Gymnodinium gracile Bergh [G. spirale var. nobilis etc.]Gymnodinium gracile Bergh [G. spirale var. nobilis etc.] Gymnodinium gracile Bergh [G. spirale var. nobilis etc.]

Gymnodinium helveticum Pénard [G. helveticum var. apiculata] Gymnodinium helveticum Pénard [G. helveticum var. apiculata] Gymnodinium helveticum Pénard [G. helveticum var. apiculata] Gymnodinium helveticum Pénard [G. helveticum var. apiculata] Gymnodinium helveticum Pénard [G. helveticum var. apiculata] Gymnodinium helveticum Pénard [G. helveticum var. apiculata] Gymnodinium helveticum Pénard [G. helveticum var. apiculata] Gymnodinium helveticum Pénard [G. helveticum var. apiculata] Gymnodinium helveticum Pénard [G. helveticum var. apiculata] Gymnodinium helveticum Pénard [G. helveticum var. apiculata] Gymnodinium helveticum Pénard [G. helveticum var. apiculata] Gymnodinium helveticum Pénard [G. helveticum var. apiculata] Gymnodinium helveticum Pénard [G. helveticum var. apiculata] Gymnodinium helveticum Pénard [G. helveticum var. apiculata]

G. heterostriatum Kofod. et SwezyG. heterostriatum Kofod. et SwezyG. heterostriatum

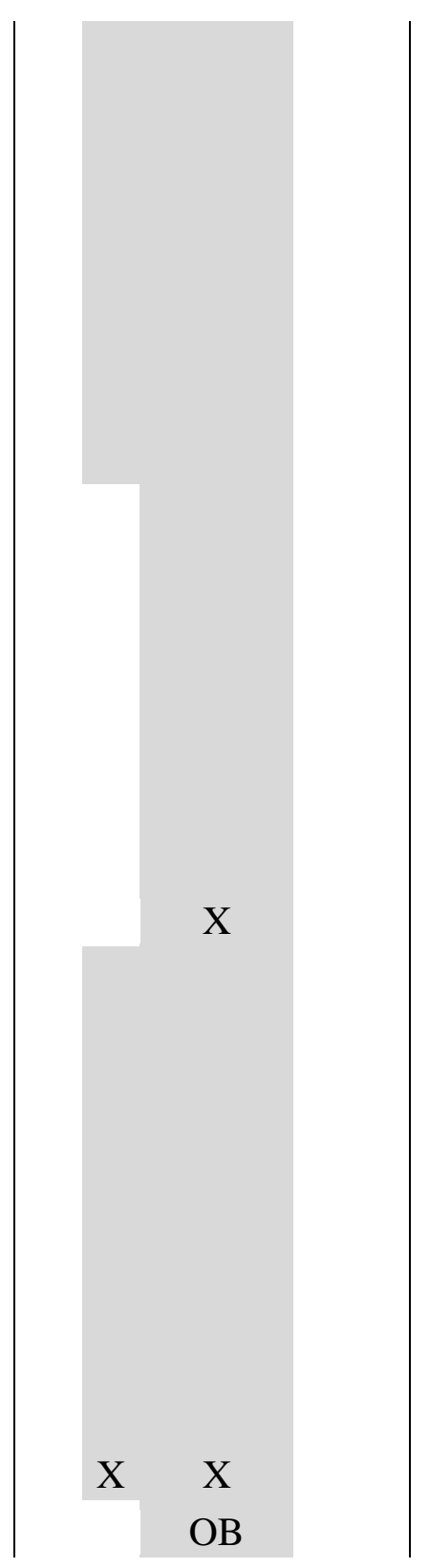


Kofod. et SwezyG. heterostriatum Kofod. et SwezyG. heterostriatum Kofod. et SwezyG. heterostriatum Kofod. et SwezyG. heterostriatum Kofod. et SwezyG. heterostriatum Kofod. et SwezyG. heterostriatum Kofod. et SwezyG. heterostriatum Kofod. et SwezyG. heterostriatum Kofod. et SwezyG. heterostriatum Kofod. et SwezyG. heterostriatum Kofod. et SwezyG. heterostriatum Kofod. et Swezy

Gymnodinium japonica HadaGymnodinium japonica HadaGymnodinium japonica HadaGymnodinium japonica HadaGymnodinium japonica HadaGymnodinium japonica HadaGymnodinium japonica HadaGymnodinium japonica HadaGymnodinium japonica HadaGymnodinium japonica HadaGymnodinium japonica HadaGymnodinium japonica HadaGymnodinium japonica HadaGymnodinium japonica Hada

Gymnodinium lacustre SchillerGymnodinium lacustre SchillerGymnodinium lacustre SchillerGymnodinium lacustre SchillerGymnodinium lacustre SchillerGymnodinium lacustre SchillerGymnodinium lacustre SchillerGymnodinium lacustre SchillerGymnodinium lacustre SchillerGymnodinium lacustre SchillerGymnodinium lacustre SchillerGymnodinium lacustre SchillerGymnodinium lacustre SchillerGymnodinium lacustre Schiller

Gymnodinium marinum Saville-Kent Gymnodinium marinum Saville-Kent Gymnodinium marinum Saville-Kent Gymnodinium marinum Saville-Kent Gymnodinium marinum Saville-Kent Gymnodinium marinum Saville-Kent Gymnodinium marinum Saville-Kent Gymnodinium marinum Saville-Kent Gymnodinium marinum Saville-Kent Gymnodinium marinum Saville-Kent Gymnodinium marinum Saville-Kent Gymnodinium marinum Saville-Kent Gymnodinium marinum Saville-Kent Gymnodinium marinum Saville-Kent Gymnodinium minus Lebour Gymnodinium minus Lebour Gymnodinium minus Lebour Gymnodinium minus Lebour Gymnodinium minus Lebour Gymnodinium minus Lebour Gymnodinium minus Lebour Gymnodinium minus Lebour Gymnodinium minus Lebour Gymnodinium minus Lebour Gymnodinium minus Lebour Gymnodinium minus Lebour Gymnodinium minus Lebour Gymnodinium minus Lebour

Gymnodinium najadeum Schiller Gymnodinium najadeum Schiller Gymnodinium najadeum Schiller Gymnodinium najadeum Schiller Gymnodinium najadeum Schiller Gymnodinium najadeum Schiller Gymnodinium najadeum Schiller Gymnodinium najadeum Schiller Gymnodinium najadeum Schiller Gymnodinium najadeum Schiller Gymnodinium najadeum Schiller Gymnodinium najadeum Schiller Gymnodinium najadeum Schiller Gymnodinium najadeum Schiller

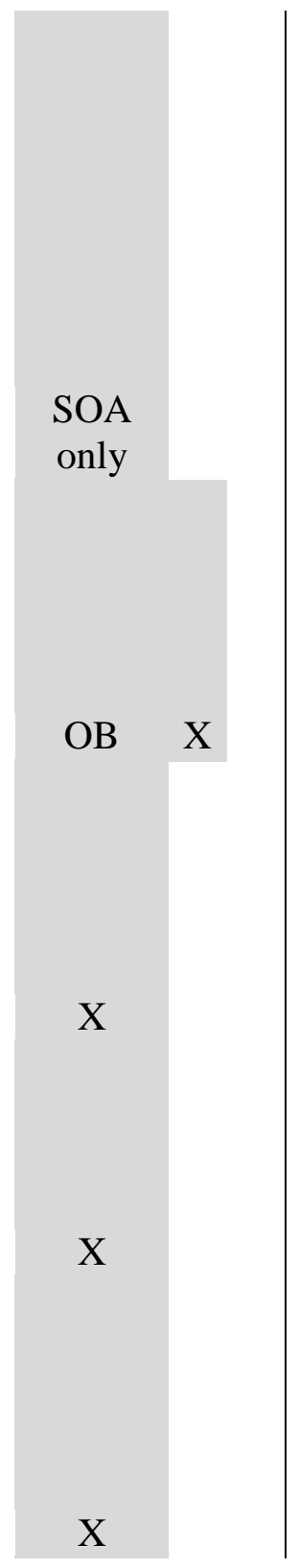


Gymnodinium neapolitanum SchillerGymnodinium neapolitanum SchillerGymnodinium neapolitanum SchillerGymnodinium neapolitanum SchillerGymnodinium neapolitanum SchillerGymnodinium neapolitanum SchillerGymnodinium neapolitanum SchillerGymnodinium neapolitanum SchillerGymnodinium neapolitanum SchillerGymnodinium neapolitanum SchillerGymnodinium neapolitanum SchillerGymnodinium neapolitanum SchillerGymnodinium neapolitanum SchillerGymnodinium neapolitanum Schiller

Gymnodinium paradoxum Schilling Gymnodinium paradoxum Schilling Gymnodinium paradoxum Schilling Gymnodinium paradoxum Schilling Gymnodinium paradoxum Schilling Gymnodinium paradoxum Schilling Gymnodinium paradoxum Schilling Gymnodinium paradoxum Schilling Gymnodinium paradoxum Schilling Gymnodinium paradoxum Schilling Gymnodinium paradoxum Schilling Gymnodinium paradoxum Schilling Gymnodinium paradoxum Schilling Gymnodinium paradoxum Schilling Gymnodinium pygmaeum Lebour [? Gymnodinium aureolum] Gymnodinium pygmaeum Lebour [? Gymnodinium aureolum] Gymnodinium pygmaeum Lebour [? Gymnodinium aureolum] Gymnodinium pygmaeum Lebour [? Gymnodinium aureolum] Gymnodinium pygmaeum Lebour [? Gymnodinium aureolum] Gymnodinium pygmaeum Lebour [? Gymnodinium aureolum] Gymnodinium pygmaeum Lebour [? Gymnodinium aureolum] Gymnodinium pygmaeum Lebour [? Gymnodinium aureolum]Gymnodinium pygmaeum Lebour [? Gymnodinium aureolum] Gymnodinium pygmaeum Lebour [? Gymnodinium aureolum] Gymnodinium pygmaeum Lebour [? Gymnodinium aureolum] Gymnodinium pygmaeum Lebour [? Gymnodinium aureolum]Gymnodinium pygmaeum Lebour [? Gymnodinium aureolum]

Gymnodinium radiatum Kofoid et Swezy Gymnodinium radiatum Kofoid et Swezy Gymnodinium radiatum Kofoid et Swezy Gymnodinium radiatum Kofoid et Swezy Gymnodinium radiatum Kofoid et Swezy Gymnodinium radiatum Kofoid et Swezy Gymnodinium radiatum Kofoid et Swezy Gymnodinium radiatum Kofoid et Swezy Gymnodinium radiatum Kofoid et Swezy Gymnodinium radiatum Kofoid et Swezy Gymnodinium radiatum Kofoid et Swezy Gymnodinium radiatum Kofoid et Swezy Gymnodinium radiatum Kofoid et Swezy

Gymnodinium rhomboides SchüttGymnodinium rhomboides SchüttGymnodinium rhomboides SchüttGymnodinium rhomboides SchüttGymnodinium rhomboides SchüttGymnodinium rhomboides SchüttGymnodinium rhomboides

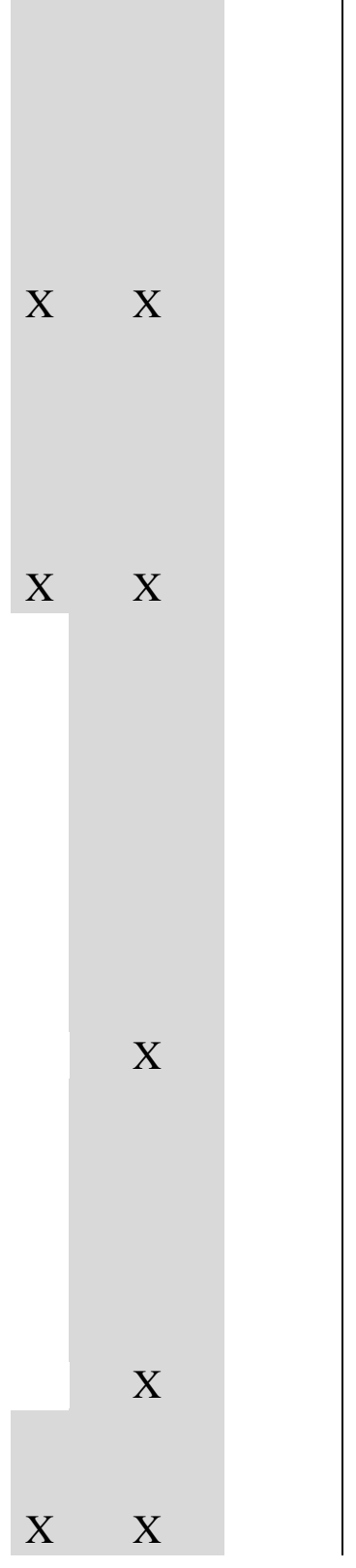


SchüttGymnodinium rhomboides SchüttGymnodinium rhomboides SchüttGymnodinium rhomboides SchüttGymnodinium rhomboides SchüttGymnodinium rhomboides SchüttGymnodinium rhomboides Schütt

Gymnodinium rotundatum Klebs Gymnodinium rotundatum Klebs Gymnodinium rotundatum Klebs Gymnodinium rotundatum Klebs Gymnodinium rotundatum Klebs Gymnodinium rotundatum Klebs Gymnodinium rotundatum Klebs Gymnodinium rotundatum Klebs Gymnodinium rotundatum Klebs Gymnodinium rotundatum Klebs Gymnodinium rotundatum Klebs Gymnodinium rotundatum Klebs Gymnodinium rotundatum Klebs

Gymnodinium sanguineum Hirasaka (Gymnodinium splendens Lebour) Gymnodinium sanguineum Hirasaka (Gymnodinium splendens Lebour) Gymnodinium sanguineum Hirasaka (Gymnodinium splendens Lebour) Gymnodinium sanguineum Hirasaka (Gymnodinium splendens Lebour) Gymnodinium sanguineum Hirasaka (Gymnodinium splendens Lebour) Gymnodinium sanguineum Hirasaka (Gymnodinium splendens Lebour) Gymnodinium sanguineum Hirasaka (Gymnodinium splendens Lebour) Gymnodinium sanguineum Hirasaka (Gymnodinium splendens Lebour) Gymnodinium sanguineum Hirasaka (Gymnodinium splendens Lebour) Gymnodinium sanguineum Hirasaka (Gymnodinium splendens Lebour) Gymnodinium sanguineum Hirasaka (Gymnodinium splendens Lebour) Gymnodinium sanguineum Hirasaka (Gymnodinium splendens Lebour) Gymnodinium sanguineum Hirasaka (Gymnodinium splendens Lebour)

Gymnodinium semidivisum SchillerGymnodinium semidivisum SchillerGymnodinium semidivisum SchillerGymnodinium semidivisum SchillerGymnodinium semidivisum SchillerGymnodinium semidivisum SchillerGymnodinium semidivisum SchillerGymnodinium semidivisum SchillerGymnodinium semidivisum SchillerGymnodinium semidivisum SchillerGymnodinium semidivisum SchillerGymnodinium semidivisum SchillerGymnodinium semidivisum Schiller Gymnodinium simplex (Lohmann) Kofoid et Swezy [Protodinium simplex] Gymnodinium simplex (Lohmann) Kofoid et Swezy [Protodinium simplex] Gymnodinium simplex (Lohmann) Kofoid et Swezy [Protodinium simplex] Gymnodinium simplex (Lohmann) Kofoid et Swezy [Protodinium simplex] Gymnodinium simplex (Lohmann) Kofoid et Swezy [Protodinium simplex] Gymnodinium simplex (Lohmann) Kofoid et Swezy [Protodinium simplex] Gymnodinium simplex (Lohmann) Kofoid et Swezy [Protodinium

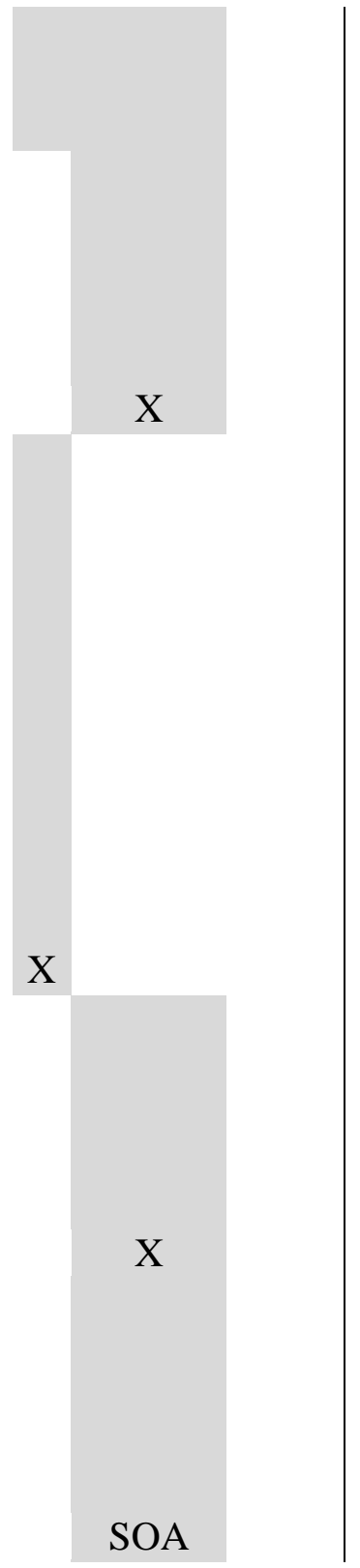


simplex] Gymnodinium simplex (Lohmann) Kofoid et Swezy [Protodinium simplex] Gymnodinium simplex (Lohmann) Kofoid et Swezy [Protodinium simplex] Gymnodinium simplex (Lohmann) Kofoid et Swezy [Protodinium simplex] Gymnodinium simplex (Lohmann) Kofoid et Swezy [Protodinium simplex] Gymnodinium simplex (Lohmann) Kofoid et Swezy [Protodinium simplex] Gymnodinium simplex (Lohmann) Kofoid et Swezy [Protodinium simplex]

Gymnodinium sphaericum (Calkins) Kofoid et Swezy [G. gracile v. sphaerica ] Gymnodinium sphaericum (Calkins) Kofoid et Swezy [G. gracile v. sphaerica] Gymnodinium sphaericum (Calkins) Kofoid et Swezy [G. gracile v. sphaerica] Gymnodinium sphaericum (Calkins) Kofoid et Swezy [G. gracile v. sphaerica ] Gymnodinium sphaericum (Calkins) Kofoid et Swezy [G. gracile v. sphaerica ] Gymnodinium sphaericum (Calkins) Kofoid et Swezy [G. gracile v. sphaerica ] Gymnodinium sphaericum (Calkins) Kofoid et Swezy [G. gracile v. sphaerica ] Gymnodinium sphaericum (Calkins) Kofoid et Swezy [G. gracile v. sphaerica ] Gymnodinium sphaericum (Calkins) Kofoid et Swezy [G. gracile v. sphaerica ] Gymnodinium sphaericum (Calkins) Kofoid et Swezy [G. gracile v. sphaerica ] Gymnodinium sphaericum (Calkins) Kofoid et Swezy [G. gracile v. sphaerica ] Gymnodinium sphaericum (Calkins) Kofoid et Swezy [G. gracile v. sphaerica ] Gymnodinium sphaericum (Calkins) Kofoid et Swezy [G. gracile v. sphaerica ] Gymnodinium stellatum Hulburt Gymnodinium stellatum Hulburt Gymnodinium stellatum Hulburt Gymnodinium stellatum Hulburt Gymnodinium stellatum Hulburt Gymnodinium stellatum Hulburt Gymnodinium stellatum Hulburt Gymnodinium stellatum Hulburt Gymnodinium stellatum Hulburt Gymnodinium stellatum Hulburt Gymnodinium stellatum Hulburt Gymnodinium stellatum Hulburt Gymnodinium stellatum Hulburt Gymnodinium sulcatum Kofoid et Swezy Gymnodinium sulcatum Kofoid et Swezy Gymnodinium sulcatum Kofoid et Swezy Gymnodinium sulcatum Kofoid et Swezy Gymnodinium sulcatum Kofoid et Swezy Gymnodinium sulcatum Kofoid et Swezy Gymnodinium sulcatum Kofoid et Swezy Gymnodinium sulcatum Kofoid et Swezy Gymnodinium sulcatum Kofoid et Swezy Gymnodinium sulcatum Kofoid et Swezy Gymnodinium sulcatum Kofoid et Swezy Gymnodinium sulcatum Kofoid et Swezy Gymnodinium sulcatum Kofoid et Swezy

G. tenuissimum van MeeG. tenuissimum van $M e e G$. tenuissimum van MeeG. tenuissimum van MeeG. tenuissimum van MeeG. tenuissimum van MeeG. tenuissimum van MeeG.

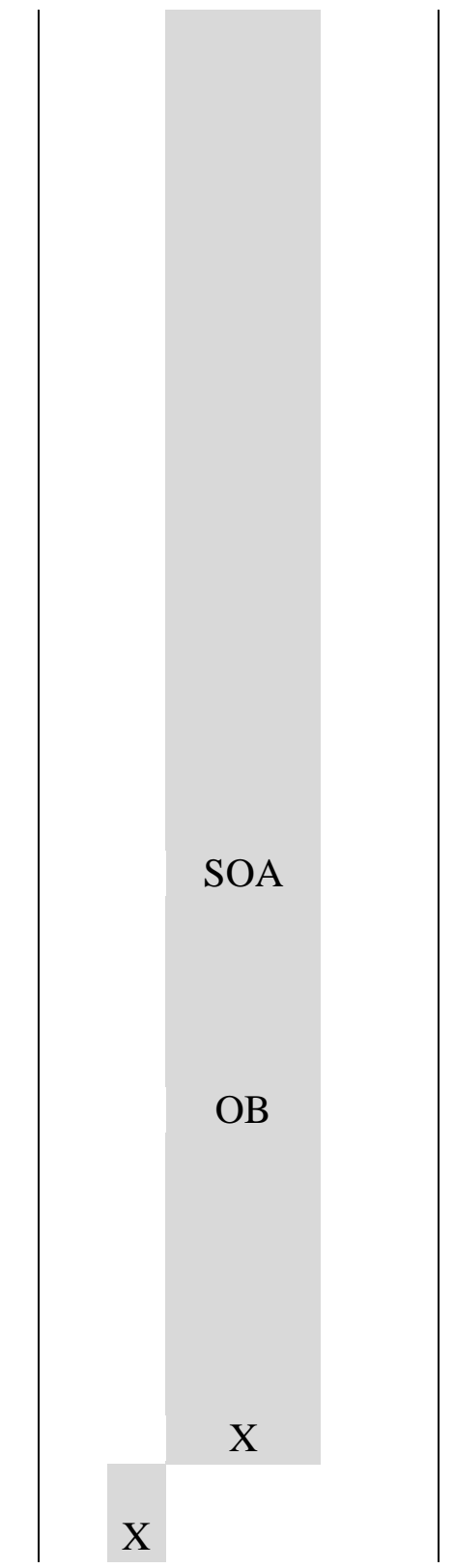


tenuissimum van MeeG. tenuissimum van MeeG. tenuissimum van MeeG. tenuissimum van MeeG. tenuissimum van MeeG. tenuissimum van Mee

Gymnodinium uberrimum (Allman) Kofoid et Swezy [G. mirabile etc.]Gymnodinium uberrimum (Allman) Kofoid et Swezy [G. mirabile etc.]Gymnodinium uberrimum (Allman) Kofoid et Swezy [G. mirabile etc.]Gymnodinium uberrimum (Allman) Kofoid et Swezy [G. mirabile etc.]Gymnodinium uberrimum (Allman) Kofoid et Swezy [G. mirabile etc.]Gymnodinium uberrimum (Allman) Kofoid et Swezy [G. mirabile etc.]Gymnodinium uberrimum (Allman) Kofoid et Swezy [G. mirabile etc.]Gymnodinium uberrimum (Allman) Kofoid et Swezy [G. mirabile etc.]Gymnodinium uberrimum (Allman) Kofoid et Swezy [G. mirabile etc.]Gymnodinium uberrimum (Allman) Kofoid et Swezy [G. mirabile etc.]Gymnodinium uberrimum (Allman) Kofoid et Swezy [G. mirabile etc.]Gymnodinium uberrimum (Allman) Kofoid et Swezy [G. mirabile etc.]Gymnodinium uberrimum (Allman) Kofoid et Swezy [G. mirabile etc.]

Gymnodinium variabile Herdman

Gymnodinium wulffii [non Gyrodinium wulffii, Glenodinium apiculatum] Gymnodinium wulffii [non Gyrodinium wulffii, Glenodinium apiculatum] Gymnodinium wulffii [non Gyrodinium wulffii, Glenodinium apiculatum] Gymnodinium wulffii [non Gyrodinium wulffii, Glenodinium apiculatum] Gymnodinium wulffii [non Gyrodinium wulffii,

Glenodinium apiculatum] Gymnodinium wulffii [non Gyrodinium wulffii, Glenodinium apiculatum] Gymnodinium wulffii [non Gyrodinium wulffii, Glenodinium apiculatum] Gymnodinium wulffii [non Gyrodinium wulffii, Glenodinium apiculatum] Gymnodinium wulffii [non Gyrodinium wulffii, Glenodinium apiculatum] Gymnodinium wulffii [non Gyrodinium wulffii, Glenodinium apiculatum] Gymnodinium wulffii [non Gyrodinium wulffii, Glenodinium apiculatum] Gymnodinium wulffii [non Gyrodinium wulffii,

Glenodinium apiculatum] Gymnodinium wulffii [non Gyrodinium wulffii, Glenodinium apiculatum]

Gyrodinium britannicum Kofoid \& Swezy [Spirodinium spirale v. acutum]Gyrodinium britannicum Kofoid \& Swezy [Spirodinium spirale v. acutum] Gyrodinium britannicum Kofoid \& Swezy [Spirodinium spirale v. acutum] Gyrodinium britannicum Kofoid \& Swezy [Spirodinium spirale v. acutum] Gyrodinium britannicum Kofoid \& Swezy [Spirodinium spirale v. acutum] Gyrodinium britannicum Kofoid \& Swezy [Spirodinium spirale v. acutum] Gyrodinium britannicum Kofoid \& Swezy [Spirodinium spirale v.

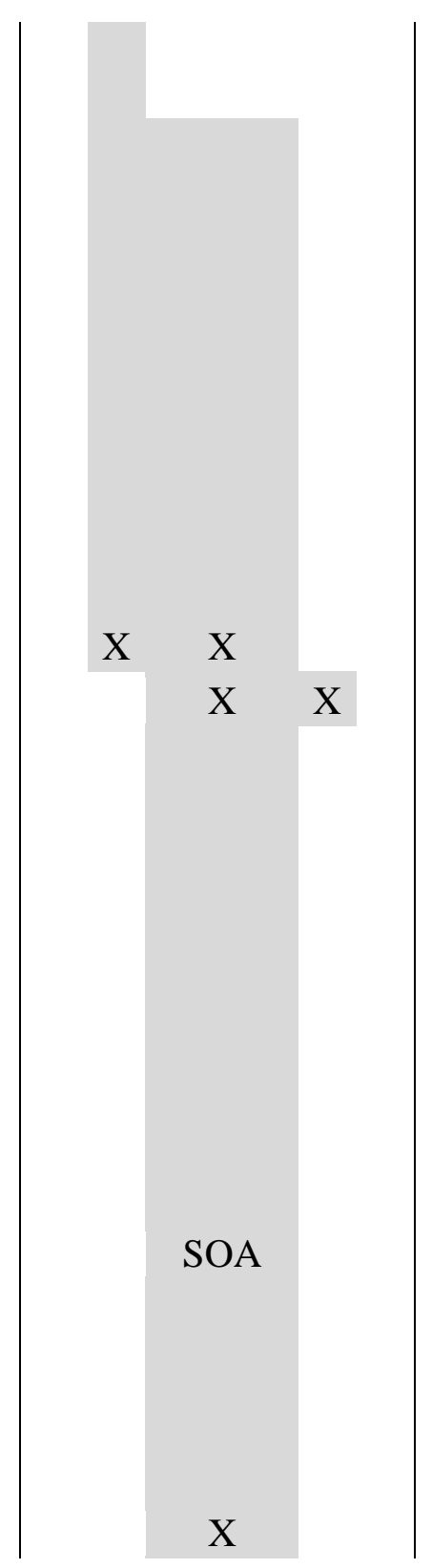


acutum] Gyrodinium britannicum Kofoid \& Swezy [Spirodinium spirale v. acutum]Gyrodinium britannicum Kofoid \& Swezy [Spirodinium spirale v. acutum] Gyrodinium britannicum Kofoid \& Swezy [Spirodinium spirale v. acutum] Gyrodinium britannicum Kofoid \& Swezy [Spirodinium spirale v. acutum] Gyrodinium britannicum Kofoid \& Swezy [Spirodinium spirale v. acutum] Gyrodinium britannicum Kofoid \& Swezy [Spirodinium spirale v. acutum] Gyrodinium capsulatum Kofoid et Swezy Gyrodinium capsulatum Kofoid et Swezy Gyrodinium capsulatum Kofoid et Swezy Gyrodinium capsulatum Kofoid et Swezy Gyrodinium capsulatum Kofoid et Swezy Gyrodinium capsulatum Kofoid et Swezy Gyrodinium capsulatum Kofoid et Swezy Gyrodinium capsulatum Kofoid et Swezy Gyrodinium capsulatum Kofoid et Swezy Gyrodinium capsulatum Kofoid et Swezy Gyrodinium capsulatum Kofoid et Swezy Gyrodinium capsulatum Kofoid et Swezy Gyrodinium capsulatum Kofoid et Swezy

Gyrodinium cornutum (Pouchet) Kofoid et Swezy [Gymnodinium spirale v. cornutum] Gyrodinium cornutum (Pouchet) Kofoid et Swezy [Gymnodinium spirale v. cornutum] Gyrodinium cornutum (Pouchet) Kofoid et Swezy [Gymnodinium spirale v. cornutum] Gyrodinium cornutum (Pouchet) Kofoid et Swezy [Gymnodinium spirale v. cornutum] Gyrodinium cornutum (Pouchet) Kofoid et Swezy [Gymnodinium spirale v. cornutum] Gyrodinium cornutum (Pouchet) Kofoid et Swezy [Gymnodinium spirale v. cornutum] Gyrodinium cornutum (Pouchet) Kofoid et Swezy [Gymnodinium spirale v. cornutum] Gyrodinium cornutum (Pouchet) Kofoid et Swezy [Gymnodinium spirale v. cornutum] Gyrodinium cornutum (Pouchet) Kofoid et Swezy [Gymnodinium spirale v. cornutum] Gyrodinium cornutum (Pouchet) Kofoid et Swezy [Gymnodinium spirale v. cornutum] Gyrodinium cornutum (Pouchet) Kofoid et Swezy [Gymnodinium spirale v. cornutum] Gyrodinium cornutum (Pouchet) Kofoid et Swezy [Gymnodinium spirale v. cornutum] Gyrodinium falcatum Kofoid et Swezy [Gymnodinium fusus pro parte] Gyrodinium falcatum Kofoid et Swezy [Gymnodinium fusus pro parte] Gyrodinium falcatum Kofoid et Swezy [Gymnodinium fusus pro parte] Gyrodinium falcatum Kofoid et Swezy [Gymnodinium fusus pro parte] Gyrodinium falcatum Kofoid et Swezy [Gymnodinium fusus pro parte] Gyrodinium falcatum Kofoid et Swezy [Gymnodinium fusus pro parte] Gyrodinium falcatum Kofoid et Swezy [Gymnodinium fusus pro parte] Gyrodinium falcatum Kofoid et Swezy [Gymnodinium fusus pro parte] Gyrodinium falcatum Kofoid et Swezy [Gymnodinium fusus pro parte] Gyrodinium falcatum Kofoid et Swezy

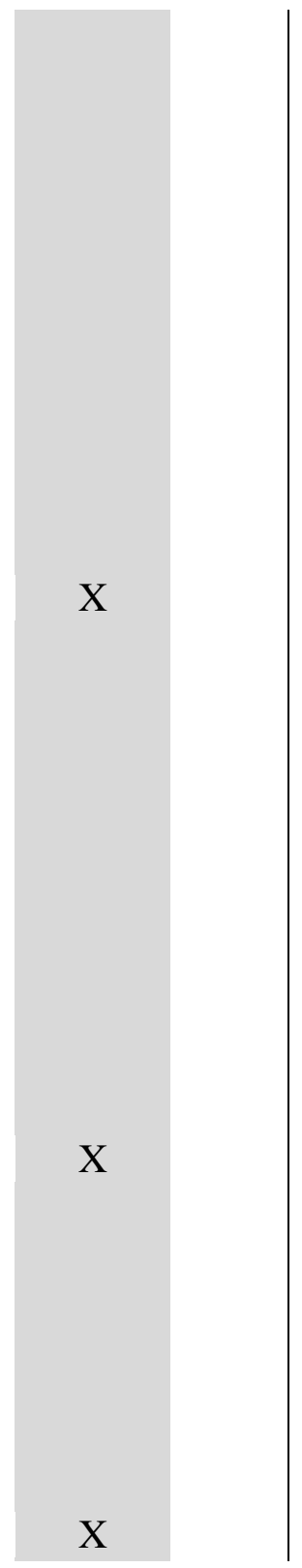


[Gymnodinium fusus pro parte] Gyrodinium falcatum Kofoid et Swezy [Gymnodinium fusus pro parte] Gyrodinium falcatum Kofoid et Swezy [Gymnodinium fusus pro parte] Gyrodinium fissum (Levander) Kofoid \& Swezy [?G. fissoides Elbrächter, Gyrodinium fissum (Levander) Kofoid \& Swezy [?G. fissoides Elbrächter, Gyrodinium fissum (Levander) Kofoid \& Swezy [?G. fissoides Elbrächter, Gyrodinium fissum (Levander) Kofoid \& Swezy [?G. fissoides Elbrächter,Gyrodinium fissum (Levander) Kofoid \& Swezy [?G. fissoides Elbrächter, Gyrodinium fissum (Levander) Kofoid \& Swezy [?G. fissoides Elbrächter,Gyrodinium fissum (Levander) Kofoid \& Swezy [?G. fissoides Elbrächter,Gyrodinium fissum (Levander) Kofoid \& Swezy [?G. fissoides Elbrächter, Gyrodinium fissum (Levander) Kofoid \& Swezy [?G. fissoides Elbrächter, Gyrodinium fissum (Levander) Kofoid \& Swezy [?G. fissoides Elbrächter, Gyrodinium fissum (Levander) Kofoid \& Swezy [?G. fissoides Elbrächter, Gyrodinium fissum (Levander) Kofoid \& Swezy [?G. fissoides Elbrächter, Gyrodinium fusus (Meunier) Akselman [Spirodinium fusus, G. fusiforme Gyrodinium fusus (Meunier) Akselman [Spirodinium fusus, G. fusiforme Gyrodinium fusus (Meunier) Akselman [Spirodinium fusus, G. fusiforme Gyrodinium fusus (Meunier) Akselman [Spirodinium fusus, G. fusiforme Gyrodinium fusus (Meunier) Akselman [Spirodinium fusus, G. fusiforme Gyrodinium fusus (Meunier) Akselman [Spirodinium fusus, G. fusiforme Gyrodinium fusus (Meunier) Akselman [Spirodinium fusus, G. fusiforme Gyrodinium fusus (Meunier) Akselman [Spirodinium fusus, G. fusiforme Gyrodinium fusus (Meunier) Akselman [Spirodinium fusus, G. fusiforme Gyrodinium fusus (Meunier) Akselman [Spirodinium fusus, G. fusiforme Gyrodinium fusus (Meunier) Akselman [Spirodinium fusus, G. fusiforme Gyrodinium fusus (Meunier) Akselman [Spirodinium fusus, G. fusiforme

Gyrodinium glaebum Hulburt [Gymnodinium mirabile Pénard] Gyrodinium glaebum Hulburt [Gymnodinium mirabile Pénard] Gyrodinium glaebum Hulburt [Gymnodinium mirabile Pénard] Gyrodinium glaebum Hulburt [Gymnodinium mirabile Pénard] Gyrodinium glaebum Hulburt [Gymnodinium mirabile Pénard] Gyrodinium glaebum Hulburt [Gymnodinium mirabile Pénard] Gyrodinium glaebum Hulburt [Gymnodinium mirabile Pénard] Gyrodinium glaebum Hulburt [Gymnodinium mirabile Pénard] Gyrodinium glaebum Hulburt [Gymnodinium mirabile Pénard] Gyrodinium glaebum Hulburt [Gymnodinium mirabile Pénard] Gyrodinium glaebum Hulburt [Gymnodinium mirabile Pénard] Gyrodinium glaebum Hulburt [Gymnodinium mirabile Pénard]

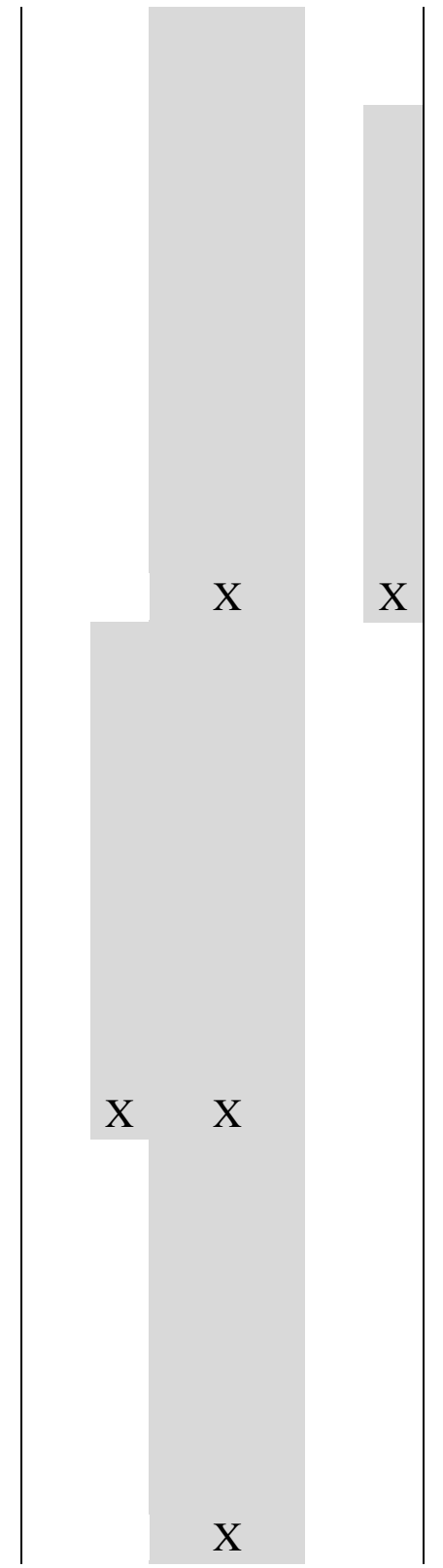


Gyrodinium lachryma (Meunier) Kofoid \& Swezy [Spirodinium lachryma Meunier] Gyrodinium lachryma (Meunier) Kofoid \& Swezy [Spirodinium lachryma Meunier] Gyrodinium lachryma (Meunier) Kofoid \& Swezy [Spirodinium lachryma Meunier] Gyrodinium lachryma (Meunier) Kofoid \& Swezy [Spirodinium lachryma Meunier] Gyrodinium lachryma (Meunier) Kofoid \& Swezy [Spirodinium lachryma Meunier] Gyrodinium lachryma (Meunier) Kofoid \& Swezy [Spirodinium lachryma Meunier] Gyrodinium lachryma (Meunier) Kofoid \& Swezy [Spirodinium lachryma Meunier] Gyrodinium lachryma (Meunier) Kofoid \& Swezy [Spirodinium lachryma Meunier] Gyrodinium lachryma (Meunier) Kofoid \& Swezy [Spirodinium lachryma Meunier] Gyrodinium lachryma (Meunier) Kofoid \& Swezy [Spirodinium lachryma Meunier] Gyrodinium lachryma (Meunier) Kofoid \& Swezy [Spirodinium lachryma Meunier] Gyrodinium lachryma (Meunier) Kofoid \& Swezy [Spirodinium lachryma Meunier] Gyrodinium nasutum (Wulff) Schiller [Spirodinium nasutum Wulff] Gyrodinium nasutum (Wulff) Schiller [Spirodinium nasutum Wulff] Gyrodinium nasutum (Wulff) Schiller [Spirodinium nasutumWulff] Gyrodinium nasutum (Wulff) Schiller [Spirodinium nasutum Wulff] Gyrodinium nasutum (Wulff) Schiller [Spirodinium nasutumWulff] Gyrodinium nasutum (Wulff) Schiller [Spirodinium nasutumWulff] Gyrodinium nasutum (Wulff) Schiller [Spirodinium nasutum Wulff] Gyrodinium nasutum (Wulff) Schiller [Spirodinium nasutum Wulff] Gyrodinium nasutum (Wulff) Schiller [Spirodinium nasutumWulff] Gyrodinium nasutum (Wulff) Schiller [Spirodinium nasutum Wulff] Gyrodinium nasutum (Wulff) Schiller [Spirodinium nasutumWulff] Gyrodinium nasutum (Wulff) Schiller [Spirodinium nasutumWulff] Gyrodinium ovum (Schütt) Kofoid \& Swezy Gyrodinium ovum (Schütt) Kofoid \& Swezy Gyrodinium ovum (Schütt) Kofoid \& Swezy Gyrodinium ovum (Schütt) Kofoid \& Swezy Gyrodinium ovum (Schütt) Kofoid \& Swezy Gyrodinium ovum (Schütt) Kofoid \& Swezy Gyrodinium ovum (Schütt) Kofoid \& Swezy Gyrodinium ovum (Schütt) Kofoid \& Swezy Gyrodinium ovum (Schütt) Kofoid \& Swezy Gyrodinium ovum (Schütt) Kofoid \& Swezy Gyrodinium ovum (Schütt) Kofoid \& Swezy Gyrodinium ovum (Schütt) Kofoid \& Swezy Gyrodinium pavillardii Biecheler Gyrodinium pavillardii Biecheler Gyrodinium pavillardii Biecheler Gyrodinium pavillardii Biecheler Gyrodinium pavillardii Biecheler Gyrodinium pavillardii Biecheler Gyrodinium pavillardii Biecheler Gyrodinium pavillardii Biecheler Gyrodinium pavillardii Biecheler Gyrodinium pavillardii Biecheler Gyrodinium pavillardii Biecheler Gyrodinium pavillardii Biecheler 
Gyrodinium pellucidum (Wulff) Schiller [Gymnodinium pellucidum Wulff] Gyrodinium pellucidum (Wulff) Schiller [Gymnodinium pellucidum Wulff] Gyrodinium pellucidum (Wulff) Schiller [Gymnodinium pellucidum Wulff] Gyrodinium pellucidum (Wulff) Schiller [Gymnodinium pellucidum Wulff] Gyrodinium pellucidum (Wulff) Schiller [Gymnodinium pellucidum Wulff] Gyrodinium pellucidum (Wulff) Schiller [Gymnodinium pellucidum Wulff] Gyrodinium pellucidum (Wulff) Schiller [Gymnodinium pellucidum Wulff] Gyrodinium pellucidum (Wulff) Schiller [Gymnodinium pellucidum Wulff] Gyrodinium pellucidum (Wulff) Schiller [Gymnodinium pellucidum Wulff] Gyrodinium pellucidum (Wulff) Schiller [Gymnodinium pellucidum Wulff] Gyrodinium pellucidum (Wulff) Schiller [Gymnodinium pellucidum Wulff] Gyrodinium pellucidum (Wulff) Schiller [Gymnodinium pellucidum Wulff]

Gyrodinium pingue (Schütt) Kofoid et Swezy [Gymnodinium spirale v. pinguis] Gyrodinium pingue (Schütt) Kofoid et Swezy [Gymnodinium spirale v. pinguis] Gyrodinium pingue (Schütt) Kofoid et Swezy [Gymnodinium spirale v. pinguis] Gyrodinium pingue (Schütt) Kofoid et Swezy [Gymnodinium spirale v. pinguis] Gyrodinium pingue (Schütt) Kofoid et Swezy [Gymnodinium spirale v. pinguis] Gyrodinium pingue (Schütt) Kofoid et Swezy [Gymnodinium spirale v. pinguis] Gyrodinium pingue (Schütt) Kofoid et Swezy [Gymnodinium spirale v. pinguis] Gyrodinium pingue (Schütt) Kofoid et Swezy [Gymnodinium spirale v. pinguis] Gyrodinium pingue (Schütt) Kofoid et Swezy [Gymnodinium spirale v. pinguis] Gyrodinium pingue (Schütt) Kofoid et Swezy [Gymnodinium spirale v. pinguis] Gyrodinium pingue (Schütt) Kofoid et Swezy [Gymnodinium spirale v. pinguis] Gyrodinium pingue (Schütt) Kofoid et Swezy [Gymnodinium spirale v. pinguis] Gyrodinium prunus (Wulff) Lebour [ Spirodinium prunus ] Gyrodinium prunus (Wulff) Lebour [ Spirodinium prunus] Gyrodinium prunus (Wulff) Lebour [ Spirodinium prunus ] Gyrodinium prunus (Wulff) Lebour [ Spirodinium prunus ] Gyrodinium prunus (Wulff) Lebour [ Spirodinium prunus] Gyrodinium prunus (Wulff) Lebour [ Spirodinium prunus ] Gyrodinium prunus (Wulff) Lebour [ Spirodinium prunus ] Gyrodinium prunus (Wulff) Lebour [ Spirodinium prunus] Gyrodinium prunus (Wulff) Lebour [ Spirodinium prunus ] Gyrodinium prunus (Wulff) Lebour [ Spirodinium prunus ] Gyrodinium prunus (Wulff) Lebour [ Spirodinium prunus] Gyrodinium prunus (Wulff) Lebour [ Spirodinium prunus l

Gyrodinium pusillum (Schilling) Kofoid et Swezy [Spirodinium pusillum etc.]Gyrodinium

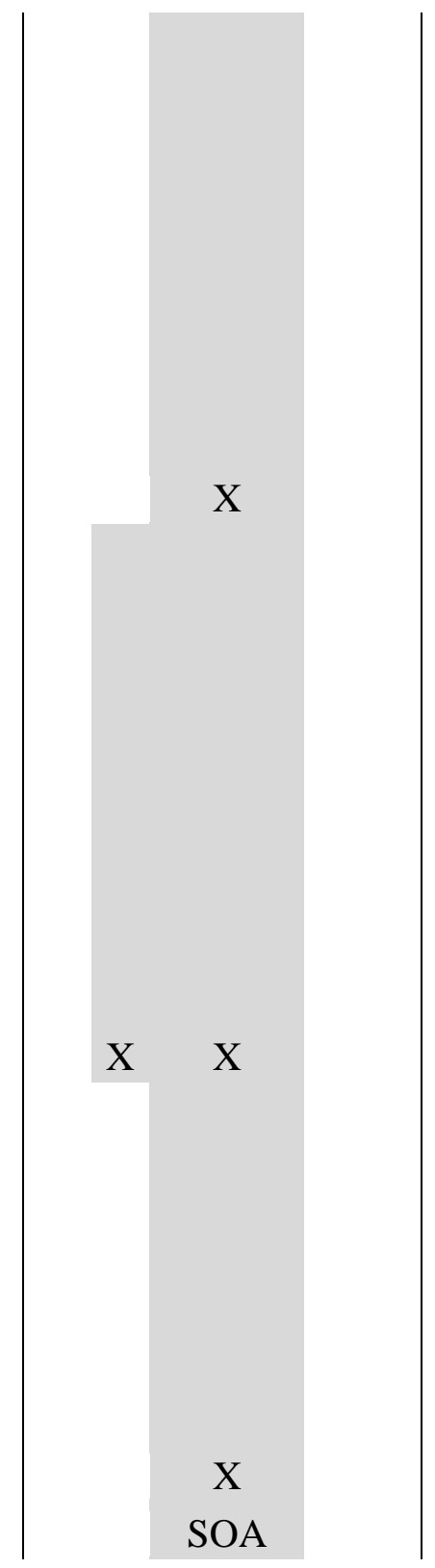


pusillum (Schilling) Kofoid et Swezy [Spirodinium pusillum etc.] Gyrodinium pusillum (Schilling) Kofoid et Swezy [Spirodinium pusillum etc.] Gyrodinium pusillum (Schilling) Kofoid et Swezy [Spirodinium pusillum etc.]Gyrodinium pusillum (Schilling) Kofoid et Swezy [Spirodinium pusillum etc.] Gyrodinium pusillum (Schilling) Kofoid et Swezy) [Spirodinium pusillum etc.] Gyrodinium pusillum (Schilling) Kofoid et Swezy [Spirodinium pusillum etc.] Gyrodinium pusillum (Schilling) Kofoid et Swezy [Spirodinium pusillum etc.] Gyrodinium pusillum (Schilling) Kofoid et Swezy [Spirodinium pusillum etc.] Gyrodinium pusillum (Schilling) Kofoid et Swezy [Spirodinium pusillum etc.] Gyrodinium pusillum (Schilling) Kofoid et Swezy [Spirodinium pusillum etc.] Gyrodinium pusillum (Schilling) Kofoid et Swezy [Spirodinium pusillum etc.]

Gyrodinium schuettii (Lemmermann) Kofoid \& Swezy, 1921Gyrodinium schuettii (Lemmermann) Kofoid \& Swezy, 1921Gyrodinium schuettii (Lemmermann) Kofoid \& Swezy, 1921Gyrodinium schuettii (Lemmermann) Kofoid \& Swezy, 1921Gyrodinium schuettii (Lemmermann) Kofoid \& Swezy, 1921Gyrodinium schuettii (Lemmermann) Kofoid \& Swezy, 1921Gyrodinium schuettii (Lemmermann) Kofoid \& Swezy, 1921 Gyrodinium schuettii (Lemmermann) Kofoid \& Swezy, 1921Gyrodinium schuettii (Lemmermann) Kofoid \& Swezy, 1921Gyrodinium schuettii (Lemmermann) Kofoid \& Swezy, 1921Gyrodinium schuettii (Lemmermann) Kofoid \& Swezy, 1921Gyrodinium schuettii (Lemmermann) Kofoid \& Swezy, 1921

Gyrodinium spirale (Bergh) Kofoid et Swezy [ Gymnodinium spirale Bergh] Gyrodinium spirale (Bergh) Kofoid et Swezy [ Gymnodinium spirale Bergh] Gyrodinium spirale (Bergh) Kofoid et Swezy [ Gymnodinium spirale Bergh] Gyrodinium spirale (Bergh) Kofoid et Swezy [ Gymnodinium spirale Bergh] Gyrodinium spirale (Bergh) Kofoid et Swezy [ Gymnodinium spirale Bergh] Gyrodinium spirale (Bergh) Kofoid et Swezy [ Gymnodinium spirale Bergh] Gyrodinium spirale (Bergh) Kofoid et Swezy [ Gymnodinium spirale Bergh] Gyrodinium spirale (Bergh) Kofoid et Swezy [ Gymnodinium spirale Bergh] Gyrodinium spirale (Bergh) Kofoid et Swezy [ Gymnodinium spirale Bergh] Gyrodinium spirale (Bergh) Kofoid et Swezy [ Gymnodinium spirale Bergh] Gyrodinium spirale (Bergh) Kofoid et Swezy [ Gymnodinium spirale Bergh] Gyrodinium spirale (Bergh) Kofoid et Swezy [ Gymnodinium spirale Bergh]

Hemidinium nasutumStein Hemidinium nasutumStein Hemidinium nasutumStein

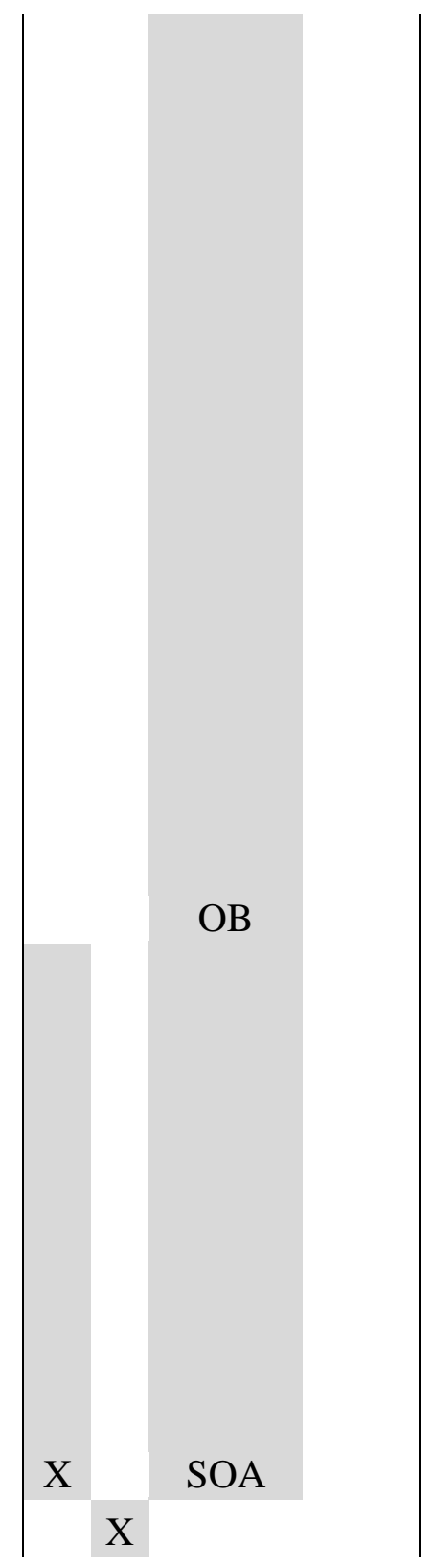


Hemidinium nasutumStein Hemidinium nasutumStein Hemidinium nasutumStein Hemidinium nasutumStein Hemidinium nasutumStein Hemidinium nasutumStein Hemidinium nasutumStein Hemidinium nasutumStein Hemidinium nasutumStein Herdmania litoralis Dodge [Gymnodinium agile] Herdmania litoralis Dodge [Gymnodinium agile] Herdmania litoralis Dodge [Gymnodinium agile] Herdmania litoralis Dodge [Gymnodinium agile] Herdmania litoralis Dodge [Gymnodinium agile] Herdmania litoralis Dodge [Gymnodinium agile] Herdmania litoralis Dodge [Gymnodinium agile] Herdmania litoralis Dodge [Gymnodinium agile] Herdmania litoralis Dodge [Gymnodinium agile] Herdmania litoralis Dodge [Gymnodinium agile] Herdmania litoralis Dodge [Gymnodinium agile]

Heterocapsa rotundata (Lohmann) G. Hansen [Amphidinium rotundatum etc.]Heterocapsa rotundata (Lohmann) G. Hansen [Amphidinium rotundatum etc.]Heterocapsa rotundata (Lohmann) G. Hansen [Amphidinium rotundatum etc.]Heterocapsa rotundata (Lohmann) G. Hansen [Amphidinium rotundatum etc.]Heterocapsa rotundata (Lohmann) G. Hansen [Amphidinium rotundatum etc.]Heterocapsa rotundata (Lohmann) G. Hansen [Amphidinium rotundatum etc.]Heterocapsa rotundata (Lohmann) G. Hansen [Amphidinium rotundatum etc.]Heterocapsa rotundata (Lohmann) G. Hansen [Amphidinium rotundatum etc.]Heterocapsa rotundata (Lohmann) G. Hansen [Amphidinium rotundatum etc.]Heterocapsa rotundata (Lohmann) G. Hansen [Amphidinium rotundatum etc.]Heterocapsa rotundata (Lohmann) G. Hansen [Amphidinium rotundatum etc.] Heterocapsa triquetra (Ehrenberg) Stein [ Glenodinium triquetrum etc.] Heterocapsa triquetra (Ehrenberg) Stein [ Glenodinium triquetrum etc.] Heterocapsa triquetra (Ehrenberg) Stein [ Glenodinium triquetrum etc.] Heterocapsa triquetra (Ehrenberg) Stein [ Glenodinium triquetrum etc.] Heterocapsa triquetra (Ehrenberg) Stein [ Glenodinium triquetrum etc.] Heterocapsa triquetra (Ehrenberg) Stein [ Glenodinium triquetrum etc.] Heterocapsa triquetra (Ehrenberg) Stein [ Glenodinium triquetrum etc.] Heterocapsa triquetra (Ehrenberg) Stein [ Glenodinium triquetrum etc.] Heterocapsa triquetra (Ehrenberg) Stein [ Glenodinium triquetrum etc.] Heterocapsa triquetra (Ehrenberg) Stein [ Glenodinium triquetrum etc.] Heterocapsa triquetra (Ehrenberg) Stein [ Glenodinium triquetrum etc.]

Heterodinium murrayi Kofoid Heterodinium murrayi Kofoid Heterodinium murrayi Kofoid Heterodinium murrayi Kofoid Heterodinium murrayi Kofoid Heterodinium

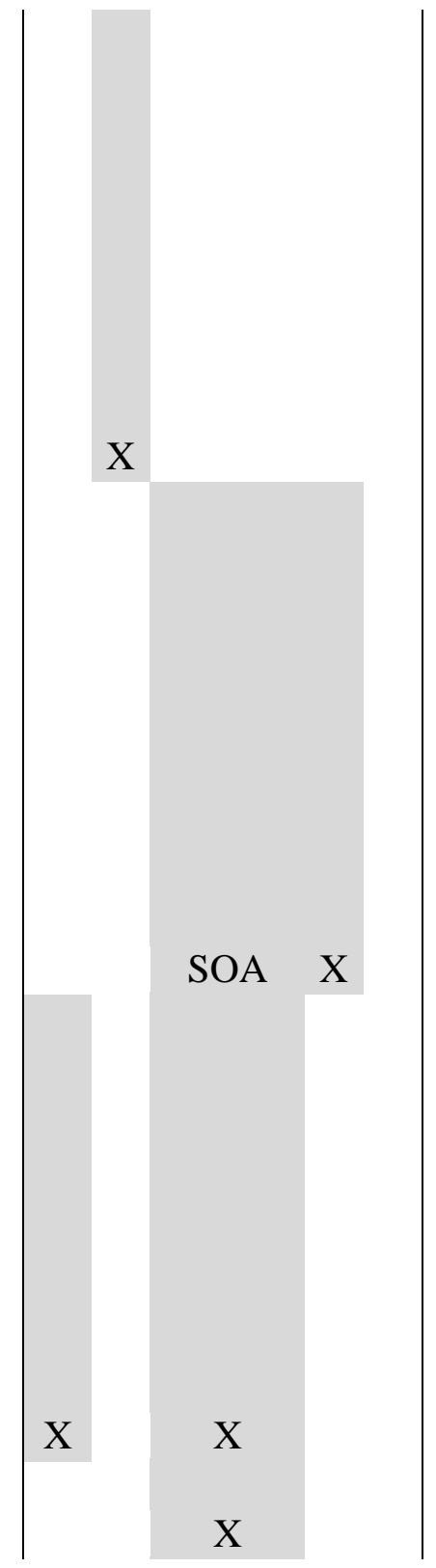


murrayi Kofoid Heterodinium murrayi Kofoid Heterodinium murrayi Kofoid Heterodinium murrayi Kofoid Heterodinium murrayi Kofoid Heterodinium murrayi Kofoid

Hypnodinium sphaericum Klebs Hypnodinium sphaericum Klebs Hypnodinium sphaericum Klebs Hypnodinium sphaericum Klebs Hypnodinium sphaericum Klebs Hypnodinium sphaericum Klebs Hypnodinium sphaericum Klebs Hypnodinium sphaericum Klebs Hypnodinium sphaericum Klebs Hypnodinium sphaericum Klebs Hypnodinium sphaericum Klebs

Katodinium fungiforme (Anissimowa) Loeblich [Gymnodinium fungiforme etc.] Katodinium fungiforme (Anissimowa) Loeblich [Gymnodinium fungiforme etc.] Katodinium fungiforme (Anissimowa) Loeblich [Gymnodinium fungiforme etc.] Katodinium fungiforme (Anissimowa) Loeblich [Gymnodinium fungiforme etc.] Katodinium fungiforme (Anissimowa) Loeblich [Gymnodinium fungiforme etc.] Katodinium fungiforme (Anissimowa) Loeblich [Gymnodinium fungiforme etc.] Katodinium fungiforme (Anissimowa) Loeblich [Gymnodinium fungiforme etc.] Katodinium fungiforme (Anissimowa) Loeblich [Gymnodinium fungiforme etc.] Katodinium fungiforme (Anissimowa) Loeblich [Gymnodinium fungiforme etc.] Katodinium fungiforme (Anissimowa) Loeblich [Gymnodinium fungiforme etc.] Katodinium fungiforme (Anissimowa) Loeblich [Gymnodinium fungiforme etc.] Katodinium vorticella (Stein) Loeblich III [ Gymnodinium vorticella etc.] Katodinium vorticella (Stein) Loeblich III [ Gymnodinium vorticella etc.] Katodinium vorticella (Stein) Loeblich III [ Gymnodinium vorticella etc.] Katodinium vorticella (Stein) Loeblich III [ Gymnodinium vorticella etc.] Katodinium vorticella (Stein) Loeblich III [ Gymnodinium vorticella etc.] Katodinium vorticella (Stein) Loeblich III [ Gymnodinium vorticella etc.] Katodinium vorticella (Stein) Loeblich III [ Gymnodinium vorticella etc.] Katodinium vorticella (Stein) Loeblich III [ Gymnodinium vorticella etc.] Katodinium vorticella (Stein) Loeblich III [ Gymnodinium vorticella etc.] Katodinium vorticella (Stein) Loeblich III [ Gymnodinium vorticella etc.] Katodinium vorticella (Stein) Loeblich III [ Gymnodinium vorticella etc.]

Kofoidinium velleloides Pavillard Kofoidinium velleloides Pavillard Kofoidinium velleloides Pavillard Kofoidinium velleloides Pavillard Kofoidinium velleloides Pavillard Kofoidinium velleloides Pavillard Kofoidinium velleloides Pavillard Kofoidinium velleloides Pavillard Kofoidinium velleloides Pavillard Kofoidinium velleloides Pavillard

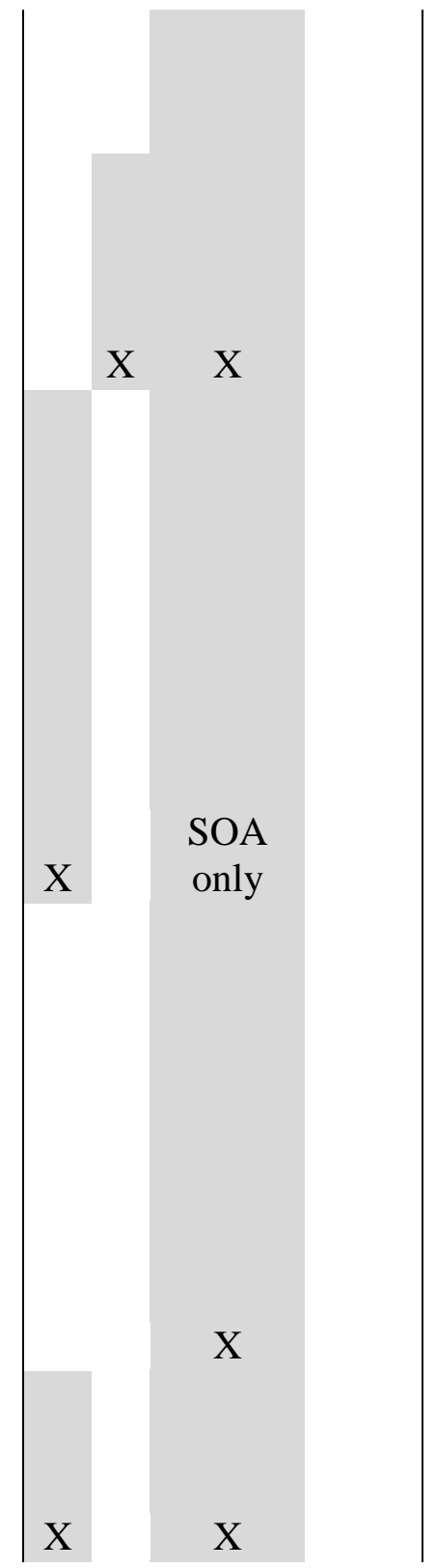


Kofoidinium velleloides Pavillard

Kolkwitziella acuta (Apstein) Elbrächter [Glenodinium acutum etc.] Kolkwitziella acuta (Apstein) Elbrächter [Glenodinium acutum etc.] Kolkwitziella acuta (Apstein) Elbrächter [Glenodinium acutum etc.] Kolkwitziella acuta (Apstein) Elbrächter [Glenodinium acutum etc.] Kolkwitziella acuta (Apstein) Elbrächter [Glenodinium acutum etc.] Kolkwitziella acuta (Apstein) Elbrächter [Glenodinium acutum etc.] Kolkwitziella acuta (Apstein) Elbrächter [Glenodinium acutum etc.] Kolkwitziella acuta (Apstein) Elbrächter [Glenodinium acutum etc.] Kolkwitziella acuta (Apstein) Elbrächter [Glenodinium acutum etc.] Kolkwitziella acuta (Apstein) Elbrächter [Glenodinium acutum etc.] Kolkwitziella acuta (Apstein) Elbrächter [Glenodinium acutum etc.]

Kryptoperidinium foliaceum (Stein) Lindemann [Glenodinium foliaceum] Kryptoperidinium foliaceum (Stein) Lindemann [Glenodinium foliaceum] Kryptoperidinium foliaceum (Stein) Lindemann [Glenodinium foliaceum] Kryptoperidinium foliaceum (Stein) Lindemann [Glenodinium foliaceum] Kryptoperidinium foliaceum (Stein) Lindemann [Glenodinium foliaceum] Kryptoperidinium foliaceum (Stein) Lindemann [Glenodinium foliaceum] Kryptoperidinium foliaceum (Stein) Lindemann [Glenodinium foliaceum] Kryptoperidinium foliaceum (Stein) Lindemann [Glenodinium foliaceum] Kryptoperidinium foliaceum (Stein) Lindemann [Glenodinium foliaceum] Kryptoperidinium foliaceum (Stein) Lindemann [Glenodinium foliaceum] Kryptoperidinium foliaceum (Stein) Lindemann [Glenodinium foliaceum]

Levanderina fissa (Levander) Moestrup, Hakanen, Hansen, Daugbjerg

\&.EllegaardLevanderina fissa (Levander) Moestrup, Hakanen, Hansen, Daugbjerg \&.EllegaardLevanderina fissa (Levander) Moestrup, Hakanen, Hansen, Daugbjerg \&.EllegaardLevanderina fissa (Levander) Moestrup, Hakanen, Hansen, Daugbjerg \&.EllegaardLevanderina fissa (Levander) Moestrup, Hakanen, Hansen, Daugbjerg \&.EllegaardLevanderina fissa (Levander) Moestrup, Hakanen, Hansen, Daugbjerg \&.EllegaardLevanderina fissa (Levander) Moestrup, Hakanen, Hansen, Daugbjerg \&.EllegaardLevanderina fissa (Levander) Moestrup, Hakanen, Hansen, Daugbjerg \&.EllegaardLevanderina fissa (Levander) Moestrup, Hakanen, Hansen, Daugbjerg \&.EllegaardLevanderina fissa (Levander) Moestrup, Hakanen, Hansen, Daugbjerg \&.EllegaardLevanderina fissa (Levander) Moestrup, Hakanen, Hansen, Daugbjerg

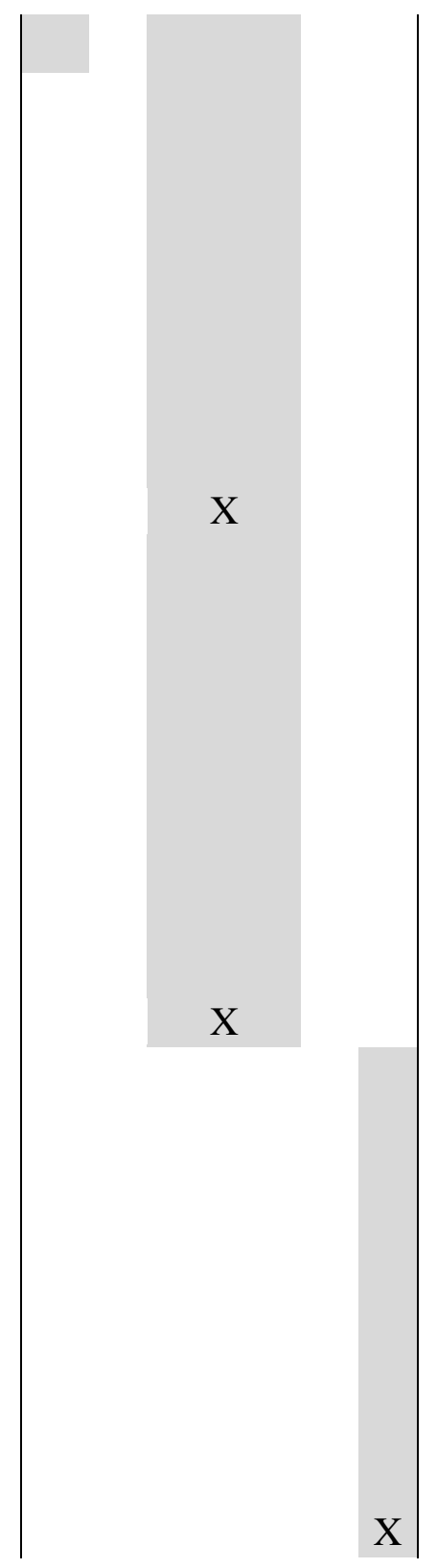




\section{\&.Ellegaard}

Lingulodinium polyedra (Stein) Dodge [Gonyaulax polyedra] Lingulodinium polyedra (Stein) Dodge [Gonyaulax polyedra] Lingulodinium polyedra (Stein) Dodge [Gonyaulax polyedra] Lingulodinium polyedra (Stein) Dodge [Gonyaulax polyedra] Lingulodinium polyedra (Stein) Dodge [Gonyaulax polyedra] Lingulodinium polyedra (Stein) Dodge [Gonyaulax polyedra] Lingulodinium polyedra (Stein) Dodge [Gonyaulax polyedra] Lingulodinium polyedra (Stein) Dodge [Gonyaulax polyedra] Lingulodinium polyedra (Stein) Dodge [Gonyaulax polyedra] Lingulodinium polyedra (Stein) Dodge [Gonyaulax polyedra] Lingulodinium polyedra (Stein) Dodge [Gonyaulax polyedra]

Mesoporos perforatus (Gran) Lillick [Exuviella perforata etc]Mesoporos perforatus (Gran) Lillick [Exuviella perforata etc]Mesoporos perforatus (Gran) Lillick [Exuviella perforata etc]Mesoporos perforatus (Gran) Lillick [Exuviella perforata etc]Mesoporos perforatus (Gran) Lillick [Exuviella perforata etc]Mesoporos perforatus (Gran) Lillick [Exuviella perforata etc]Mesoporos perforatus (Gran) Lillick [Exuviella perforata etc]Mesoporos perforatus (Gran) Lillick [Exuviella perforata etc]Mesoporos perforatus (Gran) Lillick [Exuviella perforata etc]Mesoporos perforatus (Gran) Lillick [Exuviella perforata etc]Mesoporos perforatus (Gran) Lillick [Exuviella perforata etc]

Naiadinium polonicum (Woloszynska) S. Carty [Peridinium polonicum /Naiadinium polonicum (Woloszynska) S. Carty [Peridinium polonicum/Naiadinium polonicum (Woloszynska) S. Carty [Peridinium polonicum]Naiadinium polonicum (Woloszynska) S. Carty [Peridinium polonicum] Naiadinium polonicum (Woloszynska) S. Carty [Peridinium polonicum]Naiadinium polonicum (Woloszynska) S. Carty [Peridinium polonicum /Naiadinium polonicum (Woloszynska) S. Carty /Peridinium polonicum /Naiadinium polonicum (Woloszynska) S. Carty [Peridinium polonicum /Naiadinium polonicum (Woloszynska) S. Carty [Peridinium polonicum /Naiadinium polonicum (Woloszynska) S. Carty /Peridinium polonicum 7 Naiadinium polonicum (Woloszynska) S. Carty [Peridinium polonicum] Noctiluca scintillans (Macartney) Ehrenberg [Noctiluca miliaris] Noctiluca scintillans (Macartney) Ehrenberg [Noctiluca miliaris] Noctiluca scintillans (Macartney) Ehrenberg [Noctiluca miliaris] Noctiluca scintillans (Macartney) Ehrenberg [Noctiluca miliaris] Noctiluca scintillans (Macartney) Ehrenberg [Noctiluca miliaris] Noctiluca scintillans (Macartney) Ehrenberg [Noctiluca miliaris] Noctiluca scintillans (Macartney) Ehrenberg

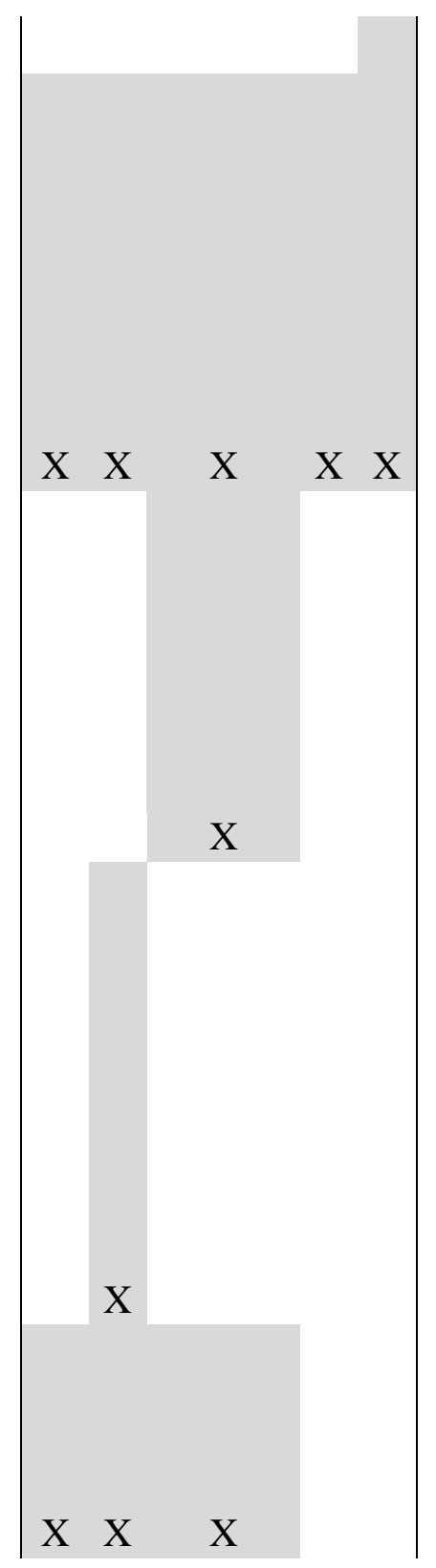


[Noctiluca miliaris] Noctiluca scintillans (Macartney) Ehrenberg [Noctiluca miliaris] Noctiluca scintillans (Macartney) Ehrenberg [Noctiluca miliaris] Noctiluca scintillans (Macartney) Ehrenberg [Noctiluca miliaris] Noctiluca scintillans (Macartney) Ehrenberg [Noctiluca miliaris]

Oblea rotunda (Lebour)Balech ex Sournia [Glenodinium rotundum Schiller]Oblea rotunda (Lebour)Balech ex Sournia [Glenodinium rotundum Schiller]Oblea rotunda (Lebour)Balech ex Sournia [Glenodinium rotundum Schiller]Oblea rotunda (Lebour)Balech ex Sournia [Glenodinium rotundum Schiller]Oblea rotunda (Lebour)Balech ex Sournia [Glenodinium rotundum Schiller]Oblea rotunda (Lebour)Balech ex Sournia [Glenodinium rotundum Schiller]Oblea rotunda (Lebour)Balech ex Sournia [Glenodinium rotundum Schiller]Oblea rotunda (Lebour)Balech ex Sournia [Glenodinium rotundum Schiller]Oblea rotunda (Lebour)Balech ex Sournia [Glenodinium rotundum Schiller]Oblea rotunda (Lebour)Balech ex Sournia [Glenodinium rotundum Schiller]Oblea rotunda (Lebour)Balech ex Sournia [Glenodinium rotundum Schiller]

Opisthoaulax vorticella (Stein) Calado [Massartia vorticella]Opisthoaulax vorticella (Stein) Calado [Massartia vorticella]Opisthoaulax vorticella (Stein) Calado [Massartia vorticella]Opisthoaulax vorticella (Stein) Calado [Massartia vorticella]Opisthoaulax vorticella (Stein) Calado [Massartia vorticella]Opisthoaulax vorticella (Stein) Calado [Massartia vorticella]Opisthoaulax vorticella (Stein) Calado [Massartia vorticella] Opisthoaulax vorticella (Stein) Calado [Massartia vorticella]Opisthoaulax vorticella (Stein) Calado [Massartia vorticella]Opisthoaulax vorticella (Stein) Calado [Massartia vorticella]

Oxyphysis oxytoxoides Kofoid Oxyphysis oxytoxoides Kofoid Oxyphysis oxytoxoides Kofoid Oxyphysis oxytoxoides Kofoid Oxyphysis oxytoxoides Kofoid Oxyphysis oxytoxoides Kofoid Oxyphysis oxytoxoides Kofoid Oxyphysis oxytoxoides Kofoid Oxyphysis oxytoxoides Kofoid Oxyphysis oxytoxoides Kofoid

Oxyrrhis marina Dujardin [O. maritima,O. tentaculifera ] Oxyrrhis marina Dujardin [O. maritima,O. tentaculifera] Oxyrrhis marina Dujardin [O. maritima,O.

tentaculifera ] Oxyrrhis marina Dujardin [O. maritima,O. tentaculifera ] Oxyrrhis marina Dujardin [O. maritima,O. tentaculifera] Oxyrrhis marina Dujardin [O. maritima,O. tentaculifera ] Oxyrrhis marina Dujardin [O. maritima,O. tentaculifera ] Oxyrrhis marina Dujardin [O. maritima,O. tentaculifera ] Oxyrrhis marina Dujardin

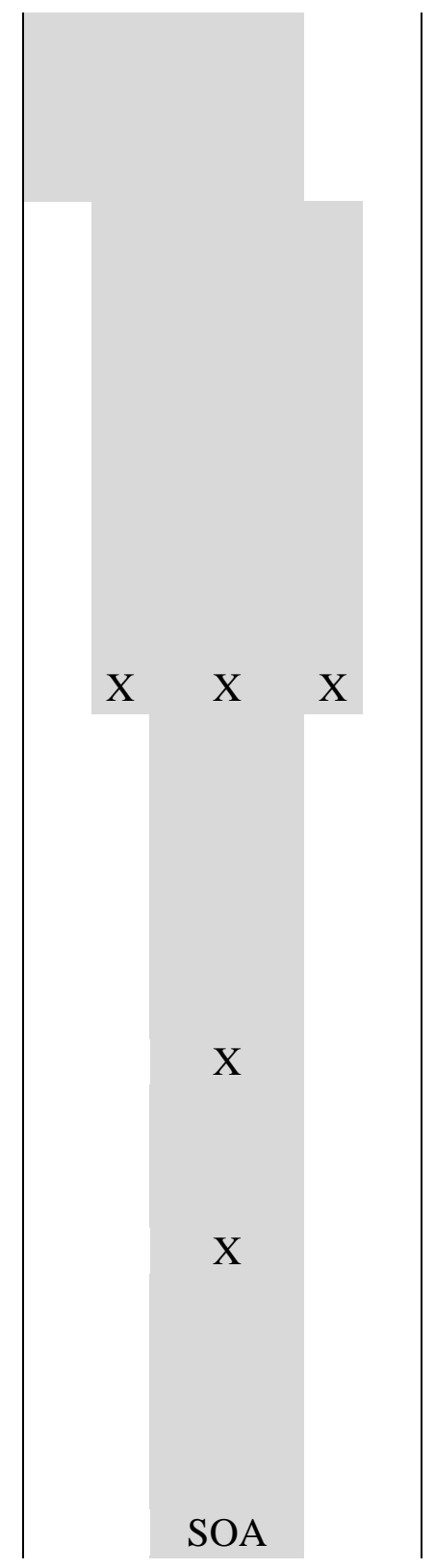


[O. maritima,O. tentaculifera ] Oxyrrhis marina Dujardin [O. maritima,O. tentaculifera ]

Oxytoxum adriaticum Schiller Oxytoxum adriaticum Schiller Oxytoxum adriaticum Schiller Oxytoxum adriaticum Schiller Oxytoxum adriaticum Schiller Oxytoxum adriaticum Schiller Oxytoxum adriaticum Schiller Oxytoxum adriaticum Schiller Oxytoxum adriaticum Schiller Oxytoxum adriaticum Schiller

Oxytoxum brunellii Rampi Oxytoxum brunellii Rampi Oxytoxum brunellii Rampi Oxytoxum brunellii Rampi Oxytoxum brunellii Rampi Oxytoxum brunellii Rampi Oxytoxum brunellii Rampi Oxytoxum brunellii Rampi Oxytoxum brunellii Rampi Oxytoxum brunellii Rampi

Oxytoxum crassum SchillerOxytoxum crassum SchillerOxytoxum crassum

SchillerOxytoxum crassum SchillerOxytoxum crassum SchillerOxytoxum crassum SchillerOxytoxum crassum SchillerOxytoxum crassum SchillerOxytoxum crassum SchillerOxytoxum crassum Schiller

Oxytoxum milneri Murray \& Whitting [ O. subulatum ] Oxytoxum milneri Murray \& Whitting [O. subulatum ] Oxytoxum milneri Murray \& Whitting [O. subulatum] Oxytoxum milneri Murray \& Whitting [ O. subulatum ] Oxytoxum milneri Murray \& Whitting [O. subulatum ] Oxytoxum milneri Murray \& Whitting [O. subulatum ] Oxytoxum milneri Murray \& Whitting [ O. subulatum ] Oxytoxum milneri Murray \& Whitting [ O. subulatum ] Oxytoxum milneri Murray \& Whitting [O. subulatum ] Oxytoxum milneri Murray \& Whitting [ O. subulatum ]

Oxytoxum mitra Stein Oxytoxum mitra Stein Oxytoxum mitra Stein Oxytoxum mitra Stein Oxytoxum mitra Stein Oxytoxum mitra Stein Oxytoxum mitra Stein Oxytoxum mitra Stein Oxytoxum mitra Stein Oxytoxum mitra Stein

Oxytoxum parvum Schiller [O. tenuistriatum reported as 'O. parvulum' Schiller] Oxytoxum parvum Schiller [O. tenuistriatum reported as 'O. parvulum' Schiller] Oxytoxum parvum Schiller [O. tenuistriatum reported as 'O. parvulum' Schiller] Oxytoxum parvum Schiller [O. tenuistriatum reported as 'O. parvulum' Schiller] Oxytoxum parvum Schiller [O. tenuistriatum reported as 'O. parvulum' Schiller] Oxytoxum parvum Schiller [O. tenuistriatum reported as 'O. parvulum' Schiller] Oxytoxum parvum Schiller [O. tenuistriatum reported as 'O. parvulum' Schiller] Oxytoxum parvum Schiller [O. tenuistriatum reported as 'O. parvulum' Schiller] Oxytoxum parvum Schiller [O. tenuistriatum reported as 'O. parvulum' Schiller]

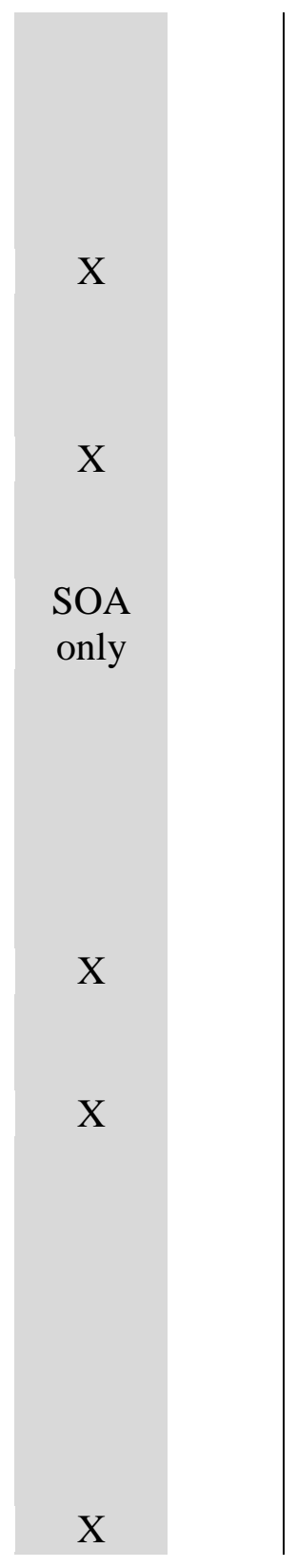


Oxytoxum parvum Schiller [O. tenuistriatum reported as 'O. parvulum' Schiller] Oxytoxum scolopax Stein Oxytoxum scolopax Stein Oxytoxum scolopax Stein Oxytoxum scolopax Stein Oxytoxum scolopax Stein Oxytoxum scolopax Stein Oxytoxum scolopax Stein Oxytoxum scolopax Stein Oxytoxum scolopax Stein Oxytoxum scolopax Stein Oxytoxum turbo Kofoid 1907 Oxytoxum turbo Kofoid 1907 Oxytoxum turbo Kofoid 1907 Oxytoxum turbo Kofoid 1907Oxytoxum turbo Kofoid 1907Oxytoxum turbo Kofoid 1907 Oxytoxum turbo Kofoid 1907 Oxytoxum turbo Kofoid 1907Oxytoxum turbo Kofoid 1907 Oxytoxum turbo Kofoid 1907

Oxytoxum variabile Schiller [Oxytoxum gracile Schiller] Oxytoxum variabile Schiller [Oxytoxum gracile Schiller] Oxytoxum variabile Schiller [Oxytoxum gracile Schiller] Oxytoxum variabile Schiller [Oxytoxum gracile Schiller] Oxytoxum variabile Schiller [Oxytoxum gracile Schiller] Oxytoxum variabile Schiller [Oxytoxum gracile Schiller] Oxytoxum variabile Schiller [Oxytoxum gracile Schiller] Oxytoxum variabile Schiller [Oxytoxum gracile Schiller] Oxytoxum variabile Schiller [Oxytoxum gracile Schiller] Oxytoxum variabile Schiller [Oxytoxum gracile Schiller]

Palaeophalacroma unicinctum Schiller [Heterodinium detonii, Epiperidinium michaelsarsi ]Palaeophalacroma unicinctum Schiller [Heterodinium detonii, Epiperidinium michaelsarsi ]Palaeophalacroma unicinctum Schiller [Heterodinium detonii, Epiperidinium michaelsarsi ]Palaeophalacroma unicinctum Schiller [Heterodinium detonii, Epiperidinium michaelsarsi]Palaeophalacroma unicinctum Schiller [Heterodinium detonii, Epiperidinium michaelsarsi ]Palaeophalacroma unicinctum Schiller [Heterodinium detonii, Epiperidinium michaelsarsi

JPalaeophalacroma unicinctum Schiller [Heterodinium detonii, Epiperidinium michaelsarsi ]Palaeophalacroma unicinctum Schiller [Heterodinium detonii, Epiperidinium michaelsarsi ]Palaeophalacroma unicinctum Schiller [Heterodinium detonii, Epiperidinium michaelsarsi ]Palaeophalacroma unicinctum Schiller [Heterodinium detonii, Epiperidinium michaelsarsi ]

Pentapharsodinium dalei Indelicato \& Loeblich III Pentapharsodinium dalei Indelicato \& Loeblich III Pentapharsodinium dalei Indelicato \& Loeblich III Pentapharsodinium dalei Indelicato \& Loeblich III Pentapharsodinium dalei Indelicato \& Loeblich III Pentapharsodinium dalei Indelicato \& Loeblich III Pentapharsodinium dalei Indelicato \& Loeblich III Pentapharsodinium dalei Indelicato \& Loeblich III Pentapharsodinium dalei Indelicato \& Loeblich III Pentapharsodinium dalei Indelicato \& Loeblich III

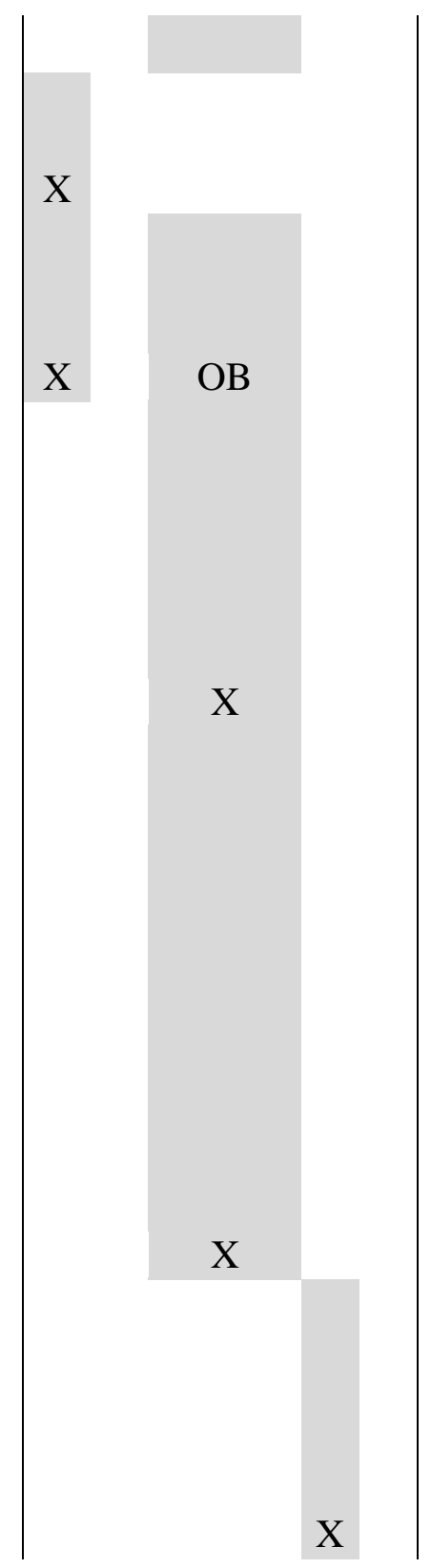


Pentapharsodinium tyrrhenicum (Balech) Montressor, Zingone \& Marino Pentapharsodinium tyrrhenicum (Balech) Montressor, Zingone \& Marino Pentapharsodinium tyrrhenicum (Balech) Montressor, Zingone \& Marino Pentapharsodinium tyrrhenicum (Balech) Montressor, Zingone \& Marino Pentapharsodinium tyrrhenicum (Balech) Montressor, Zingone \& Marino Pentapharsodinium tyrrhenicum (Balech) Montressor, Zingone \& Marino Pentapharsodinium tyrrhenicum (Balech) Montressor, Zingone \& Marino Pentapharsodinium tyrrhenicum (Balech) Montressor, Zingone \& Marino Pentapharsodinium tyrrhenicum (Balech) Montressor, Zingone \& Marino Pentapharsodinium tyrrhenicum (Balech) Montressor, Zingone \& Marino Peridiniella danica (Paulsen) Okolodkov, Dodge [Glenodinium danicum Paulsen] Peridiniella danica (Paulsen) Okolodkov, Dodge [Glenodinium danicum Paulsen] Peridiniella danica (Paulsen) Okolodkov, Dodge [Glenodinium danicum Paulsen] Peridiniella danica (Paulsen) Okolodkov, Dodge [Glenodinium danicum Paulsen] Peridiniella danica (Paulsen) Okolodkov, Dodge [Glenodinium danicum Paulsen] Peridiniella danica (Paulsen) Okolodkov, Dodge [Glenodinium danicum Paulsen] Peridiniella danica (Paulsen) Okolodkov, Dodge [Glenodinium danicum Paulsen] Peridiniella danica (Paulsen) Okolodkov, Dodge [Glenodinium danicum Paulsen] Peridiniella danica (Paulsen) Okolodkov, Dodge [Glenodinium danicum Paulsen] Peridiniella danica (Paulsen) Okolodkov, Dodge [Glenodinium danicum Paulsen] Peridiniella berolinense (Lemmermann) Bourelly Peridiniella berolinense (Lemmermann) Bourelly Peridiniella berolinense (Lemmermann) Bourelly Peridiniella berolinense (Lemmermann) Bourelly Peridiniella berolinense (Lemmermann) Bourelly Peridiniella berolinense (Lemmermann) Bourelly Peridiniella berolinense (Lemmermann) Bourelly Peridiniella berolinense (Lemmermann) Bourelly Peridiniella berolinense (Lemmermann) Bourelly

Peridiniella charcowiensis (Matvienko) BourellyPeridiniella charcowiensis (Matvienko) BourellyPeridiniella charcowiensis (Matvienko) BourellyPeridiniella charcowiensis (Matvienko) BourellyPeridiniella charcowiensis (Matvienko) BourellyPeridiniella charcowiensis (Matvienko) BourellyPeridiniella charcowiensis (Matvienko) BourellyPeridiniella charcowiensis (Matvienko) BourellyPeridiniella charcowiensis (Matvienko) Bourelly

Peridiniella sphaeroidea Kofoid \& MichenerPeridiniella sphaeroidea Kofoid \&

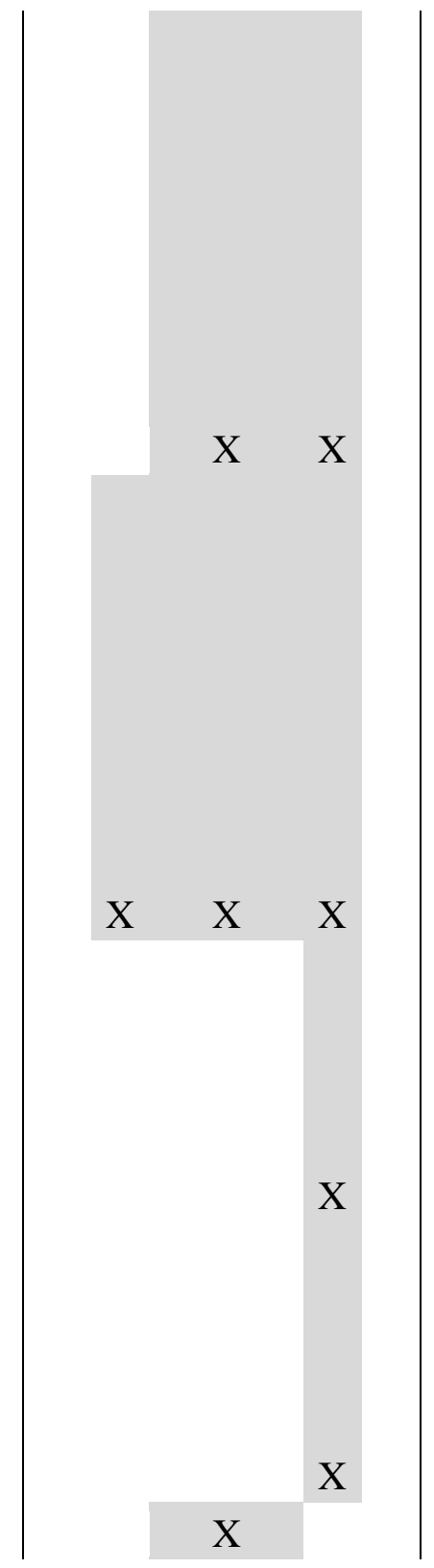


MichenerPeridiniella sphaeroidea Kofoid \& MichenerPeridiniella sphaeroidea Kofoid \& MichenerPeridiniella sphaeroidea Kofoid \& MichenerPeridiniella sphaeroidea Kofoid \& MichenerPeridiniella sphaeroidea Kofoid \& MichenerPeridiniella sphaeroidea Kofoid \& MichenerPeridiniella sphaeroidea Kofoid \& Michener

Peridiniopsis borgei Lemmermann Peridiniopsis borgei Lemmermann Peridiniopsis borgei Lemmermann Peridiniopsis borgei Lemmermann Peridiniopsis borgei Lemmermann Peridiniopsis borgei Lemmermann Peridiniopsis borgei Lemmermann Peridiniopsis borgei Lemmermann Peridiniopsis borgei Lemmermann

Peridiniopsis cunningtonii Lemmermann [Peridinium cunningtonii]Peridiniopsis cunningtonii Lemmermann [Peridinium cunningtonii]Peridiniopsis cunningtonii Lemmermann [Peridinium cunningtonii]Peridiniopsis cunningtonii Lemmermann [Peridinium cunningtonii]Peridiniopsis cunningtonii Lemmermann [Peridinium cunningtonii]Peridiniopsis cunningtonii Lemmermann [Peridinium cunningtonii]Peridiniopsis cunningtonii Lemmermann [Peridinium cunningtonii]Peridiniopsis cunningtonii Lemmermann [Peridinium cunningtonii]Peridiniopsis cunningtonii Lemmermann [Peridinium cunningtonii] Peridiniopsis elpatiewskyi (Ostenfeld) Bourrelly [Peridinium pygmaeum] Peridiniopsis elpatiewskyi (Ostenfeld) Bourrelly [Peridinium pygmaeum] Peridiniopsis elpatiewskyi (Ostenfeld) Bourrelly [Peridinium pygmaeum] Peridiniopsis elpatiewskyi (Ostenfeld) Bourrelly [Peridinium pygmaeum] Peridiniopsis elpatiewskyi (Ostenfeld) Bourrelly [Peridinium pygmaeum] Peridiniopsis elpatiewskyi (Ostenfeld) Bourrelly [Peridinium pygmaeum] Peridiniopsis elpatiewskyi (Ostenfeld) Bourrelly [Peridinium pygmaeum] Peridiniopsis elpatiewskyi (Ostenfeld) Bourrelly [Peridinium pygmaeum] Peridiniopsis elpatiewskyi (Ostenfeld) Bourrelly [Peridinium pygmaeum]

Peridiniopsis gymnodinium (Penard) Bourrelly (Glenodinium gymnodinium Penard) Peridiniopsis gymnodinium (Penard) Bourrelly (Glenodinium gymnodinium Penard) Peridiniopsis gymnodinium (Penard) Bourrelly (Glenodinium gymnodinium Penard) Peridiniopsis gymnodinium (Penard) Bourrelly (Glenodinium gymnodinium Penard) Peridiniopsis gymnodinium (Penard) Bourrelly (Glenodinium gymnodinium Penard) Peridiniopsis gymnodinium (Penard) Bourrelly (Glenodinium gymnodinium Penard) Peridiniopsis gymnodinium (Penard) Bourrelly (Glenodinium gymnodinium Penard) Peridiniopsis gymnodinium (Penard) Bourrelly (Glenodinium gymnodinium Penard) Peridiniopsis gymnodinium (Penard) Bourrelly (Glenodinium gymnodinium Penard)

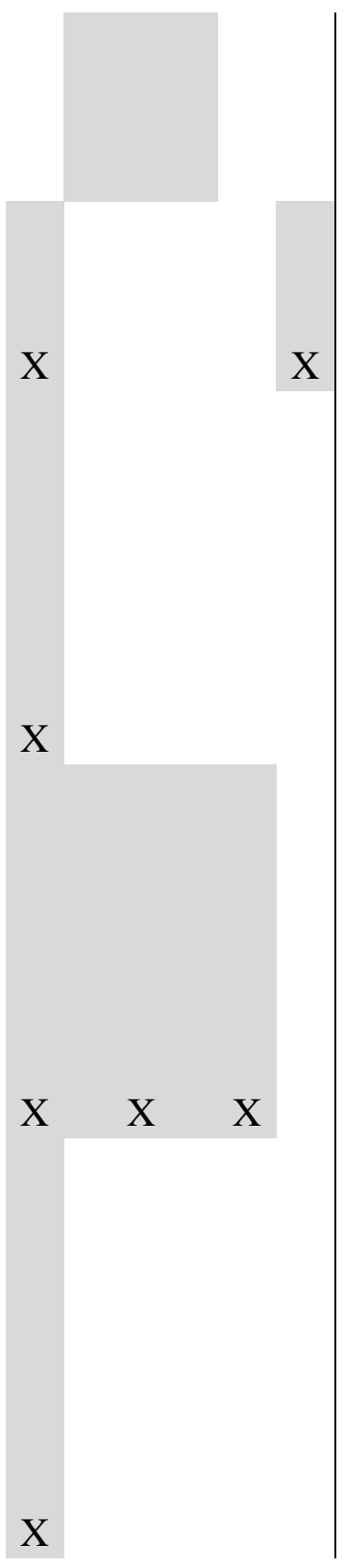


Peridiniopsis lenticula (Bergh) StarmachPeridiniopsis lenticula (Bergh)

StarmachPeridiniopsis lenticula (Bergh) StarmachPeridiniopsis lenticula (Bergh)

StarmachPeridiniopsis lenticula (Bergh) StarmachPeridiniopsis lenticula (Bergh)

StarmachPeridiniopsis lenticula (Bergh) StarmachPeridiniopsis lenticula (Bergh)

StarmachPeridiniopsis lenticula (Bergh) Starmach

Peridiniopsis oculatum (Stein) Bourrelly (Glenodinium oculatum Stein) Peridiniopsis

oculatum (Stein) Bourrelly (Glenodinium oculatum Stein) Peridiniopsis oculatum (Stein) Bourrelly (Glenodinium oculatum Stein) Peridiniopsis oculatum (Stein) Bourrelly

(Glenodinium oculatum Stein) Peridiniopsis oculatum (Stein) Bourrelly (Glenodinium

oculatum Stein) Peridiniopsis oculatum (Stein) Bourrelly (Glenodinium oculatum Stein)

Peridiniopsis oculatum (Stein) Bourrelly (Glenodinium oculatum Stein) Peridiniopsis

oculatum (Stein) Bourrelly (Glenodinium oculatum Stein) Peridiniopsis oculatum (Stein)

Bourrelly (Glenodinium oculatum Stein)

Peridiniopsis penardiforme (Lindemann) Bourrelly [Peridinium

penardiforme]Peridiniopsis penardiforme (Lindemann) Bourrelly [Peridinium penardiforme]Peridiniopsis penardiforme (Lindemann) Bourrelly [Peridinium penardiforme]Peridiniopsis penardiforme (Lindemann) Bourrelly [Peridinium penardiforme]Peridiniopsis penardiforme (Lindemann) Bourrelly [Peridinium penardiforme]Peridiniopsis penardiforme (Lindemann) Bourrelly [Peridinium penardiforme]Peridiniopsis penardiforme (Lindemann) Bourrelly [Peridinium penardiforme]Peridiniopsis penardiforme (Lindemann) Bourrelly [Peridinium penardiforme]Peridiniopsis penardiforme (Lindemann) Bourrelly [Peridinium penardiforme]$$
\text { Der }
$$

Peridiniopsis penardii (Lemmermann) Bourrelly [Peridinium penardii] Peridiniopsis penardii (Lemmermann) Bourrelly [Peridinium penardii] Peridiniopsis penardii (Lemmermann) Bourrelly [Peridinium penardii] Peridiniopsis penardii (Lemmermann) Bourrelly [Peridinium penardii] Peridiniopsis penardii (Lemmermann) Bourrelly [Peridinium penardii] Peridiniopsis penardii (Lemmermann) Bourrelly [Peridinium penardii] Peridiniopsis penardii (Lemmermann) Bourrelly [Peridinium penardii] Peridiniopsis penardii (Lemmermann) Bourrelly [Peridinium penardii] Peridiniopsis penardii (Lemmermann) Bourrelly [Peridinium penardii]

Peridiniopsis polonicum (Woloszynska) Bourrelly [Glenodinium gymnodinium]

Peridiniopsis polonicum (Woloszynska) Bourrelly [Glenodinium gymnodinium] 
Peridiniopsis polonicum (Woloszynska) Bourrelly [Glenodinium gymnodinium] Peridiniopsis polonicum (Woloszynska) Bourrelly [Glenodinium gymnodinium] Peridiniopsis polonicum (Woloszynska) Bourrelly [Glenodinium gymnodinium] Peridiniopsis polonicum (Woloszynska) Bourrelly [Glenodinium gymnodinium] Peridiniopsis polonicum (Woloszynska) Bourrelly [Glenodinium gymnodinium] Peridiniopsis polonicum (Woloszynska) Bourrelly [Glenodinium gymnodinium] Peridiniopsis polonicum (Woloszynska) Bourrelly [Glenodinium gymnodinium] Peridiniopsis pygmeus Lindemann [Glenodinium pygmaeum]Peridiniopsis pygmeus Lindemann [Glenodinium pygmaeum]Peridiniopsis pygmeus Lindemann [Glenodinium pygmaeum]Peridiniopsis pygmeus Lindemann [Glenodinium pygmaeum]Peridiniopsis pygmeus Lindemann [Glenodinium pygmaeum]Peridiniopsis pygmeus Lindemann [Glenodinium pygmaeum]Peridiniopsis pygmeus Lindemann [Glenodinium pygmaeum] Peridiniopsis pygmeus Lindemann [Glenodinium pygmaeum]Peridiniopsis pygmeus Lindemann [Glenodinium pygmaeum]

Peridiniopsis quadridens (Stein) Bourrelly Peridiniopsis quadridens (Stein) Bourrelly Peridiniopsis quadridens (Stein) Bourrelly Peridiniopsis quadridens (Stein) Bourrelly Peridiniopsis quadridens (Stein) Bourrelly Peridiniopsis quadridens (Stein) Bourrelly Peridiniopsis quadridens (Stein) Bourrelly Peridiniopsis quadridens (Stein) Bourrelly Peridiniopsis quadridens (Stein) Bourrelly

Peridiniopsis thompsonii (Thompson) Bourrelly [Glenodinium quadridens ]Peridiniopsis thompsonii (Thompson) Bourrelly [Glenodinium quadridens ]Peridiniopsis thompsonii (Thompson) Bourrelly [Glenodinium quadridens ]Peridiniopsis thompsonii (Thompson) Bourrelly [Glenodinium quadridens ]Peridiniopsis thompsonii (Thompson) Bourrelly [Glenodinium quadridens ]Peridiniopsis thompsonii (Thompson) Bourrelly [Glenodinium quadridens ]Peridiniopsis thompsonii (Thompson) Bourrelly [Glenodinium quadridens JPeridiniopsis thompsonii (Thompson) Bourrelly [Glenodinium quadridens JPeridiniopsis thompsonii (Thompson) Bourrelly [Glenodinium quadridens ]

Peridinium aciculiferum Lemmermann Peridinium aciculiferum Lemmermann Peridinium aciculiferum Lemmermann Peridinium aciculiferum Lemmermann Peridinium aciculiferum Lemmermann Peridinium aciculiferum Lemmermann Peridinium aciculiferum Lemmermann Peridinium aciculiferum Lemmermann Peridinium aciculiferum Lemmermann

Peridinium achromaticum Levander Peridinium achromaticum Levander Peridinium

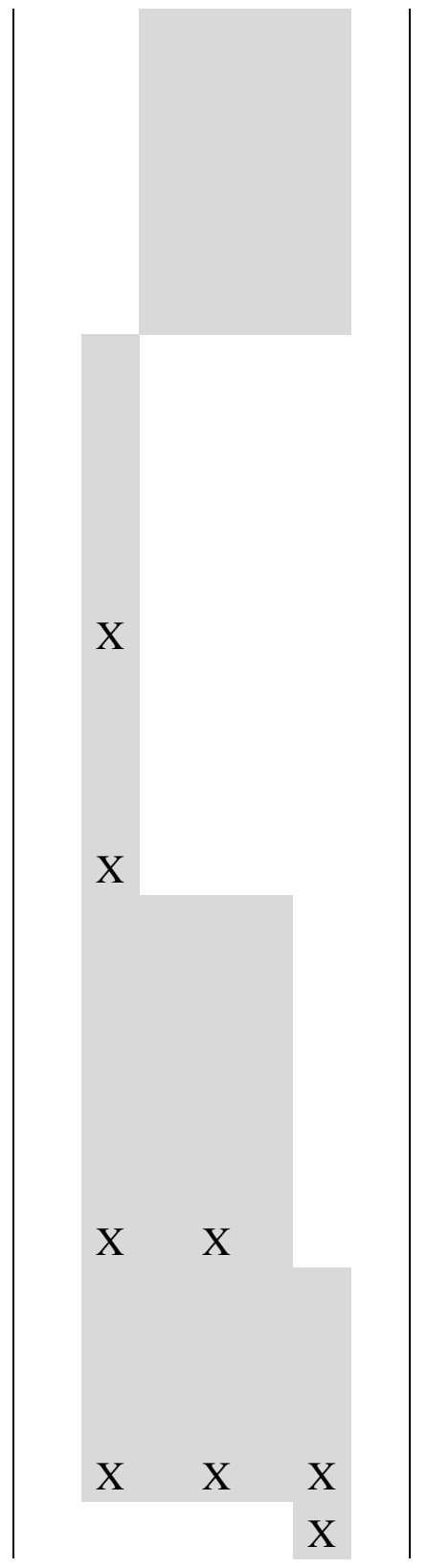


achromaticum Levander Peridinium achromaticum Levander Peridinium achromaticum Levander Peridinium achromaticum Levander Peridinium achromaticum Levander Peridinium achromaticum Levander

Peridinium bipes Stein [Peridinium tabulatum] Peridinium bipes Stein [Peridinium tabulatum] Peridinium bipes Stein [Peridinium tabulatum] Peridinium bipes Stein [Peridinium tabulatum] Peridinium bipes Stein [Peridinium tabulatum] Peridinium bipes Stein [Peridinium tabulatum] Peridinium bipes Stein [Peridinium tabulatum] Peridinium bipes Stein [Peridinium tabulatum]

Peridinium cinctum (Müller) Ehrenberg Peridinium cinctum (Müller) Ehrenberg Peridinium cinctum (Müller) Ehrenberg Peridinium cinctum (Müller) Ehrenberg Peridinium cinctum (Müller) Ehrenberg Peridinium cinctum (Müller) Ehrenberg Peridinium cinctum (Müller) Ehrenberg Peridinium cinctum (Müller) Ehrenberg Peridinium excentricum PaulsenPeridinium excentricum PaulsenPeridinium excentricum PaulsenPeridinium excentricum PaulsenPeridinium excentricum PaulsenPeridinium excentricum PaulsenPeridinium excentricum PaulsenPeridinium excentricum Paulsen Peridinium lomnickii Woloszynska [Chimonodinium lomnickii]Peridinium lomnickii Woloszynska [Chimonodinium lomnickii]Peridinium lomnickii Woloszynska [Chimonodinium lomnickii]Peridinium lomnickii Woloszynska [Chimonodinium lomnickii]Peridinium lomnickii Woloszynska [Chimonodinium lomnickii]Peridinium lomnickii Woloszynska [Chimonodinium lomnickii]Peridinium lomnickii Woloszynska [Chimonodinium lomnickii]Peridinium lomnickii Woloszynska [Chimonodinium lomnickii]

Peridinium orbiculare Paulsen var. temarisPeridinium orbiculare Paulsen var. temarisPeridinium orbiculare Paulsen var. temarisPeridinium orbiculare Paulsen var. temarisPeridinium orbiculare Paulsen var. temarisPeridinium orbiculare Paulsen var. temarisPeridinium orbiculare Paulsen var. temarisPeridinium orbiculare Paulsen var. temaris

Peridinium palatinum Lauterbomm Peridinium palatinum Lauterbomm Peridinium palatinum Lauterbomm Peridinium palatinum Lauterbomm Peridinium palatinum Lauterbomm Peridinium palatinum Lauterbomm Peridinium palatinum Lauterbomm Peridinium palatinum Lauterbomm

Peridinium ponticum Vershinin \& MortonPeridinium ponticum Vershinin \&

MortonPeridinium ponticum Vershinin \& MortonPeridinium ponticum Vershinin \&

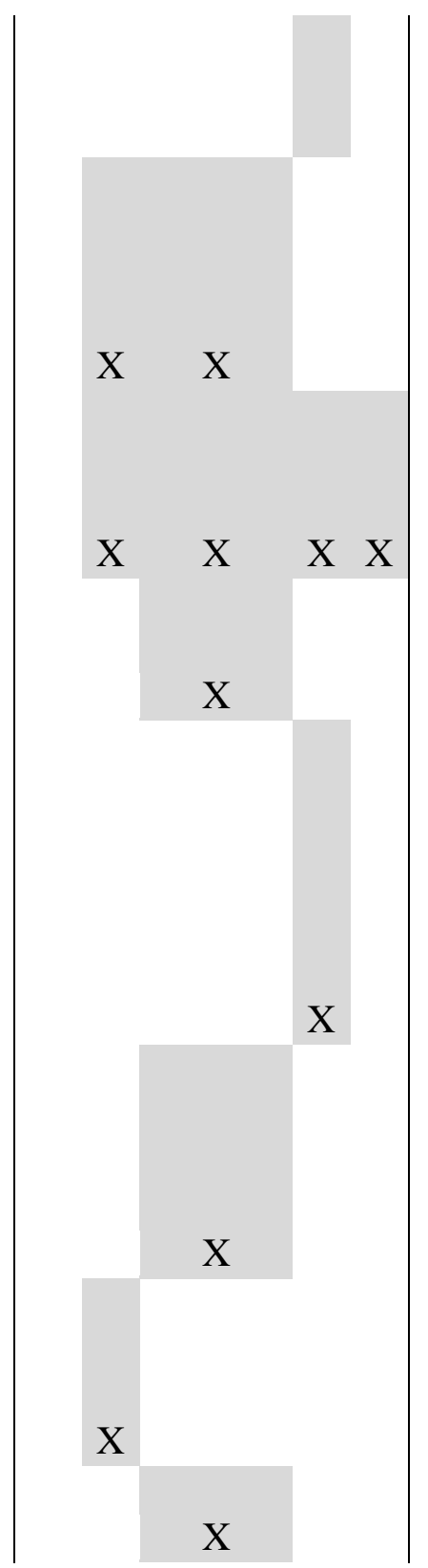


MortonPeridinium ponticum Vershinin \& MortonPeridinium ponticum Vershinin \& MortonPeridinium ponticum Vershinin \& MortonPeridinium ponticum Vershinin \& Morton

Peridinium pusillum (Pénard) Lemmermann Peridinium pusillum (Pénard) Lemmermann Peridinium pusillum (Pénard) Lemmermann Peridinium pusillum (Pénard) Lemmermann Peridinium pusillum (Pénard) Lemmermann Peridinium pusillum (Pénard) Lemmermann Peridinium pusillum (Pénard) Lemmermann Peridinium pusillum (Pénard) Lemmermann Peridinium quadridens Stein Peridinium quadridens Stein Peridinium quadridens Stein Peridinium quadridens Stein Peridinium quadridens Stein Peridinium quadridens Stein Peridinium quadridens Stein Peridinium quadridens Stein

Peridinium raciborskii Woloszynska [Peridinium palustre] Peridinium raciborskii Woloszynska [Peridinium palustre] Peridinium raciborskii Woloszynska [Peridinium palustre] Peridinium raciborskii Woloszynska [Peridinium palustre] Peridinium raciborskii Woloszynska [Peridinium palustre] Peridinium raciborskii Woloszynska [Peridinium palustre] Peridinium raciborskii Woloszynska [Peridinium palustre] Peridinium raciborskii Woloszynska [Peridinium palustre]

Peridinium spiniferum Claparède \& LachmannPeridinium spiniferum Claparède \& LachmannPeridinium spiniferum Claparède \& LachmannPeridinium spiniferum Claparède \& LachmannPeridinium spiniferum Claparède \& LachmannPeridinium spiniferum Claparède \& LachmannPeridinium spiniferum Claparède \& LachmannPeridinium spiniferum Claparède \& Lachmann

Peridinium triquetum SchillerPeridinium triquetum SchillerPeridinium triquetum SchillerPeridinium triquetum SchillerPeridinium triquetum SchillerPeridinium triquetum SchillerPeridinium triquetum SchillerPeridinium triquetum Schiller

Peridinium umbonatum Stein [Peridinium inconspicuum etc.]Peridinium umbonatum Stein [Peridinium inconspicuum etc.]Peridinium umbonatum Stein [Peridinium inconspicuum etc.]Peridinium umbonatum Stein [Peridinium inconspicuum etc.]Peridinium umbonatum Stein [Peridinium inconspicuum etc.]Peridinium umbonatum Stein [Peridinium inconspicuum etc.]Peridinium umbonatum Stein [Peridinium inconspicuum etc.]Peridinium umbonatum Stein [Peridinium inconspicuum etc.] Peridinium umbonatum v. goslaviense (Woloszynskya) Popovsky \& Pfiester Peridinium umbonatum v. goslaviense (Woloszynskya) Popovsky \& Pfiester Peridinium umbonatum v. goslaviense (Woloszynskya) Popovsky \& Pfiester Peridinium umbonatum v.

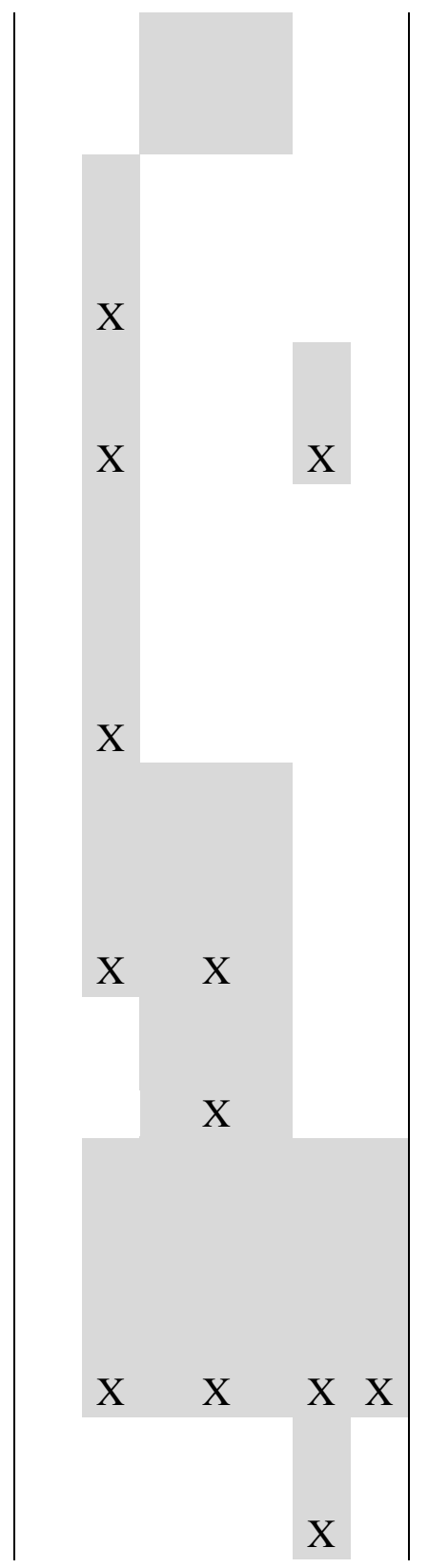


goslaviense (Woloszynskya) Popovsky \& Pfiester Peridinium umbonatum v. goslaviense (Woloszynskya) Popovsky \& Pfiester Peridinium umbonatum v. goslaviense (Woloszynskya) Popovsky \& Pfiester Peridinium umbonatum v. goslaviense (Woloszynskya) Popovsky \& Pfiester Peridinium umbonatum v. goslaviense (Woloszynskya) Popovsky \& Pfiester Peridinium willei Huitfeldt-Kaas [Peridinium volzii] Peridinium willei Huitfeldt-Kaas [Peridinium volzii] Peridinium willei Huitfeldt-Kaas [Peridinium volzii] Peridinium willei Huitfeldt-Kaas [Peridinium volzii] Peridinium willei Huitfeldt-Kaas [Peridinium volzii] Peridinium willei Huitfeldt-Kaas [Peridinium volzii] Peridinium willei HuitfeldtKaas [Peridinium volzii] Peridinium willei Huitfeldt-Kaas [Peridinium volzii]

Peridinium wisconsinense Eddy Peridinium wisconsinense Eddy Peridinium wisconsinense Eddy Peridinium wisconsinense Eddy Peridinium wisconsinense Eddy Peridinium wisconsinense Eddy Peridinium wisconsinense Eddy

Petalodinium porcelio Cachon et Cachon Petalodinium porcelio Cachon et Cachon Petalodinium porcelio Cachon et Cachon Petalodinium porcelio Cachon et Cachon Petalodinium porcelio Cachon et Cachon Petalodinium porcelio Cachon et Cachon Petalodinium porcelio Cachon et Cachon

Phalacroma acutum (Schütt) Pavillard [ P. vastumvar. Acutum Schütt ]Phalacroma acutum (Schütt) Pavillard [ P. vastumvar. Acutum Schütt ]Phalacroma acutum (Schütt) Pavillard [ P. vastumvar. Acutum Schütt ]Phalacroma acutum (Schütt) Pavillard [ P. vastumvar. Acutum Schütt] Phalacroma acutum (Schütt) Pavillard [ P. vastumvar. Acutum Schütt ]Phalacroma acutum (Schütt) Pavillard [ P. vastumvar. Acutum Schütt ]Phalacroma acutum (Schütt) Pavillard [ P. vastumvar. Acutum Schütt

Phalacroma favus Kofoid et Michener [Dinophysis favus ] Phalacroma favus Kofoid et Michener [Dinophysis favus] Phalacroma favus Kofoid et Michener [Dinophysis favus ] Phalacroma favus Kofoid et Michener [Dinophysis favus] Phalacroma favus Kofoid et Michener [Dinophysis favus] Phalacroma favus Kofoid et Michener [Dinophysis favus ] Phalacroma favus Kofoid et Michener [Dinophysis favus ] Phalacroma ovatum (Claparède et Lachmann) Jørgensen [Dinophysis ovata] Phalacroma ovatum (Claparède et Lachmann) Jørgensen [Dinophysis ovata] Phalacroma ovatum (Claparède et Lachmann) Jørgensen [Dinophysis ovata] Phalacroma ovatum (Claparède et Lachmann) Jørgensen [Dinophysis ovata]

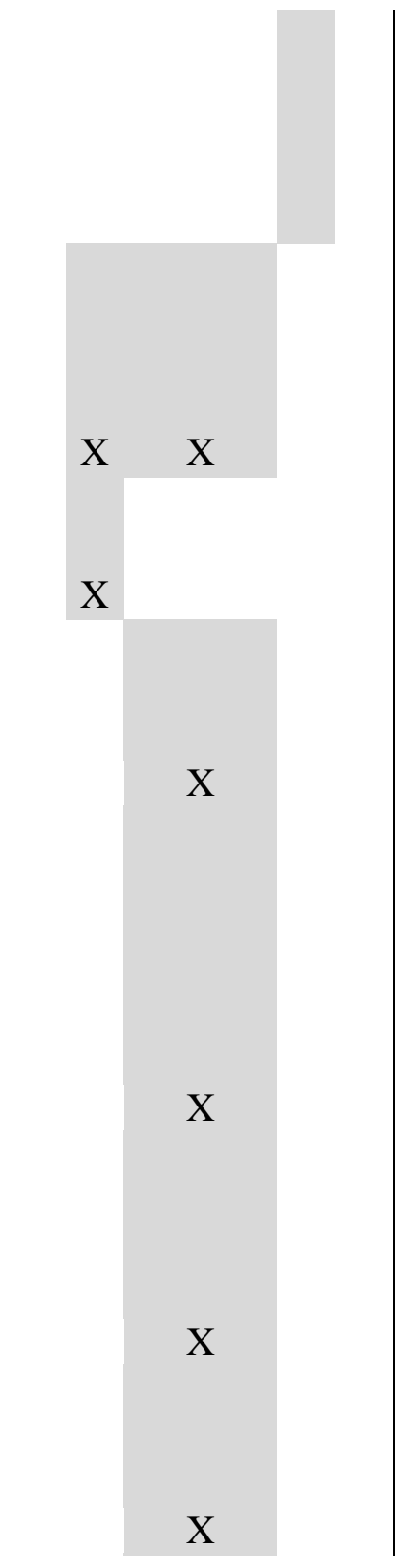


Phalacroma ovatum (Claparède et Lachmann) Jørgensen [Dinophysis ovata] Phalacroma ovatum (Claparède et Lachmann) Jørgensen [Dinophysis ovata] Phalacroma ovatum (Claparède et Lachmann) Jørgensen [Dinophysis ovata]

Phalacroma oxytoxoides (Kofoid) F.Gomez, P.Lopez-Garcia \& D. Moreira Phalacroma oxytoxoides (Kofoid) F.Gomez, P.Lopez-Garcia \& D. Moreira Phalacroma oxytoxoides (Kofoid) F.Gomez, P.Lopez-Garcia \& D. Moreira Phalacroma oxytoxoides (Kofoid) F.Gomez, P.Lopez-Garcia \& D. Moreira Phalacroma oxytoxoides (Kofoid) F.Gomez, P.Lopez-Garcia \& D. Moreira Phalacroma oxytoxoides (Kofoid) F.Gomez, P.LopezGarcia \& D. Moreira Phalacroma oxytoxoides (Kofoid) F.Gomez, P.Lopez-Garcia \& D. Moreira

Phalacroma parvulum (Schütt) Jørgensen [P. porodictyum v. parvula]Phalacroma parvulum (Schütt) Jørgensen [P. porodictyum v. parvula]Phalacroma parvulum (Schütt) Jørgensen [P. porodictyum v. parvula]Phalacroma parvulum (Schütt) Jørgensen [P. porodictyum v. parvula]Phalacroma parvulum (Schütt) Jørgensen [P. porodictyum v. parvula]Phalacroma parvulum (Schütt) Jørgensen [P. porodictyum $v$. parvula]Phalacroma parvulum (Schütt) Jørgensen [P. porodictyum v. parvula] Phalacroma pulchellum Lebour [Dinophysis pulchella] Phalacroma pulchellum Lebour [Dinophysis pulchella] Phalacroma pulchellum Lebour [Dinophysis pulchella] Phalacroma pulchellum Lebour [Dinophysis pulchella] Phalacroma pulchellum Lebour [Dinophysis pulchella] Phalacroma pulchellum Lebour [Dinophysis pulchella] Phalacroma pulchellum Lebour [Dinophysis pulchella]

Phalacroma rotundatum (Claparède et Lachmann) Kofoid \& Michener [D.

rotundata]Phalacroma rotundatum (Claparède et Lachmann) Kofoid \& Michener [D. rotundata]Phalacroma rotundatum (Claparède et Lachmann) Kofoid \& Michener [D. rotundata]Phalacroma rotundatum (Claparède et Lachmann) Kofoid \& Michener [D. rotundata]Phalacroma rotundatum (Claparède et Lachmann) Kofoid \& Michener [D. rotundata]Phalacroma rotundatum (Claparède et Lachmann) Kofoid \& Michener [D. rotundata]Phalacroma rotundatum (Claparède et Lachmann) Kofoid \& Michener [D. rotundata]

Phalacroma rudgei Murray \& Whitting Phalacroma rudgei Murray \& Whitting Phalacroma rudgei Murray \& Whitting Phalacroma rudgei Murray \& Whitting Phalacroma rudgei Murray \& Whitting Phalacroma rudgei Murray \& Whitting Phalacroma rudgei Murray \& Whitting

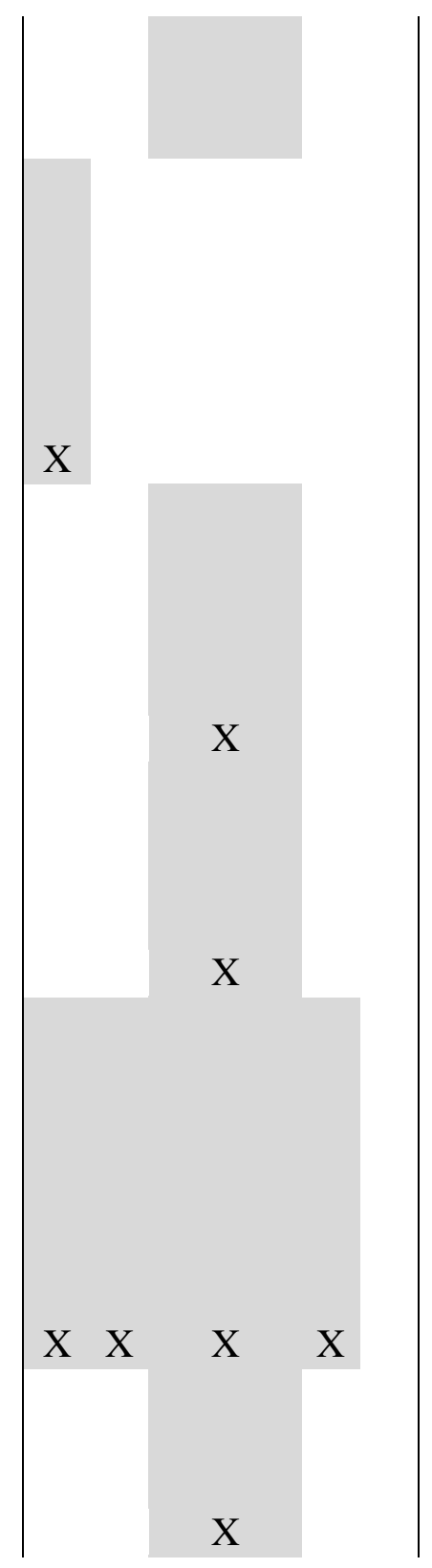


Phalacroma sphaeroideumSchillerPhalacroma sphaeroideumSchillerPhalacroma sphaeroideumSchillerPhalacroma sphaeroideumSchillerPhalacroma sphaeroideumSchillerPhalacroma sphaeroideumSchillerPhalacroma sphaeroideumSchiller

Phytodinium cf. P. simplex KlebsPhytodinium cf. P. simplex KlebsPhytodinium $c f . P$. simplex KlebsPhytodinium cf. P. simplex KlebsPhytodinium cf. P. simplex KlebsPhytodinium cf. P. simplex KlebsPhytodinium cf. P. simplex Klebs

Plectodinium nucleovolvatum Biecheler [P. miniatum, Cochlodinium miniatum] Plectodinium nucleovolvatum Biecheler [P. miniatum, Cochlodinium miniatum] Plectodinium nucleovolvatum Biecheler [P. miniatum, Cochlodinium miniatum] Plectodinium nucleovolvatum Biecheler [P. miniatum, Cochlodinium miniatum] Plectodinium nucleovolvatum Biecheler [P. miniatum, Cochlodinium miniatum] Plectodinium nucleovolvatum Biecheler [P. miniatum, Cochlodinium miniatum] Plectodinium nucleovolvatum Biecheler [P. miniatum, Cochlodinium miniatum]

Podolampas elegans Schütt Podolampas elegans Schütt Podolampas elegans Schütt Podolampas elegans Schütt Podolampas elegans Schütt Podolampas elegans Schütt Podolampas elegans Schütt

Podolampas palmipes Stein Podolampas palmipes Stein Podolampas palmipes Stein Podolampas palmipes Stein Podolampas palmipes Stein Podolampas palmipes Stein Podolampas palmipes Stein

Podolampas spinifera Okamura Podolampas spinifera Okamura Podolampas spinifera Okamura Podolampas spinifera Okamura Podolampas spinifera Okamura Podolampas spinifera Okamura Podolampas spinifera Okamura

Polykrikos kofoidii Chatton [P. schwarzii pro parte] Polykrikos kofoidii Chatton [P. schwarzii pro parte] Polykrikos kofoidii Chatton [P. schwarzii pro parte] Polykrikos kofoidii Chatton [P. schwarzii pro parte] Polykrikos kofoidii Chatton [P. schwarzii pro parte] Polykrikos kofoidii Chatton [P. schwarzii pro parte]

Polykrikos schwartzii Bütschli [P. auricularia] Polykrikos schwartzii Bütschli [P. auricularia] Polykrikos schwartzii Bütschli [P. auricularia] Polykrikos schwartzii Bütschli [P. auricularia] Polykrikos schwartzii Bütschli [P. auricularia] Polykrikos schwartzii Bütschli [P. auricularia]

Preperidinium meunieri (Pavillard) Elbrächter [Diplopsalis lenticula f.

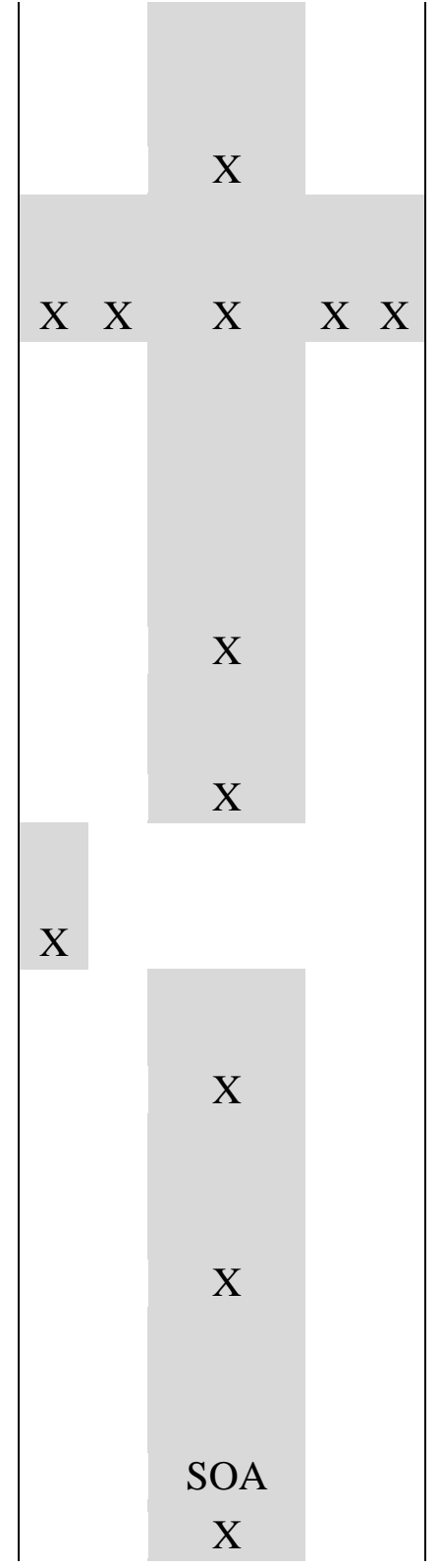


|minor]Preperidinium meunieri (Pavillard) Elbrächter [Diplopsalis lenticula f. minor]Preperidinium meunieri (Pavillard) Elbrächter [Diplopsalis lenticula f. minor]Preperidinium meunieri (Pavillard) Elbrächter [Diplopsalis lenticula f. minor]Preperidinium meunieri (Pavillard) Elbrächter [Diplopsalis lenticula f. minor]Preperidinium meunieri (Pavillard) Elbrächter [Diplopsalis lenticula f. minor] Pronoctiluca acuta (Lohmann) Schiller Pronoctiluca acuta (Lohmann) Schiller Pronoctiluca acuta (Lohmann) Schiller Pronoctiluca acuta (Lohmann) Schiller Pronoctiluca acuta (Lohmann) Schiller Pronoctiluca acuta (Lohmann) Schiller Pronoctiluca pelagica Fabre-Domergue [Rhynchomonas marina, Pelagorhynchus marinus] Pronoctiluca pelagica Fabre-Domergue [Rhynchomonas marina, Pelagorhynchus marinus] Pronoctiluca pelagica Fabre-Domergue [Rhynchomonas marina, Pelagorhynchus marinus] Pronoctiluca pelagica Fabre-Domergue [Rhynchomonas marina, Pelagorhynchus marinus] Pronoctiluca pelagica FabreDomergue [Rhynchomonas marina, Pelagorhynchus marinus] Pronoctiluca pelagica Fabre-Domergue [Rhynchomonas marina, Pelagorhynchus marinus]

Pronoctiluca spinifera (Lohmann) Schiller [P. tentaculata] Pronoctiluca spinifera (Lohmann) Schiller [P. tentaculata] Pronoctiluca spinifera (Lohmann) Schiller [P. tentaculata] Pronoctiluca spinifera (Lohmann) Schiller [P. tentaculata] Pronoctiluca spinifera (Lohmann) Schiller [P. tentaculata] Pronoctiluca spinifera (Lohmann) Schiller [P. tentaculata]

Prorocentrum aporum (Schiller) Dodge [P. antarcticum, Exuviella granii] Prorocentrum aporum (Schiller) Dodge [P. antarcticum, Exuviella granii] Prorocentrum aporum (Schiller) Dodge [P. antarcticum, Exuviella granii] Prorocentrum aporum (Schiller) Dodge [P. antarcticum, Exuviella granii] Prorocentrum aporum (Schiller) Dodge [P. antarcticum, Exuviella granii] Prorocentrum aporum (Schiller) Dodge [P. antarcticum, Exuviella granii] Prorocentrum balticum (Lohmann) Loeblich III [ P. pomoideumProrocentrum balticum (Lohmann) Loeblich III [ P. pomoideumProrocentrum balticum (Lohmann) Loeblich III [ P. pomoideumProrocentrum balticum (Lohmann) Loeblich III [ P. pomoideumProrocentrum balticum (Lohmann) Loeblich III [ P.

pomoideumProrocentrum balticum (Lohmann) Loeblich III [ P. pomoideum

Prorocentrum compressum (Bailey)Abé ex JD Dodge [Exuviaella

compressa]Prorocentrum compressum (Bailey)Abé ex JD Dodge [Exuviaella

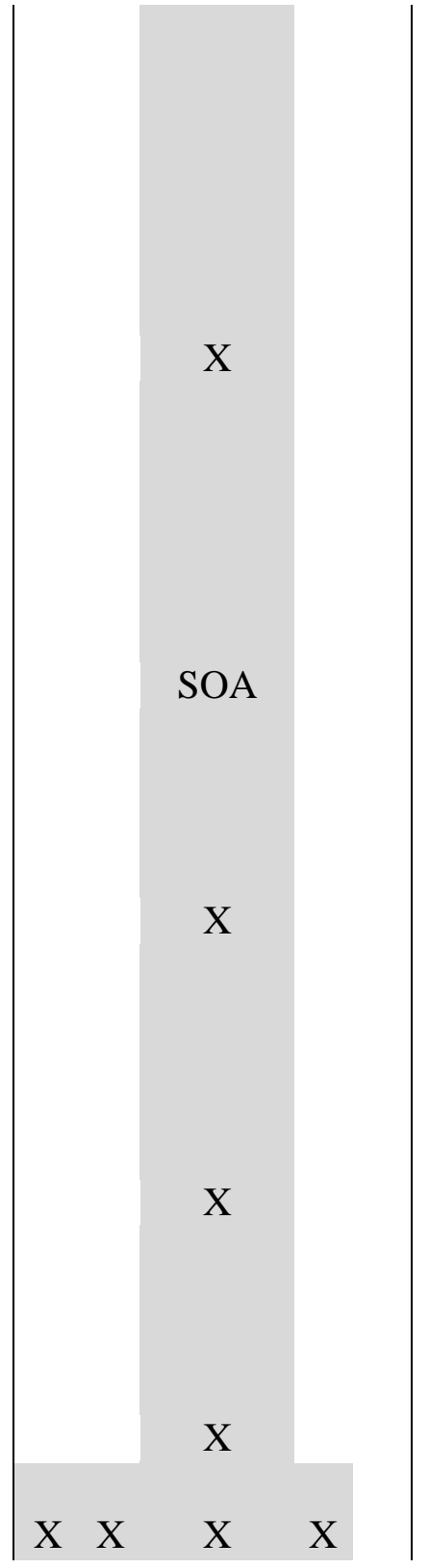


compressa]Prorocentrum compressum (Bailey)Abé ex JD Dodge [Exuviaella compressa]Prorocentrum compressum (Bailey)Abé ex JD Dodge [Exuviaella compressa]Prorocentrum compressum (Bailey)Abé ex JD Dodge [Exuviaella compressa]Prorocentrum compressum (Bailey)Abé ex JD Dodge [Exuviaella compressa] Prorocentrum cordatum (Ostenfeld) Dodge [Exuviaella cordata, P. minimum] Prorocentrum cordatum (Ostenfeld) Dodge [Exuviaella cordata, P. minimum] Prorocentrum cordatum (Ostenfeld) Dodge [Exuviaella cordata, P. minimum] Prorocentrum cordatum (Ostenfeld) Dodge [Exuviaella cordata, P. minimum] Prorocentrum cordatum (Ostenfeld) Dodge [Exuviaella cordata, P. minimum] Prorocentrum cordatum (Ostenfeld) Dodge [Exuviaella cordata, P. minimum]

Prorocentrum dentatum Stein [P. obtusidens, P. veloi, P. monacense] Prorocentrum dentatum Stein [P. obtusidens, P. veloi, P. monacense ] Prorocentrum dentatum Stein [P. obtusidens, P. veloi, P. monacense ] Prorocentrum dentatum Stein [P. obtusidens, $P$. veloi, P. monacense ] Prorocentrum dentatum Stein [P. obtusidens, $P$. veloi, $P$. monacense ] Prorocentrum dentatum Stein [P. obtusidens, P. veloi, P. monacense ] Prorocentrum lima (Ehrenberg) Dodge [Exuviella marina, E. caspica, E. ostenfeldii]Prorocentrum lima (Ehrenberg) Dodge [Exuviella marina, E. caspica, E. ostenfeldii]Prorocentrum lima (Ehrenberg) Dodge [Exuviella marina, E. caspica, E. ostenfeldii]Prorocentrum lima (Ehrenberg) Dodge [Exuviella marina, E. caspica, E. ostenfeldii]Prorocentrum lima (Ehrenberg) Dodge [Exuviella marina, E. caspica, E. ostenfeldii]Prorocentrum lima (Ehrenberg) Dodge [Exuviella marina, E. caspica, E. ostenfeldii]

Prorocentrum maximum (Gourret) Schiller [P. brochii] Prorocentrum maximum (Gourret) Schiller [P. brochii] Prorocentrum maximum (Gourret) Schiller [P. brochii] Prorocentrum maximum (Gourret) Schiller [P. brochii] Prorocentrum maximum (Gourret) Schiller [P. brochii] Prorocentrum maximum (Gourret) Schiller [P. brochii] Prorocentrum micans Ehrenberg [P. schilleri, P. levantoides] Prorocentrum micans Ehrenberg [P. schilleri, P. levantoides] Prorocentrum micans Ehrenberg [P. schilleri, $P$. levantoides ] Prorocentrum micans Ehrenberg [P. schilleri, P. levantoides] Prorocentrum micans Ehrenberg [P. schilleri, P. levantoides] Prorocentrum micans Ehrenberg [P. schilleri, P. levantoides]

Prorocentrum minimum (Pavillard) Schiller [P. mariae-lebourae etc.]Prorocentrum minimum (Pavillard) Schiller [P. mariae-lebourae etc.]Prorocentrum minimum

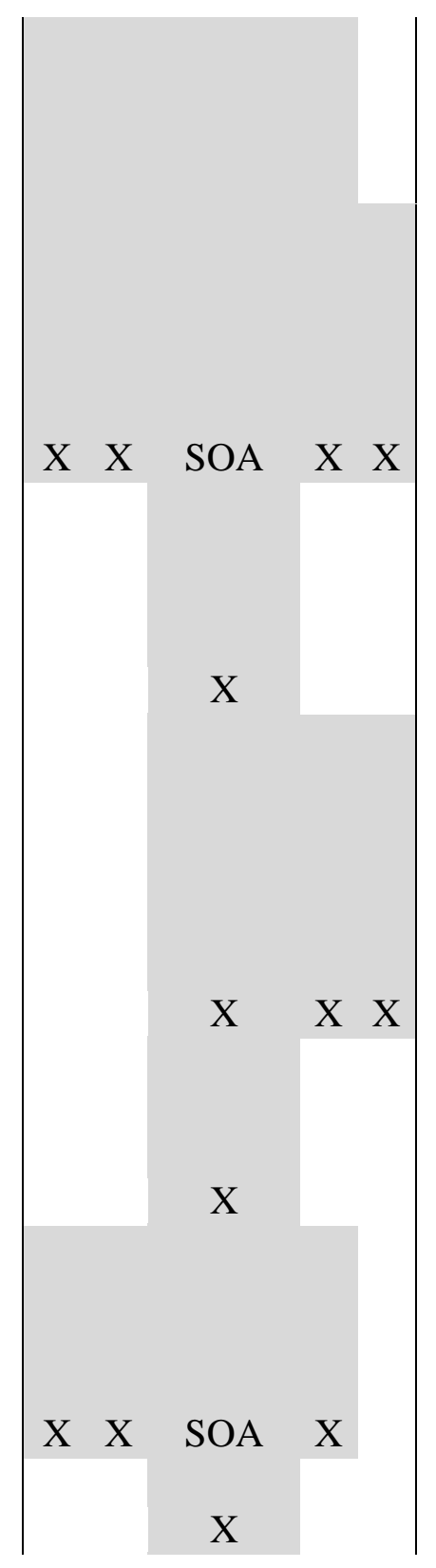

382 
(Pavillard) Schiller [P. mariae-lebourae etc.]Prorocentrum minimum (Pavillard) Schiller [P. mariae-lebourae etc.]Prorocentrum minimum (Pavillard) Schiller [P. mariae-lebourae etc.]Prorocentrum minimum (Pavillard) Schiller [P. mariae-lebourae etc.]

Prorocentrum obtusum Ostenfeld Prorocentrum obtusum Ostenfeld Prorocentrum obtusum Ostenfeld Prorocentrum obtusum Ostenfeld Prorocentrum obtusum Ostenfeld Prorocentrum obtusum Ostenfeld

Prorocentrum ovum (Schiller) Dogde [Exuviaella ovum] Prorocentrum ovum (Schiller) Dogde [Exuviaella ovum] Prorocentrum ovum (Schiller) Dogde [Exuviaella ovum] Prorocentrum ovum (Schiller) Dogde [Exuviaella ovum] Prorocentrum ovum (Schiller) Dogde [Exuviaella ovum]

Prorocentrum proximum Makarova 1967 Prorocentrum proximum Makarova 1967

Prorocentrum proximum Makarova 1967 Prorocentrum proximum Makarova 1967

Prorocentrum proximum Makarova 1967

Prorocentrum pusillum (Schiller) Loeblich [Exuviella pusilla] Prorocentrum pusillum (Schiller) Loeblich [Exuviella pusilla ] Prorocentrum pusillum (Schiller) Loeblich [Exuviella pusilla ] Prorocentrum pusillum (Schiller) Loeblich [Exuviella pusilla ] Prorocentrum pusillum (Schiller) Loeblich [Exuviella pusilla]

Prorocentrum rostratum Stein [Prorocentrum styliferum] Prorocentrum rostratum Stein [Prorocentrum styliferum] Prorocentrum rostratum Stein [Prorocentrum styliferum] Prorocentrum rostratum Stein [Prorocentrum styliferum] Prorocentrum rostratum Stein [Prorocentrum styliferum]

Prorocentrum rotundatum Schiller Prorocentrum rotundatum Schiller Prorocentrum rotundatum Schiller Prorocentrum rotundatum Schiller Prorocentrum rotundatum Schiller

Prorocentrum scutellum Schröder Prorocentrum scutellum Schröder Prorocentrum scutellum Schröder Prorocentrum scutellum Schröder Prorocentrum scutellum Schröder Prorocentrum triestinum Schiller [P. redfieldii, P. pyrenoideum Bursa] Prorocentrum triestinum Schiller [P. redfieldii, P. pyrenoideum Bursa] Prorocentrum triestinum Schiller [P. redfieldii, P. pyrenoideum Bursa] Prorocentrum triestinum Schiller [P. redfieldii, $P$. pyrenoideum Bursa] Prorocentrum triestinum Schiller [P. redfieldii, $P$. pyrenoideum Bursa]

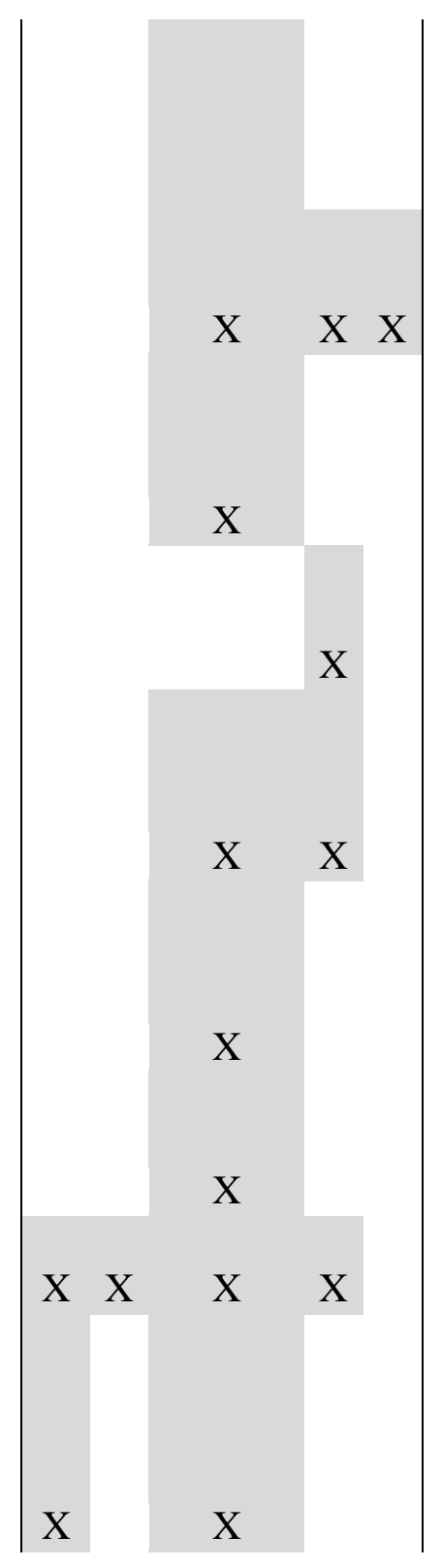


Prorocentrum vaginulum (Stein) Dodge [Dinopyxis vaginula, Exuviaella vaginula] Prorocentrum vaginulum (Stein) Dodge [Dinopyxis vaginula, Exuviaella vaginula] Prorocentrum vaginulum (Stein) Dodge [Dinopyxis vaginula, Exuviaella vaginula] Prorocentrum vaginulum (Stein) Dodge [Dinopyxis vaginula, Exuviaella vaginula] Prorocentrum vaginulum (Stein) Dodge [Dinopyxis vaginula, Exuviaella vaginula] Protoceratium areolatum Kofoid Protoceratium areolatum Kofoid Protoceratium areolatum Kofoid Protoceratium areolatum Kofoid Protoceratium areolatum Kofoid Protoceratium reticulatum (Claparède \& Lachmann) Bütschli [Gonyaulax grindleyi] Protoceratium reticulatum (Claparède \& Lachmann) Bütschli [Gonyaulax grindleyi] Protoceratium reticulatum (Claparède \& Lachmann) Bütschli [Gonyaulax grindleyi] Protoceratium reticulatum (Claparède \& Lachmann) Bütschli [Gonyaulax grindleyi] Protoceratium reticulatum (Claparède \& Lachmann) Bütschli [Gonyaulax grindleyi] Protoperidinium abei (Paulsen) Balech [Peridinium abei] Protoperidinium abei (Paulsen) Balech [Peridinium abei] Protoperidinium abei (Paulsen) Balech [Peridinium abei] Protoperidinium abei (Paulsen) Balech [Peridinium abei] Protoperidinium abei (Paulsen) Balech [Peridinium abei]

Protoperidinium achromaticum (Levander) Balech [P. finitimum etc.]Protoperidinium achromaticum (Levander) Balech [P. finitimum etc.]Protoperidinium achromaticum (Levander) Balech [P. finitimum etc.]Protoperidinium achromaticum (Levander) Balech [P. finitimum etc.]Protoperidinium achromaticum (Levander) Balech [P. finitimum etc.]

Protoperidinium bipes (Paulsen) Balech Protoperidinium bipes (Paulsen) Balech Protoperidinium bipes (Paulsen) Balech Protoperidinium bipes (Paulsen) Balech Protoperidinium bipes (Paulsen) Balech

Protoperidinium brevipes (Paulsen) BalechProtoperidinium brevipes (Paulsen) BalechProtoperidinium brevipes (Paulsen) BalechProtoperidinium brevipes (Paulsen) BalechProtoperidinium brevipes (Paulsen) Balech

Protoperidinium brochii (Kofoid et Swezy) Balech [P. adriaticum] Protoperidinium brochii (Kofoid et Swezy) Balech [P. adriaticum] Protoperidinium brochii (Kofoid et Swezy) Balech [P. adriaticum] Protoperidinium brochii (Kofoid et Swezy) Balech [P. adriaticum] Protoperidinium brochii (Kofoid et Swezy) Balech [P. adriaticum]

Protoperidinium brevipes (Paulsen) BalechProtoperidinium brevipes (Paulsen)

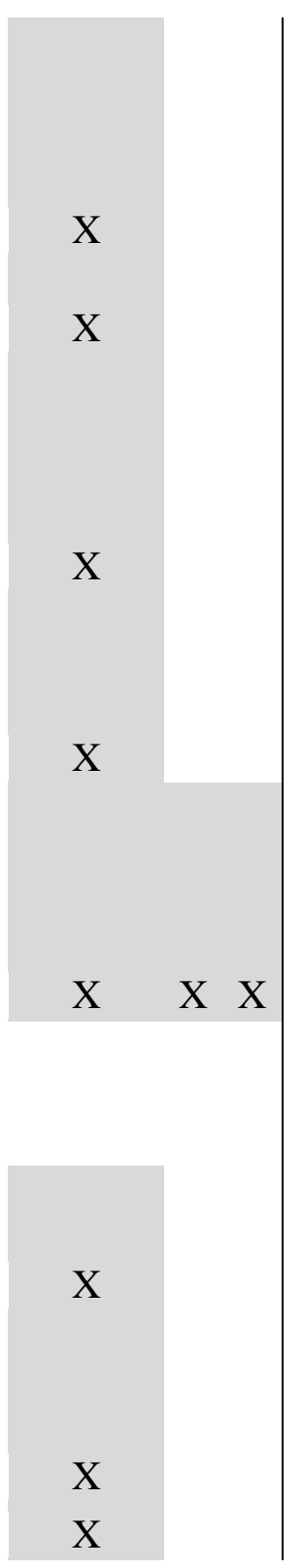


BalechProtoperidinium brevipes (Paulsen) BalechProtoperidinium brevipes (Paulsen) BalechProtoperidinium brevipes (Paulsen) Balech

Protoperidinium claudicans (Paulsen) Balech [Peridinium claudicans] Protoperidinium claudicans (Paulsen) Balech [Peridinium claudicans ] Protoperidinium claudicans (Paulsen) Balech [Peridinium claudicans ] Protoperidinium claudicans (Paulsen) Balech [Peridinium claudicans]

Protoperidinium conicoides (Paulsen) Balech [Peridinium conicoides Protoperidinium conicoides (Paulsen) Balech [Peridinium conicoides Protoperidinium conicoides (Paulsen) Balech [Peridinium conicoides Protoperidinium conicoides (Paulsen) Balech [Peridinium conicoides

Protoperidinium conicum (Gran) Balech [ Peridinium divergens var. conica Gran] Protoperidinium conicum (Gran) Balech [ Peridinium divergens var. conica Gran] Protoperidinium conicum (Gran) Balech [ Peridinium divergens var. conica Gran] Protoperidinium conicum (Gran) Balech [ Peridinium divergens var. conica Gran] Protoperidinium crassipes (Kofoid) Balech Protoperidinium crassipes (Kofoid) Balech Protoperidinium crassipes (Kofoid) Balech Protoperidinium crassipes (Kofoid) Balech Protoperidinium curtipes (Jørgensen) Balech [Peridinium curtipes etc.]Protoperidinium curtipes (Jørgensen) Balech [Peridinium curtipes etc.]Protoperidinium curtipes (Jørgensen) Balech [Peridinium curtipes etc.]Protoperidinium curtipes (Jørgensen) Balech [Peridinium curtipes etc.] Protoperidinium curvipes (Ostenfeld) Balech [ Peridinium curvipes] Protoperidinium curvipes (Ostenfeld) Balech [ Peridinium curvipes] Protoperidinium curvipes (Ostenfeld) Balech [ Peridinium curvipes] Protoperidinium curvipes (Ostenfeld) Balech [ Peridinium curvipes]

Protoperidinium decipiens (Jørgensen) Parke et Dodge [Peridinium decipiens] Protoperidinium decipiens (Jørgensen) Parke et Dodge [Peridinium decipiens] Protoperidinium decipiens (Jørgensen) Parke et Dodge [Peridinium decipiens] Protoperidinium decipiens (Jørgensen) Parke et Dodge [Peridinium decipiens] Protoperidinium deficiens (Meunier) Balech [Peridinium deficiens Meunier] Protoperidinium deficiens (Meunier) Balech [Peridinium deficiens Meunier] Protoperidinium deficiens (Meunier) Balech [Peridinium deficiens Meunier] Protoperidinium deficiens (Meunier) Balech [Peridinium deficiens Meunier]

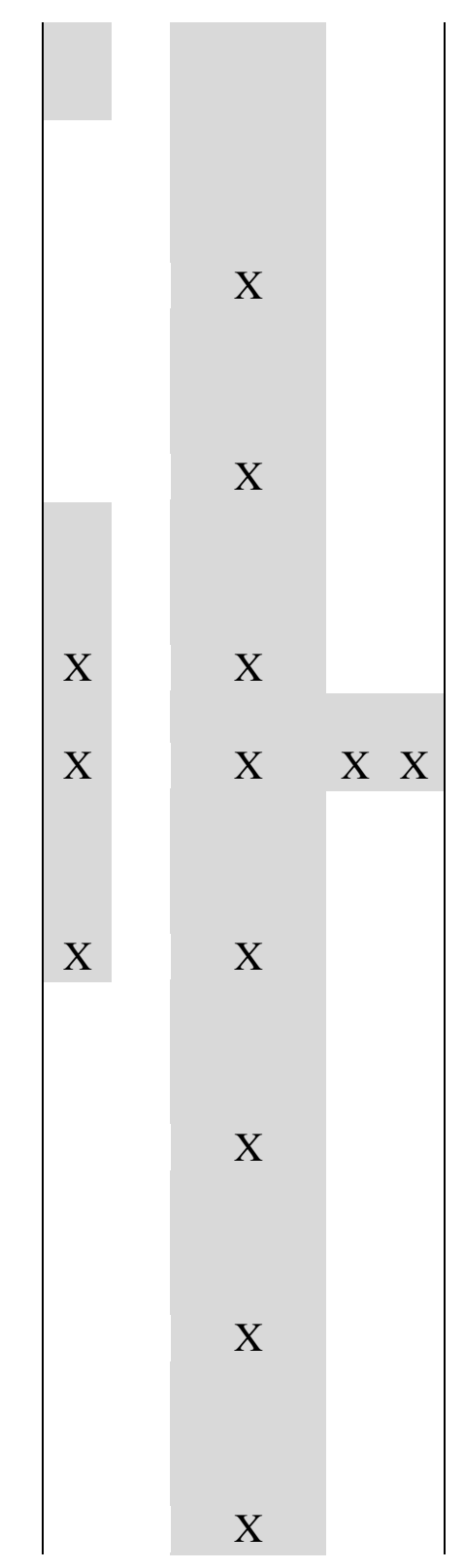


Protoperidinium depressum (Bailey) Balech [Peridinium depressum Bailey] Protoperidinium depressum (Bailey) Balech [Peridinium depressum Bailey] Protoperidinium depressum (Bailey) Balech [Peridinium depressum Bailey] Protoperidinium depressum (Bailey) Balech [Peridinium depressum Bailey] Protoperidinium diabolus (Cleve) Balech [Peridinium diabolus incl. P. longipes Protoperidinium diabolus (Cleve) Balech [Peridinium diabolus incl. P. longipes Protoperidinium diabolus (Cleve) Balech [Peridinium diabolus incl. P. longipes Protoperidinium diabolus (Cleve) Balech [Peridinium diabolus incl. P. longipes Protoperidinium divergens (Ehrenberg) Balech [ Peridinium divergens] Protoperidinium divergens (Ehrenberg) Balech [ Peridinium divergens] Protoperidinium divergens (Ehrenberg) Balech [ Peridinium divergens] Protoperidinium divergens (Ehrenberg) Balech [ Peridinium divergens] Protoperidinium elegans (Cleve) Balech [ P. fatulipes] Protoperidinium elegans (Cleve) Balech [ P. fatulipes] Protoperidinium elegans (Cleve) Balech [ P. fatulipes] Protoperidinium elegans (Cleve) Balech [ P. fatulipes]

Protoperidinium excentricum (Paulsen) Balech [ Peridinium excentricum, P. perrieri JProtoperidinium excentricum (Paulsen) Balech [ Peridinium excentricum, P. perrieri JProtoperidinium excentricum (Paulsen) Balech [ Peridinium excentricum, $P$. perrieri JProtoperidinium excentricum (Paulsen) Balech [ Peridinium excentricum, P. perrieri] Protoperidinium globulus (Stein) Balech [ Peridinium ovatum etc.]Protoperidinium globulus (Stein) Balech [ Peridinium ovatum etc.]Protoperidinium globulus (Stein) Balech [ Peridinium ovatum etc.]Protoperidinium globulus (Stein) Balech [ Peridinium ovatum etc.]

Protoperidinium grande (Kofoid) Balech [ P. truncatum (Graham) Balech] Protoperidinium grande (Kofoid) Balech [ P. truncatum (Graham) Balech] Protoperidinium grande (Kofoid) Balech [ P. truncatum (Graham) Balech] Protoperidinium grande (Kofoid) Balech [ P. truncatum (Graham) Balech] Protoperidinium granii (Ostenfield) Balech (Peridinium granii Ostenfeld)Protoperidinium granii (Ostenfield) Balech (Peridinium granii Ostenfeld)Protoperidinium granii (Ostenfield) Balech (Peridinium granii Ostenfeld)Protoperidinium granii (Ostenfield) Balech (Peridinium granii Ostenfeld)

Protoperidinium inflatum (Okamura) Balech [ Peridinium inflatum, P.

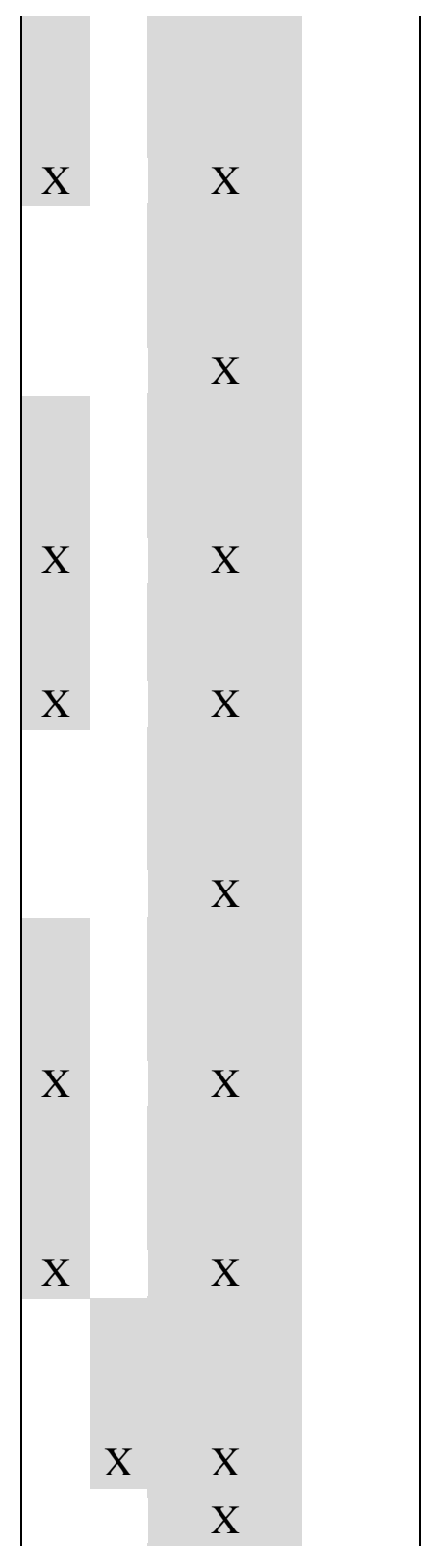


crassum]Protoperidinium inflatum (Okamura) Balech [ Peridinium inflatum, $P$. crassum]Protoperidinium inflatum (Okamura) Balech [ Peridinium inflatum, P. crassum] Protoperidinium knipowitschii (Ussatschew) Balech [Peridinium knipowitschii] Protoperidinium knipowitschii (Ussatschew) Balech [Peridinium knipowitschii] Protoperidinium knipowitschii (Ussatschew) Balech [Peridinium knipowitschii] Protoperidinium leonis (Pavillard) Balech [ Peridinium leonis etc.]Protoperidinium leonis (Pavillard) Balech [ Peridinium leonis etc.]Protoperidinium leonis (Pavillard) Balech [ Peridinium leonis etc.]

Protoperidinium longipes Balech Protoperidinium longipes Balech Protoperidinium longipes Balech

Protoperidinium longispinum (Kofoid) Balech [Peridinium longispinum] Protoperidinium longispinum (Kofoid) Balech [Peridinium longispinum] Protoperidinium longispinum (Kofoid) Balech [Peridinium longispinum] P. michaelis Ehrenberg [pro parte] P. michaelis Ehrenberg [pro parte] P. michaelis Ehrenberg [pro parte]

Protoperidinium marielebourae (Paulsen) Balech [ Peridinium obtusum]Protoperidinium marielebourae (Paulsen) Balech [ Peridinium obtusum]Protoperidinium marielebourae (Paulsen) Balech [ Peridinium obtusum] Protoperidinium oblongum (Aurivillius) Parke \& DodgeProtoperidinium oblongum (Aurivillius) Parke \& DodgeProtoperidinium oblongum (Aurivillius) Parke \& Dodge Protoperidinium obtusum (Karsten) Faure-FremietProtoperidinium obtusum (Karsten) Faure-FremietProtoperidinium obtusum (Karsten) Faure-Fremiet

Protoperidinium ovatum Pouchet [Peridinium globulus v. ovatum]Protoperidinium ovatum Pouchet [Peridinium globulus v. ovatum]Protoperidinium ovatum Pouchet [Peridinium globulus $v$. ovatum]

Protoperidinium minutum (Kofoid) Loeblich III [now Archaeperidinium minutum ] Protoperidinium minutum (Kofoid) Loeblich III [now Archaeperidinium minutum ] Protoperidinium minutum (Kofoid) Loeblich III [now Archaeperidinium minutum ] Protoperidinium mite (Pavillard) Balech Protoperidinium mite (Pavillard) Balech Protoperidinium mite (Pavillard) Balech

Protoperidinium oblongum (Aurivillius) Parke et Dodge [ Peridinium oblongum etc.]Protoperidinium oblongum (Aurivillius) Parke et Dodge [ Peridinium oblongum

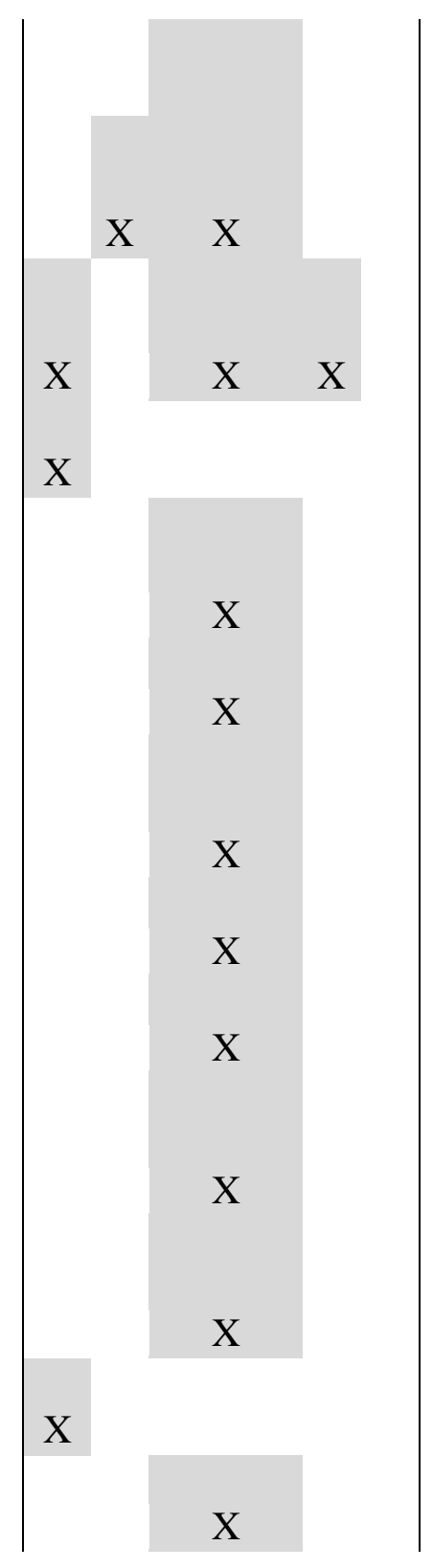


etc.]Protoperidinium oblongum (Aurivillius) Parke et Dodge [ Peridinium oblongum etc.]

Protoperidinium oceanicum (Vanhöffen) Balech [Peridinium divergens v. oceanicum] Protoperidinium oceanicum (Vanhöffen) Balech [Peridinium divergens v. oceanicum] Protoperidinium oceanicum (Vanhöffen) Balech [Peridinium divergens v. oceanicum] Protoperidinium pallidum (Ostenfeld) Balech [Peridinium pallidum ] Protoperidinium pallidum (Ostenfeld) Balech [Peridinium pallidum ] Protoperidinium pallidum (Ostenfeld) Balech [Peridinium pallidum ]

Protoperidinium pedunculatum (Schütt) Balech [ Peridinium pedunculatum] Protoperidinium pedunculatum (Schütt) Balech [ Peridinium pedunculatum] Protoperidinium pedunculatum (Schütt) Balech [ Peridinium pedunculatum] Protoperidinium pellucidum Bergh [ Peridinium pellucidum (Bergh) Schütt] Protoperidinium pellucidum Bergh [ Peridinium pellucidum (Bergh) Schïtt] Protoperidinium pentagonum (Gran) Balech [Peridinium pentagonum, $P$. sinuosum]Protoperidinium pentagonum (Gran) Balech [Peridinium pentagonum, $P$. sinuosum]

Protoperidinium punctulatum (Paulsen) Balech [Peridinium subinerme v. punctulatum] Protoperidinium punctulatum (Paulsen) Balech [Peridinium subinerme v. punctulatum]

Protoperidinium pyriforme (Paulsen) Balech [Peridinium steinii var. pyriformis] Protoperidinium pyriforme (Paulsen) Balech [Peridinium steinii var. pyriformis] Protoperidinium similum (Paulsen) Balech Protoperidinium similum (Paulsen) Balech Protoperidinium sinaicum (Matzenauer) Balech [Peridinium sinaicum Matzenauer] Protoperidinium sinaicum (Matzenauer) Balech [Peridinium sinaicum Matzenauer] Protoperidinium solidicorne (Mangin) Balech [P. spiniferum, P. spinosum ] Protoperidinium solidicorne (Mangin) Balech [P. spiniferum, P. spinosum ] Protoperidinium steinii (Jörgensen) Balech [Peridinium steinii Jörgensen]Protoperidinium steinii (Jörgensen) Balech [Peridinium steinii Jörgensen] Protoperidinium subinerme (Paulsen) Loeblich III [ Peridinium subinerme Paulsen] Protoperidinium subinerme (Paulsen) Loeblich III [ Peridinium subinerme Paulsen] Protoperidinium thorianum (Paulsen) Balech [ Peridinium thorianum etc.] Protoperidinium thorianum (Paulsen) Balech [ Peridinium thorianum etc.]




Ptychodiscus noctiluca Stein [P. inflatus Pavillard, P. carinatus Kofoid] Ptychodiscus noctiluca Stein [P. inflatus Pavillard, P. carinatus Kofoid]

Pyrocystis elegans Pavillard Pyrocystis elegans Pavillard

Pyrocystis lunula (Schütt) Schütt [Gymnodinium lunula Schütt] Pyrocystis lunula (Schütt) Schütt [Gymnodinium lunula Schütt]

Pyrophacus horologium Stein emend. Wall et Dale Pyrophacus horologium Stein emend. Wall et Dale

Pyrophacus steinii (Schiller) Wall et Dale [ P. horologicum var. steinii Schiller] Pyrophacus steinii (Schiller) Wall et Dale [ P. horologicum var. steinii Schiller] Scaphodinium mirabile Margalef [Leptospathium navicula Cachon \& Cachon] Scaphodinium mirabile Margalef [Leptospathium navicula Cachon \& Cachon]

Scrippsiella acuminata (Ehrenberg) Kretschmann

Scrippsiella trochoidea (Stein) Loeblich III [Peridinium trochoideum, Peridinium faeroense]

Spatulodinium pseudonoctiluca (Pouchet) Cachon \& Cachon ex Loeblich \& Loeblich III

Torodinium robustum Kofoid et Swezy [ Gymnodinium teredo Schütt pro parte]

Tripos extensus (Gourret) F. Gómez [Ceratium extensum]

Tripos strictus (Okamura \& Nishikawa) F.Gómez [Ceratium strictum]

Warnowia maculata (Kofoid et Swezy) Lindemann [Pouchetia maculata]

Warnowia schuettii (Kofoid \& Swezy) Schiller

Woloszynskia coronata (Woloszynska) Thompson [Gymnodinium coronatum]

Woloszynskia neglecta (Schilling) Thompson [Gymnodinium neglectum]

Woloszynskia pascheri (Suchlandt) Stosch (Gymnodinium polonicum]

Woloszynskia polonica (Woloszynska) Thompson

Woloszynskia hiemale (Woloszynska) Thompson

Woloszynskia tenuissima (Lauterborn) Thompson

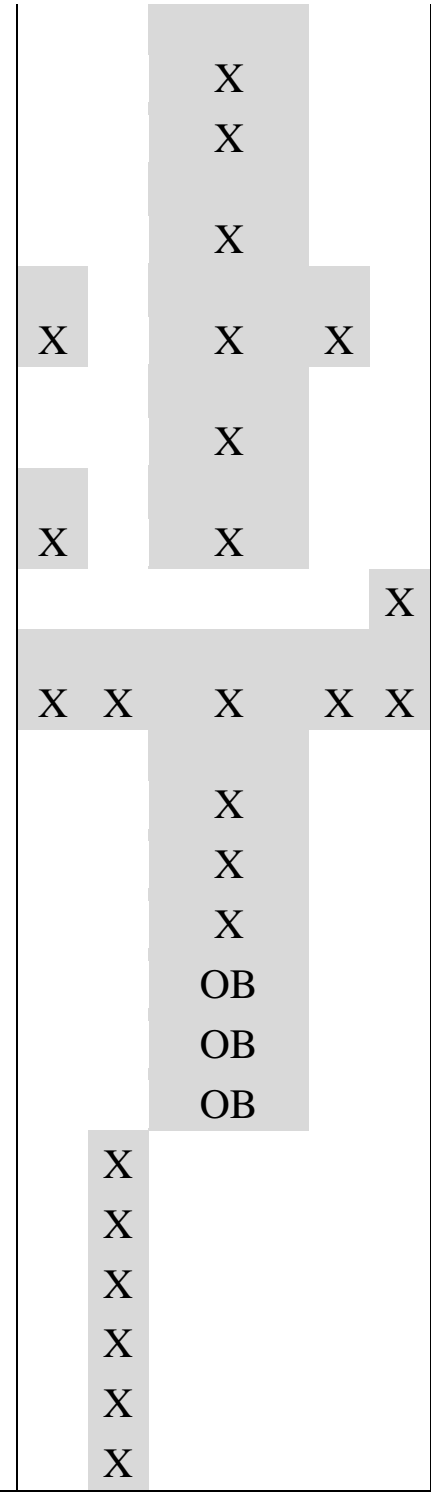




\begin{tabular}{|c|c|c|c|c|c|c|}
\hline CYST NAME & $\begin{array}{l}\text { PLA } \\
\text { TE }\end{array}$ & $\begin{array}{r}\mathbf{M} \\
\mathbf{A P}\end{array}$ & $\begin{array}{r}\mathbf{H} \\
\mathbf{A B}\end{array}$ & $\begin{array}{l}\text { TROPHI } \\
\text { SM }\end{array}$ & $\begin{array}{l}\text { MOTILE STAGE } \\
\text { NAME }\end{array}$ & $\begin{array}{l}\text { CO } \\
\text { DE }\end{array}$ \\
\hline 1. Achomosphaera sp. & $\begin{array}{l}\text { No } \\
\text { plate }\end{array}$ & $\begin{array}{l}\text { Fig } \\
\text { ure } 7\end{array}$ & & $\mathrm{P}$ & Gonyaulax sp. & $\begin{array}{l}\text { Ach } \\
\text { sp }\end{array}$ \\
\hline 2. Ataxiodinium choane & $\begin{array}{rr} & \text { Plate } \\
1 & \end{array}$ & $\begin{array}{l}\text { Fig } \\
\text { ure } 8\end{array}$ & & $\mathrm{P}$ & Gonyaulax sp. & $\begin{array}{l}\text { Ach } \\
\text { o }\end{array}$ \\
\hline 3. Bitectatodinium tepikiense & $\begin{array}{lr} & \text { Plate } \\
2 & \end{array}$ & $\begin{array}{r}\text { Fig } \\
\text { ure } 9\end{array}$ & $\mathrm{X}$ & $\mathrm{P}$ & Gonyaulax digitale & Btep \\
\hline 4. Brigantedinium cariacoense & $\begin{array}{l}\text { Plate } \\
3\end{array}$ & $\begin{array}{r}\text { Fig } \\
\text { ure } 10\end{array}$ & & $\mathrm{H}$ & $\begin{array}{l}\text { Protoperidinium } \\
\text { avellana }\end{array}$ & Bcar \\
\hline 5. Brigantedinium simplex & Plate & $\begin{array}{r}\text { Fig } \\
\text { ure } 11\end{array}$ & & $\mathrm{H}$ & $\begin{array}{l}\text { Protoperidinium } \\
\text { conicoides }\end{array}$ & $\begin{array}{l}\text { Bsi } \\
\mathrm{m}\end{array}$ \\
\hline 6. Brigantedinium spp. & $\begin{array}{l}\text { No } \\
\text { plate }\end{array}$ & $\begin{array}{r}\text { Fig } \\
\text { ure } 12\end{array}$ & & $\mathrm{H}$ & Protoperidinium $\mathrm{sp}$. & $\begin{array}{l}\text { Bsp } \\
\mathrm{p}\end{array}$ \\
\hline 7. Caspidinium rugosum & $\begin{array}{r}\text { Plate } \\
4 \quad\end{array}$ & $\begin{array}{r}\text { Fig } \\
\text { ure } 13\end{array}$ & & $\mathrm{P}$ & Unknown & $\begin{array}{l}\text { Cru } \\
\mathrm{g}\end{array}$ \\
\hline 8. Cyst of Alexandrium pseudogonyaulax & $\begin{array}{rr} & \text { Plate } \\
1 & \end{array}$ & $\begin{array}{r}\text { Fig } \\
\text { ure } 14\end{array}$ & $\mathrm{X}$ & $\mathrm{P}+$ & $\begin{array}{c}\text { Alexandrium } \\
\text { pseudogonyaulax }\end{array}$ & $\begin{array}{l}\text { Aps } \\
\text { eu }\end{array}$ \\
\hline 9. Cyst of Alexandrium spp & $\begin{array}{ll} & \text { Plate } \\
5 & \end{array}$ & $\begin{array}{r}\text { Fig } \\
\text { ure } 15\end{array}$ & $\mathrm{X}$ & $\mathrm{P}$ & Alexandrium spp. & Alex \\
\hline 10. Cyst of Barrufeta respendens* & Plate & & & $\mathrm{P}+$ & Barrufeta resplendens & \\
\hline
\end{tabular}




\begin{tabular}{|c|c|c|c|c|c|c|}
\hline & 6 & & & & & \\
\hline 11. Cyst of cf. Biecheleria baltica & $\begin{array}{l}\text { Plate } \\
7\end{array}$ & $\begin{array}{r}\text { Fig } \\
\text { ure } 16\end{array}$ & $\mathrm{X}$ & $\mathrm{P}$ & Unknown & Bbal \\
\hline $\begin{array}{l}\text { 12. Cyst of Cochlodinium polykrikoides sensu Li } \\
\text { et al. } 2015\end{array}$ & $\begin{array}{l}\text { Plate } \\
8\end{array}$ & $\begin{array}{r}\text { Fig } \\
\text { ure } 17\end{array}$ & $\mathrm{X}$ & $\mathrm{M}$ & $\begin{array}{l}\text { Cochlodinium } \\
\text { polykrikoides }\end{array}$ & Cpol \\
\hline 13. Cyst of Cochlodinium sensu Fukuyo 1982 & $6^{\text {Plate }}$ & $\begin{array}{r}\text { Fig } \\
\text { ure } 18\end{array}$ & $X$ & M & $\begin{array}{l}\text { Cochlodinium sp. ss } \\
\text { Fukuyo }\end{array}$ & $\begin{array}{l}\text { Coc } \\
\mathrm{h}\end{array}$ \\
\hline 14. Cyst of Diplopelta symmetrica & $\begin{array}{ll} & \text { Plate } \\
9 & \end{array}$ & $\begin{array}{r}\text { Fig } \\
\text { ure } 19\end{array}$ & & $\mathrm{H}$ & Diplopelta symmetrica & $\begin{array}{l}\text { Dsy } \\
\mathrm{m}\end{array}$ \\
\hline $\begin{array}{l}\text { 15. Cyst of Fragilidium sp.of Owen \& Norris } \\
1985^{*}\end{array}$ & $\begin{array}{l}\text { Plate } \\
5\end{array}$ & & & M & Fragilidium sp. & \\
\hline 16. Cyst of Gymnodinium catenatum* & Plate & & $\mathrm{X}$ & $\mathrm{P}+$ & $\begin{array}{l}\text { Gymnodinium } \\
\text { catenatum* }^{*}\end{array}$ & \\
\hline $\begin{array}{l}\text { 17. Cyst of Gymnodinium } \\
\text { nolleri/microreticulatum }\end{array}$ & $\begin{array}{l}\text { Plate } \\
10\end{array}$ & $\begin{array}{r}\text { Fig } \\
\text { ure } 20\end{array}$ & & $\mathrm{P}+$ & $\begin{array}{l}\text { G.nolleri/microreticulat } \\
\text { um }\end{array}$ & $\begin{array}{l}\text { Gno } \\
1\end{array}$ \\
\hline 18. Cyst of Kolkwitziella acuta & $\begin{array}{l}\text { Plate } \\
11\end{array}$ & $\begin{array}{r}\text { Fig } \\
\text { ure } 21\end{array}$ & & $\mathrm{H}$ & Kolkwitziella acuta & $\begin{array}{l}\mathrm{Kac} \\
\mathrm{u}\end{array}$ \\
\hline 19. Cyst of Pentapharsodinium dalei & $\begin{array}{l}\text { Plate } \\
12\end{array}$ & $\begin{array}{r}\text { Fig } \\
\text { ure } 22\end{array}$ & & $\mathrm{P}$ & $\begin{array}{l}\text { Pentapharsodinium } \\
\text { dalei }\end{array}$ & Pdal \\
\hline 20. Cyst of Peridinium cf. willei & $\begin{array}{rr} & \text { Plate } \\
1 & \end{array}$ & $\begin{array}{r}\text { Fig } \\
\text { ure } 23\end{array}$ & & $\mathrm{P}$ & Peridinium cf. willei & Pwil \\
\hline 21. Cyst of Polykrikos hartmannii & Plate & Fig & $\mathrm{X}$ & $\mathrm{M}$ & Polykrikos hartmannii & Phar \\
\hline
\end{tabular}




\begin{tabular}{|c|c|c|c|c|c|c|}
\hline & 13 & ure 24 & & & & \\
\hline $\begin{array}{l}\text { 22. Cyst of Polykrikos kofoidii/schwartzii sensu } \\
\text { Matsuoka et al. } 2009\end{array}$ & $\begin{array}{l}\text { Plate } \\
13\end{array}$ & $\begin{array}{r}\text { Fig } \\
\text { ure } 25\end{array}$ & $\mathrm{X}$ & $\mathrm{H}$ & $\begin{array}{l}\text { Polykrikos } \\
\text { schwartzii/kofoidii }\end{array}$ & Pkoi \\
\hline 23. Cyst of Protoperidinium nudum & $\begin{array}{l}\text { Plate } \\
14\end{array}$ & $\begin{array}{r}\text { Fig } \\
\text { ure } 26\end{array}$ & & $\mathrm{H}$ & $\begin{array}{l}\text { Protoperidinium } \\
\text { nudum... }\end{array}$ & $\begin{array}{l}\text { Pnu } \\
\mathrm{d}\end{array}$ \\
\hline 24. Cyst of Protoperidinium stellatum & $\begin{array}{l}\text { Plate } \\
10\end{array}$ & $\begin{array}{r}\text { Fig } \\
\text { ure } 27\end{array}$ & & $\mathrm{H}$ & $\begin{array}{l}\text { Protoperidinium } \\
\text { stellatum }\end{array}$ & Pstel \\
\hline 25. Cyst of Scrippsiella trifida & $\begin{array}{ll} & \text { Plate } \\
5 & \end{array}$ & $\begin{array}{r}\text { Fig } \\
\text { ure } 28\end{array}$ & & $\mathrm{P}+$ & Scrippsiella trifida & Strif \\
\hline 26. Cyst of Scrippsiella trochoidea & Plate & $\begin{array}{r}\text { Fig } \\
\text { ure } 30\end{array}$ & & M & Scrippsiella trochoidea & Stro \\
\hline 27. Cyst of Scrippsiella spp. & & $\begin{array}{r}\text { Fig } \\
\text { ure } 29\end{array}$ & & $\mathrm{P}$ & Cyst of Scrippsiella sp & $\begin{array}{l}\text { Scri } \\
\mathrm{p}\end{array}$ \\
\hline 28. Cyst Type A of Verleye et al. 2009 & $\begin{array}{l}\text { Plate } \\
15\end{array}$ & $\begin{array}{r}\text { Fig } \\
\text { ure } 31\end{array}$ & & $\mathrm{H}$ & Unknown & $\begin{array}{l}\text { Tav } \\
\text { er }\end{array}$ \\
\hline 29. Dubridinium caperatum & 3 Plate & $\begin{array}{r}\text { Fig } \\
\text { ure } 32\end{array}$ & & $\mathrm{H}$ & Preperidinium meunieri & $\begin{array}{l}\text { Dca } \\
\mathrm{p}\end{array}$ \\
\hline 30. Echinidinium spp. & $\begin{array}{l}\text { No } \\
\text { plate }\end{array}$ & $\begin{array}{r}\text { Fig } \\
\text { ure } 34\end{array}$ & & $\mathrm{H}$ & Unkown & $\begin{array}{l}\text { Esp } \\
\mathrm{p}\end{array}$ \\
\hline 31. Echinidinium transparantum & $\begin{array}{l}\text { No } \\
\text { plate }\end{array}$ & & & $\mathrm{H}$ & Unknown & \\
\hline 32. Echinidinium zonneveldiae & Plate & Fig & & $\mathrm{H}$ & Unknown & Ezo \\
\hline
\end{tabular}




\begin{tabular}{|c|c|c|c|c|c|c|}
\hline & 9 & ure 33 & & & & $\mathrm{n}$ \\
\hline 33. Impagidinium caspienense & $\begin{array}{l}\text { Plate } \\
16\end{array}$ & $\begin{array}{r}\text { Fig } \\
\text { ure } 35\end{array}$ & & $\mathrm{P}$ & Gonyaulax sp. indet. & Icas \\
\hline 34. Impagidinium inaequalis* & $\begin{aligned} & \text { Plate } \\
4 & \end{aligned}$ & & & $\mathrm{P}$ & Gonyaulax sp. indet. & \\
\hline 35. cf. Islandinium minutum & $\begin{array}{l}\text { No } \\
\text { plate }\end{array}$ & & & $\mathrm{H}$ & Protoperidinium sp. & \\
\hline 36. Lejeunecysta oliva ${ }^{*}$ & $\begin{array}{l}\text { Plate } \\
17\end{array}$ & & & $\mathrm{H}$ & Protoperidinium sp. & \\
\hline 37. Lejeunecysta marieae & $\begin{array}{l}\text { Plate } \\
17\end{array}$ & & & $\mathrm{H}$ & Protoperidinium sp. & $\begin{array}{l}\text { Lma } \\
\mathrm{r}\end{array}$ \\
\hline 38. Lejeunecysta spp.* & No & & & $\mathrm{H}$ & Protoperidinium sp. & Leje \\
\hline 39. Lingulodinium machaerophorum process $>10$ & $\begin{array}{l}\text { Plate } \\
18\end{array}$ & $\begin{array}{r}\text { Fig } \\
\text { ure } 36\end{array}$ & $\mathrm{X}$ & M & $\begin{array}{l}\text { Lingulodinium } \\
\text { polyedra }\end{array}$ & $\begin{array}{l}\text { Lma } \\
\text { csl }\end{array}$ \\
\hline 40. Lingulodinium machaerophorum process $<10$ & $\begin{array}{l}\text { Plate } \\
18\end{array}$ & $\begin{array}{r}\text { Fig } \\
\text { ure } 37\end{array}$ & $\mathrm{X}$ & $\mathrm{M}$ & $\begin{array}{l}\text { Lingulodinium } \\
\text { polyedra }\end{array}$ & $\begin{array}{l}\text { Lma } \\
\text { csp }\end{array}$ \\
\hline 41. Lingulodinium machaerophorum f. clavatum & $\begin{array}{l}\text { Plate } \\
18\end{array}$ & $\begin{array}{r}\text { Fig } \\
\text { ure } 38\end{array}$ & $\mathrm{X}$ & M & $\begin{array}{l}\text { Lingulodinium } \\
\text { polyedra }\end{array}$ & $\begin{array}{l}\text { Lma } \\
\mathrm{ccl}\end{array}$ \\
\hline 42. Nematosphaeropsis labyrinthus & $\begin{array}{l}\text { Plate } \\
19\end{array}$ & $\begin{array}{r}\text { Fig } \\
\text { ure } 39\end{array}$ & & $\mathrm{P}$ & $\begin{array}{l}\text { Gonyaulax spinifera } \\
\text { complex }\end{array}$ & Nlab \\
\hline 43. Operculodinium centrocarpum sensu Wall & Plate & Fig & $\mathrm{X}$ & $\mathrm{P}$ & Protoceratium & Oce \\
\hline
\end{tabular}




\begin{tabular}{|c|c|c|c|c|c|}
\hline and Dale 1966 & 20 & ure 40 & & reticulatum & $\mathrm{n}$ \\
\hline $\begin{array}{l}\text { 44. Operculodinium centrocarpum form B de } \\
\text { Vernal et al. } 1989^{*}\end{array}$ & $\begin{array}{l}\text { No } \\
\text { plate }\end{array}$ & & $\mathrm{P}$ & Unknown & \\
\hline 45. Operculodinium israelianum* & 12 & & $\mathrm{P}$ & Unknown & \\
\hline 46. Peridinium ponticum & 21 & $\begin{array}{r}\text { Fig } \\
\text { ure } 41\end{array}$ & $\mathrm{H}$ ? & $\begin{array}{l}\text { Protoperidinium sp. } \\
\text { indet. }\end{array}$ & $\begin{array}{l}\text { Ppo } \\
\mathrm{n}\end{array}$ \\
\hline 47. Pyxidinopsis psilata & $\begin{array}{l}\text { Plate } \\
22\end{array}$ & $\begin{array}{r}\text { Fig } \\
\text { ure } 42\end{array}$ & $\mathrm{P}$ & Unknown & Ppsi \\
\hline 48. Quinquecuspis concreta & $\begin{array}{l}\text { Plate } \\
17\end{array}$ & $\begin{array}{r}\text { Fig } \\
\text { ure } 43\end{array}$ & $\mathrm{H}$ & Protoperidinium leonis & $\begin{array}{l}\text { Qco } \\
\mathrm{n}\end{array}$ \\
\hline 49. Quinquecuspis sp. & plate & $\begin{array}{r}\text { Fig } \\
\text { ure } 44\end{array}$ & $\mathrm{H}$ & $\begin{array}{l}\text { Protoperidinium } \mathrm{sp} . \\
\text { indet }\end{array}$ & $\begin{array}{l}\text { Qui } \\
\text { n }\end{array}$ \\
\hline 50. Round Brown Cysts (RBC) & $\begin{array}{l}\text { Plate } \\
15\end{array}$ & $\begin{array}{r}\text { Fig } \\
\text { ure } 45\end{array}$ & $\mathrm{H}$ ? & $\begin{array}{l}\text { Protoperidinioid } \\
\text { /diplopsalid }\end{array}$ & $\begin{array}{l}\mathrm{RB} \\
\mathrm{C}\end{array}$ \\
\hline 51. Selenopemphix nephroides & $\begin{array}{l}\text { Plate } \\
21\end{array}$ & $\begin{array}{r}\text { Fig } \\
\text { ure } 46\end{array}$ & $\mathrm{H}$ & $\begin{array}{l}\text { Protoperidinium } \\
\text { subinerme }\end{array}$ & $\begin{array}{l}\text { Sne } \\
\mathrm{p}\end{array}$ \\
\hline 52. Selenopemphix quanta & $\begin{array}{l}\text { Plate } \\
14\end{array}$ & $\begin{array}{r}\text { Fig } \\
\text { ure } 47\end{array}$ & $\mathrm{H}$ & $\begin{array}{l}\text { Protoperidinium } \\
\text { conicum }\end{array}$ & $\begin{array}{l}\text { Squ } \\
\text { a }\end{array}$ \\
\hline 53. Spiny Brown Cysts & $\begin{array}{l}\text { No } \\
\text { Plate }\end{array}$ & $\begin{array}{r}\text { Fig } \\
\text { ure } 48\end{array}$ & $\mathrm{H}$ ? & Unknown & SBC \\
\hline 54. Spiniferites belerius & Plate & Fig & $\mathrm{P}$ & Gonyaulax scrippsae & Sbel \\
\hline
\end{tabular}




\begin{tabular}{|c|c|c|c|c|c|c|}
\hline & 23 & ure 49 & & & & \\
\hline 55. Spiniferites bentorii & $\begin{array}{l}\text { Plate } \\
24\end{array}$ & $\begin{array}{r}\text { Fig } \\
\text { ure } 50\end{array}$ & & $\mathrm{P}$ & Gonyaulax digitale & $\begin{array}{l}\text { Sbe } \\
\mathrm{n}\end{array}$ \\
\hline 56. Spiniferites sp. 1 cf. S. bulloideus s. s. & $\begin{array}{l}\text { Plate } \\
30\end{array}$ & $\begin{array}{r}\text { Fig } \\
\text { ure } 51\end{array}$ & & $\mathrm{P}$ & Gonyaulax sp. & Sbul \\
\hline 57. Spiniferites cruciformis & $\begin{array}{l}\text { Plate } \\
25\end{array}$ & $\begin{array}{r}\text { Fig } \\
\text { ure } 52\end{array}$ & & $\mathrm{P}$ & Gonyaulax sp. & Scru \\
\hline 58. Spiniferites delicatus & $\begin{array}{l}\text { Plate } \\
26\end{array}$ & $\begin{array}{r}\text { Fig } \\
\text { ure } 53\end{array}$ & & $\mathrm{P}$ & Gonyaulax sp. & Sdel \\
\hline 59. Spiniferites hyperacanthus $+S$. hainanensis & $\begin{array}{l}\text { Plate } \\
27\end{array}$ & $\begin{array}{r}\text { Fig } \\
\text { ure } 54\end{array}$ & & $\mathrm{P}$ & Gonyaulax sp. & $\begin{array}{l}\text { Shy } \\
\text { p }\end{array}$ \\
\hline 60. Spiniferites membranaceus & $2^{\text {Plate }}$ & $\begin{array}{r}\text { Fig } \\
\text { ure } 55\end{array}$ & $\mathrm{X}$ & $\mathrm{P}$ & $\begin{array}{r}\text { Gonyaulax } \\
\text { membranacea }\end{array}$ & $\begin{array}{l}\text { Sme } \\
\mathrm{m}\end{array}$ \\
\hline 61. Spiniferites mirabilis s. 1. & $\begin{array}{l}\text { Plate } \\
29\end{array}$ & $\begin{array}{r}\text { Fig } \\
\text { ure } 56\end{array}$ & $\mathrm{X}$ & $\mathrm{P}$ & Gonyaulax spinifera & Smir \\
\hline 62. Spiniferites ramosus & $\begin{array}{l}\text { Plate } \\
19\end{array}$ & $\begin{array}{r}\text { Fig } \\
\text { ure } 57\end{array}$ & $\mathrm{X}$ & $\mathrm{P}$ & Gonyaulax spinifera & $\begin{array}{l}\text { Sra } \\
\mathrm{m}\end{array}$ \\
\hline 63. Spiniferites septentrionalis & $\begin{array}{l}\text { Plate } \\
30\end{array}$ & $\begin{array}{r}\text { Fig } \\
\text { ure } 58\end{array}$ & & $\mathrm{P}$ & Gonyaulax sp. & Ssep \\
\hline 64. Spiniferites spp.* & $\begin{array}{l}\text { No } \\
\text { plate }\end{array}$ & & & $\mathrm{P}$ & Gonyaulax sp. & \\
\hline 65. Tectatodinium pellitum & Plate & Fig & $\mathrm{X}$ & $\mathrm{P}$ & Gonyaulax spinifera & Tpel \\
\hline
\end{tabular}




\begin{tabular}{|c|c|c|c|c|c|c|}
\hline & 2 & ure 59 & & & & \\
\hline 66. Trinovantedinium applanatum & $\begin{array}{l}\text { Plate } \\
21\end{array}$ & $\begin{array}{r}\text { Fig } \\
\text { ure } 60\end{array}$ & & $\mathrm{H}+$ & $\begin{array}{l}\text { Protoperidinium } \\
\text { shanghaiense }\end{array}$ & $\begin{array}{l}\text { Tap } \\
\mathrm{p}\end{array}$ \\
\hline 67 Votadinium calvum & $\begin{array}{l}\text { Plate } \\
31\end{array}$ & $\begin{array}{r}\text { Fig } \\
\text { ure } 61\end{array}$ & & $\mathrm{H}+$ & $\begin{array}{l}\text { Protoperidinium } \\
\text { oblongum }\end{array}$ & Vcal \\
\hline 68. Votadinium spinosum* & $\begin{array}{l}\text { Plate } \\
11\end{array}$ & & & $\mathrm{H}+$ & $\begin{array}{l}\text { Protoperidinium } \\
\text { claudicans }\end{array}$ & \\
\hline 69. Xandarodinium xanthum & $\begin{array}{ll} & \text { Plate } \\
8 & \end{array}$ & $\begin{array}{r}\text { Fig } \\
\text { ure } 62\end{array}$ & & $\mathrm{H}$ & $\begin{array}{l}\text { Protoperidinium } \\
\text { divaricatum }\end{array}$ & $\begin{array}{l}\text { Xxa } \\
\mathrm{n}\end{array}$ \\
\hline 70. Unknown Hyaline Cysts* & $\begin{array}{l}\text { No } \\
\text { plate }\end{array}$ & & $\mathrm{n}$ & $\mathrm{P}$ & Unknown & \\
\hline 71. Uncertain Modern Occurrences* & & & & & & \\
\hline 72. Polysphaeridium zoharyi* & 8 & & $\mathrm{X}$ & $\mathrm{P}$ & Pyrodinium bahamense & \\
\hline 73. Spiniferites pachydermus* & & & & $\mathrm{P}$ & $\begin{array}{l}\text { Gonyaulax } \\
\text { ellegaardiae }\end{array}$ & \\
\hline 74. Tuberculodinium vancampoae* & & & & $\mathrm{P}$ & Pyrophacus steinii & \\
\hline 75. Cyst of Gonyaulax apiculata* & & & & $\mathrm{P}$ & Gonyaulax apiculata & \\
\hline 76. Cyst of cf. Peridinium inconspicuum* & & & & $\mathrm{P}$ & Unknown & \\
\hline 77. Galeacysta etrusca* & & & & nd & Unknown & \\
\hline 78. Romanodinium areolatum* & & & & nd & Unknown & \\
\hline 79. Spiniferites balcanicus* & & & & nd & Unknown & \\
\hline
\end{tabular}


Table 1. Dinocyst species included in the Black Sea Corridor Atlas, their corresponding Plate and map numbers, occurrence in Harmful Algal Blooms (HAB), and trophic habit of corresponding motile stage. $\mathrm{P}=$ Phototrophic (i.e. with pigments and either photoAutotrophic using light only or Auxotrophic, using organic micronutrient supplements); $\mathrm{H}=$ heterotrophic (dependent on nutrients synthesised by other organisms); $\mathrm{M}=$ mixotrophic (using both photosynthesis and heterotrophy). $\mathrm{P}+$ and $\mathrm{H}+$ denote phototrophs and heterotrophs known to also be phagotrophic, as determined by Jeong et al. (2012); ? indicates uncertainty because of lack of laboratory data. $*$ taxon is described but not mapped; red font $=$ apparent recent introductions. 
Table 2. Water surface area and estimates of net potential evaporation (NPE) for Eurasian marginal and inland seas (from Hiscott et al., 2007 and Toroğlu, 2014), and average pre-2005 average surface salinity (SSS), Na, Mg and Ca concentrations (mg/l) of Black Sea Corridor seas (from Zenkevich, 1963; Sorokin, 2002; Zavialov, 2005; Kozarev et al., 2007). *excluding Don estuary and Sivash saltlakes. $\mathrm{P}-\mathrm{E}=$ Precipitation minus Evaporation.

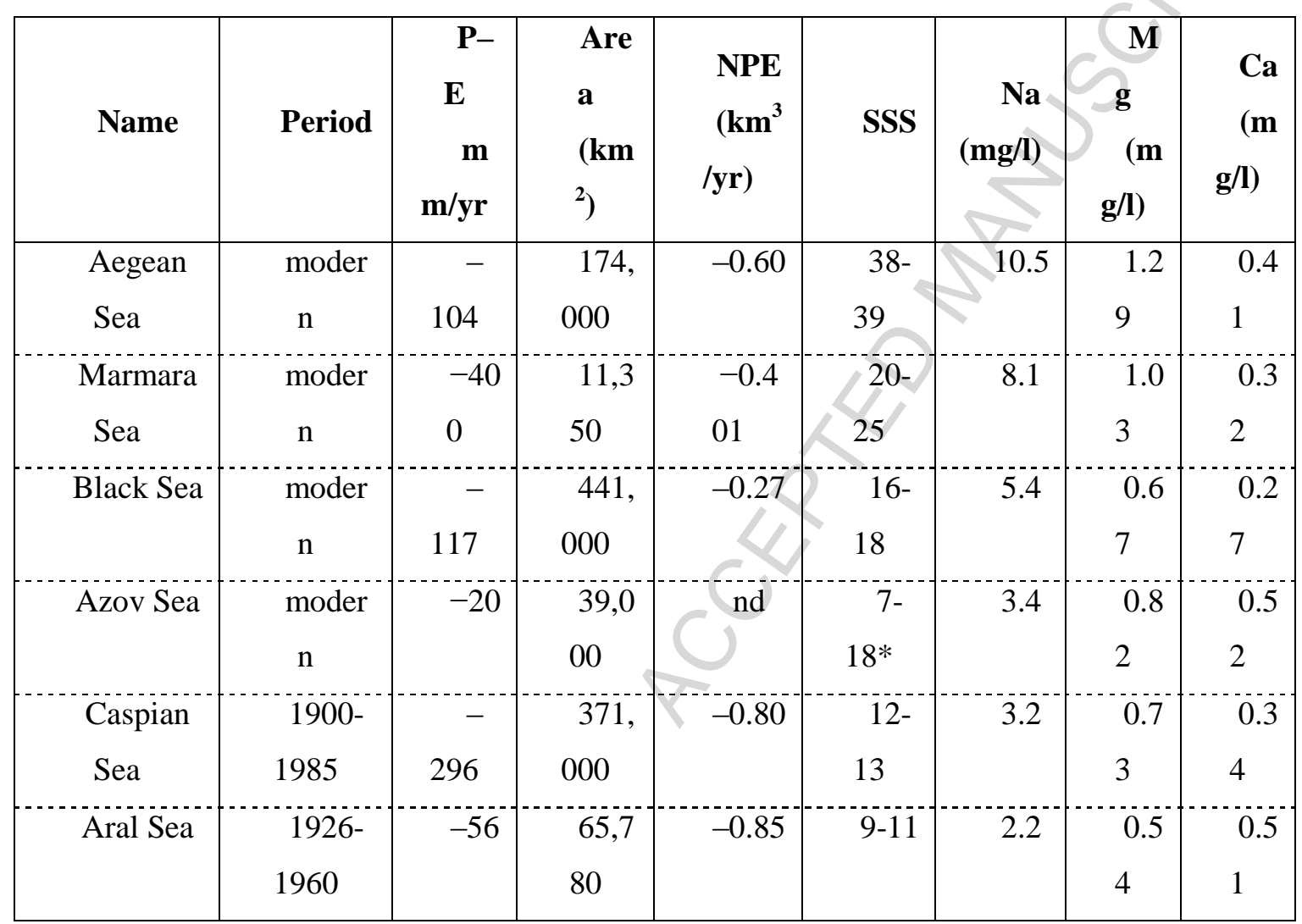


Table 3A. Comparative plankton biodiversity of the BSC seas as reported in available literature from 1963 to 2002 . *Caspian spp. included in total. Literature sources and abbreviations are listed below the table.

\begin{tabular}{lcccccc}
\hline BSC Region & \multicolumn{2}{c}{ Phytoplankton spp. } & \multicolumn{2}{c}{ Zooplankton spp. } \\
\hline & & & & & \\
& Total & Endemic Alien & Total & Endemic & Alien \\
\hline & & & & & & \\
Marmara $^{1,2}$ & 125 & 0 & $56 ?$ & $41-111$ & 0 & $(23 \mathrm{BS}+35 \mathrm{MS})$ \\
Black $^{3,4,5}$ & 350 & 0 & 13 & $88(+? 70)$ & 5 & $5+53 \mathrm{MS}$ \\
Caspian $^{3}$ & 441 & 7 & 6 & 715 & 64 & 7 \\
Aral $^{3,6,7,8}$ & $39-375$ & nd & nd & $4-85^{*}$ & 0 & 3 \\
& & & & & & \\
\hline
\end{tabular}

Literature sources: 1. Balkis et al., 2004; 2. http://www.devotes-project.eu/sea-of-marmara/; 3. Zenkevitch, 1963; 4. Sorokin, 2002; 5. Moncheva and Kamburska, 2002; 6. Mirabdullayev et al., 2004; 7. Stolberg et al., 2006 in GIWA Caspian Sea WIAC Assessment 23; 8. Aladin et al., 2008. ?indicates number of new taxa discovered in Marmara Sea after 2000 AD; (+?) = additional brackish/freshwater taxa along shoreline; BS=native spp. of Black Sea origin; MS= native spp. of Mediterranean Sea origin. 
Table 3B. Comparative species diversity of motile and resting stage dinoflagellates reported for BSC seas and relative abundances (\% Cysts) of cyst taxa as percentage of motile taxa in each region. Literature sources of motile data are listed below. ? indicates inclusion of taxa of uncertain identification' nd = no data.

\begin{tabular}{|c|c|c|c|c|c|c|c|}
\hline \multirow[t]{2}{*}{ BSC Region } & \multicolumn{3}{|c|}{ Motile Dinoflagellate spp. } & \multicolumn{3}{|c|}{ Dinoflagellate Cysts } & $\%$ Cysts \\
\hline & Total & Endemic & Alien & Total & Endemic & Alien & All \\
\hline Marmara $^{1}$ & $45-85$ & 0 & 4 & 50 & 0 & nd & $35-59$ \\
\hline Black $^{, 2,3,4}$ & $233-456$ & $3 ?$ & $39 ?$ & 71 & 1 & $5 ?$ & 30 \\
\hline Caspian $^{5}$ & 44 & $1-3 ?$ & $23 ?$ & 9 & $4 ?$ & 1 & 20 \\
\hline $\mathrm{Aral}^{6,7}$ & $3-28$ & $2 ?$ & 1 & 9 & 0 & 3 & 11 \\
\hline Azov $^{8.9}$ & $34-52$ & 0 & nd & 19 & 0 & 0 & 36 \\
\hline
\end{tabular}

Motile data sources 1. Balkis et al., 2016; 2.Gómez and Boicenco, 2004 + Torok, 2009; 3. Krakhmalny et al., 2012; 4. Shiganova and Ötürk, 2009; 5. Gogorev, 2015; 6. Ostenfeld, 1908; 7. Mirabdullayev et al., 2004; 8. Zenkevitch, 1963; 9. Kovaleva, 2008; cyst data are from Table 1. 


\begin{tabular}{|c|c|c|c|c|c|c|c|c|c|c|c|c|c|c|c|c|c|c|c|c|c|c|c|c|}
\hline $\begin{array}{c}\text { Statio } \\
\text { ns }\end{array}$ & $\begin{array}{l}\text { Lati } \\
\text { tud } \\
\mathrm{e} \\
\left({ }^{\circ} \mathrm{N}\right)\end{array}$ & $\begin{array}{l}\text { Lon } \\
\text { gitu } \\
\text { de } \\
\left({ }^{\circ} \mathrm{E}\right)\end{array}$ & \begin{tabular}{|c|} 
W \\
at \\
er \\
de \\
pt \\
h \\
$(\mathrm{m}$ \\
)
\end{tabular} & $\begin{array}{c}\text { Cor } \\
\text { e } \\
\text { type }\end{array}$ & $\begin{array}{c}\text { Refere } \\
\text { nces }\end{array}$ & $\begin{array}{l}\text { Se } \\
\text { cto } \\
\text { rs }\end{array}$ & $\begin{array}{c}\text { Tot } \\
\text { al } \\
\text { din } \\
\text { osu } \\
\text { m }\end{array}$ & $\begin{array}{c}\text { [cys } \\
\text { ts } / g \\
\text { r] }\end{array}$ & $\begin{array}{c}\text { [cys } \\
\text { ts } / \mathrm{m} \\
\text { I] }\end{array}$ & $\begin{array}{l}S \\
S \\
T \\
Y\end{array}$ & $\begin{array}{l}\mathbf{S} \\
\mathbf{S} \\
\mathbf{S} \\
\mathrm{Y}\end{array}$ & $\begin{array}{c}\text { SS } \\
\text { TJF } \\
\text { M }\end{array}$ & $\begin{array}{c}\text { SS } \\
\text { SJF } \\
M\end{array}$ & $\begin{array}{l}\text { SS } \\
\text { TA } \\
\text { MJ }\end{array}$ & $\begin{array}{l}\text { SS } \\
\text { SA } \\
\text { MJ }\end{array}$ & $\begin{array}{l}\text { SS } \\
\text { TJ } \\
\text { AS }\end{array}$ & $\begin{array}{l}\text { SS } \\
\text { SJ } \\
\text { AS }\end{array}$ & \begin{tabular}{|l|} 
SS \\
TO \\
ND
\end{tabular} & $\begin{array}{l}\text { SS } \\
\text { SO } \\
\text { ND }\end{array}$ & $\begin{array}{c}\text { Chlo } \\
\text { roph } \\
\text { yll } \\
{[\mu \mathrm{g} / \mathrm{l}]}\end{array}$ & $\begin{array}{c}\text { Pho } \\
\text { spha } \\
\text { te } \\
{[\mu \mathrm{m}} \\
\text { ol/ll] }\end{array}$ & $\begin{array}{c}\mathrm{Nit} \\
\text { rat } \\
\mathrm{e} \\
{[\mu} \\
\mathrm{mo} \\
\mathrm{I} / \mathrm{I}]\end{array}$ & $\begin{array}{c}\text { Sili } \\
\text { cat } \\
e \\
{[\mu} \\
\mathrm{mo} \\
\mathrm{I} / \mathrm{I}]\end{array}$ & $\begin{array}{c}\text { Bot } \\
\text { to } \\
\text { m } \\
\text { Ox } \\
\text { yg } \\
\text { en } \\
{[\mathrm{ml}} \\
/ \mathrm{l}]\end{array}$ \\
\hline $\begin{array}{c}\text { MAR0 } \\
2-01\end{array}$ & $\begin{array}{l}40 . \\
35\end{array}$ & $\begin{array}{c}27.3 \\
9\end{array}$ & 14 & grab & $\begin{array}{c}\text { Mudie, } \\
\text { unpubli } \\
\text { shed }\end{array}$ & $\begin{array}{c}\mathrm{MA} \\
\mathrm{R}\end{array}$ & 117 & $\begin{array}{c}195 \\
8 \\
\end{array}$ & & \begin{tabular}{|l|}
16 \\
.4 \\
2 \\
\end{tabular} & $\begin{array}{c}29 \\
.6 \\
6 \\
\end{array}$ & $\begin{array}{c}9.5 \\
9\end{array}$ & $\begin{array}{l}31 . \\
43\end{array}$ & $\begin{array}{l}17 . \\
04\end{array}$ & $\begin{array}{l}29 . \\
52\end{array}$ & $\begin{array}{l}22 . \\
99\end{array}$ & $\begin{array}{l}25 \\
86\end{array}$ & $\begin{array}{l}16 . \\
04\end{array}$ & $\begin{array}{c}30.6 \\
2\end{array}$ & 0.94 & .06 & $\begin{array}{c}0.9 \\
0\end{array}$ & $\begin{array}{c}33 . \\
6\end{array}$ & $\begin{array}{c}4.0 \\
8\end{array}$ \\
\hline $\begin{array}{c}\text { MAR0 } \\
2-10\end{array}$ & $\begin{array}{l}40 . \\
53\end{array}$ & $\begin{array}{c}27.3 \\
9\end{array}$ & 60 & grab & $\begin{array}{c}\text { Mudie, } \\
\text { unpubli } \\
\text { shed }\end{array}$ & $\begin{array}{c}\mathrm{MA} \\
\mathrm{R}\end{array}$ & 109 & \begin{tabular}{|c|}
461 \\
2 \\
\end{tabular} & & \begin{tabular}{|c|}
16 \\
.3 \\
4 \\
\end{tabular} & $\begin{array}{c}29 \\
.2 \\
5 \\
\end{array}$ & $\begin{array}{c}9.3 \\
9\end{array}$ & $\begin{array}{l}31 . \\
15\end{array}$ & $\begin{array}{l}17 . \\
02\end{array}$ & $\begin{array}{c}29 . \\
01\end{array}$ & $\begin{array}{c}23 . \\
00\end{array}$ & $\begin{array}{l}25 . \\
95\end{array}$ & $\begin{array}{l}15 . \\
94\end{array}$ & $\begin{array}{c}30.2 \\
7\end{array}$ & 0.94 & 0.07 & $\begin{array}{c}0.7 \\
1\end{array}$ & $\begin{array}{c}26 . \\
0\end{array}$ & $\begin{array}{c}3.8 \\
4 \\
\end{array}$ \\
\hline $\begin{array}{c}\text { MAR0 } \\
2-12\end{array}$ & $\begin{array}{l}40 . \\
57\end{array}$ & $\begin{array}{c}27.3 \\
9\end{array}$ & 70 & grab & $\begin{array}{c}\text { Mudie, } \\
\text { unpubli } \\
\text { shed }\end{array}$ & $\begin{array}{c}\mathrm{MA} \\
\mathrm{R}\end{array}$ & 183 & $\begin{array}{c}900 \\
7\end{array}$ & & \begin{tabular}{|l|}
16 \\
.3 \\
0 \\
\end{tabular} & \begin{tabular}{|c|}
29 \\
.0 \\
5 \\
\end{tabular} & $\begin{array}{c}9.2 \\
8\end{array}$ & $\begin{array}{l}31 . \\
01\end{array}$ & $\begin{array}{l}17 . \\
01\end{array}$ & $\begin{array}{l}28 . \\
75\end{array}$ & $\begin{array}{c}23 . \\
00\end{array}$ & $\begin{array}{l}25 . \\
99\end{array}$ & $\begin{array}{l}15 . \\
89\end{array}$ & $\begin{array}{c}30.0 \\
9\end{array}$ & 0.94 & 0.08 & $\begin{array}{c}0.6 \\
2\end{array}$ & $\begin{array}{c}22 . \\
1\end{array}$ & $\begin{array}{c}3.5 \\
4 \\
\end{array}$ \\
\hline $\begin{array}{c}\text { MAR0 } \\
2-14\end{array}$ & $\begin{array}{l}40 . \\
59\end{array}$ & $\begin{array}{c}27.4 \\
0\end{array}$ & 79 & grab & $\begin{array}{c}\text { Mudie, } \\
\text { unpubli } \\
\text { shed }\end{array}$ & $\begin{array}{c}\mathrm{MA} \\
\mathrm{R}\end{array}$ & 206 & $\begin{array}{c}131 \\
88 \\
\end{array}$ & & \begin{tabular}{|l|}
16 \\
.2 \\
6 \\
\end{tabular} & \begin{tabular}{|c|}
28 \\
.8 \\
9 \\
\end{tabular} & $\begin{array}{c}9.2 \\
1\end{array}$ & $\begin{array}{l}30 . \\
89\end{array}$ & $\begin{array}{l}17 . \\
00\end{array}$ & $\begin{array}{l}28 . \\
54\end{array}$ & $\begin{array}{l}23 . \\
00\end{array}$ & $\begin{array}{l}25 . \\
96\end{array}$ & $\begin{array}{l}15 . \\
84\end{array}$ & $\begin{array}{c}29.9 \\
6\end{array}$ & 0.94 & 0.08 & $\begin{array}{c}0.5 \\
7 \\
\end{array}$ & $\begin{array}{c}20 . \\
1\end{array}$ & $\begin{array}{c}3.3 \\
7\end{array}$ \\
\hline $\begin{array}{c}\text { MAR0 } \\
2-19\end{array}$ & $\begin{array}{l}40 . \\
64\end{array}$ & $\begin{array}{c}27.4 \\
2\end{array}$ & $\begin{array}{c}12 \\
1\end{array}$ & grab & \begin{tabular}{|c|} 
Mudie, \\
unpubli \\
shed
\end{tabular} & $\begin{array}{c}\mathrm{MA} \\
\mathrm{R}\end{array}$ & 125 & \begin{tabular}{|c|}
771 \\
5 \\
\end{tabular} & & \begin{tabular}{|c|}
16 \\
.1 \\
8 \\
\end{tabular} & \begin{tabular}{|c|}
28 \\
.5 \\
1 \\
\end{tabular} & $\begin{array}{c}9.0 \\
3\end{array}$ & $\begin{array}{l}30 . \\
63\end{array}$ & $\begin{array}{l}16 . \\
97\end{array}$ & $\begin{array}{l}28 . \\
06\end{array}$ & $\begin{array}{c}23 . \\
00\end{array}$ & $\begin{array}{l}25 \\
87\end{array}$ & $\begin{array}{l}15 . \\
74\end{array}$ & $\begin{array}{c}29.6 \\
4\end{array}$ & 0.94 & 0.09 & \begin{tabular}{|c|}
0.4 \\
5 \\
\end{tabular} & $\begin{array}{c}15 . \\
0\end{array}$ & $\begin{array}{c}2.9 \\
0 \\
\end{array}$ \\
\hline $\begin{array}{c}\text { MAR9 } \\
8-02\end{array}$ & $\begin{array}{l}40 . \\
90\end{array}$ & $\begin{array}{c}27.6 \\
0\end{array}$ & $\begin{array}{l}10 \\
80\end{array}$ & $\begin{array}{c}\text { gravi } \\
\text { ty } \\
\text { core }\end{array}$ & $\begin{array}{l}\text { Mudie } \\
\text { et al., } \\
2002\end{array}$ & $\begin{array}{c}\text { MA } \\
\mathrm{R}\end{array}$ & 121 & $\begin{array}{c}270 \\
0 \\
\end{array}$ & & \begin{tabular}{|l|}
15 \\
.6 \\
9 \\
\end{tabular} & \begin{tabular}{|c|}
26 \\
.1 \\
3 \\
\end{tabular} & $\begin{array}{c}7.9 \\
8\end{array}$ & $\begin{array}{c}28 . \\
88\end{array}$ & $\begin{array}{l}16 . \\
76\end{array}$ & $\begin{array}{l}25 . \\
08\end{array}$ & $\begin{array}{l}22 . \\
90\end{array}$ & $\begin{array}{l}22 . \\
97\end{array}$ & $\begin{array}{c}15 . \\
10\end{array}$ & $\begin{array}{c}27.5 \\
7\end{array}$ & 0.94 & 0.10 & $\begin{array}{c}0.1 \\
2\end{array}$ & 7.3 & $\begin{array}{c}1.9 \\
1 \\
\end{array}$ \\
\hline $\begin{array}{c}\text { MAR9 } \\
8-12\end{array}$ & $\begin{array}{l}40 . \\
80\end{array}$ & $\begin{array}{c}27.8 \\
0\end{array}$ & $\begin{array}{c}54 \\
9\end{array}$ & grab & $\begin{array}{c}\text { Mudie, } \\
\text { unpubli } \\
\text { shed }\end{array}$ & $\begin{array}{c}\mathrm{MA} \\
\mathrm{R}\end{array}$ & 110 & $\begin{array}{c}250 \\
0 \\
\end{array}$ & & \begin{tabular}{|l|}
15 \\
.6 \\
0 \\
\end{tabular} & $\begin{array}{l}25 \\
.6 \\
4 \\
\end{array}$ & $\begin{array}{c}7.9 \\
9\end{array}$ & $\begin{array}{c}28 . \\
30\end{array}$ & $\begin{array}{l}16 . \\
63\end{array}$ & $\begin{array}{l}24 . \\
62\end{array}$ & $\begin{array}{l}22 . \\
79\end{array}$ & $\begin{array}{l}22 . \\
44\end{array}$ & $\begin{array}{l}14 . \\
98\end{array}$ & $\begin{array}{c}27.0 \\
6\end{array}$ & 0.94 & 0.03 & \begin{tabular}{|c|}
0.1 \\
5 \\
\end{tabular} & 4.5 & $\begin{array}{c}2.2 \\
5 \\
\end{array}$ \\
\hline $\begin{array}{c}\text { MAR9 } \\
7-11\end{array}$ & $\begin{array}{l}40 . \\
70\end{array}$ & $\begin{array}{c}28.4 \\
0\end{array}$ & $\begin{array}{c}11 \\
1\end{array}$ & grab & $\begin{array}{c}\text { Mudie, } \\
\text { unpubli } \\
\text { shed }\end{array}$ & $\begin{array}{c}\mathrm{MA} \\
\mathrm{R}\end{array}$ & 315 & $\begin{array}{c}233 \\
0\end{array}$ & & \begin{tabular}{|c|}
15 \\
.3 \\
3
\end{tabular} & $\begin{array}{c}23 \\
.4 \\
3 \\
\end{array}$ & $\begin{array}{c}8.0 \\
5\end{array}$ & $\begin{array}{c}25 \\
45\end{array}$ & $\begin{array}{l}16 . \\
13\end{array}$ & $\begin{array}{l}22 . \\
48\end{array}$ & $\begin{array}{c}22 \\
47\end{array}$ & $\begin{array}{l}21 . \\
13\end{array}$ & $\begin{array}{c}14 . \\
69\end{array}$ & $\begin{array}{c}24.7 \\
4\end{array}$ & 0.94 & 0.13 & $\begin{array}{c}0.5 \\
2\end{array}$ & $\begin{array}{c}10 . \\
3\end{array}$ & $\begin{array}{c}1.4 \\
9\end{array}$ \\
\hline
\end{tabular}




\begin{tabular}{|c|c|c|c|c|c|c|c|c|c|c|c|c|c|c|c|c|c|c|c|c|c|c|c|}
\hline $\begin{array}{c}\text { MAR9 } \\
7-09\end{array}$ & $\begin{array}{l}40 . \\
90\end{array}$ & $\begin{array}{c}28.9 \\
0\end{array}$ & 64 & grab & $\begin{array}{c}\text { Mudie, } \\
\text { unpubli } \\
\text { shed }\end{array}$ & $\begin{array}{c}\mathrm{MA} \\
\mathrm{R}\end{array}$ & 188 & \begin{tabular}{|c}
297 \\
0
\end{tabular} & \begin{tabular}{|c|}
14 \\
.7 \\
2 \\
\end{tabular} & \begin{tabular}{|c|}
20 \\
.7 \\
2 \\
\end{tabular} & $\begin{array}{c}7.6 \\
5\end{array}$ & $\begin{array}{l}22 . \\
35\end{array}$ & $\begin{array}{l}15 . \\
20\end{array}$ & $\begin{array}{l}19 . \\
99\end{array}$ & $\begin{array}{l}22 . \\
18\end{array}$ & $\begin{array}{l}19 . \\
34\end{array}$ & $\begin{array}{l}13 . \\
87\end{array}$ & $\begin{array}{c}21.5 \\
1\end{array}$ & 0.94 & 0.10 & $\begin{array}{c}0.1 \\
4 \\
\end{array}$ & 6.5 & $\begin{array}{c}2.6 \\
2\end{array}$ \\
\hline $\begin{array}{c}\text { MAR0 } \\
2-88\end{array}$ & $\begin{array}{l}40 . \\
63\end{array}$ & $\begin{array}{c}28.8 \\
4\end{array}$ & $\begin{array}{c}36 \\
9\end{array}$ & $a b$ & $\begin{array}{c}\text { Mudie, } \\
\text { unpubli } \\
\text { shed }\end{array}$ & $\begin{array}{c}\text { MA } \\
R\end{array}$ & 126 & \begin{tabular}{|c}
831 \\
5 \\
\end{tabular} & \begin{tabular}{|c|}
14 \\
.9 \\
0 \\
\end{tabular} & $\begin{array}{l}21 \\
.7 \\
0 \\
\end{array}$ & $\begin{array}{c}7.8 \\
8\end{array}$ & $\begin{array}{l}23 \\
39\end{array}$ & $\begin{array}{l}15 \\
45 \\
\end{array}$ & $\begin{array}{l}20 . \\
99\end{array}$ & $\begin{array}{l}22 . \\
19\end{array}$ & $\begin{array}{l}20 \\
21\end{array}$ & $\begin{array}{l}14 . \\
17\end{array}$ & $\begin{array}{c}22.5 \\
5\end{array}$ & 0.94 & .26 & \begin{tabular}{|c|}
0.7 \\
9 \\
\end{tabular} & .0 & \begin{tabular}{|c}
1.2 \\
8 \\
\end{tabular} \\
\hline $\begin{array}{c}\text { MAR9 } \\
4-05\end{array}$ & $\begin{array}{l}40 . \\
90\end{array}$ & $\begin{array}{c}28.1 \\
0\end{array}$ & $\begin{array}{l}10 \\
80\end{array}$ & grab & $\begin{array}{c}\text { Mudie, } \\
\text { unpubli } \\
\text { shed }\end{array}$ & $\begin{array}{c}\text { MA } \\
\mathrm{R}\end{array}$ & 110 & $\begin{array}{c}787 \\
0\end{array}$ & \begin{tabular}{|c|}
15 \\
.3 \\
9
\end{tabular} & \begin{tabular}{|c|}
23 \\
.8 \\
5 \\
\end{tabular} & $\begin{array}{c}7.7 \\
7\end{array}$ & 31 & $\begin{array}{l}16 . \\
39\end{array}$ & $\begin{array}{l}22 . \\
78\end{array}$ & $\begin{array}{l}22 . \\
66\end{array}$ & $\begin{array}{l}21 . \\
23\end{array}$ & $\begin{array}{l}14 . \\
72\end{array}$ & $\begin{array}{c}25.3 \\
2\end{array}$ & 0.94 & 0.10 & $\begin{array}{c}0.1 \\
2\end{array}$ & 0.6 & $\begin{array}{c}1.9 \\
7\end{array}$ \\
\hline $\begin{array}{c}\text { MAR0 } \\
2-77\end{array}$ & $\begin{array}{l}41 . \\
33\end{array}$ & $\begin{array}{c}28.8 \\
5\end{array}$ & 58 & grab & \begin{tabular}{|c} 
Mudie, \\
unpubli \\
shed
\end{tabular} & $\begin{array}{l}\text { BS } \\
\text { SW }\end{array}$ & 116 & \begin{tabular}{|c}
247 \\
5 \\
\end{tabular} & \begin{tabular}{|c|}
14 \\
.9 \\
6 \\
\end{tabular} & \begin{tabular}{|c|}
17 \\
.7 \\
8 \\
\end{tabular} & $\begin{array}{c}7.5 \\
9 \\
\end{array}$ & $\begin{array}{l}18 . \\
01 \\
\end{array}$ & $\begin{array}{l}14 . \\
57 \\
\end{array}$ & $\begin{array}{l}17 . \\
68 \\
\end{array}$ & $\begin{array}{l}23 \\
25 \\
\end{array}$ & $\begin{array}{l}17 . \\
73 \\
\end{array}$ & $\begin{array}{l}14 . \\
37 \\
\end{array}$ & \begin{tabular}{|c|}
17.8 \\
7 \\
\end{tabular} & 1.52 & 0.06 & $\begin{array}{c}0.2 \\
2 \\
\end{array}$ & .7 & $\begin{array}{c}6.0 \\
9 \\
\end{array}$ \\
\hline $\begin{array}{c}\text { MAR0 } \\
2-78\end{array}$ & $\begin{array}{l}41 . \\
33\end{array}$ & $\begin{array}{c}28.8 \\
4\end{array}$ & 55 & grab & $\begin{array}{c}\text { Mudie, } \\
\text { unpubli } \\
\text { shed }\end{array}$ & $\begin{array}{l}\text { BS } \\
\text { SW }\end{array}$ & 99 & $\begin{array}{c}446 \\
1 \\
\end{array}$ & \begin{tabular}{|c|}
14 \\
.9 \\
6 \\
\end{tabular} & \begin{tabular}{|l|}
17 \\
.7 \\
8 \\
\end{tabular} & $\begin{array}{c}7.5 \\
9 \\
\end{array}$ & $\begin{array}{l}18 . \\
01 \\
\end{array}$ & $\begin{array}{l}14 . \\
57 \\
\end{array}$ & $\begin{array}{l}17 . \\
67 \\
\end{array}$ & $\begin{array}{l}23 . \\
25 \\
\end{array}$ & $\begin{array}{l}17 . \\
74 \\
\end{array}$ & $\begin{array}{l}14 . \\
37 \\
\end{array}$ & \begin{tabular}{|c|}
17.8 \\
7 \\
\end{tabular} & 1.53 & 0.06 & $\begin{array}{c}0.2 \\
2 \\
\end{array}$ & 8.7 & $\begin{array}{c}6.0 \\
9 \\
\end{array}$ \\
\hline $\begin{array}{c}\text { MAR0 } \\
2-45\end{array}$ & $\begin{array}{l}41 . \\
69\end{array}$ & $\begin{array}{c}28.3 \\
2\end{array}$ & 69 & grab & $\begin{array}{c}\text { Marret } \\
\text { et al } \\
2009\end{array}$ & $\begin{array}{l}\text { BS } \\
\text { SW }\end{array}$ & 244 & \begin{tabular}{|c}
120 \\
84 \\
\end{tabular} & \begin{tabular}{|c|}
14 \\
.8 \\
5 \\
\end{tabular} & \begin{tabular}{|c|}
17 \\
.7 \\
3 \\
\end{tabular} & \begin{tabular}{|c|}
7.3 \\
3 \\
\end{tabular} & $\begin{array}{l}17 . \\
98 \\
\end{array}$ & $\begin{array}{l}14 . \\
47 \\
\end{array}$ & $\begin{array}{l}17 . \\
57 \\
\end{array}$ & \begin{tabular}{|l|}
23. \\
27 \\
\end{tabular} & $\begin{array}{l}17 . \\
52 \\
\end{array}$ & $\begin{array}{l}14 . \\
33 \\
\end{array}$ & $\begin{array}{c}17.8 \\
9 \\
\end{array}$ & 2.94 & 0.08 & $\begin{array}{c}0.1 \\
8 \\
\end{array}$ & .5 & \begin{tabular}{|c}
6.1 \\
8 \\
\end{tabular} \\
\hline $\begin{array}{c}\text { MAR0 } \\
2-74\end{array}$ & $\begin{array}{l}41 . \\
39\end{array}$ & $\begin{array}{c}28.9 \\
0\end{array}$ & 74 & grab & \begin{tabular}{|c} 
Mudie, \\
unpubli \\
shed
\end{tabular} & $\begin{array}{l}\text { BS } \\
\text { SW }\end{array}$ & 156 & $\begin{array}{c}360 \\
3\end{array}$ & \begin{tabular}{|c|}
14 \\
.9 \\
6 \\
\end{tabular} & \begin{tabular}{|c|}
17 \\
.8 \\
0 \\
\end{tabular} & $\begin{array}{c}7.5 \\
7 \\
\end{array}$ & $\begin{array}{l}18 . \\
02 \\
\end{array}$ & $\begin{array}{l}14 . \\
57 \\
\end{array}$ & $\begin{array}{l}17 . \\
70 \\
\end{array}$ & $\begin{array}{l}23 . \\
30 \\
\end{array}$ & $\begin{array}{l}17 . \\
65 \\
\end{array}$ & $\begin{array}{l}14 . \\
38 \\
\end{array}$ & $\begin{array}{c}17.8 \\
8 \\
\end{array}$ & 1.81 & 0.07 & $\begin{array}{c}0.1 \\
8 \\
\end{array}$ & $\begin{array}{c}13 . \\
1\end{array}$ & \begin{tabular}{|c}
5.5 \\
2 \\
\end{tabular} \\
\hline $\begin{array}{c}\text { MAR0 } \\
5-51\end{array}$ & $\begin{array}{l}41 . \\
49\end{array}$ & $\begin{array}{c}29.0 \\
7\end{array}$ & 91 & grab & $\begin{array}{c}\text { Mudie, } \\
\text { unpubli } \\
\text { shed }\end{array}$ & $\begin{array}{l}\text { BS } \\
\text { SW }\end{array}$ & 209 & \begin{tabular}{|c}
588 \\
0 \\
\end{tabular} & \begin{tabular}{|c|}
14 \\
.9 \\
6 \\
\end{tabular} & \begin{tabular}{|l|}
17 \\
.8 \\
4 \\
\end{tabular} & \begin{tabular}{|c|}
7.5 \\
3 \\
\end{tabular} & $\begin{array}{l}18 . \\
04 \\
\end{array}$ & $\begin{array}{l}14 . \\
57 \\
\end{array}$ & $\begin{array}{l}17 . \\
76 \\
\end{array}$ & $\begin{array}{c}23 . \\
31 \\
\end{array}$ & $\begin{array}{l}17 . \\
65 \\
\end{array}$ & $\begin{array}{c}14 . \\
41 \\
\end{array}$ & $\begin{array}{c}17.9 \\
0 \\
\end{array}$ & 1.60 & 0.08 & $\begin{array}{c}0.1 \\
3 \\
\end{array}$ & $\begin{array}{c}12 . \\
1 \\
\end{array}$ & $\begin{array}{c}3.8 \\
9 \\
\end{array}$ \\
\hline $\begin{array}{c}\text { MAR9 } \\
8-04\end{array}$ & $\begin{array}{l}41 . \\
50\end{array}$ & $\begin{array}{c}29.3 \\
0\end{array}$ & $\begin{array}{l}11 \\
2\end{array}$ & grab & $\begin{array}{c}\text { Mudie, } \\
\text { unpubli } \\
\text { shed }\end{array}$ & $\begin{array}{l}\text { BS } \\
\text { SW }\end{array}$ & 159 & $\begin{array}{c}672 \\
7 \\
\end{array}$ & \begin{tabular}{|c|}
14 \\
.9 \\
8 \\
\end{tabular} & \begin{tabular}{|c|}
17 \\
.8 \\
6 \\
\end{tabular} & \begin{tabular}{|c}
7.5 \\
4 \\
\end{tabular} & $\begin{array}{l}18 . \\
05 \\
\end{array}$ & $\begin{array}{l}14 . \\
59 \\
\end{array}$ & $\begin{array}{l}17 . \\
79 \\
\end{array}$ & $\begin{array}{l}23 . \\
33 \\
\end{array}$ & $\begin{array}{l}17 . \\
68 \\
\end{array}$ & $\begin{array}{l}14 . \\
47 \\
\end{array}$ & $\begin{array}{c}17.9 \\
1 \\
\end{array}$ & 1.24 & 0.08 & $\begin{array}{c}0.1 \\
0 \\
\end{array}$ & $\begin{array}{c}12 . \\
1\end{array}$ & $\begin{array}{c}1.5 \\
1 \\
\end{array}$ \\
\hline $\begin{array}{c}\text { MAR0 } \\
2-68\end{array}$ & $\begin{array}{l}41 . \\
54\end{array}$ & $\begin{array}{c}29.0 \\
5\end{array}$ & $\begin{array}{c}11 \\
3\end{array}$ & grab & $\begin{array}{c}\text { Mudie, } \\
\text { unpubli } \\
\text { shed }\end{array}$ & $\begin{array}{l}\text { BS } \\
\text { SW }\end{array}$ & 131 & $\begin{array}{c}628 \\
9 \\
\end{array}$ & \begin{tabular}{|c|}
14 \\
.9 \\
5 \\
\end{tabular} & \begin{tabular}{|c|}
17 \\
.8 \\
5 \\
\end{tabular} & \begin{tabular}{|c|}
7.5 \\
2 \\
\end{tabular} & $\begin{array}{l}18 . \\
05 \\
\end{array}$ & $\begin{array}{l}14 . \\
56\end{array}$ & $\begin{array}{l}17 . \\
77 \\
\end{array}$ & $\begin{array}{c}23 . \\
31 \\
\end{array}$ & $\begin{array}{l}17 . \\
67 \\
\end{array}$ & $\begin{array}{l}14 . \\
40 \\
\end{array}$ & $\begin{array}{c}17.9 \\
1 \\
\end{array}$ & 1.60 & 0.07 & $\begin{array}{c}0.1 \\
4 \\
\end{array}$ & 9.8 & $\begin{array}{c}3.1 \\
9 \\
\end{array}$ \\
\hline AAR0 & 41. & 29.0 & 11 & grab & Mudie, & BS & 228 & 101 & 14 & 17 & 7.5 & 18. & 14. & 17. & 23. & 17. & 14. & 17.9 & 1.62 & 0.07 & 0.1 & 9.1 & 2.7 \\
\hline
\end{tabular}




\begin{tabular}{|c|c|c|c|c|c|c|c|c|c|c|c|c|c|c|c|c|c|c|c|c|c|c|c|}
\hline $2-65$ & 56 & 6 & 2 & & $\begin{array}{c}\text { unpubli } \\
\text { shed }\end{array}$ & SW & & 13 & \begin{tabular}{l|}
.9 \\
5 \\
\end{tabular} & \begin{tabular}{|l|}
.8 \\
5 \\
\end{tabular} & 1 & 05 & 56 & \begin{tabular}{|l|}
78 \\
\end{tabular} & 32 & \begin{tabular}{|l|}
67 \\
\end{tabular} & 40 & 2 & & & 4 & & 3 \\
\hline B13 & $\begin{array}{l}42 . \\
00\end{array}$ & $\begin{array}{c}37.9 \\
0\end{array}$ & $\begin{array}{l}20 \\
20\end{array}$ & $\begin{array}{l}\text { box } \\
\text { core }\end{array}$ & $\begin{array}{l}\text { Mudie } \\
\text { et al., } \\
2001 \\
\end{array}$ & BS & 144 & $\begin{array}{c}348 \\
00 \\
\end{array}$ & \begin{tabular}{c|}
15 \\
.6 \\
1 \\
\end{tabular} & \begin{tabular}{|c|}
18 \\
.1 \\
4 \\
\end{tabular} & \begin{tabular}{|c}
8.3 \\
2 \\
\end{tabular} & $\begin{array}{l}18 . \\
17 \\
\end{array}$ & $\begin{array}{l}15 . \\
46 \\
\end{array}$ & $\begin{array}{l}18 . \\
15\end{array}$ & $\begin{array}{l}23 . \\
78 \\
\end{array}$ & $\begin{array}{l}18 . \\
06 \\
\end{array}$ & $\begin{array}{c}14 . \\
88 \\
\end{array}$ & $\begin{array}{c}18.1 \\
7\end{array}$ & 2.38 & 0.08 & $\begin{array}{c}0.1 \\
7\end{array}$ & .7 & $\begin{array}{c}0.1 \\
6 \\
\end{array}$ \\
\hline B7 & $\begin{array}{l}42 . \\
50\end{array}$ & $\begin{array}{c}37.0 \\
0\end{array}$ & $\begin{array}{l}21 \\
20\end{array}$ & $\begin{array}{l}\text { box } \\
\text { core }\end{array}$ & $\begin{array}{l}\text { Mudie } \\
\text { et al., } \\
2001 \\
\end{array}$ & BS & 149 & $\begin{array}{c}241 \\
50 \\
\end{array}$ & \begin{tabular}{c|}
15 \\
.0 \\
9 \\
\end{tabular} & \begin{tabular}{|c|}
18 \\
.2 \\
1 \\
\end{tabular} & $\begin{array}{c}8.0 \\
5 \\
\end{array}$ & $\begin{array}{l}18 . \\
23\end{array}$ & $\begin{array}{l}14 . \\
86\end{array}$ & $\begin{array}{l}18 . \\
27 \\
\end{array}$ & $\begin{array}{c}23 . \\
34 \\
\end{array}$ & $\begin{array}{c}18 . \\
12 \\
\end{array}$ & $\begin{array}{c}14 . \\
11 \\
\end{array}$ & $\begin{array}{c}18.2 \\
3 \\
\end{array}$ & 7 & .06 & $\begin{array}{c}0.1 \\
1\end{array}$ & .3 & $\begin{array}{c}0.0 \\
7\end{array}$ \\
\hline $\begin{array}{c}\text { Razim } \\
\text { R09- } \\
20^{*} \\
\end{array}$ & $\begin{array}{l}44 . \\
78\end{array}$ & $\begin{array}{c}29.1 \\
4\end{array}$ & 2 & grab & $\begin{array}{l}\text { Mudie, } \\
\text { unpubli } \\
\text { shed }\end{array}$ & $\begin{array}{l}\text { BS } \\
\text { NW }\end{array}$ & 25 & \begin{tabular}{|c|}
163 \\
0 \\
\end{tabular} & \begin{tabular}{|l|}
11 \\
.0 \\
0
\end{tabular} & $\begin{array}{l}1 . \\
40\end{array}$ & $\begin{array}{c}3.0 \\
0\end{array}$ & $\begin{array}{c}1.5 \\
0 \\
\end{array}$ & $\begin{array}{l}12 . \\
66 \\
\end{array}$ & $\begin{array}{c}0.5 \\
0 \\
\end{array}$ & $\begin{array}{c}20 . \\
80 \\
\end{array}$ & $\begin{array}{c}2.2 \\
0 \\
\end{array}$ & $\begin{array}{c}6.5 \\
0 \\
\end{array}$ & 2.80 & 74 & .27 & $\begin{array}{c}3.1 \\
0\end{array}$ & .1 & $\begin{array}{c}6.8 \\
9 \\
\end{array}$ \\
\hline $\begin{array}{l}\text { MN9 } \\
\text { M/9A }\end{array}$ & $\begin{array}{l}45 . \\
01\end{array}$ & $\begin{array}{c}29.7 \\
9\end{array}$ & 17 & $\begin{array}{l}\text { push } \\
\text { core }\end{array}$ & $\begin{array}{l}\text { Mudie, } \\
\text { unpubli } \\
\text { shed }\end{array}$ & $\begin{array}{l}\text { BS } \\
\text { NW }\end{array}$ & 108 & $\begin{array}{c}197 \\
1 \\
\end{array}$ & \begin{tabular}{|c|}
14 \\
.0 \\
0 \\
\end{tabular} & \begin{tabular}{|c|}
15 \\
8 \\
4 \\
\end{tabular} & $\begin{array}{c}5.7 \\
0 \\
\end{array}$ & $\begin{array}{l}16 . \\
54\end{array}$ & $\begin{array}{l}14 . \\
31\end{array}$ & $\begin{array}{l}14 . \\
82 \\
\end{array}$ & $\begin{array}{l}22 . \\
74 \\
\end{array}$ & $\begin{array}{l}15 . \\
73 \\
\end{array}$ & $\begin{array}{l}13 . \\
24 \\
\end{array}$ & $\begin{array}{c}16.4 \\
8 \\
\end{array}$ & 2.89 & 0.29 & \begin{tabular}{|c|}
4.3 \\
0
\end{tabular} & $\begin{array}{c}12 . \\
9\end{array}$ & $\begin{array}{c}5.8 \\
3 \\
\end{array}$ \\
\hline $\begin{array}{c}\text { MN10 } \\
M\end{array}$ & $\begin{array}{l}45 . \\
08\end{array}$ & $\begin{array}{c}29.7 \\
8\end{array}$ & 21 & $\begin{array}{l}\text { push } \\
\text { core }\end{array}$ & $\begin{array}{c}\text { Mudie, } \\
\text { unpubli } \\
\text { shed }\end{array}$ & $\begin{array}{l}\text { BS } \\
\text { NW }\end{array}$ & 102 & $\begin{array}{c}100 \\
61 \\
\end{array}$ & 14 & \begin{tabular}{l|}
15 \\
.7 \\
0
\end{tabular} & $\begin{array}{c}5.6 \\
9 \\
\end{array}$ & $\begin{array}{l}16 . \\
45\end{array}$ & $\begin{array}{l}14 . \\
37\end{array}$ & $\begin{array}{l}14 . \\
64 \\
\end{array}$ & $\begin{array}{l}22 . \\
82\end{array}$ & $\begin{array}{l}15 . \\
52 \\
\end{array}$ & $\begin{array}{l}13 . \\
27\end{array}$ & \begin{tabular}{|c|}
16.3 \\
7
\end{tabular} & 3.26 & 0.33 & \begin{tabular}{|c|}
4.7 \\
8
\end{tabular} & $\begin{array}{c}12 . \\
2\end{array}$ & $\begin{array}{c}5.7 \\
2\end{array}$ \\
\hline $\begin{array}{c}\text { MN10 } \\
\text { A }\end{array}$ & $\begin{array}{l}45 . \\
08\end{array}$ & $\begin{array}{c}29.7 \\
8\end{array}$ & 21 & $\begin{array}{l}\text { push } \\
\text { core }\end{array}$ & $\begin{array}{c}\text { Mudie, } \\
\text { unpubli } \\
\text { shed }\end{array}$ & $\begin{array}{l}\text { BS } \\
\text { NW }\end{array}$ & 131 & $\begin{array}{c}570 \\
1\end{array}$ & \begin{tabular}{|c|}
14 \\
.0 \\
4 \\
\end{tabular} & \begin{tabular}{l|}
15 \\
.7 \\
0 \\
\end{tabular} & \begin{tabular}{|c|}
5.6 \\
9 \\
\end{tabular} & $\begin{array}{l}16 . \\
45 \\
\end{array}$ & $\begin{array}{l}14 . \\
37 \\
\end{array}$ & $\begin{array}{l}14 . \\
64 \\
\end{array}$ & $\begin{array}{l}22 . \\
82 \\
\end{array}$ & $\begin{array}{l}15 . \\
52 \\
\end{array}$ & $\begin{array}{l}13 . \\
27\end{array}$ & \begin{tabular}{|c|}
16.3 \\
7 \\
\end{tabular} & 3.26 & 0.33 & \begin{tabular}{|c|}
4.7 \\
8 \\
\end{tabular} & $\begin{array}{c}12 . \\
2\end{array}$ & $\begin{array}{c}5.7 \\
2 \\
\end{array}$ \\
\hline $\begin{array}{c}\text { MN8 } \\
M\end{array}$ & $\begin{array}{l}45 . \\
02\end{array}$ & $\begin{array}{c}29.9 \\
9\end{array}$ & 34 & $\begin{array}{l}\text { push } \\
\text { core }\end{array}$ & $\begin{array}{l}\text { Mudie, } \\
\text { unpubli } \\
\text { shed }\end{array}$ & $\begin{array}{l}\text { BS } \\
\text { NW }\end{array}$ & 275 & \begin{tabular}{|c|}
206 \\
97 \\
\end{tabular} & \begin{tabular}{|c|}
14 \\
.0 \\
7 \\
\end{tabular} & \begin{tabular}{l|}
16 \\
.0 \\
7 \\
\end{tabular} & $\begin{array}{c}5.9 \\
3 \\
\end{array}$ & $\begin{array}{l}16 . \\
75 \\
\end{array}$ & $\begin{array}{l}14 . \\
31\end{array}$ & $\begin{array}{c}15 . \\
16 \\
\end{array}$ & $\begin{array}{l}22 . \\
75 \\
\end{array}$ & $\begin{array}{l}15 . \\
80 \\
\end{array}$ & $\begin{array}{l}13 . \\
30\end{array}$ & \begin{tabular}{|c|}
16.6 \\
4
\end{tabular} & 2.74 & 0.26 & $\begin{array}{c}4.5 \\
8 \\
\end{array}$ & $\begin{array}{c}10 . \\
2\end{array}$ & $\begin{array}{c}5.3 \\
7 \\
\end{array}$ \\
\hline MN8A & $\begin{array}{l}45 . \\
02\end{array}$ & $\begin{array}{c}29.9 \\
9\end{array}$ & 34 & $\begin{array}{l}\text { push } \\
\text { core }\end{array}$ & $\begin{array}{c}\text { Mudie, } \\
\text { unpubli } \\
\text { shed }\end{array}$ & \begin{tabular}{|l} 
BS \\
NW
\end{tabular} & 131 & \begin{tabular}{|c}
578 \\
8 \\
\end{tabular} & \begin{tabular}{|c|}
14 \\
.0 \\
7 \\
\end{tabular} & \begin{tabular}{|l|}
16 \\
.0 \\
7 \\
\end{tabular} & \begin{tabular}{|c|}
5.9 \\
3 \\
\end{tabular} & $\begin{array}{l}16 . \\
75\end{array}$ & $\begin{array}{l}14 . \\
31\end{array}$ & $\begin{array}{c}15 . \\
16 \\
\end{array}$ & $\begin{array}{l}22 . \\
75 \\
\end{array}$ & $\begin{array}{l}15 . \\
80 \\
\end{array}$ & $\begin{array}{l}13 . \\
30\end{array}$ & \begin{tabular}{|c|}
16.6 \\
4 \\
\end{tabular} & 2.74 & 0.26 & $\begin{array}{c}4.5 \\
8 \\
\end{array}$ & $\begin{array}{c}10 . \\
2\end{array}$ & $\begin{array}{c}5.3 \\
7 \\
\end{array}$ \\
\hline $\begin{array}{c}\text { MN7 } \\
\text { M }\end{array}$ & $\begin{array}{l}44 . \\
99\end{array}$ & $\begin{array}{c}30.2 \\
5\end{array}$ & 46 & $\begin{array}{l}\text { push } \\
\text { core }\end{array}$ & $\begin{array}{l}\text { Mudie, } \\
\text { unpubli } \\
\text { shed }\end{array}$ & $\begin{array}{l}\text { BS } \\
\text { NW }\end{array}$ & 223 & \begin{tabular}{|c|}
178 \\
15 \\
\end{tabular} & \begin{tabular}{|c|}
14 \\
.1 \\
5 \\
\end{tabular} & \begin{tabular}{c|}
16 \\
.4 \\
1 \\
\end{tabular} & $\begin{array}{c}6.2 \\
2 \\
\end{array}$ & $\begin{array}{l}17 . \\
04 \\
\end{array}$ & $\begin{array}{l}14 . \\
29 \\
\end{array}$ & $\begin{array}{l}15 . \\
69 \\
\end{array}$ & $\begin{array}{l}22 . \\
72 \\
\end{array}$ & $\begin{array}{l}16 . \\
09 \\
\end{array}$ & $\begin{array}{l}13 . \\
35 \\
\end{array}$ & $\begin{array}{c}16.8 \\
7 \\
\end{array}$ & 2.54 & 0.17 & \begin{tabular}{|c|}
3.4 \\
0 \\
\end{tabular} & 6.4 & $\begin{array}{c}5.1 \\
2 \\
\end{array}$ \\
\hline V7A & $\begin{array}{c}44 . \\
99\end{array}$ & $\begin{array}{c}30.2 \\
5\end{array}$ & 46 & $\begin{array}{l}\text { push } \\
\text { core }\end{array}$ & $\begin{array}{l}\text { Mudie, } \\
\text { unpubli }\end{array}$ & $\begin{array}{l}\mathrm{BS} \\
\mathrm{NW}\end{array}$ & 211 & \begin{tabular}{|c|}
679 \\
86 \\
\end{tabular} & \begin{tabular}{|c|}
14 \\
.1
\end{tabular} & \begin{tabular}{l|}
16 \\
.4 \\
\end{tabular} & \begin{tabular}{|c|}
6.2 \\
2 \\
\end{tabular} & $\begin{array}{l}17 . \\
04\end{array}$ & $\begin{array}{l}14 . \\
29\end{array}$ & $\begin{array}{l}15 . \\
69 \\
\end{array}$ & \begin{tabular}{l|}
22. \\
72 \\
\end{tabular} & \begin{tabular}{|c|}
16. \\
09 \\
\end{tabular} & $\begin{array}{l}13 . \\
35 \\
\end{array}$ & \begin{tabular}{|c|}
6.8 \\
7
\end{tabular} & 2.54 & 0.17 & \begin{tabular}{|c|}
3.4 \\
0
\end{tabular} & 6.4 & $\begin{array}{c}5.1 \\
2\end{array}$ \\
\hline
\end{tabular}




\begin{tabular}{|c|c|c|c|c|c|c|c|c|c|c|c|c|c|c|c|c|c|c|c|c|c|c|c|}
\hline & & & & & shed & & & & 5 & 1 & & & & & & & & & & & & & \\
\hline MN6A & $\begin{array}{l}44 . \\
90\end{array}$ & $\begin{array}{c}30.5 \\
0\end{array}$ & 55 & $\begin{array}{l}\text { push } \\
\text { core }\end{array}$ & $\begin{array}{l}\text { Mudie, } \\
\text { unpubli } \\
\text { shed }\end{array}$ & $\begin{array}{l}\text { BS } \\
\text { NW }\end{array}$ & 344 & \begin{tabular}{|l}
135 \\
250
\end{tabular} & \begin{tabular}{|l|}
14 \\
.2 \\
3
\end{tabular} & \begin{tabular}{c|}
16 \\
.7 \\
7
\end{tabular} & $\begin{array}{c}6.5 \\
1\end{array}$ & $\begin{array}{l}17 . \\
31\end{array}$ & $\begin{array}{l}14 . \\
28\end{array}$ & $\begin{array}{l}16 . \\
23\end{array}$ & $\begin{array}{l}22 . \\
69\end{array}$ & $\begin{array}{l}16 . \\
43\end{array}$ & $\begin{array}{l}13 . \\
41\end{array}$ & $\begin{array}{c}17.1 \\
3\end{array}$ & 2.61 & 0.16 & $\begin{array}{c}2.6 \\
6\end{array}$ & 4.8 & $\begin{array}{c}5.6 \\
6\end{array}$ \\
\hline $\begin{array}{c}\text { MN6 } \\
\text { M }\end{array}$ & $\begin{array}{l}44 . \\
90\end{array}$ & $\begin{array}{c}30.5 \\
0\end{array}$ & 55 & $\begin{array}{l}\text { push } \\
\text { core }\end{array}$ & $\begin{array}{c}\text { Mudie, } \\
\text { unpubli } \\
\text { shed }\end{array}$ & \begin{tabular}{|l} 
BS \\
NW
\end{tabular} & 309 & \begin{tabular}{|c}
232 \\
28 \\
\end{tabular} & \begin{tabular}{|c|}
14 \\
.2 \\
3 \\
\end{tabular} & \begin{tabular}{|c|}
16 \\
.7 \\
7 \\
\end{tabular} & \begin{tabular}{|c|}
6.5 \\
1 \\
\end{tabular} & $\begin{array}{l}17 . \\
31 \\
\end{array}$ & $\begin{array}{l}14 . \\
28 \\
\end{array}$ & $\begin{array}{l}16 . \\
23 \\
\end{array}$ & $\begin{array}{c}22 . \\
69 \\
\end{array}$ & $\begin{array}{l}16 . \\
43 \\
\end{array}$ & $\begin{array}{c}13 . \\
41 \\
\end{array}$ & $\begin{array}{c}17.1 \\
3 \\
\end{array}$ & 2.61 & 0.16 & $\begin{array}{c}2.6 \\
6 \\
\end{array}$ & 4.8 & \begin{tabular}{|c}
5.6 \\
6 \\
\end{tabular} \\
\hline $\begin{array}{c}\text { MN5 } \\
\text { M }\end{array}$ & $\begin{array}{l}44 . \\
82\end{array}$ & $\begin{array}{c}30.7 \\
5\end{array}$ & 65 & $\begin{array}{l}\text { push } \\
\text { core }\end{array}$ & $\begin{array}{c}\text { Mudie, } \\
\text { unpubli } \\
\text { shed }\end{array}$ & \begin{tabular}{|l} 
BS \\
NW
\end{tabular} & 274 & $\begin{array}{c}730 \\
10\end{array}$ & \begin{tabular}{|c|}
14 \\
.2 \\
8 \\
\end{tabular} & \begin{tabular}{|l|}
17 \\
.0 \\
7 \\
\end{tabular} & $\begin{array}{c}6.7 \\
5\end{array}$ & $\begin{array}{l}17 . \\
54\end{array}$ & $\begin{array}{l}14 . \\
25\end{array}$ & $\begin{array}{l}16 . \\
69\end{array}$ & $\begin{array}{l}22 . \\
63\end{array}$ & $\begin{array}{l}16 . \\
69\end{array}$ & $\begin{array}{l}13 . \\
45\end{array}$ & $\begin{array}{c}17.3 \\
4\end{array}$ & 1.64 & 0.14 & $\begin{array}{c}3.0 \\
5\end{array}$ & 5.2 & $\begin{array}{c}5.4 \\
8\end{array}$ \\
\hline MN5A & $\begin{array}{l}44 . \\
82\end{array}$ & $\begin{array}{c}30.7 \\
5\end{array}$ & 65 & $\begin{array}{l}\text { push } \\
\text { core }\end{array}$ & $\begin{array}{c}\text { Mudie, } \\
\text { unpubli } \\
\text { shed }\end{array}$ & $\begin{array}{l}\text { BS } \\
\text { NW }\end{array}$ & 154 & $\begin{array}{c}365 \\
16\end{array}$ & \begin{tabular}{|c|}
14 \\
.2 \\
8 \\
\end{tabular} & \begin{tabular}{|c|}
17 \\
.0 \\
7 \\
\end{tabular} & $\begin{array}{c}6.7 \\
5\end{array}$ & $\begin{array}{l}17 . \\
54\end{array}$ & $\begin{array}{l}14 . \\
25\end{array}$ & $\begin{array}{l}16 . \\
69\end{array}$ & $\begin{array}{l}22 . \\
63 \\
\end{array}$ & $\begin{array}{l}16 . \\
69\end{array}$ & $\begin{array}{l}13 . \\
45\end{array}$ & $\begin{array}{c}17.3 \\
4\end{array}$ & 1.64 & 0.14 & $\begin{array}{c}3.0 \\
5\end{array}$ & 5.2 & $\begin{array}{c}5.4 \\
8\end{array}$ \\
\hline $\begin{array}{c}\text { MN4 } \\
\text { M }\end{array}$ & $\begin{array}{l}44 . \\
55\end{array}$ & $\begin{array}{c}30.4 \\
5\end{array}$ & 78 & $\begin{array}{l}\text { push } \\
\text { core }\end{array}$ & $\begin{array}{c}\text { Mudie, } \\
\text { unpubli } \\
\text { shed }\end{array}$ & $\begin{array}{l}\text { BS } \\
\text { NW }\end{array}$ & 498 & $\begin{array}{c}324 \\
09\end{array}$ & \begin{tabular}{|c|}
14 \\
.3 \\
8
\end{tabular} & \begin{tabular}{|l|}
17 \\
.0 \\
9
\end{tabular} & $\begin{array}{c}6.7 \\
9\end{array}$ & $\begin{array}{l}17 . \\
54\end{array}$ & $\begin{array}{l}14 . \\
41\end{array}$ & $\begin{array}{l}16 . \\
67\end{array}$ & $\begin{array}{l}22 . \\
77\end{array}$ & $\begin{array}{l}16 . \\
78\end{array}$ & $\begin{array}{l}13 . \\
52\end{array}$ & $\begin{array}{c}17.3 \\
7\end{array}$ & 0.89 & 0.23 & $\begin{array}{c}2.9 \\
7\end{array}$ & 6.1 & $\begin{array}{c}5.7 \\
8\end{array}$ \\
\hline $\begin{array}{c}\text { MN16 } \\
\text { M }\end{array}$ & $\begin{array}{l}44 . \\
01\end{array}$ & $\begin{array}{c}29.5 \\
9\end{array}$ & 25 & $\begin{array}{l}\text { push } \\
\text { core }\end{array}$ & $\begin{array}{c}\text { Mudie, } \\
\text { unpubli } \\
\text { shed }\end{array}$ & $\begin{array}{l}\text { BS } \\
\text { NW }\end{array}$ & 119 & $\begin{array}{c}725 \\
8 \\
\end{array}$ & \begin{tabular}{|c|}
14 \\
.2 \\
8 \\
\end{tabular} & \begin{tabular}{|l|}
17 \\
.0 \\
8 \\
\end{tabular} & $\begin{array}{c}6.2 \\
7\end{array}$ & $\begin{array}{l}17 . \\
43 \\
\end{array}$ & $\begin{array}{l}14 . \\
49 \\
\end{array}$ & $\begin{array}{l}16 . \\
61 \\
\end{array}$ & $\begin{array}{l}22 . \\
84 \\
\end{array}$ & $\begin{array}{l}16 . \\
95\end{array}$ & $\begin{array}{l}13 . \\
53\end{array}$ & $\begin{array}{c}17.3 \\
4\end{array}$ & 0.77 & 0.25 & $\begin{array}{c}2.1 \\
5\end{array}$ & $\begin{array}{c}13 . \\
0\end{array}$ & $\begin{array}{c}5.9 \\
4\end{array}$ \\
\hline $\begin{array}{c}\text { MN15 } \\
\text { A }\end{array}$ & $\begin{array}{l}44 . \\
00\end{array}$ & $\begin{array}{c}29.7 \\
0\end{array}$ & 50 & $\begin{array}{l}\text { push } \\
\text { core }\end{array}$ & $\begin{array}{l}\text { Mudie, } \\
\text { unpubli } \\
\text { shed }\end{array}$ & \begin{tabular}{|l} 
BS \\
NW
\end{tabular} & 162 & $\begin{array}{c}154 \\
20\end{array}$ & \begin{tabular}{|c|}
14 \\
.3 \\
2
\end{tabular} & $\begin{array}{c}17 \\
.1 \\
7\end{array}$ & $\begin{array}{c}6.4 \\
0\end{array}$ & \begin{tabular}{|l}
17. \\
52
\end{tabular} & $\begin{array}{l}14 . \\
49\end{array}$ & $\begin{array}{l}16 . \\
74\end{array}$ & $\begin{array}{l}22 . \\
86\end{array}$ & $\begin{array}{l}17 . \\
04\end{array}$ & $\begin{array}{l}13 . \\
55\end{array}$ & $\begin{array}{c}17.4 \\
0\end{array}$ & 0.72 & 0.26 & $\begin{array}{c}2.1 \\
6\end{array}$ & $\begin{array}{c}12 . \\
1\end{array}$ & $\begin{array}{c}5.9 \\
6\end{array}$ \\
\hline $\begin{array}{c}\text { MN15 } \\
\text { M }\end{array}$ & $\begin{array}{l}44 . \\
00\end{array}$ & $\begin{array}{c}29.7 \\
0\end{array}$ & 50 & $\begin{array}{l}\text { push } \\
\text { core }\end{array}$ & $\begin{array}{c}\text { Mudie, } \\
\text { unpubli } \\
\text { shed }\end{array}$ & \begin{tabular}{|l} 
BS \\
NW
\end{tabular} & 217 & $\begin{array}{c}297 \\
10 \\
\end{array}$ & \begin{tabular}{|c|}
14 \\
.3 \\
2 \\
\end{tabular} & \begin{tabular}{c|}
17 \\
.1 \\
7 \\
\end{tabular} & \begin{tabular}{|c|}
6.4 \\
0 \\
\end{tabular} & $\begin{array}{l}17 . \\
52 \\
\end{array}$ & $\begin{array}{c}14 . \\
49 \\
\end{array}$ & $\begin{array}{l}16 . \\
74 \\
\end{array}$ & $\begin{array}{l}22 . \\
86 \\
\end{array}$ & $\begin{array}{l}17 . \\
04 \\
\end{array}$ & $\begin{array}{l}13 . \\
55 \\
\end{array}$ & $\begin{array}{c}17.4 \\
0 \\
\end{array}$ & 0.72 & 0.26 & \begin{tabular}{|c}
2.1 \\
6 \\
\end{tabular} & $\begin{array}{c}12 . \\
1 \\
\end{array}$ & \begin{tabular}{|c}
5.9 \\
6 \\
\end{tabular} \\
\hline $\begin{array}{c}\text { MN14 } \\
\text { A }\end{array}$ & $\begin{array}{l}44 . \\
50\end{array}$ & $\begin{array}{c}29.8 \\
5\end{array}$ & 62 & $\begin{array}{l}\text { push } \\
\text { core }\end{array}$ & $\begin{array}{c}\text { Mudie, } \\
\text { unpubli } \\
\text { shed }\end{array}$ & $\begin{array}{l}\text { BS } \\
\text { NW }\end{array}$ & 275 & $\begin{array}{c}687 \\
10\end{array}$ & \begin{tabular}{|c|}
14 \\
.1 \\
6 \\
\end{tabular} & \begin{tabular}{|c|}
16 \\
.6 \\
5 \\
\end{tabular} & $\begin{array}{c}6.1 \\
6\end{array}$ & $\begin{array}{l}17 . \\
12\end{array}$ & $\begin{array}{l}14 . \\
39\end{array}$ & $\begin{array}{l}15 . \\
97\end{array}$ & $\begin{array}{l}22 . \\
73\end{array}$ & $\begin{array}{l}16 . \\
46\end{array}$ & $\begin{array}{l}13 . \\
35\end{array}$ & $\begin{array}{c}17.0 \\
7\end{array}$ & 1.67 & 0.27 & $\begin{array}{c}3.1 \\
5\end{array}$ & $\begin{array}{c}11 . \\
2\end{array}$ & $\begin{array}{c}5.8 \\
7\end{array}$ \\
\hline $\begin{array}{c}\text { MN14 } \\
\text { M }\end{array}$ & $\begin{array}{l}44 . \\
50\end{array}$ & $\begin{array}{c}29.8 \\
5\end{array}$ & 62 & $\begin{array}{l}\text { push } \\
\text { core }\end{array}$ & $\begin{array}{c}\text { Mudie, } \\
\text { unpubli } \\
\text { shed }\end{array}$ & $\begin{array}{l}\text { BS } \\
\text { NW }\end{array}$ & 295 & $\begin{array}{c}325 \\
97\end{array}$ & \begin{tabular}{|c|}
14 \\
.1 \\
6 \\
\end{tabular} & \begin{tabular}{|c|}
16 \\
.6 \\
5 \\
\end{tabular} & $\begin{array}{c}6.1 \\
6\end{array}$ & $\begin{array}{l}17 . \\
12 \\
\end{array}$ & $\begin{array}{l}14 . \\
39 \\
\end{array}$ & $\begin{array}{l}15 . \\
97\end{array}$ & $\begin{array}{l}22 . \\
73 \\
\end{array}$ & $\begin{array}{l}16 . \\
46 \\
\end{array}$ & $\begin{array}{l}13 . \\
35 \\
\end{array}$ & $\begin{array}{c}17.0 \\
7 \\
\end{array}$ & 1.67 & 0.27 & $\begin{array}{c}3.1 \\
5\end{array}$ & $\begin{array}{c}11 . \\
2\end{array}$ & \begin{tabular}{|c}
5.8 \\
7
\end{tabular} \\
\hline
\end{tabular}




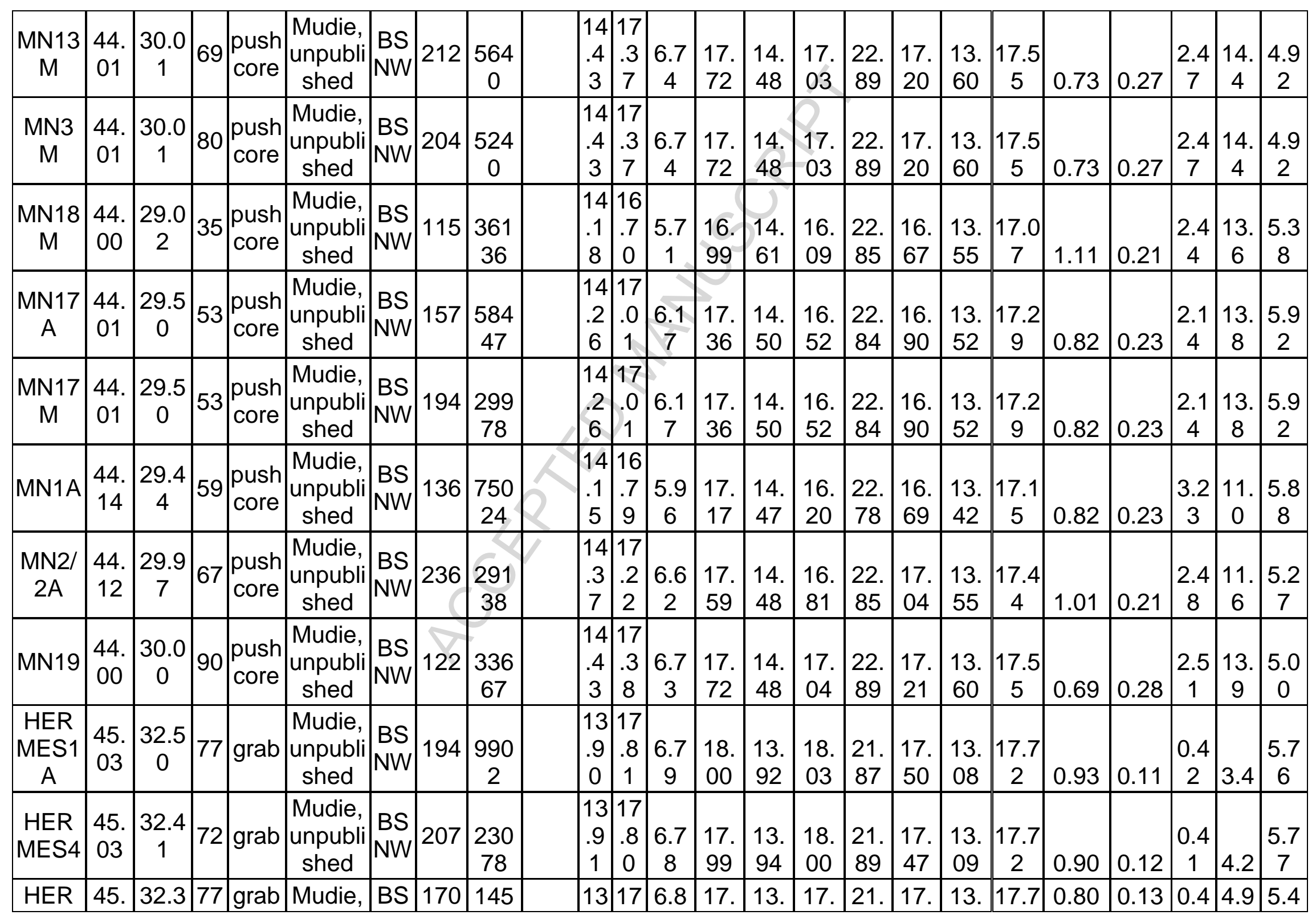




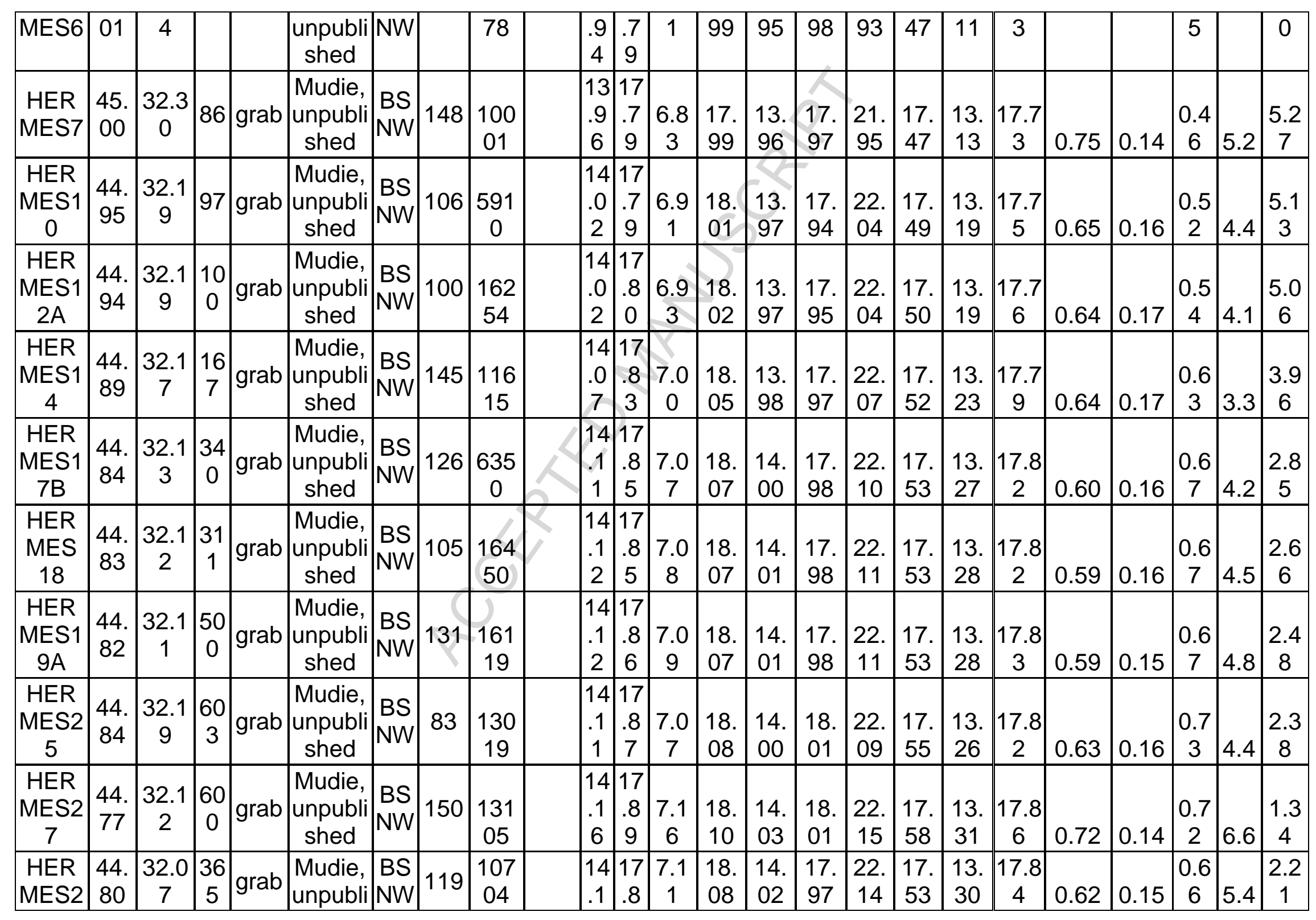




\begin{tabular}{|c|c|c|c|c|c|c|c|c|c|c|c|c|c|c|c|c|c|c|c|c|c|c|c|c|}
\hline 8 & & & & & shed & & & & & 4 & 6 & & & & & & & & & & & & & \\
\hline \begin{tabular}{|c|} 
HER \\
MES3 \\
0 \\
\end{tabular} & $\begin{array}{l}44 . \\
80\end{array}$ & $\begin{array}{c}31.9 \\
6\end{array}$ & $\begin{array}{c}10 \\
6\end{array}$ & grab & $\begin{array}{c}\text { Mudie, } \\
\text { unpubli } \\
\text { shed }\end{array}$ & \begin{tabular}{|l} 
BS \\
NW \\
\end{tabular} & 132 & $\begin{array}{c}523 \\
6\end{array}$ & & $\begin{array}{l}14 \\
.1 \\
5\end{array}$ & $\begin{array}{l}17 \\
.8 \\
2 \\
\end{array}$ & $\begin{array}{c}7.0 \\
9\end{array}$ & $\begin{array}{l}18 . \\
05 \\
\end{array}$ & $\begin{array}{l}14 . \\
02\end{array}$ & $\begin{array}{l}17 . \\
91\end{array}$ & $\begin{array}{l}22 . \\
17 \\
\end{array}$ & $\begin{array}{l}17 . \\
48 \\
\end{array}$ & $\begin{array}{l}13 . \\
31 \\
\end{array}$ & $\begin{array}{c}17.8 \\
2 \\
\end{array}$ & 0.54 & 0.14 & $\begin{array}{c}0.5 \\
8\end{array}$ & 5.2 & $\begin{array}{c}3.0 \\
2 \\
\end{array}$ \\
\hline \begin{tabular}{|c|} 
HER \\
MES3 \\
$1 \mathrm{~A}$ \\
\end{tabular} & $\begin{array}{l}44 . \\
79\end{array}$ & $\begin{array}{c}31.9 \\
3\end{array}$ & $\begin{array}{c}18 \\
6\end{array}$ & grab & $\begin{array}{c}\text { Mudie, } \\
\text { unpubli } \\
\text { shed }\end{array}$ & \begin{tabular}{|l} 
BS \\
NW \\
\end{tabular} & 102 & $\begin{array}{c}177 \\
07 \\
\end{array}$ & & $\begin{array}{l}14 \\
.1 \\
5\end{array}$ & $\begin{array}{l}17 \\
.8 \\
2 \\
\end{array}$ & $\begin{array}{c}7.1 \\
0 \\
\end{array}$ & $\begin{array}{l}18 . \\
05 \\
\end{array}$ & $\begin{array}{l}14 . \\
02 \\
\end{array}$ & $\begin{array}{l}17 . \\
90 \\
\end{array}$ & $\begin{array}{l}22 . \\
18 \\
\end{array}$ & $\begin{array}{l}17 . \\
48 \\
\end{array}$ & $\begin{array}{l}13 . \\
31 \\
\end{array}$ & $\begin{array}{c}17.8 \\
3 \\
\end{array}$ & 0.53 & 0.13 & $\begin{array}{c}0.5 \\
9\end{array}$ & 5.4 & $\begin{array}{c}2.8 \\
4 \\
\end{array}$ \\
\hline \begin{tabular}{|c|} 
HER \\
MES3 \\
2 \\
\end{tabular} & $\begin{array}{l}44 . \\
77\end{array}$ & $\begin{array}{c}31.9 \\
3\end{array}$ & $\begin{array}{c}33 \\
4\end{array}$ & grab & $\begin{array}{c}\text { Mudie, } \\
\text { unpubli } \\
\text { shed }\end{array}$ & $\begin{array}{c}\text { BS } \\
\text { NW }\end{array}$ & 184 & $\begin{array}{c}245 \\
50\end{array}$ & & $\begin{array}{l}14 \\
.1 \\
7\end{array}$ & $\begin{array}{c}17 \\
.8 \\
3\end{array}$ & $\begin{array}{c}7.1 \\
2\end{array}$ & 18. & $\begin{array}{l}14 . \\
03\end{array}$ & $\begin{array}{l}17 . \\
92\end{array}$ & $\begin{array}{l}22 . \\
20\end{array}$ & $\begin{array}{l}17 . \\
50\end{array}$ & $\begin{array}{l}13 . \\
32\end{array}$ & $\begin{array}{c}17.8 \\
4\end{array}$ & 0.56 & 0.13 & $\begin{array}{c}0.6 \\
6\end{array}$ & 5.8 & $\begin{array}{c}2.2 \\
1\end{array}$ \\
\hline \begin{tabular}{|c|} 
HER \\
MES3 \\
3 \\
\end{tabular} & $\begin{array}{l}44 . \\
72\end{array}$ & $\begin{array}{c}31.9 \\
3\end{array}$ & $\begin{array}{c}65 \\
5\end{array}$ & grab & $\begin{array}{c}\text { Mudie, } \\
\text { unpubli } \\
\text { shed } \\
\end{array}$ & $\mid \begin{array}{c}B S \\
\text { NW }\end{array}$ & 146 & \begin{tabular}{|c|}
224 \\
82 \\
\end{tabular} & & $\begin{array}{l}14 \\
.2 \\
0 \\
\end{array}$ & $\begin{array}{l}17 \\
.8 \\
6 \\
\end{array}$ & $\begin{array}{c}7.1 \\
9 \\
\end{array}$ & $\begin{array}{l}18 . \\
08 \\
\end{array}$ & $\begin{array}{l}14 . \\
06 \\
\end{array}$ & $\begin{array}{l}17 . \\
95 \\
\end{array}$ & $\begin{array}{l}22 . \\
24 \\
\end{array}$ & $\begin{array}{l}17 . \\
56 \\
\end{array}$ & $\begin{array}{l}13 . \\
35 \\
\end{array}$ & $\begin{array}{c}17.8 \\
7 \\
\end{array}$ & 0.75 & 0.13 & $\begin{array}{c}0.7 \\
9 \\
\end{array}$ & 6.2 & \begin{tabular}{|c}
1.0 \\
4 \\
\end{tabular} \\
\hline $\mid \begin{array}{c}\text { HER } \\
\text { M33A }\end{array}$ & $\begin{array}{l}44 . \\
66\end{array}$ & $\begin{array}{c}31.9 \\
3\end{array}$ & $\begin{array}{c}90 \\
5\end{array}$ & grab & $\begin{array}{c}\text { Mudie, } \\
\text { unpubli } \\
\text { shed }\end{array}$ & $\begin{array}{l}\text { BS } \\
\text { NW }\end{array}$ & 226 & $\begin{array}{c}287 \\
16\end{array}$ & & $\begin{array}{l}14 \\
2 \\
4 \\
\end{array}$ & $\begin{array}{l}17 \\
.9 \\
0\end{array}$ & $\begin{array}{c}7.2 \\
6\end{array}$ & $\begin{array}{l}18 . \\
10\end{array}$ & $\begin{array}{l}14 . \\
09\end{array}$ & $\begin{array}{l}17 . \\
98\end{array}$ & $\begin{array}{l}22 . \\
27\end{array}$ & $\begin{array}{l}17 . \\
61 \\
\end{array}$ & $\begin{array}{l}13 . \\
37\end{array}$ & $\begin{array}{c}17.9 \\
1\end{array}$ & 0.88 & 0.12 & $\begin{array}{c}0.8 \\
3\end{array}$ & 6.1 & $\begin{array}{c}0.6 \\
6\end{array}$ \\
\hline \begin{tabular}{|c|} 
HER \\
MES3 \\
5 \\
\end{tabular} & $\begin{array}{l}44 . \\
62\end{array}$ & $\begin{array}{c}31.7 \\
4\end{array}$ & $\begin{array}{c}64 \\
3\end{array}$ & grab & $\begin{array}{c}\text { Mudie, } \\
\text { unpubli } \\
\text { shed } \\
\end{array}$ & \begin{tabular}{|l|} 
BS \\
NW \\
\end{tabular} & 81 & \begin{tabular}{|r|}
247 \\
31 \\
\end{tabular} & & $\begin{array}{l}14 \\
.2 \\
8 \\
\end{array}$ & \begin{tabular}{c|}
17 \\
.8 \\
5 \\
\end{tabular} & $\begin{array}{c}7.2 \\
7 \\
\end{array}$ & \begin{tabular}{|l|}
18. \\
07 \\
\end{tabular} & $\begin{array}{r}14 . \\
12 \\
\end{array}$ & $\begin{array}{l}17 . \\
89 \\
\end{array}$ & $\begin{array}{l}22 . \\
34 \\
\end{array}$ & $\begin{array}{l}17 . \\
55 \\
\end{array}$ & $\begin{array}{l}13 . \\
41 \\
\end{array}$ & $\begin{array}{c}17.8 \\
9 \\
\end{array}$ & 0.97 & 0.11 & $\begin{array}{c}0.6 \\
9 \\
\end{array}$ & 5.7 & $\begin{array}{c}0.5 \\
2 \\
\end{array}$ \\
\hline \begin{tabular}{|c|} 
HER \\
MES3 \\
6 \\
\end{tabular} & $\begin{array}{l}44 . \\
72\end{array}$ & $\begin{array}{c}31.6 \\
5\end{array}$ & $\begin{array}{c}10 \\
9\end{array}$ & grab & $\begin{array}{c}\text { Mudie, } \\
\text { unpubli } \\
\text { shed }\end{array}$ & \begin{tabular}{|l} 
BS \\
NW \\
\end{tabular} & 125 & $\begin{array}{c}630 \\
8\end{array}$ & & $\begin{array}{l}14 \\
.2 \\
3 \\
\end{array}$ & $\begin{array}{r}17 \\
.7 \\
5\end{array}$ & $\begin{array}{c}7.1 \\
4 \\
\end{array}$ & $\begin{array}{c}18 . \\
01\end{array}$ & $\begin{array}{r}14 . \\
08\end{array}$ & $\begin{array}{l}17 . \\
76 \\
\end{array}$ & $\begin{array}{l}22 . \\
33 \\
\end{array}$ & $\begin{array}{l}17 . \\
43 \\
\end{array}$ & $\begin{array}{l}13 . \\
38 \\
\end{array}$ & $\begin{array}{c}17.8 \\
1 \\
\end{array}$ & 0.66 & 0.10 & $\begin{array}{c}0.7 \\
0\end{array}$ & 5.1 & $\begin{array}{c}2.1 \\
2 \\
\end{array}$ \\
\hline \begin{tabular}{|c|} 
HER \\
MES3 \\
7 \\
\end{tabular} & $\begin{array}{l}44 . \\
60\end{array}$ & $\begin{array}{c}31.5 \\
4\end{array}$ & $\begin{array}{c}74 \\
6\end{array}$ & grab & \begin{tabular}{|c|} 
Mudie, \\
unpubli \\
shed \\
\end{tabular} & $\begin{array}{c}\mathrm{BS} \\
\mathrm{NW}\end{array}$ & 143 & \begin{tabular}{|c|}
179 \\
25 \\
\end{tabular} & & $\begin{array}{l}14 \\
.3 \\
2 \\
\end{array}$ & $\begin{array}{l}17 \\
.7 \\
7 \\
\end{array}$ & $\begin{array}{c}7.2 \\
6 \\
\end{array}$ & \begin{tabular}{|l}
18. \\
03 \\
\end{tabular} & $\begin{array}{l}14 . \\
16 \\
\end{array}$ & $\begin{array}{l}17 . \\
77 \\
\end{array}$ & $\begin{array}{l}22 . \\
42 \\
\end{array}$ & \begin{tabular}{|l|}
17. \\
46 \\
\end{tabular} & \begin{tabular}{|l}
13. \\
44 \\
\end{tabular} & $\begin{array}{c}17.8 \\
4 \\
\end{array}$ & 0.99 & 0.13 & $\begin{array}{c}0.4 \\
6 \\
\end{array}$ & 5.1 & $\begin{array}{c}0.3 \\
3 \\
\end{array}$ \\
\hline \begin{tabular}{|c|} 
HER \\
MES3 \\
8 \\
\end{tabular} & $\begin{array}{l}44 . \\
69\end{array}$ & $\begin{array}{c}31.4 \\
5\end{array}$ & $\begin{array}{c}19 \\
2\end{array}$ & grab & $\begin{array}{c}\text { Mudie, } \\
\text { unpubli } \\
\text { shed } \\
\end{array}$ & \begin{tabular}{|c|} 
BS \\
NW \\
\end{tabular} & 213 & $\begin{array}{c}176 \\
35 \\
\end{array}$ & & $\begin{array}{l}14 \\
.2 \\
7 \\
\end{array}$ & $\begin{array}{r}17 \\
.6 \\
7 \\
\end{array}$ & $\begin{array}{c}7.1 \\
3 \\
\end{array}$ & $\begin{array}{l}17 . \\
96 \\
\end{array}$ & $\begin{array}{l}14 . \\
13 \\
\end{array}$ & $\begin{array}{l}17 . \\
62 \\
\end{array}$ & $\begin{array}{l}22 . \\
43 \\
\end{array}$ & $\begin{array}{l}17 . \\
35 \\
\end{array}$ & $\begin{array}{l}13 . \\
42 \\
\end{array}$ & $\begin{array}{c}17.7 \\
6 \\
\end{array}$ & 0.75 & 0.10 & $\begin{array}{c}0.5 \\
4 \\
\end{array}$ & 4.9 & $\begin{array}{c}1.9 \\
0 \\
\end{array}$ \\
\hline \begin{tabular}{|c|} 
HER \\
MES4 \\
0 \\
\end{tabular} & $\begin{array}{l}44 . \\
68\end{array}$ & $\begin{array}{c}31.3 \\
7\end{array}$ & $\begin{array}{c}11 \\
2\end{array}$ & grab & \begin{tabular}{|c|} 
Mudie, \\
unpubli \\
shed \\
\end{tabular} & \begin{tabular}{|l} 
BS \\
NW
\end{tabular} & 207 & $\begin{array}{c}848 \\
8\end{array}$ & & $\begin{array}{c}14 \\
.2 \\
9 \\
\end{array}$ & \begin{tabular}{l|}
17 \\
.6 \\
3 \\
\end{tabular} & $\begin{array}{c}7.1 \\
3 \\
\end{array}$ & $\begin{array}{l}17 . \\
94 \\
\end{array}$ & $\begin{array}{l}14 . \\
15 \\
\end{array}$ & $\begin{array}{l}17 . \\
56 \\
\end{array}$ & $\begin{array}{l}22 . \\
46 \\
\end{array}$ & $\begin{array}{l}17 . \\
31 \\
\end{array}$ & $\begin{array}{l}13 . \\
43 \\
\end{array}$ & $\begin{array}{c}17.7 \\
4 \\
\end{array}$ & 0.77 & 0.10 & $\begin{array}{c}0.4 \\
9\end{array}$ & 4.6 & $\begin{array}{c}1.9 \\
7\end{array}$ \\
\hline
\end{tabular}




\begin{tabular}{|c|c|c|c|c|c|c|c|c|c|c|c|c|c|c|c|c|c|c|c|c|c|c|c|}
\hline \begin{tabular}{|c|} 
HER \\
MES4 \\
2 \\
\end{tabular} & $\begin{array}{l}44 . \\
64\end{array}$ & $\begin{array}{c}31.3 \\
0\end{array}$ & $\begin{array}{c}23 \\
4\end{array}$ & grab & \begin{tabular}{|c} 
Mudie, \\
unpubli \\
shed
\end{tabular} & $\begin{array}{l}\text { BS } \\
\text { NW }\end{array}$ & 110 & $\begin{array}{c}631 \\
6\end{array}$ & \begin{tabular}{|c|}
14 \\
.3 \\
3
\end{tabular} & \begin{tabular}{c|}
17 \\
.6 \\
2
\end{tabular} & $\begin{array}{c}7.1 \\
5\end{array}$ & $\begin{array}{l}17 . \\
93\end{array}$ & $\begin{array}{l}14 . \\
19\end{array}$ & $\begin{array}{l}17 . \\
53\end{array}$ & $\begin{array}{l}22 . \\
50\end{array}$ & $\begin{array}{l}17 . \\
30\end{array}$ & $\begin{array}{l}13 . \\
46\end{array}$ & $\begin{array}{c}17.7 \\
3\end{array}$ & 0.81 & 0.11 & $\begin{array}{c}0.4 \\
1\end{array}$ & 4.3 & $\begin{array}{c}1.3 \\
3\end{array}$ \\
\hline \begin{tabular}{|c|} 
HER \\
MES4 \\
3 \\
\end{tabular} & $\begin{array}{l}44 . \\
63\end{array}$ & $\begin{array}{c}31.2 \\
2\end{array}$ & $\begin{array}{c}19 \\
5\end{array}$ & grab & $\begin{array}{c}\text { Mudie, } \\
\text { unpubli } \\
\text { shed }\end{array}$ & $\begin{array}{l}\text { BS } \\
\text { NW }\end{array}$ & 115 & \begin{tabular}{|c}
274 \\
7 \\
\end{tabular} & \begin{tabular}{|l|}
14 \\
.3 \\
4 \\
\end{tabular} & $\begin{array}{c}17 \\
.5 \\
8 \\
\end{array}$ & \begin{tabular}{|c|}
7.1 \\
4 \\
\end{tabular} & $\begin{array}{l}17 . \\
90 \\
\end{array}$ & $\begin{array}{l}14 . \\
22 \\
\end{array}$ & $\begin{array}{l}17 . \\
46 \\
\end{array}$ & $\begin{array}{l}22 . \\
54 \\
\end{array}$ & $\begin{array}{l}17 . \\
25 \\
\end{array}$ & $\begin{array}{l}13 . \\
48 \\
\end{array}$ & $\begin{array}{c}17.7 \\
1 \\
\end{array}$ & 0.78 & 0.11 & \begin{tabular}{|c|}
0.4 \\
2 \\
\end{tabular} & 4.4 & $\begin{array}{c}1.5 \\
0 \\
\end{array}$ \\
\hline \begin{tabular}{|c|} 
HER \\
MES4 \\
4 \\
\end{tabular} & $\begin{array}{l}44 . \\
67\end{array}$ & $\begin{array}{c}31.2 \\
9\end{array}$ & $\begin{array}{c}11 \\
3\end{array}$ & grab & $\begin{array}{c}\text { Mudie, } \\
\text { unpubli } \\
\text { shed }\end{array}$ & $\begin{array}{l}\text { BS } \\
\text { NW }\end{array}$ & 133 & $\begin{array}{c}819 \\
7\end{array}$ & \begin{tabular}{|c|}
14 \\
.3 \\
1 \\
\end{tabular} & \begin{tabular}{c|}
17 \\
.5 \\
9
\end{tabular} & \begin{tabular}{|c|}
7.1 \\
2 \\
\end{tabular} & $\begin{array}{l}17 . \\
91\end{array}$ & $\begin{array}{l}14 . \\
18 \\
\end{array}$ & $\begin{array}{l}17 . \\
49 \\
\end{array}$ & $\begin{array}{l}22 . \\
50 \\
\end{array}$ & \begin{tabular}{|l|}
17 \\
27 \\
\end{tabular} & $\begin{array}{l}13 . \\
45 \\
\end{array}$ & \begin{tabular}{|c|}
17.7 \\
1 \\
\end{tabular} & 0.77 & 0.10 & $\begin{array}{c}0.5 \\
0 \\
\end{array}$ & 4.5 & $\begin{array}{c}2.1 \\
6 \\
\end{array}$ \\
\hline $\begin{array}{l}\text { CORE } \\
45 B-1\end{array}$ & $\begin{array}{l}44 . \\
67\end{array}$ & $\begin{array}{c}31.2 \\
9\end{array}$ & $\begin{array}{c}10 \\
7\end{array}$ & $\begin{array}{c}\text { Grav } \\
\text { ity } \\
\text { core } \\
\end{array}$ & $\begin{array}{c}\text { Mudie, } \\
\text { unpubli } \\
\text { shed }\end{array}$ & $\begin{array}{l}\text { BS } \\
\text { NW }\end{array}$ & 132 & $\begin{array}{c}881 \\
1 \\
\end{array}$ & \begin{tabular}{|c|}
14 \\
.3 \\
1 \\
\end{tabular} & \begin{tabular}{c|}
17 \\
.5 \\
9 \\
\end{tabular} & $\begin{array}{c}7.1 \\
2 \\
\end{array}$ & $\begin{array}{l}17 . \\
91\end{array}$ & $\begin{array}{l}14 . \\
18 \\
\end{array}$ & $\begin{array}{l}17 . \\
49 \\
\end{array}$ & $\begin{array}{l}22 . \\
50 \\
\end{array}$ & \begin{tabular}{|l|}
17 \\
27 \\
\end{tabular} & $\begin{array}{l}13 . \\
45 \\
\end{array}$ & \begin{tabular}{|c|}
17.7 \\
1 \\
\end{tabular} & 0.77 & 0.10 & $\begin{array}{c}0.5 \\
0 \\
\end{array}$ & 4.5 & $\begin{array}{c}2.1 \\
6 \\
\end{array}$ \\
\hline $\begin{array}{c}7 \mathrm{MUC} \\
5\end{array}$ & $\begin{array}{c}42 . \\
98\end{array}$ & $\begin{array}{c}32.0 \\
1\end{array}$ & $\begin{array}{l}15 \\
31\end{array}$ & $\begin{array}{c}\text { multi } \\
\text { core } \\
r\end{array}$ & \begin{tabular}{|c|} 
Shumil \\
ovskhik \\
h, \\
unpubli \\
shed
\end{tabular} & $\begin{array}{l}\text { BS } \\
\text { NW }\end{array}$ & 304 & \begin{tabular}{|c}
732 \\
5 \\
\end{tabular} & $\begin{array}{l}14 \\
.8 \\
2 \\
\end{array}$ & $\begin{array}{l}18 \\
.3 \\
2 \\
\end{array}$ & $\begin{array}{c}7.8 \\
4 \\
\end{array}$ & $\begin{array}{l}18 . \\
38\end{array}$ & $\begin{array}{l}14 . \\
29 \\
\end{array}$ & $\begin{array}{l}18 . \\
39\end{array}$ & $\begin{array}{l}23 . \\
08\end{array}$ & $\begin{array}{l}18 . \\
26 \\
\end{array}$ & $\begin{array}{l}14 . \\
05\end{array}$ & \begin{tabular}{|c|}
18.2 \\
2 \\
\end{tabular} & 0.94 & 0.13 & $\begin{array}{c}0.4 \\
8 \\
\end{array}$ & 5.8 & $\begin{array}{c}0.1 \\
2 \\
\end{array}$ \\
\hline $\begin{array}{c}14 \mathrm{MU} \\
\mathrm{C} 7\end{array}$ & $\begin{array}{l}44 . \\
58\end{array}$ & $\begin{array}{c}36.3 \\
5\end{array}$ & $\begin{array}{c}27 \\
5\end{array}$ & $\mid \begin{array}{c}\text { multi } \\
\text { core } \\
r\end{array}$ & $\begin{array}{c}\text { Shumil } \\
\text { ovskhik } \\
\text { h, } \\
\text { unpubli } \\
\text { shed }\end{array}$ & $\begin{array}{l}\text { BS } \\
\text { NE }\end{array}$ & 304 & $\begin{array}{c}321 \\
9\end{array}$ & $\begin{array}{c}14 \\
.5 \\
3 \\
\end{array}$ & \begin{tabular}{c|}
16 \\
.9 \\
8 \\
\end{tabular} & $\begin{array}{c}7.1 \\
6 \\
\end{array}$ & $\begin{array}{l}17 . \\
11 \\
\end{array}$ & $\begin{array}{l}15 . \\
12 \\
\end{array}$ & $\begin{array}{l}17 . \\
05\end{array}$ & $\begin{array}{l}23 . \\
06\end{array}$ & $\begin{array}{l}16 . \\
93\end{array}$ & $\begin{array}{l}12 . \\
77\end{array}$ & $\begin{array}{c}16.8 \\
0\end{array}$ & 0.51 & 0.12 & $\begin{array}{c}0.4 \\
3 \\
\end{array}$ & 4.1 & $\begin{array}{c}0.9 \\
3\end{array}$ \\
\hline $\begin{array}{c}17 \mathrm{MU} \\
\mathrm{C} 4\end{array}$ & $\begin{array}{l}44 . \\
68\end{array}$ & $\begin{array}{c}36.0 \\
3\end{array}$ & $\begin{array}{c}52 \\
3\end{array}$ & $\begin{array}{c}\text { multi } \\
\text { core } \\
r\end{array}$ & \begin{tabular}{|c|} 
Shumil \\
ovskhik \\
h, \\
unpubli \\
shed
\end{tabular} & $\begin{array}{l}\text { BS } \\
\text { NE }\end{array}$ & 310 & $\begin{array}{c}975 \\
1 \\
\end{array}$ & $\begin{array}{l}14 \\
.4 \\
3 \\
\end{array}$ & $\begin{array}{l}16 \\
.7 \\
6 \\
\end{array}$ & $\begin{array}{c}7.0 \\
2 \\
\end{array}$ & $\begin{array}{l}17 . \\
00\end{array}$ & $\begin{array}{l}15 . \\
13 \\
\end{array}$ & $\begin{array}{l}16 . \\
79 \\
\end{array}$ & $\begin{array}{l}23 . \\
01\end{array}$ & $\begin{array}{l}16 . \\
78 \\
\end{array}$ & $\begin{array}{l}12 . \\
54 \\
\end{array}$ & \begin{tabular}{|c|}
16.5 \\
7 \\
\end{tabular} & 0.67 & 0.09 & $\begin{array}{c}0.2 \\
2 \\
\end{array}$ & 4.1 & $\begin{array}{c}2.0 \\
0 \\
\end{array}$ \\
\hline $\begin{array}{c}18 \mathrm{MU} \\
\mathrm{C} 4\end{array}$ & $\begin{array}{l}44 . \\
56\end{array}$ & $\begin{array}{c}36.0 \\
0\end{array}$ & $\begin{array}{c}97 \\
9\end{array}$ & $\mid \begin{array}{c}\text { multi } \\
\text { core } \\
r\end{array}$ & \begin{tabular}{|} 
Shumil \\
ovskhik \\
h, \\
unpubli \\
shed
\end{tabular} & $\begin{array}{l}\text { BS } \\
\text { NE }\end{array}$ & 313 & $\begin{array}{c}454 \\
4\end{array}$ & $\begin{array}{c}14 \\
.4 \\
8\end{array}$ & $\begin{array}{l}17 \\
.0 \\
4\end{array}$ & $\begin{array}{c}7.1 \\
5\end{array}$ & $\begin{array}{l}17 . \\
22\end{array}$ & $\begin{array}{l}15 . \\
09\end{array}$ & $\begin{array}{l}17 . \\
10\end{array}$ & $\begin{array}{c}23 . \\
01\end{array}$ & $\begin{array}{l}16 . \\
96\end{array}$ & $\begin{array}{l}12 . \\
68\end{array}$ & $\begin{array}{c}16.8 \\
5\end{array}$ & 0.54 & 0.09 & $\begin{array}{c}0.3 \\
2\end{array}$ & 4.7 & $\begin{array}{c}0.8 \\
1\end{array}$ \\
\hline
\end{tabular}




\begin{tabular}{|c|c|c|c|c|c|c|c|c|c|c|c|c|c|c|c|c|c|c|c|c|c|c|c|}
\hline $\begin{array}{c}20 \mathrm{MU} \\
\mathrm{C} 3\end{array}$ & $\begin{array}{c}43 . \\
95\end{array}$ & $\begin{array}{c}35.6 \\
3\end{array}$ & $\begin{array}{l}20 \\
47\end{array}$ & $\begin{array}{c}\text { multi } \\
\text { core } \\
r\end{array}$ & $\begin{array}{c}\text { Shumil } \\
\text { ovskhik } \\
\text { h, } \\
\text { unpubli } \\
\text { shed }\end{array}$ & $\begin{array}{l}B S \\
\text { NE }\end{array}$ & 300 & $\begin{array}{c}520 \\
1 \\
\end{array}$ & \begin{tabular}{|c|}
14 \\
.6 \\
4
\end{tabular} & \begin{tabular}{|c|}
18 \\
.0 \\
1 \\
\end{tabular} & \begin{tabular}{|c}
7.6 \\
0 \\
\end{tabular} & $\begin{array}{c}18 . \\
10 \\
\end{array}$ & $\begin{array}{l}14 . \\
79 \\
\end{array}$ & $\begin{array}{l}18 . \\
14\end{array}$ & $\begin{array}{c}23 . \\
03\end{array}$ & $\begin{array}{l}17 . \\
98 \\
\end{array}$ & $\begin{array}{l}13 . \\
14 \\
\end{array}$ & $\begin{array}{c}17.8 \\
4 \\
\end{array}$ & 0.93 & 0.13 & $\begin{array}{c}0.3 \\
1 \\
\end{array}$ & $\begin{array}{c}10 . \\
1\end{array}$ & $\begin{array}{c}0.3 \\
9 \\
\end{array}$ \\
\hline $\begin{array}{c}24 \mathrm{MU} \\
\mathrm{C} 1\end{array}$ & $\begin{array}{l}41 . \\
46\end{array}$ & $\begin{array}{c}37.1 \\
8\end{array}$ & $\begin{array}{c}20 \\
8\end{array}$ & $\begin{array}{c}\text { multi } \\
\text { core } \\
r\end{array}$ & $\begin{array}{c}\text { Shumil } \\
\text { ovskhik } \\
\text { h, } \\
\text { unpubli } \\
\text { shed }\end{array}$ & $\begin{array}{l}B S \\
\text { SE }\end{array}$ & 309 & $\begin{array}{c}779 \\
0\end{array}$ & $\begin{array}{l}15 \\
.7 \\
2\end{array}$ & \begin{tabular}{|c|}
17 \\
.9 \\
9
\end{tabular} & $\begin{array}{c}8.4 \\
0\end{array}$ & $\begin{array}{l}18 . \\
05\end{array}$ & $\begin{array}{l}15 . \\
31\end{array}$ & $\begin{array}{l}17 . \\
92\end{array}$ & $\begin{array}{c}23 . \\
93\end{array}$ & $\begin{array}{l}17 . \\
99\end{array}$ & $\begin{array}{l}15 . \\
24\end{array}$ & $\begin{array}{c}18.0 \\
1\end{array}$ & 1.50 & 0.06 & $\begin{array}{c}0.1 \\
1\end{array}$ & 2.1 & $\begin{array}{c}0.1 \\
2\end{array}$ \\
\hline $\begin{array}{c}32- \\
23 \mathrm{MU} \\
\mathrm{C}\end{array}$ & $\begin{array}{c}43 . \\
51\end{array}$ & $\begin{array}{c}32.4 \\
6\end{array}$ & $\begin{array}{l}20 \\
30\end{array}$ & $\begin{array}{c}\text { multi } \\
\text { core } \\
r\end{array}$ & $\begin{array}{c}\text { Shumil } \\
\text { ovskhik } \\
\text { h, } \\
\text { unpubli } \\
\text { shed }\end{array}$ & $\begin{array}{l}\text { BS } \\
\text { NW }\end{array}$ & 307 & $\begin{array}{c}178 \\
07\end{array}$ & $\begin{array}{c}14 \\
.6 \\
7\end{array}$ & $\begin{array}{c}18 \\
.3 \\
0\end{array}$ & $\begin{array}{c}7.9 \\
1\end{array}$ & $\begin{array}{l}18 . \\
38\end{array}$ & $\begin{array}{l}14 . \\
32\end{array}$ & $\begin{array}{l}18 . \\
38\end{array}$ & $\begin{array}{l}22 . \\
76\end{array}$ & $\begin{array}{l}18 . \\
22\end{array}$ & $\begin{array}{l}13 . \\
71\end{array}$ & $\begin{array}{c}18.2 \\
3\end{array}$ & 0.95 & 0.13 & $\begin{array}{c}0.2 \\
3\end{array}$ & 5.1 & $\begin{array}{c}0.1 \\
0\end{array}$ \\
\hline $\begin{array}{c}42- \\
3 \mathrm{MUC}\end{array}$ & $\begin{array}{c}43 . \\
91\end{array}$ & $\begin{array}{c}36.2 \\
1\end{array}$ & $\begin{array}{l}20 \\
83\end{array}$ & $\begin{array}{c}\text { multi } \\
\text { core } \\
r\end{array}$ & \begin{tabular}{|c} 
Shumil \\
i ovskhik \\
h, \\
unpubli \\
shed
\end{tabular} & $\begin{array}{l}B S \\
N E\end{array}$ & 307 & $\begin{array}{c}296 \\
19\end{array}$ & $\mid \begin{array}{c}14 \\
.7 \\
1\end{array}$ & $\begin{array}{c}18 \\
.0 \\
1\end{array}$ & $\begin{array}{c}7.6 \\
0\end{array}$ & $\begin{array}{l}17 . \\
98\end{array}$ & $\begin{array}{l}14 . \\
88\end{array}$ & $\begin{array}{c}18 . \\
18\end{array}$ & $\begin{array}{c}23 . \\
09\end{array}$ & $\begin{array}{l}18 . \\
01\end{array}$ & $\begin{array}{l}13 . \\
26\end{array}$ & $\begin{array}{c}17.8 \\
7\end{array}$ & 0.88 & 0.18 & $\begin{array}{c}0.2 \\
8\end{array}$ & 6.0 & $\begin{array}{c}0.0 \\
3\end{array}$ \\
\hline $\begin{array}{c}59- \\
1 \mathrm{MUC}\end{array}$ & $\begin{array}{l}41 . \\
70\end{array}$ & $\begin{array}{c}36.9 \\
1\end{array}$ & $\begin{array}{c}31 \\
2\end{array}$ & $\begin{array}{c}\text { multi } \\
\text { core } \\
r\end{array}$ & \begin{tabular}{|c} 
Shumil \\
i ovskhik \\
h, \\
unpubli \\
shed
\end{tabular} & $\begin{array}{l}B S \\
S E\end{array}$ & 304 & $\begin{array}{c}682 \\
8\end{array}$ & $\left|\begin{array}{c}15 \\
.1 \\
6\end{array}\right|$ & $\begin{array}{c}18 \\
.0 \\
8\end{array}$ & $\begin{array}{c}8.0 \\
7\end{array}$ & $\begin{array}{c}18 . \\
15\end{array}$ & $\begin{array}{l}14 . \\
65\end{array}$ & $\begin{array}{l}18 . \\
04\end{array}$ & $\begin{array}{c}23 \\
43\end{array}$ & $\begin{array}{l}18 . \\
05\end{array}$ & $\begin{array}{l}14 . \\
52\end{array}$ & $\begin{array}{c}18.0 \\
7\end{array}$ & 1.99 & 0.05 & $\begin{array}{c}0.1 \\
5\end{array}$ & 1.7 & $\begin{array}{c}0.0 \\
7\end{array}$ \\
\hline Ash3 & $\begin{array}{c}44 . \\
51\end{array}$ & $\begin{array}{c}37.9 \\
5\end{array}$ & 75 & $\begin{array}{l}\text { Grav } \\
\text { ity } \\
\text { core }\end{array}$ & \begin{tabular}{|c} 
Shumil \\
ovskhik \\
h, \\
unpubli \\
shed
\end{tabular} & $\begin{array}{l}\mathrm{BS} \\
\mathrm{NE}\end{array}$ & 303 & $\begin{array}{c}573 \\
3\end{array}$ & $\mid \begin{array}{c}15 \\
.3 \\
6\end{array}$ & \begin{tabular}{|c|}
17 \\
.5 \\
8
\end{tabular} & $\begin{array}{c}8.3 \\
4\end{array}$ & $\begin{array}{l}17 . \\
56\end{array}$ & $\begin{array}{l}15 . \\
57\end{array}$ & $\begin{array}{l}17 . \\
63\end{array}$ & $\begin{array}{l}23 . \\
26\end{array}$ & $\begin{array}{l}17 . \\
71\end{array}$ & $\begin{array}{l}14 . \\
25\end{array}$ & $\begin{array}{c}17.5 \\
3\end{array}$ & 0.51 & 0.09 & $\begin{array}{c}0.3 \\
7\end{array}$ & 6.1 & $\begin{array}{c}4.3 \\
3\end{array}$ \\
\hline $\begin{array}{c}26- \\
2 M U C\end{array}$ & $\begin{array}{l}45 . \\
01\end{array}$ & $\begin{array}{c}31.1 \\
3\end{array}$ & 56 & $\begin{array}{l}\text { multi } \\
\text { core }\end{array}$ & $\begin{array}{l}\text { Shumil } \\
\text { ovskhik }\end{array}$ & \begin{tabular}{|l|} 
BS \\
NW
\end{tabular} & 318 & \begin{tabular}{|c|}
507 \\
25
\end{tabular} & \begin{tabular}{|c|}
14 \\
.1
\end{tabular} & $\begin{array}{l}17 \\
.2 \\
\end{array}$ & $\begin{array}{c}6.6 \\
5\end{array}$ & $\begin{array}{l}17 . \\
66\end{array}$ & $\begin{array}{l}14 . \\
05\end{array}$ & $\begin{array}{l}16 . \\
97\end{array}$ & $\begin{array}{l}22 . \\
39\end{array}$ & $\begin{array}{l}16 . \\
80\end{array}$ & $\begin{array}{l}13 . \\
32 \\
\end{array}$ & \begin{tabular}{|c|}
17.4 \\
2 \\
\end{tabular} & 1.47 & 0.12 & $\begin{array}{c}0.7 \\
0\end{array}$ & 4.9 & \begin{tabular}{|c}
5.7 \\
9 \\
\end{tabular} \\
\hline
\end{tabular}









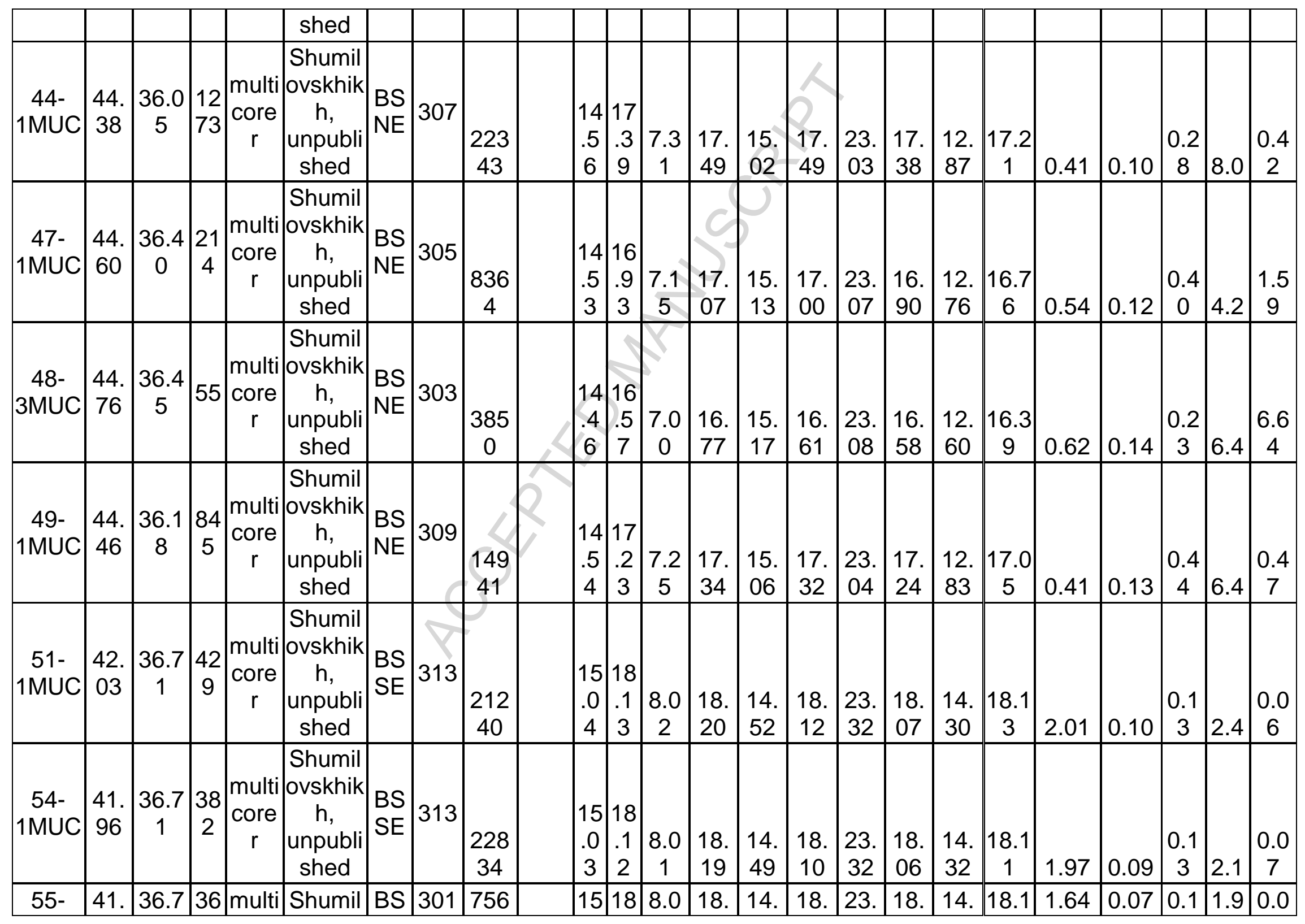




\begin{tabular}{|c|c|c|c|c|c|c|c|c|c|c|c|c|c|c|c|c|c|c|c|c|c|c|c|c|}
\hline 2MUC & 90 & 6 & 2 & $\begin{array}{c}\text { core } \\
r\end{array}$ & $\begin{array}{c}\text { ovskhik } \\
\text { h, } \\
\text { unpubli } \\
\text { shed }\end{array}$ & SE & & 3 & & \begin{tabular}{|l|}
0 \\
5
\end{tabular} & \begin{tabular}{|l|}
.1 \\
1 \\
\end{tabular} & 2 & 18 & 52 & 09 & 34 & 06 & 35 & 1 & & & 3 & & 7 \\
\hline $\begin{array}{c}66- \\
15 \mathrm{MU} \\
\mathrm{C}\end{array}$ & $\begin{array}{c}43 . \\
51\end{array}$ & $\begin{array}{c}36.0 \\
8\end{array}$ & $\begin{array}{l}21 \\
74\end{array}$ & $\begin{array}{c}\text { multi } \\
\text { core } \\
r\end{array}$ & \begin{tabular}{|c|} 
Shumil \\
ovskhik \\
h, \\
unpubli \\
shed
\end{tabular} & $\begin{array}{l}\mathrm{BS} \\
\mathrm{NE}\end{array}$ & 311 & $\begin{array}{c}256 \\
65\end{array}$ & & $\begin{array}{c}14 \\
.7 \\
6\end{array}$ & \begin{tabular}{|c|}
18 \\
.2 \\
4 \\
\end{tabular} & \begin{tabular}{|c}
7.7 \\
4
\end{tabular} & $\begin{array}{l}18 . \\
25\end{array}$ & $\begin{array}{l}14 . \\
68\end{array}$ & $\begin{array}{l}18 . \\
39\end{array}$ & $\begin{array}{c}23 . \\
15\end{array}$ & $\begin{array}{l}18 . \\
18\end{array}$ & $\begin{array}{l}13 . \\
46\end{array}$ & $\begin{array}{c}18.1 \\
3\end{array}$ & 0.39 & 0.08 & $\begin{array}{c}0.2 \\
4\end{array}$ & 5.1 & $\begin{array}{c}0.0 \\
5\end{array}$ \\
\hline $\begin{array}{c}\text { Ash } \\
04\end{array}$ & $\begin{array}{l}44 . \\
53\end{array}$ & $\begin{array}{c}38.0 \\
1\end{array}$ & 33 & $\begin{array}{c}\text { Grav } \\
\text { ity } \\
\text { core }\end{array}$ & $\begin{array}{c}\text { Marret, } \\
\text { unpubli } \\
\text { shed }\end{array}$ & $\begin{array}{l}\mathrm{BS} \\
\mathrm{NE}\end{array}$ & 113 & & \begin{tabular}{|c|}
443 \\
0 \\
\end{tabular} & \begin{tabular}{|c|}
15 \\
.3 \\
9 \\
\end{tabular} & \begin{tabular}{|c|}
17 \\
.5 \\
7 \\
\end{tabular} & $\begin{array}{c}8.3 \\
9 \\
\end{array}$ & $\begin{array}{l} \\
17 . \\
55 \\
\end{array}$ & $\begin{array}{l}15 . \\
55 \\
\end{array}$ & $\begin{array}{l}17 . \\
62 \\
\end{array}$ & $\begin{array}{c}23 . \\
26\end{array}$ & $\begin{array}{l}17 . \\
73 \\
\end{array}$ & $\begin{array}{l}14 . \\
33 \\
\end{array}$ & $\begin{array}{c}17.5 \\
3 \\
\end{array}$ & 0.48 & 0.09 & $\begin{array}{c}0.3 \\
9 \\
\end{array}$ & 5.9 & \begin{tabular}{|c}
6.3 \\
3 \\
\end{tabular} \\
\hline \begin{tabular}{|c|} 
GeoB \\
$7625-$ \\
2 \\
\end{tabular} & $\begin{array}{l}41 . \\
44\end{array}$ & $\begin{array}{c}31.0 \\
7\end{array}$ & $\begin{array}{l}12 \\
42\end{array}$ & $\begin{array}{c}\text { Grav } \\
\text { ity } \\
\text { core }\end{array}$ & \begin{tabular}{|c|} 
Verley \\
e et al., \\
2009
\end{tabular} & $\left|\begin{array}{c}B S \\
S W\end{array}\right|$ & 300 & \begin{tabular}{|c|}
443 \\
80 \\
\end{tabular} & & \begin{tabular}{|c|}
15 \\
2 \\
0 \\
\end{tabular} & \begin{tabular}{|c|}
17 \\
.9 \\
4 \\
\end{tabular} & $\begin{array}{c}7.9 \\
1 \\
\end{array}$ & $\begin{array}{c}18 . \\
01 \\
\end{array}$ & $\begin{array}{l}14 . \\
50 \\
\end{array}$ & $\begin{array}{l}17 . \\
95 \\
\end{array}$ & $\begin{array}{c}23 . \\
25\end{array}$ & $\begin{array}{l}17 . \\
85 \\
\end{array}$ & $\begin{array}{c}15 . \\
14 \\
\end{array}$ & \begin{tabular}{|c|}
17.9 \\
4 \\
\end{tabular} & 0.66 & 0.05 & $\begin{array}{c}0.1 \\
4 \\
\end{array}$ & 3.4 & $\begin{array}{c}0.2 \\
9 \\
\end{array}$ \\
\hline GC27 & $\begin{array}{l}44 . \\
84\end{array}$ & $\begin{array}{c}32.0 \\
2\end{array}$ & 95 & $\begin{array}{c}\text { Grav } \\
\text { ity } \\
\text { core }\end{array}$ & \begin{tabular}{|c|} 
Verley \\
e et al., \\
2009
\end{tabular} & $\begin{array}{l}\mathrm{BS} \\
\mathrm{NE}\end{array}$ & 304 & $\begin{array}{c}570 \\
0 \\
\end{array}$ & & \begin{tabular}{|c|}
14 \\
.1 \\
1 \\
\end{tabular} & \begin{tabular}{|l|}
17 \\
.8 \\
2 \\
\end{tabular} & \begin{tabular}{|c|}
7.0 \\
5 \\
\end{tabular} & $\begin{array}{l}18 . \\
05 \\
\end{array}$ & $\begin{array}{l}14 . \\
00 \\
\end{array}$ & $\begin{array}{l}17 . \\
92 \\
\end{array}$ & $\begin{array}{c}22 . \\
13 \\
\end{array}$ & $\begin{array}{l}17 . \\
48 \\
\end{array}$ & $\begin{array}{l}13 . \\
28 \\
\end{array}$ & $\begin{array}{c}17.8 \\
1 \\
\end{array}$ & 0.54 & 0.15 & $\begin{array}{c}0.5 \\
3 \\
\end{array}$ & 4.1 & $\begin{array}{c}3.9 \\
0 \\
\end{array}$ \\
\hline GC29 & $\begin{array}{l}44 . \\
84\end{array}$ & $\begin{array}{c}31.9 \\
8\end{array}$ & 92 & $\begin{array}{c}\text { Grav } \\
\text { ity } \\
\text { core }\end{array}$ & \begin{tabular}{|c|} 
Verley \\
e et al., \\
2009
\end{tabular} & $\begin{array}{c}\mathrm{BS} \\
\mathrm{NW}\end{array}$ & 307 & $\begin{array}{c}600 \\
0 \\
\end{array}$ & & \begin{tabular}{|c|}
14 \\
.1 \\
2 \\
\end{tabular} & \begin{tabular}{|c|}
17 \\
.8 \\
0 \\
\end{tabular} & \begin{tabular}{|c|}
7.0 \\
4 \\
\end{tabular} & $\begin{array}{l}18 . \\
04 \\
\end{array}$ & $\begin{array}{l}14 . \\
00 \\
\end{array}$ & $\begin{array}{l}17 . \\
90 \\
\end{array}$ & $\begin{array}{c}22 . \\
14 \\
\end{array}$ & $\begin{array}{l}17 . \\
46\end{array}$ & $\begin{array}{l}13 . \\
28 \\
\end{array}$ & \begin{tabular}{|c|}
17.8 \\
0 \\
\end{tabular} & 0.52 & 0.14 & $\begin{array}{c}0.4 \\
8 \\
\end{array}$ & 4.0 & $\begin{array}{c}4.3 \\
5 \\
\end{array}$ \\
\hline GC49 & $\begin{array}{l}44 . \\
85\end{array}$ & $\begin{array}{c}31.9 \\
9\end{array}$ & 79 & $\begin{array}{c}\text { Grav } \\
\text { ity } \\
\text { core }\end{array}$ & \begin{tabular}{|c} 
Verley \\
e et al., \\
2009
\end{tabular} & $\begin{array}{c}\mathrm{BS} \\
\mathrm{NW}\end{array}$ & 297 & $\begin{array}{c}210 \\
0\end{array}$ & & \begin{tabular}{|c|}
14 \\
.1 \\
1
\end{tabular} & \begin{tabular}{|c|}
17 \\
.8 \\
0
\end{tabular} & $\begin{array}{c}7.0 \\
3\end{array}$ & $\begin{array}{l}18 . \\
04\end{array}$ & $\begin{array}{c}13 . \\
99\end{array}$ & $\begin{array}{l}17 . \\
90\end{array}$ & $\begin{array}{c}22 . \\
13\end{array}$ & $\begin{array}{l}17 . \\
46\end{array}$ & $\begin{array}{l}13 . \\
28\end{array}$ & $\begin{array}{c}17.8 \\
0\end{array}$ & 0.54 & 0.14 & $\begin{array}{c}0.4 \\
7\end{array}$ & 3.8 & \begin{tabular}{|c}
4.5 \\
5
\end{tabular} \\
\hline GGC4 & $\begin{array}{l}41 . \\
84\end{array}$ & $\begin{array}{c}28.6 \\
9\end{array}$ & $\begin{array}{c}21 \\
1\end{array}$ & $\begin{array}{c}\text { Gian } \\
t \\
\text { gravi } \\
\text { ty } \\
\text { core }\end{array}$ & $\begin{array}{c}\text { Desme } \\
t\end{array}$ & $\begin{array}{l}\text { BS } \\
\text { SW }\end{array}$ & 302 & $\mathrm{~N} / \mathrm{A}$ & & \begin{tabular}{|c|}
14 \\
.8 \\
6 \\
\end{tabular} & \begin{tabular}{|c|}
17 \\
.8 \\
3 \\
\end{tabular} & $\begin{array}{c}7.3 \\
2 \\
\end{array}$ & $\begin{array}{l}18 . \\
02 \\
\end{array}$ & $\begin{array}{l}14 . \\
50 \\
\end{array}$ & $\begin{array}{l}17 . \\
73 \\
\end{array}$ & $\begin{array}{c}23 . \\
29 \\
\end{array}$ & $\begin{array}{l}17 . \\
64 \\
\end{array}$ & $\begin{array}{l}14 . \\
33 \\
\end{array}$ & $\begin{array}{c}17.9 \\
3 \\
\end{array}$ & 1.40 & 0.06 & $\begin{array}{c}0.0 \\
7 \\
\end{array}$ & 3.1 & $\begin{array}{c}1.2 \\
9 \\
\end{array}$ \\
\hline GGC7 & $\begin{array}{l}41 . \\
84\end{array}$ & $\begin{array}{c}28.6 \\
9\end{array}$ & $\begin{array}{c}20 \\
8\end{array}$ & $\begin{array}{c}\text { Gian } \\
t \\
\text { gravi }\end{array}$ & $\begin{array}{c}\text { Desme } \\
t\end{array}$ & $\begin{array}{l}B S \\
S W\end{array} \mid$ & 304 & $\mathrm{~N} / \mathrm{A}$ & & \begin{tabular}{|c|}
14 \\
.8 \\
6
\end{tabular} & \begin{tabular}{|c|}
17 \\
.8 \\
3 \\
\end{tabular} & $\begin{array}{c}7.3 \\
2\end{array}$ & $\begin{array}{l}18 . \\
02\end{array}$ & $\begin{array}{c}14 . \\
50\end{array}$ & $\begin{array}{l}17 . \\
73\end{array}$ & $\begin{array}{c}23 . \\
29\end{array}$ & $\begin{array}{l}17 . \\
64\end{array}$ & $\begin{array}{c}14 . \\
33\end{array}$ & $\begin{array}{c}17.9 \\
3\end{array}$ & 1.40 & 0.06 & $\begin{array}{c}0.0 \\
7\end{array}$ & 3.1 & $\begin{array}{c}1.2 \\
9\end{array}$ \\
\hline
\end{tabular}




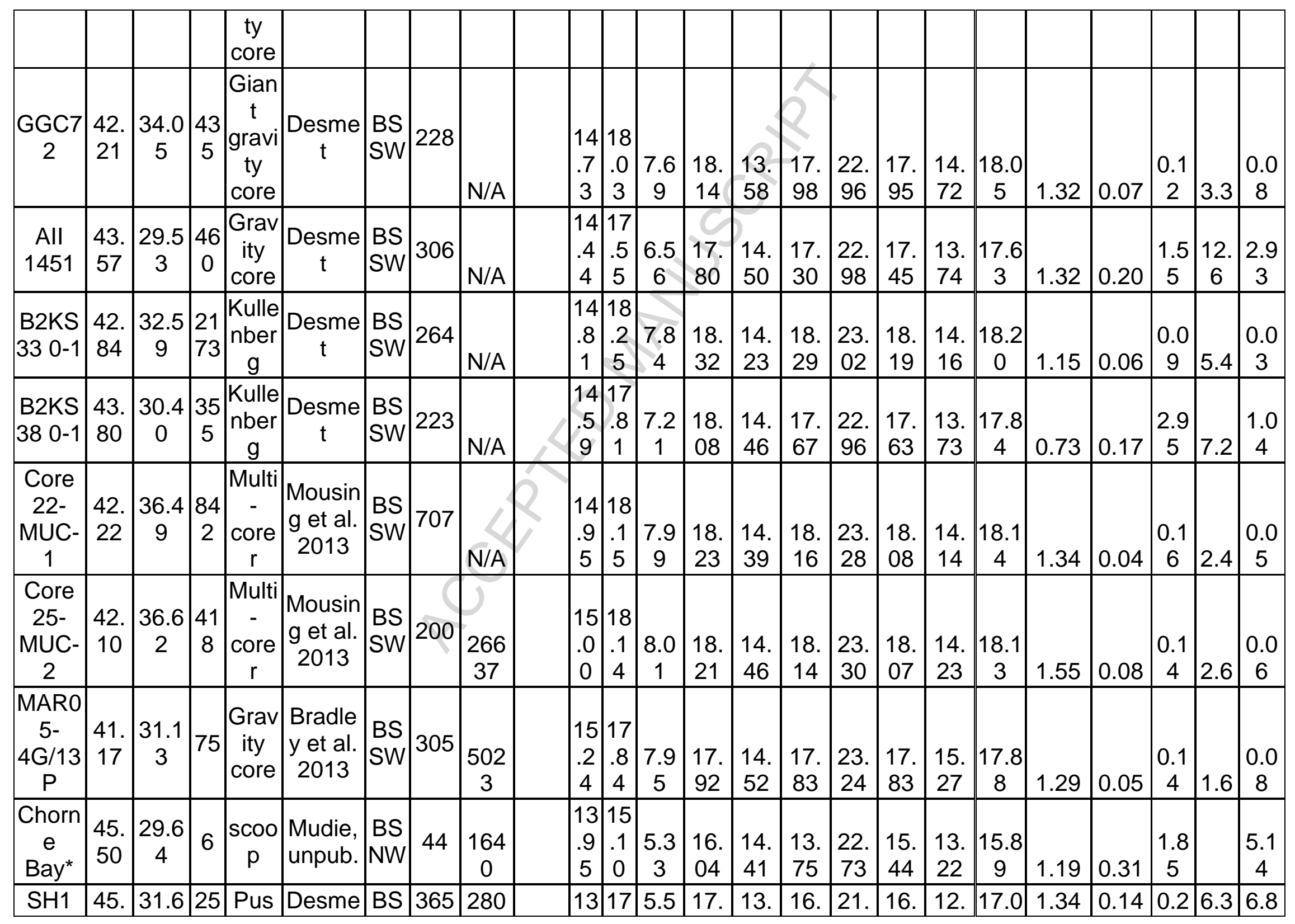




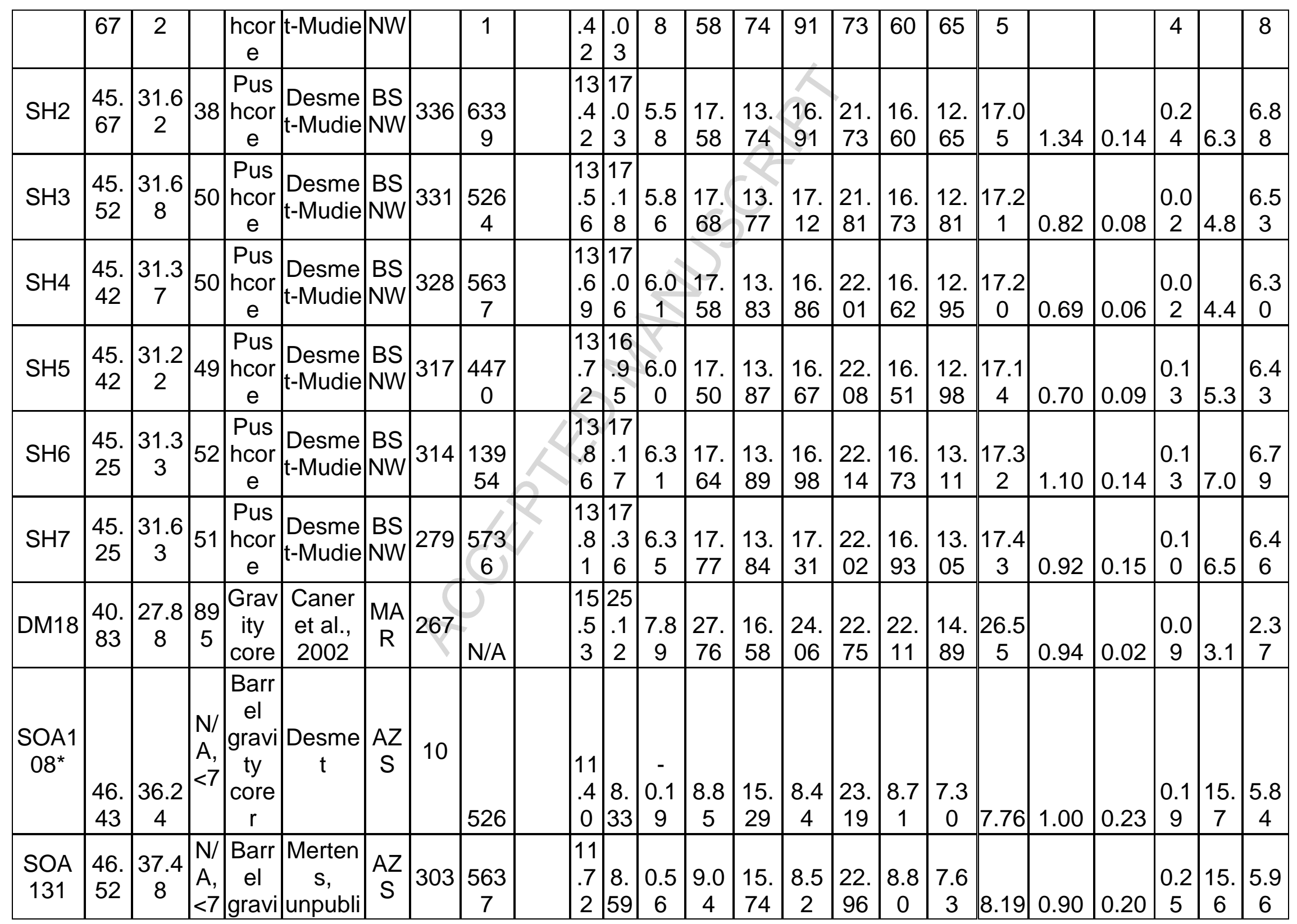




\begin{tabular}{|c|c|c|c|c|c|c|c|c|c|c|c|c|c|c|c|c|c|c|c|c|c|c|c|c|}
\hline & & & & \begin{tabular}{|c} 
ty \\
core \\
$r$
\end{tabular} & shed & & & & & & & & & & & & & & & & & & & \\
\hline $\begin{array}{c}\text { SOA } \\
48\end{array}$ & $\begin{array}{r}46 . \\
82\end{array}$ & $\begin{array}{c}37.5 \\
4\end{array}$ & $\begin{array}{l}N / \\
A, \\
<7\end{array}$ & $\begin{array}{c}\text { Barr } \\
\text { el } \\
\text { gravi } \\
\text { ty } \\
\text { core } \\
r\end{array}$ & $\begin{array}{c}\text { Merten } \\
\text { S, } \\
\text { unpubli } \\
\text { shed }\end{array}$ & $\begin{array}{c}A Z \\
S\end{array}$ & 295 & $\begin{array}{c}446 \\
9\end{array}$ & & $\begin{array}{l}11 \\
.7 \\
1\end{array}$ & $\begin{array}{l}8 . \\
92\end{array}$ & $\begin{array}{c}0.6 \\
6\end{array}$ & $\begin{array}{c}9.1 \\
8\end{array}$ & $\begin{array}{l}15 . \\
81\end{array}$ & $\begin{array}{c}8.8 \\
7\end{array}$ & $\begin{array}{l}22 . \\
77\end{array}$ & $\begin{array}{c}8.9 \\
5\end{array}$ & $\begin{array}{c}7.6 \\
2\end{array}$ & 8.61 & 0.97 & 0.22 & $\begin{array}{c}0.3 \\
0\end{array} \mid$ & $\begin{array}{c}21 . \\
0\end{array}$ & $\begin{array}{c}5.8 \\
4\end{array}$ \\
\hline $\mathrm{N} 14^{*}$ & \begin{tabular}{c|}
45. \\
34 \\
\end{tabular} & \begin{tabular}{|c}
36.4 \\
7 \\
\end{tabular} & 5 & \begin{tabular}{|c}
$\begin{array}{c}\text { Pus } \\
\text { hcor } \\
\mathrm{e}\end{array}$ \\
\end{tabular} & $\begin{array}{c}\text { Mudie, } \\
\text { unpubli } \\
\text { shed }\end{array}$ & $\begin{array}{c}A Z \\
S\end{array}$ & 23 & $\begin{array}{c}120 \\
7 \\
\end{array}$ & & \begin{tabular}{|c|}
13 \\
.8 \\
5 \\
\end{tabular} & \begin{tabular}{|c|}
15 \\
.4 \\
4 \\
\end{tabular} & $\begin{array}{c}5.7 \\
2\end{array}$ & $\begin{array}{l}0 \\
78\end{array}$ & $\begin{array}{l}14 . \\
77\end{array}$ & $\begin{array}{l}15 . \\
48\end{array}$ & $\begin{array}{l}23 . \\
12\end{array}$ & $\begin{array}{l}14 . \\
24\end{array}$ & $\begin{array}{l}11 . \\
83\end{array}$ & $\begin{array}{c}15.2 \\
3\end{array}$ & 0.66 & 0.24 & $\begin{array}{c}0.1 \\
5\end{array}$ & $\begin{array}{c}15 \\
5\end{array}$ & $\begin{array}{c}5.9 \\
5\end{array}$ \\
\hline N22* & $\begin{array}{c}45 . \\
34\end{array}$ & $\begin{array}{c}36.4 \\
7\end{array}$ & 3 & \begin{tabular}{|c} 
Pus \\
hcor \\
e
\end{tabular} & $\begin{array}{c}\text { Mudie, } \\
\text { unpubli } \\
\text { shed }\end{array}$ & $\begin{array}{c}A Z \\
S\end{array}$ & 14 & 581 & & $\begin{array}{c}13 \\
.8 \\
5\end{array}$ & \begin{tabular}{|}
15 \\
.4 \\
4
\end{tabular} & $\begin{array}{c}5.7 \\
2\end{array}$ & $\begin{array}{l}15 \\
78\end{array}$ & $\begin{array}{l}14 . \\
77\end{array}$ & $\begin{array}{l}15 . \\
48\end{array}$ & $\begin{array}{l}23 . \\
12\end{array}$ & $\begin{array}{l}14 . \\
24\end{array}$ & $\begin{array}{l}11 . \\
83\end{array}$ & $\begin{array}{c}15.2 \\
3\end{array}$ & 0.66 & 0.24 & $\begin{array}{c}0.1 \\
5\end{array}$ & $\begin{array}{c}15 . \\
5\end{array}$ & $\begin{array}{c}5.9 \\
5\end{array}$ \\
\hline $\mathrm{N} 4(\mathrm{~A})$ & $\begin{array}{l}45 . \\
34\end{array}$ & $\begin{array}{c}36.4 \\
7\end{array}$ & 4 & \begin{tabular}{|c}
$\begin{array}{c}\text { Pus } \\
\text { hcor } \\
\mathrm{e}\end{array}$ \\
\end{tabular} & $\begin{array}{l}\text { Desme } \\
\text { t-Mudie }\end{array}$ & $\begin{array}{c}A Z \\
S\end{array}$ & 97 & 390 & & \begin{tabular}{|c|}
13 \\
.8 \\
5 \\
\end{tabular} & \begin{tabular}{|c|}
15 \\
.4 \\
4 \\
\end{tabular} & \begin{tabular}{|c|}
5.7 \\
2 \\
\end{tabular} & $\begin{array}{l}15 . \\
78\end{array}$ & $\begin{array}{l}14 . \\
77\end{array}$ & $\begin{array}{l}15 . \\
48\end{array}$ & $\begin{array}{l}23 . \\
12\end{array}$ & $\begin{array}{l}14 . \\
24\end{array}$ & $\begin{array}{l}11 . \\
83\end{array}$ & $\begin{array}{c}15.2 \\
3\end{array}$ & 0.66 & 0.24 & $\begin{array}{c}0.1 \\
5\end{array}$ & $\begin{array}{c}15 \\
5\end{array}$ & $\begin{array}{c}5.9 \\
5\end{array}$ \\
\hline N18* & $\begin{array}{c}45 . \\
34\end{array}$ & $\begin{array}{c}36.4 \\
7\end{array}$ & 2 & \begin{tabular}{|c}
$\begin{array}{c}\text { Pus } \\
\text { hcor } \\
\text { e }\end{array}$ \\
\end{tabular} & $\begin{array}{l}\text { unpubli } \\
\text { shed }\end{array}$ & $\begin{array}{c}A Z \\
S\end{array}$ & 60 & 566 & & \begin{tabular}{|c|}
13 \\
.8 \\
5 \\
\end{tabular} & \begin{tabular}{|l|}
15 \\
.4 \\
4 \\
\end{tabular} & \begin{tabular}{|c|}
5.7 \\
2 \\
\end{tabular} & $\begin{array}{l}15 . \\
78 \\
\end{array}$ & $\begin{array}{l}14 . \\
77 \\
\end{array}$ & $\begin{array}{l}15 . \\
48 \\
\end{array}$ & $\begin{array}{l}23 . \\
12 \\
\end{array}$ & $\begin{array}{l}14 . \\
24\end{array}$ & $\begin{array}{l}11 . \\
83 \\
\end{array}$ & $\begin{array}{c}15.2 \\
3 \\
\end{array}$ & 0.66 & 0.24 & \begin{tabular}{|c|}
0.1 \\
5 \\
\end{tabular} & $\begin{array}{c}15 \\
5 \\
\end{array}$ & $\begin{array}{c}5.9 \\
5 \\
\end{array}$ \\
\hline US01 & $\begin{array}{l}38 . \\
73\end{array}$ & $\begin{array}{c}53.1 \\
8\end{array}$ & 13 & $\begin{array}{c}\text { Usn } \\
\text { ell }\end{array}$ & $\begin{array}{l}\text { Leroy } \\
\text { et al., } \\
2013 b\end{array}$ & $\begin{array}{l}\text { CA } \\
\text { SP }\end{array}$ & 531 & & \begin{tabular}{|c|}
143 \\
21 \\
\end{tabular} & \begin{tabular}{|l|}
17 \\
.2 \\
5 \\
\end{tabular} & \begin{tabular}{|c|}
13 \\
.2 \\
8 \\
\end{tabular} & $\begin{array}{c}9.0 \\
1\end{array}$ & $\begin{array}{l}13 . \\
26\end{array}$ & $\begin{array}{l}17 . \\
21 \\
\end{array}$ & $\begin{array}{l}13 . \\
22 \\
\end{array}$ & $\begin{array}{l}26 . \\
38\end{array}$ & $\begin{array}{l}13 . \\
34\end{array}$ & $\begin{array}{l}16 . \\
62 \\
\end{array}$ & $\mid \begin{array}{c}13.3 \\
2\end{array}$ & 0.94 & 0.16 & $\begin{array}{c}0.0 \\
5\end{array}$ & 4.5 & $\begin{array}{c}6.6 \\
8\end{array}$ \\
\hline US02 & $\begin{array}{l}39 . \\
27\end{array}$ & $\begin{array}{c}51.4 \\
8\end{array}$ & $\begin{array}{c}31 \\
5\end{array}$ & $\begin{array}{l}\text { Usn } \\
\text { ell }\end{array}$ & $\begin{array}{l}\text { Marret } \\
\text { et al., } \\
2004\end{array}$ & CA & 203 & & $\begin{array}{c}490 \\
6\end{array}$ & $\begin{array}{c}17 \\
.0 \\
9\end{array}$ & \begin{tabular}{|c|}
12 \\
.8 \\
8
\end{tabular} & $\begin{array}{c}9.7 \\
2\end{array}$ & $\begin{array}{l}12 . \\
87\end{array}$ & $\begin{array}{l}16 . \\
86\end{array}$ & $\begin{array}{l}12 . \\
85\end{array}$ & $\begin{array}{l}24 . \\
90\end{array}$ & $\begin{array}{l}12 . \\
94\end{array}$ & $\begin{array}{l}16 . \\
92\end{array}$ & $\begin{array}{c}12.9 \\
3\end{array}$ & 0.94 & 0.10 & $\begin{array}{c}0.0 \\
1\end{array}$ & 0.2 & $\begin{array}{c}2.5 \\
2\end{array}$ \\
\hline US24 & \begin{tabular}{c|}
43. \\
32 \\
\end{tabular} & \begin{tabular}{|c}
49.1 \\
0 \\
\end{tabular} & 61 & $\begin{array}{c}\text { Usn } \\
\text { ell }\end{array}$ & $\begin{array}{l}\text { Leroy } \\
\text { et al., } \\
2013 b \\
\end{array}$ & $\begin{array}{l}\text { CA } \\
\text { SP }\end{array}$ & $\begin{array}{c}200 \\
8\end{array}$ & & \begin{tabular}{|c|}
193 \\
16 \\
\end{tabular} & \begin{tabular}{|c|}
13 \\
.6 \\
1 \\
\end{tabular} & \begin{tabular}{|c|}
12 \\
.4 \\
4 \\
\end{tabular} & \begin{tabular}{|c|}
4.5 \\
6 \\
\end{tabular} & $\begin{array}{l}12 . \\
59 \\
\end{array}$ & $\begin{array}{c}14 . \\
41 \\
\end{array}$ & $\begin{array}{l}12 . \\
63 \\
\end{array}$ & $\begin{array}{l}22 . \\
94 \\
\end{array}$ & $\begin{array}{l}11 . \\
92\end{array}$ & $\begin{array}{l}12 . \\
53 \\
\end{array}$ & $\begin{array}{c}12.6 \\
2 \\
\end{array}$ & 0.94 & 0.07 & $\begin{array}{c}0.0 \\
1 \\
\end{array}$ & 3.9 & $\begin{array}{c}6.9 \\
7 \\
\end{array}$ \\
\hline US26 & \begin{tabular}{|l|}
43. \\
32
\end{tabular} & $\begin{array}{c}49.0 \\
9\end{array}$ & 61 & $\begin{array}{c}\text { Usn } \\
\text { ell }\end{array}$ & $\begin{array}{l}\text { Leroy } \\
\text { et al., }\end{array}$ & $\begin{array}{l}\text { CA } \\
\text { SP }\end{array}$ & $\begin{array}{c}311 \\
7\end{array}$ & & $\begin{array}{c}140 \\
75\end{array}$ & $\begin{array}{l}13 \\
.6\end{array}$ & $\begin{array}{c}12 \\
.4\end{array}$ & $\begin{array}{c}4.5 \\
5\end{array}$ & $\begin{array}{l}12 . \\
59\end{array}$ & $\begin{array}{l}14 . \\
42\end{array}$ & $\begin{array}{l}12 . \\
62\end{array}$ & $\begin{array}{l}22 . \\
94\end{array}$ & $\begin{array}{l}11 . \\
91\end{array}$ & $\begin{array}{l}12 . \\
53\end{array}$ & $\begin{array}{c}12.6 \\
1\end{array}$ & 0.94 & 0.07 & $\begin{array}{c}0.0 \\
1\end{array}$ & 3.9 & $\begin{array}{c}6.9 \\
7\end{array}$ \\
\hline
\end{tabular}




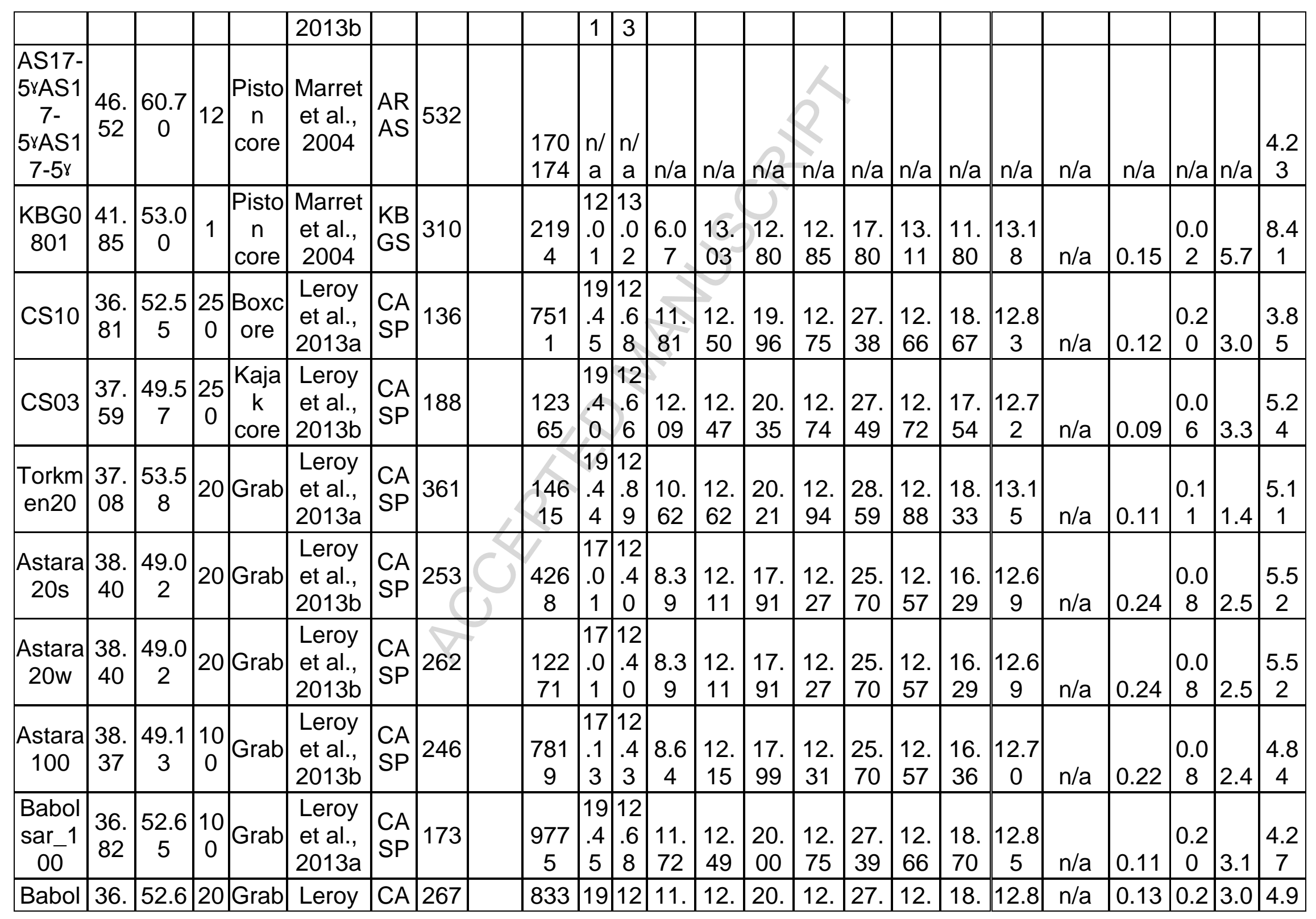









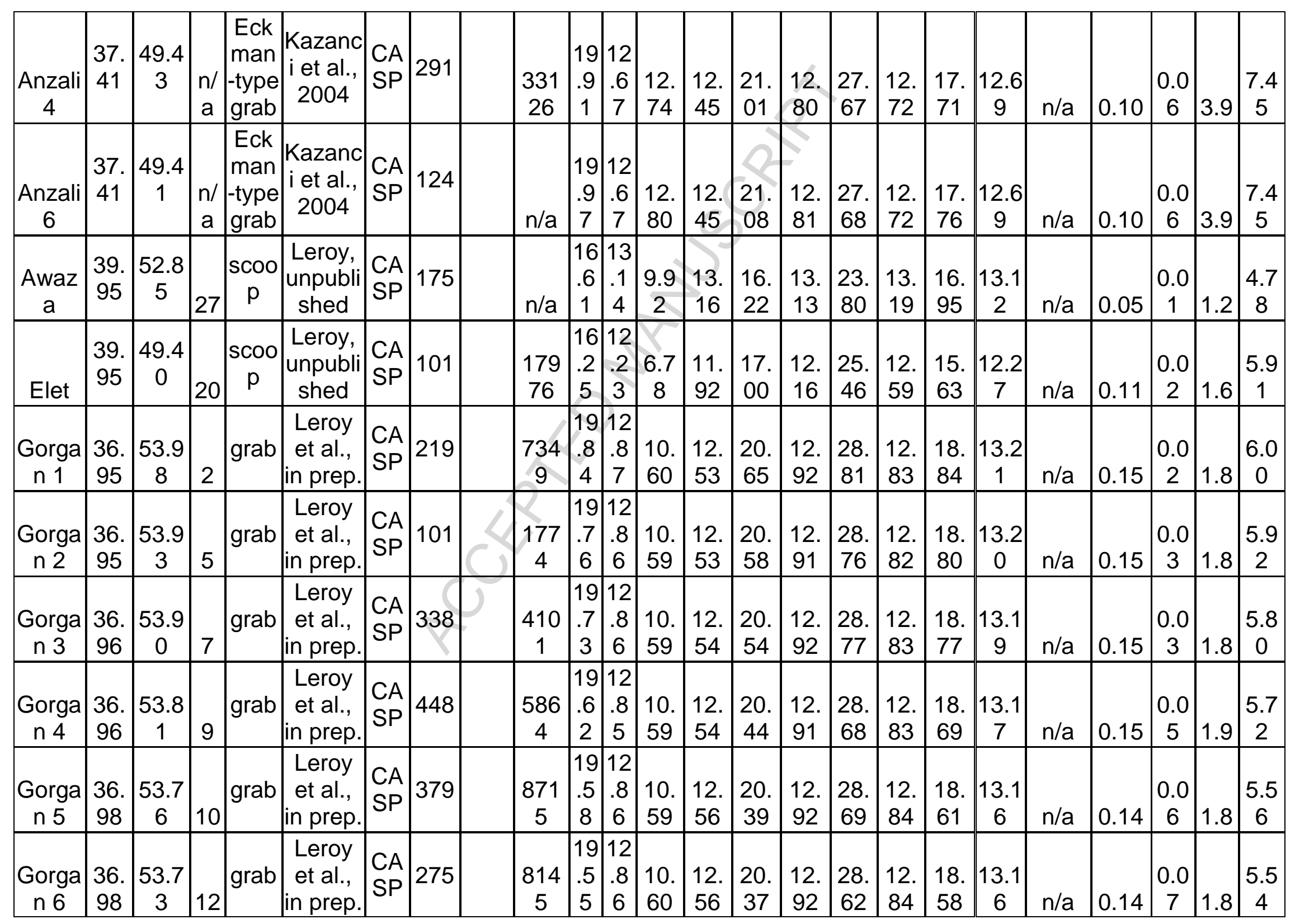




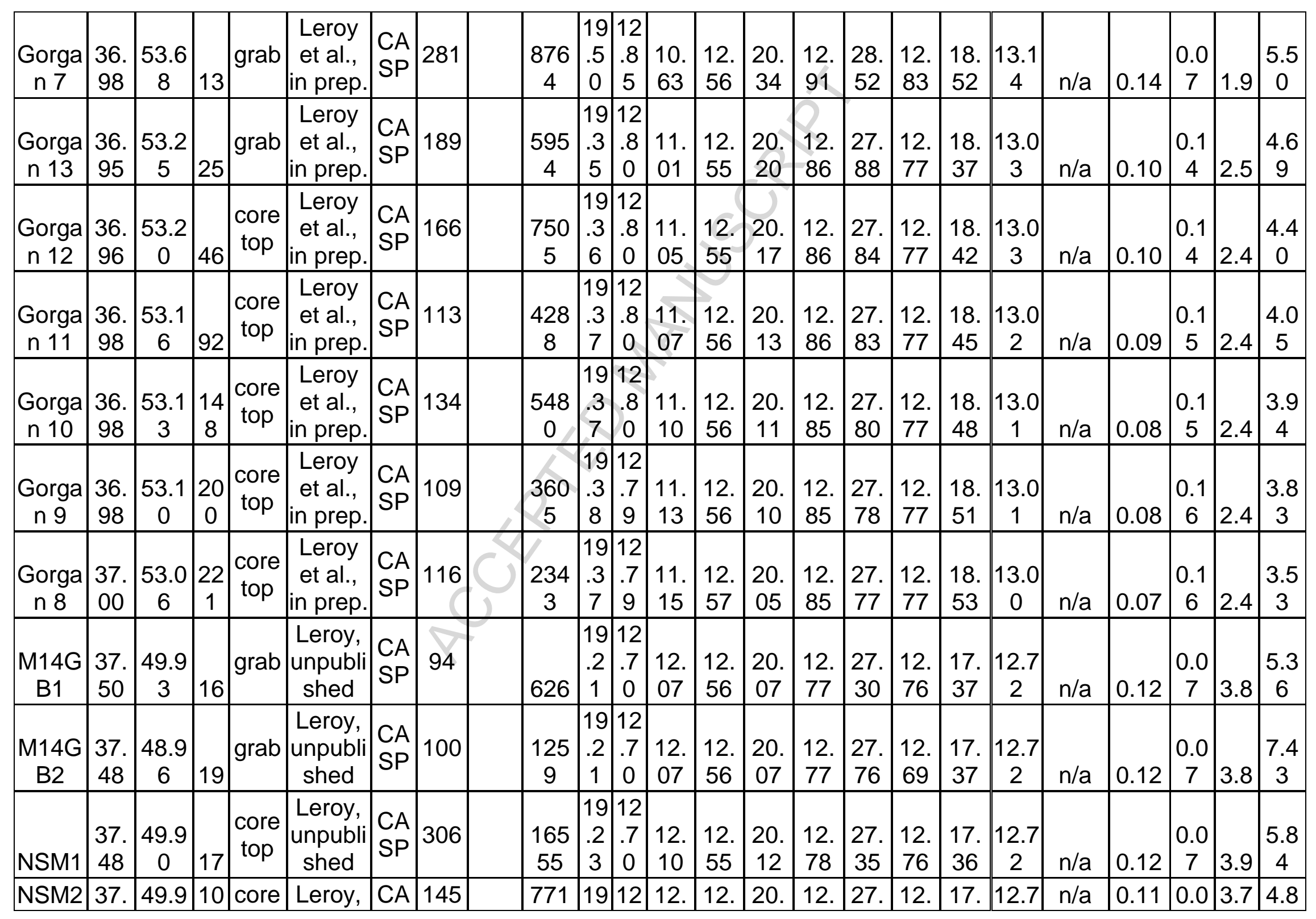




\begin{tabular}{|c|c|c|c|c|c|c|c|c|c|c|c|c|c|c|c|c|c|c|c|c|c|c|c|c|}
\hline & 53 & 0 & 5 & top & $\begin{array}{l}\text { unpubli } \\
\text { shed }\end{array}$ & SP & & & 2 & $\begin{array}{l}.1 \\
8 \\
\end{array}$ & \begin{tabular}{|l|}
7 \\
0 \\
\end{tabular} & 01 & 55 & 04 & 77 & 29 & 75 & 38 & 3 & & & 7 & & 6 \\
\hline NSM3 & $\begin{array}{l}37 . \\
55\end{array}$ & $\begin{array}{c}49.8 \\
8\end{array}$ & $\begin{array}{c}30 \\
1\end{array}$ & $\begin{array}{c}\text { core } \\
\text { top }\end{array}$ & $\begin{array}{l}\text { Leroy, } \\
\text { unpubli } \\
\text { shed }\end{array}$ & $\begin{array}{l}\text { CA } \\
\text { SP }\end{array}$ & 131 & & $\begin{array}{c}238 \\
91\end{array}$ & \begin{tabular}{c|}
19 \\
.1 \\
6
\end{tabular} & \begin{tabular}{|c|}
12 \\
.7 \\
0 \\
\end{tabular} & $\begin{array}{l}11 . \\
97\end{array}$ & $\begin{array}{l}12 . \\
55\end{array}$ & $\begin{array}{l}20 . \\
02\end{array}$ & $\begin{array}{l}12 . \\
76\end{array}$ & $\begin{array}{l}27 . \\
28\end{array}$ & $\begin{array}{l}12 . \\
75\end{array}$ & $\begin{array}{l}17 . \\
38\end{array}$ & $\begin{array}{c}12.7 \\
3\end{array}$ & $\mathrm{n} / \mathrm{a}$ & 0.11 & $\begin{array}{c}0.0 \\
6\end{array}$ & 3.7 & $\begin{array}{c}4.5 \\
3\end{array}$ \\
\hline NSM4 & $\begin{array}{l}37 . \\
56 \\
\end{array}$ & $\begin{array}{c}49.8 \\
8 \\
\end{array}$ & $\begin{array}{c}43 \\
1 \\
\end{array}$ & $\begin{array}{c}\text { core } \\
\text { top }\end{array}$ & $\begin{array}{l}\text { Leroy, } \\
\text { unpubli } \\
\text { shed }\end{array}$ & $\begin{array}{l}\text { CA } \\
\text { SP }\end{array}$ & 119 & & $\begin{array}{c}228 \\
5 \\
\end{array}$ & \begin{tabular}{|c|}
19 \\
.1 \\
5 \\
\end{tabular} & \begin{tabular}{|c|}
12 \\
.7 \\
0 \\
\end{tabular} & $\begin{array}{l}11 . \\
95\end{array}$ & $\begin{array}{l}12 . \\
55 \\
\end{array}$ & $\begin{array}{c}20 . \\
01 \\
\end{array}$ & $\begin{array}{l}12 . \\
76\end{array}$ & $\begin{array}{l}27 . \\
27 \\
\end{array}$ & $\begin{array}{l}12 . \\
74\end{array}$ & $\begin{array}{l}17 . \\
39 \\
\end{array}$ & $\begin{array}{c}12.7 \\
3\end{array}$ & $\mathrm{n} / \mathrm{a}$ & 0.10 & $\begin{array}{c}0.0 \\
6 \\
\end{array}$ & 3.6 & $\begin{array}{c}4.3 \\
6\end{array}$ \\
\hline NSM5 & $\begin{array}{l}37 . \\
58\end{array}$ & $\begin{array}{c}49.8 \\
8\end{array}$ & $\begin{array}{c}47 \\
0\end{array}$ & $\begin{array}{c}\text { core } \\
\text { top }\end{array}$ & $\begin{array}{l}\text { Leroy, } \\
\text { unpubli } \\
\text { shed }\end{array}$ & $\begin{array}{l}\text { CA } \\
\text { SP }\end{array}$ & 182 & & $\begin{array}{c}105 \\
98\end{array}$ & \begin{tabular}{|l|}
19 \\
.1 \\
3 \\
\end{tabular} & \begin{tabular}{|c|}
12 \\
.7 \\
0 \\
\end{tabular} & $\begin{array}{l}11 . \\
91\end{array}$ & $\begin{array}{l}12 . \\
55\end{array}$ & $\begin{array}{l}19 . \\
98\end{array}$ & $\begin{array}{l}12 . \\
75\end{array}$ & $\begin{array}{l}27 . \\
25\end{array}$ & $\begin{array}{l}12 . \\
74\end{array}$ & $\begin{array}{l}17 . \\
39\end{array}$ & $\begin{array}{c}12.7 \\
3\end{array}$ & $\mathrm{n} / \mathrm{a}$ & 0.10 & $\begin{array}{c}0.0 \\
6\end{array}$ & 3.5 & $\begin{array}{c}4.0 \\
4\end{array}$ \\
\hline $\begin{array}{c}\mathrm{CH}_{2} / 1 \\
\gamma\end{array}$ & $\begin{array}{l}45 . \\
96\end{array}$ & $\begin{array}{c}59.2 \\
3\end{array}$ & 22 & $\begin{array}{l}\text { core } \\
\text { top }\end{array}$ & $\begin{array}{l}\text { Sorrel } \\
\text { et al., } \\
2006\end{array}$ & $\begin{array}{l}A R \\
A S\end{array}$ & 100 & $\begin{array}{c}100 \\
0\end{array}$ & & $\begin{array}{l}n \\
\mathrm{a}\end{array}$ & $\begin{array}{l}n / \\
a\end{array}$ & $n / a$ & $n / a$ & $n / a$ & n/a & $n / a$ & $\mathrm{n} / \mathrm{a}$ & $n / a$ & $\mathrm{n} / \mathrm{a}$ & $\mathrm{n} / \mathrm{a}$ & $\mathrm{n} / \mathrm{a}$ & $n / a$ & $\mathrm{n} / \mathrm{a}$ & $\begin{array}{c}2.2 \\
5\end{array}$ \\
\hline $\begin{array}{l}\text { AS- } \\
\text { salty }\end{array}$ & $\begin{array}{l}45 . \\
03 \\
\end{array}$ & $\begin{array}{c}58.5 \\
8 \\
\end{array}$ & 2 & $\begin{array}{c}\text { scoo } \\
\text { ped } \\
\text { by } \\
\text { divin } \\
g \\
\end{array}$ & $\begin{array}{l}\text { Leroy, } \\
\text { unpubli } \\
\text { shed }\end{array}$ & $\begin{array}{l}\text { AR } \\
\text { AS }\end{array}$ & 147 & & 198 & $\begin{array}{l}\mathrm{n} / \\
\mathrm{a}\end{array}$ & $\begin{array}{l}n / \\
a\end{array}$ & $n / a$ & $n / a$ & $n / a$ & n/a & $n / a$ & $\mathrm{n} / \mathrm{a}$ & $n / a$ & $\mathrm{n} / \mathrm{a}$ & $\mathrm{n} / \mathrm{a}$ & $\mathrm{n} / \mathrm{a}$ & $n / a$ & $\mathrm{n} / \mathrm{a}$ & $\begin{array}{c}4.1 \\
0\end{array}$ \\
\hline DO9* & $\begin{array}{l}46 . \\
42 \\
\end{array}$ & \begin{tabular}{|c}
48.7 \\
1 \\
\end{tabular} & 0 & $\begin{array}{c}\text { core } \\
\text { top }\end{array}$ & $\begin{array}{c}\text { Richar } \\
\text { ds et } \\
\text { al.,201 } \\
4 \\
\end{array}$ & $\begin{array}{l}\text { CA } \\
\text { SP }\end{array}$ & 9 & $n / a$ & $\mathrm{n} / \mathrm{a}$ & $\begin{array}{l}11 \\
.7 \\
6 \\
\end{array}$ & $\begin{array}{r}6 . \\
35 \\
\end{array}$ & $\begin{array}{c}- \\
0.0 \\
8\end{array}$ & \begin{tabular}{|c}
7.8 \\
3 \\
\end{tabular} & $\begin{array}{l}18 . \\
03 \\
\end{array}$ & $\begin{array}{c}5.4 \\
6 \\
\end{array}$ & \begin{tabular}{r|}
25. \\
18 \\
\end{tabular} & $\begin{array}{c}5.9 \\
4 \\
\end{array}$ & $\begin{array}{c}4.1 \\
8 \\
\end{array}$ & 6.16 & $\mathrm{n} / \mathrm{a}$ & 0.23 & $\begin{array}{c}0.0 \\
5 \\
\end{array}$ & $\begin{array}{c}15 . \\
2 \\
\end{array}$ & $\begin{array}{c}3.9 \\
3 \\
\end{array}$ \\
\hline$\underset{*}{\text { AVD2 }}$ & $\begin{array}{l}45 . \\
81\end{array}$ & $\begin{array}{c}47.6 \\
9 \\
\end{array}$ & 0 & $\begin{array}{c}0-20 \\
\mathrm{~cm}\end{array}$ & $\begin{array}{c}\text { Richar } \\
\text { ds et } \\
\text { al.,201 } \\
4\end{array}$ & $\begin{array}{l}\text { CA } \\
\text { SP }\end{array}$ & 7 & $n / a$ & $\mathrm{n} / \mathrm{a}$ & $\begin{array}{r}13 \\
.7 \\
3 \\
\end{array}$ & \begin{tabular}{|l}
6. \\
34 \\
\end{tabular} & \begin{tabular}{|c}
1.5 \\
0 \\
\end{tabular} & $\begin{array}{c}7.4 \\
4\end{array}$ & $\begin{array}{l}18 . \\
34\end{array}$ & $\begin{array}{c}5.6 \\
5\end{array}$ & $\begin{array}{c}27 . \\
09\end{array}$ & $\begin{array}{c}6.2 \\
3\end{array}$ & $\begin{array}{l}10 . \\
80\end{array}$ & 6.00 & $\mathrm{n} / \mathrm{a}$ & 0.21 & $\begin{array}{c}0.0 \\
9\end{array}$ & $\begin{array}{c}23 . \\
6\end{array}$ & $\begin{array}{c}6.0 \\
0\end{array}$ \\
\hline $\begin{array}{c}\text { Caspi } \\
\text { an } \\
\mathrm{M}^{*}\end{array}$ & $\begin{array}{l}37 . \\
51\end{array}$ & $\begin{array}{c}49.9 \\
1\end{array}$ & 25 & $\begin{array}{c}\text { Van } \\
\text { Vee } \\
\text { n } \\
\text { grab } \\
\text { surfa }\end{array}$ & $\begin{array}{c}\text { Merten } \\
\text { s et al., } \\
2015\end{array}$ & $\begin{array}{l}\text { CA } \\
\text { SP }\end{array}$ & $\mathrm{n} / \mathrm{a}$ & $\mathrm{n} / \mathrm{a}$ & $\mathrm{n} / \mathrm{a}$ & $\begin{array}{c}19 \\
.2 \\
0\end{array}$ & \begin{tabular}{|c|}
12 \\
.7 \\
0 \\
\end{tabular} & $\begin{array}{l}12 . \\
05\end{array}$ & $\begin{array}{l}12 . \\
55\end{array}$ & $\begin{array}{l}20 . \\
07\end{array}$ & $\begin{array}{l}12 . \\
77 \\
\end{array}$ & $\begin{array}{l}27 . \\
31\end{array}$ & $\begin{array}{l}12 . \\
75\end{array}$ & $\begin{array}{l}17 . \\
37\end{array}$ & $\begin{array}{c}12.7 \\
2\end{array}$ & $\mathrm{n} / \mathrm{a}$ & 0.11 & $\begin{array}{c}0.0 \\
7\end{array}$ & 3.8 & $\begin{array}{c}5.2 \\
2\end{array}$ \\
\hline
\end{tabular}




\begin{tabular}{|c|c|c|c|c|c|c|c|c|c|c|c|c|c|c|c|c|c|c|c|c|c|c|c|c|}
\hline & & & & $\mathrm{ce}$ & & & & & & & & & & & & & & & & & & & & \\
\hline $\begin{array}{c}\text { Caspi } \\
\text { an } \\
\times 37^{*}\end{array}$ & $\begin{array}{l}37 . \\
55\end{array}$ & $\begin{array}{c}49.4 \\
8\end{array}$ & 35 & $\begin{array}{c}\text { Van } \\
\text { Vee } \\
n \\
\text { grab } \\
\text { surfa } \\
\text { ce }\end{array}$ & $\begin{array}{c}\text { Merten } \\
\text { s et al., } \\
2015\end{array}$ & $\begin{array}{l}\text { CA } \\
\text { SP }\end{array}$ & $n / a$ & $\mathrm{n} / \mathrm{a}$ & $\mathrm{n} / \mathrm{a}$ & $\begin{array}{c}19 \\
.6 \\
3 \\
\end{array}$ & $\begin{array}{l}12 \\
6 \\
6 \\
\end{array}$ & \begin{tabular}{|l}
12. \\
35
\end{tabular} & $\begin{array}{l}12 . \\
46\end{array}$ & $\begin{array}{l}20 . \\
65\end{array}$ & $\begin{array}{l}12 . \\
76\end{array}$ & $\begin{array}{l}27 . \\
62\end{array}$ & $\begin{array}{c}12 . \\
71\end{array}$ & $\begin{array}{l}17 . \\
66\end{array}$ & $\begin{array}{c}12.7 \\
1\end{array}$ & $\mathrm{n} / \mathrm{a}$ & 0.09 & $\begin{array}{c}0.0 \\
6\end{array}$ & 3.4 & $\begin{array}{c}6.0 \\
5\end{array}$ \\
\hline $\begin{array}{c}\text { Caspi } \\
\text { an } \\
25 m^{*}\end{array}$ & $\begin{array}{l}37 . \\
51\end{array}$ & $\begin{array}{c}49.4 \\
8 \\
\end{array}$ & 25 & \begin{tabular}{|c} 
Van \\
Vee \\
$\mathrm{n}$ \\
grab \\
surfa \\
ce \\
\end{tabular} & $\begin{array}{c}\text { Merten } \\
\text { s et al., } \\
2015\end{array}$ & $\begin{array}{l}\text { CA } \\
\text { SP }\end{array}$ & $\mathrm{n} / \mathrm{a}$ & $\mathrm{n} / \mathrm{a}$ & $\mathrm{n} / \mathrm{a}$ & \begin{tabular}{|c|}
19 \\
.6 \\
7 \\
\end{tabular} & $\begin{array}{c}12 \\
.6 \\
6 \\
\end{array}$ & $\begin{array}{l}12 . \\
42 \\
\end{array}$ & $\begin{array}{l}12 . \\
46 \\
\end{array}$ & $\begin{array}{l}20 . \\
70\end{array}$ & $\begin{array}{l}12 . \\
77 \\
\end{array}$ & $\begin{array}{l}27 . \\
63 \\
\end{array}$ & $\begin{array}{l}12 . \\
72 \\
\end{array}$ & $\begin{array}{l}17 . \\
65 \\
\end{array}$ & $\begin{array}{c}12.7 \\
1 \\
\end{array}$ & $\mathrm{n} / \mathrm{a}$ & 0.09 & $\begin{array}{c}0.0 \\
6\end{array}$ & 3.6 & $\begin{array}{c}6.4 \\
5\end{array}$ \\
\hline $\begin{array}{c}\text { Caspi } \\
\text { an } \\
35 m^{*}\end{array}$ & $\begin{array}{l}37 . \\
56 \\
\end{array}$ & $\begin{array}{c}49.5 \\
0 \\
\end{array}$ & 35 & \begin{tabular}{|c} 
Van \\
Vee \\
$n$ \\
grab \\
surfa \\
ce \\
\end{tabular} & $\begin{array}{c}\text { Merten } \\
\text { s et al., } \\
2015\end{array}$ & $\begin{array}{l}\text { CA } \\
\text { SP }\end{array}$ & $\mathrm{n} / \mathrm{a}$ & $\mathrm{n} / \mathrm{a}$ & $\mathrm{n} / \mathrm{a}$ & $\begin{array}{c}19 \\
.5 \\
7 \\
\end{array}$ & $\begin{array}{c}12 \\
.6 \\
6 \\
\end{array}$ & $\begin{array}{l}12 . \\
28 \\
\end{array}$ & $\begin{array}{l}12 . \\
46 \\
\end{array}$ & $\begin{array}{l}20 . \\
57 \\
\end{array}$ & $\begin{array}{l}12 . \\
75 \\
\end{array}$ & $\begin{array}{l}27 . \\
59 \\
\end{array}$ & $\begin{array}{c}12 . \\
71 \\
\end{array}$ & $\begin{array}{l}17 . \\
63 \\
\end{array}$ & $\begin{array}{c}12.7 \\
2\end{array}$ & $\mathrm{n} / \mathrm{a}$ & 0.09 & $\begin{array}{c}0.0 \\
6 \\
\end{array}$ & 3.4 & $\begin{array}{c}5.8 \\
8 \\
\end{array}$ \\
\hline$\underset{*}{\mathrm{DM}}$ & $\begin{array}{l}40 . \\
76\end{array}$ & $\begin{array}{c}27.7 \\
5\end{array}$ & $\begin{array}{c}70 \\
9\end{array}$ & $\begin{array}{c}\text { Grav } \\
\text { ity } \\
\text { core }\end{array}$ & $\begin{array}{c}\text { Cagatay } \\
\text { et al., } \\
2000\end{array}$ & $\begin{array}{c}\text { MA } \\
\mathrm{R}\end{array}$ & n/a & $\mathrm{n} / \mathrm{a}$ & $\mathrm{n} / \mathrm{a}$ & $\begin{array}{c}n \\
a\end{array}$ & $\begin{array}{c}n / \\
a\end{array}$ & n/a & $n / a$ & $\mathrm{n} / \mathrm{a}$ & $\mathrm{n} / \mathrm{a}$ & $n / a$ & $n / a$ & $n / a$ & $\mathrm{n} / \mathrm{a}$ & $\mathrm{n} / \mathrm{a}$ & $\mathrm{n} / \mathrm{a}$ & n/a & $n / a$ & n/a \\
\hline
\end{tabular}

Table 4. Locations, water depths, type of sampler used to recover the surface layer (0-1 or 0-2 cm depth) of sediments from samples in the BSC study region, and names of authors responsible for counts. ${ }^{8}$ samples not retained for statistical analysis due to incomplete/

lack of abiotic parameters. * samples not retained for statistical analysis due to cyst sum $<80$. Red font Holocene cores 
422

Table 5

\begin{tabular}{|c|c|c|c|c|c|c|c|c|c|c|c|c|c|c|}
\hline & $\begin{array}{c}\text { SS } \\
\mathrm{T} \\
\text { Annua } \\
1\end{array}$ & $\begin{array}{c}\text { SSS } \\
\text { Annua } \\
1\end{array}$ & $\begin{array}{r}\text { SS } \\
\text { TJFM }\end{array}$ & $\begin{array}{c}\text { SSS } \\
\text { JFM }\end{array}$ & $\begin{array}{r}\text { SS } \\
\text { TAMJ }\end{array}$ & $\begin{array}{l}\text { SSS } \\
\text { AMJ }\end{array}$ & $\begin{array}{r}\text { SS } \\
\text { TJAS }\end{array}$ & $\begin{array}{r}\text { SSS } \\
\text { JAS }\end{array}$ & $\begin{array}{r}\text { SS } \\
\text { TOND }\end{array}$ & $\begin{array}{c}\text { SSS } \\
\text { OND }\end{array}$ & $\begin{array}{c}\text { Phos } \\
\text { phate } \\
{[\mu \mathrm{mol} / \mathrm{l}]}\end{array}$ & $\begin{array}{l}\text { Nitr } \\
\text { ate } \\
{[\mu \mathrm{mol} /} \\
1]\end{array}$ & $\begin{array}{c}\text { Sili } \\
\text { cate } \\
{[\mu \mathrm{mol} /} \\
1]\end{array}$ & $\begin{array}{c}\text { Bot } \\
\text { tom } \\
\text { Oxyge } \\
\mathrm{n} \\
{[\mathrm{ml} / \mathrm{l}]}\end{array}$ \\
\hline SSSY & $\begin{array}{r}- \\
0.28\end{array}$ & & & & & & & & & & & & & \\
\hline SSTJFM & $\begin{array}{l}0.9 \\
3\end{array}$ & $\begin{array}{r}- \\
0.06\end{array}$ & & & & & & & & & & & & \\
\hline SSSJFM & $\begin{array}{r}- \\
0.31\end{array}$ & $\begin{array}{l}0.9 \\
9\end{array}$ & $\begin{array}{r}- \\
0.11\end{array}$ & & & & & & & & & & & \\
\hline SSTAMJ & $\begin{array}{l}0.9 \\
4\end{array}$ & $\begin{array}{r}- \\
0.43\end{array}$ & $\begin{array}{l}0.7 \\
7\end{array}$ & $\begin{array}{r}- \\
0.43\end{array}$ & & & & & & & & & & \\
\hline SSSAMJ & $\begin{array}{r}- \\
0.26\end{array}$ & $\begin{array}{l}1.0 \\
0\end{array}$ & $\begin{array}{r}- \\
0.03\end{array}$ & $\begin{array}{l}0.9 \\
8\end{array}$ & $\begin{array}{r}- \\
\\
0.41\end{array}$ & & & & & & & & & \\
\hline SSTJAS & $\begin{array}{l}0.9 \\
3\end{array}$ & $\begin{array}{r}- \\
0.52\end{array}$ & $\begin{array}{l}0.7 \\
4\end{array}$ & $\begin{array}{r}- \\
0.54\end{array}$ & $\begin{array}{l}0.9 \\
6\end{array}$ & $\begin{array}{r}- \\
0.51\end{array}$ & & & & & & & & \\
\hline SSSJAS & $\begin{array}{r}- \\
0.30\end{array}$ & $\begin{array}{l}0.9 \\
9\end{array}$ & $\begin{array}{r}- \\
0.06\end{array}$ & $\begin{array}{l}0.9 \\
7\end{array}$ & $\begin{array}{r}- \\
0.47\end{array}$ & $\begin{array}{l}0.9 \\
9\end{array}$ & $\begin{array}{r}- \\
0.55\end{array}$ & & & & & & & \\
\hline SSTOND & $\begin{array}{l}0.9 \\
4\end{array}$ & $\begin{array}{r}- \\
0.06\end{array}$ & $\begin{array}{l}0.9 \\
3\end{array}$ & $\begin{array}{r}- \\
0.10\end{array}$ & $\begin{array}{l}0.7 \\
8\end{array}$ & $\begin{array}{r}- \\
0.04\end{array}$ & $\begin{array}{l}0.7 \\
9\end{array}$ & $\begin{array}{r}- \\
0.07\end{array}$ & & & & & & \\
\hline
\end{tabular}


423

\begin{tabular}{|c|c|c|c|c|c|c|c|c|c|c|c|c|c|c|}
\hline SSSOND & $\begin{array}{r}- \\
0.26\end{array}$ & $\begin{array}{l}1.0 \\
0\end{array}$ & $\begin{array}{r}- \\
0.05\end{array}$ & $\begin{array}{l}1.0 \\
0\end{array}$ & $\begin{array}{r}- \\
0.40\end{array}$ & $\begin{array}{l}0.9 \\
9\end{array}$ & $\begin{array}{r}- \\
0.51\end{array}$ & $\begin{array}{l}0.9 \\
8\end{array}$ & $\begin{array}{r}- \\
0.05\end{array}$ & & & & & \\
\hline $\begin{array}{l}\text { Phosphate } \\
{[\mu \mathrm{mol} / 1]}\end{array}$ & $\begin{array}{r}- \\
0.32\end{array}$ & $\begin{array}{r}- \\
0.24\end{array}$ & $\begin{array}{r}- \\
0.45\end{array}$ & $\begin{array}{r}- \\
0.21\end{array}$ & $\begin{array}{r}- \\
0.21\end{array}$ & $\begin{array}{r}- \\
0.29\end{array}$ & $\begin{array}{r}- \\
0.17\end{array}$ & 0.25 & $\begin{array}{r}- \\
0.37\end{array}$ & $\begin{array}{r}- \\
0.23\end{array}$ & & & & \\
\hline $\begin{array}{c}\text { Nitrate } \\
{[\mu \mathrm{mol} / \mathrm{l}]}\end{array}$ & $\begin{array}{r}- \\
0.36\end{array}$ & $\begin{array}{l}0.0 \\
7\end{array}$ & $\begin{array}{r}- \\
0.36\end{array}$ & $\begin{array}{l}0.1 \\
0\end{array}$ & $\begin{array}{r}- \\
0.37\end{array}$ & $\begin{array}{l}0.0 \\
2\end{array}$ & $\begin{array}{r}- \\
0.33\end{array}$ & $\begin{array}{l}0.0 \\
9\end{array}$ & $\begin{array}{r}- \\
0.29\end{array}$ & $\begin{array}{l}0.1 \\
0\end{array}$ & 0.67 & & & \\
\hline $\begin{array}{l}\text { Silicate } \\
{[\mu \mathrm{mol} / 1]}\end{array}$ & $\begin{array}{r}- \\
0.40\end{array}$ & $\begin{array}{l}0.2 \\
8\end{array}$ & $\begin{array}{r}- \\
\\
0.46\end{array}$ & $\begin{array}{l}0.3 \\
2\end{array}$ & $\begin{array}{r}- \\
0.24\end{array}$ & $\begin{array}{l}0.2 \\
5\end{array}$ & 0.32 & $\begin{array}{l}0.2 \\
2\end{array}$ & $\begin{array}{r}- \\
\\
0.44\end{array}$ & $\begin{array}{l}0.2 \\
8\end{array}$ & 0.41 & $\begin{array}{l}0.3 \\
5\end{array}$ & & \\
\hline $\begin{array}{c}\text { Bottom } \\
\text { Oxygen }[\mathrm{ml} / \mathrm{l}]\end{array}$ & $\begin{array}{l}0.2 \\
3\end{array}$ & $\begin{array}{r}- \\
0.45\end{array}$ & $\begin{array}{l}0.0 \\
7\end{array}$ & $\begin{array}{r}- \\
0.43\end{array}$ & $\begin{array}{l}0.3 \\
4\end{array}$ & 0.47 & $\begin{array}{l}0.3 \\
1\end{array}$ & $\begin{array}{r}- \\
0.49\end{array}$ & $\begin{array}{l}0.1 \\
3\end{array}$ & $\begin{array}{r}- \\
0.43\end{array}$ & 0.34 & $\begin{array}{l}0.1 \\
7\end{array}$ & $\begin{array}{l}0.1 \\
4\end{array}$ & \\
\hline $\begin{array}{l}\text { Species } \\
\text { diversity }\end{array}$ & $\begin{array}{r}- \\
0.69\end{array}$ & $\begin{array}{l}0.6 \\
0\end{array}$ & $\begin{array}{r}- \\
0.56\end{array}$ & $\begin{array}{r}- \\
0.71\end{array}$ & $\begin{array}{l}0.5 \\
7\end{array}$ & $\begin{array}{l}0.6 \\
5\end{array}$ & $\begin{array}{r}- \\
0.73\end{array}$ & $\begin{array}{r}- \\
0.62\end{array}$ & $\begin{array}{r}- \\
0.62\end{array}$ & $\begin{array}{l}0.5 \\
6\end{array}$ & 0.16 & $\begin{array}{l}0.3 \\
7\end{array}$ & $\begin{array}{l}0.3 \\
7\end{array}$ & $\begin{array}{r}- \\
0.35\end{array}$ \\
\hline Richness & $\begin{array}{r}- \\
0.68\end{array}$ & $\begin{array}{l}0.6 \\
2\end{array}$ & $\begin{array}{r}- \\
0.55\end{array}$ & $\begin{array}{r}- \\
0.71\end{array}$ & & $\begin{array}{l}0.6 \\
8\end{array}$ & $\begin{array}{r}- \\
0.72\end{array}$ & $\begin{array}{r}- \\
0.61\end{array}$ & $\begin{array}{l}0.6 \\
2\end{array}$ & $\begin{array}{l}0.6 \\
0\end{array}$ & 0.18 & $\begin{array}{l}0.3 \\
9\end{array}$ & $\begin{array}{l}0.4 \\
1\end{array}$ & $\begin{array}{r}- \\
0.35\end{array}$ \\
\hline Evenness & $\begin{array}{r}- \\
0.19\end{array}$ & $\begin{array}{l}0.2 \\
7\end{array}$ & $\begin{array}{r}- \\
0.08\end{array}$ & $\begin{array}{r}- \\
0.26\end{array}$ & $\begin{array}{l}0.2 \\
6\end{array}$ & $\begin{array}{l}0.2 \\
9\end{array}$ & $\begin{array}{l}0.2 \\
0\end{array}$ & $\begin{array}{r}- \\
0.21\end{array}$ & $\begin{array}{l}0.2 \\
9\end{array}$ & $\begin{array}{l}0.2 \\
6\end{array}$ & 0.05 & $\begin{array}{c}- \\
0.004\end{array}$ & $\begin{array}{l}0.1 \\
6\end{array}$ & $\begin{array}{r}- \\
0.34\end{array}$ \\
\hline
\end{tabular}


Table 6: PCA eigenvalues for the 14 abiotic parameters (181 sites)

\begin{tabular}{|c|c|c|}
\hline Variables & PC1 axis & PC2 axis \\
\hline SSTY & -0.114 & $\mathbf{0 . 3 5 4}$ \\
\hline SSTJFM & -0.067 & 0.205 \\
\hline SSTAMJ & -0.155 & 0.181 \\
\hline SSTJAS & -0.163 & 0.346 \\
\hline SSTOND & -0.067 & 0.143 \\
\hline SSSY & 0.414 & 0.123 \\
\hline SSSJFM & $\mathbf{0 . 4 6 0}$ & 0.163 \\
\hline SSSAMJ & 0.404 & 0.138 \\
\hline SSSJAS & 0.356 & 0.153 \\
\hline SSSOND & 0.429 & -0.007 \\
\hline$[P]$ & -0.001 & -0.079 \\
\hline$[$ N $]$ & 0.019 & $\mathbf{- 0 . 6 9 5}$ \\
\hline$\left[\right.$ Sot. $\left.{ }_{2}\right]$ & 0.240 & -0.105 \\
\hline
\end{tabular}


Table 7. Non-indigenous (NIS) dinoflagellate species with cysts in surface sediments of the western BSC, showing associated regional and local surface water salinities, possible origin and general biogeography. * indicates species of Paavola et al. (2005) with unconfirmed cyst occurrences. Cosmop = cosmopolitan; temp = temperate; s.trop $=$ subtropical; $c=$ cyst stage; $m=$ motile stage .

\begin{tabular}{|c|c|c|c|c|}
\hline \multirow[t]{2}{*}{ Motile Species } & \multicolumn{2}{|c|}{ Salinity (psu) } & \multirow[t]{2}{*}{ Origin } & \multirow[t]{2}{*}{ Biogeography } \\
\hline & BSC & World & & \\
\hline Alexandrium monilatum* & $10-18$ & $30-40$ & antic & op \\
\hline Gymnodinium uberrimum* & $15-18$ & $0-0.5$ & nop. & tem \\
\hline Alexandrium pseudogonyaulax & $17.6(\mathrm{c}), 13-14(\mathrm{~m})$ & $15-38$ & Cosmopolitan & cool \\
\hline Alexandrium spp. & $8.6-31.1$ & $23.6-24$ & N. Hem., Aus. & s.pol-s.trop \\
\hline Barrufeta resplendens & $18.14-18.27(6)$ & $11-34$ & Atlantic-Medit. & temp-s.trop \\
\hline Biecheleria cf. baltica & $17.0(\sim 14.5-3 \mid 2.5)$ & $? 3-30$ & N. Atlant-Med. & cool temp-s.trop \\
\hline Cochlodinium polykrikoides & $17.5(14-27.8)$ & $30-34$ & politan & cool temp-trop \\
\hline Cochlodinium sp. cf. Fukyo & $14.25-31$ & $32-33.5$ & Japan & ?temp. \\
\hline Protoperidinium shanghaiense & $17(6.5-31.1)$ & $31.1-39.2$ & cosmopolitan & s.pol - trop \\
\hline
\end{tabular}




\section{ACCEPTED MANUSCRIPT}
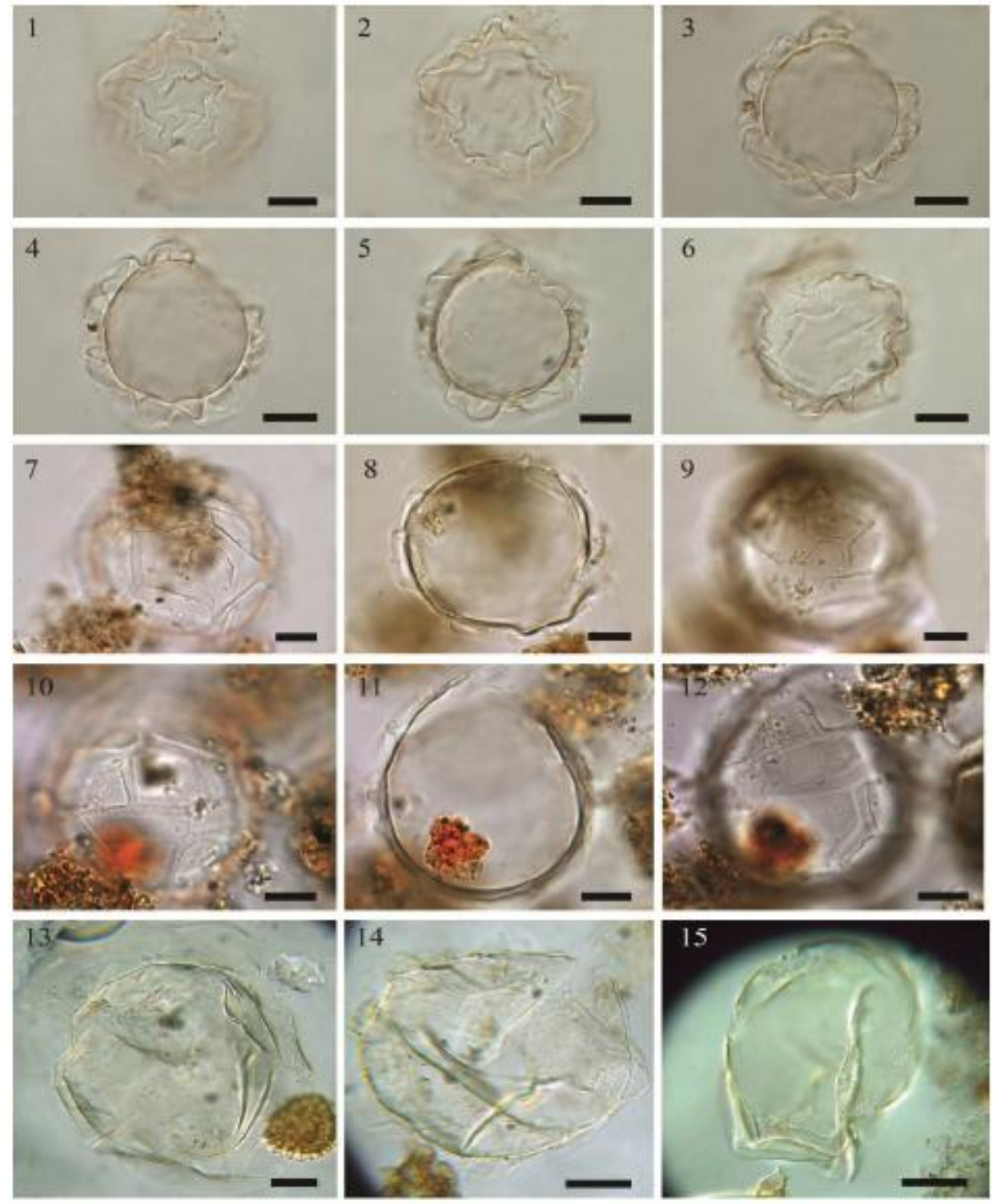

Plate 1 

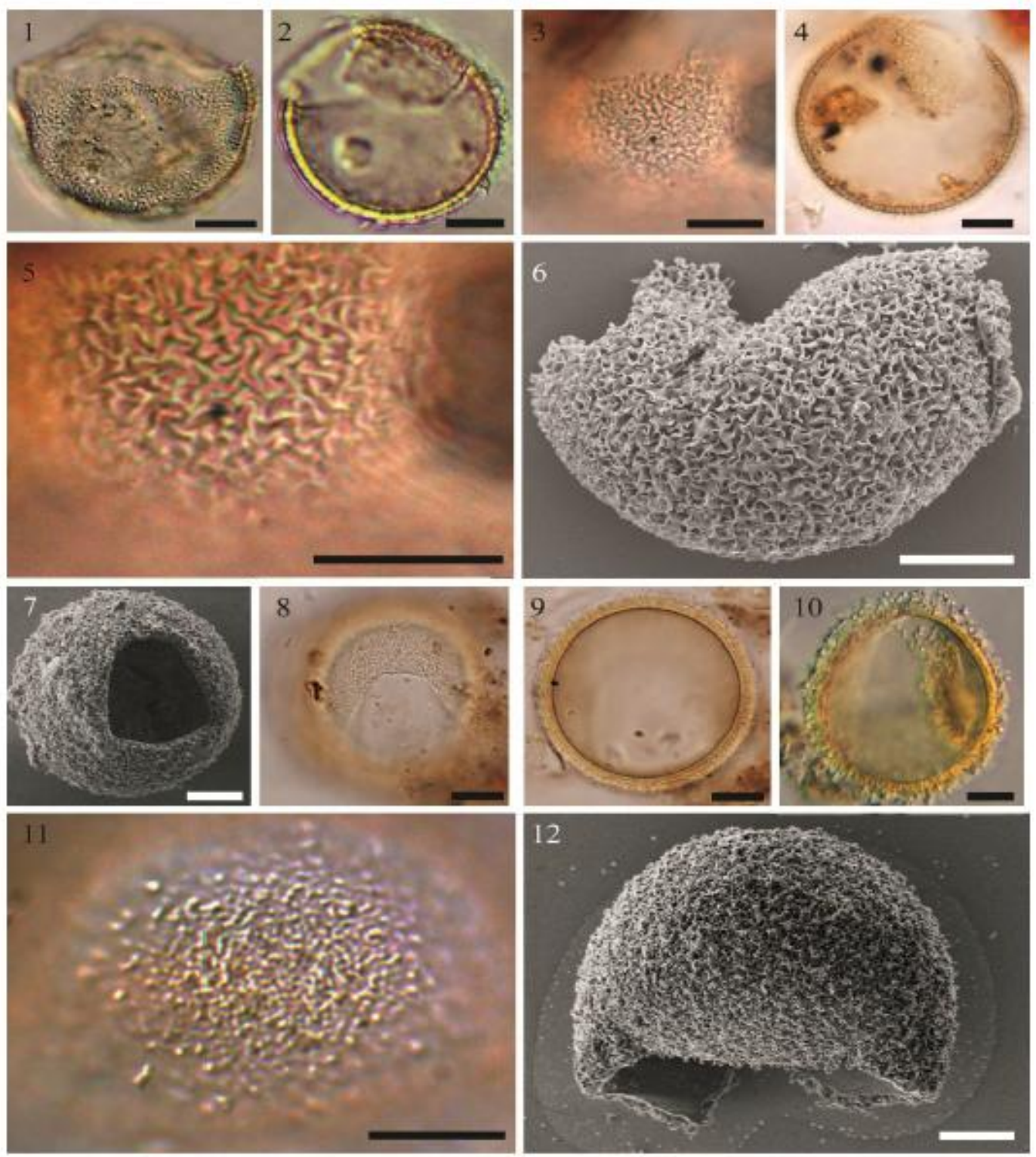

Plate 2 


\section{ACCEPTED MANUSCRIPT}
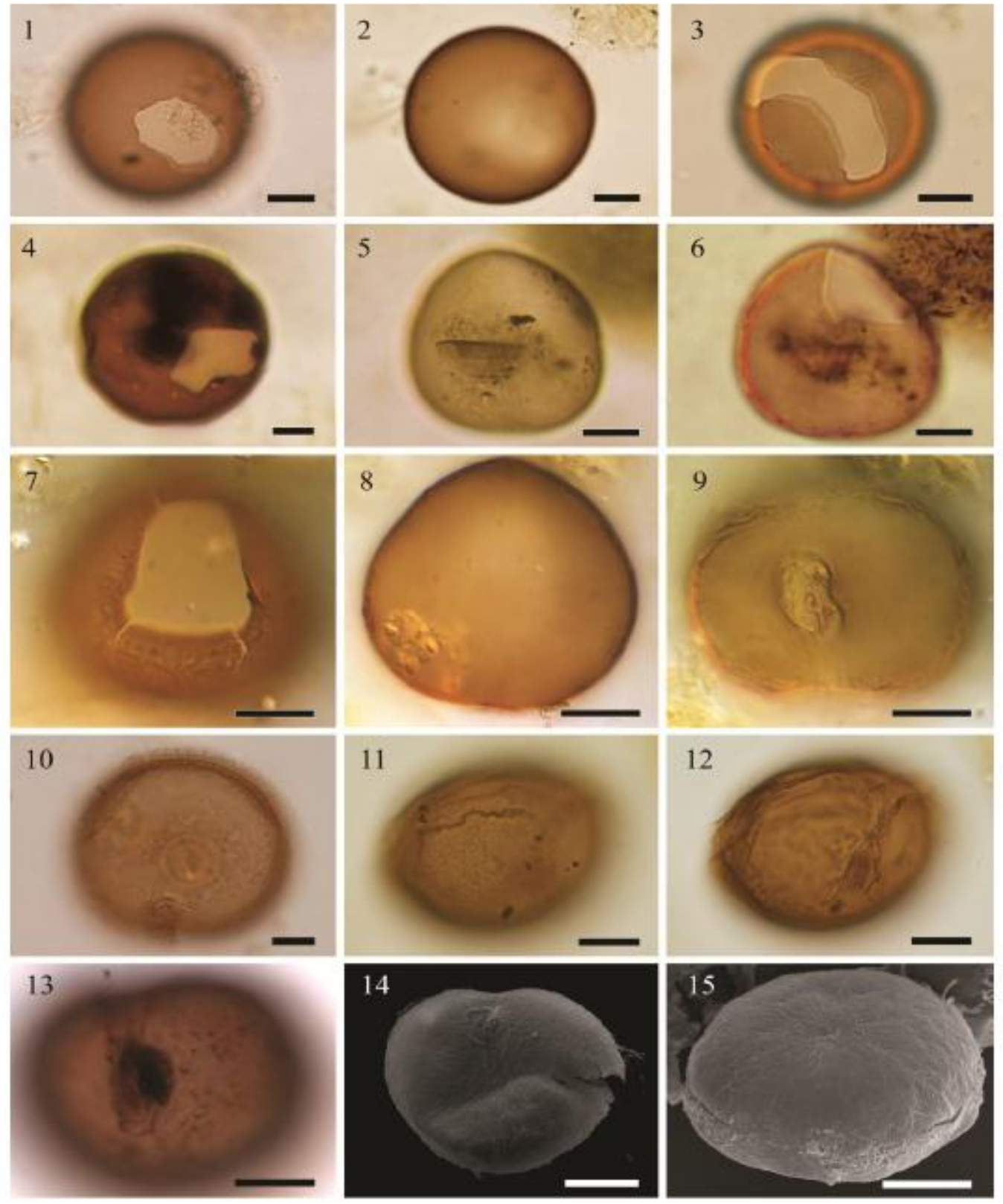

Plate 3 


\section{ACCEPTED MANUSCRIPT}
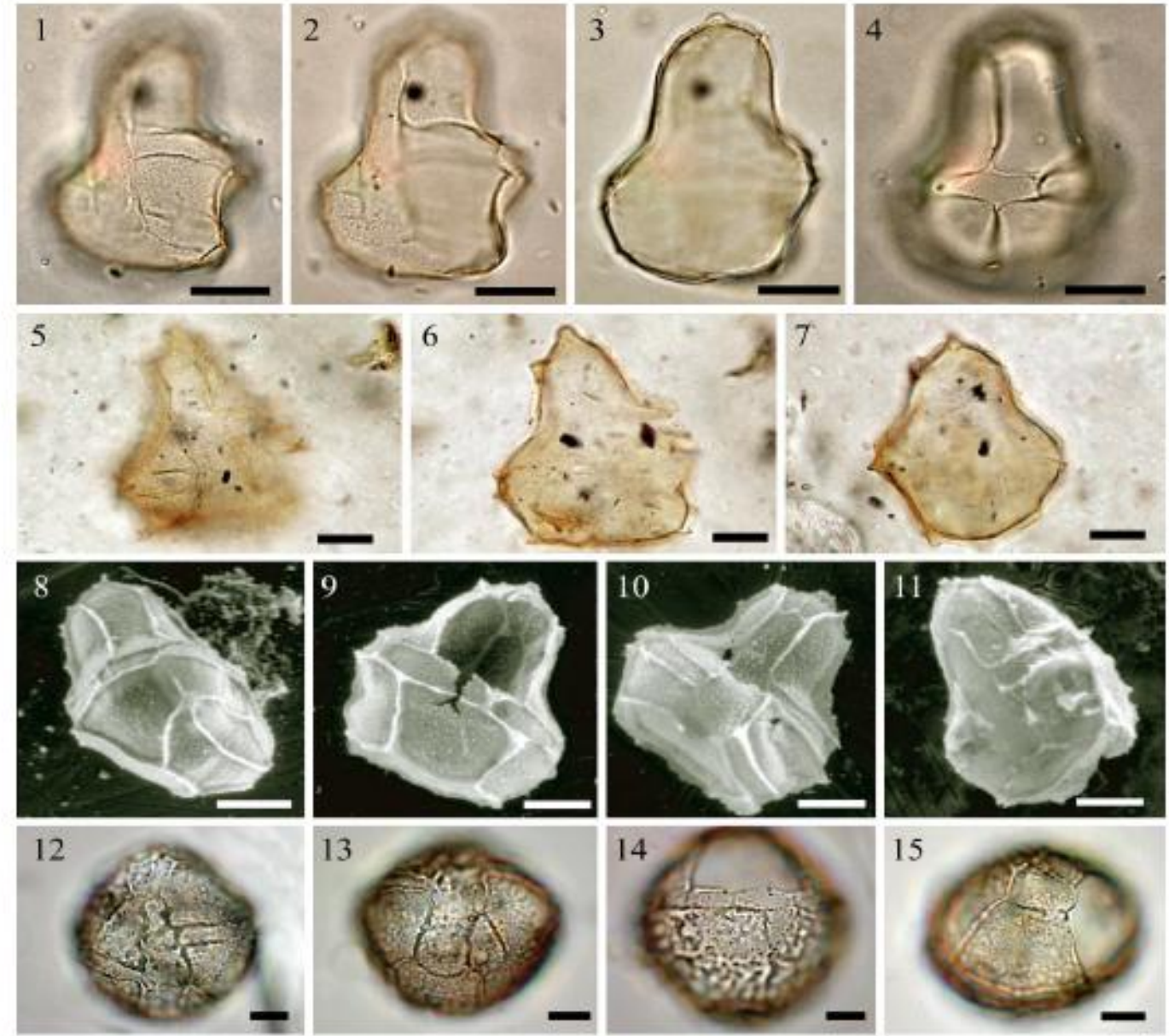

15


Plate 4 


\section{ACCEPTED MANUSCRIPT}
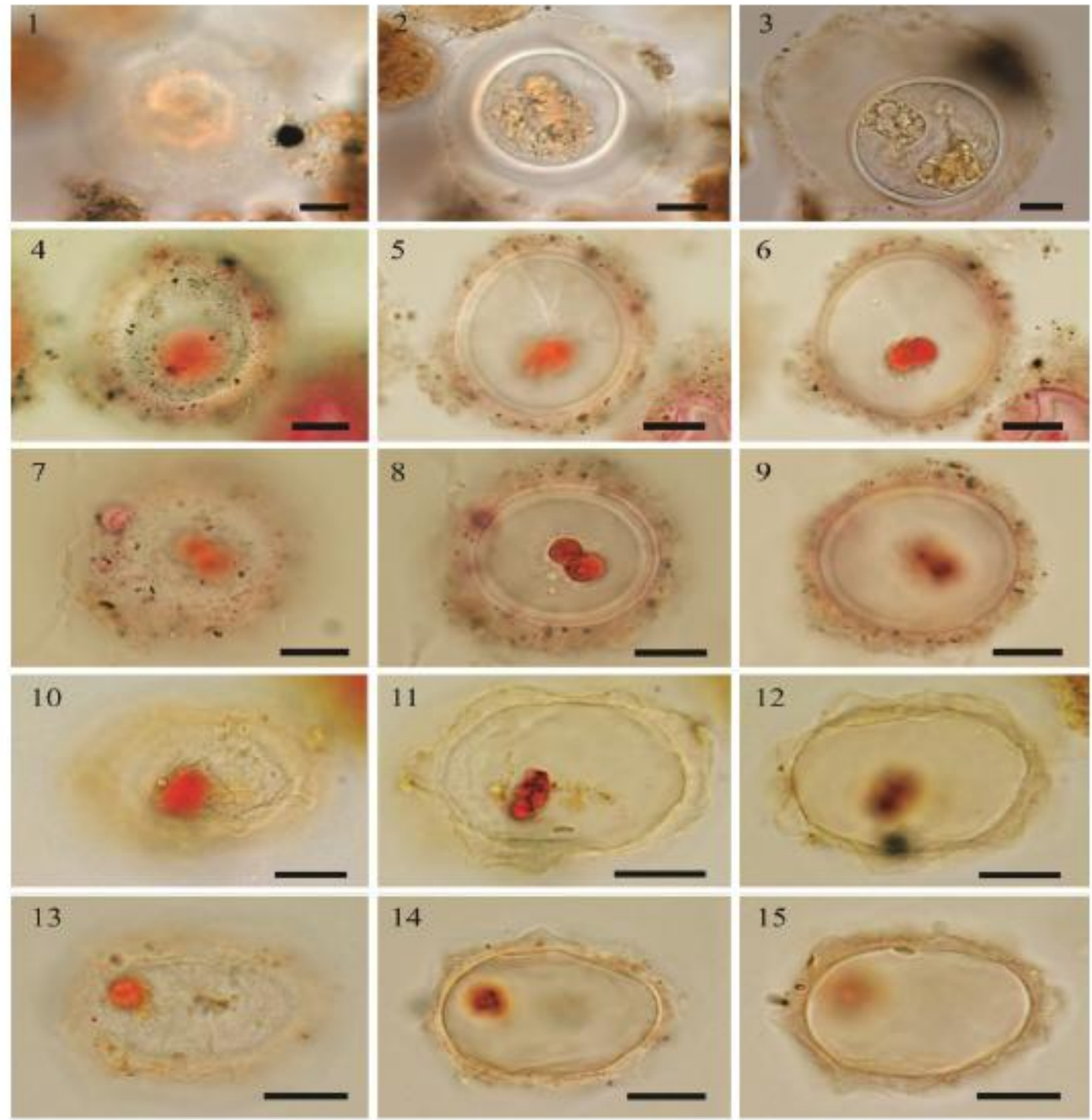

Plate 5 


\section{ACCEPTED MANUSCRIPT}
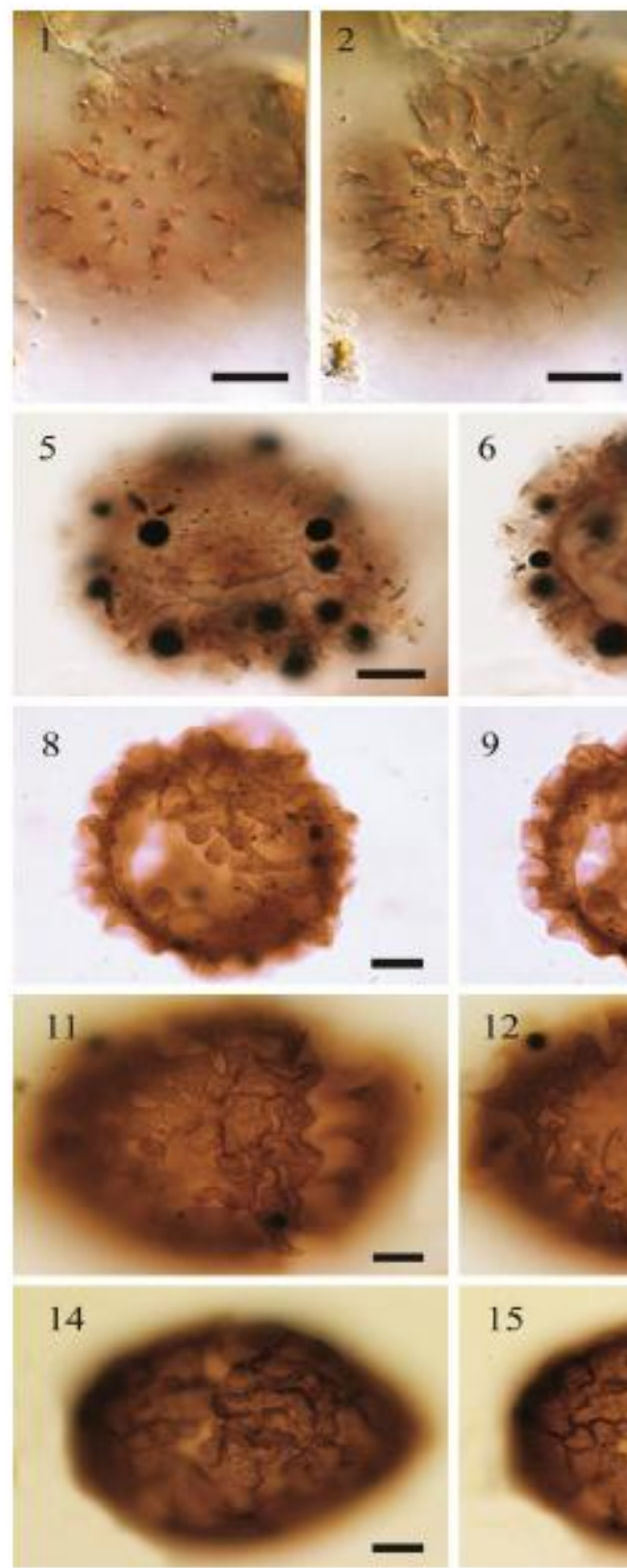
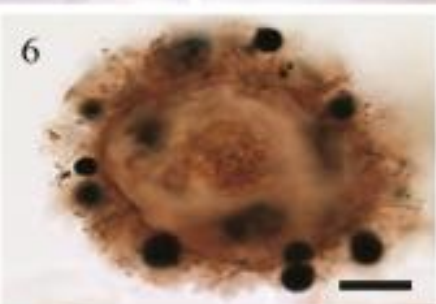

9
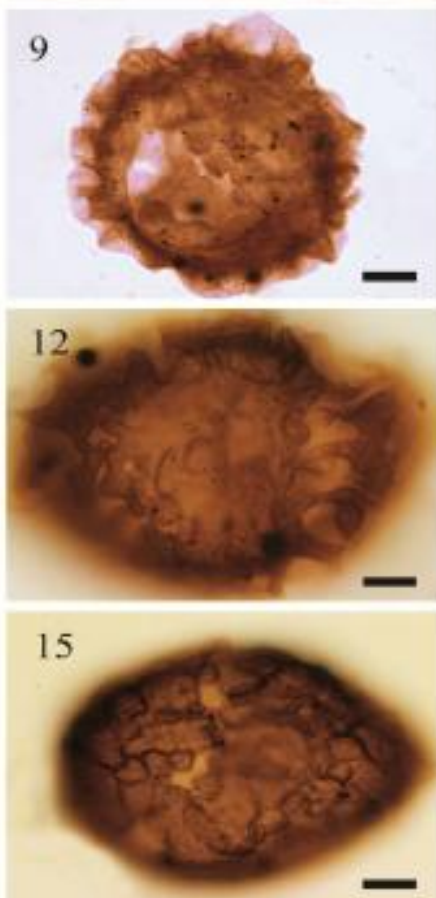
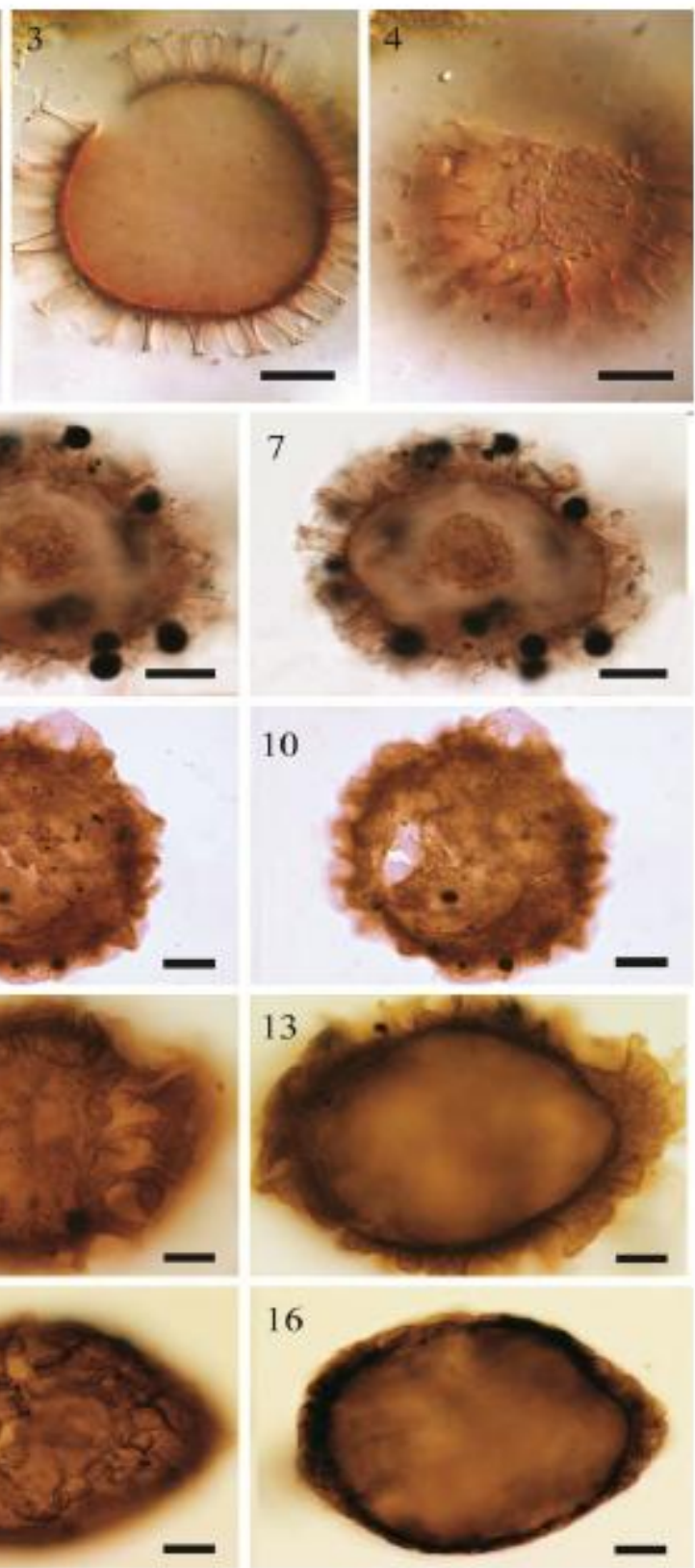

Plate 6 


\section{ACCEPTED MANUSCRIPT}
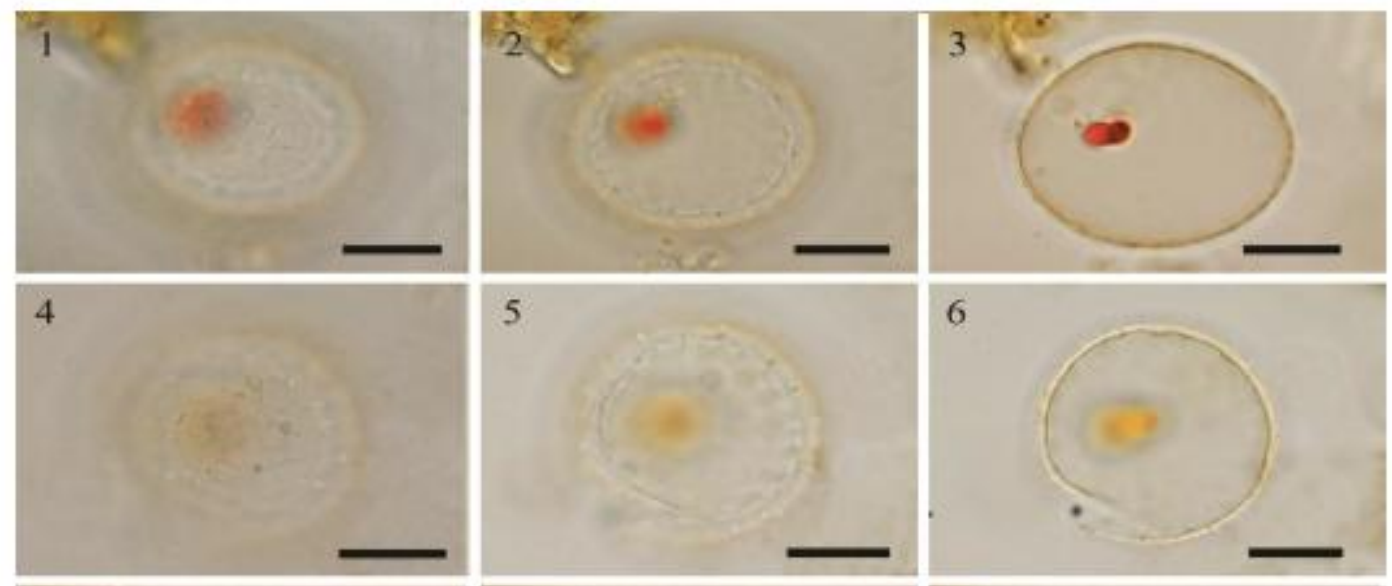

5
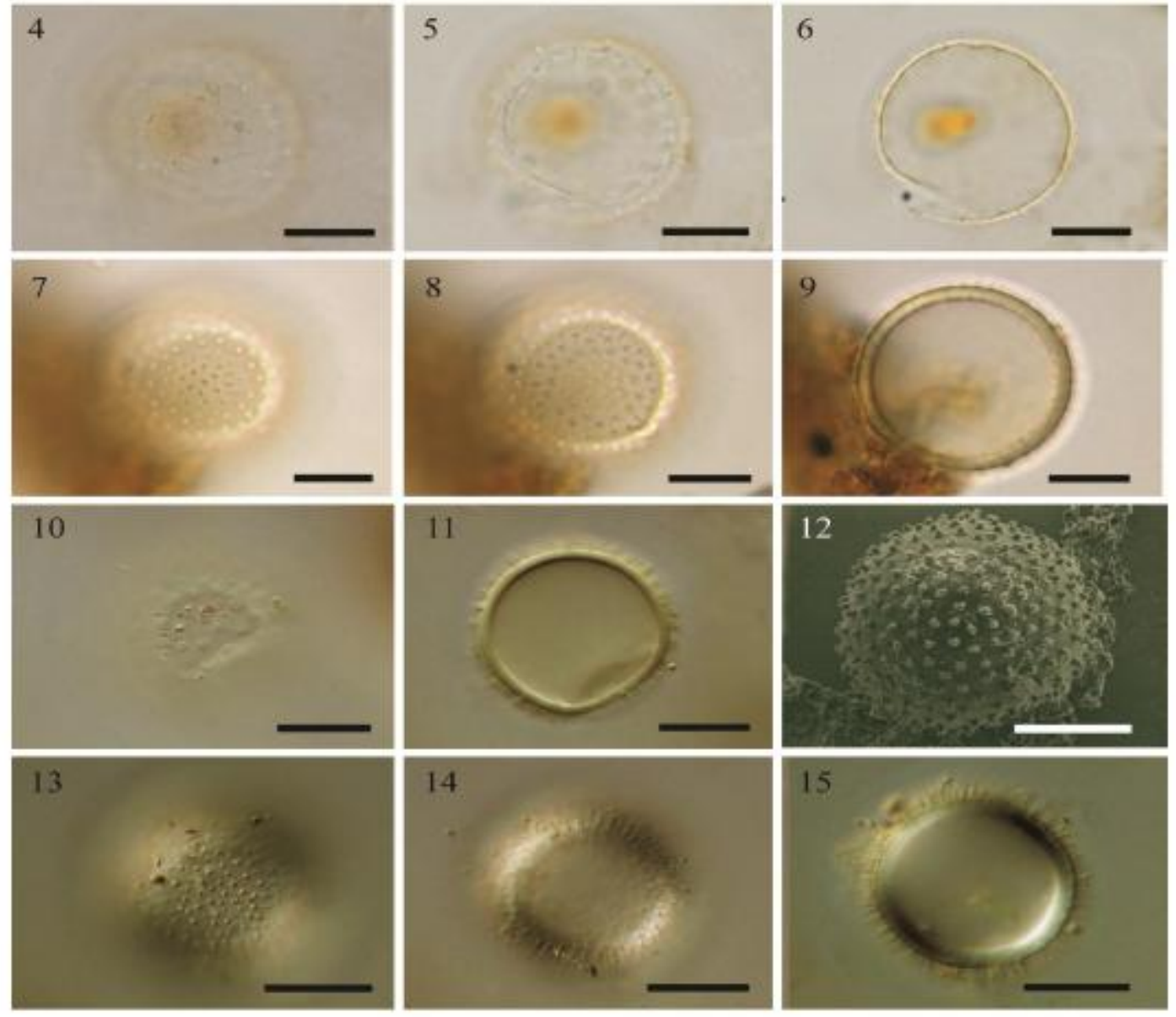

Plate 7 


\section{ACCEPTED MANUSCRIPT}
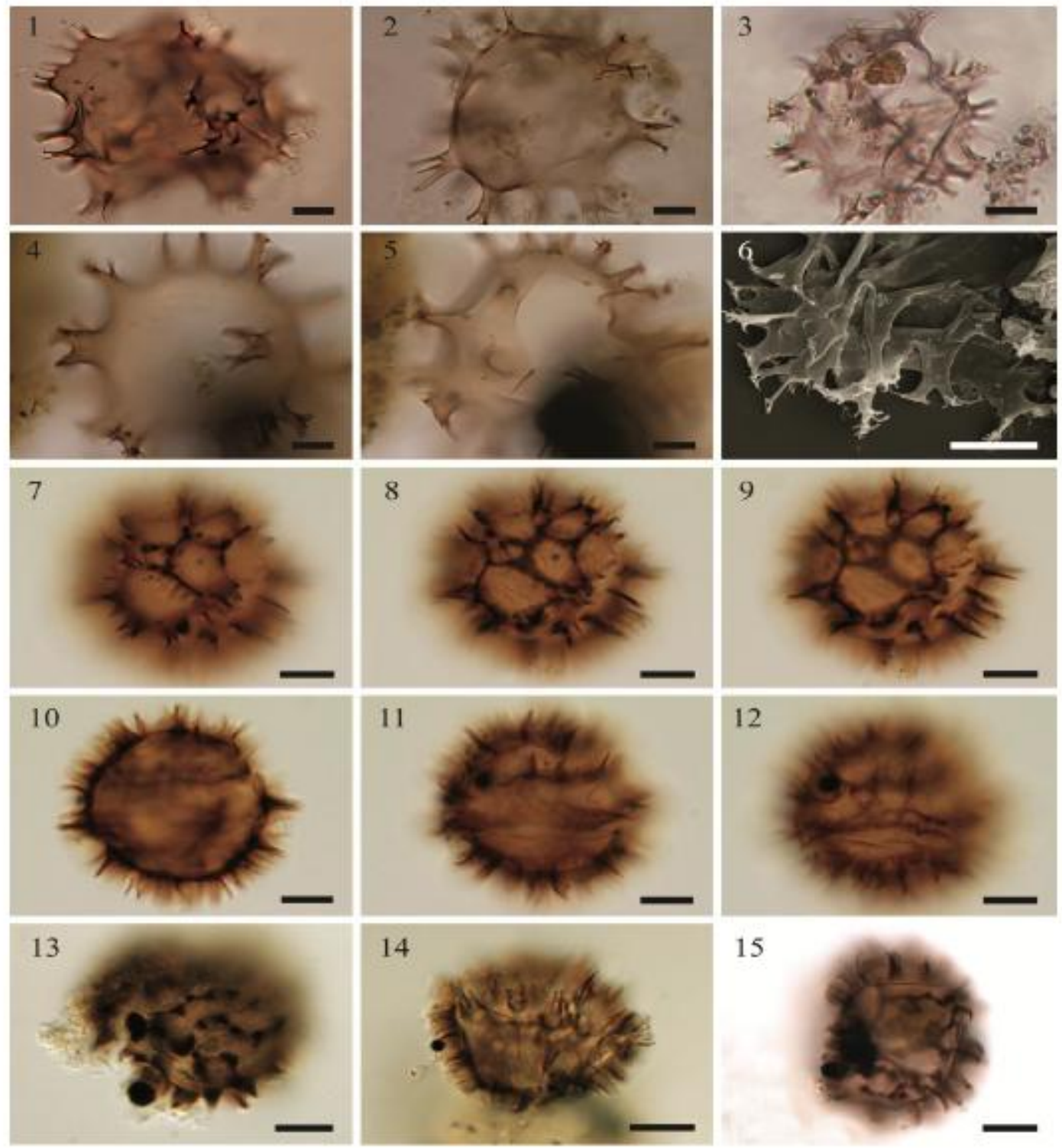

Plate 8 


\section{ACCEPTED MANUSCRIPT}
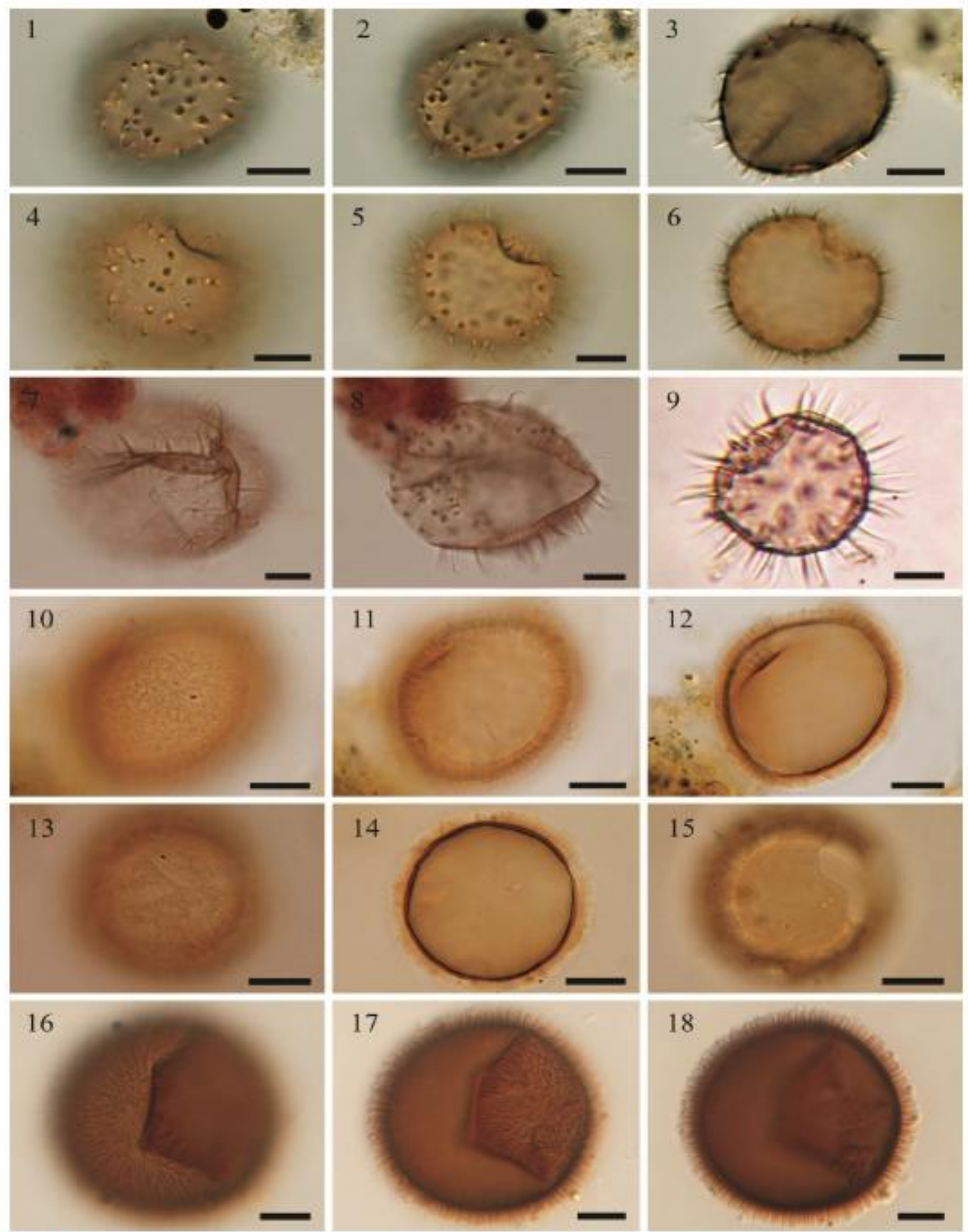

Plate 9 


\section{ACCEPTED MANUSCRIPT}
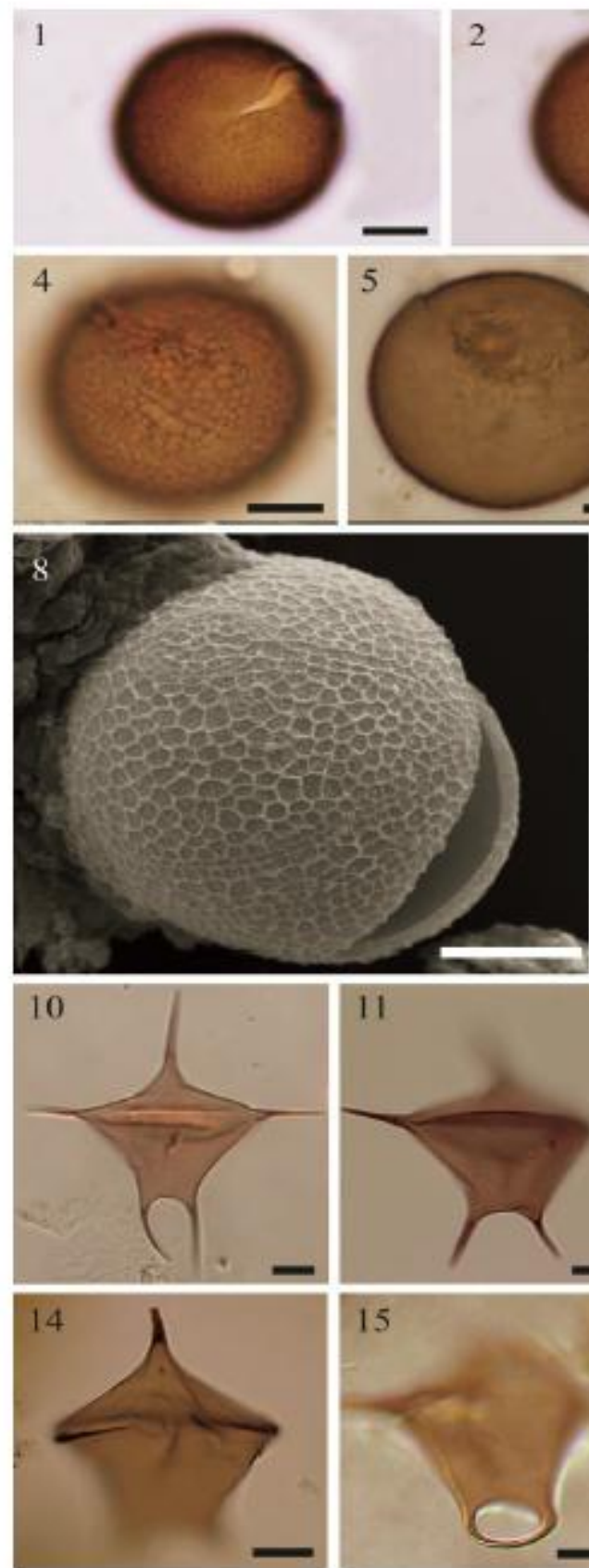

2
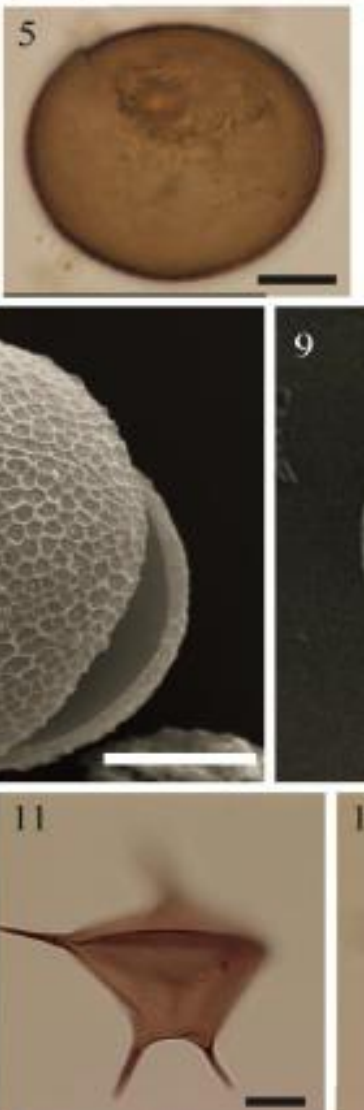
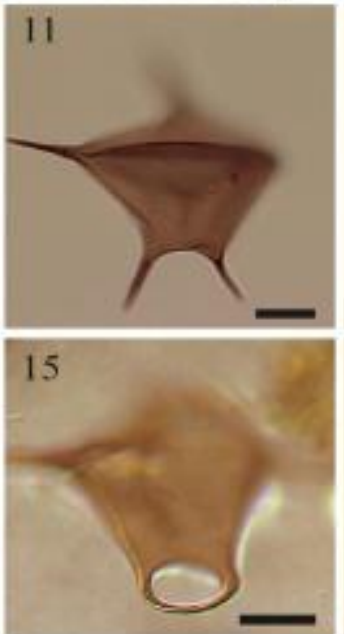

12


3
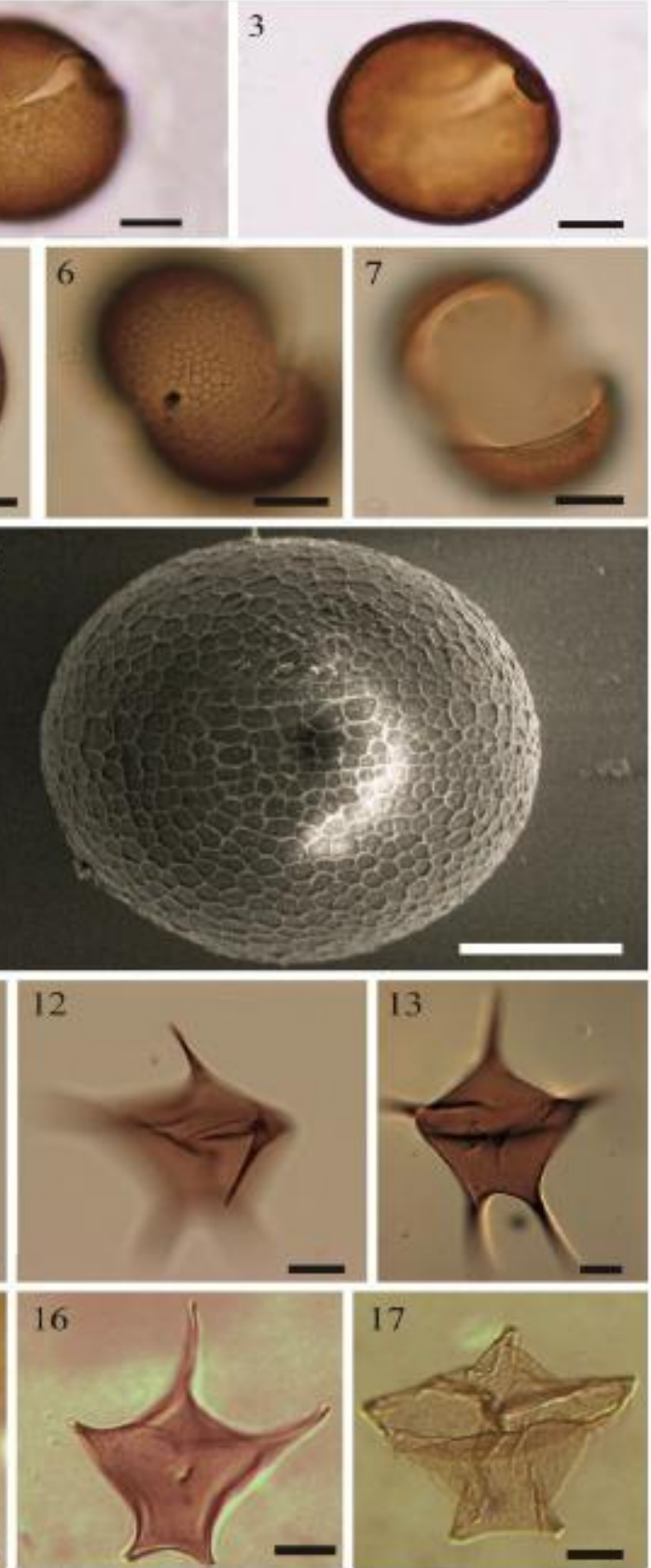

Plate 10 


\section{ACCEPTED MANUSCRIPT}
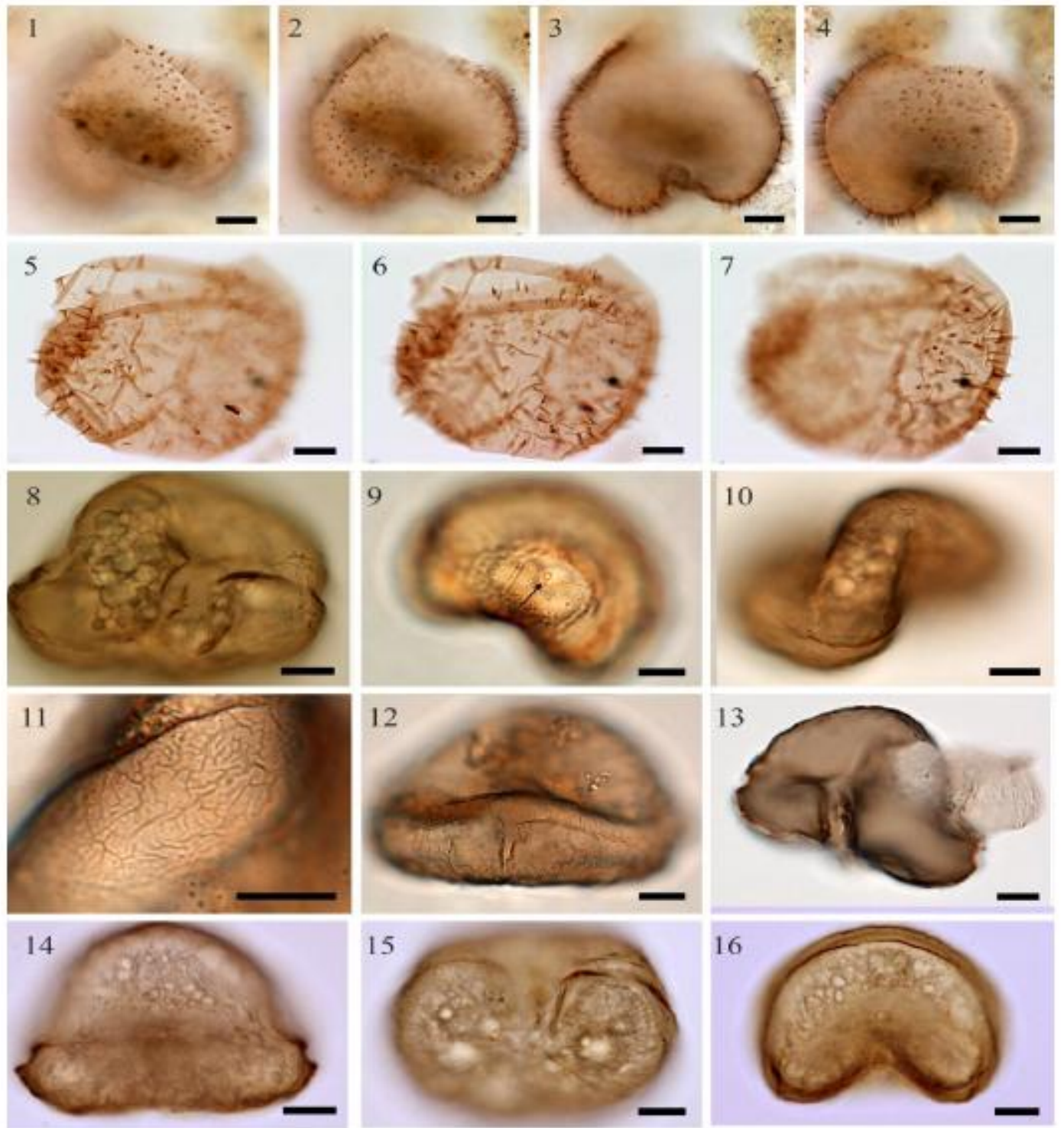

Plate 11 


\section{ACCEPTED MANUSCRIPT}

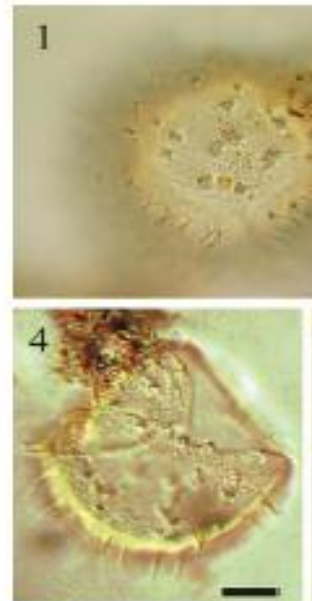

2
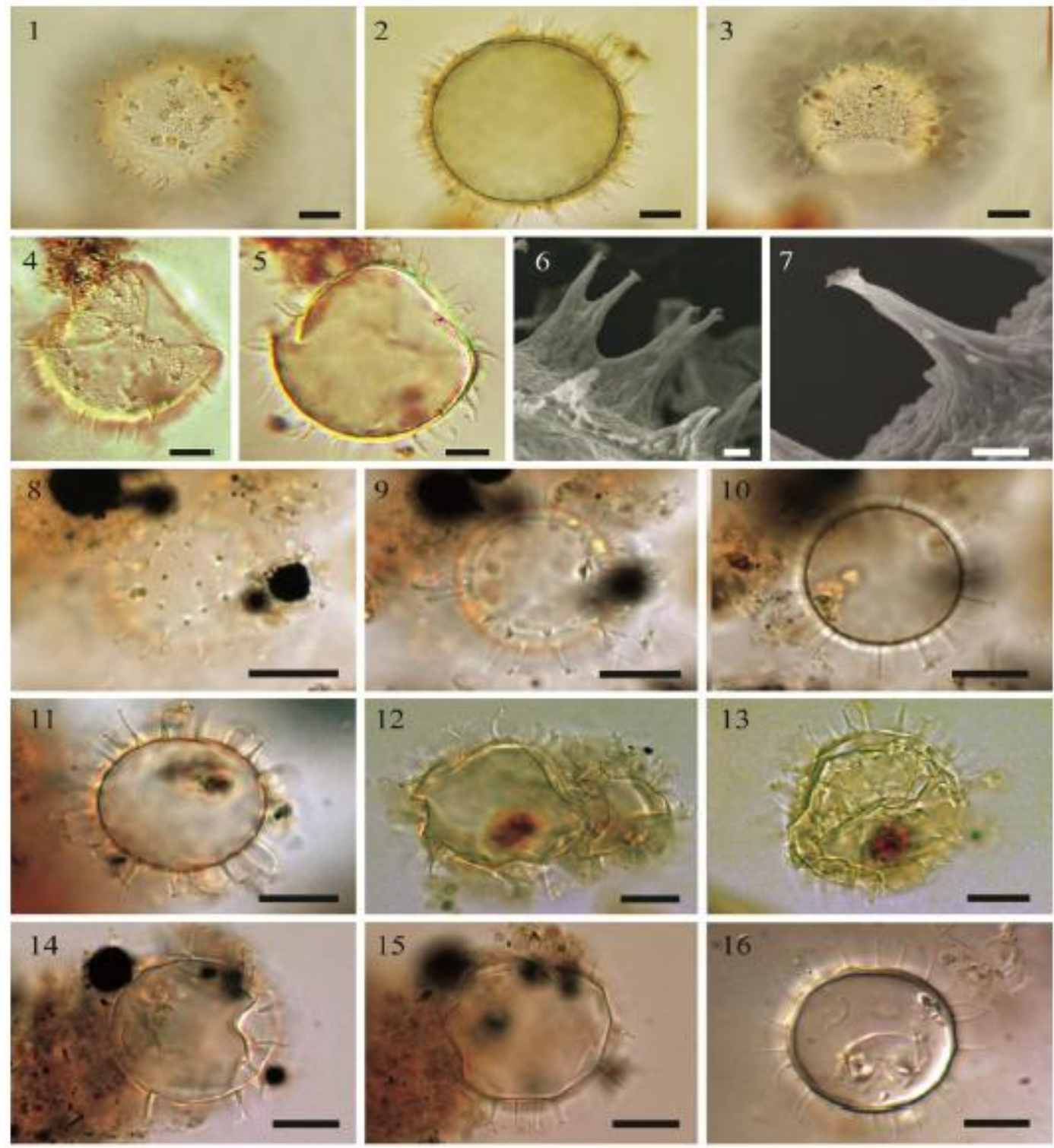

Plate 12 


\section{ACCEPTED MANUSCRIPT}
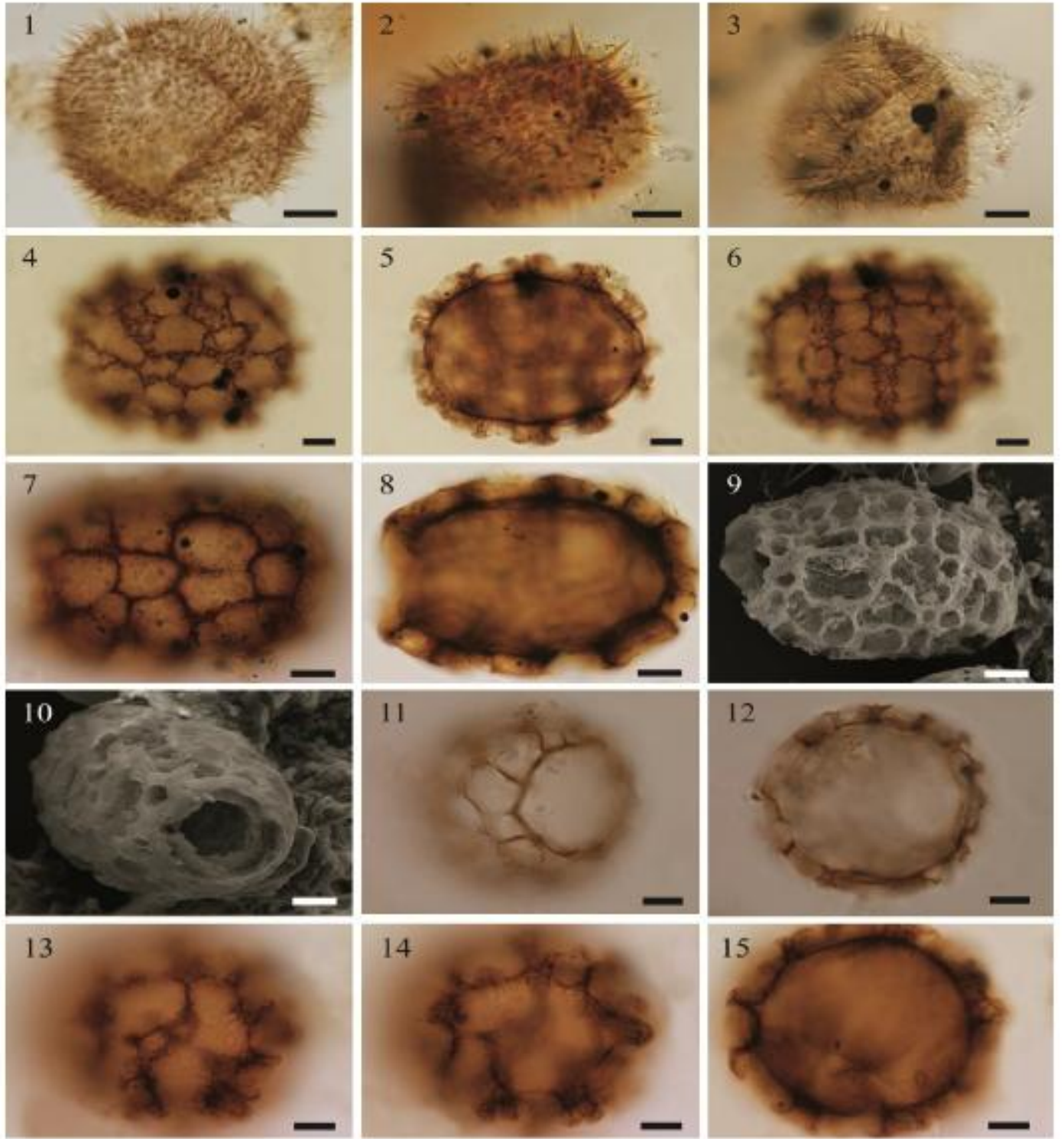

Plate 13 


\section{ACCEPTED MANUSCRIPT}


Plate 14 


\section{ACCEPTED MANUSCRIPT}
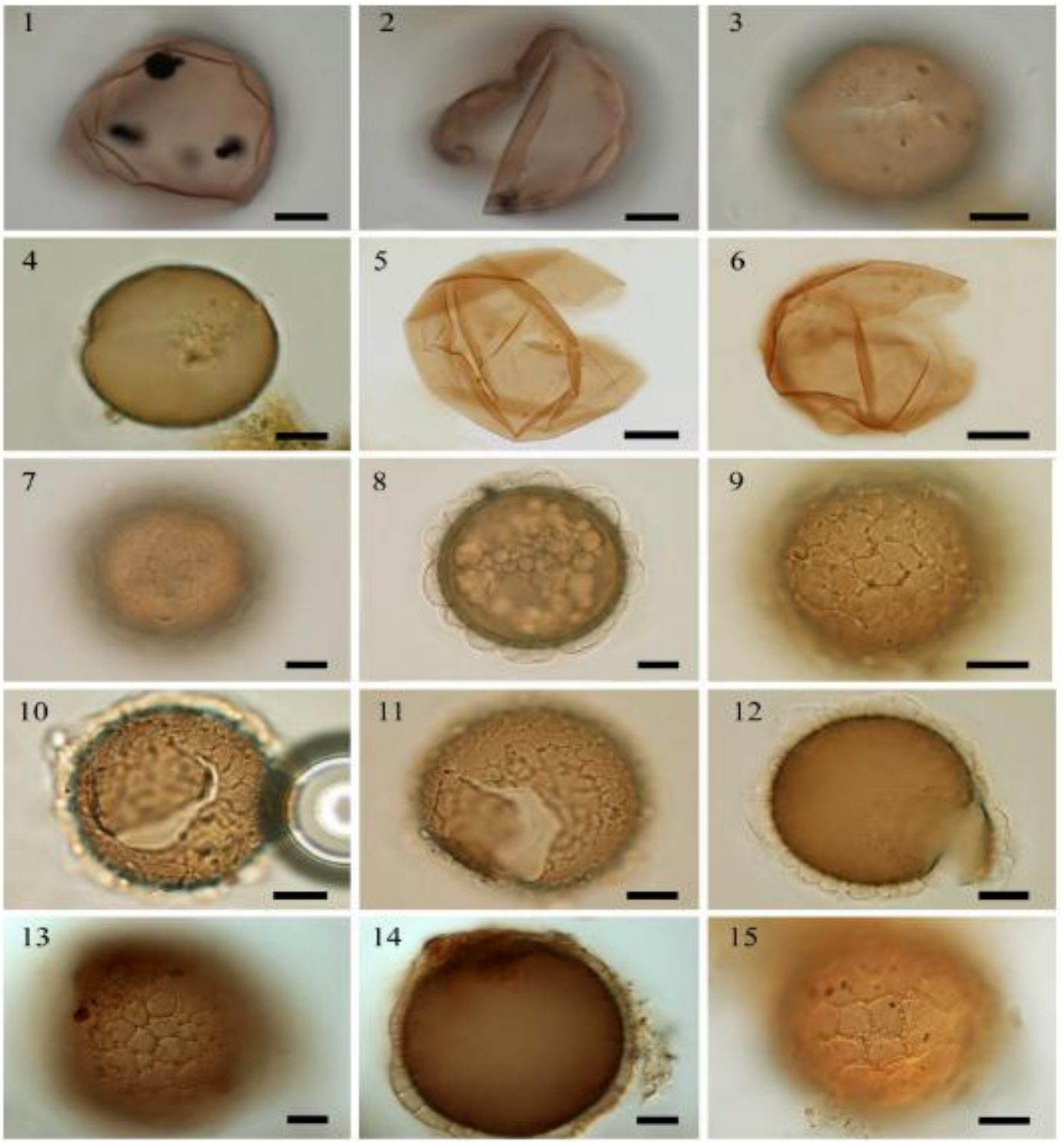

Plate 15 


\section{ACCEPTED MANUSCRIPT}
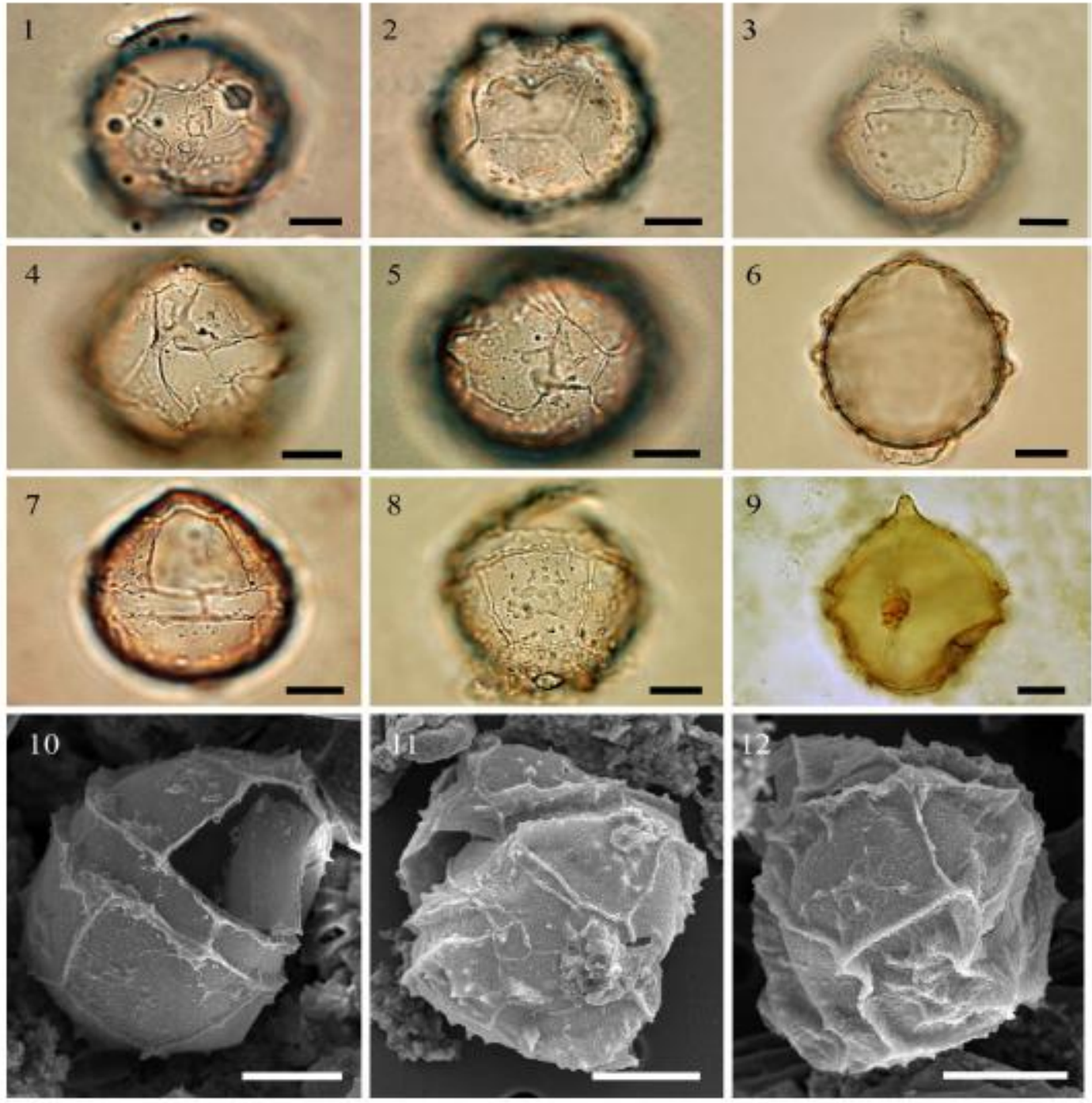

Plate 16 


\section{ACCEPTED MANUSCRIPT}
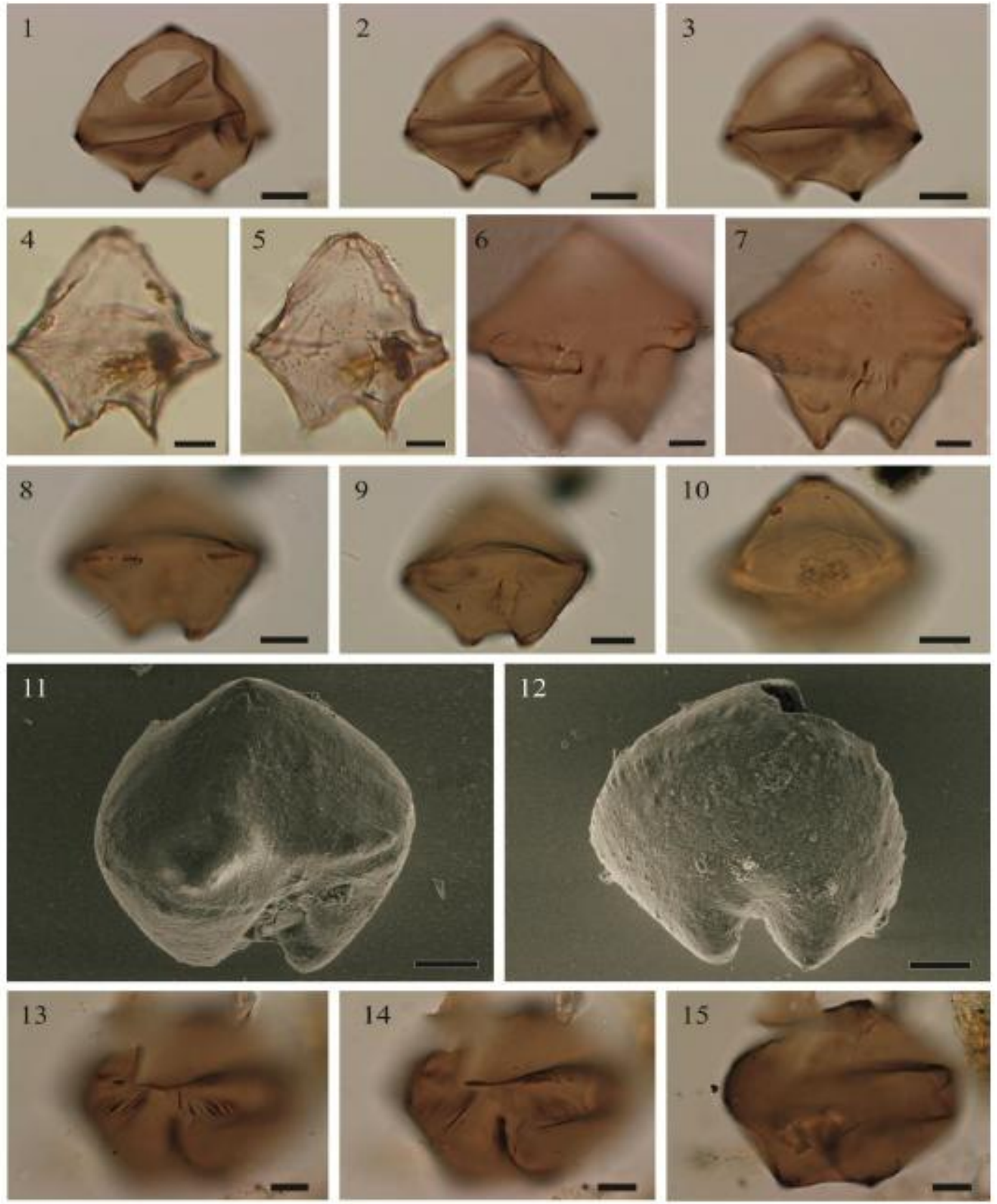

Plate 17 


\section{ACCEPTED MANUSCRIPT}
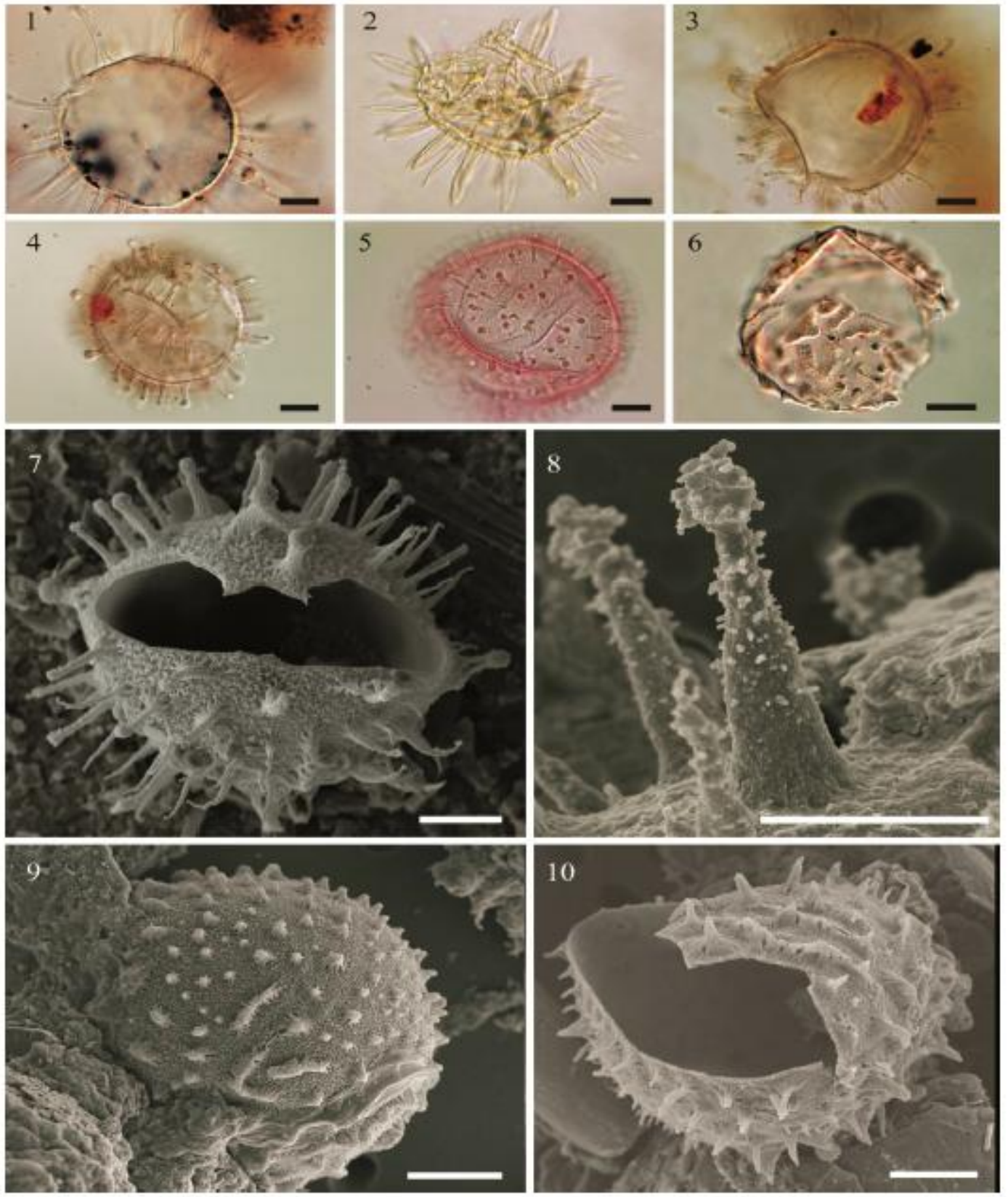

Plate 18 


\section{ACCEPTED MANUSCRIPT}
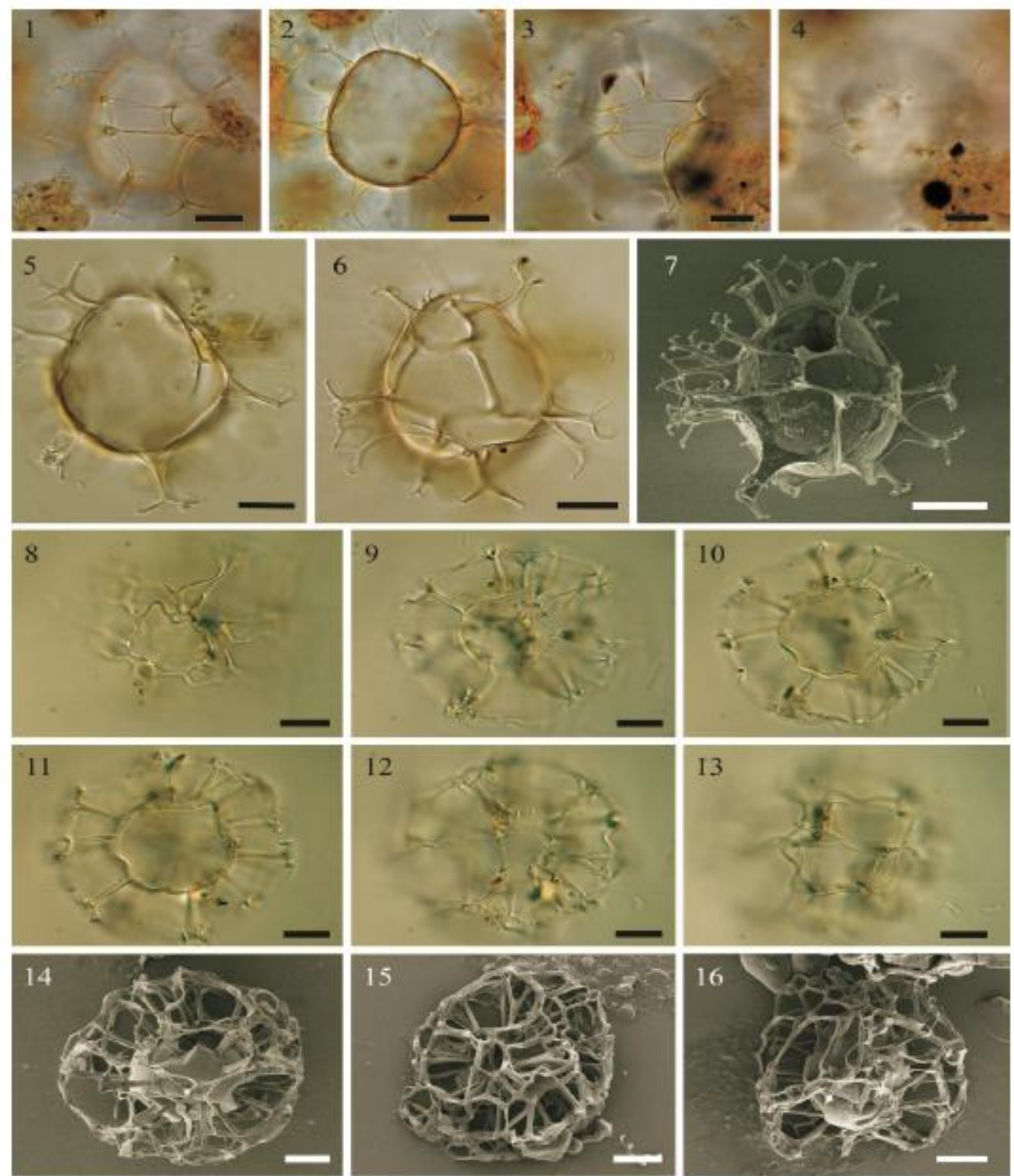

Plate 19 


\section{ACCEPTED MANUSCRIPT}
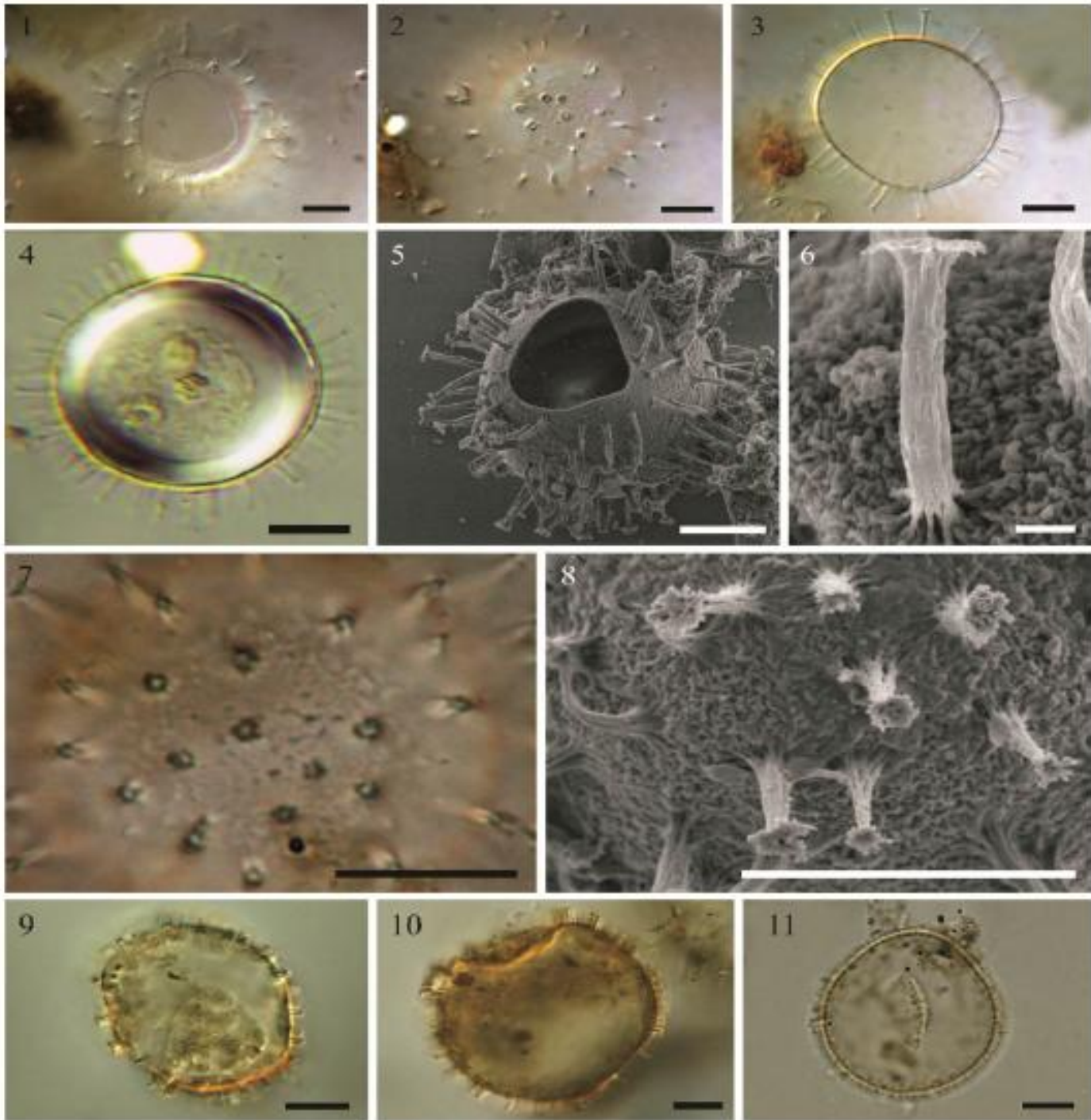

Plate 20 


\section{ACCEPTED MANUSCRIPT}
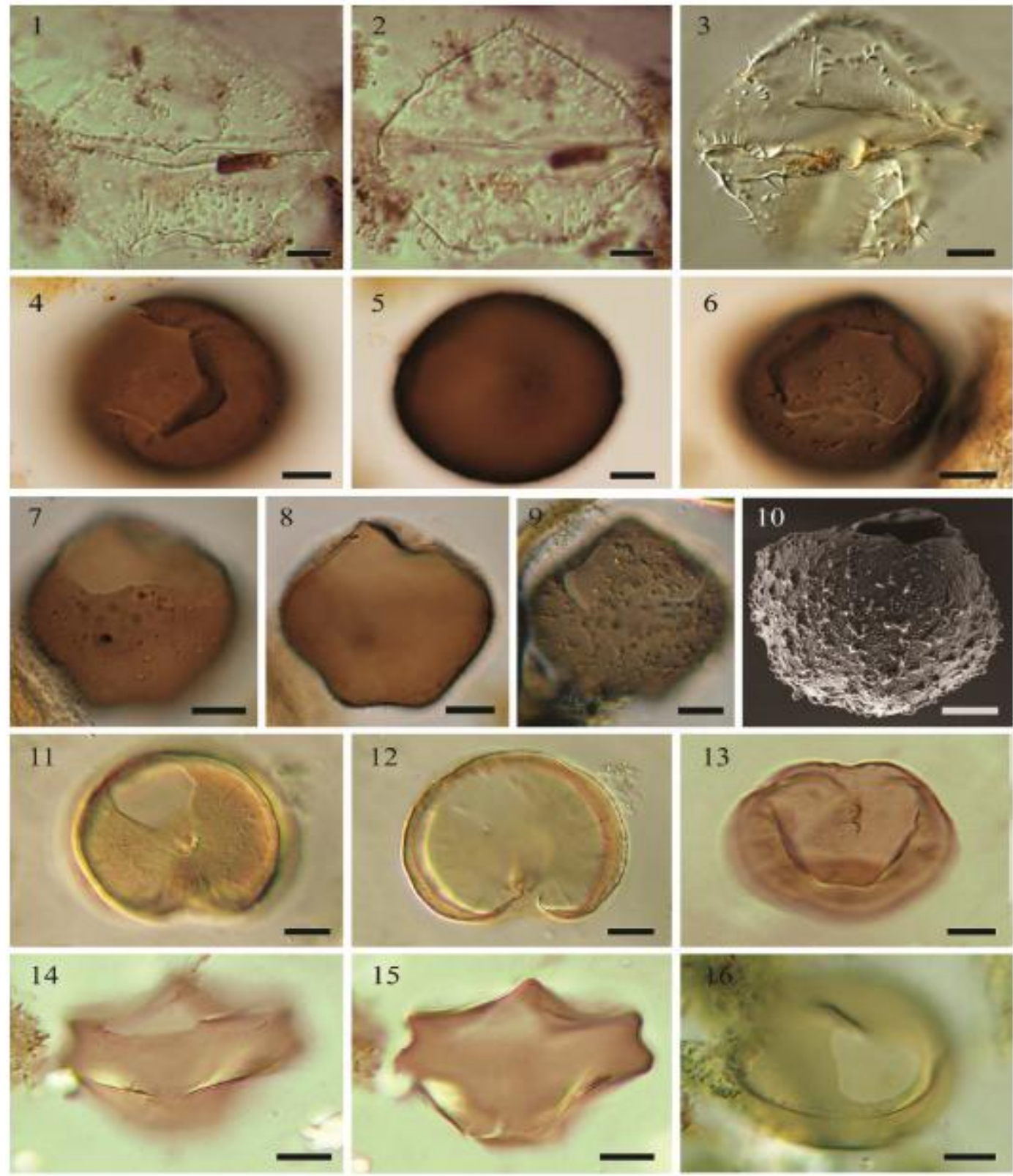

Plate 21 


\section{ACCEPTED MANUSCRIPT}
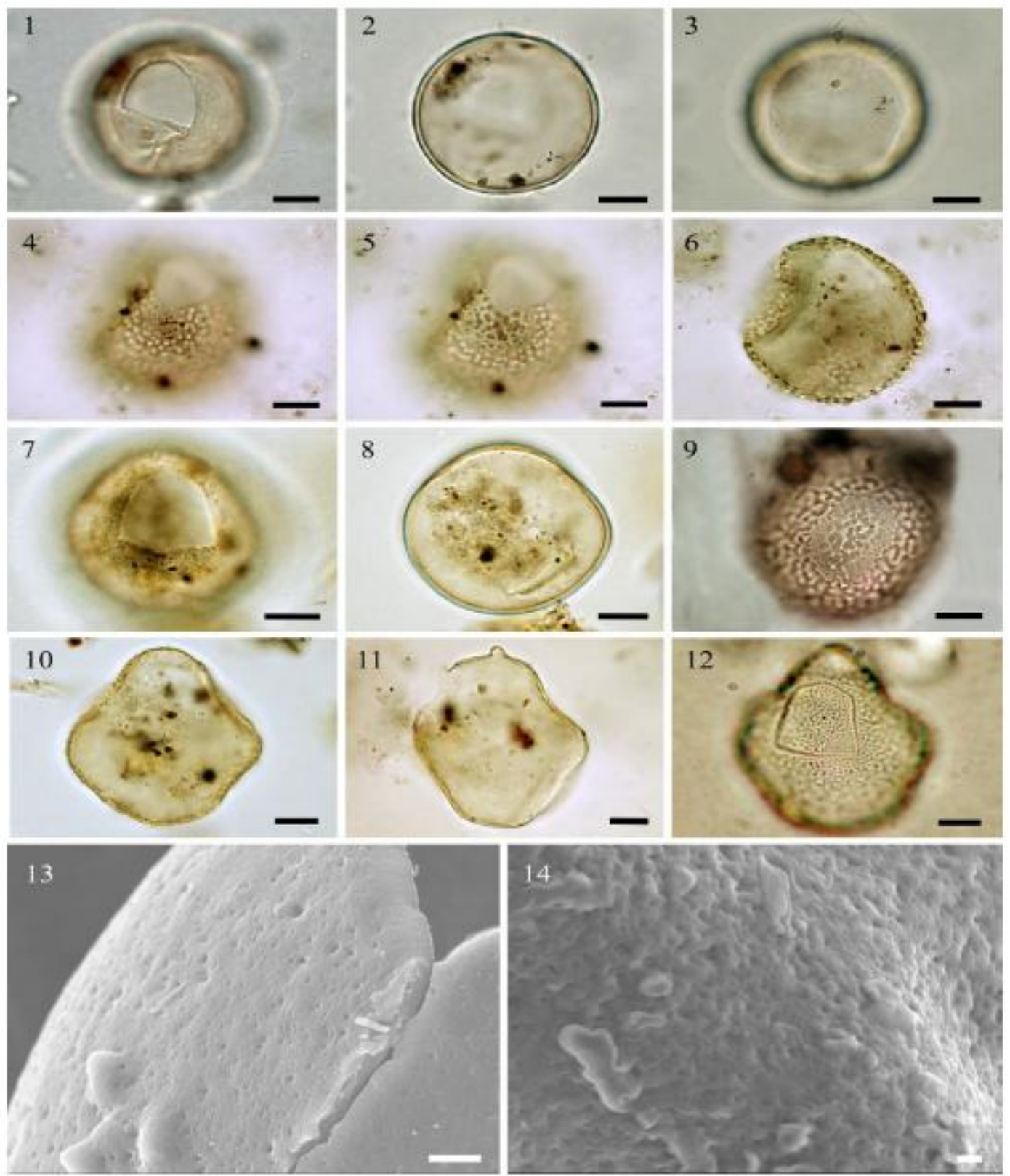

Plate 22 


\section{ACCEPTED MANUSCRIPT}
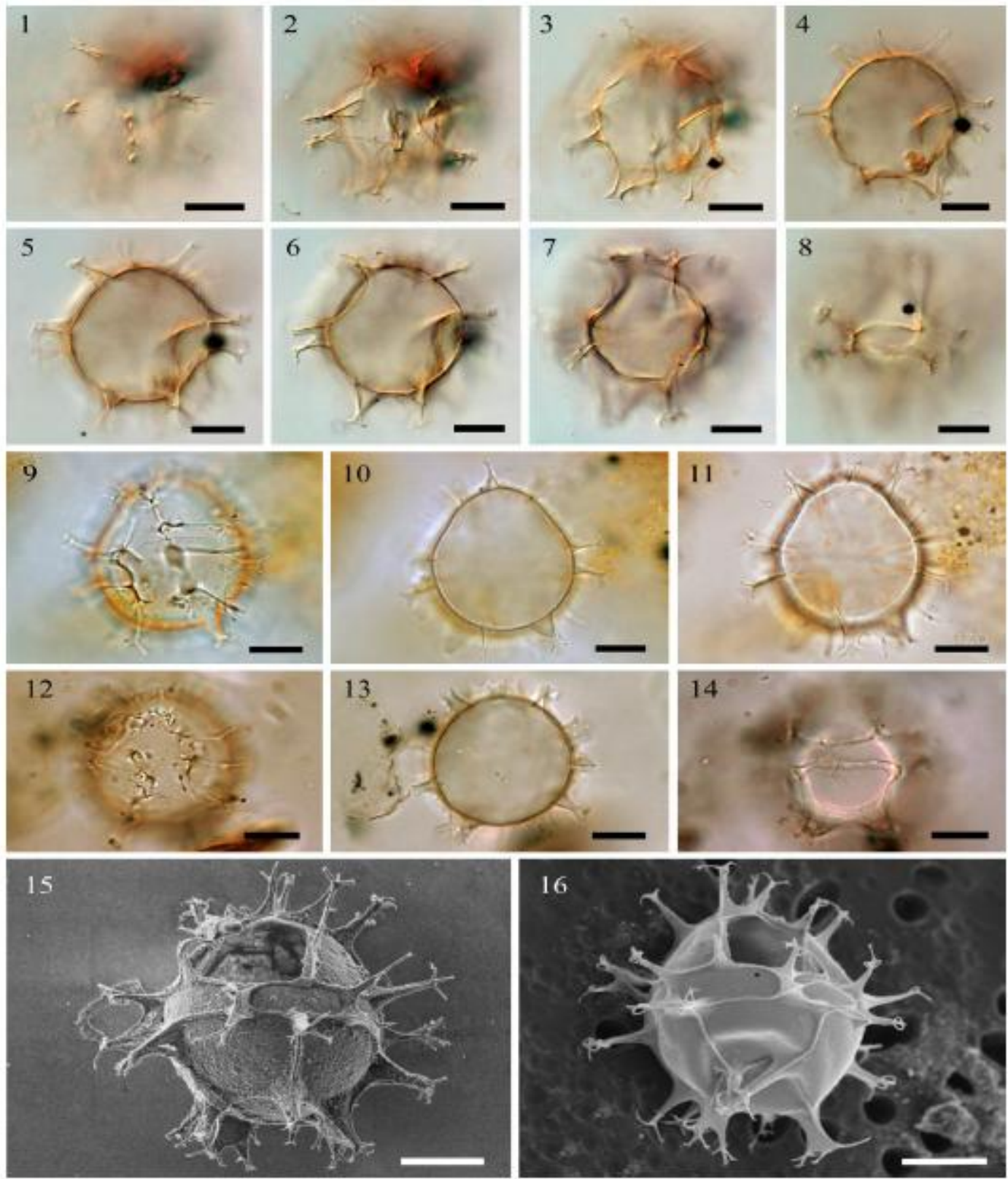

Plate 23 


\section{ACCEPTED MANUSCRIPT}
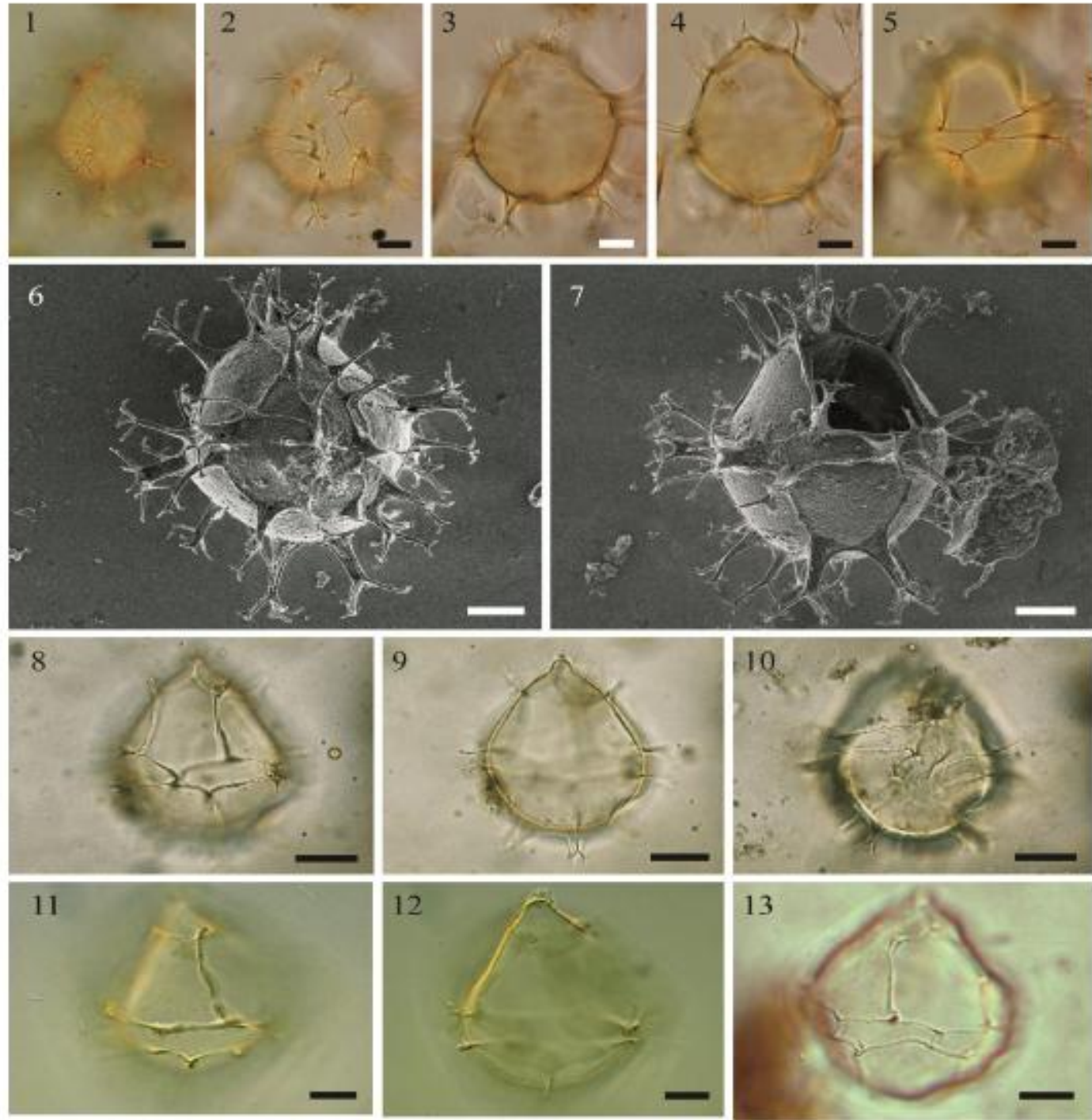

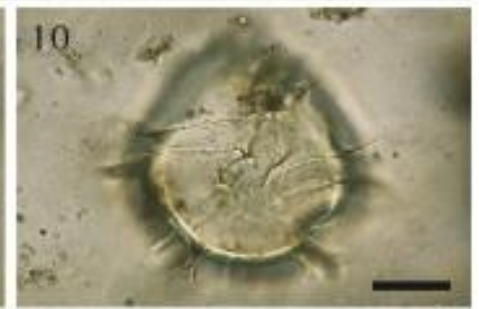

13

Plate 24 

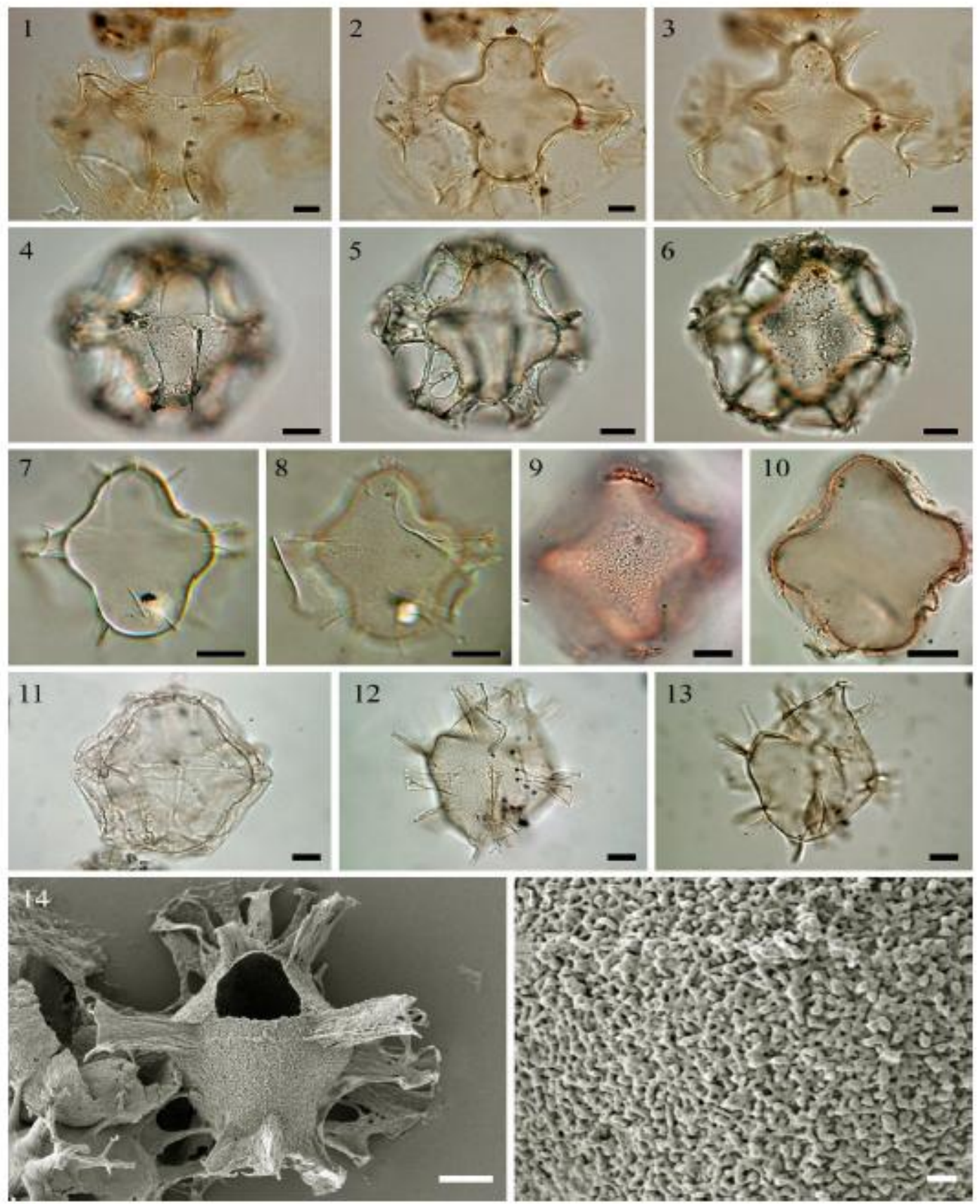

Plate 25 


\section{ACCEPTED MANUSCRIPT}
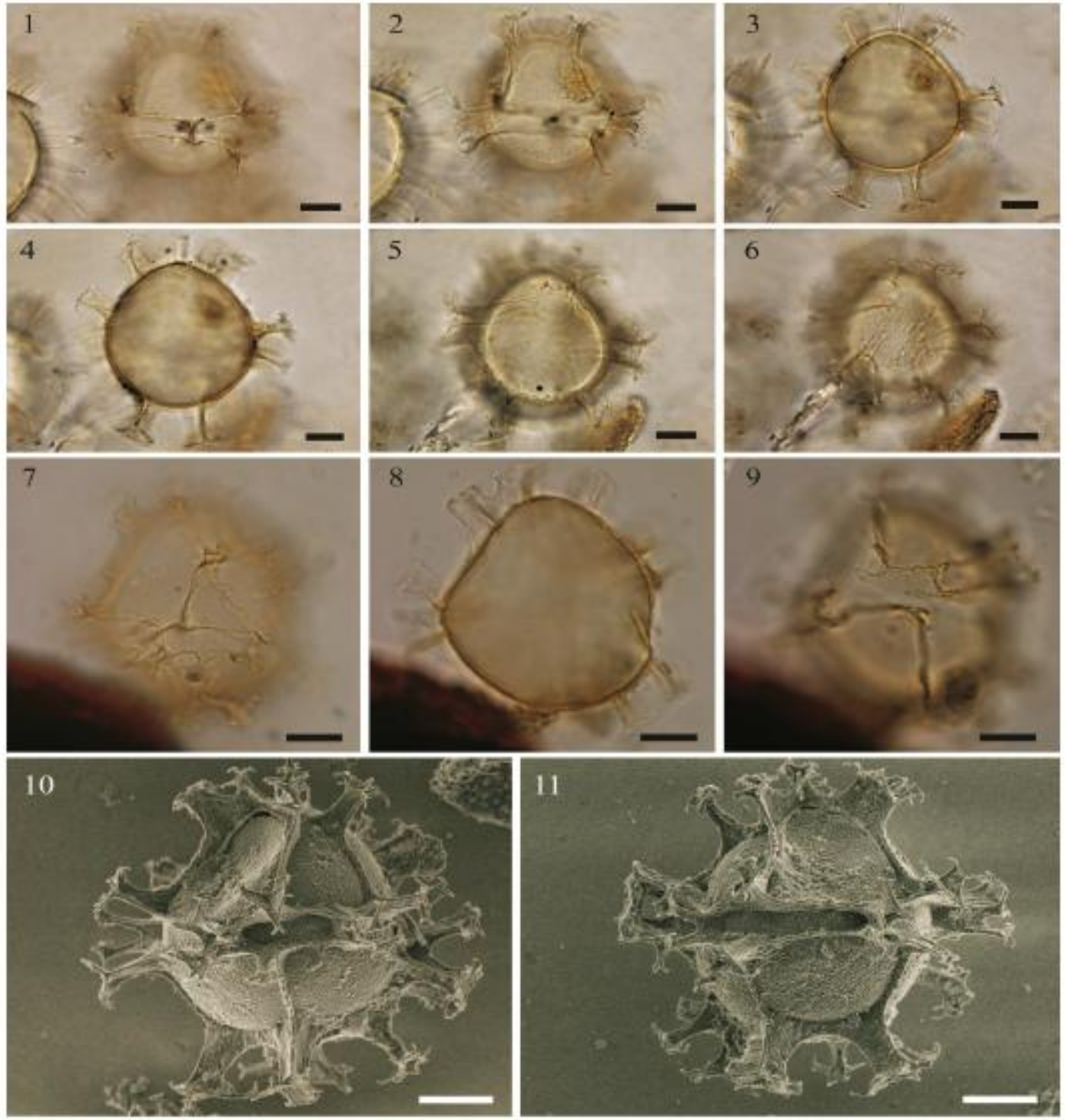

Plate 26 


\section{ACCEPTED MANUSCRIPT}
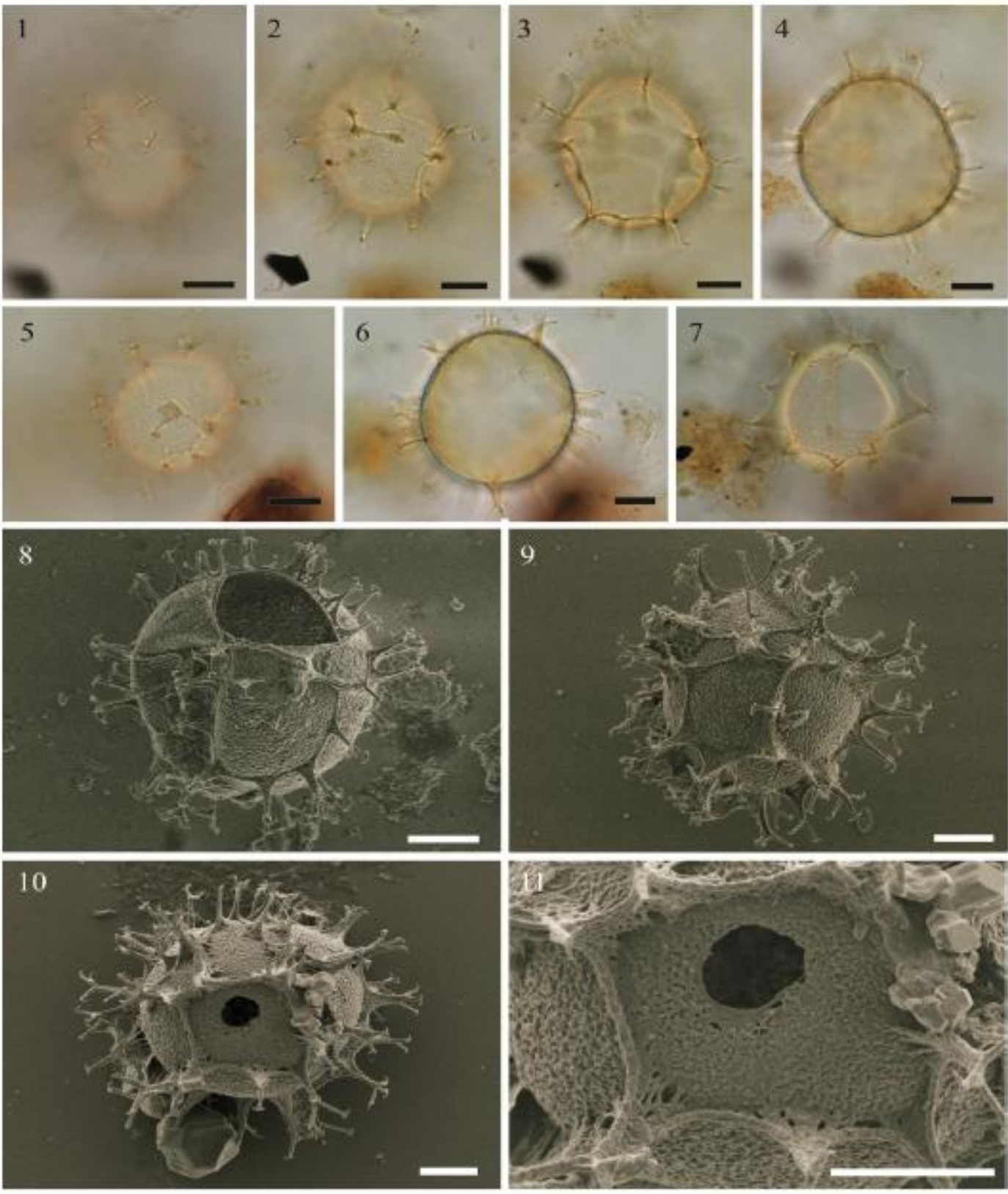

Plate 27 


\section{ACCEPTED MANUSCRIPT}
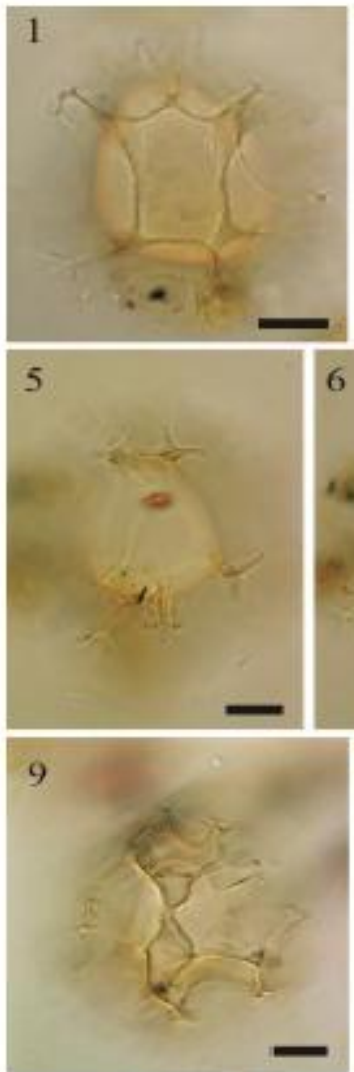

13

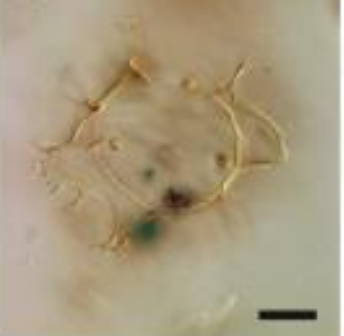

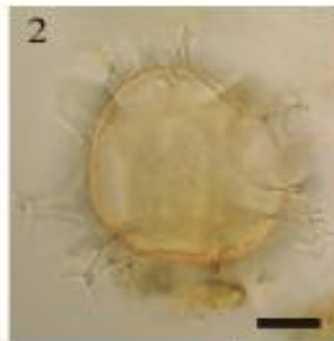

6
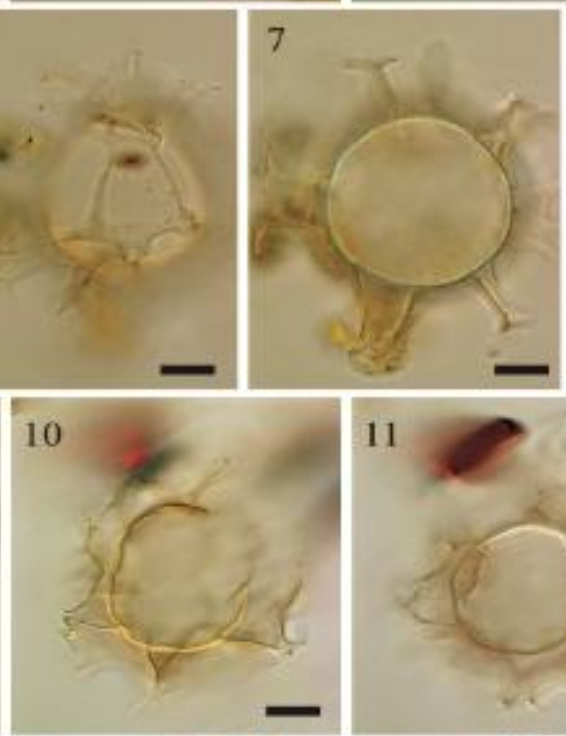

11



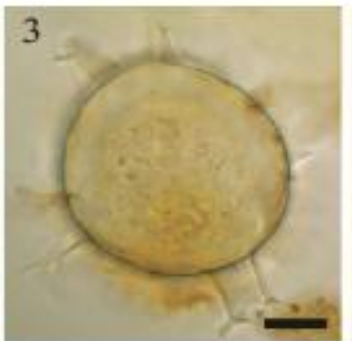

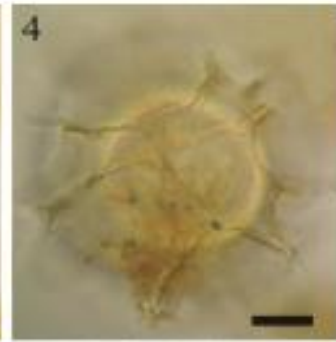

\section{8}

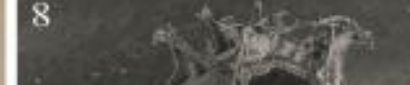

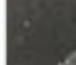

$+23^{2}$

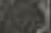

93.
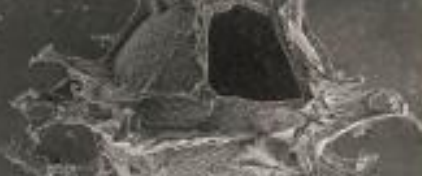

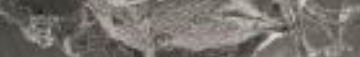

$2=$


12
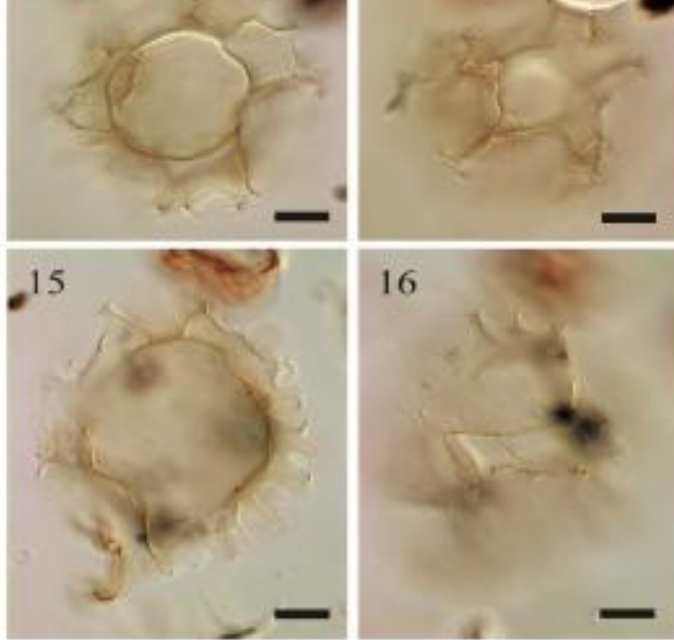

16

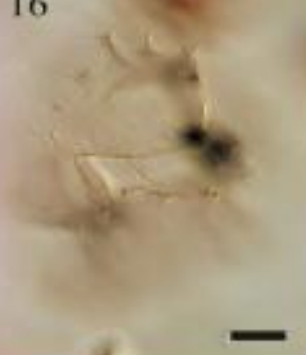

Plate 28 


\section{ACCEPTED MANUSCRIPT}
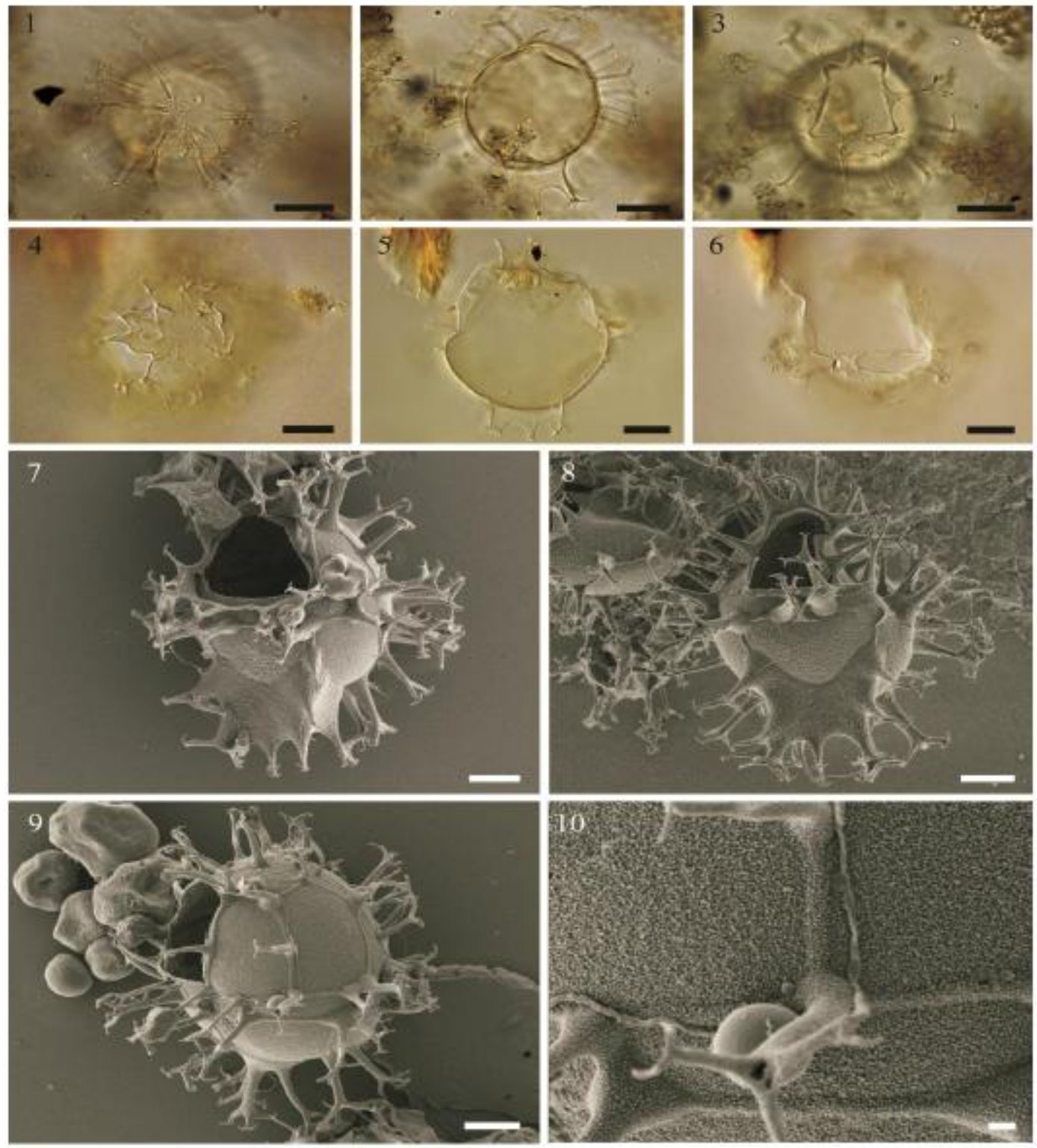

Plate 29 


\section{ACCEPTED MANUSCRIPT}
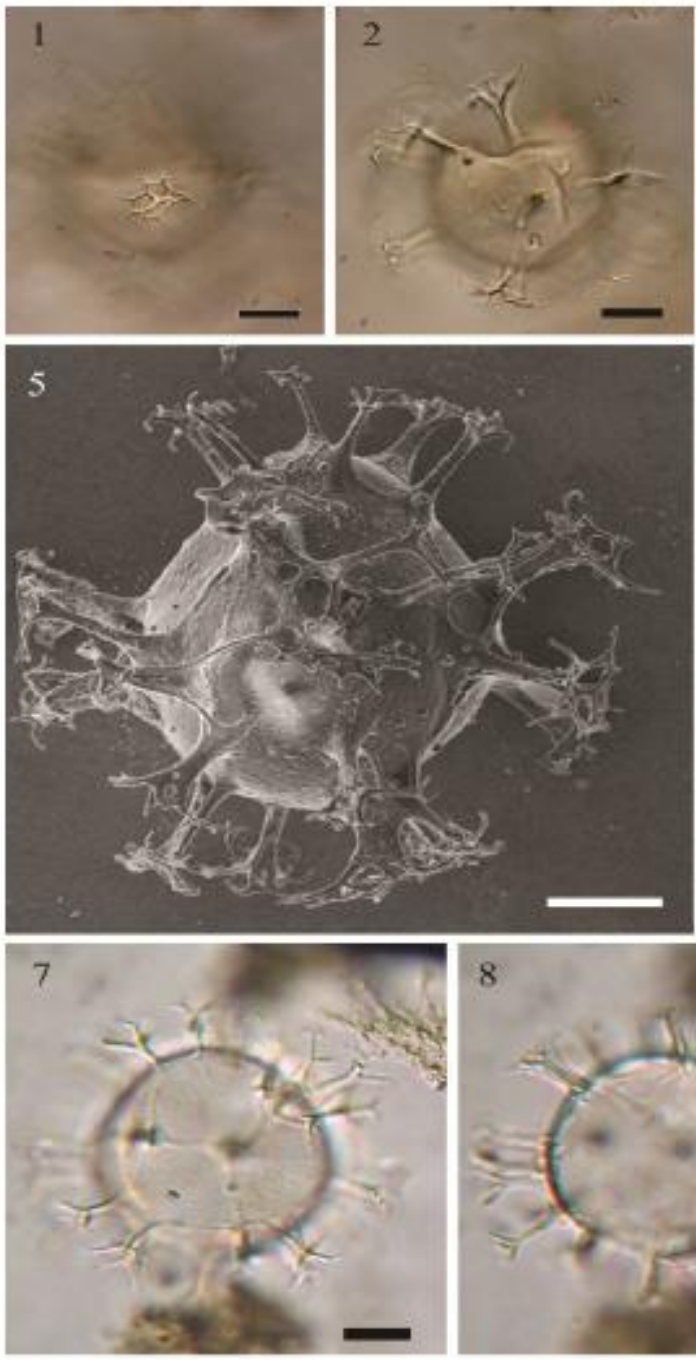
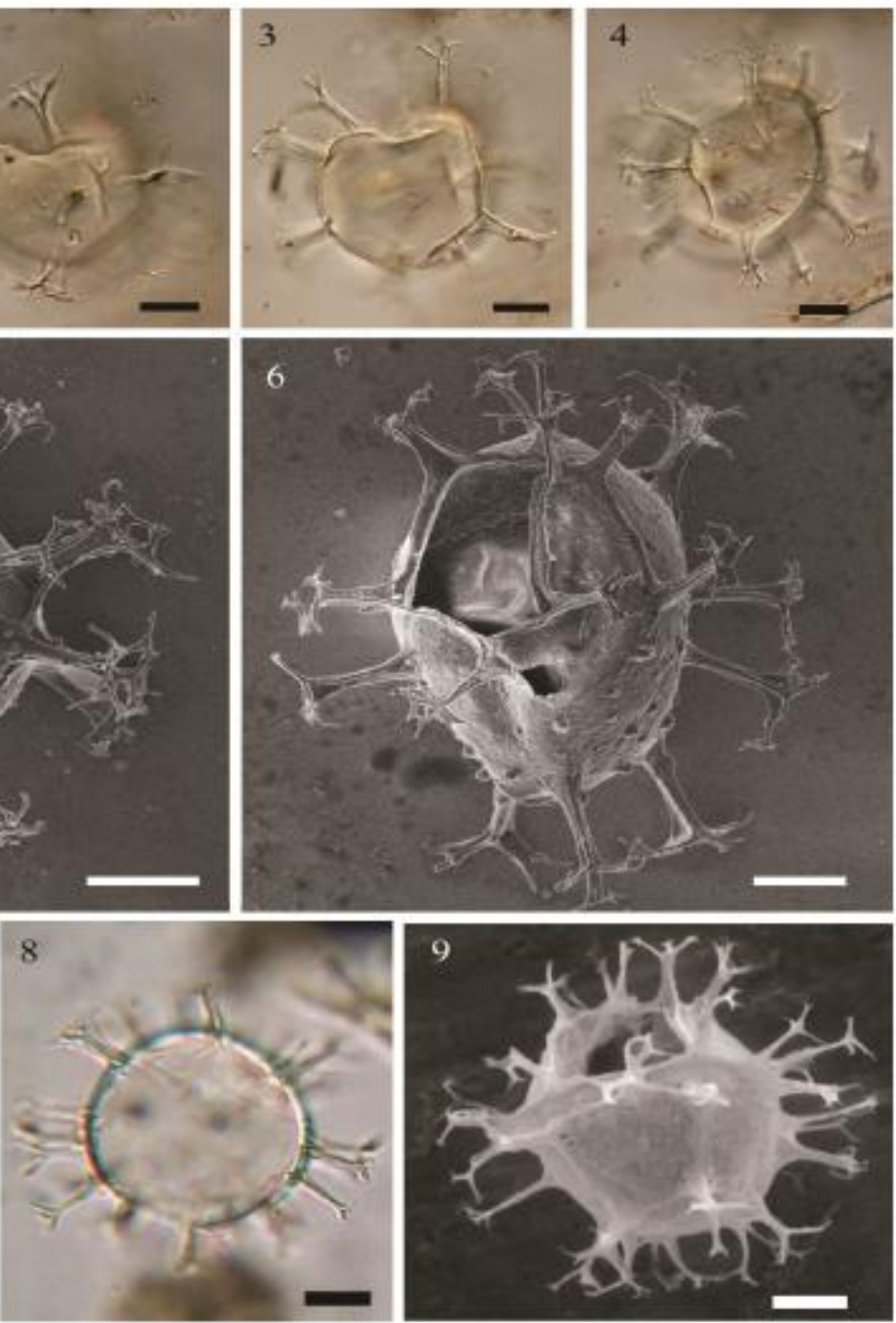

Plate 30 


\section{ACCEPTED MANUSCRIPT}
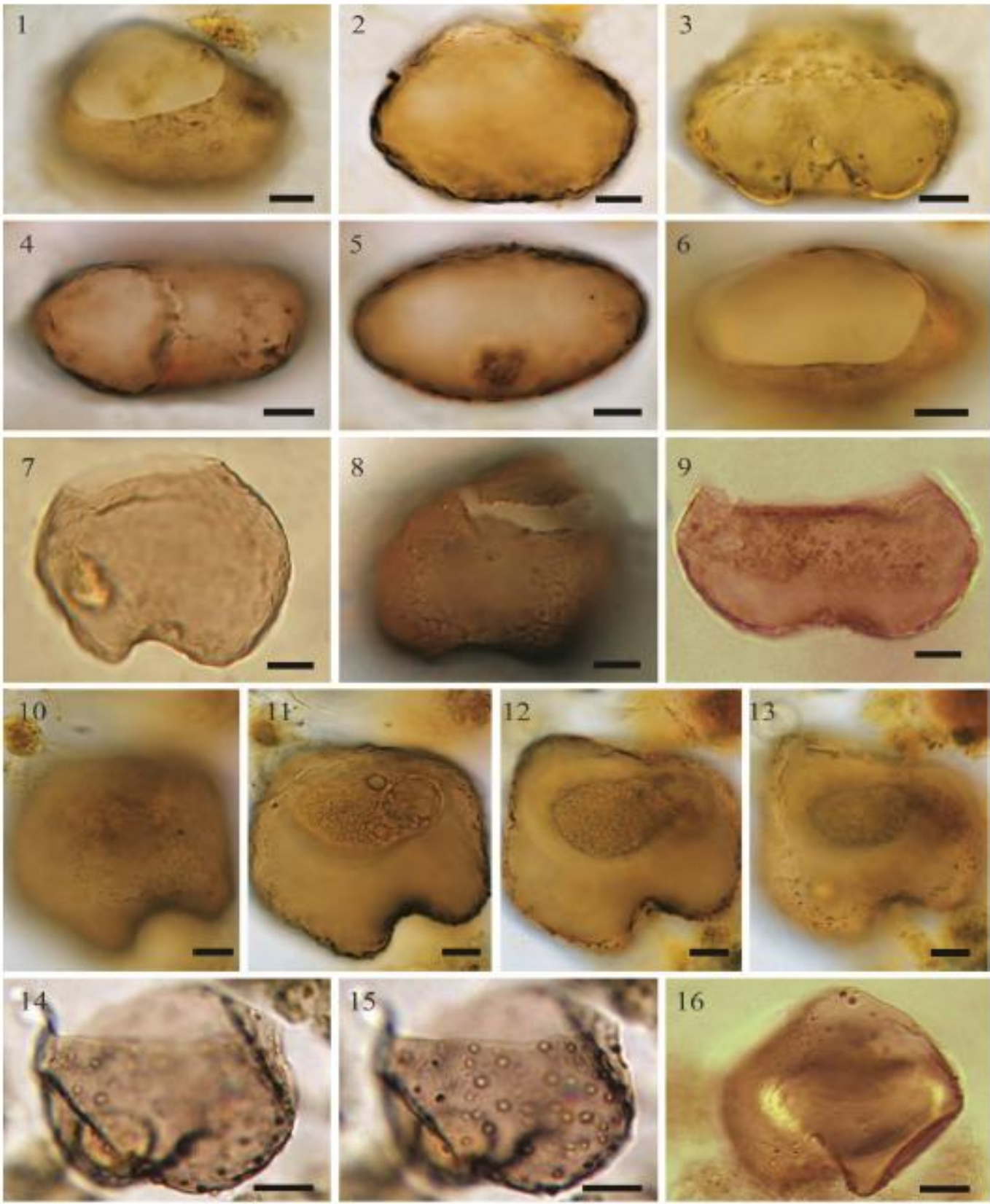

Plate 31 


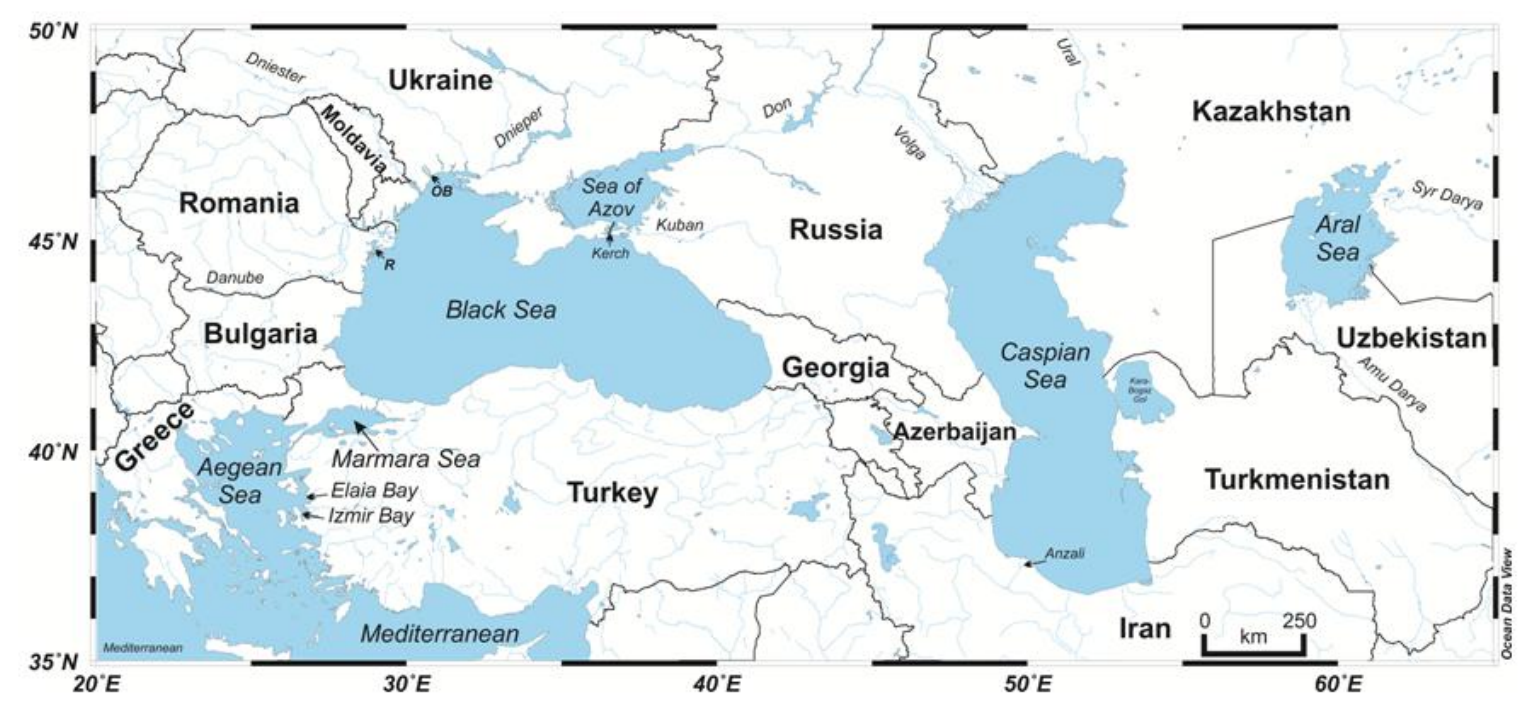

Figure 1 


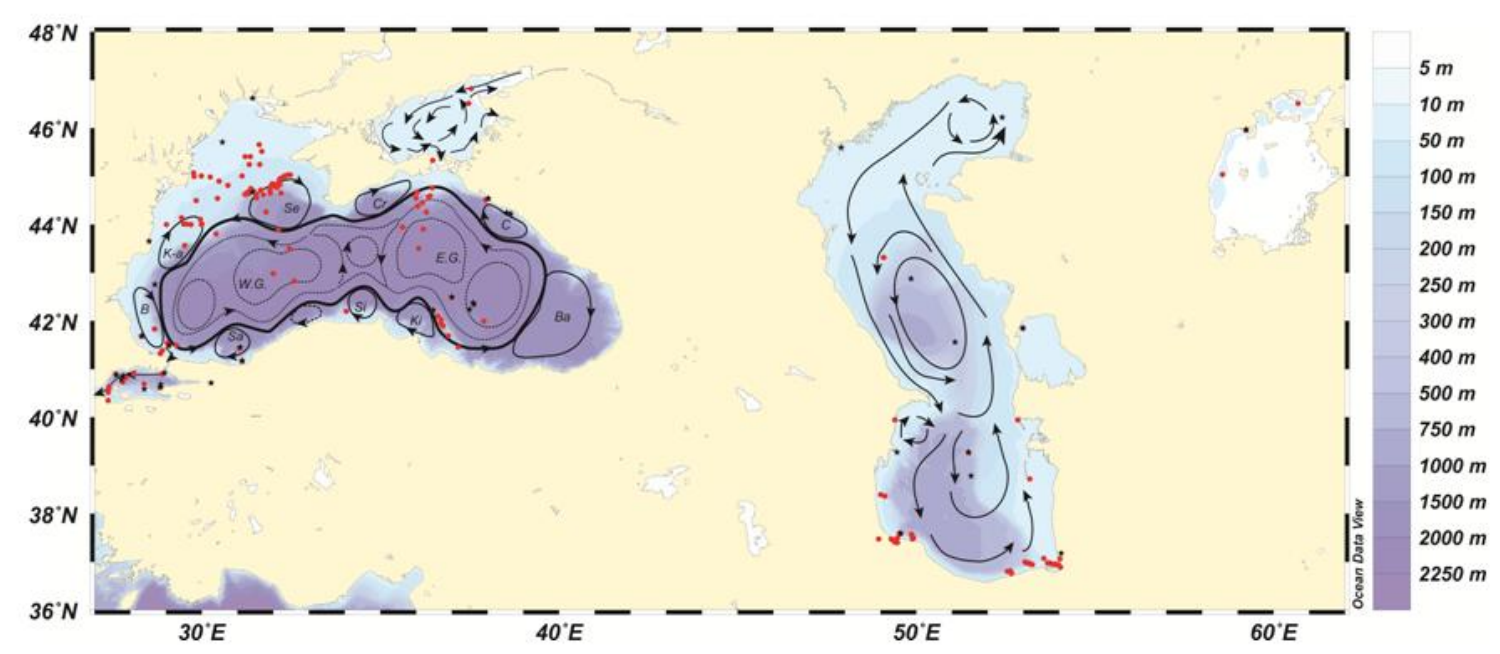

Figure 2 

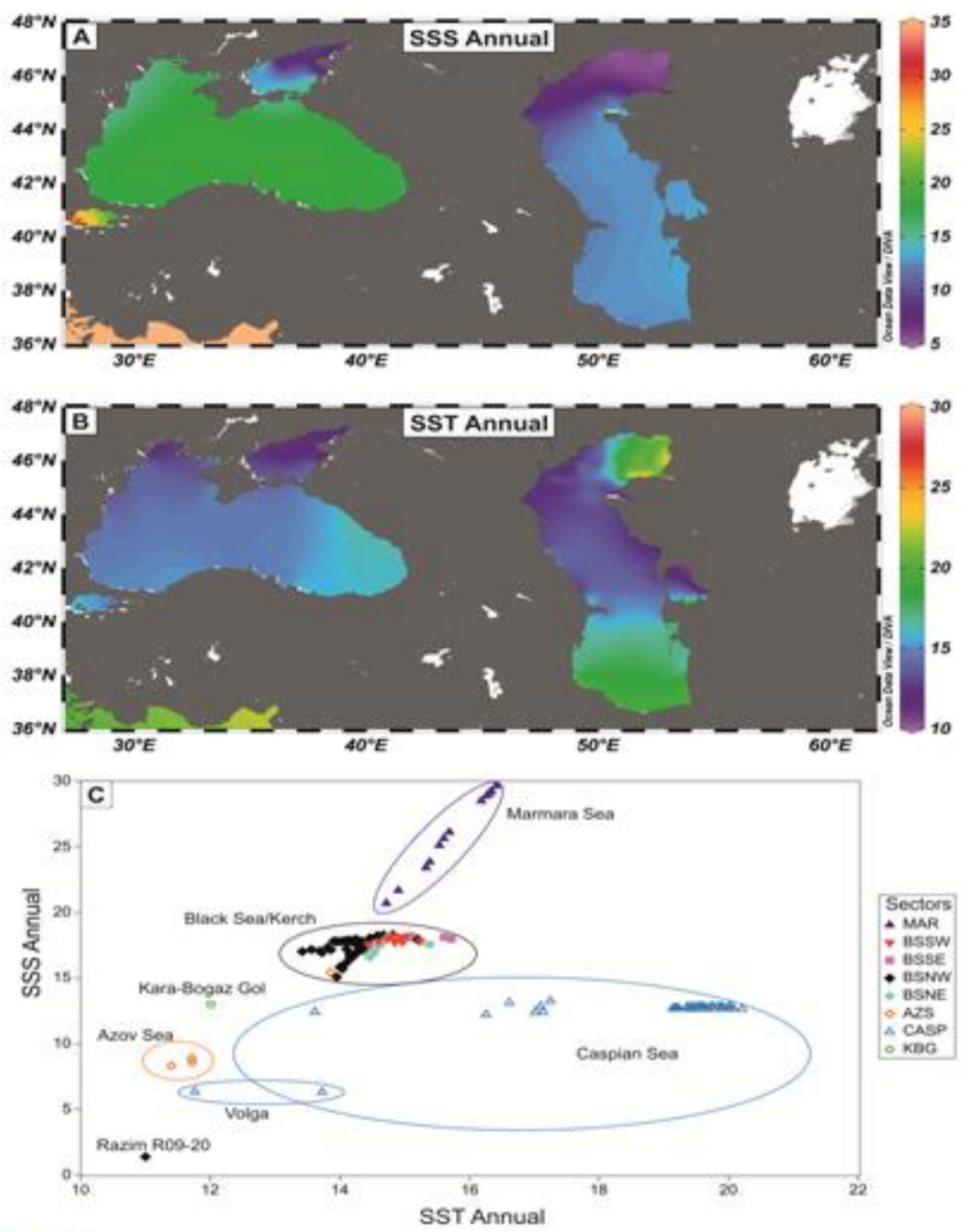

Figure 3 

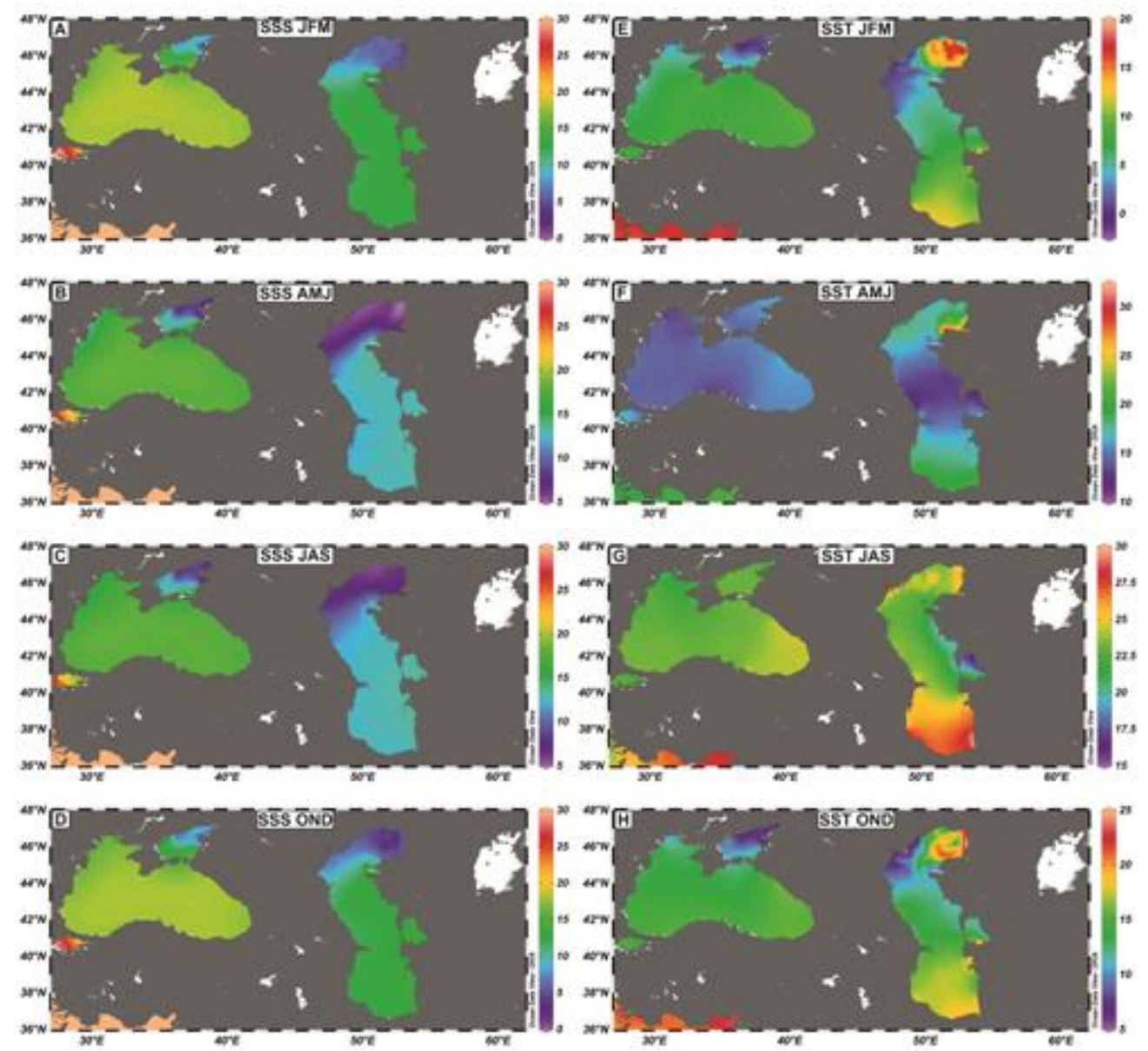

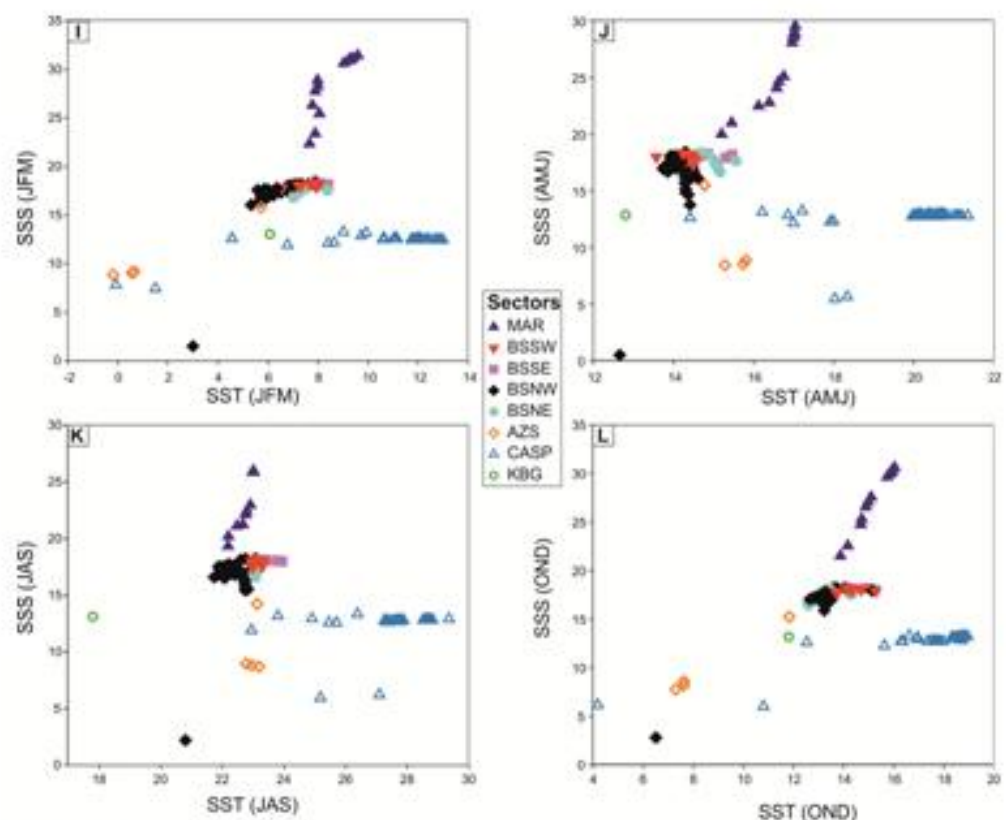

nas

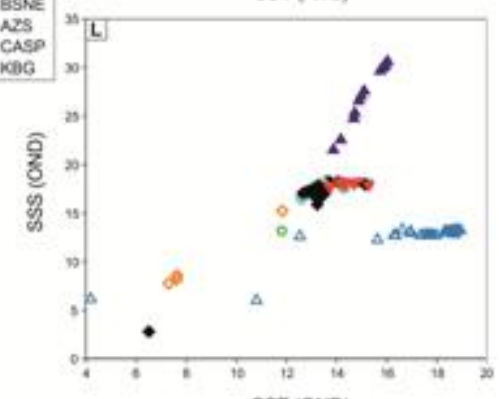

Figure 4

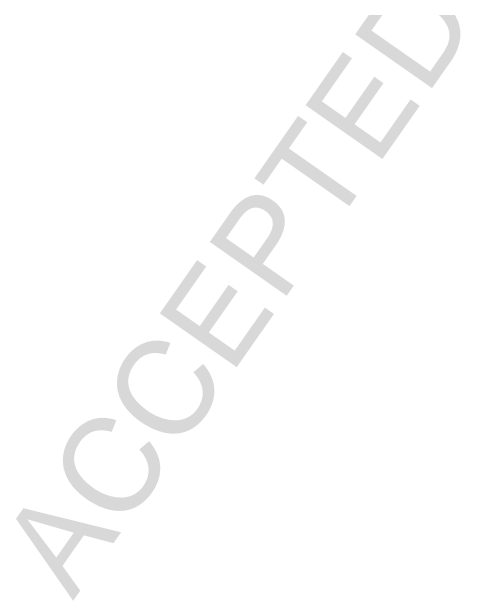






Figure 5

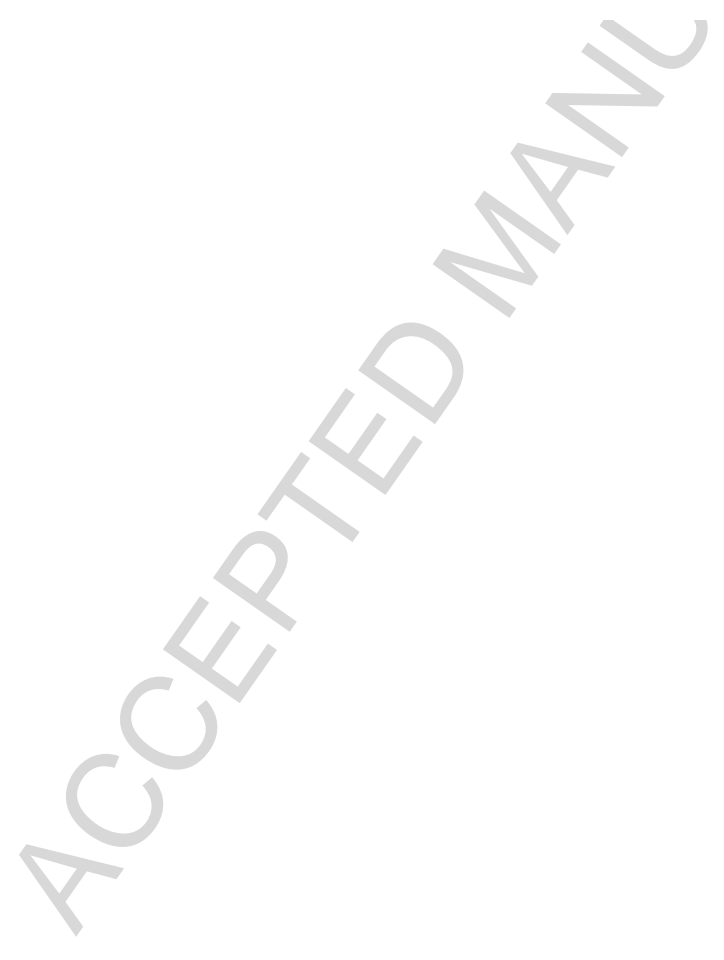




\section{ACCEPTED MANUSCRIPT}

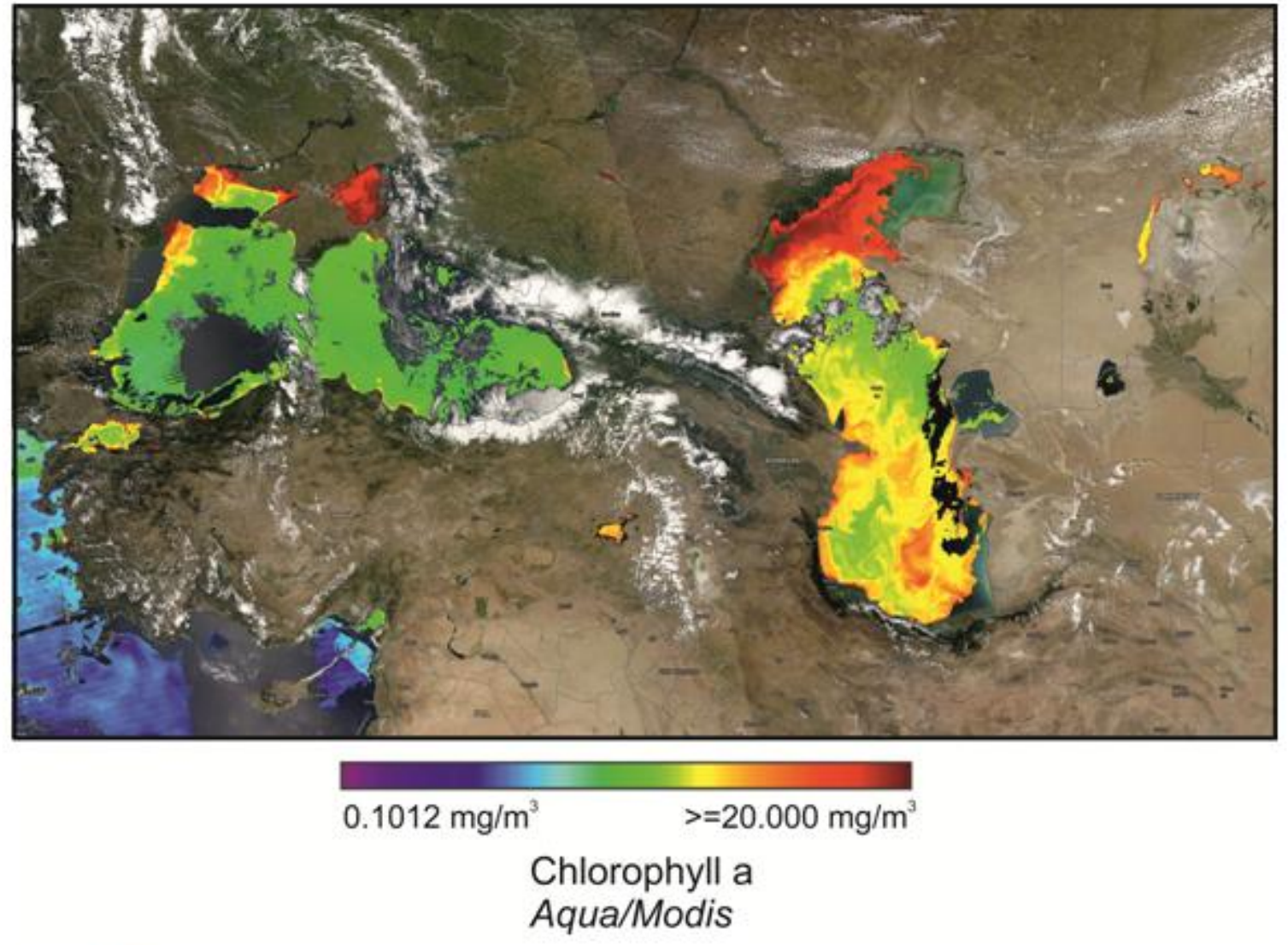

Figure 6

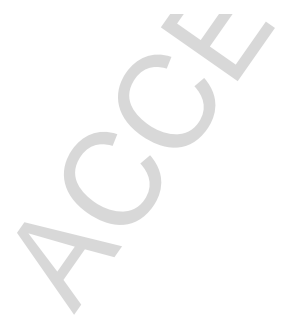



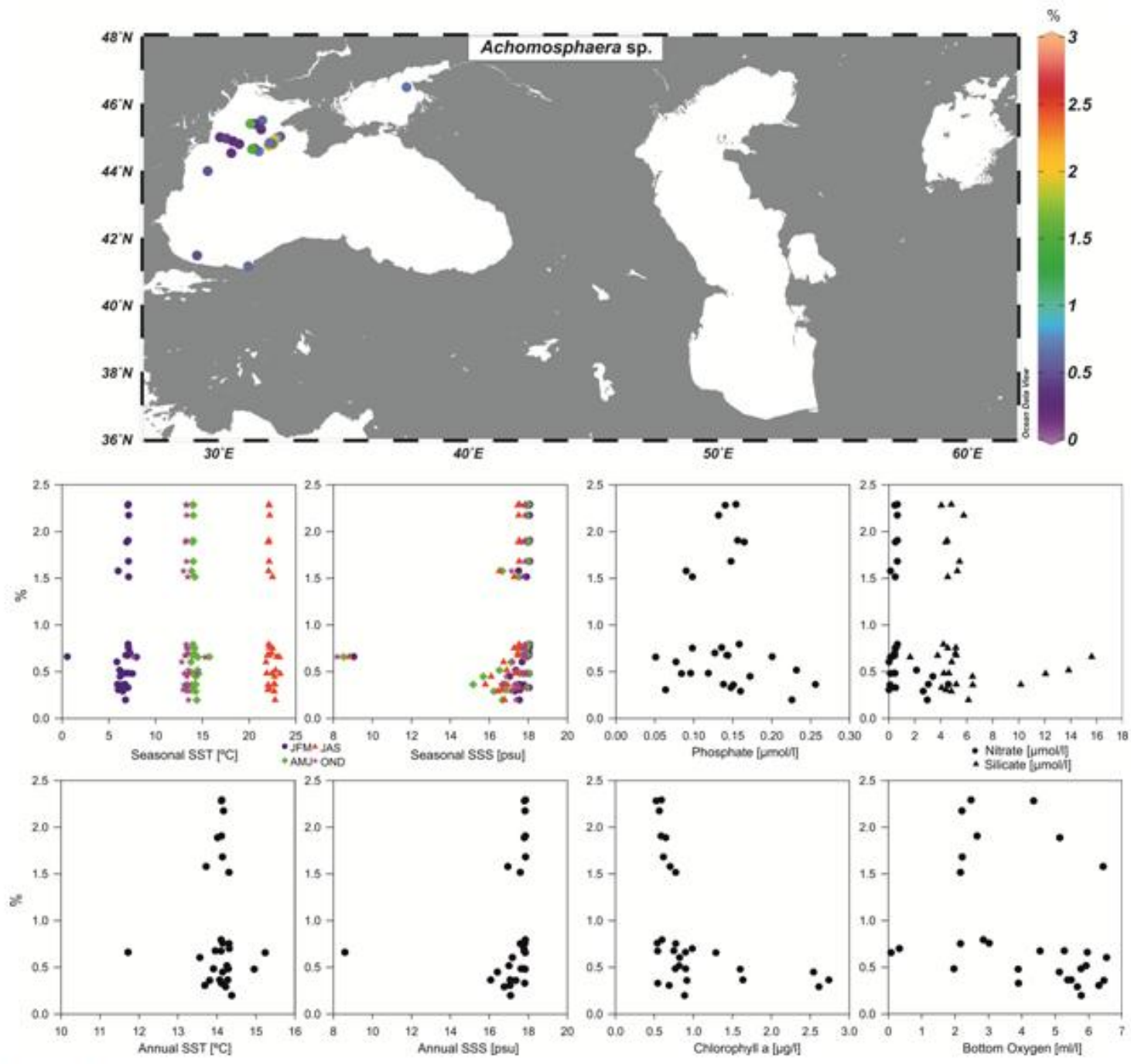

Figure 7 

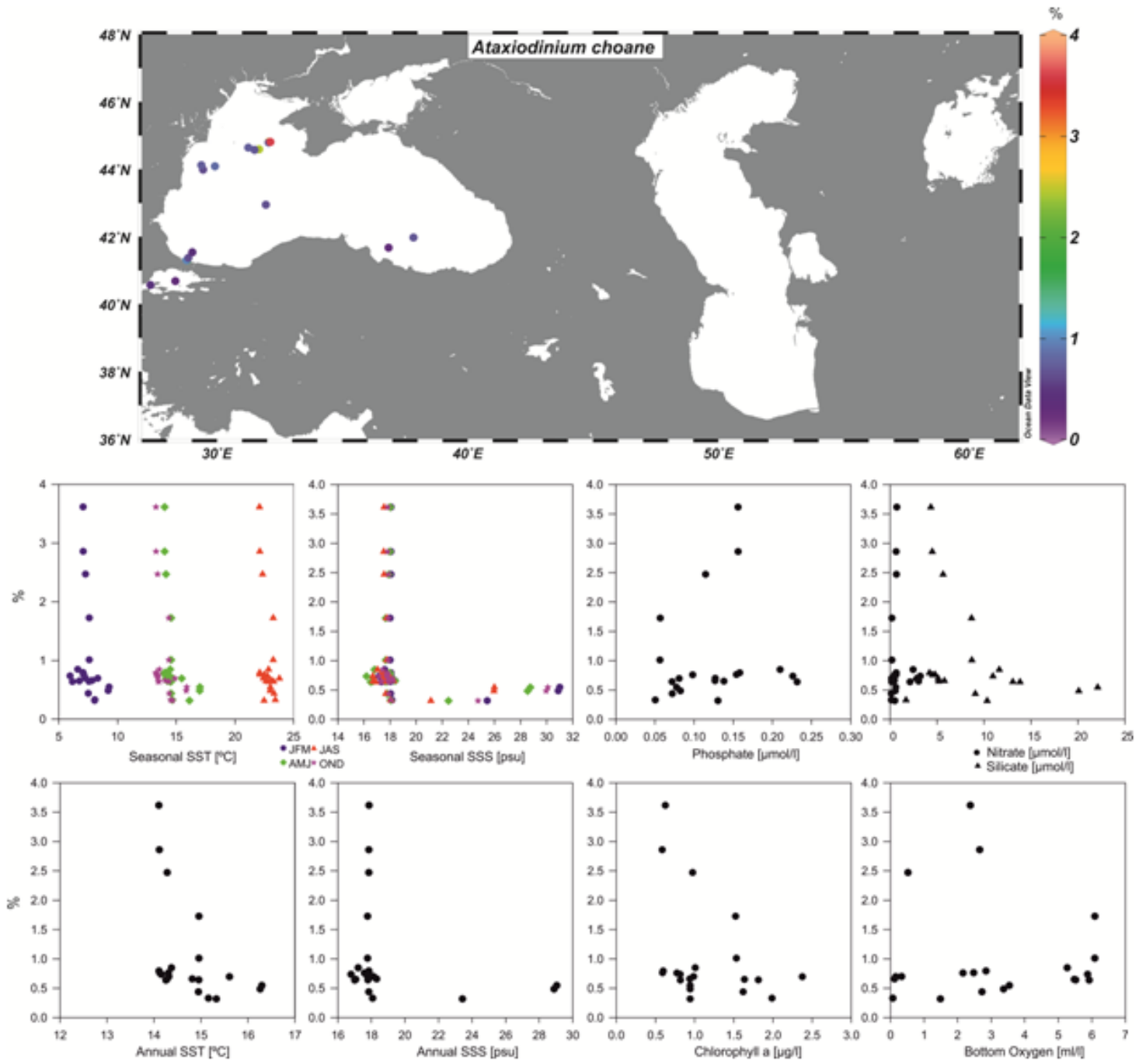

Figure 8 

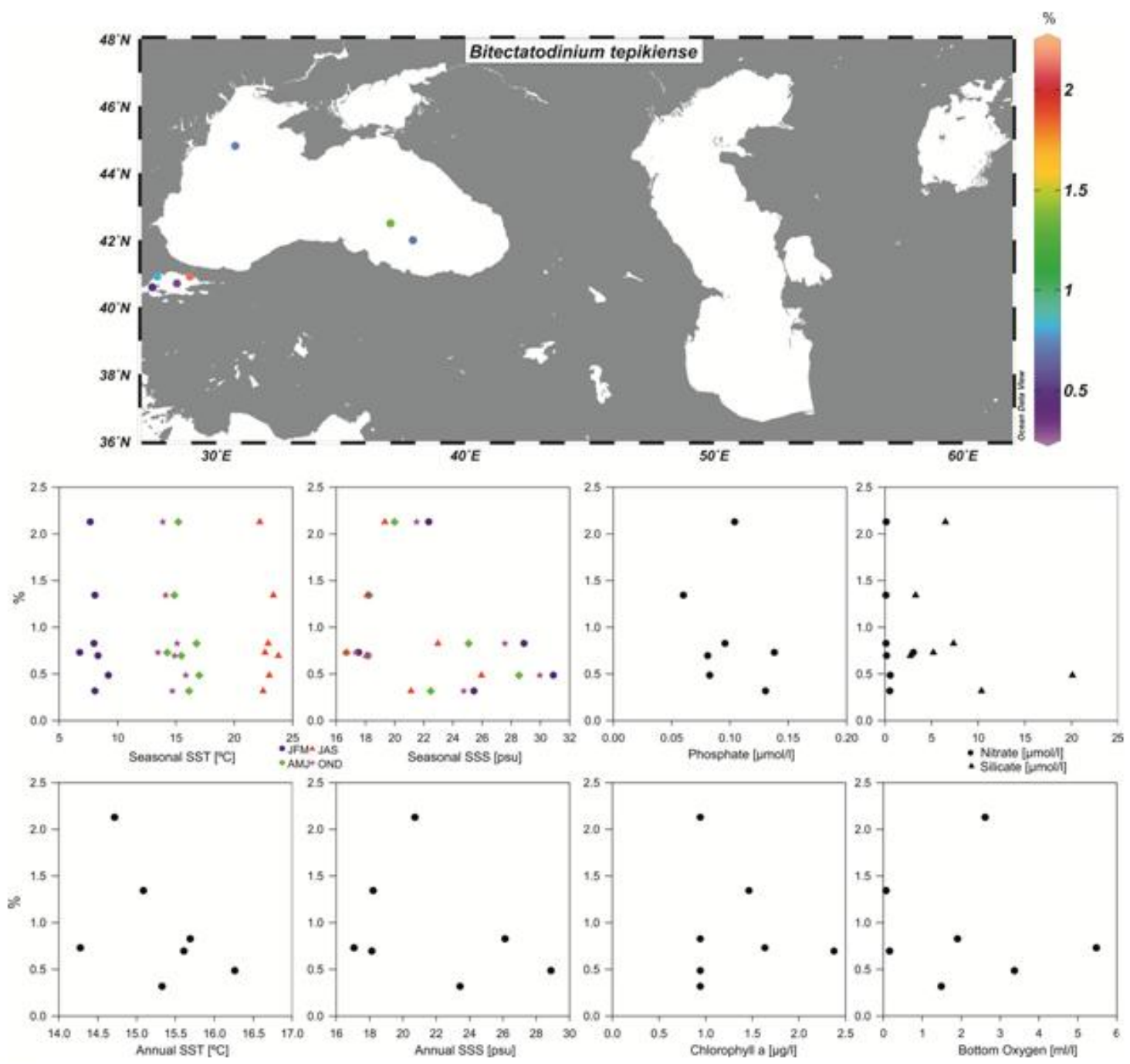

Figure 9 



Figure 10 

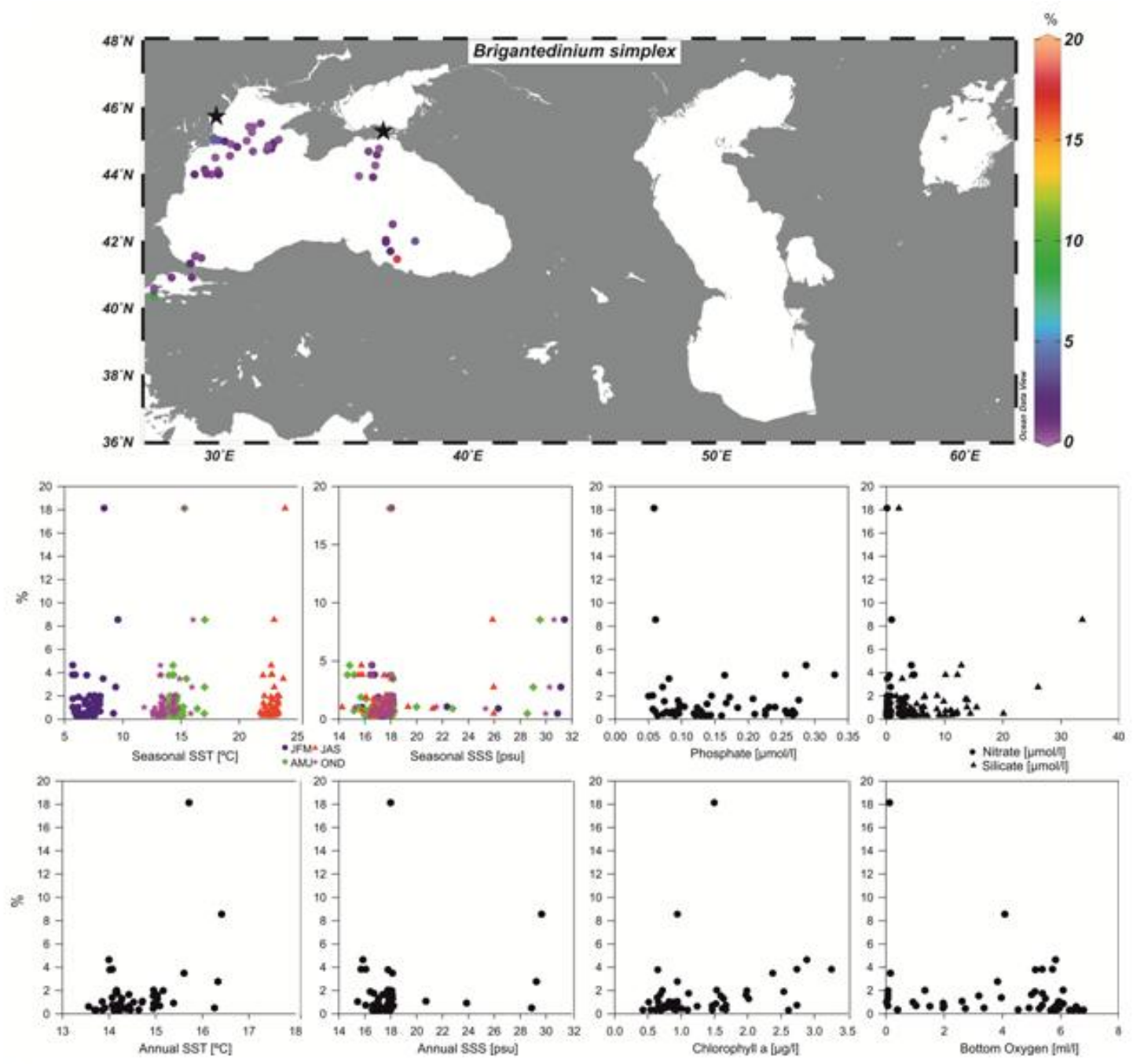

Figure 11 

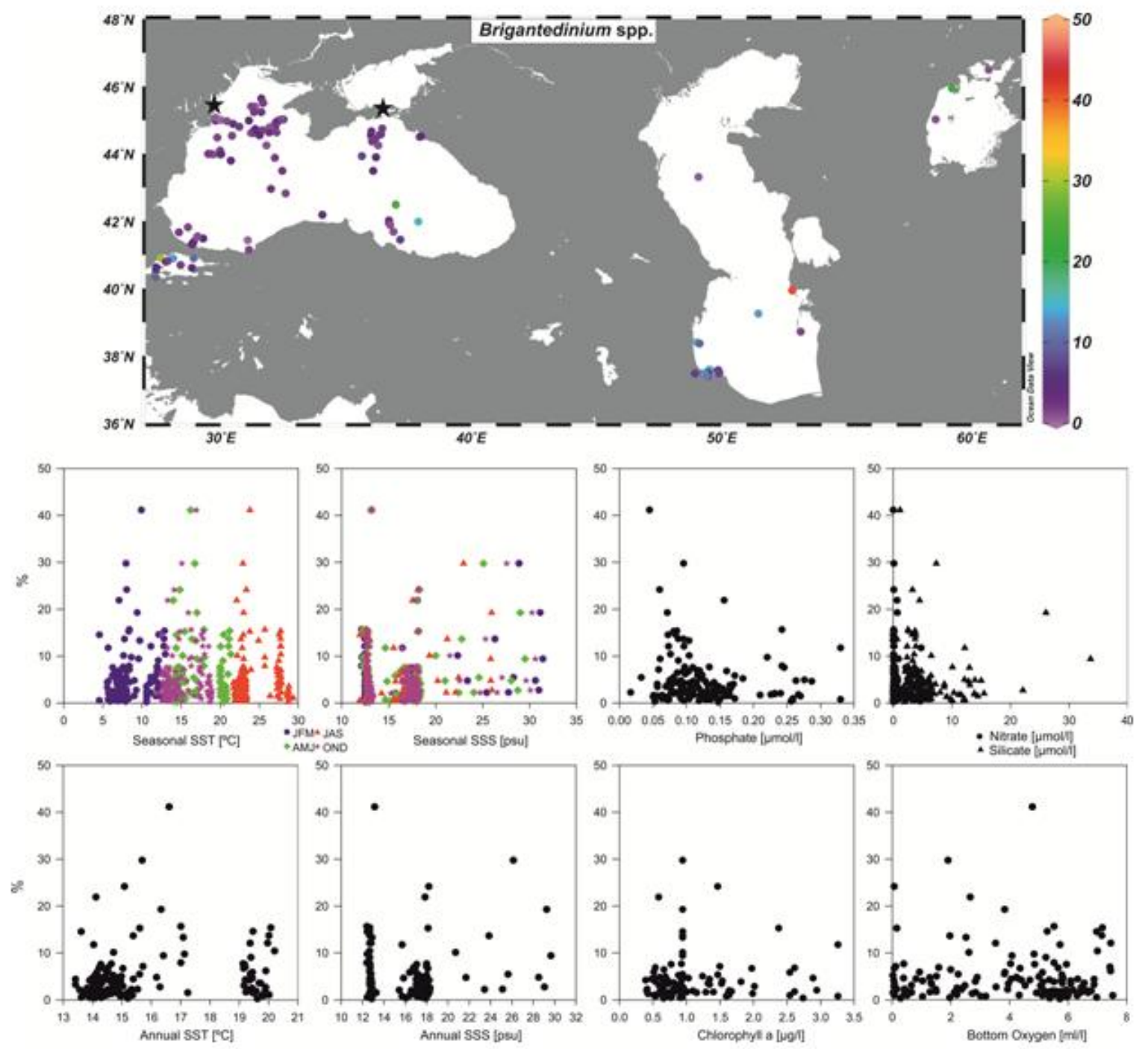

Figure 12 

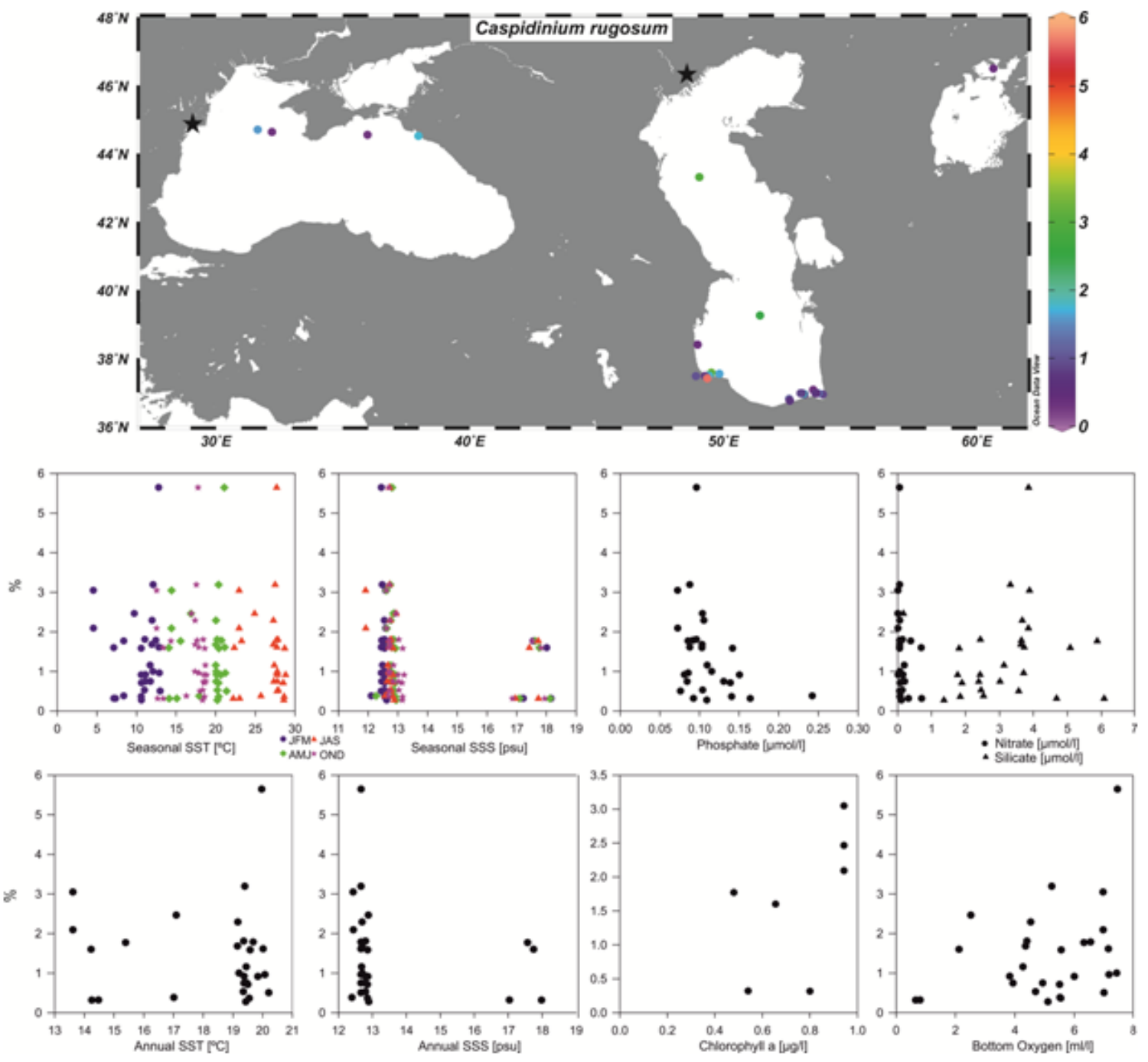

Figure 13 

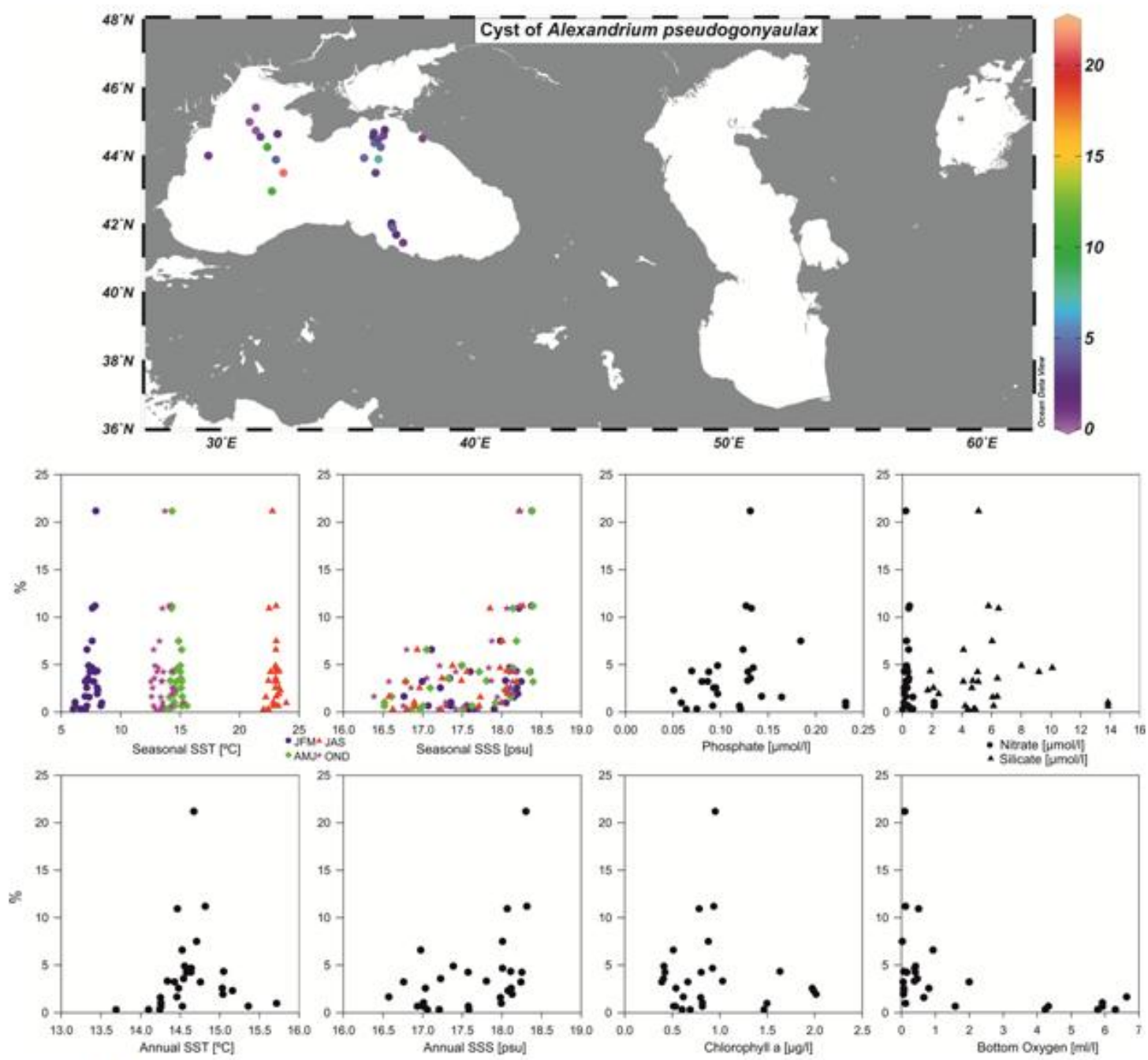

Figure 14 

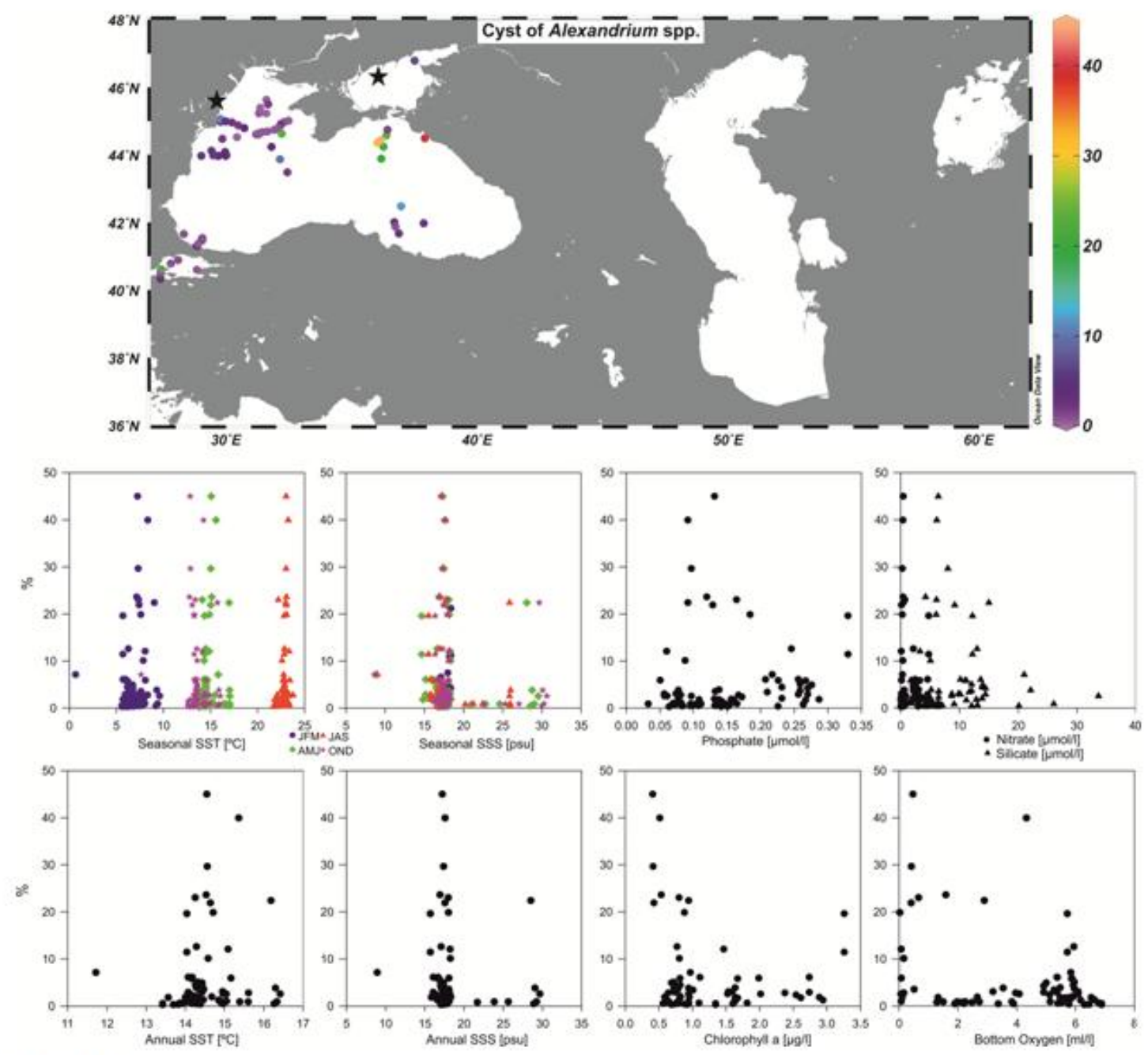

Figure 15 

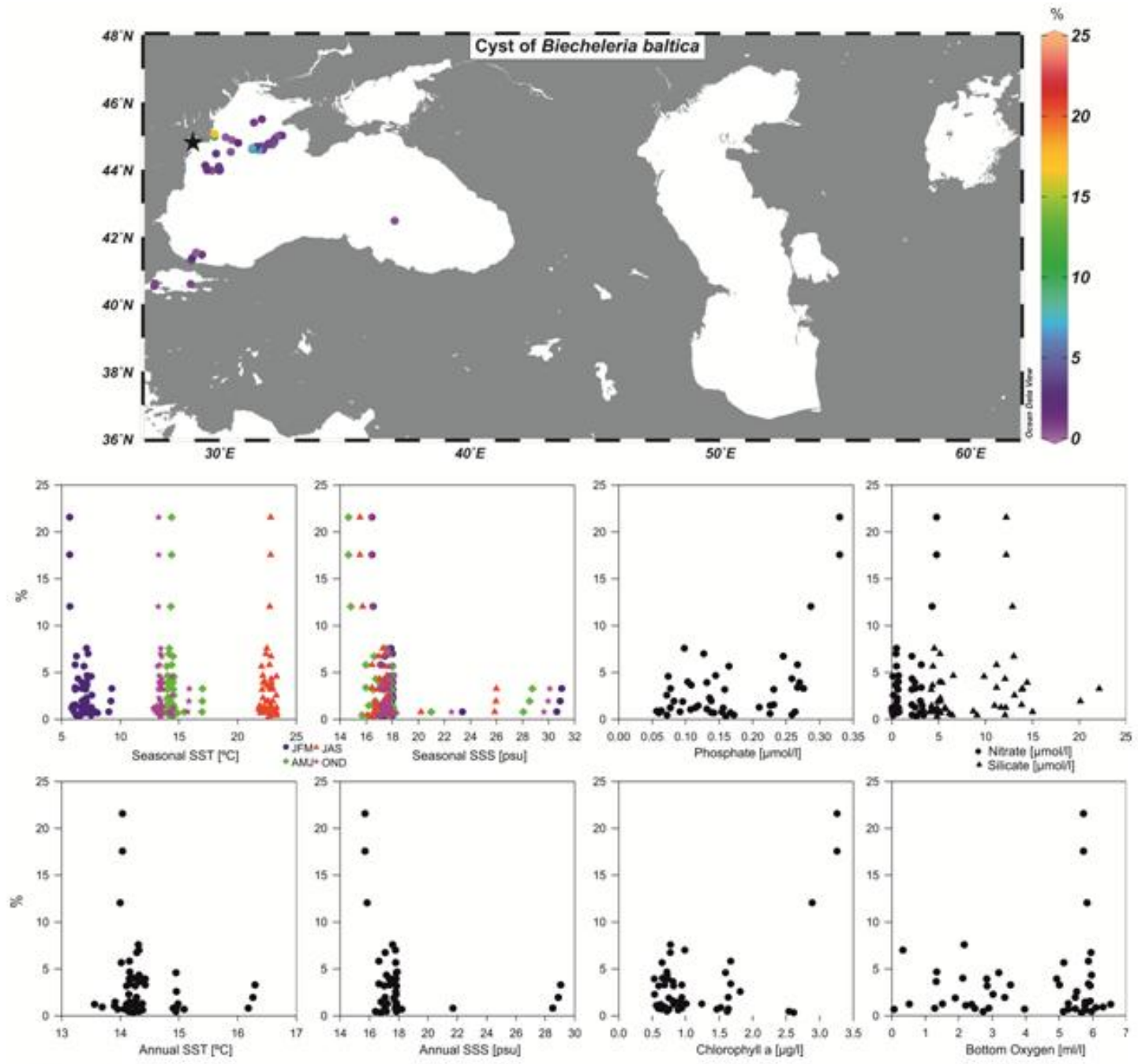

Figure 16 

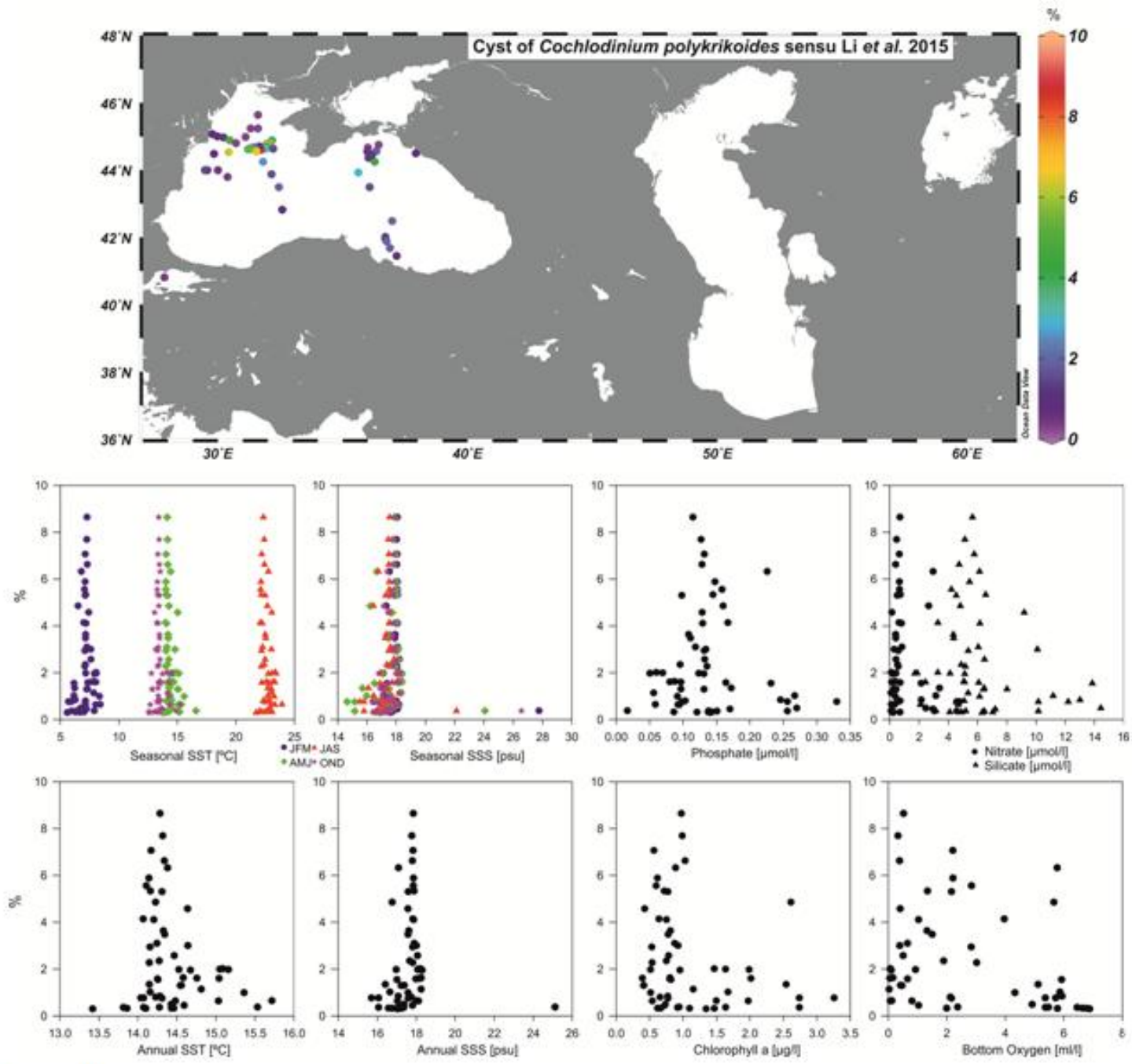

Figure 17 

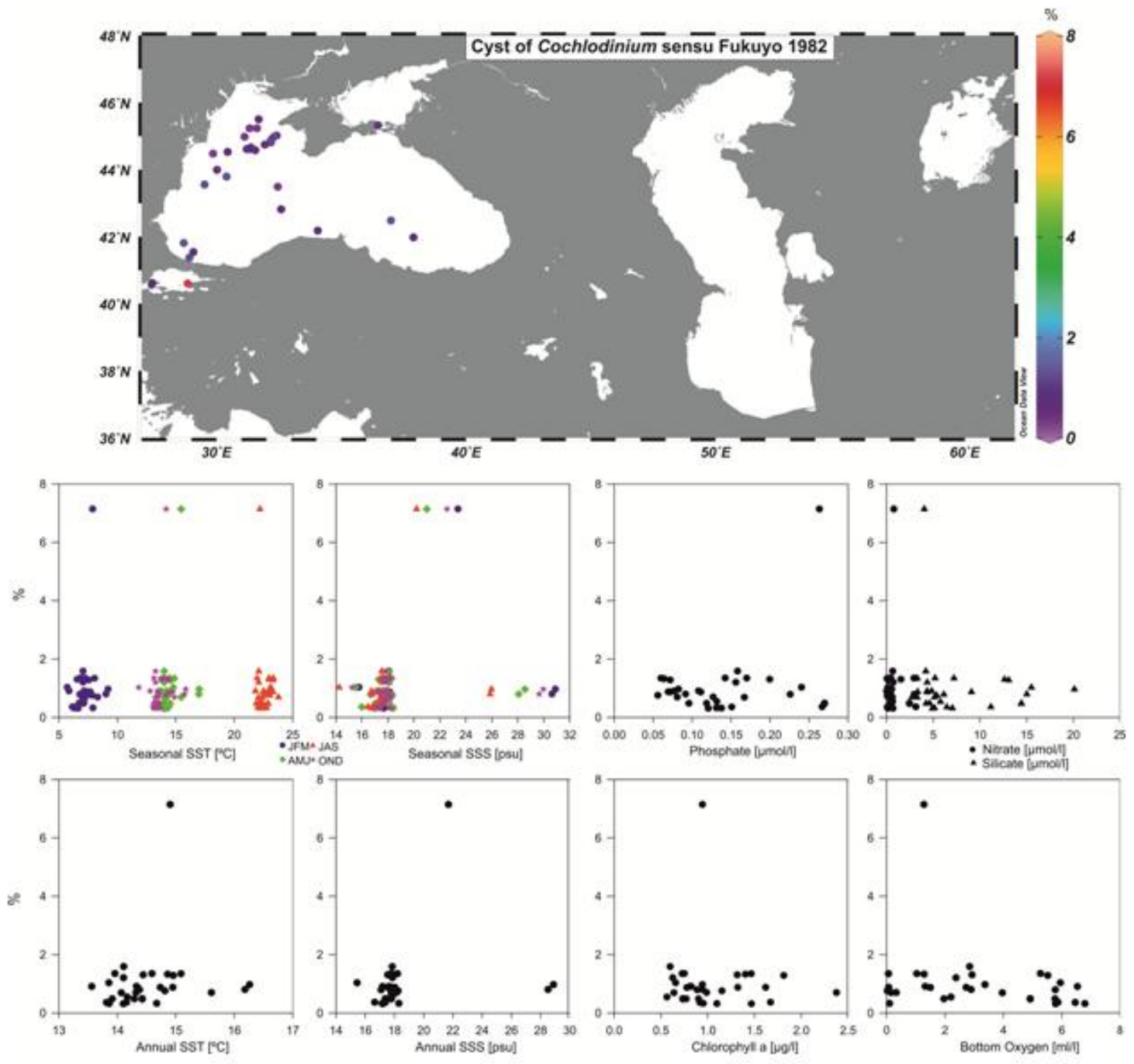

Figure 18 

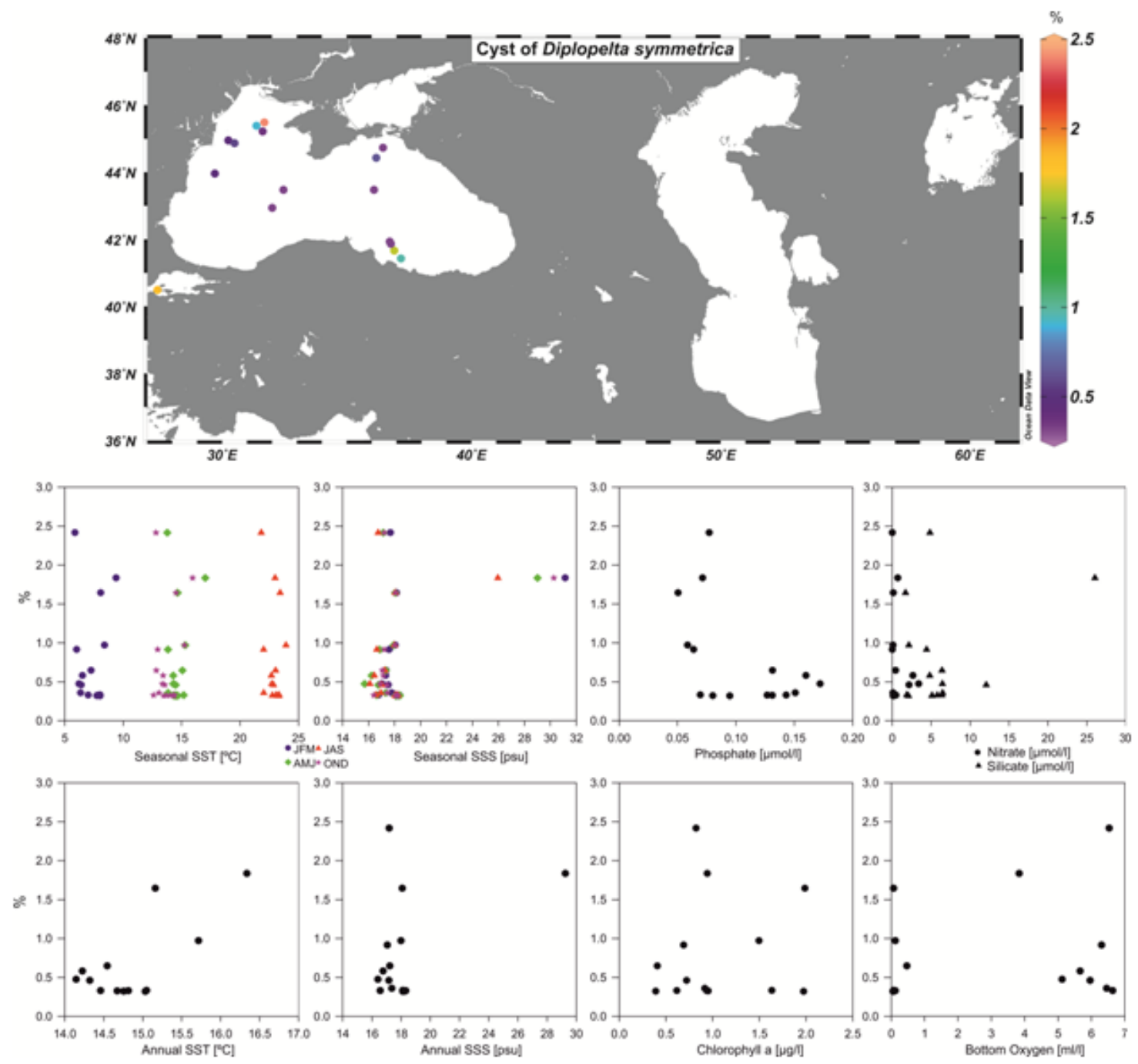

Figure 19 

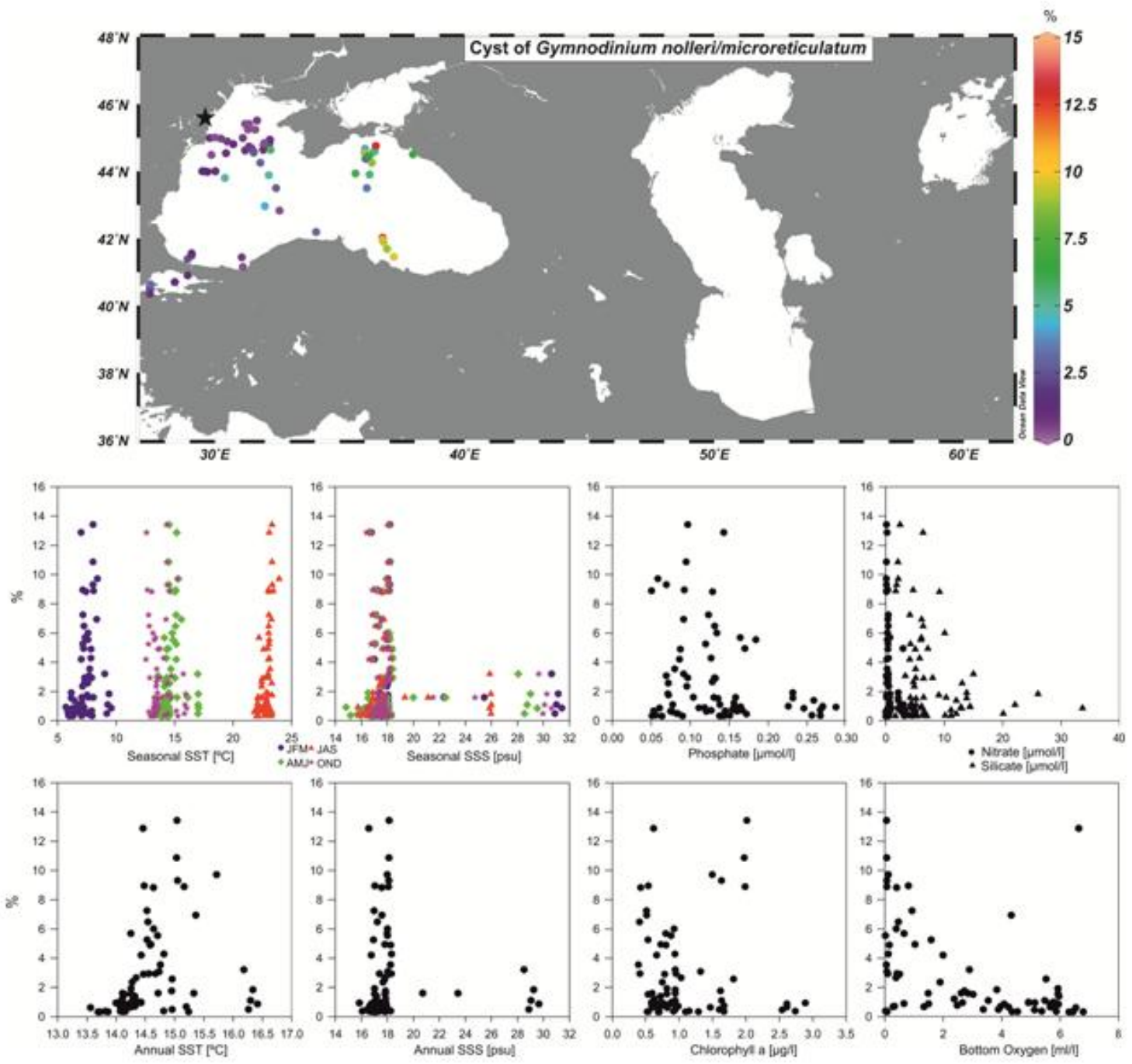

Figure 20 


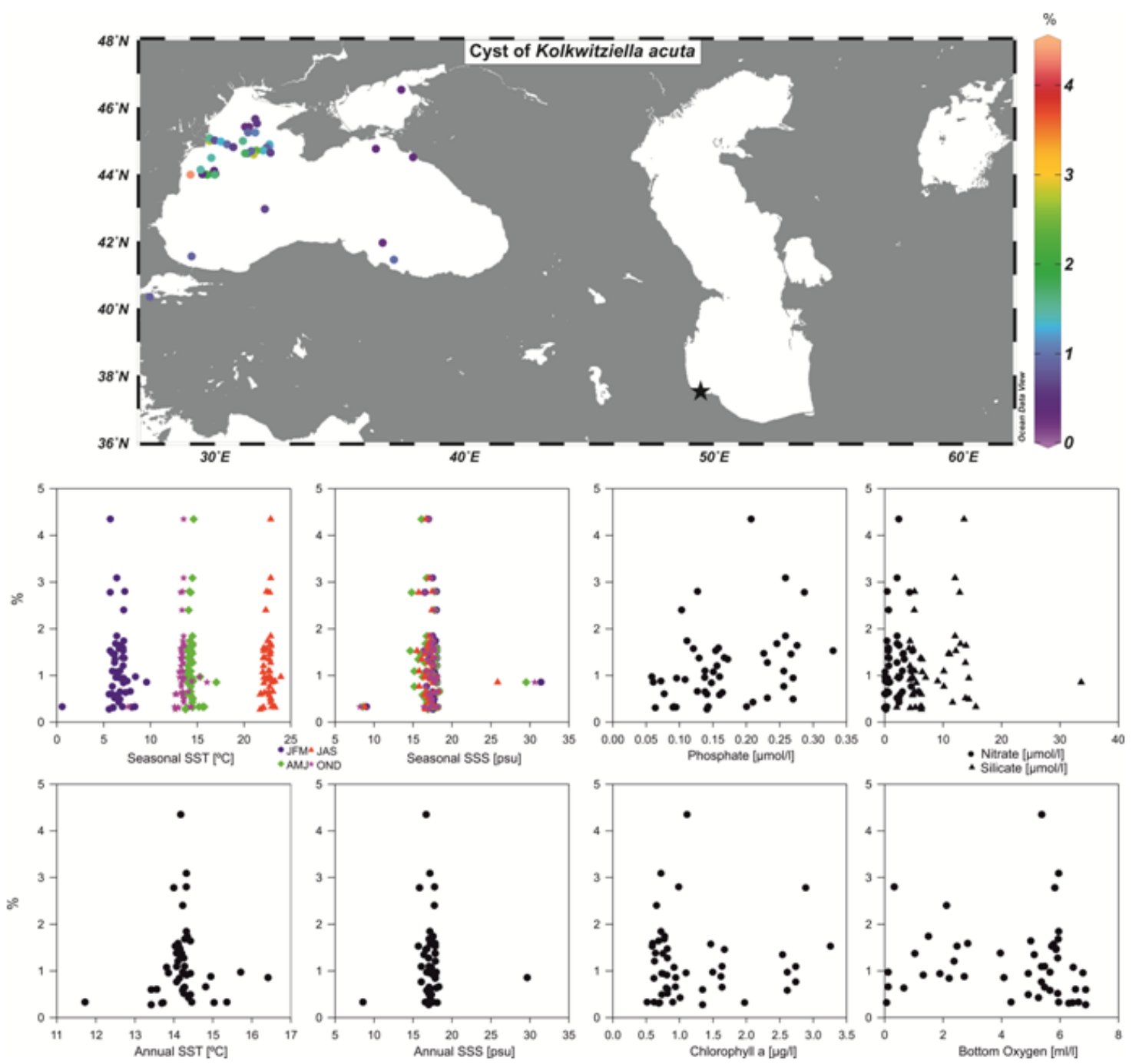

Figure 21 



Figure 22| 

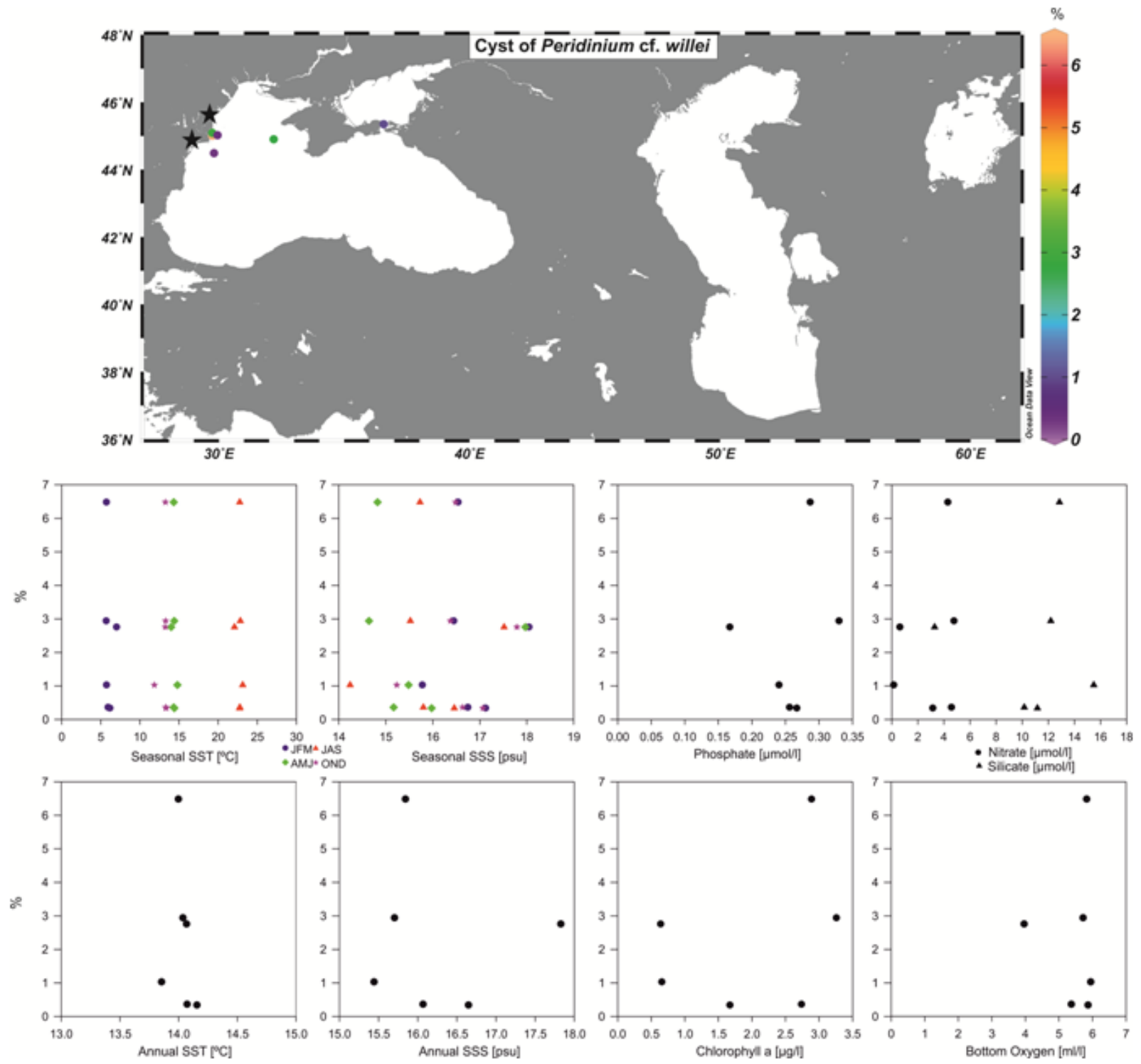

Figure 23 

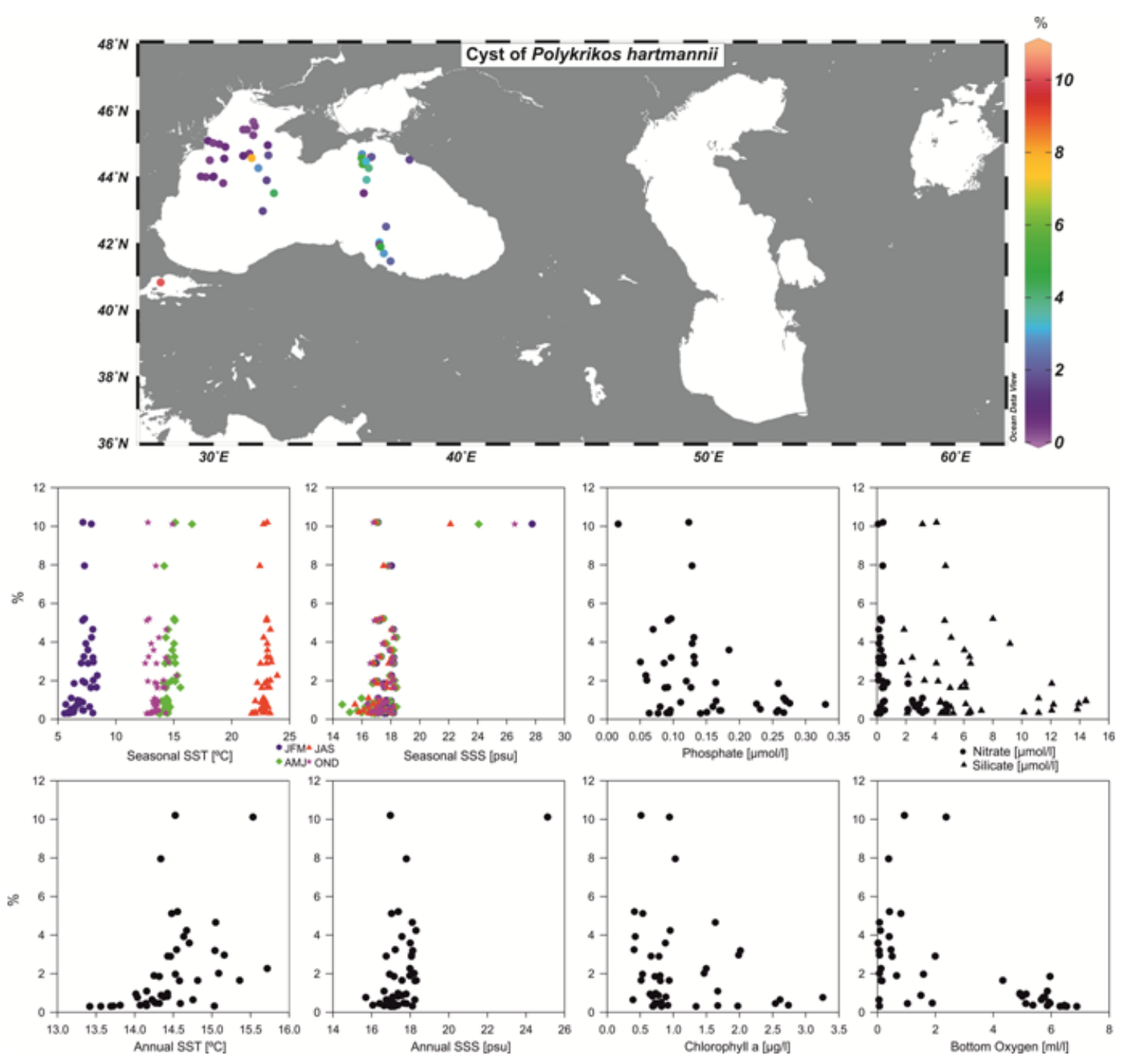

Figure 24 

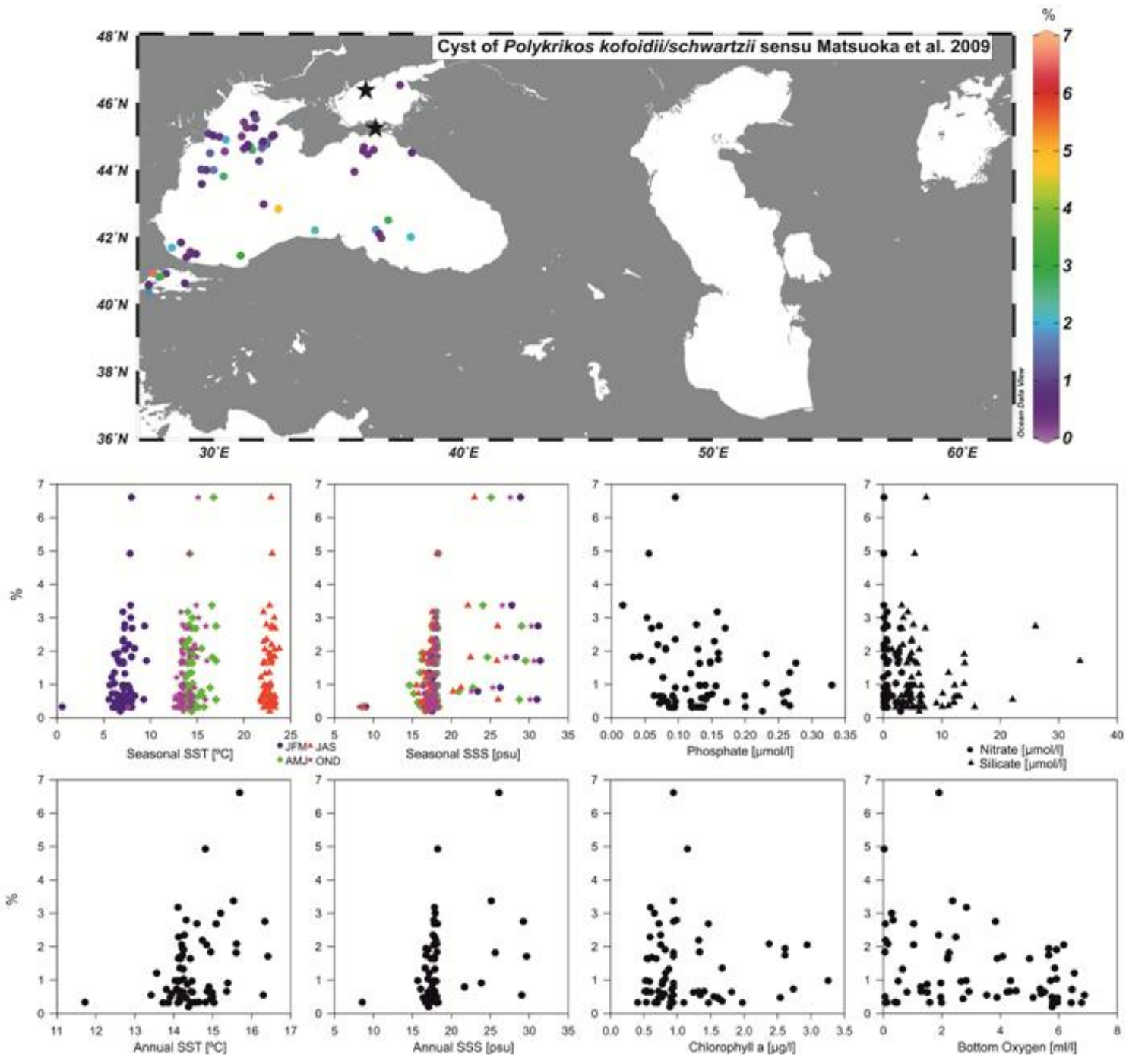

Figure 25 

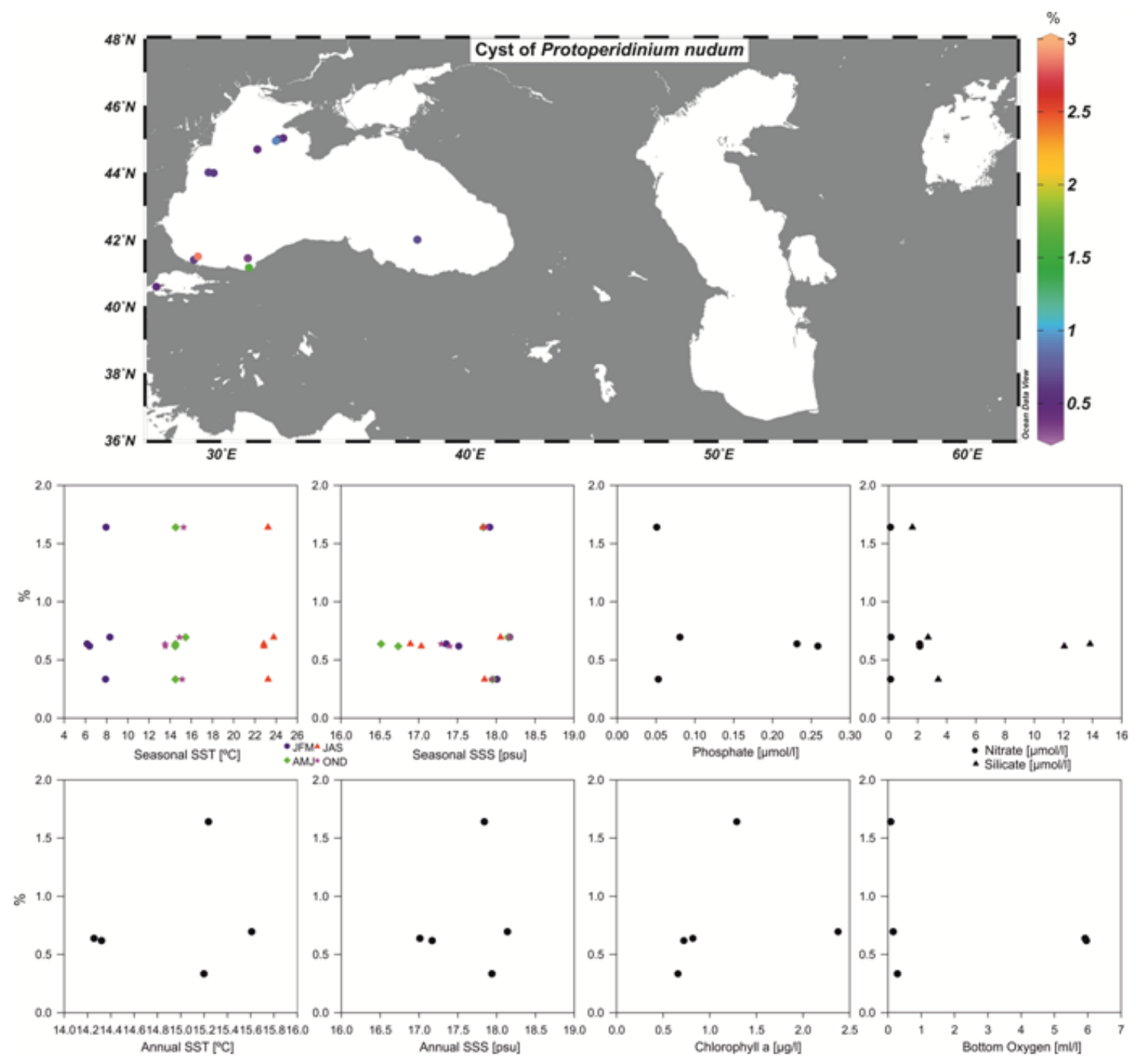

Figure 26 

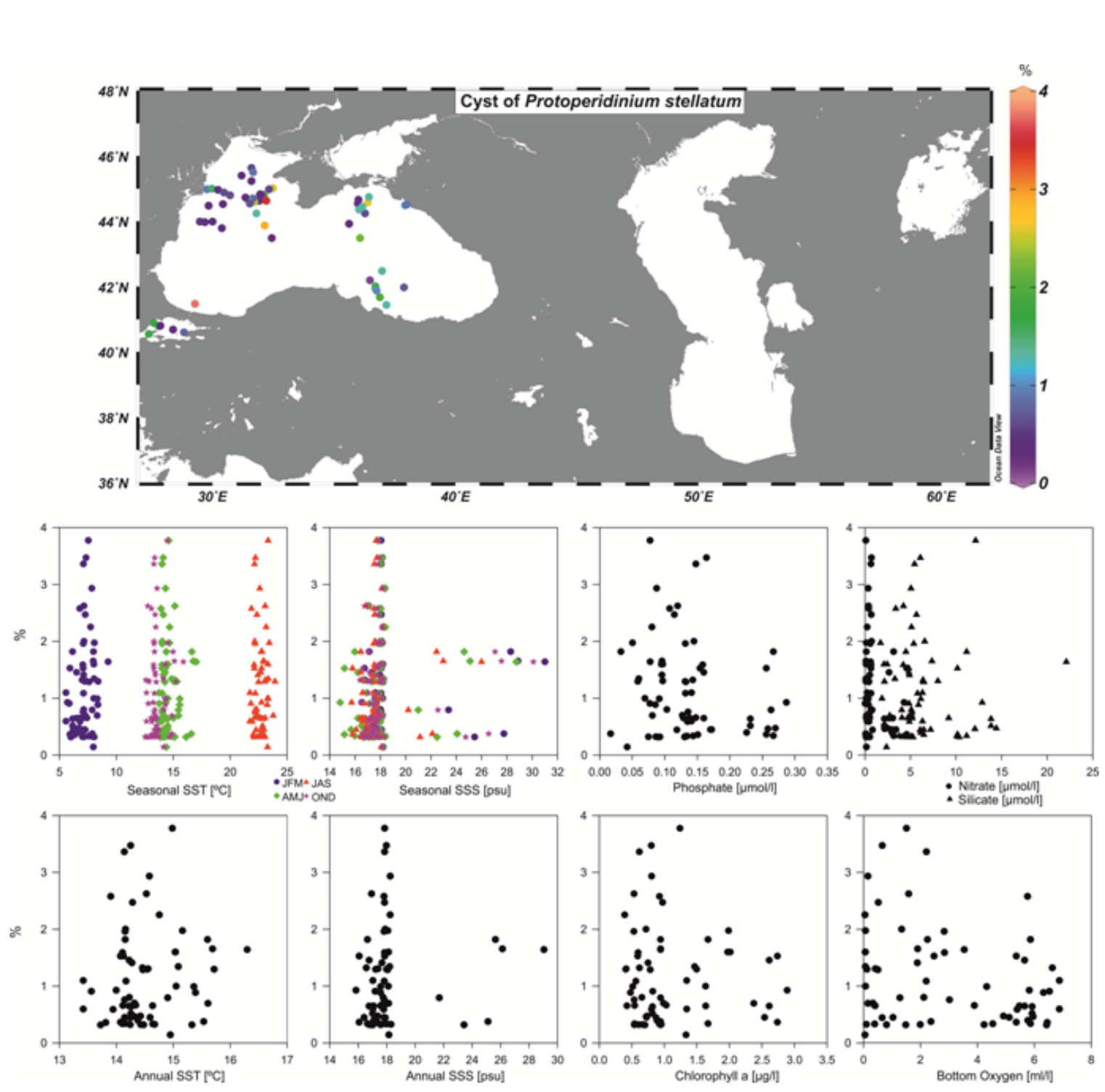

Figure 27 

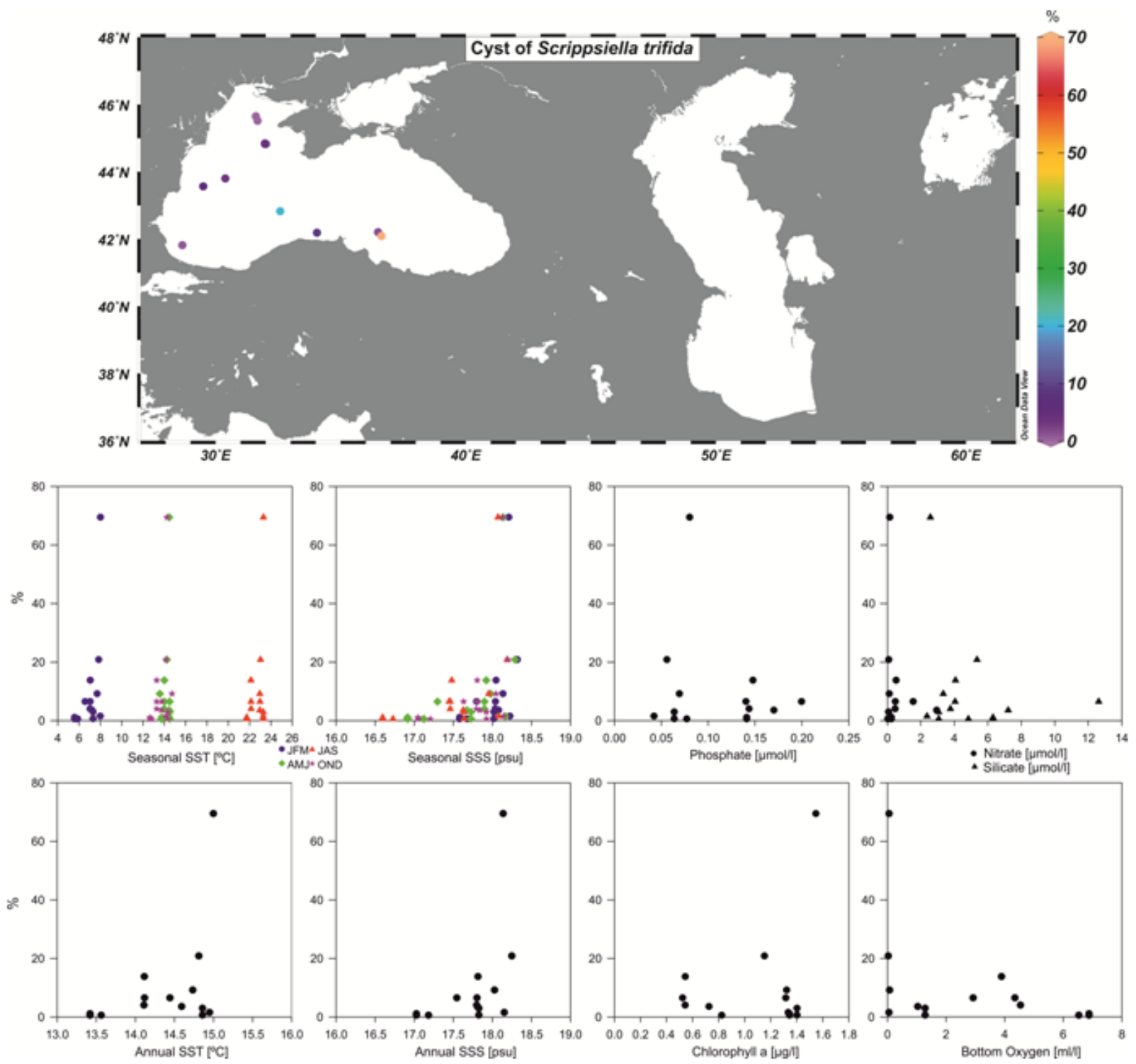

Figure 28 

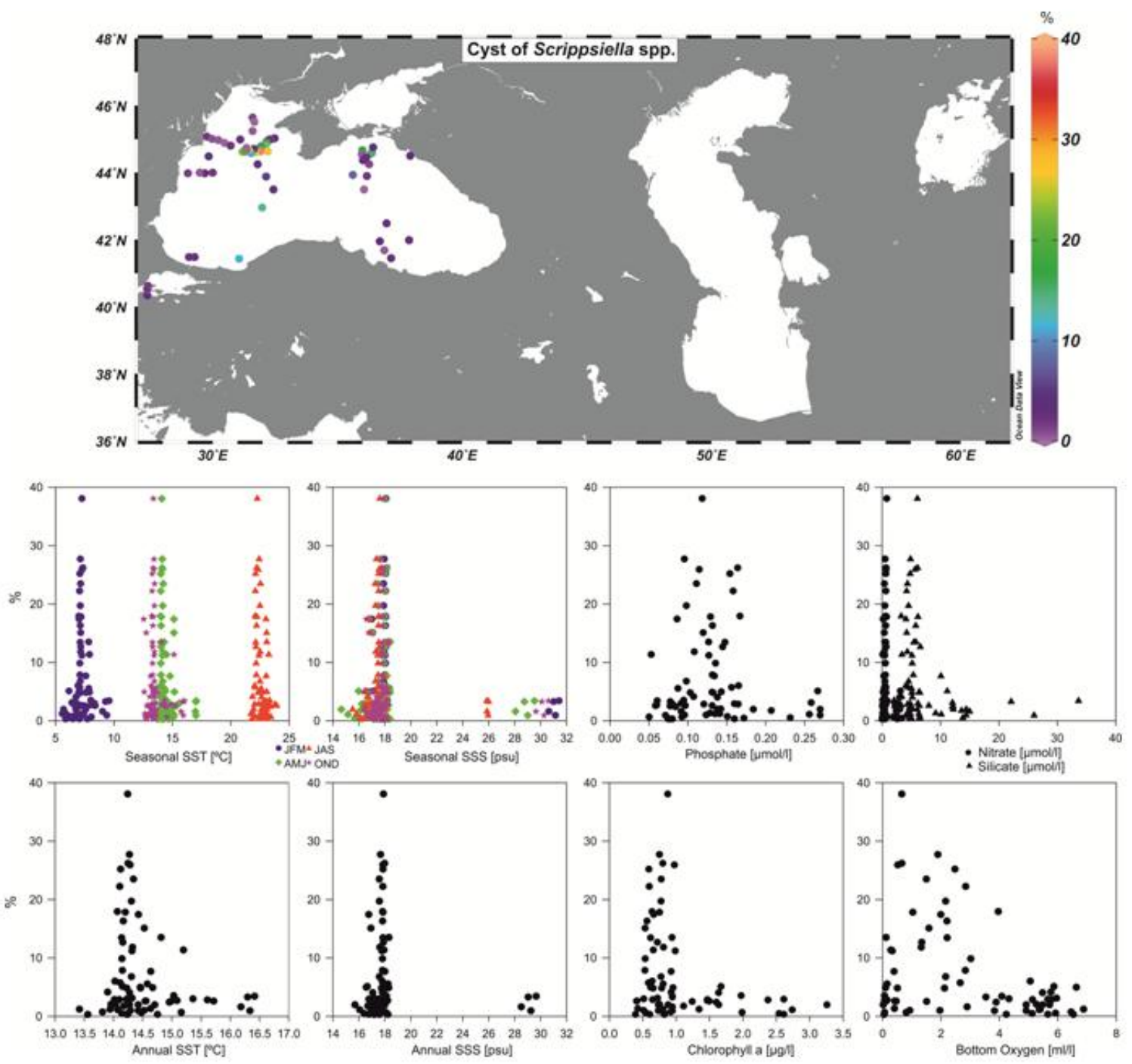

Figure 29 


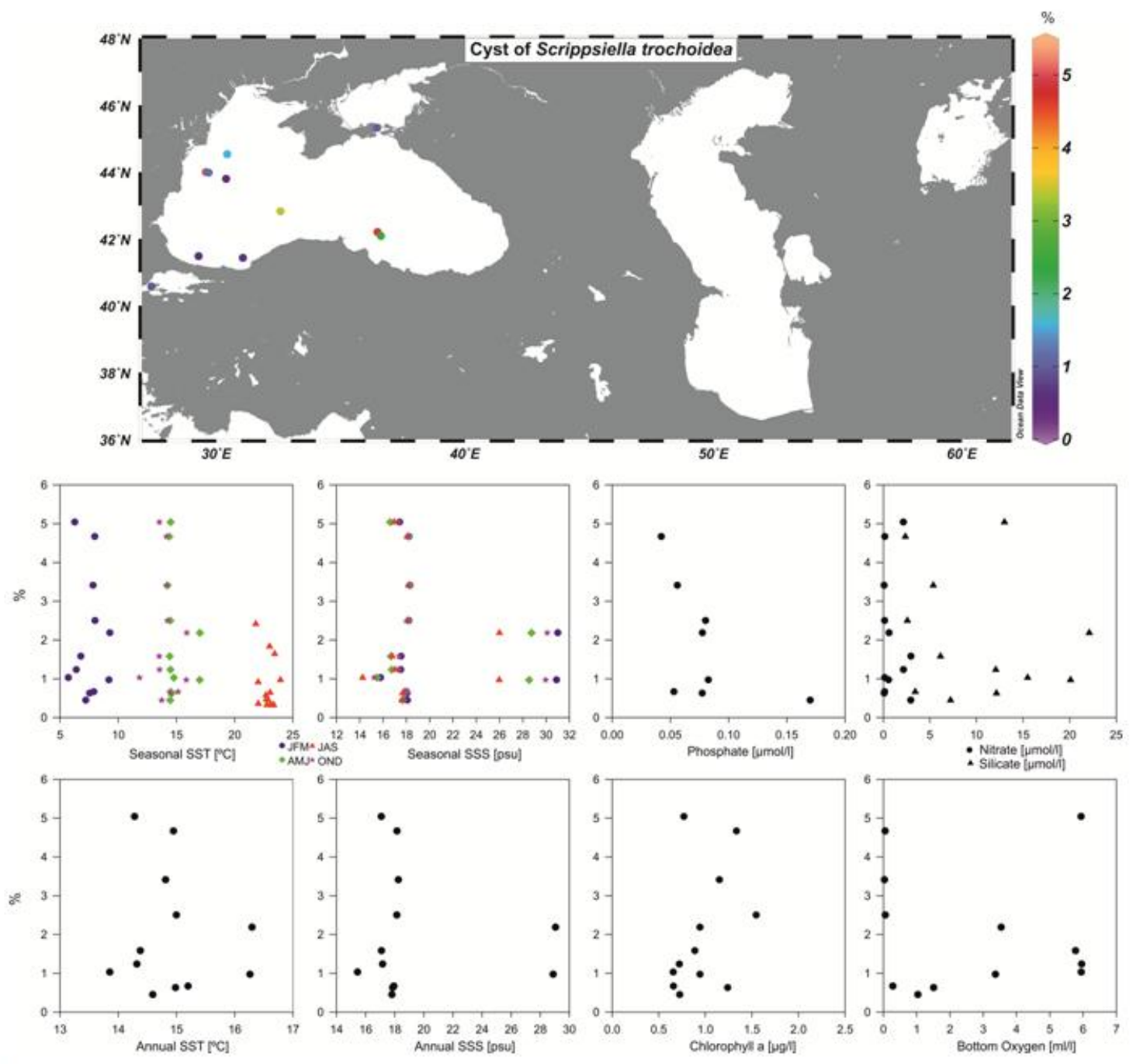

Figure 30 

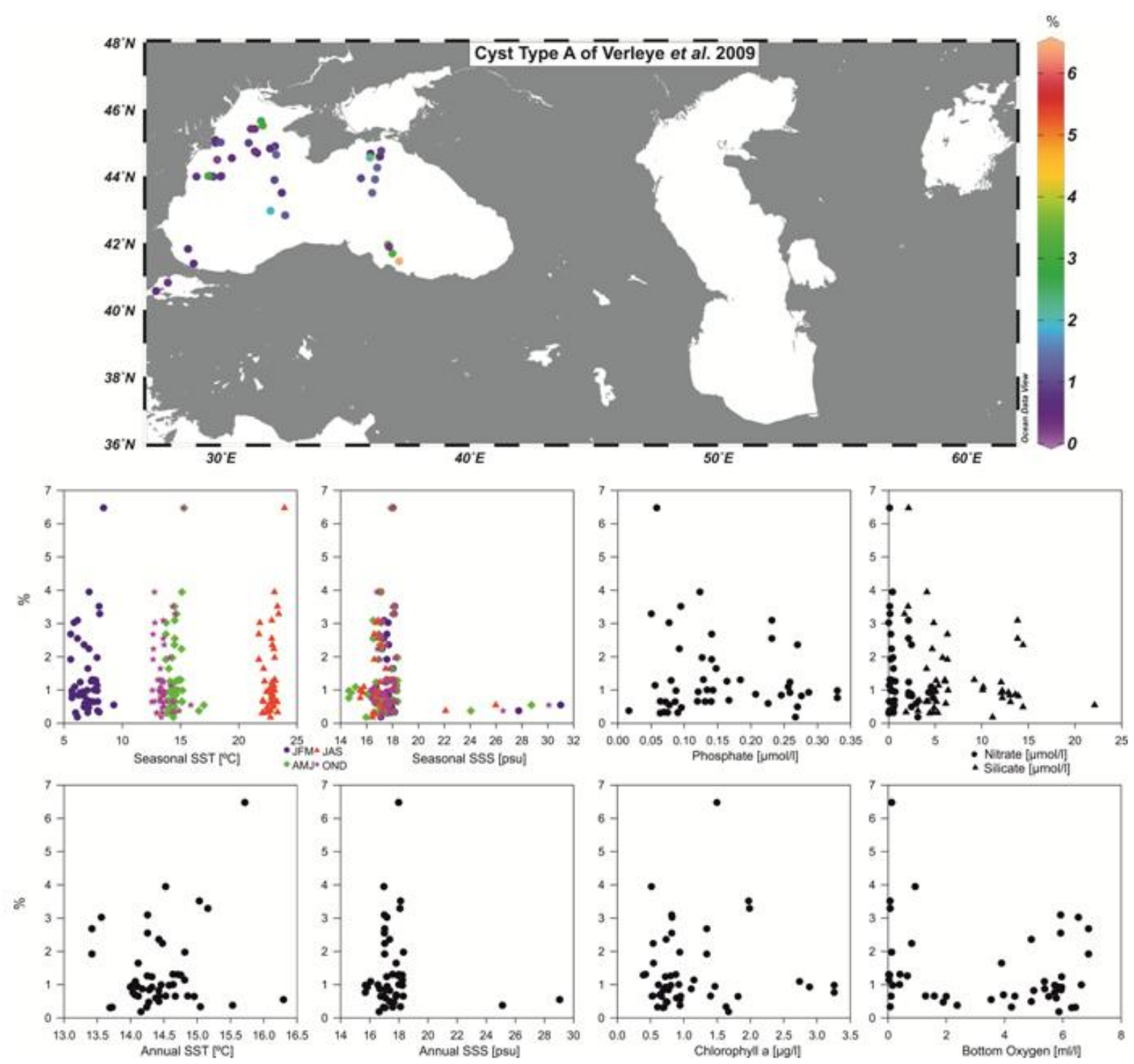

Figure 31 

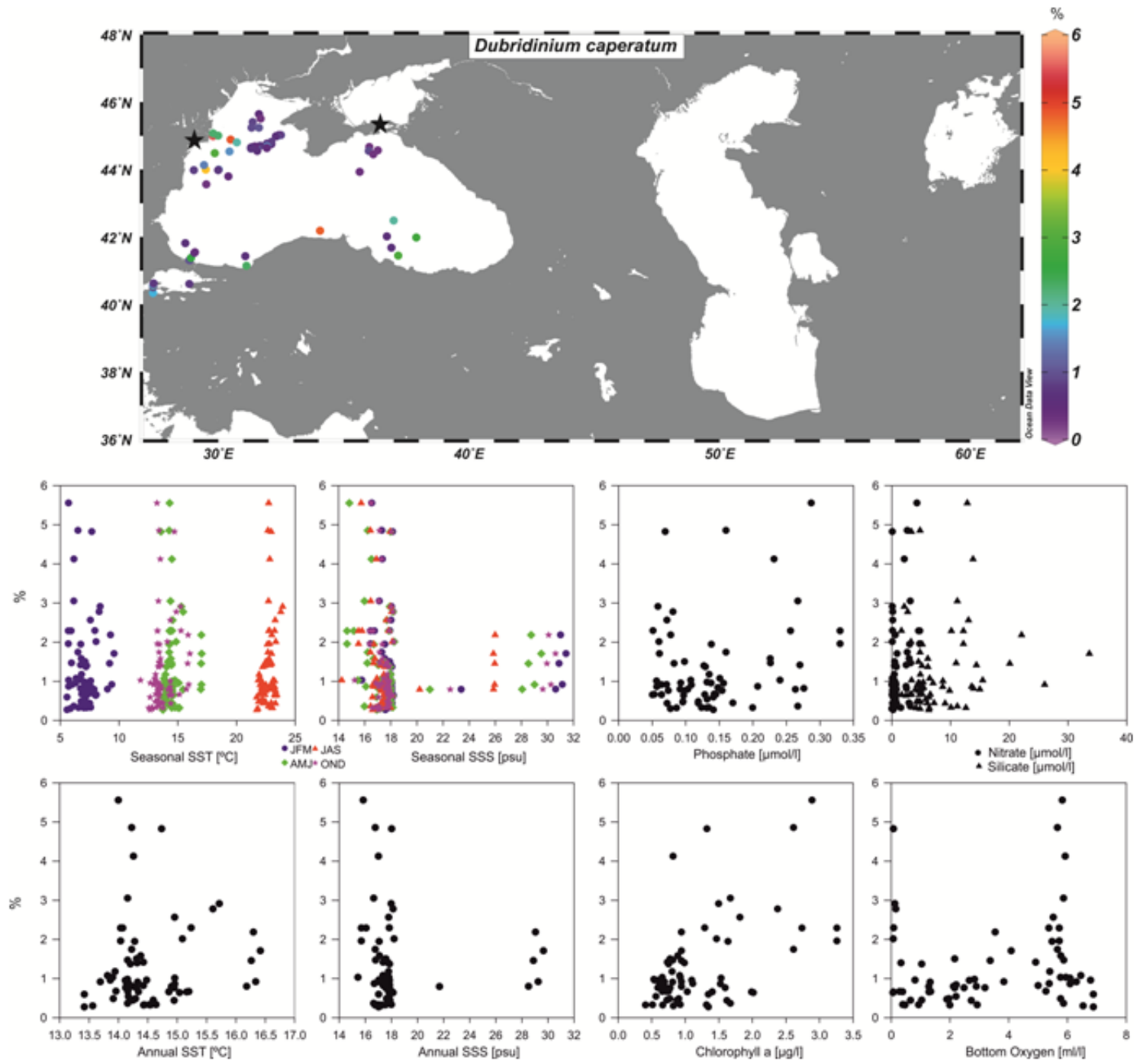

Figure 32 

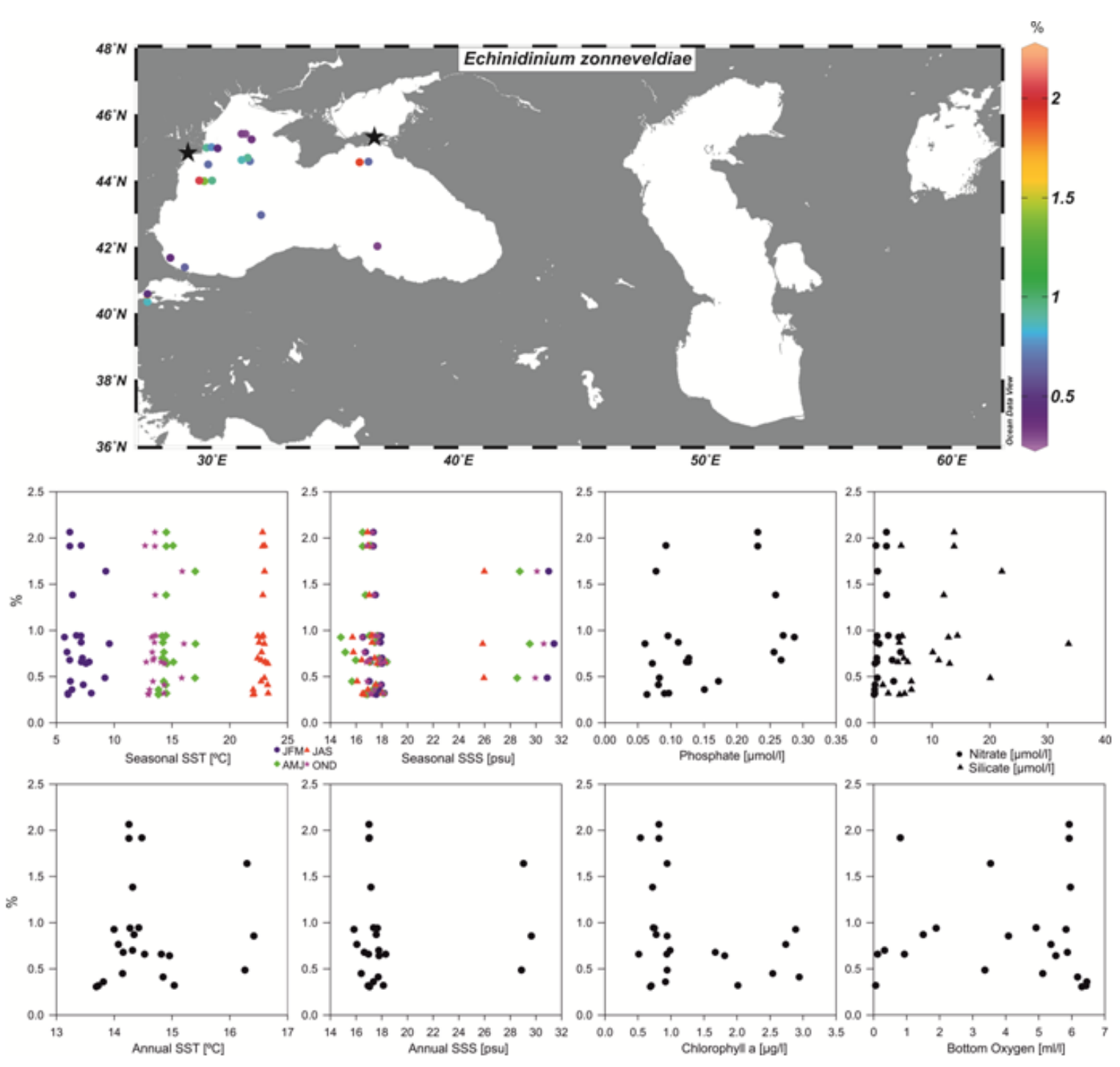

Figure 33 

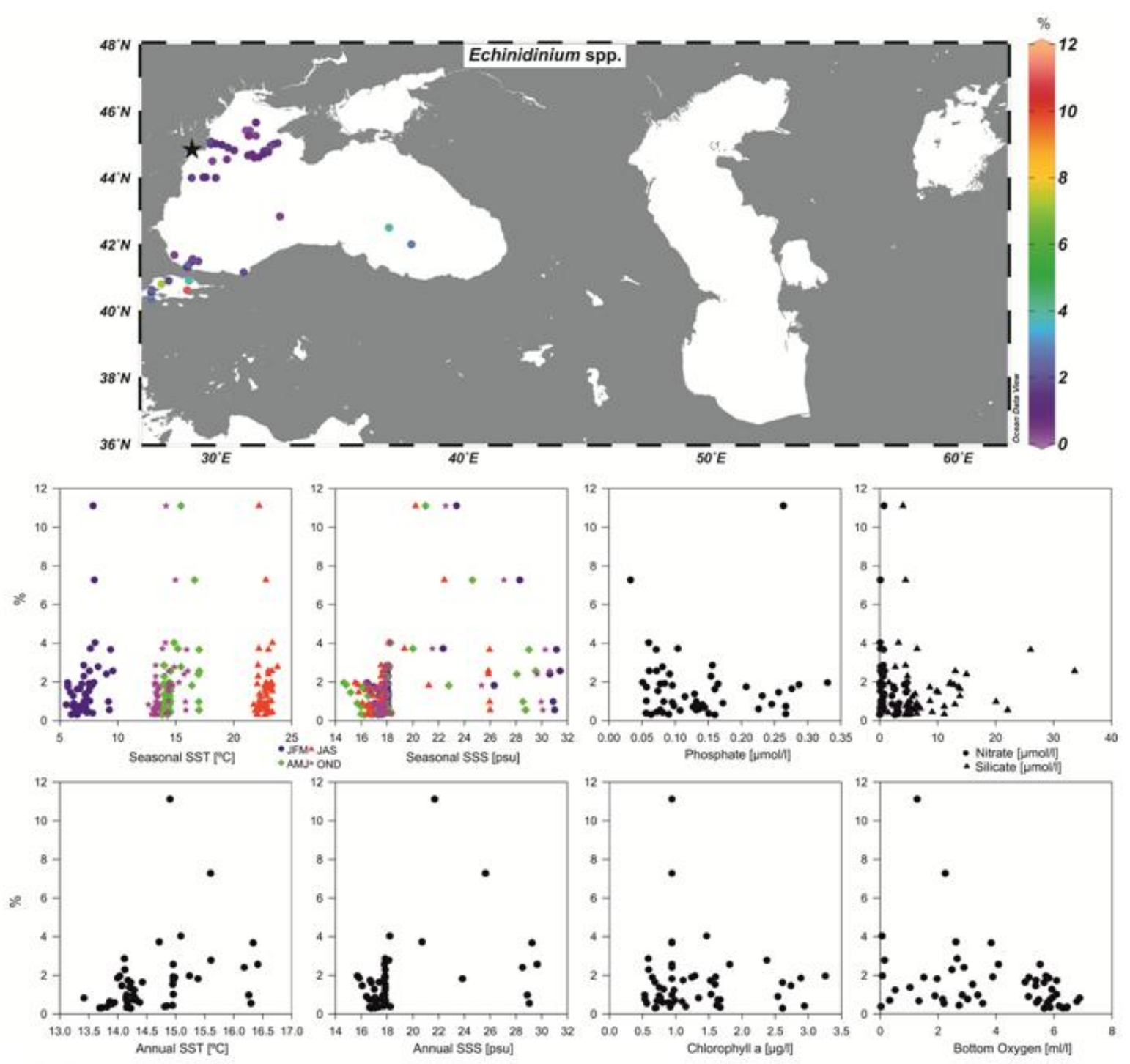

Figure 34 


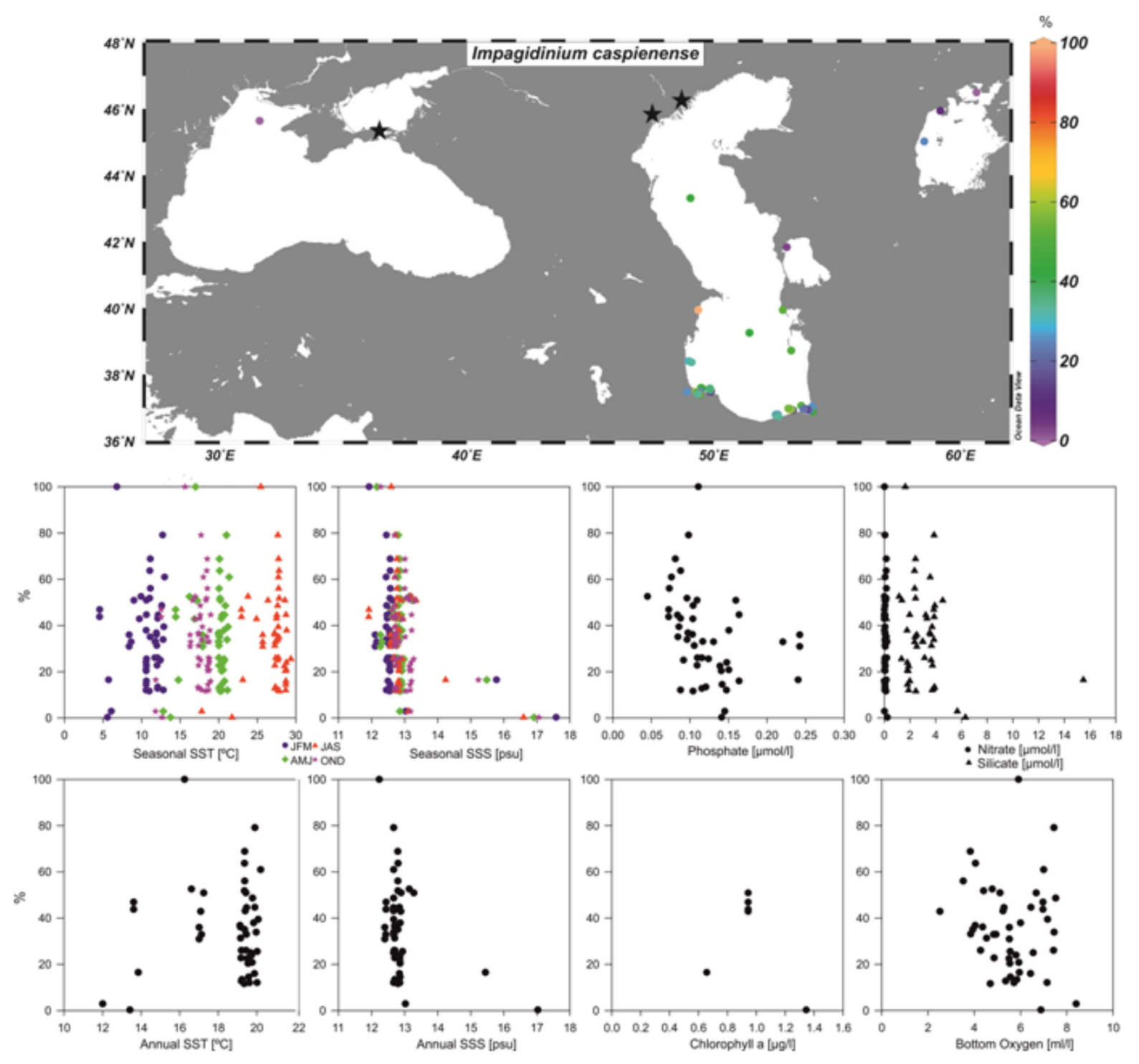

Figure 35 



Figure 36 

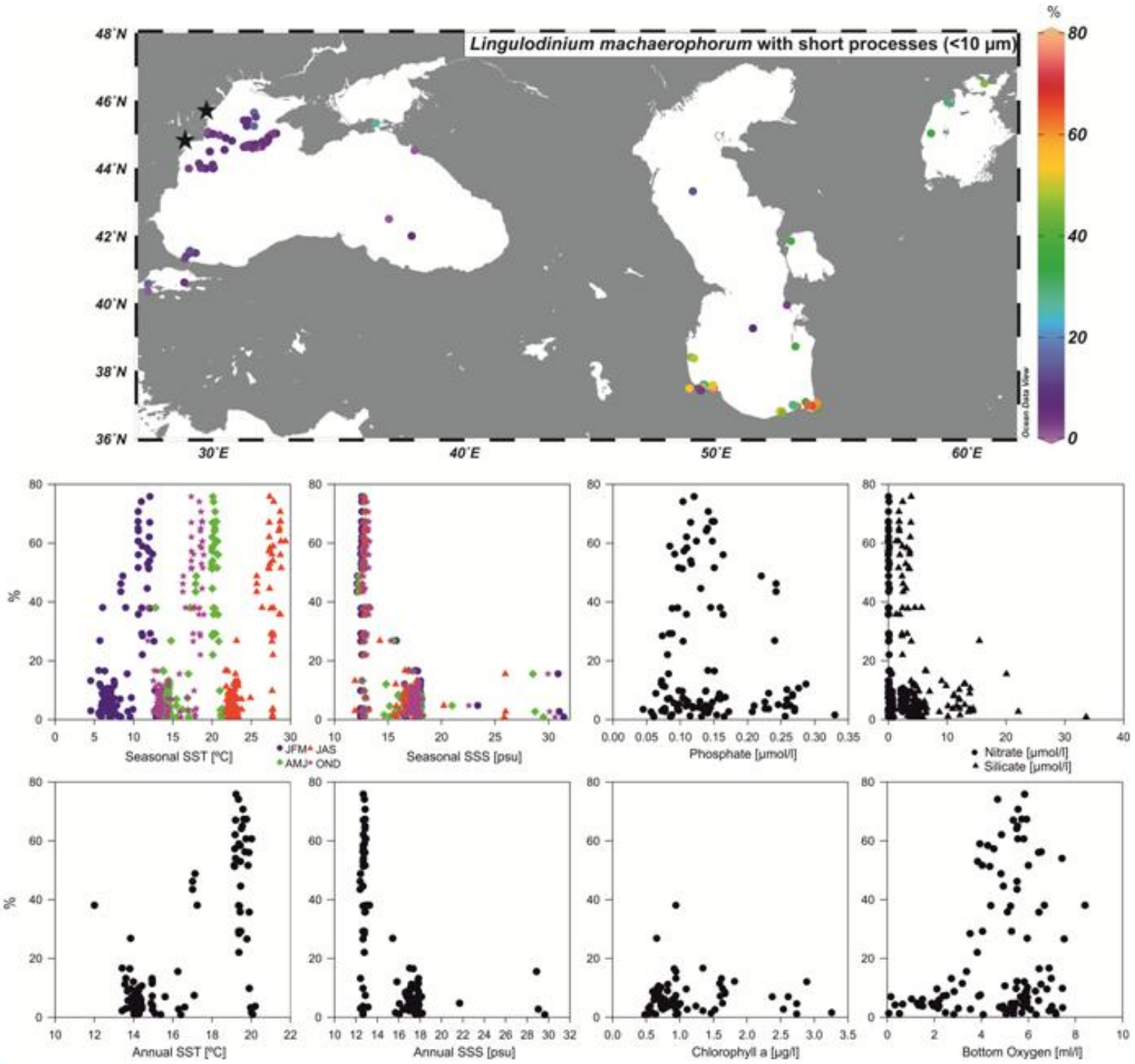

Figure 37 



Figure 38 



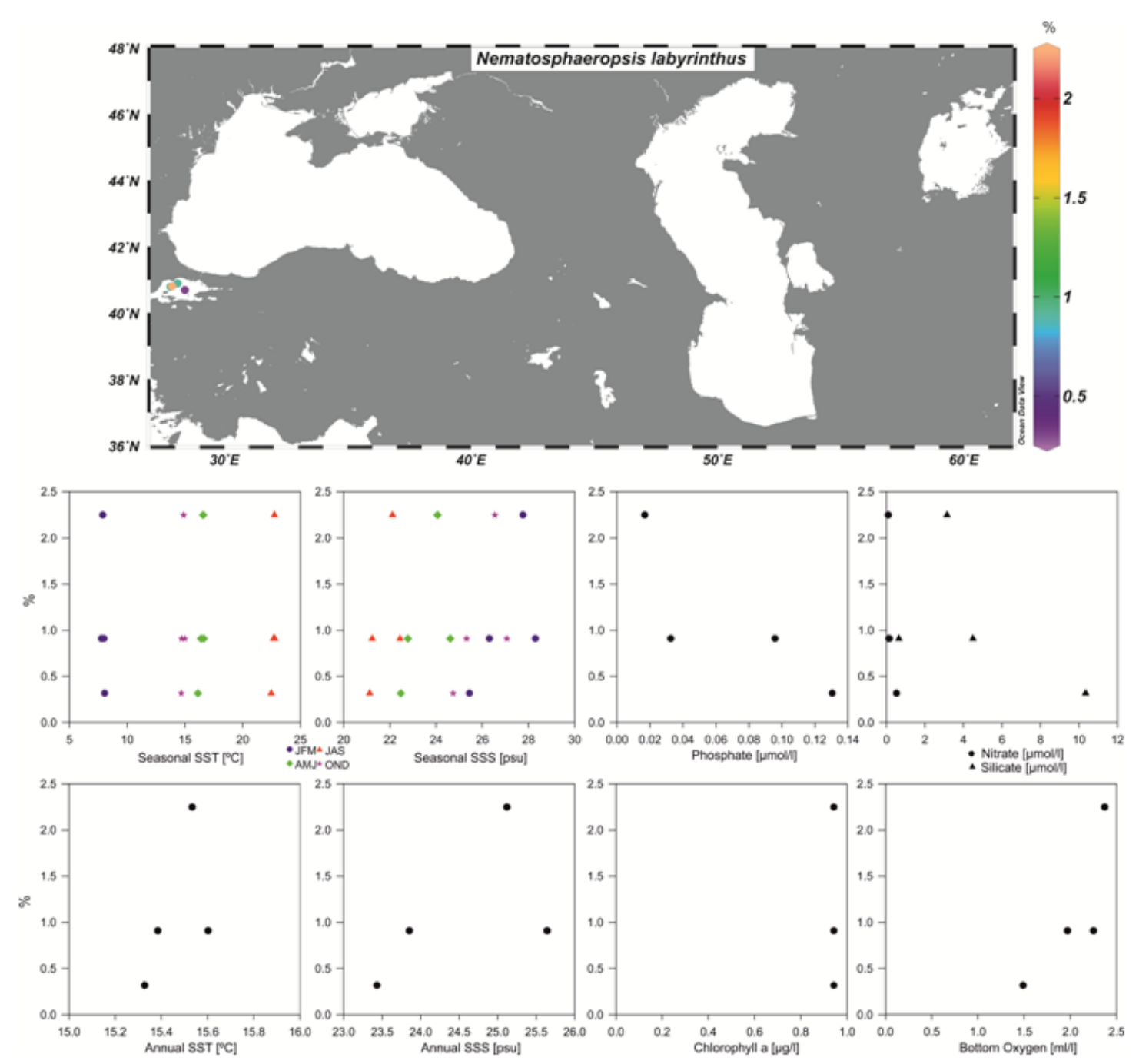

Figure 39 

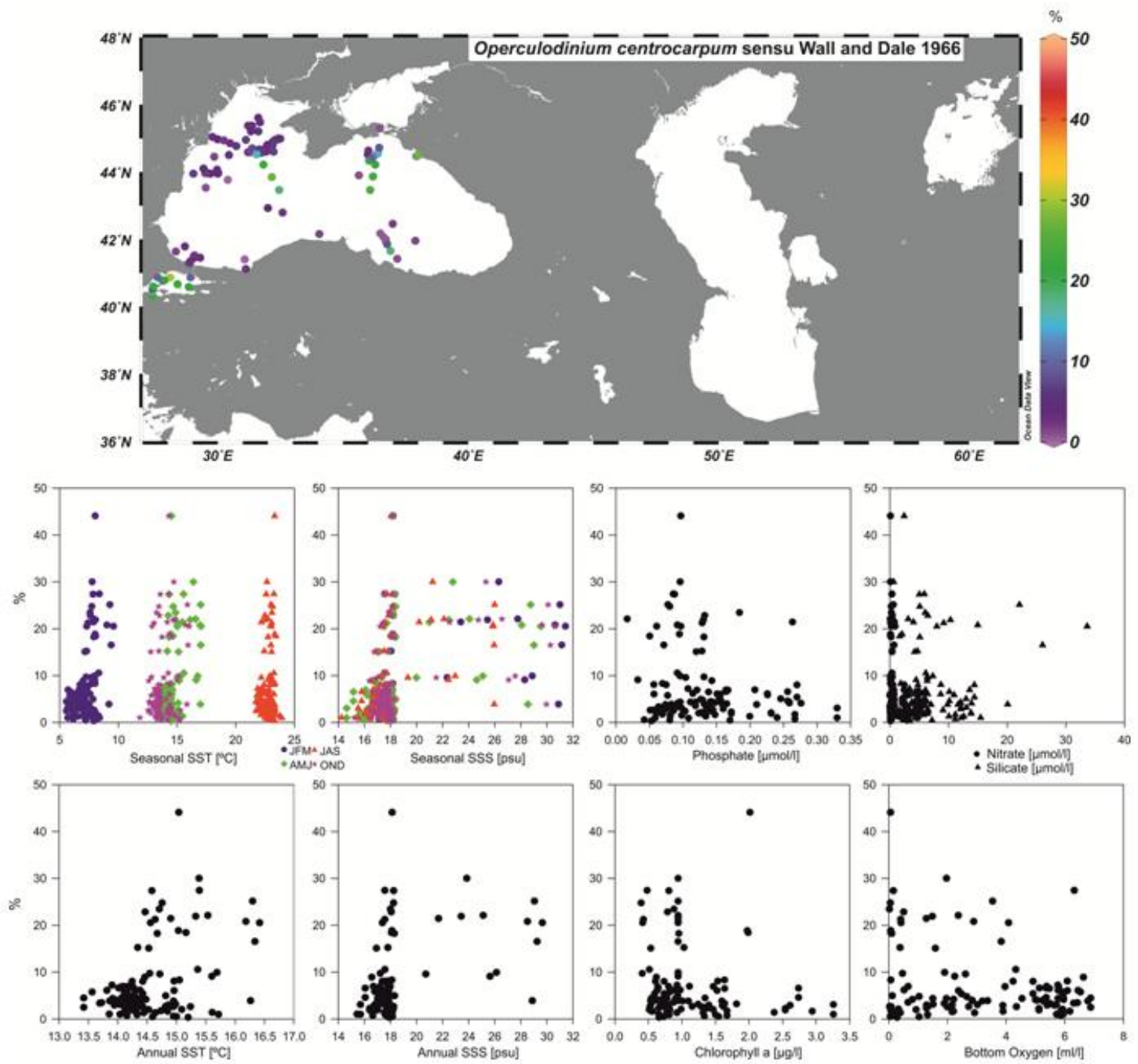

Figure 40 

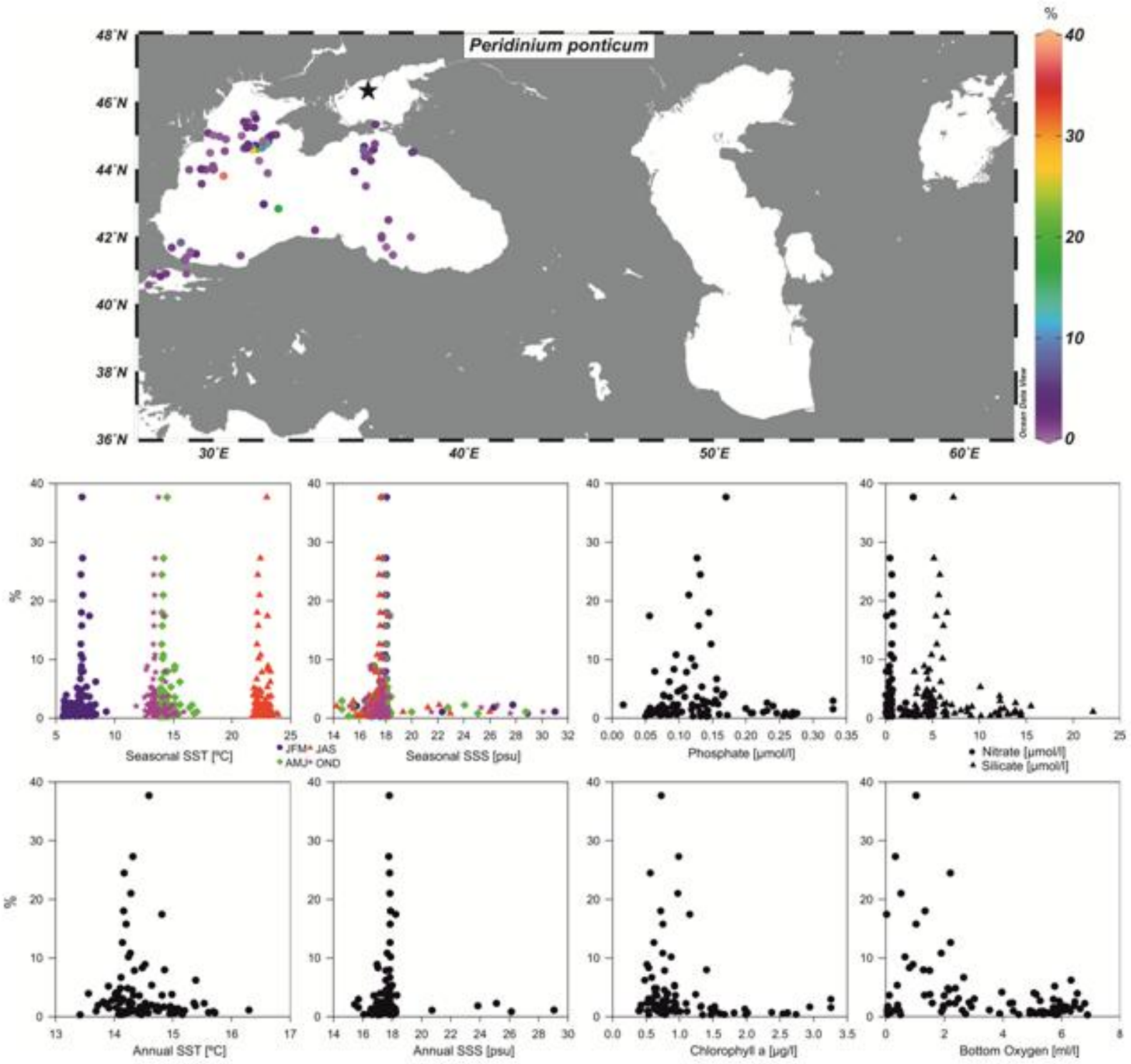

Figure 41 

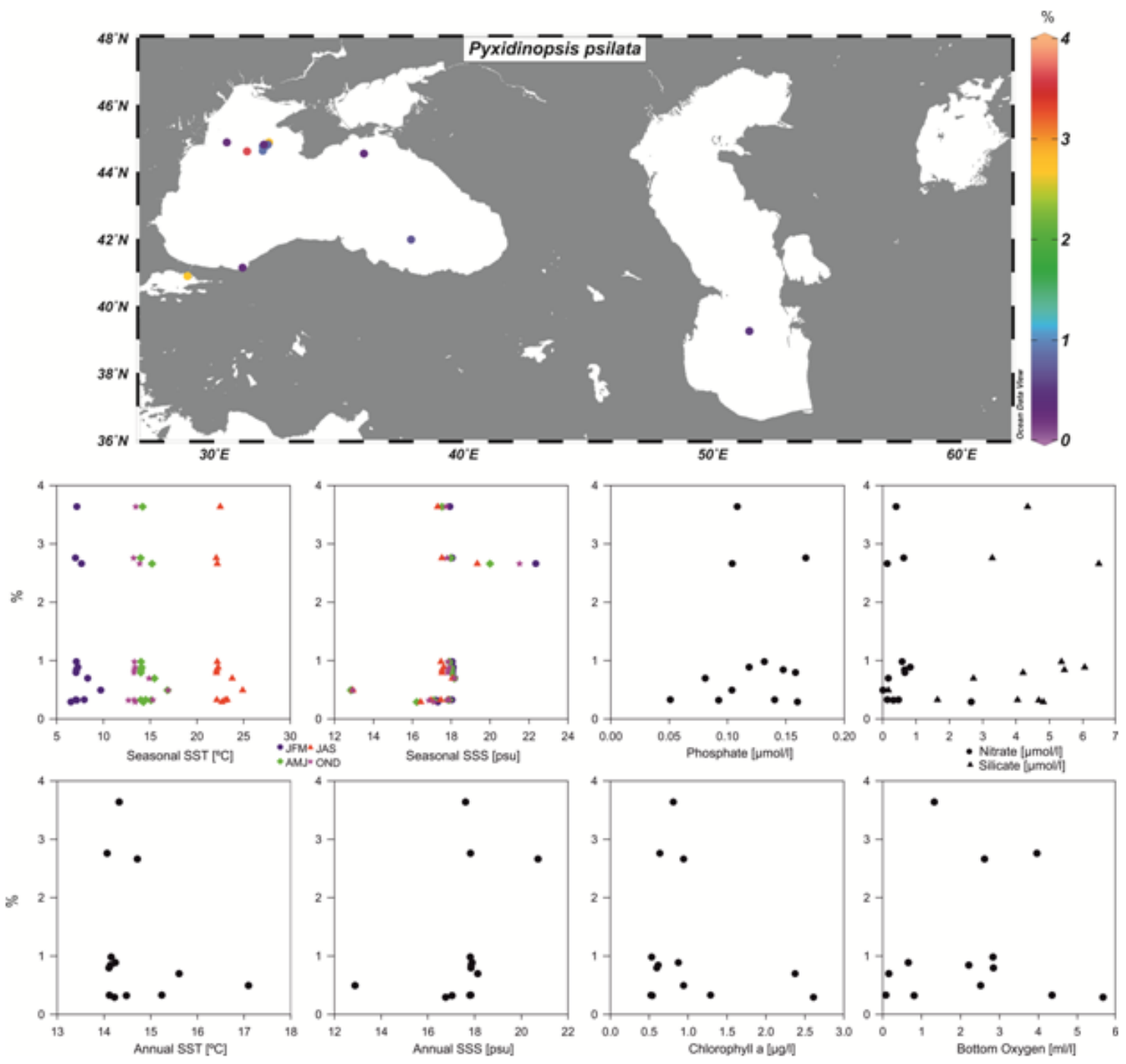

Figure 42 

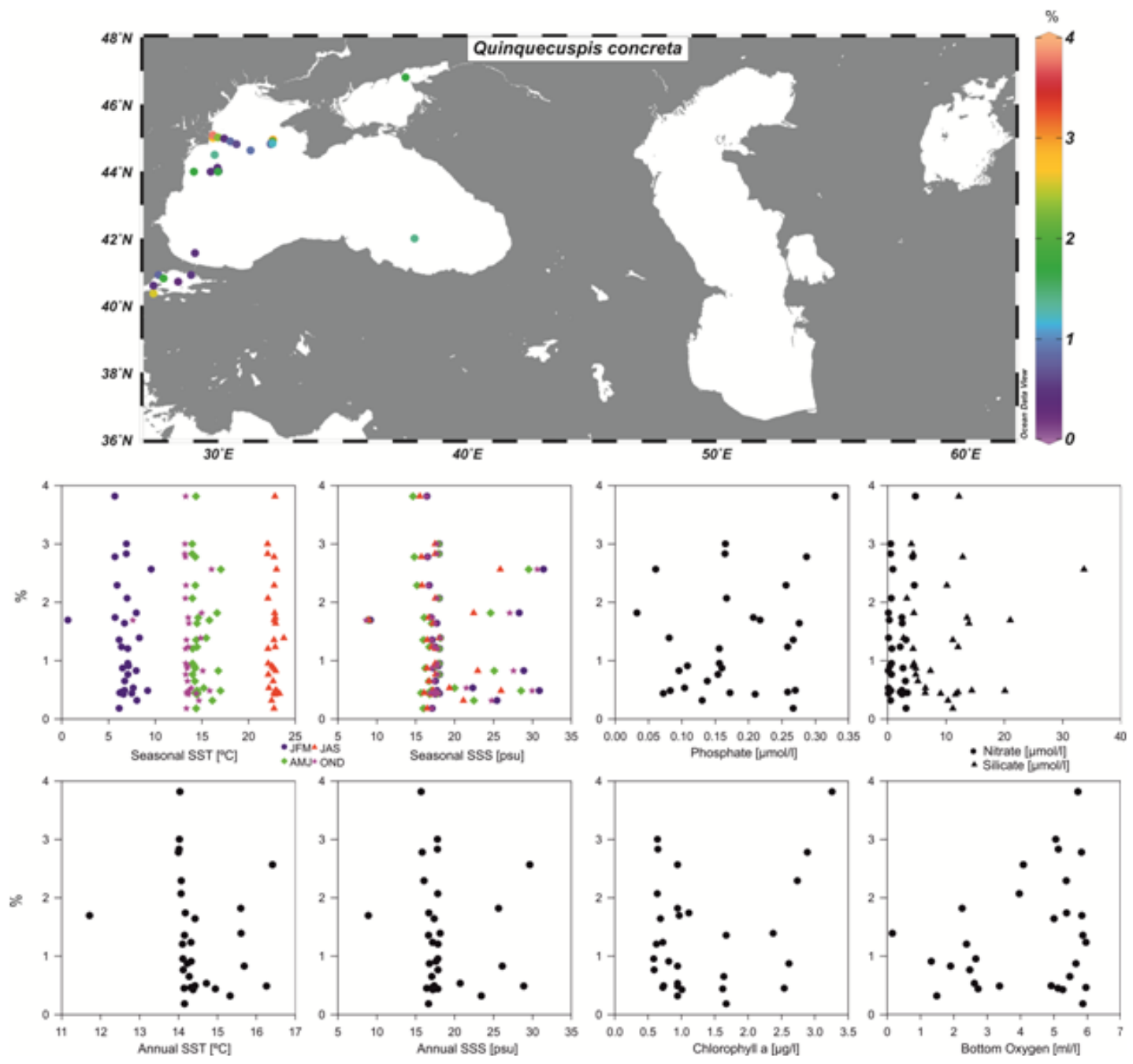

Figure 43 

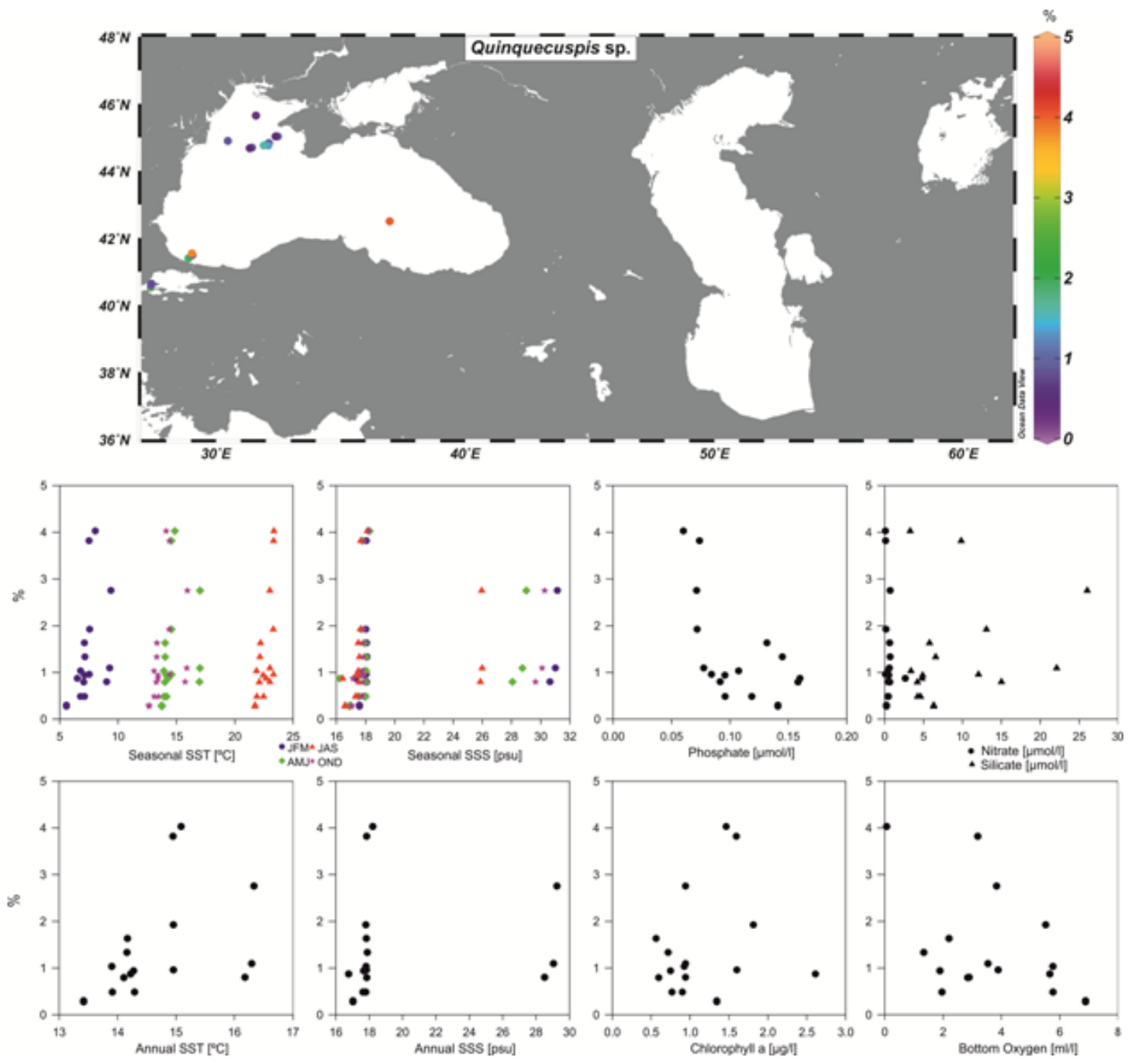

Figure 44 

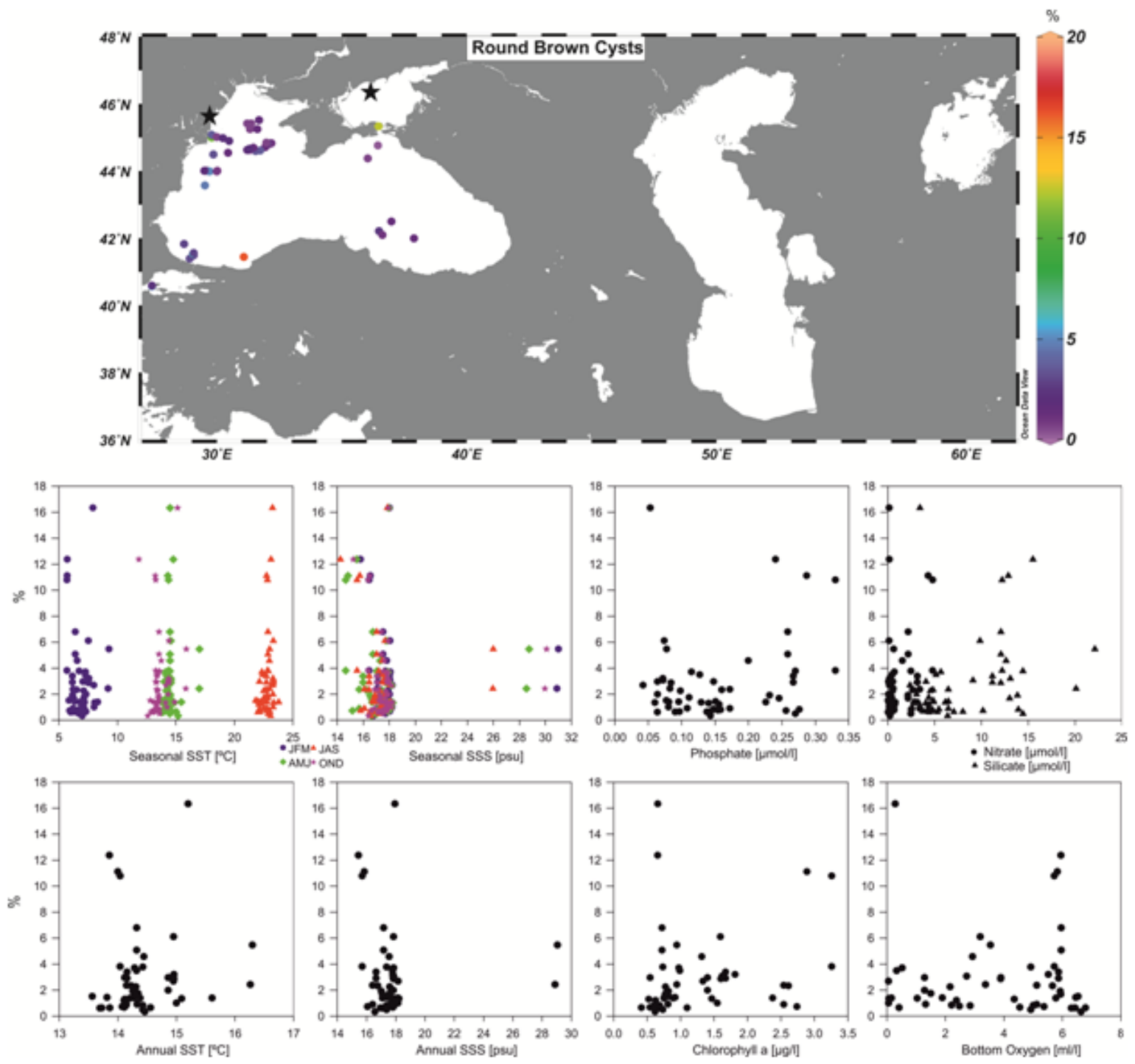

Figure 45 

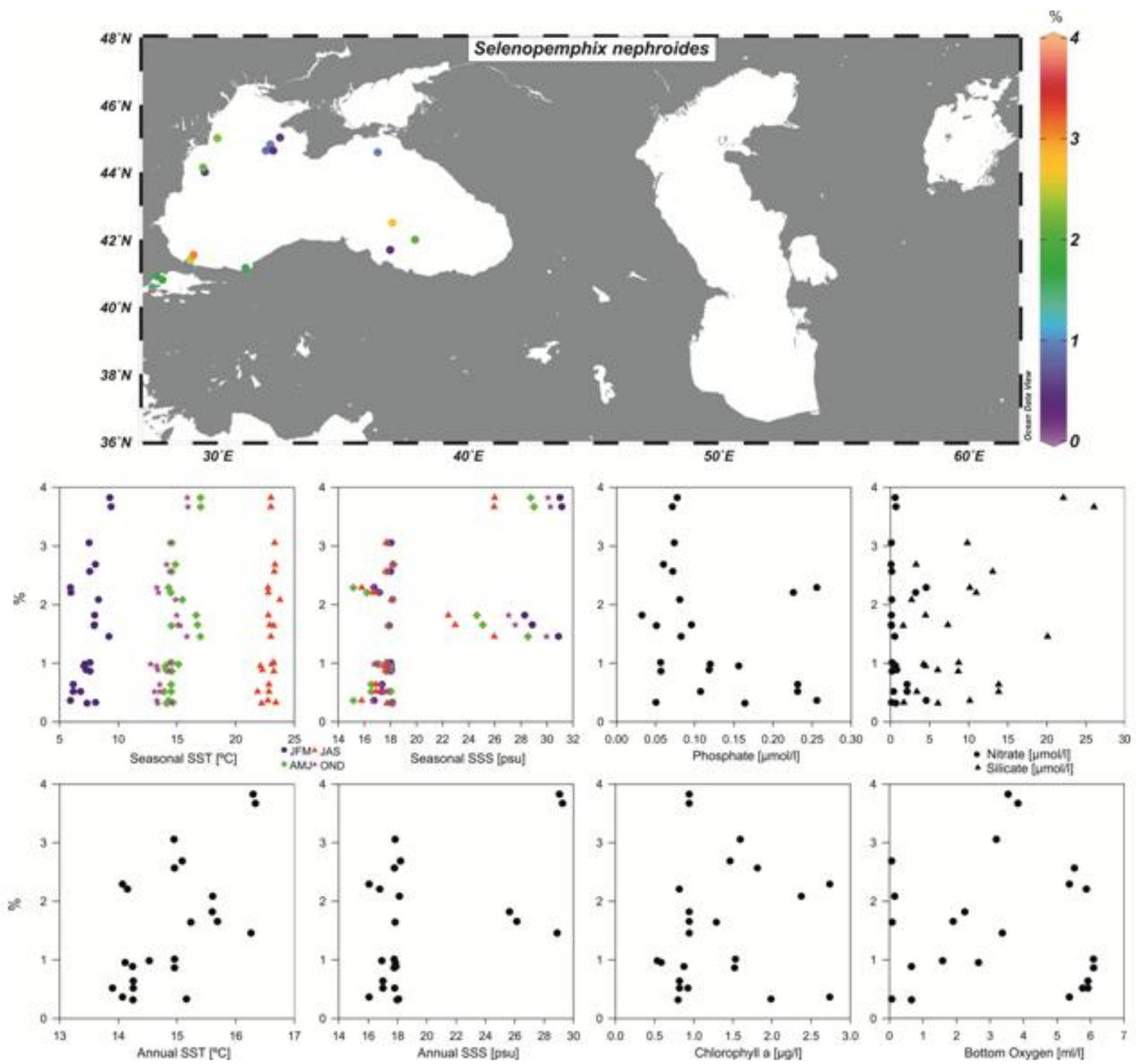

Figure 46 

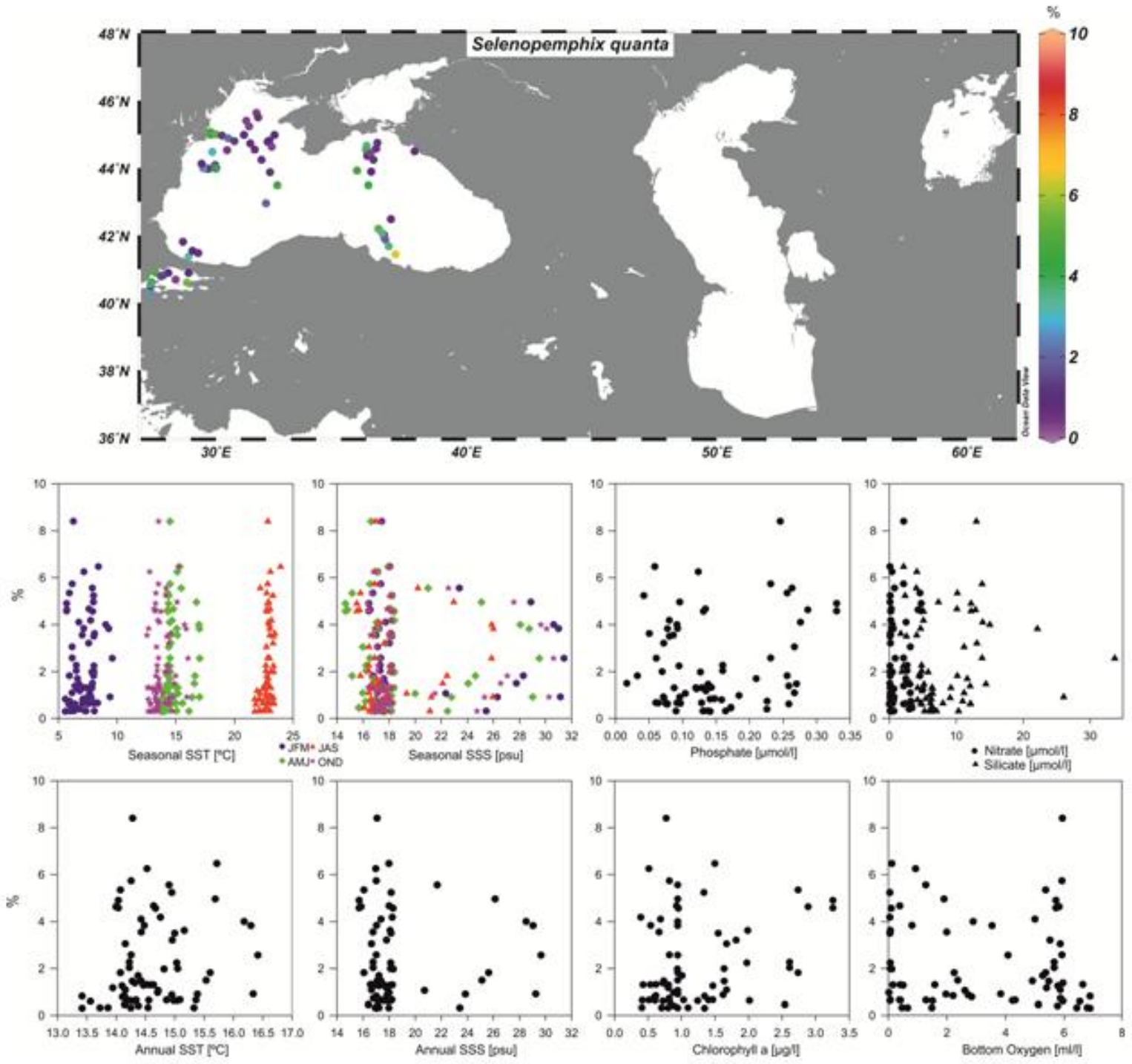

Figure 47 

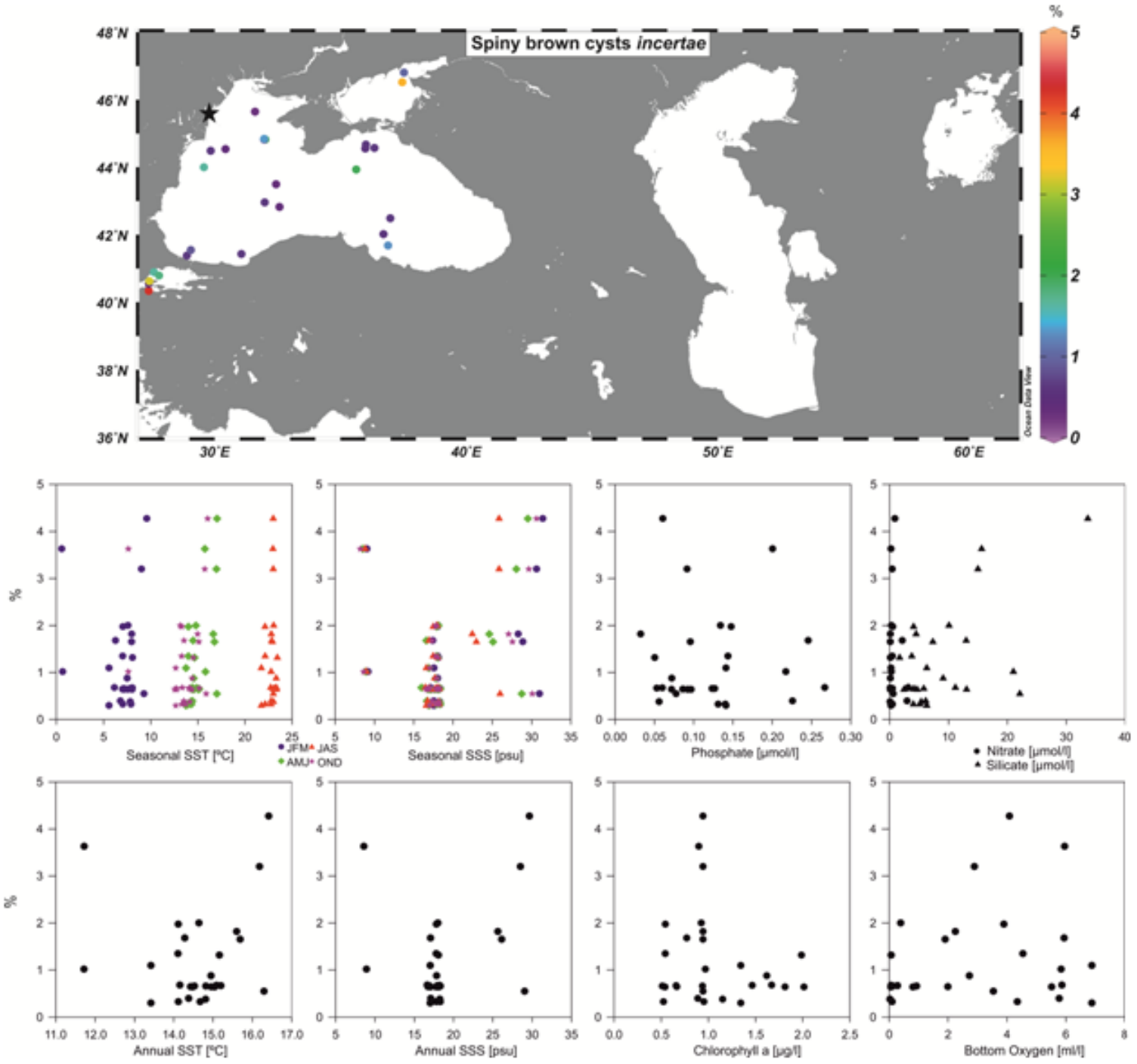

Figure 48 

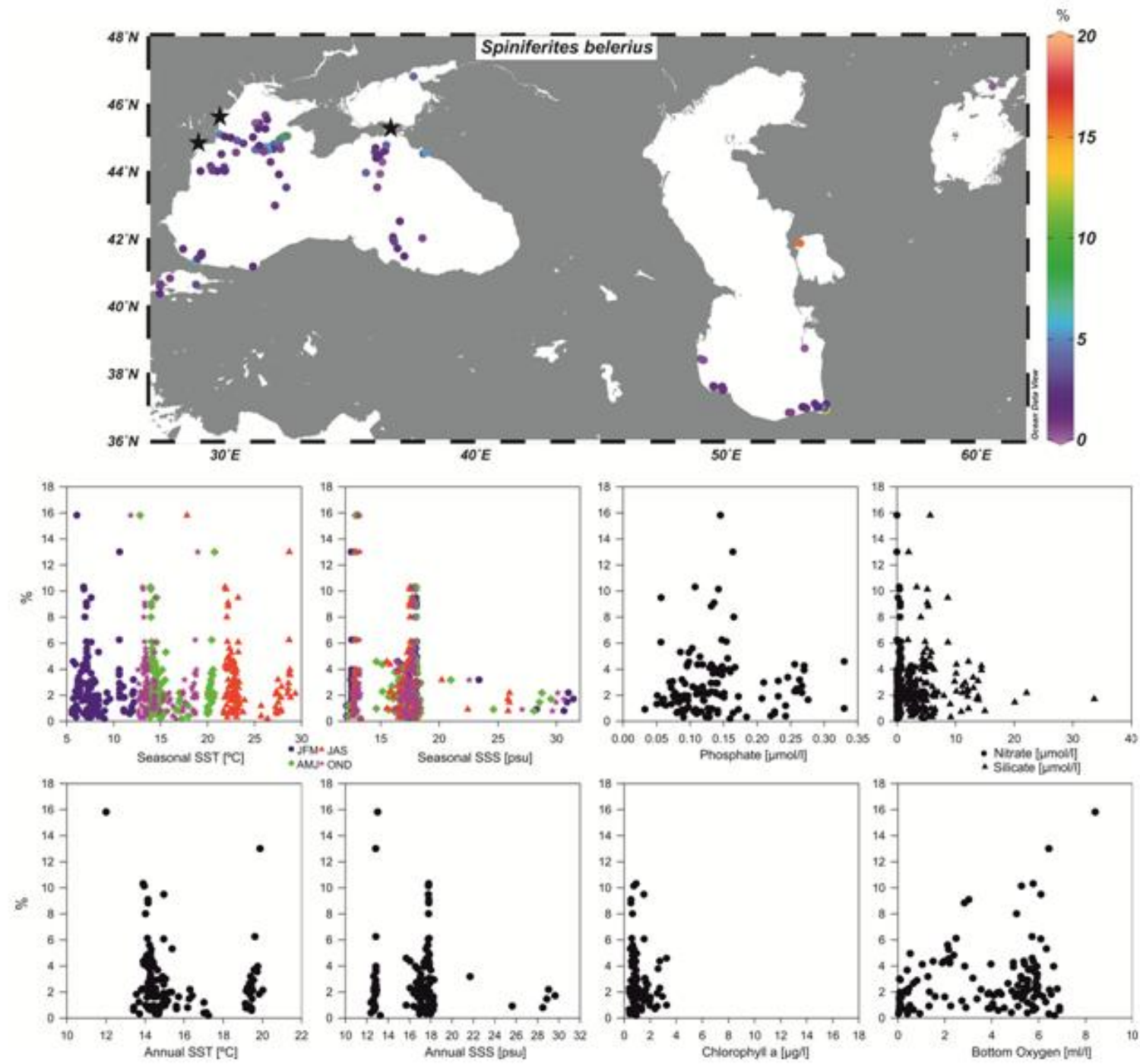

Figure 49 

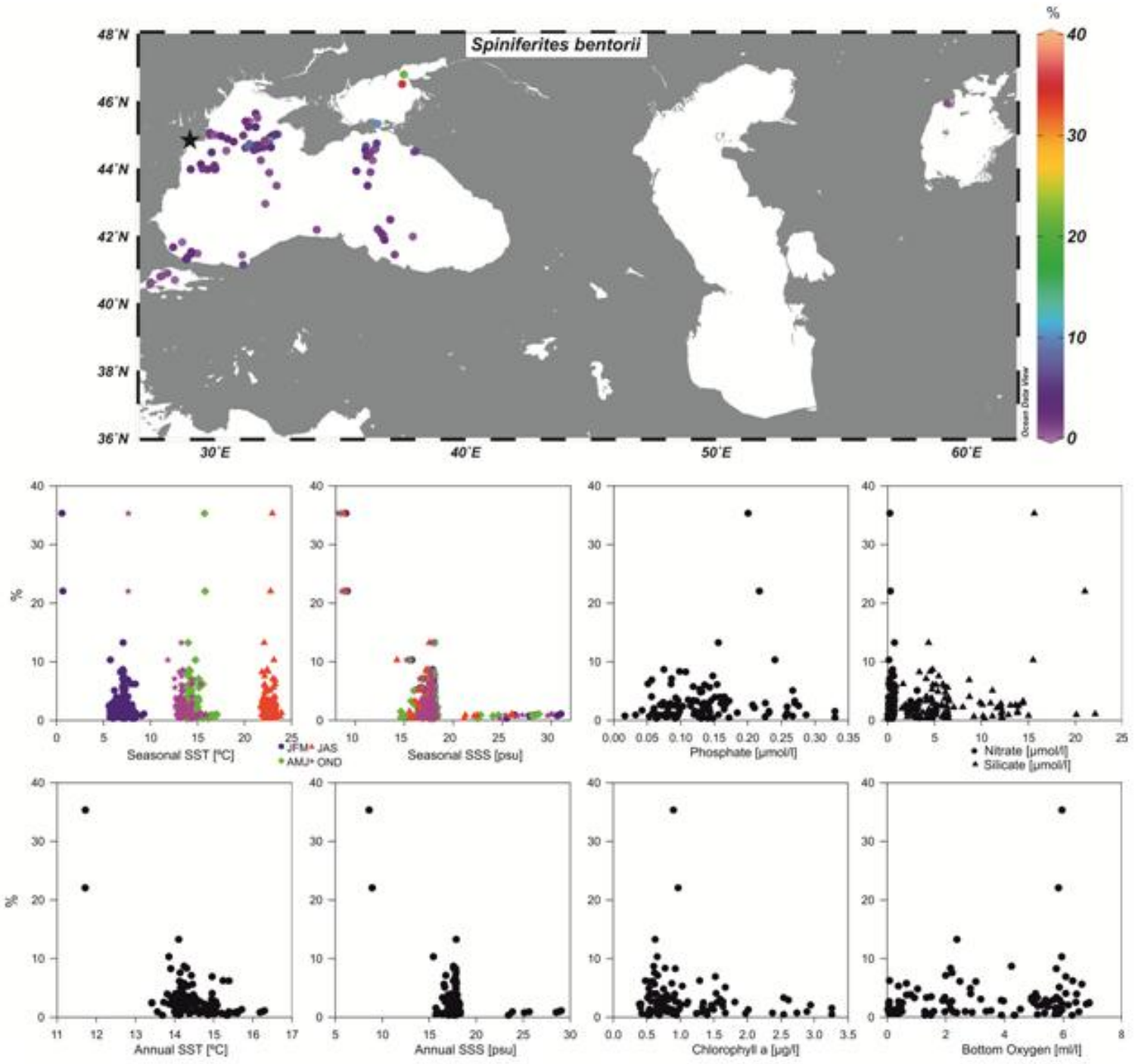

Figure 50 

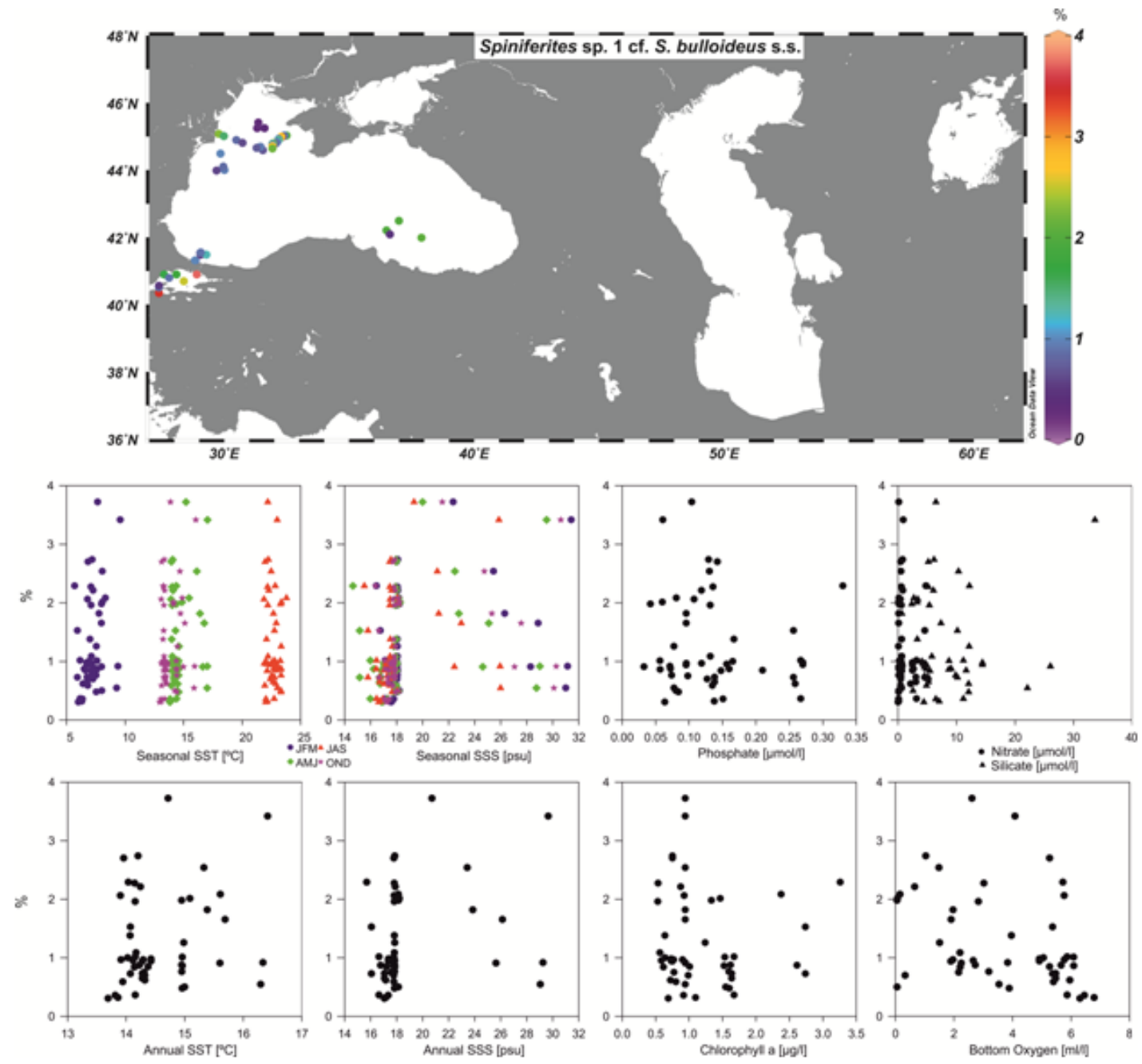

Figure 51 

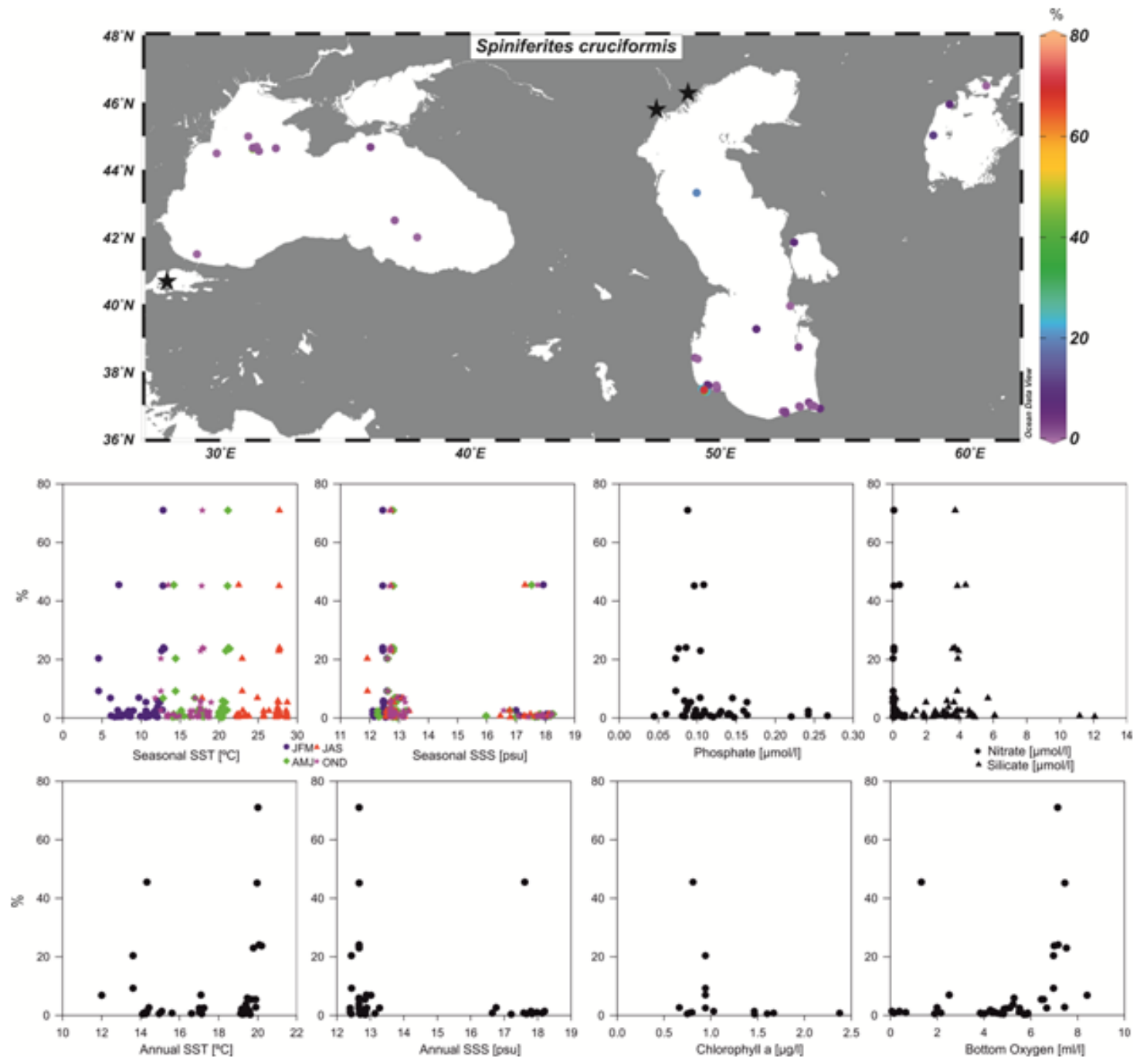

Figure 52 

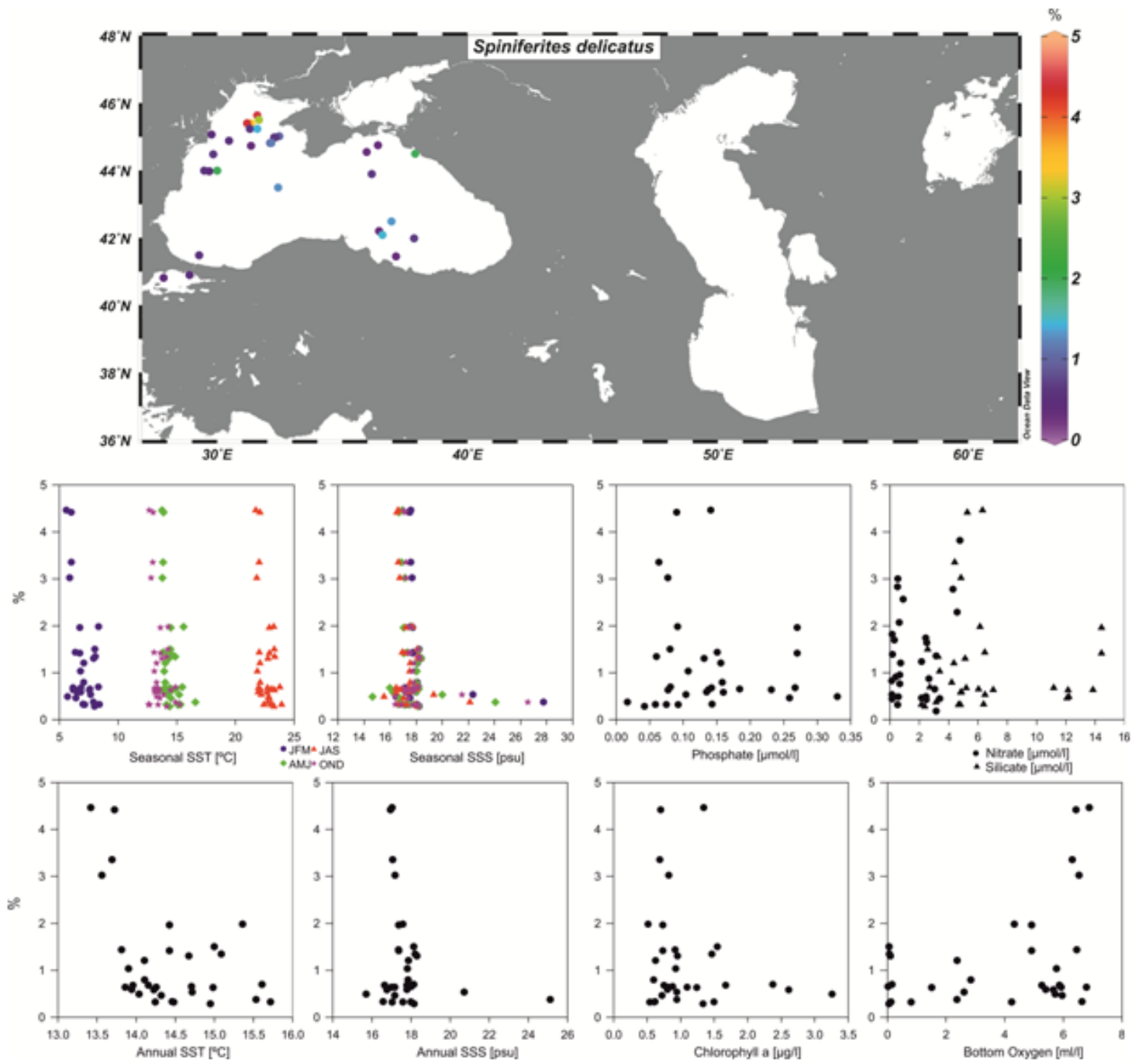

Figure 53 

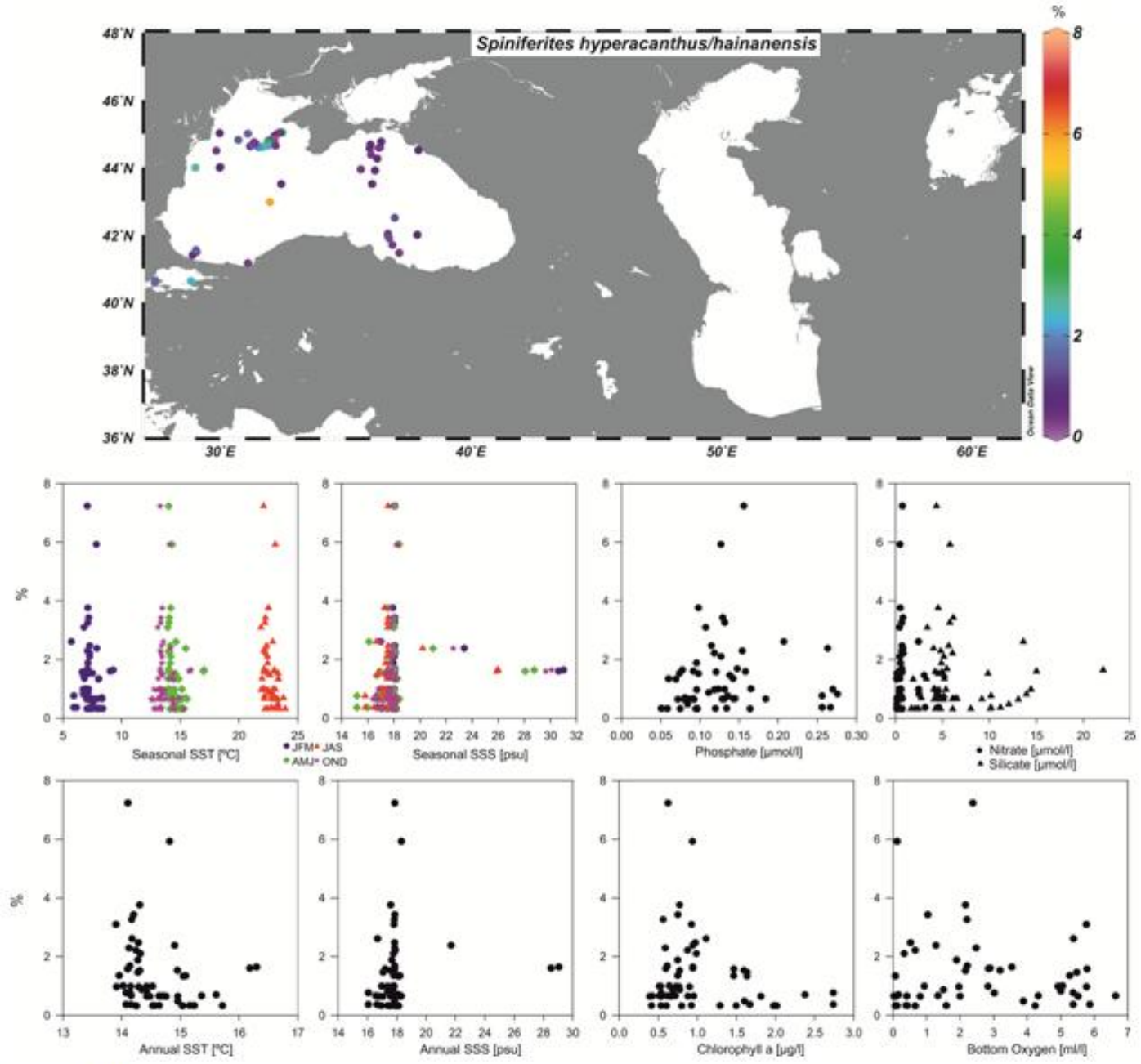

Figure 54 

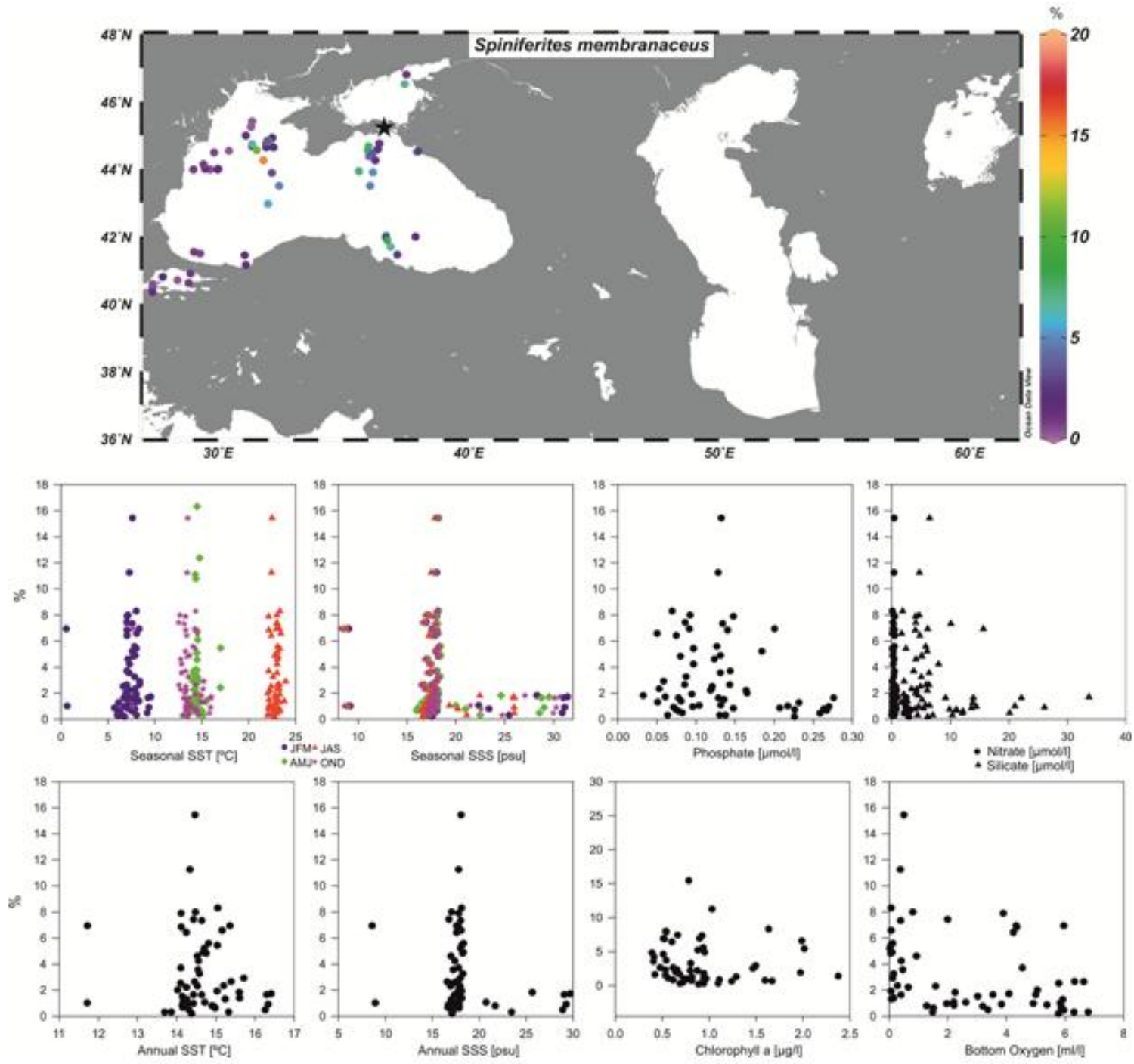

Figure 55 

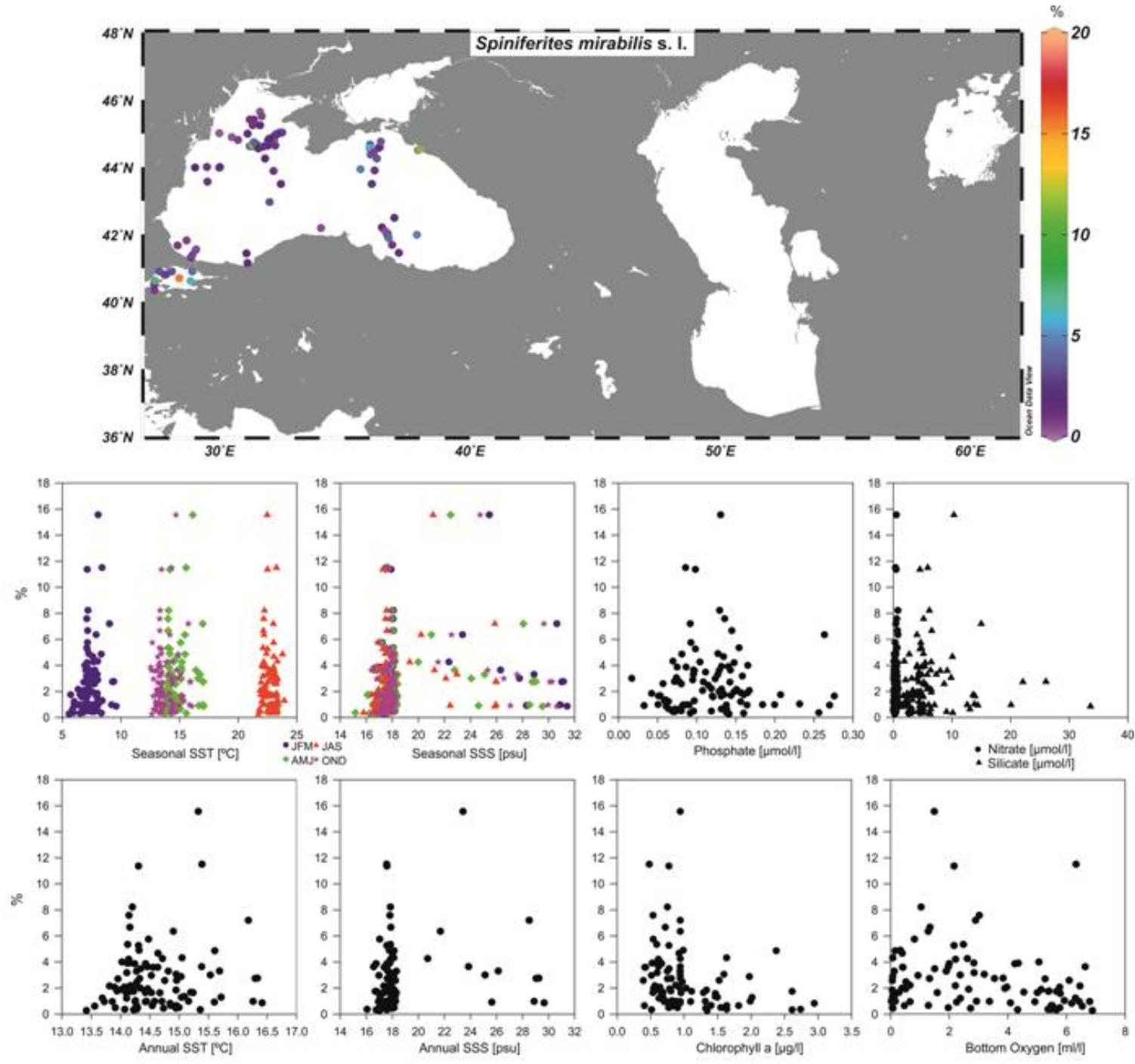

Figure 56 

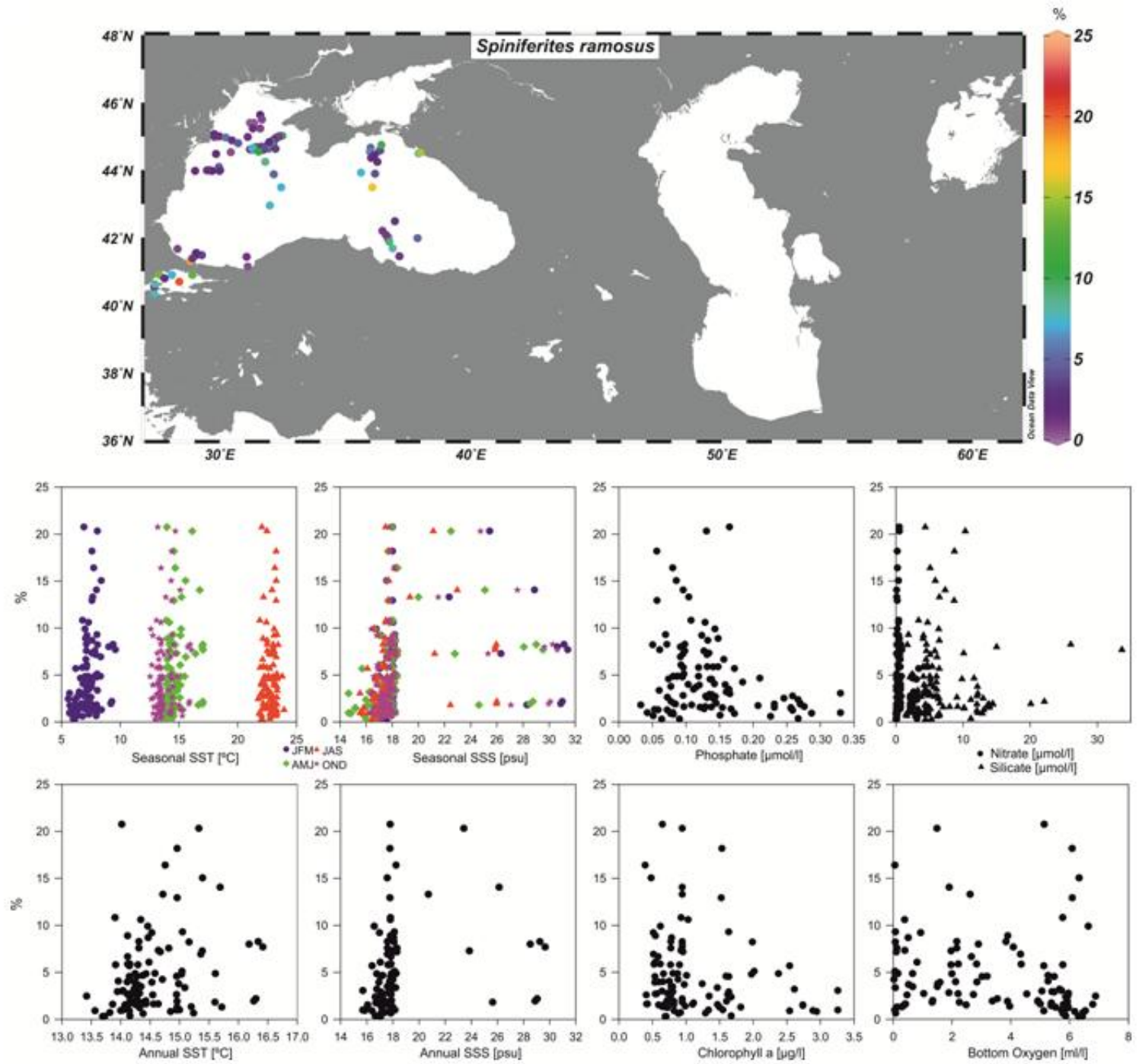

Figure 57 

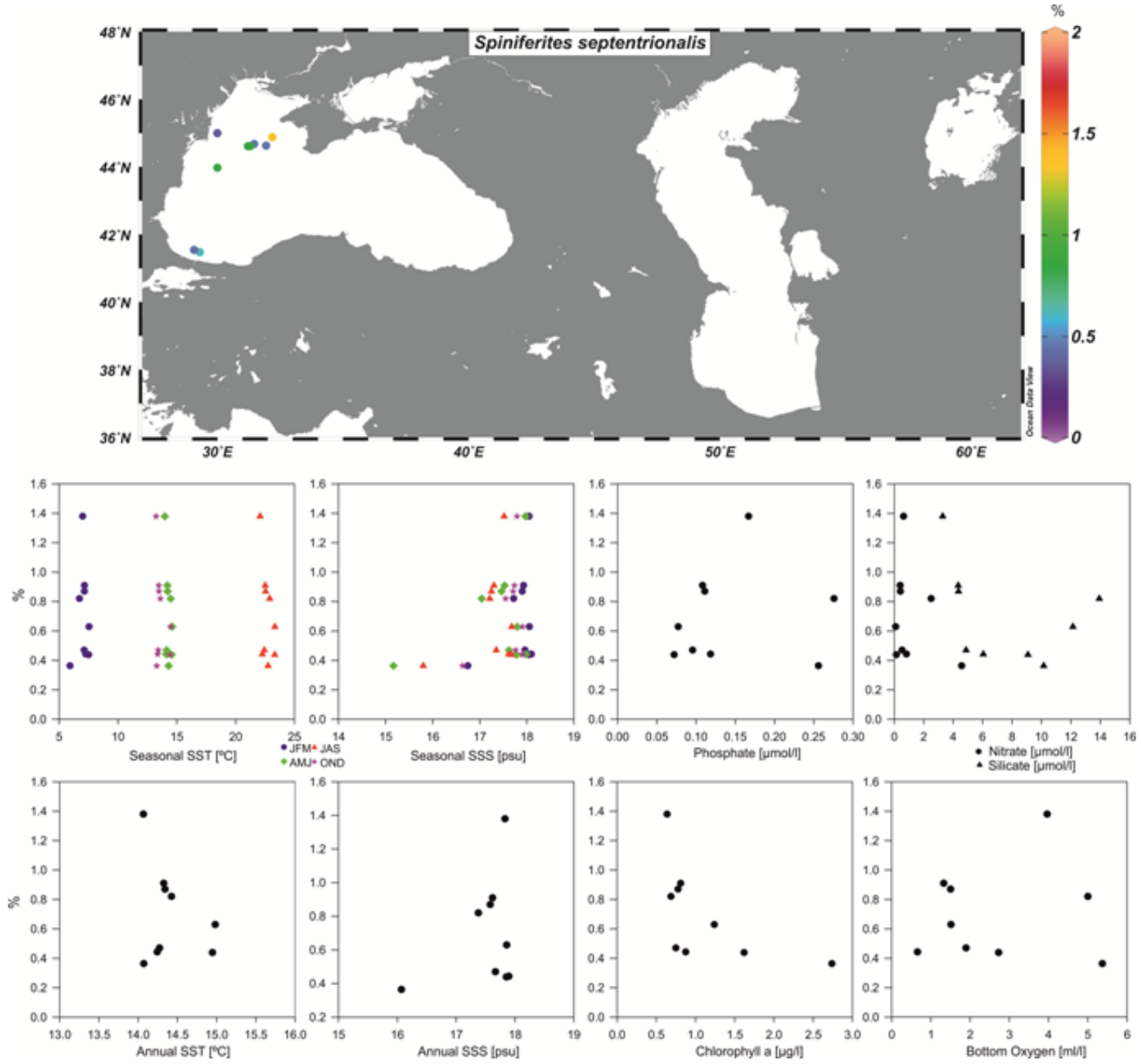

Figure 58 


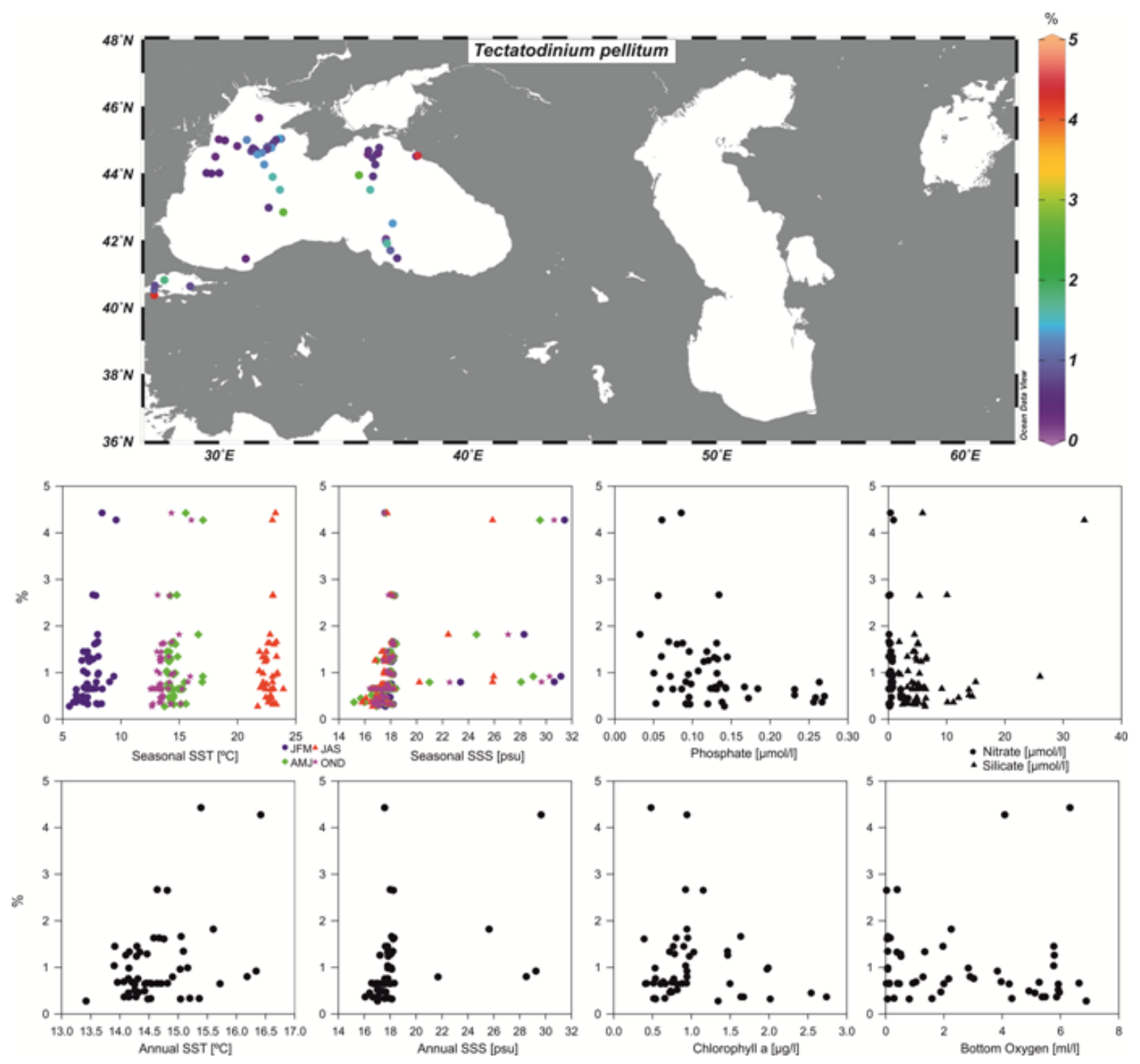

Figure 59 



Figure 60 

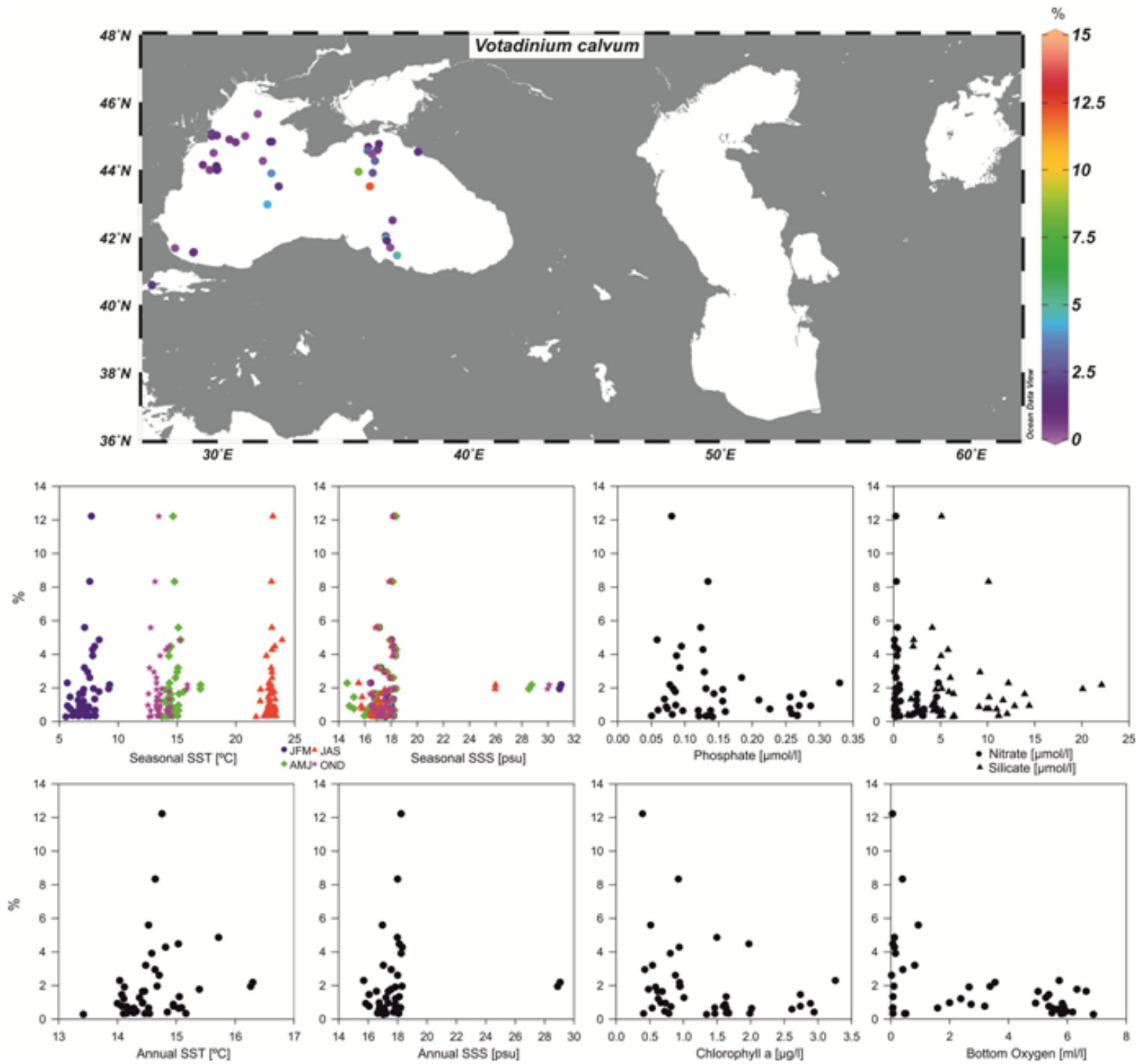

Figure 61 

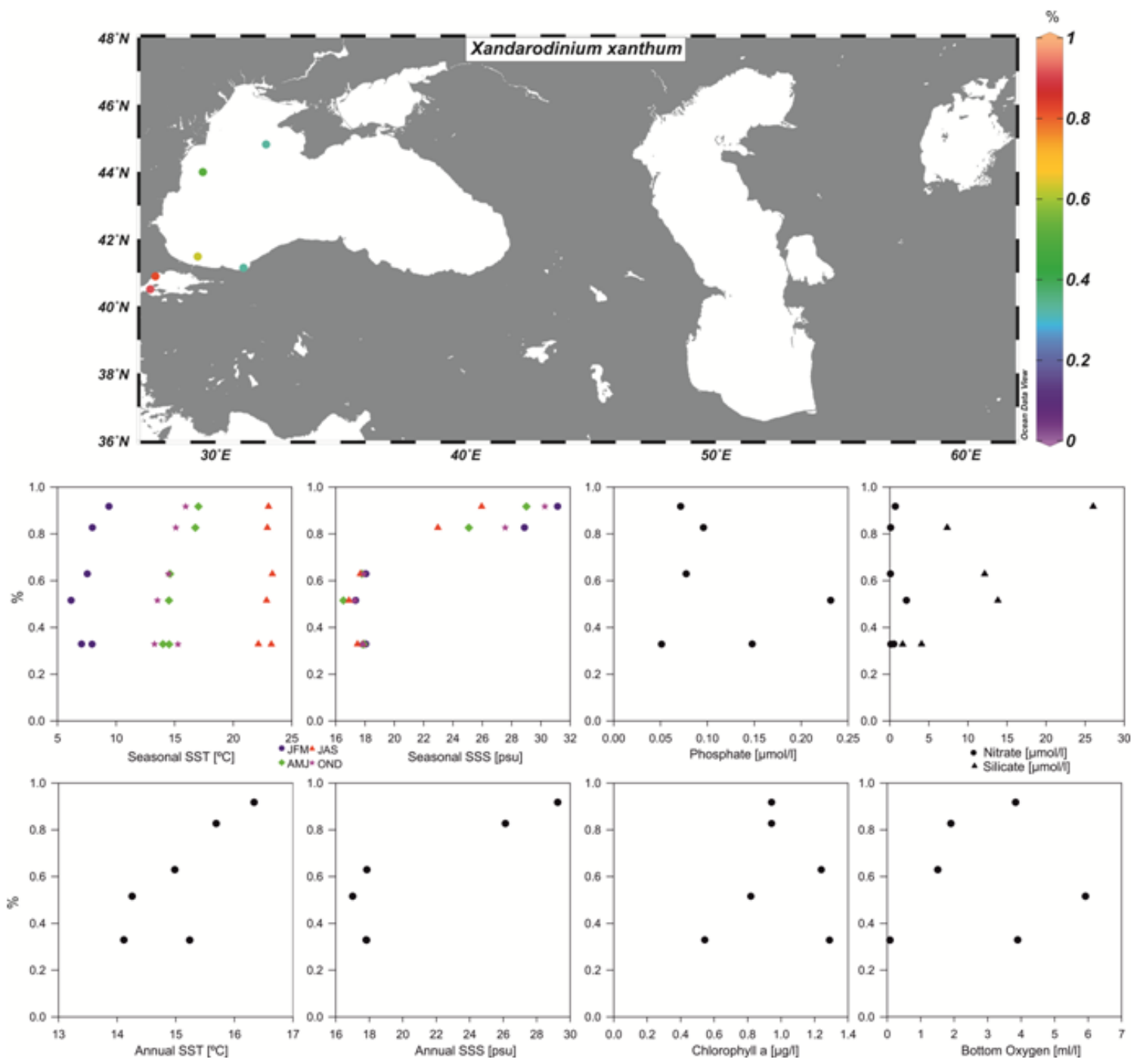

Figure 62 


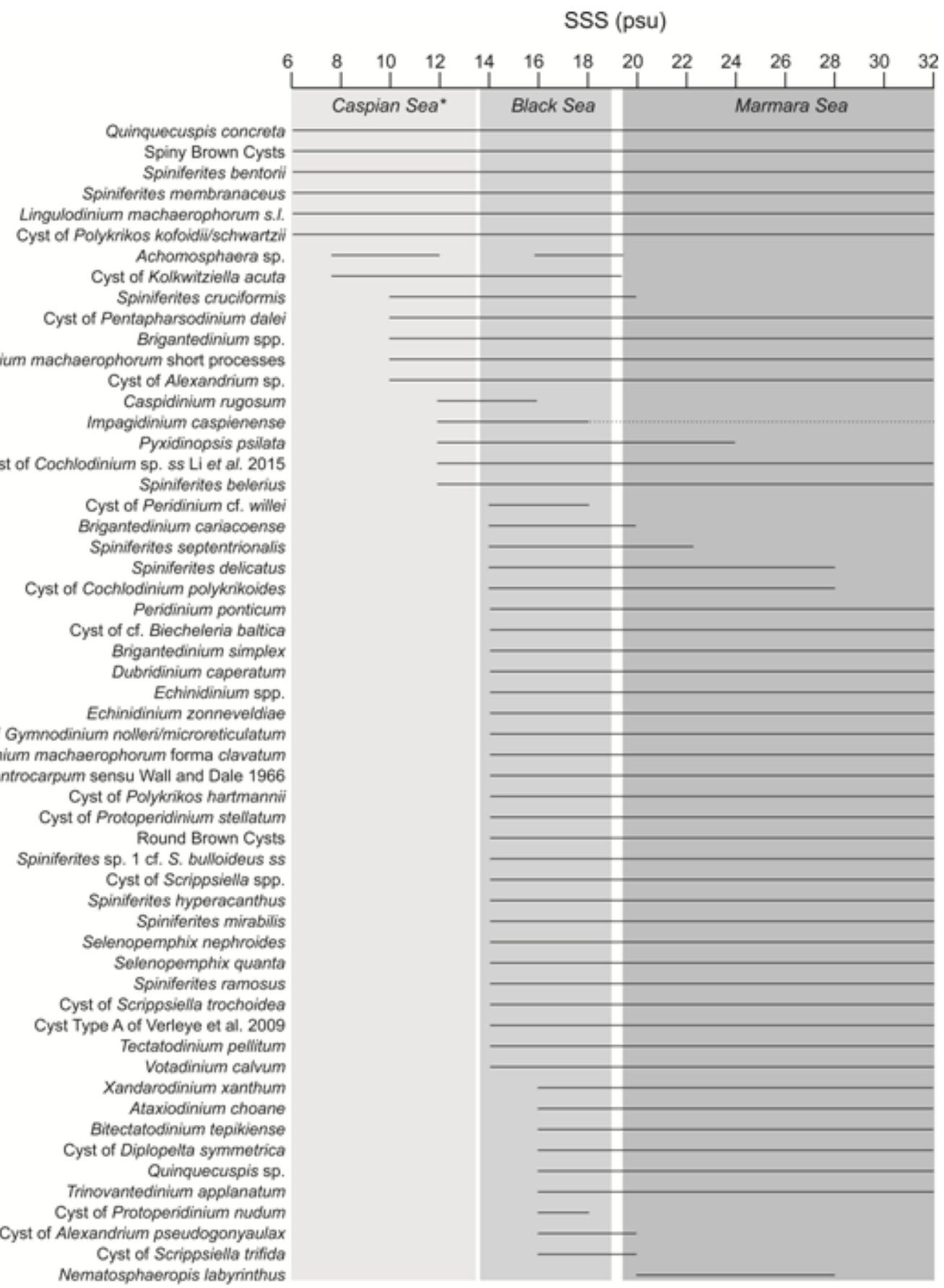


521

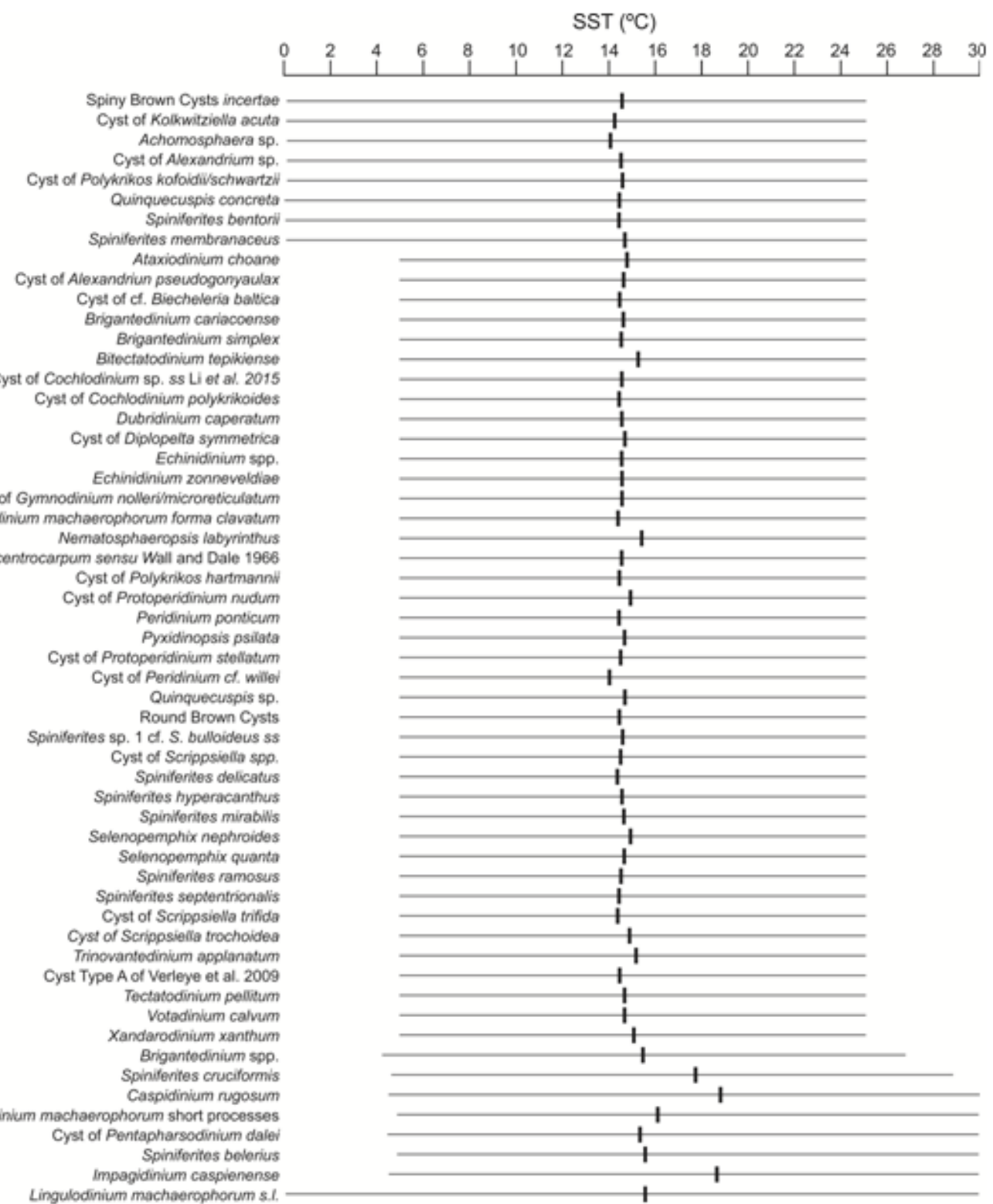

Figure 63 

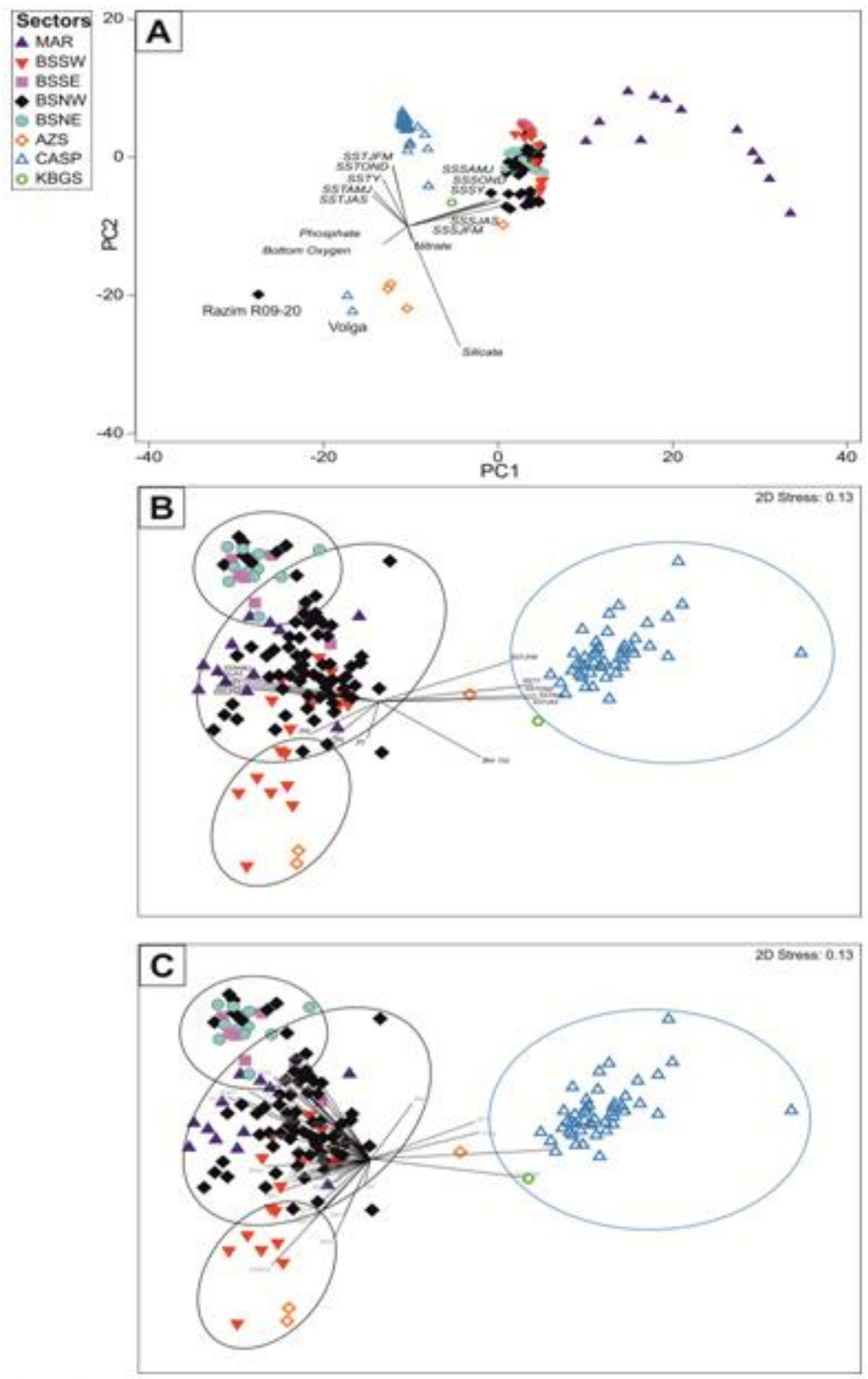

Figure 64 


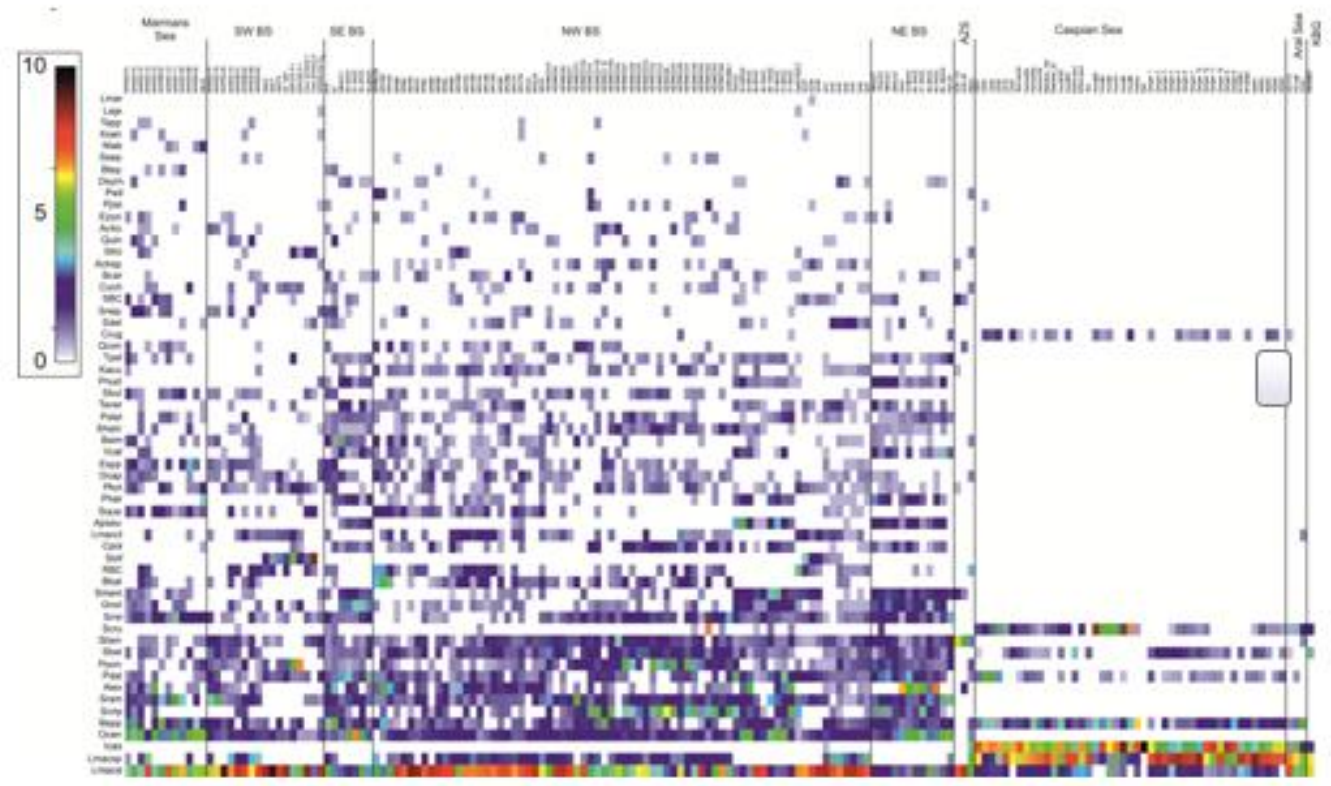

Figure 65 


\section{ACCEPTED MANUSCRIPT}
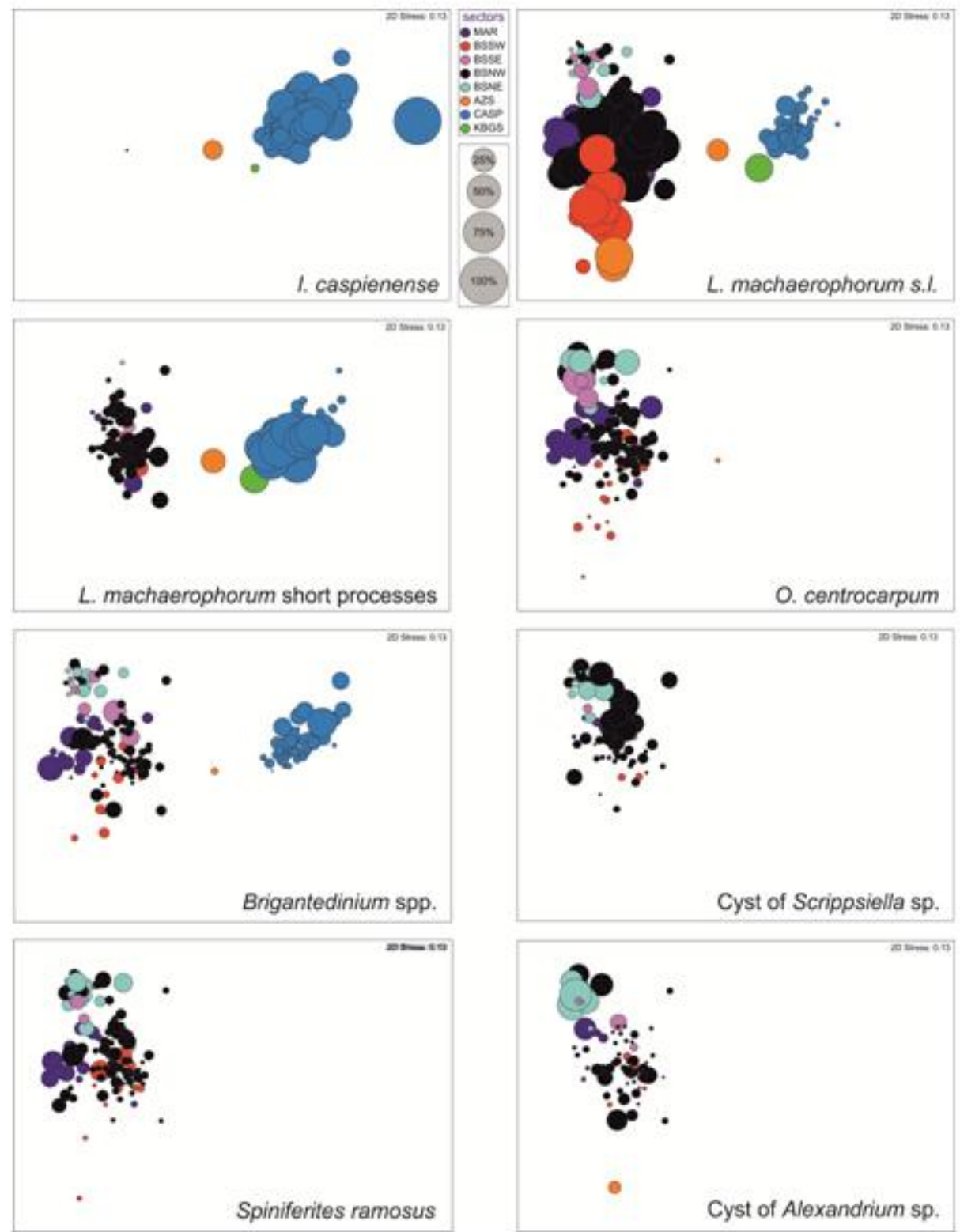

Figure 66 


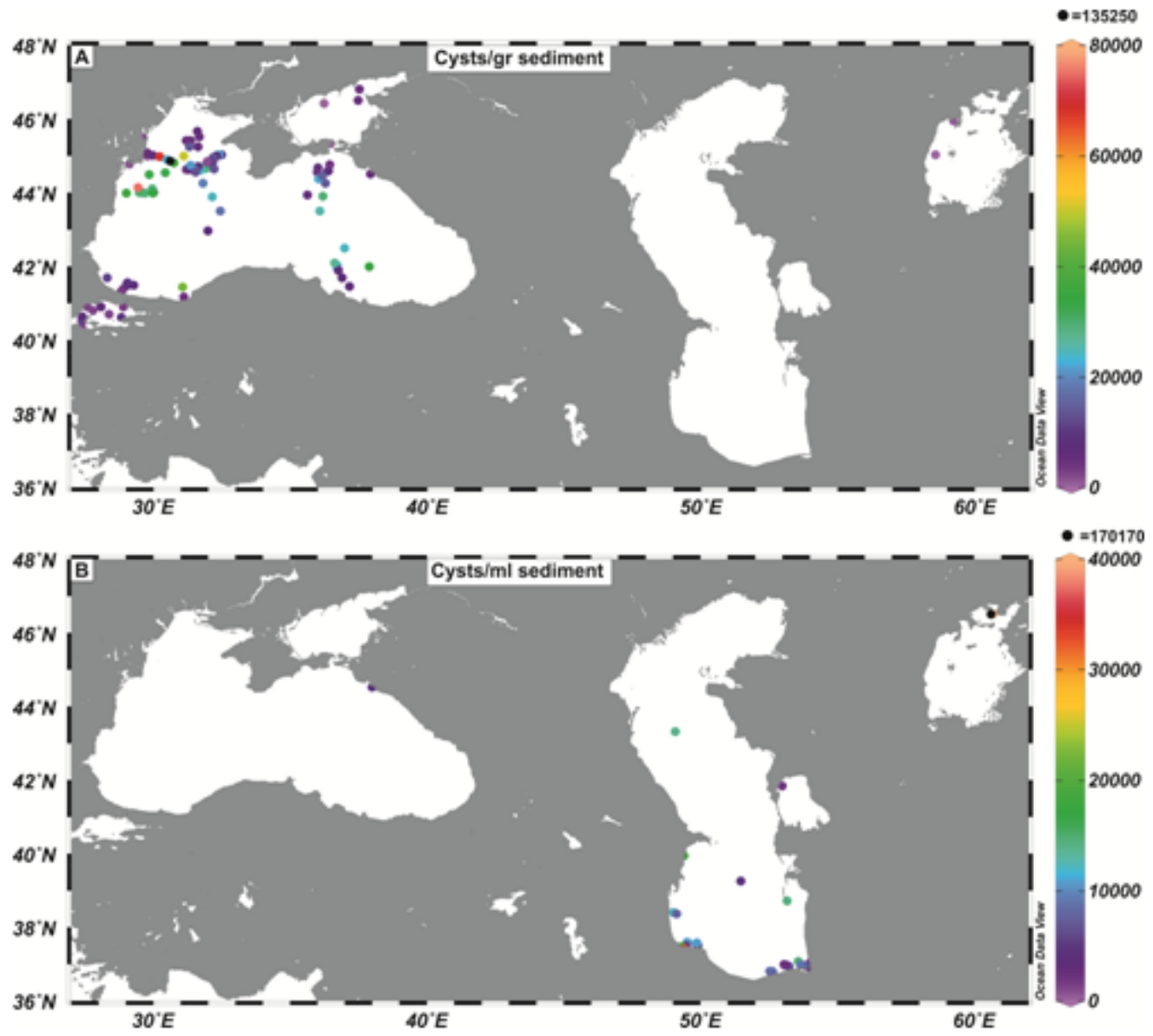

Figure 67 


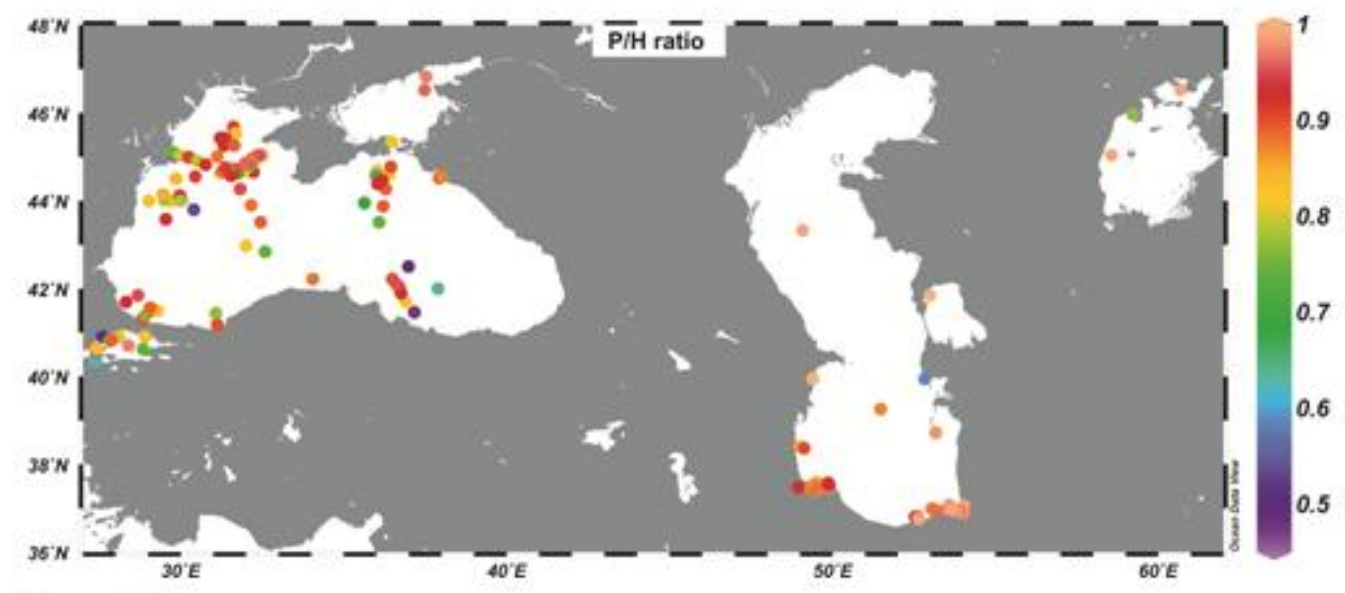

Figure 68 

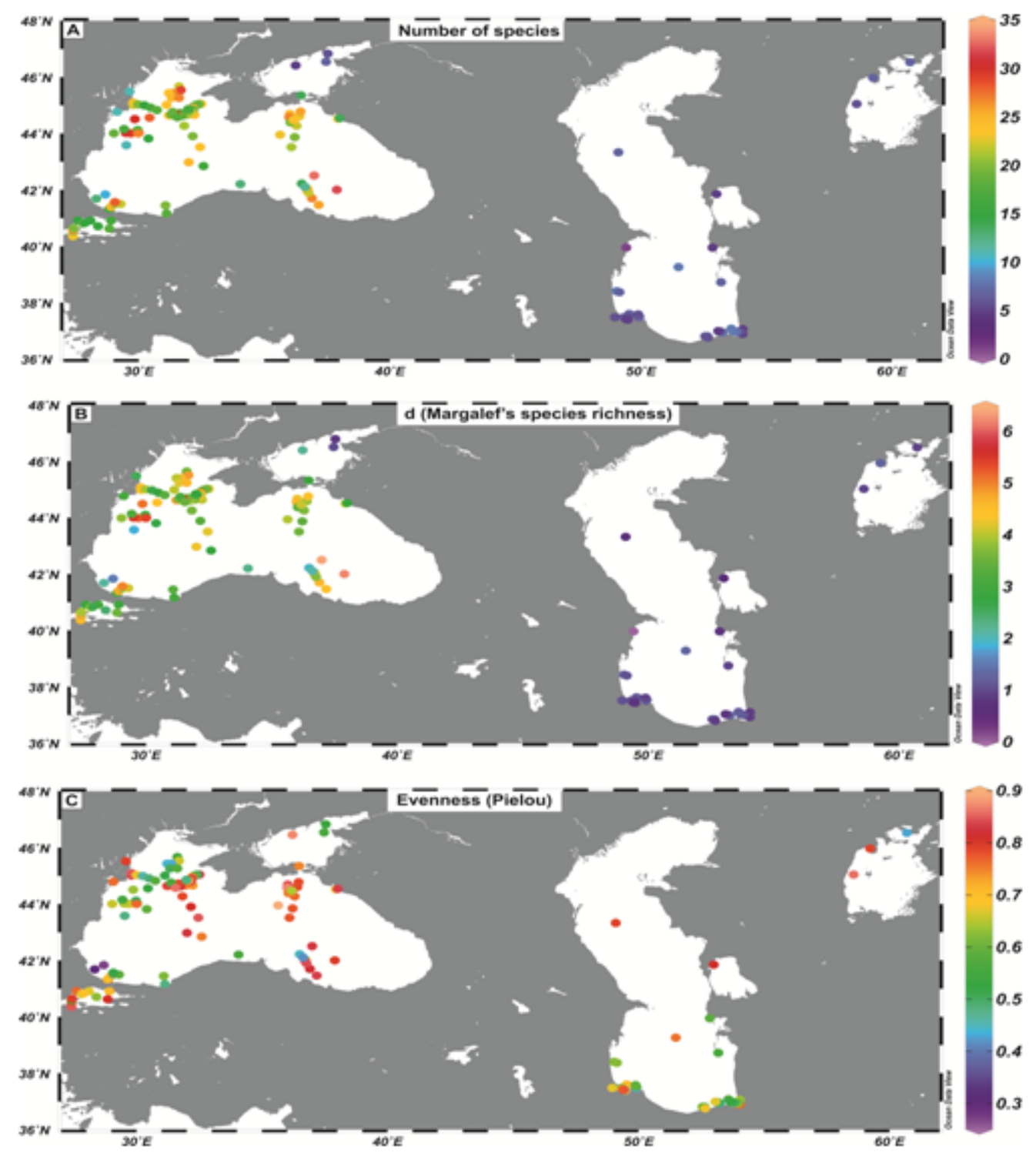

Figure 69 